\begin{tabular}{c|c|c} 
REFERENCE & NIST & AlIIUJ OOLIIIB
\end{tabular}

NBSIR $86-3050$

NATL STANDARDS \& TECH R.I.C.

NATLINH)

A11 103004118

A111

imaterlals studles for mas $9086 \mathrm{~V} 19 \mathrm{C.}$.

TECHNICAL REPORTS

\author{
MATERIALS STUDIES FOR \\ MAGNETIC FUSION ENERGY \\ APPLICATIONS AT LOW TEMPERATURES - IX
}
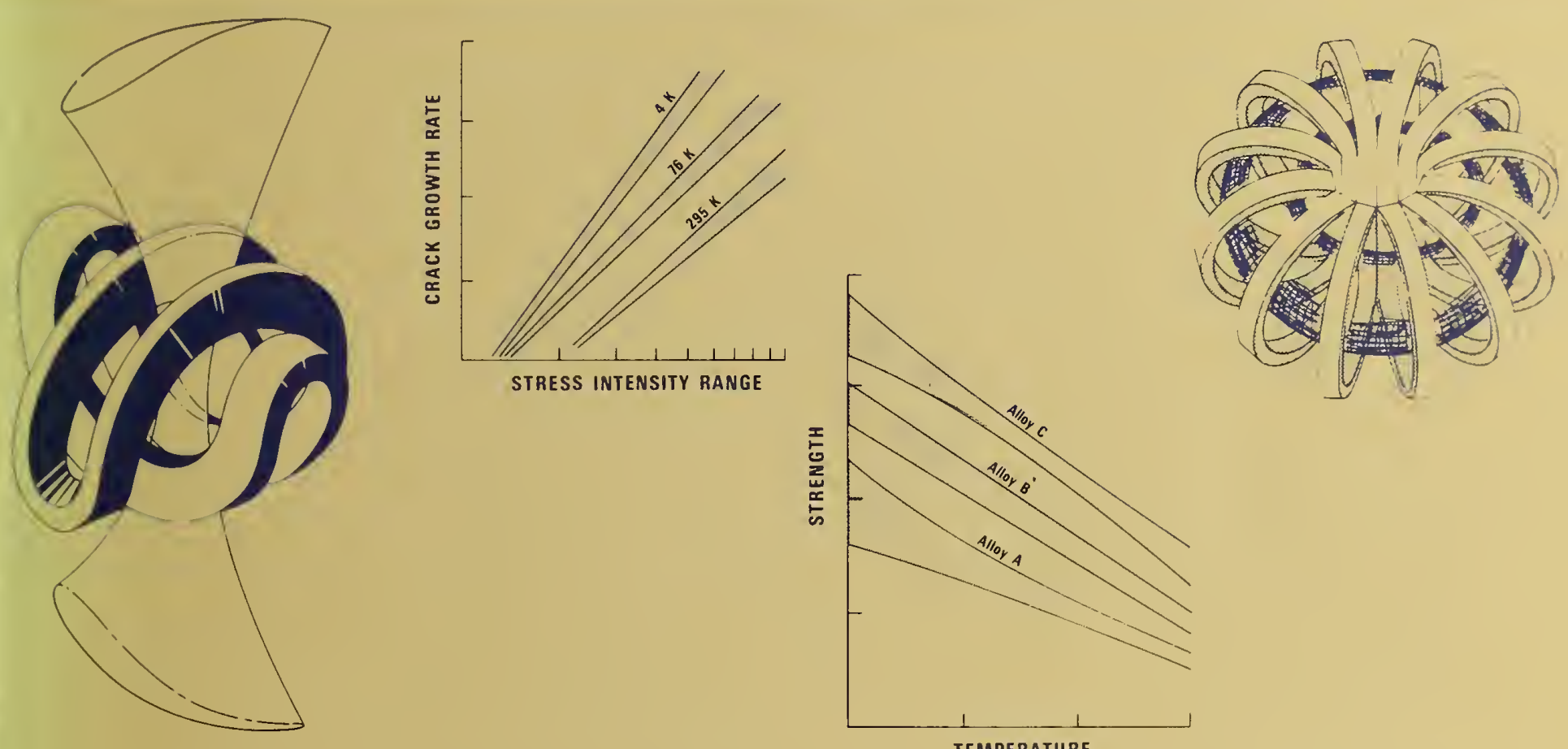

To

Department of Energy

Office of Fusion Energy

Wrahington, D.C. 20545 $Q C$

100

.456

$86-3050$

Prepared by

Fracture and Deformation Division National Bureau of Standards Boulder, Colorado 80303 
NATIONAL INSTITUTE OF STANDARDS \&

TECHNOLOGY

Research Information Center

Gaithersburg, MD 20899 
NBSIR $86-3050$

TECHNICAL REPORTS

\section{MATERIALS STUDIES FOR \\ MAGNETIC FUSION ENERGY \\ APPLICATIONS AT LOW TEMPERATURES - IX}

Edited by

R.P. Reed

Fracture and Deformation Division

National Bureau of Standards

Boulder, Colorado 80303

May 1986

Sponsored by

Department of Energy

Office of Fusion Energy

Washington, D.C. 20545

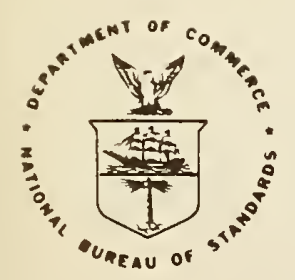

U.S. DEPARTMENT OF COMMERCE, Malcolm Baldrige, Secretary

NATIONAL BUREAU OF STANDARDS, Ernest Ambler, Director 



\section{CONTENTS}

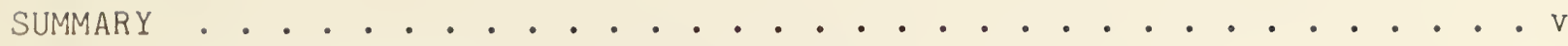

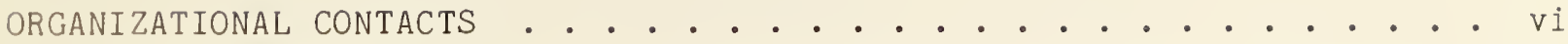

PROGRAM DESCRIPTION . . . . . . . . . . . . . . . . . . . . . vii

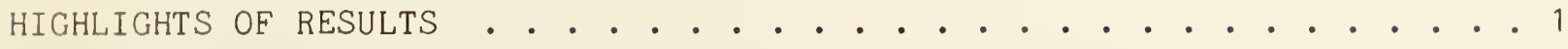

STRUCTURAL ALLOYS

Structural Alloys Program . . . . . . . . . . . . . 11

Summary of Mechanical Property Measurements of Structural Alloys . 12

Alloy $316 \mathrm{LN}$ for Low Temperature Structures:

A Summary of Tensile and Fracture Data . . . . . . . . . . 15

R. P. Reed, N. J. Simon, P. T. Purtscher, and R. L. Tobler

Strength and Toughness of AISI 304 and 316 at 4 K . . . . . . 27

N. J. Simon and R. P. Reed

Near-Threshold Fatigue Crack Growth Behavior of

AISI 316 Stainless Steel . . . . . . . . . . . . 43

R. L. Tobler

The Toughness of Austenitic Stainless Steels at $4 \mathrm{~K}$. . . . . . 53

P. T. Purtscher and R. P. Reed

Absence of Stretch Zones in Austenitic Stainless

Steels Fractured at Cryogenic Temperatures . . . . . . . . . . 89

P. T. Purtscher

Low Temperature Deformation of Copper and an

Austenitic Stainless Steel . . . . . . . . . . . . . . . . 95

R. P. Reed and R. P. Walsh

Low Temperature Tensile Characteristics

of Copper and Aluminum . . . . . . . . . . . . . . 107

R. P. Reed and R. P. Walsh

Effect of Prior Deformation on the 76-K Fracture Toughness of

AISI 304L and AWS 308L Stainless Steels. . . . . . . . . . 141

P. T. Purtscher and D. T. Read

Carbon and Nitrogen Effects on the Elastic Constant,s

of a Stainless Steel at $4 \mathrm{~K}$. . . . . . . . . . . . . . 159

H. M. Ledbetter, M. W. Austin, and S. A. Kim

Effects of Interstitial Carbon and Nitrogen on

the Low-Temperature Magnetic Properties of FCC

$\mathrm{Fe}-\mathrm{Cr}-\mathrm{Ni}$ Alloys . . . . . . . . . . . . . . 167

E. R. Jones, Jr., T. Datta, C. Almasan,

and H. M. Ledbetter 


\section{STRUCTURAL ALLOYS (continued)}

Proposed Standard Method for Tensile Testing of

Structural Alloys at Liquid Helium Temperature . . . . . . . . . .177

Proposed Standard Method for Fracture Toughness Testing

of Structural Alloys at Liquid Helium Temperature. . . . . . . . .195

Minutes of Low Temperature Structural Materials and Standards

Workshop . . . . . . . . . . . . . . . . . . 209

WELDING

Welding Program. . . . . . . . . . . . . . . . . 213

Summary of Mechanical Property Measurements of Welds . . . . . . .214

Manganese and Nitrogen in Stainless Steel SMA Welds

for Cryogenic Service. . . . . . . . . . . . . . . . . .217

C. N. McCowan, T. A. Siewert, and R. P. Reed, and F. B. Lake

Strength-Toughness Relationship for Austenitic

Stainless Steel Welds at $4 \mathrm{~K}$. . . . . . . . . . . . . . 239

R. L. Tobler, T. A. Siewert, and H. I. McHenry

Tensile and Fracture Properties of an Fe-18Cr-20Ni-5Mn-0.16N

Fully Austenitic Weld Metal at $4 \mathrm{~K}$. . . . . . . . . . . . 247

C. N. McCowan, T. A. Siewert, and R. L. Tobler

Tensile, Fatigue, and Fracture Properties of an

Fe-18Cr-16Ni-6.5Mn-2.4Mo Fully Austenitic SMA Weld at $4 \mathrm{~K}$. . . . 257

R. L. Tobler, R. E. Trevisan, H. I. McHenry,

P. T. Purtscher, and T. A. Siewert

NONMETALLICS

Nonmetallics Program . . . . . . . . . . . . . . 279

Irradiation Effects on Organic Insulators. . . . . . . . . . .281

M. B. Kasen

Screening the Performance of Organic Insulators

under Cryogenic Neutron Irradiation

M. B. Kasen and R. B. Stoddard

Young Modulus and Internal Friction of a

Fiber-Reinforced Composite . . . . . . . . . . . . . 301

H. M. Ledbetter, M. Lei, and M. W. Austin

Edge Stresses in Woven Laminates at Low Temperatures . . . . . . 307 R. D. Kriz

TECHNOLOGY TRANSFER

Technology Transfer Program. . . . . . . . . . . . . . 327

Cryogenic Structural Materials Workshop . . . . . . . . . . .329

Information Retrieval Services . . . . . . . . . . . . 337 


\section{SUMMARY}

This report contains results of a research program to produce material property data that will facilitate design and development of cryogenic structures for the superconducting magnets of magnetic fusion energy power plants and prototypes. The program was developed jointly by the staffs of the National Bureau of Standards and the Office of Fusion Energy of the Department of Energy; it is managed by NBS and sponsored by DOE. Research is conducted at NBS and at various other laboratories through subcontracts with NBS.

Research results for 1985 are summarized in an initial "Highlights of Results" section and reported in detail in the technical papers that form the main body of this report. The technical papers are presented under four headings reflecting the main program areas: Welding, Nonmetallics,' Structural Alloys, and Technology Transfer. Objectives, approaches, and achievements are summarized in an introduction to each program area.

Note: Certain commercial equipment, instruments, or materials are identified in this report to specify the experimental procedure adequately. In a few instances, company names are used to identify the source of specific research. In no case does such identification imply recommendation or endorsement by the National Bureau of Standards, nor does it imply that the material or equipment identified is necessarily the best available for the purpose. 


\section{ORGANIZATIONAL CONTACTS}

The staff contributing to the various major aspects of the program during fiscal year 1986 are listed below so that specific technical questions may be directed to them.

Department of Energy, Office of Fusion Energy, Washington, D.C. 20545

Program Monitor

V. K. Der

(301) $353-5736$

(FTS) 233-5736

National Bureau of Standards, Boulder, Colorado 80303

Program Manager

Structural Alloys

Welding

Nonmetallics

Technology Transfer
R. P. Reed

(303) 497-3870

(FTS) $320-3870$

(303) 497-3504

(303) 497-3504

(303) 497-3443

(303) 497-5789

(303) 497-3870

(303) 497-3687

(303) 497-3421

(303) 497-3537

R. P. Walsh

C. N. McCowan

H. I. McHenry

P. T. Purtscher

R. P. Reed

T. A. Siewert

R. L. Tobler

D. P. Vigliotti

M. W. Austin

M. B. Kasen

R. D. Kriz

H. M. Ledbetter

M. Lei

(303) 497-3523

(303) 497-3268

(303) 497-5789

(303) $497-3870$

(303) 497-3523

(303) $497-3421$

(303) 497-3222

(303) 497-3504

(303) 497-3558

(303) 497-3547

(303) 497-3443

(303) 497-3504

(303) $497-3870$

(303) $497-3687$ 


\section{PROGRAM DESCRIPTION}

The overall objective of the program is to assist in the design, construction, and safe operation of low-temperature magnetic fusion energy (MFE) systems, especially superconducting magnets, through effective materials research and materials technology transfer. The specific steps taken to achieve this objective are: (1) evaluation of low-temperature materials research needs specific to MFE devices; (2) development and monitoring of a research program to acquire the necessary data; and (3) rapid dissemination of the data to potential users through personal contacts, publications, and workshops.

Efforts directed at the first specific objective began with the publication of the "Survey of Low Temperature Materials for Magnetic Fusion Energy" in March 1977. A recent publication updating part of this survey, "Structural Alloys for Superconducting Magnets in Fusion Energy Systems," was included in volume IV (1981) of this series. In volume VI (1983), reviews of the properties of austenitic stainless steels and of austenitic-steel elastic constants also contributed to this objective. Through interactions with low-temperature design, construction, and measurement programs, such as the Large Coil Project and MFTF-B, we are aware of new problems as they arise. Research projects contributing to the second objective are outlined in the following table. The results appear later in this report. Again, emphasis has been on research oriented toward the establishment of test standards. The third objective is satisfied, in part, by these annual reports and by the series of workshops on Materials at Low Temperatures. Since 1982, handbook pages presenting the available data for specific materials have been distributed to those members of the magnetic fusion energy community involved with low-temperature materials. 
- Development of strong, tough austenitic steels

- Characterization of high-strength, high-conductivity copper and copper alloys

- Development of low-temperature test standards
- Development of improved filler metals for low-temperature service

- Detection and evaluation of defects in stainless-steel weldments

- Evaluation of mechanical properties of weldments at low temperatures
Nonmetallics

M. B. Kasen, Leader
Technology Transfer

N. J. Simon, Leader
- Measurement, modeling, and understanding properties of composites

- Development of specifications for insulating laminates

- Development of test methods for materials selection
- Evaluation of data on austenitic steels, copper, and copper alloys

- Organization of cryogenic structural materials workshop

- Dissemination of materials properties data to DOE and the fusion energy community 
HIGHLIGHTS OF RESULTS 


\section{HIGHLIGHTS OF RESULTS}

\section{STRUCTURAL ALLOYS}

\section{Strong, Tough Alloys}

The tensile-deformation characteristics and effect of strain rate were studied on relatively pure CDA 101 copper, 1100 aluminum, and solid-solutionstrengthened AISI 310. Tensile strain rate was varied between $2 \times 10^{-3}$ and $2 \times 10^{-5} \mathrm{~s}^{-1}$ at temperatures ranging from 4 to $295 \mathrm{~K}$. Tensile stress-strain and strain-hardening curves were determined for these temperatures. The effect of strain-rate changes on tensile flow strength was measured from strains near 0.002 (yield strength) to over 0.300. The data reflect three distinct ranges of face-centered cubic, polycrystalline plastic deformation whose characteristics depend on the solute content.

Provisional equations for the yield strength of AISI 304- and 316-type alloys at $4 \mathrm{~K}$ as a function of nitrogen content and grain size were developed. Provisional equations for the $4-\mathrm{K}$ fracture toughness, $\mathrm{K}_{\mathrm{Ic}}(\mathrm{J})$, of these alloys are presented in which the effects of yield strength, nitrogen and manganese content, and inclusion spacing are expressed quantitatively. The equations result from regression analyses of a matrix of NBS measurements that includes more extensive numerical data on alloying, refining, and processing parameters than have previously been available.

For structural use in superconducting magnet applications, alloy AISI 316LN offers higher strength than AISI 304LN with equivalent toughness. Tensile and fracture toughness data at $4 \mathrm{~K}$ were measured for a variety of AISI 316- and 316LN-alloy specimens obtained from suppliers in Japan, Europe, and the United States.

Five elastic constants of nine AISI 304-type stainless steel alloys were studied between 295 and $4 \mathrm{~K}$. The carbon-plus-nitrogen contents of these alloys ranged from 0.080 to 0.359 wt.\%. Longitudinal, Young's, shear, and bulk moduli and Poisson's ratio were determined by a pulse echo ultrasonic method. Except for the bulk modulus, all the elastic stiffnesses increased slightly with increasing interstitial content.

The role of alloying and inclusions in changing the toughness of austenitic stainless steels was assessed. The toughness was evaluated according to ASTM E 813 standard for elastic-plastic fracture. The alloys were chosen carefully so that the effect of substitutional alloying elements (nickel, manganese, molybdenum) could be studied; other variables that influence the strength and toughness were kept to a minimum. This information is valuable in designing alloys that will meet specifications for service at $4 \mathrm{~K}$ with alloying elements that are cost effective. 
Strong, Fatigue-Resistant Alloys

A new facility is in use that facilitates the difficult and timeconsuming measurement of threshold fatigue. It is capable of measuring fatigue-crack growth rates as low as one angstrom (less than one lattice spacing) per load cycle in the temperature range 295 to $4 \mathrm{~K}$. Near-threshold fatigue-crack growth rates and threshold stress intensity factors are important because they are used to determine the stress limits below which existing cracks cease to grow.

The near-threshold fatigue behavior of an AISI 316 alloy was characterized using this new, fully automatic fatigue test apparatus. Significant differences in the near-threshold behavior at temperatures of 295 and $4 \mathrm{~K}$ were observed. At $295 \mathrm{~K}$, where the operationally defined threshold at $10^{-10} \mathrm{~m} / \mathrm{cycle}$ is insensitive to stress ratio and strongly affected by crack closure, the effective threshold stress intensity factor is about 4.65 $\mathrm{MPa} \cdot \mathrm{m}^{1 / 2}$ at $\mathrm{R}=0.3$ and $6.1 \mathrm{MPa} \cdot \mathrm{m}^{1 / 2}$ at $\mathrm{R}=0.1$.

\section{Codes and Standards}

A proposed standard method for tensile testing of structural alloys at $4 \mathrm{~K}$ was developed. Procedures used in displacement-controlled tensile testing of structural alloys and weldments at this temperature are described. The format corresponds closely to ASTM standard designation E 8-83 entitled "Standard Methods of Tensile Testing of Metallic Materials." The contents include modifications to accommodate the special needs of cryogenic testing.

A proposed standard method for fracture toughness testing of structural alloys at $4 \mathrm{~K}$ was also developed. It covers the equipment, procedures, and data analysis used for determining the fracture toughness of structural alloys and weldments at this temperature. The procedures incorporated represent adaptations of the $\mathrm{K}_{\mathrm{Ic}}$ and $\mathrm{J}_{\mathrm{Ic}}$ plane strain fracture toughness tests, as described in ASTM Standards E $399-83$ and E 813-81, respectively, to accommodate the specific requirements of cryogenic testing. 


\section{WELDING}

A series of welds based on an AISI 308-type composition was used to clarify the effects of manganese ( 1.5 to $10 \mathrm{wt} . \%)$, nitrogen (0.04 to 0.26 wt. $\%$ ), and molybdenum ( 0 to 4 wt. $\%$ ) on SMA weld properties for cryogenic service. The 4-K yield strength was found to be strongly increased by nitrogen, but only weakly increased by manganese. The 76-K lateral expansion had a more linear correlation to the strength and alloy content than the CVN absorbed energy. Present equations for predicting ferrite numbers were found to be quite inaccurate for welds with high manganese and nitrogen levels. Improved predictive equations were determined.

A fully austenitic welding electrode was evaluated at $4 \mathrm{~K}$. A 1.2-mdiameter electrode with a composition of Fe-18Cr-20Ni-5Mn-0.16N was used to produce a gas-metal-arc weld in 25-mm-thick AISI 304-type stainless steel plate. The yield strength ( $1015 \mathrm{MPa})$ and fracture toughness $\left(203 \mathrm{MPa} \cdot \mathrm{m}^{1 / 2}\right.$ ) compare favorably with existing base metal properties for AISI 304-type alloys.

A fully austenitic butt weld, produced by shielded-metal-arc welding with the composition Fe-18Cr-16Ni-6.5Mn-2.4Mo, was evaluated at $4 \mathrm{~K}$. An average fracture toughness, $\mathrm{K}_{\mathrm{Ic}}(\mathrm{J})$, of $191 \mathrm{MPa} \cdot \mathrm{m}^{1 / 2}$ was measured on the 25-mm-thick specimens. A yield strength $842 \mathrm{MPa}$ was measured, and the tearing modulus was determined to be 50 . The fracture toughness was better than common AWI 308- and 316-type welds, but poorer than base materials of comparable strength.

The strength-toughness relationships for welds evaluated at NBS over the past decade were collected and compared with the corresponding base material properties. An inverse linear correlation was found between yield strength and fracture toughness for AWI 308- and 316-type welds at $4 \mathrm{~K}$. The AWI 308and 316-type welds had a significantly lower toughness than base materials of comparable strength. Newer, fully austenitic alloys produced welds with better toughness. 


\section{NONMETALLICS}

\section{Standard Specimen Development}

Recognizing the unique demands placed on specimens to be used in cryogenic radiation research, we continued development of the technology for producing specimens combining the attributes of low cost, a high degree of characterization, small size, flexibility in component selection and treatment, and adaptability to many test procedures. Continuing our emphasis on the basic 3.2-mm-diameter rod configuration, we have extended our production capability to include a solid component epoxy resin system (G-IlCR) and a bismaleimide polyimide. Materials required to perform an initial irradiation test run in the NLTNIF reactor have been produced and sent to ORNL. These consist of three epoxy resin systems and one bismaleimide system, each produced as unreinforced resin and as composites reinforced with 48 volume percent glass fiber.

\section{Standard Specimen Test Methods}

We developed and validated the apparatus required to assess the influence of cryogenic neutron irradiation on mechanical property degradation of highly characterized test specimens. Emphasis was placed on test methods sensitive to degradation of fiber-matrix interfacial properties. We have successfully modified the conventional short-beam shear test procedure to accept the standard rod specimens. We have developed the complete capability for efficiently conducting torsional shear tests at cryogenic temperatures and have demonstrated the sensitivity of this test method to assessing interfacial property changes. This test method has not been applied previously to composite materials at cryogenic temperatures. We have also developed a simple, novel method of obtaining quantitative information on the longitudinal fracture strength, $G_{I c}$, of the standard composite rod specimens at cryogenic temperatures. This is also a new development in cryogenic composite testing technology.

International Cooperation

The cooperative international program directed toward development of radiation-resistant, organic-matrix insulators is continuing. The group at ISIR, Osaka University, Japan, headed by Prof. T. Okada, continues to produce and test standard composite specimens of configuration identical to those developed at NBS. Prof. Okada will provide an additional series of specimens to be irradiated at the NLTNIF facility at ORNL during 1986 and will provide personnel from his organization to conduct the subsequent test work at NBS-Boulder. 


\section{Property Determination and Modeling}

We developed a finite element model that predicts stress singularities near the stress-free edges of laminates. The edge stresses parallel to the surface are nonzero and large enough to cause the formation of ply cracks and delaminations. In the laboratory, we rarely observed delamination initiation at the edges of woven laminates at low temperatures. Finite element theory explains the influence of weave geometry on these edge stresses and the amount of stress required to initiate edge delamination.

By a kilohertz-frequency resonance method, we determined the Young's modulus and internal friction of a uniaxially fiber-reinforced composite. The composite comprised glass fibers in an epoxy-resin matrix. We studied three fiber contents: 0,41 , and 49 vol.\%. Young's modulus fit a linear rule of mixture. The internal friction fit a classical free-damped-oscillator model where one assumes a linear rule of mixture for three quantities: mass, force constant, and mechanical-resistance constant. 


\section{TECHNOLOGY TRANSFER}

The workshop on Materials at Low Temperatures that has been organized by NBS in past years took place at LBL, in Berkeley, California, October 2-4, 1985, under the sponsorship of LBL and LLNL. The workshop brought together material specialists and magnet designers to report recent research and to identify and discuss structural materials problems in superconducting magnet design and construction for fusion energy systems. The proceedings of this informal workshop were not published; however, a copy of the program and an informal summary of the proceedings may be found in the Technology Transfer section of this report.

Handbook and supporting documentation pages on mechanical properties of AISI 304 stainless steels with nitrogen content $\geqq 0.1$ wt.\% were distributed in preliminary draft format in March 1985. Properties covered included: tensile strength, yield strength, elongation, reduction of area, stressstrain curves, elastic constants, impact energy, fracture toughness, stressand strain-controlled fatigue life, and fatigue crack growth rate over the temperature range 300 to $4 \mathrm{~K}$. The scope of the handbook has been expanded to include analysis and correlation of AISI 304 properties with respect to interstitial carbon and nitrogen content. Since very little physical property data on high nitrogen 304 alloys exist, an inclusive survey of physical property data from 300 to $4 \mathrm{~K}$ on all 304 stainless steel alloys was undertaken. A preliminary draft of handbook and supporting documentation pages on the physical properties of AISI 304 alloys was distributed in late 1985. Properties covered were: specific heat, thermal conductivity, thermal expansion, electrical resistivity, magnetization, and magnetic susceptibility. Preliminary work on handbook pages covering properties of CDA 102 copper and selected copper alloys is in progress. 
STRUCTURAL ALLOYS 


\section{STRUCTURAL ALLOYS PROGRAM}

LEADER :

CONTRIBUTORS :
R. P. Reed

M. W. Austin, S. A. Kim, R. D. Kriz, H. M. Ledbetter,

P. T. Purtscher, Y. Shindo, N. J. Simon, R. L. Tobler,

R. P. Walsh

\section{OBJECTIVES}

- Development of strong, tough structural alloys for use in superconducting magnets at $4 \mathrm{~K}$

- Development of strong, fatigue-resistant structural alloys for use in pulsed superconducting magnets at $4 \mathrm{~K}$

- Development of effective codes and standards related to low-temperature property measurements and structural design

\section{RESEARCH PAST YEAR (1985)}

- Low-temperature strain-hardening and strain-rate effects of copper, aluminum, and AISI 310

- Threshold fatigue crack growth behavior of austenitic stainless steels

- Drafts of proposed standard methods for tensile and fracture toughness testing at $4 \mathrm{~K}$

- Summary of strength and toughness characteristics of AISI 304- and 316 -type alloys

- Elastic properties of austenitic stainless steels at low temperatures

\section{RESEARCH THIS YEAR (1986)}

- Low-temperature strain-hardening and strain-rate effects of austenitic stainless steels

- Cooperative program with industry on high-nitrogen, high-molybdenum austenitic stainless steels

- Continued development of standard methods for tensile and fracture toughness testing at $4 \mathrm{~K}$ by R. L. Tobler at Tohoku University, Sendai, Japan

- Cooperative program with LLNL and MIT on high-strength, high-conductivity copper alloy properties

- Creep studies of austenitic stainless steels and copper at low temperatures

- Study of plastic fracture in austenitic stainless steels at $4 \mathrm{~K}$

- Study of the effects of magnetic field on the crack tip singularities in ferromagnetic materials; participation of $Y$. Shindo, Tohoku University, in this study 
SUMMARY OF MECHANICAL PROPERTY MEASUREMENTS OF STRUCTURAL ALLOYS

\begin{tabular}{|c|c|c|c|c|c|c|c|}
\hline $\begin{array}{c}\text { Alloy } \\
\text { (Designation) }\end{array}$ & $\begin{array}{l}\text { Country } \\
\text { of } \\
\text { Supplier }\end{array}$ & $\begin{array}{l}\text { Tensile } \\
295-4 \mathrm{~K}\end{array}$ & $\begin{array}{l}\text { Elastic } \\
295-4 \mathrm{~K}\end{array}$ & $\begin{array}{c}\text { Fracture } \\
\text { Toughness } \\
295,76,4 \mathrm{~K}\end{array}$ & $\begin{array}{l}\text { Fatigue Crack } \\
\text { Growth Rate } \\
295,76,4 \mathrm{~K}\end{array}$ & $\begin{array}{c}\text { Fatigue } \\
\text { S-N } \\
4 \mathrm{~K}\end{array}$ & $\begin{array}{l}\text { Report Volume* } \\
\text { (page) }\end{array}$ \\
\hline \multicolumn{8}{|l|}{ AUSTENITIC STEELS } \\
\hline $\mathrm{Fe}-5 \mathrm{Cr}-25 \mathrm{Mn}-0.2 \mathrm{C}$ & Japan & VII & & & & & $\operatorname{VII}(65)$ \\
\hline $\mathrm{Fe}-5 \mathrm{Cr}-26 \mathrm{Mn}$ & Japan & & VI & & & & $V I(181)$ \\
\hline $\mathrm{Fe}-13 \mathrm{Cr}-19 \mathrm{Mn}$ & USSR & & III & & VI & & $\operatorname{III}(79), \operatorname{VI}(41)$ \\
\hline $\mathrm{Fe}-13 \mathrm{Cr}-22 \mathrm{Mn}-0.2 \mathrm{~N}$ & Japan & VII & & & & & $\operatorname{VII}(65)$ \\
\hline$F e-16 C r-8 N i-8 M n$ & U.S. & VIII & & VIII & & & $\operatorname{VIII}(151,181)$ \\
\hline $\mathrm{Fe}-17 \mathrm{Cr}-18 \mathrm{Mn}-0.5 \mathrm{~N}$ & U.S. & VII,VIII & & VIII & & & $\operatorname{VII}(65), \operatorname{VIII}(181)$ \\
\hline $\mathrm{Fe}-17 \mathrm{Cr}-9 \mathrm{Ni}-8 \mathrm{Mn}$ & U.S. & & III & & & & $\operatorname{III}(91)$ \\
\hline $\begin{array}{l}\mathrm{Fe}-17 \mathrm{Cr}-13 \mathrm{Ni}-2 \mathrm{Mo} \\
\quad(316)\end{array}$ & U.S. & $\begin{array}{l}I, I I, I I I, \\
\text { IV,VI,VIII }\end{array}$ & VI & $\begin{array}{l}\text { I,II, } \\
\text { VIII }\end{array}$ & II, VIII & I & $\begin{array}{l}\text { I }(15,71), \operatorname{II}(79), \operatorname{III}(49, \\
105,117), \operatorname{IV}(147), \operatorname{V}(185), \\
\operatorname{VI}(87), \operatorname{VI}(157), \operatorname{VIII}(181, \\
209,251)\end{array}$ \\
\hline $\begin{array}{l}\mathrm{Fe}-17 \mathrm{Cr}-13 \mathrm{Ni}-2 \mathrm{Mo} \\
\quad(316 \mathrm{LN})\end{array}$ & U.S. & II & & II & II & & II (79) \\
\hline $\mathrm{Fe}-18 \mathrm{Cr}-3 \mathrm{Ni}-13 \mathrm{Mn}$ & U.S. & $I, V I, V I I I$ & III & I,VIII & $I, V I, V I I$ & & $\begin{array}{l}I(93), \operatorname{III}(91), \operatorname{VI}(53) \\
\operatorname{VII}(85), \operatorname{VIII}(167,219)\end{array}$ \\
\hline $\begin{array}{l}\mathrm{Fe}-19 \mathrm{Cr}-(6-15) \mathrm{Ni}- \\
4 \mathrm{Mn}-(0.1-0.3) \mathrm{N}\end{array}$ & USSR & VIII & & VIII & & & VIII(123) \\
\hline $\begin{array}{l}\mathrm{Fe}-19 \mathrm{Cr}-9 \mathrm{Ni} \\
(304)\end{array}$ & U.S. & $\begin{array}{l}I, I I, I I I \\
I V, V I, V I I\end{array}$ & $\begin{array}{l}I, I I, I I I \\
\text { IV,VI,VII }\end{array}$ & $\begin{array}{l}I, I I, I I I, \\
I V\end{array}$ & II, III, IV & I & $\begin{array}{l}\text { I }(15,71,213), \operatorname{II}(79,149, \\
175), \operatorname{III}(15,91,105, \\
117), \operatorname{IV}(37,101,203,215, \\
227), V(71), V I(73), V I I \\
(13), \operatorname{VII}(47), V I I(75), \\
\operatorname{VII}(157)\end{array}$ \\
\hline $\begin{array}{l}\mathrm{Fe}-19 \mathrm{Cr}-9 \mathrm{Ni} \\
\quad(304 \mathrm{~L})\end{array}$ & U.S. & $\begin{array}{l}\text { II, III, } \\
\text { IV,VIII }\end{array}$ & $I, I I, I V$ & $\begin{array}{l}\text { III, IV } \\
\text { VIII }\end{array}$ & $\begin{array}{l}\text { III, IV } \\
\text { VIII }\end{array}$ & & $\begin{array}{l}\operatorname{I}(213), \operatorname{II}(79,123,175) \\
\operatorname{IV}(37,101,131,215,302) \\
\operatorname{VIII}(181,229,251)\end{array}$ \\
\hline $\begin{array}{l}\mathrm{Fe}-19 \mathrm{Cr}-9 \mathrm{Ni}-(1-8) \mathrm{Mn} \\
\quad(304 \mathrm{LN})\end{array}$ & U.S. & IV , V, VIII & v & IV , V , VIII & & & $\begin{array}{l}\operatorname{IV}(77), \operatorname{V}(15,59,189) \\
\operatorname{VIII}(181)\end{array}$ \\
\hline $\begin{array}{l}\mathrm{Fe}-19 \mathrm{Cr}-9 \mathrm{Ni}-\mathrm{N} \\
\quad(304 \mathrm{~N})\end{array}$ & U.S. & $\begin{array}{l}\text { I, III, } \\
\text { IV }\end{array}$ & IV & $I, I I I, I V$ & I,III,IV & & $\begin{array}{l}I(93), \operatorname{III}(15), \operatorname{IV}(37, \\
101,203,215)\end{array}$ \\
\hline $\begin{array}{l}\mathrm{Fe}-19 \mathrm{Cr}-9 \mathrm{Ni}-\mathrm{N} \\
\quad(304 \mathrm{LN})\end{array}$ & U.S. & $\begin{array}{l}\text { II, III, } \\
\text { IV,V,VI, } \\
\text { VIII }\end{array}$ & IV , VIII & $\begin{array}{l}\text { II, III, IV, } \\
\text { VIII }\end{array}$ & $\begin{array}{l}\text { II, III, IV, } \\
\text { VIII }\end{array}$ & II & $\begin{array}{l}\operatorname{II}(35,79), \operatorname{III}(15), \operatorname{IV} \\
(37,101,203), V(29), V I \\
(113), \operatorname{VIII}(181,207,229)\end{array}$ \\
\hline $\begin{array}{l}\mathrm{Fe}-19 \mathrm{Cr}-10 \mathrm{Ni}- \\
(0.03-0.29) \mathrm{N}- \\
(0.03-0.09) \mathrm{C}\end{array}$ & U.S. & III,VIII & VIII & III,VIII & III & & $\operatorname{III}(15), \operatorname{VIII}(145,181)$ \\
\hline $\begin{array}{l}\mathrm{Fe}-20 \mathrm{Cr}-7 \mathrm{Ni}-8 \mathrm{Mn} \\
\quad(216)\end{array}$ & U.S. & VIII & & VIII & & & $\operatorname{VIII}(151,181)$ \\
\hline
\end{tabular}

*MATERIALS STUDIES FOR MAGNETIC FUSION ENERGY APPLICATIONS AT LOW TEMPERATURES: NBSIR 78-884 (I); NBSIR 79-1609 (II); NBSIR 80-1627 (III); NBSIR 81-1645 (IV); NBSIR 82-1667 (V); NBSIR 83-1690(VI); NBSIR 84-3000 (VII); NBSIR 85-3025 (VIII). 
SUMMARY OF MECHANICAL PROPERTY MEASUREMENTS OF STRUCTURAL ALLOYS, continUed

\begin{tabular}{|c|c|c|c|c|c|c|c|}
\hline $\begin{array}{c}\text { Alloy } \\
\text { (Designation) }\end{array}$ & $\begin{array}{l}\text { Country } \\
\text { of } \\
\text { Supplier }\end{array}$ & $\begin{array}{l}\text { Tensile } \\
295-4 \mathrm{~K}\end{array}$ & $\begin{array}{l}\text { Elastic } \\
295-4 \mathrm{~K}\end{array}$ & $\begin{array}{l}\text { Fracture } \\
\text { Toughness } \\
295,76,4 \mathrm{~K}\end{array}$ & $\begin{array}{l}\text { Fatigue Crack } \\
\text { Growth Rate } \\
295,76,4 \mathrm{~K}\end{array}$ & $\begin{array}{c}\text { Fatigue } \\
\mathrm{S}-\mathrm{N} \\
4 \mathrm{~K}\end{array}$ & $\begin{array}{l}\text { Report Volume* } \\
\text { (page) }\end{array}$ \\
\hline $\begin{array}{l}\mathrm{Fe}-20 \mathrm{Cr}-8 \mathrm{N1}-2 \mathrm{Mn} \\
\quad(304 \mathrm{HN})\end{array}$ & U.S. & VIII & & VIII & & & $\operatorname{VIII}(151,181)$ \\
\hline $\mathrm{Fe}-20 \mathrm{Cr}-16 \mathrm{NI}-6 \mathrm{Mn}$ & USSR & $V, V I$ & v & & & & $V(29,213), V I(113)$ \\
\hline$F e-21 C r-6 N i-9 M n$ & U.S. & I , VIII & III, VI & I,VIII & & I & $\begin{array}{l}\operatorname{I}(15,71), \operatorname{III}(91), \\
\operatorname{VI}(157), \operatorname{VIII}(151,181)\end{array}$ \\
\hline $\mathrm{Fe}-21 \mathrm{Cr}-12 \mathrm{N1}-5 \mathrm{Mn}$ & U.S. & I, II & III & I, II & I, II & & $\operatorname{I}(93), \operatorname{II}(79), \operatorname{III}(91)$ \\
\hline $\begin{array}{l}\mathrm{Fe}-25 \mathrm{Cr}-21 \mathrm{N1} \\
\quad(310)\end{array}$ & U.S. & $\begin{array}{l}\text { V,VI, VII, } \\
\text { VIII }\end{array}$ & III, VI & V,VIII & & & $\begin{array}{l}\operatorname{III}(105,117), \operatorname{V}(71,145) \\
\operatorname{VI}(73), \operatorname{VII}(65), \operatorname{VIII}(181)\end{array}$ \\
\hline $\begin{array}{l}\mathrm{Fe}-19 \mathrm{~N} 1-9 \mathrm{Co} \\
\quad(200-300 \text { grades })\end{array}$ & U.S. & & IV & & & & $\operatorname{IV}(237)$ \\
\hline Reviews of Alloys & & $I V, V, V I$ & IV $, V, V I$ & $I V, V, V I$ & $\begin{array}{l}\text { IV , V , VI, } \\
\text { VII }\end{array}$ & IV,VI & $\begin{array}{l}\operatorname{IV}(17,257), \operatorname{V}(171) \\
\operatorname{VI}(11), \operatorname{VI}(127), \operatorname{VI}(157) \\
\operatorname{VII}(103)\end{array}$ \\
\hline \multicolumn{8}{|l|}{ ALUMINUM ALLOYS } \\
\hline $\begin{array}{l}\mathrm{Al}-6 \mathrm{Cu}-0.2 \mathrm{Mn}-0.1 \mathrm{Fe} \\
\quad(5083-0) \\
\mathrm{Al}-4 \mathrm{Mg} \\
\quad(5083-0)\end{array}$ & $\begin{array}{l}\text { U.S. } \\
\text { U.S. }\end{array}$ & IV & II & II & II & $\begin{array}{l}\text { II } \\
\text { II }\end{array}$ & $\begin{array}{l}\operatorname{II}(19) \\
\operatorname{II}(35), \operatorname{IV}(185)\end{array}$ \\
\hline SUPERCONDUCTORS & & & & & & & \\
\hline $\mathrm{Nb}-45 \mathrm{Ti}$ & U.S. & & III & & & & $\operatorname{III}(133)$ \\
\hline
\end{tabular}

*MATERIALS STUDIES FOR MAGNETIC FUSION ENERGY APPLICATIONS AT LOW TEMPERATURES: NBSIR 78-884 (I); NBSIR 79-1609 (II); NBSIR 80-1627 (III); NBSIR 81-1645 (IV); NBSIR 82-1667 (V); NBSIR 83-1690(VI); NBSIR 84-3000 (VII); NBSIR 85-3025 (VIII). 



ALLOY 316LN FOR LOW TEMPERATURE STRUCTURES:

A SUMMARY OF TENSILE AND FRACTURE DATA*

\author{
R. P. Reed, N. J. Simon, P. T. Purtscher, and R. L. Tobler \\ Fracture and Deformation Division \\ National Bureau of Standards \\ Boulder, Colorado
}

For structural use in superconducting magnet applications, alloy $316 \mathrm{LN}$ offers higher strength than $304 \mathrm{LN}$ with equivalent toughness. Nitrogen additions permit one to obtain a range of yield strength levels with little added cost. Tensile and fracture toughness data at $4 \mathrm{~K}$ are presented for a variety of 316 and $316 \mathrm{LN}$ alloys. The specimens were obtained from suppliers in Japan, Europe, and the United States and were tested at NBS. Elastic-plastic fracture toughness was determined from J-integral measurements.

\title{
INTRODUCTION
}

A number of alloys suitable for structural use at low temperatures have been studied at the National Bureau of Standards. These austenitic steels, containing nitrogen additions to increase their tensile yield strength at $4 \mathrm{~K}$, include: 304-type ( $\mathrm{Fe}, 18-20 \mathrm{Cr}, 8-10 \mathrm{Ni}, 1-2 \mathrm{Mn}, 0.10-0.20 \mathrm{~N})$, high-manganese (Fe, 13-21 Cr, 1-7Ni, 9-25Mn, 0.20-0.30N), and 316-type alloys (Fe, 17-19Cr, $11-14 \mathrm{Ni}, 1-2 \mathrm{Mn}, 2-3 \mathrm{Mo}, 0.10-0.25 \mathrm{~N})$. These alloys generally have sufficient strength, toughness, and weldability required of the principal structural material for high-field superconducting magnets. Tensile and fracture toughness data of the 316-type alloys are reported and reviewed in this paper.

\section{PROCEDURES}

The chemical composition, hardness, and type and number of inclusions for each 316 and $316 \mathrm{LN}$ alloy that we have studied at $4 \mathrm{~K}$ are listed in Table 1. only alloys $B$ and $D$ are from laboratory heats; the remainder are from commercial heats that have been used in superconducting magnet construction. The alloys were prepared in Europe, Japan, and the United States. The inclusions were analyzed using a scanning electron microscope with energy-dispersive $\mathrm{X}$-ray analyses. The sensitivity of particle detection was about $0.5 \mu \mathrm{m}$. The typical size of inclusions was $1.0 \mu \mathrm{m}$. The inclusions were analyzed on polished surfaces, not on the fracture surface. Stringers of manganese sulfide were observed in all alloys except $B$ and $D$; the content of other inclusions included $\mathrm{Al}, \mathrm{Ti}, \mathrm{Cr}, \mathrm{Mg}, \mathrm{Ca}$, and $\mathrm{Si}$.

\footnotetext{
*Submitted to Proceedings of the 11 th International Cryogenic Engineering Conference.
} 
All tensile specimens were about $6 \mathrm{~mm}$ in diameter with a reduced section about 40-mm long. Strain-gage, clamp-on extensometers with a 25-mm gage length were used to record strain. All tensile procedures and experimental sensitivities and accuracies have been previously discussed.1

To determine the fracture toughness at $4 \mathrm{~K}$, J-integral measurements were employed. Our technique uses compact tensile specimens and follows ASTM E 813 procedures. 2 To convert the measured $\mathrm{J}_{\mathrm{Ic}}$ to $\mathrm{K}_{\mathrm{IC}}(\mathrm{J})$, the expression

$$
J_{I C}=\frac{\left[K_{I c}(J)\right]^{2}}{E}
$$

was used. Here $J I_{c}$ is the measured critical value of the $J$-integral and $E$ is Young's modulus ( $207 \mathrm{GPa}$ at $4 \mathrm{~K}$ ). Our previously reported values ${ }^{3}$ of $\mathrm{K}_{\mathrm{Ic}}(\mathrm{J})$ for alloys $E, F$, and $G$ were calculated using the Poisson's ratio factor $\left(1-v^{2}\right)$ in the denominator of Eq. (1). These values are adjusted in this paper to Eq. (1) formulation. In all reported measurements, we used 25-mmthick compact tensiie specimens with a strain-gage, clip-on extensometer to measure crack-opening displacement.

RESULTS AND DISCUSSION

\section{(a) Strength}

The tensile yield strength ( $\sigma_{\mathrm{y}}, 0.2 \%$ offset) at $4 \mathrm{~K}$ of the completely austenitic 316-type alloys depends primarily on two variables: grain size and $\mathrm{N}$ content. The grain sizes and yield strengths of the alloys tested are given in Table 2; their $\mathrm{N}$ content, in Table 1.

Grain size was related to the yield strength for alloy $G$ in a previous study by Tobler et al. 4 The dependence of yield strength on grain size (obtained by recrystallization and annealing for different times at $1323 \mathrm{~K}$ ) of alloys $B$ and $D$ is shown in Figure 1. Here $d^{-1 / 2}$ ( $d$ is the average grain diameter in $\mu \mathrm{m}$ ) is linearly related to yield strength, as predicted from the well-known Hall-Petch relationship

$$
\sigma_{\mathrm{y}}=\sigma_{\mathrm{o}}+\mathrm{md}^{-1 / 2} \text {, }
$$

with $\sigma_{0}$ the single-crystal yield strength and $m$ a proportionality constant.

The strong dependence of yield strength on $\mathrm{N}$ content is shown in Figure 2. Here, the yield strengths are normalized to a grain size of $50 \mu \mathrm{m}$, using the average dependence of alloys B and D (Fig. 1). As an interstitial, $\mathrm{N}$ contributes substantially more to the low temperature strength than other alloying elements.

Our linear least-squares computer program was used to analyze the entire data set of Table 2 for the effect of grain size and $\mathrm{N}$ content in wt.\% ([N]) on $\sigma_{\mathrm{y}}$ at $4 \mathrm{~K}$. The equation developed, 


$$
\sigma_{\mathrm{y}}(\mathrm{MPa})=381+2778[\mathrm{~N}]+811 \mathrm{~d}^{-1 / 2},
$$

has a standard deviation (SD) of $55 \mathrm{MPa}$ for $\sigma_{\mathrm{y}}$, and SD's of 34, 193, and 199 for the constant term and the coefficients of $[\mathrm{N}]$ and $\mathrm{d}^{-1 / 2}$.

The dependence on [N] is not as large as that reported by Reed and Simon ${ }^{5}$ for 304 and $304 \mathrm{LN}$ alloys:

$$
\sigma_{y}(\mathrm{MPa})=325+3400[\mathrm{~N}] \text {. }
$$

In their analyses, $C$ content was included as a variable, the dependence on grain size was not considered, and data from other laboratories were also included. The higher value of the constant term in Eq. (3) was expected, since added strengthening is obtained from Mo addition in the 316 alloys. In both studies, the concentrations of the other elements were held rather constant: 18-19 wt.\% $\mathrm{Cr}, 8-12$ wt.\% Ni, 1-2 wt.\% Mn, 2-2.5 wt.\% Mo, and 0.03 wt.\% C. Thus, by maintaining this composition one can use Eq. (3) to predict yield strength at $4 \mathrm{~K}$ on the basis of grain size and $\mathrm{N}$ content.

The addition or control of $\mathrm{N}$ content is less expensive than control of grain size of strong, thick-section plate, which demands large-capacity rolling mills, accurate temperature control, and perhaps, facilities for rapid cooling from the hot-rolled condition to near room temperature. However, the solubility of $\mathrm{N}$ in a 316-type alloy may be restricted to slightly over $0.20 \mathrm{wt} . \%$. Solid-solution strength increases beyond the contribution of 0.20 wt.\% $\mathrm{N}$ must come from more expensive Mo additions.

\section{(b) Toughness}

The fracture toughness of austenitic steels at $4 \mathrm{~K}$ is primarily dependent on alloy content, strength, and inclusions. Previously, we have shown that toughness depends on $\mathrm{Ni}$ content when inclusions and strength are held constant, and that toughness depends on $\mathrm{N}$ content only through its strengthening effect. 6 In this paper we consider the dependence of toughness on strength and inclusion spacing for the 316-type alloys.

Most metastable and stable austenitic steels fracture in a ductile manner. Their fracture surfaces exhibit a dimpled appearance, typical of ductile fracture, in which microvoids form at initiation sites (usually inclusions) and eventually coalesce into voids. Linkage of the voids produces fracture. Alloys $B-H$ exhibited ductile fracture in J-integral tests at $4 \mathrm{~K}$. Alloy $\mathrm{A}$, aged at $873 \mathrm{~K}$ from the hot-worked condition, showed irregular dimpled areas combined with planar, brittle-appearing areas. The $\mathrm{K}_{\mathrm{Ic}}(\mathrm{J})$ data of alloy $\mathrm{A}$ are not used in the following correlations.

The fracture toughness $\mathrm{K}_{\mathrm{Ic}}(\mathrm{J})$ at $4 \mathrm{~K}$ is given in Table 2, and its dependence on tensile yield strength (also at $4 \mathrm{~K}$ ) is shown in Figure 3 and in the following equation:

$$
\mathrm{K}_{\mathrm{IC}}(\mathrm{J})\left(\mathrm{MPa} \cdot \mathrm{m}^{1 / 2}\right)=516-0.306 \sigma_{\mathrm{y}} \cdot
$$


The SD values are $70 \mathrm{MPa} \cdot \mathrm{m}^{1 / 2}$ for $\mathrm{K}_{\mathrm{IC}}(\mathrm{J}), 111$ for the constant term, and 0.13 for the coefficient of $\sigma_{y}$. There is an inverse linear dependence of $\mathrm{K}_{\mathrm{Ic}}(J)$ on $\sigma_{\mathrm{y}}$, like that of the $304-a l l o y$ series, 7 but there is a sizable SD. However, this variability is from alloy to alloy; when parameters such as the grain size are varied for one alloy (see Table 2, alloys B and D), the scatter is considerably reduced. This leads one to suspect that inclusions, the initiation sites for the ductile fracture mechanisms, are responsible for the large alloy-to-alloy data scatter.

A tabulation of the reciprocal square root of the average number of inclusions per $\mathrm{mm}^{2}\left(\mathrm{n}^{-1 / 2}\right)$ for each alloy is included in Table 1. The types of inclusions vary and are dependent on refining, deoxidizing, and alloying practices. In Figure 4 we plot the product of the fracture toughness and the yield strength versus $\mathrm{n}^{-1 / 2}$, corresponding to particle density. The product $\mathrm{K}_{\mathrm{Ic}}(\mathrm{J}) \cdot \sigma_{\mathrm{y}}$ is used to normalize the strength effect on toughness, that is, the strong, inverse dependence of $\mathrm{K}_{\mathrm{Ic}}$ on $\sigma_{\mathrm{y}}$ is neutralized. Previously we have used this quantity, which we have labeled the Quality Index, to portray the effect of alloying on the relationship between $K_{I c}(J)$ and $\sigma_{y} \cdot{ }^{6}$ We found a strong dependence of the Quality Index on Ni content. Therefore, because the $\mathrm{Ni}$ content varied from 10.9 to 13.9 wt.\% (Table 1), we adjusted the Quality Index to $12 \mathrm{wt. \%} \mathrm{Ni}$ for each alloy using an equation derived from the data presented by Reed and Purtscher. 6 There is an approximately linear dependence of adjusted $\mathrm{K}_{\mathrm{I} c}(J) \cdot \sigma_{\mathrm{y}}$ versus $\mathrm{n}^{-1 / 2}$ (Figure 4 ) that can be expressed as

$$
\mathrm{K}_{\mathrm{Ic}}^{\prime}(\mathrm{J}) \cdot \sigma_{\mathrm{y}}\left(10^{3} \mathrm{MPa}^{2} \cdot \mathrm{m}^{1 / 2}\right)=74+1800 \mathrm{n}^{1 / 2}
$$
The SD values are 28 for $\mathrm{K}_{\mathrm{IC}}^{\prime}(J) \cdot \sigma_{\mathrm{y}}, 22$ for the constant term, and 278 for the
coefficient of $\mathrm{n}^{-1 / 2}$.

It is reasonable to assume that inclusion density principally affects the toughness, not the strength, of our austegitic alloys. Sakamota et al. have reported data that support this premise. Therefore, in Figure 5, we present the same data, with the $\mathrm{K}_{\mathrm{Ic}}(\mathrm{J})$ data adjusted to $\mathrm{n}^{-1 / 2}=0.047$ and to 12 wt.\% $\mathrm{Ni}$ with $\sigma_{\mathrm{y}}$ held constant. Normalization of the toughness data of Figure 3 to constant particle density and $\mathrm{Ni}$ content considerably reduces the data scatter (SD is reduced from 70 to 29), and the slope more nearly reflects the dependence of $\mathrm{K}_{\mathrm{IC}}(\mathrm{J})$ on strength

$$
\mathrm{K}_{\mathrm{IC}}(\mathrm{J})\left(\mathrm{MPa} \cdot \mathrm{m}^{1 / 2}\right)=433-0.28 \sigma_{\mathrm{y}}
$$

for an average particle spacing $\left(\mathrm{n}^{-1 / 2}\right)$ of 0.047 . The SD values are 29 for $\mathrm{K}_{\mathrm{IC}}^{\prime \prime}(J), 45$ for the constant term, and 0.05 for the coefficient of $\sigma_{\mathrm{y}}$.

Finally, since we have demonstrated that the toughness varies with number of inclusions and yield strength and have previously shown toughness to be dependent on $\mathrm{Ni}$ content, we performed a linear regression least-squares fit on these variables for our original 316-type alloy data set (Table 2). We found that

$$
\mathrm{K}_{\mathrm{IC}}(\mathrm{J})\left(\mathrm{MPa} \cdot \mathrm{m}^{1 / 2}\right)=130-0.338 \sigma_{\mathrm{y}}+2250 \mathrm{n}^{-1 / 2}+20.2[\mathrm{Ni}] .
$$


The SD values are $31 \mathrm{MPa} \cdot \mathrm{m}^{1 / 2}$ for $\mathrm{K}_{\mathrm{Ic}}(\mathrm{J}), 89$ for the constant, 0.059 for the coefficient of $\sigma_{y}, 310$ for the $n=1 / 2$, and 5.2 for the [Ni] coefficient. All independent variables contributed to a reduction of the SD for $\mathrm{K}_{\mathrm{Ic}}(\mathrm{J})$, and as indicated, the SD values for the coefficients of the independent variables were reasonable. This equation is discussed further by Simon and Reed. 9

Thus, the requirements for optimum toughness are a minimum inclusion density (attained by careful refining treatment), optimum $\mathrm{Ni}$ content, and minimal strength. The first two are achieved only by added cost, the third at the expense of design efficiency. Considering that $\mathrm{K}_{\mathrm{Ic}}(\mathrm{J})$ has a linear inverse relationship with $\sigma_{y}$, the designer has the flexibility of adjusting the strength-to-toughness ratio through nitrogen content. Higher $\mathrm{N}$ increases strength at the expense of reduced toughness; lower $\mathrm{N}$ decreases strength but increases toughness.

SUMMARY

Two parameters are most effective in controlling the $4-K$ strength of 316-type alloys: grain size and $\mathrm{N}$ content. Of these, the variation of $\mathrm{N}$ content is the least expensive. Grain-size control of thick plates requires exceptional rolling capacity.

Toughness is shown to depend on $\mathrm{Ni}$ content, inclusion density, and strength. The addition of $\mathrm{Ni}$ is rather expensive, and reduction of inclusions demands careful refining practices. Toughness is sacrificed by increasing strength.

The 316-type alloys provide excellent flexibility for alloy design of a structural material for use at $4 \mathrm{~K}$. Both strength and toughness may be adjusted by alloy addition, refining practice, and thermomechanical processing.

\section{ACKNOWLEDGMENTS}

The research was partially supported by the Office of Fusion Energy, U.S. Department of Energy, V. Der, Project Monitor. We are indebted to $R$. P. Walsh for conducting all the tensile tests and many of the fracture toughness tests. L. L. Scull also greatly assisted us by determining interstitial contents in most of the alloys. AMAX Materials Research Center (P. J. Grobner) and Nippon Kokan Steel, Technical Research Center (C. Ouchi) supplied a series of laboratory heats. Other alloys were provided by Lawrence Livermore National Laboratory (E. N. C. Dalder), Oak Ridge National Laboratory, and Kernforschungszentrum Karlsruhe, Institut für Technische Physik (A. Nyilas).

\section{REFERENCES}

1. R. P. Reed and R. P. Walsh, Low Temperature Deformation of Copper and an Austenitic Stainless Steel. Advances in Cryogenic Engineering-Materials, vol. 32, Plenum Press, New York (1986), pp. 303-312; in press. 
2. Standard Test Method for J Ic, A Measure of Fracture Toughness, 1982 Annual Book of ASTM Standards, Part 10, ASTM E 813-81, American society for Testing and Materials, Philadelphia (1982), pp. 822-840.

3. D. T. Read and R. P. Reed, Fracture and Strength Properties of Selected Austenitic Stainless Steels at Cryogenic Temperatures, Cryogenics, vol. 21 (1981), pp. 415-417.

4. R. L. Tobler, D. H. Beekman, and R. P. Reed, Factors Influencing the Low-Temperature Dependence of Yielding in AISI 316 Stainless Steels, Austenitic Steels at Low Temperatures, Plenum Press, New York (1983), pp. 135-157.

5. R. P. Reed and N. J. Simon, Low Temperature Strengthening of Austenitic Stainless Steels with Nitrogen and Carbon, Advances in Cryogenic Engineering-Materials, vol. 30, Plenum Press, New York (1984), pp. 127-136.

6. R. P. Reed and P. T. Purtscher, Nickel and Nitrogen Alloying Effects on the Strength and Toughness of Austenitic Stainless Steels, Advances in Cryogenic Engineering--Materials, vol. 32, Plenum Press, New York (1986), pp. 43-50; in press.

7. R. L. Tobler, D. T. Read, and R. P. Reed, Strength/Toughness Relationship for Interstitially Strengthened AISI 304 Stainless Steels at $4 \mathrm{~K}$ Temperature, ASTM STP 743, American Society for Testing and Materials, Philadelphia (1982), pp. 250-268.

8. T. Sakamoto, Y. Nakagama, I. Yamauchi, and T. Zaizen, Nitrogen-Containing $25 \mathrm{Cr}=13 \mathrm{Ni}$ Stainless Steel as a Cryogenic Structural Material, Advances in Cryogenic Engineering--Materials, vol. 30, Plenum Presi, New York (1984), pp. 137-144.

9. N. J. Simon and R. P. Reed, Strength and Toughness of AISI 304 and 316 at $4 \mathrm{~K}$, Materials Studies for Magnetic Fusion Energy Applications at Low Temperatures - IX, R. P. Reed, ed., Internal Report, National Bureau of Standards, Boulder, Colorado (1986), pp. 27-42. 
Table 1. Characterization of 316-type Alloys

\begin{tabular}{|c|c|c|c|c|c|c|c|c|c|c|c|}
\hline \multirow[t]{2}{*}{ Alloy } & \multicolumn{9}{|c|}{ Chemical Composition (wt.\%) } & \multirow{2}{*}{$\begin{array}{l}\text { Hardness } \\
\mathrm{R}_{\mathrm{B}}\end{array}$} & \multirow{2}{*}{$\begin{array}{c}\text { Inclusions } \\
n^{-1 / 2}\end{array}$} \\
\hline & $\mathrm{Cr}$ & $\mathrm{Ni}$ & $M n$ & Mo & C & N & $P$ & $S$ & Si & & \\
\hline A & 16.7 & 13.7 & 1.26 & 2.7 & 0.032 & 0.16 & 0.01 & 0.01 & 0.41 & 89 & 0.13 \\
\hline B & 18.5 & 11.4 & 1.40 & 2.5 & 0.008 & 0.17 & 0.002 & 0.001 & 0.40 & 89 & 0.11 \\
\hline C & 16.8 & 13.9 & 1.84 & 2.2 & 0.028 & 0.10 & 0.022 & 0.009 & 0.33 & 88 & 0.095 \\
\hline D & 18.6 & 10.9 & 1.01 & 2.2 & 0.020 & 0.12 & 0.002 & 0.003 & 0.29 & $96-102$ & 0.082 \\
\hline$E$ & 17.4 & 13.9 & 1.58 & 2.5 & 0.016 & 0.16 & 0.021 & 0.021 & 0.48 & 83 & 0.057 \\
\hline F & 17.2 & 13.5 & 1.86 & 2.3 & 0.057 & 0.03 & 0.024 & 0.019 & 0.58 & 79 & 0.054 \\
\hline G & $17 \cdot 3$ & 12.2 & 1.55 & 2.2 & 0.051 & 0.03 & 0.026 & 0.014 & 0.68 & 86 & 0.092 \\
\hline $\mathrm{H}$ & 18.0 & 10.5 & 1.10 & 2.1 & 0.016 & 0.14 & 0.020 & 0.015 & 0.54 & 86 & 0.048 \\
\hline
\end{tabular}

${ }^{*} \mathrm{n}=$ number of inclusions within an area of $1 \mathrm{~mm}^{2}$ 
Table 2. Mechanical Properties of 316-type Alloys at $4 \mathrm{~K}$

\begin{tabular}{|c|c|c|c|c|c|}
\hline Alloy & Tensile & $\begin{array}{l}\text { Elonga- } \\
\text { tion }\end{array}$ & $\begin{array}{l}\text { Reduction } \\
\text { of Area }\end{array}$ & $\begin{array}{c}\text { Fracture Toughness } \\
\mathrm{K}_{\mathrm{Ic}}(\mathrm{J})\end{array}$ & $\begin{array}{c}\text { Grain Size } \\
(\mu \mathrm{m})\end{array}$ \\
\hline
\end{tabular}

\begin{tabular}{|c|c|c|c|c|c|c|c|}
\hline A & 935 & 1480 & 36 & 58 & 140 & 63 & Aged-837 K \\
\hline \multirow[t]{4}{*}{ B } & 1080 & -- & -- & -- & 220 & 13 & Annealed \\
\hline & 942 & 1590 & 42 & 56 & -- & 70 & Annealed \\
\hline & 924 & 1560 & 49 & 61 & 320 & 91 & Annealed \\
\hline & 917 & 1570 & 45 & 57 & 310 & 129 & Annealed \\
\hline C & 830 & 1360 & 45 & 53 & 360 & 31 & Annealed \\
\hline \multirow[t]{9}{*}{$D$} & 1060 & 1730 & 36 & 49 & 150 & -- & Annealed \\
\hline & 940 & 1690 & 41 & 54 & 180 & 11 & Annealed \\
\hline & 880 & 1620 & 41 & 58 & 190 & 20 & Annealed \\
\hline & 870 & 1640 & 43 & 58 & - & 30 & Annealed \\
\hline & 840 & 1630 & 43 & 52 & -- & 50 & Annealed \\
\hline & 1140 & 1750 & 34 & 42 & 180 & 44 & Hot rolled \\
\hline & 1080 & 1750 & 38 & 48 & 170 & 51 & Hot rolled \\
\hline & 1020 & 1710 & 37 & 54 & 200 & 53 & Hot rolled \\
\hline & 1020 & 1700 & 38 & 55 & 180 & 41 & Hot rolled \\
\hline $\mathrm{E}$ & 1010 & 1390 & 35 & 50 & 210 & 105 & Annealed \\
\hline F & 710 & 1300 & 48 & 57 & 250 & 65 & Annealed \\
\hline \multirow[t]{2}{*}{ G } & 550 & 1330 & 52 & -- & 400 & -- & Annealed \\
\hline & $500-690$ & - & -- & -- & -- & $20-140$ & Annealed \\
\hline $\mathrm{H}^{*}$ & 860 & 1640 & 55 & & 170 & 70 & Annealed \\
\hline $\mathrm{H}^{+}$ & 850 & 1640 & 52 & & 200 & 70 & Annealed \\
\hline
\end{tabular}

*long itudinal; + transverse 


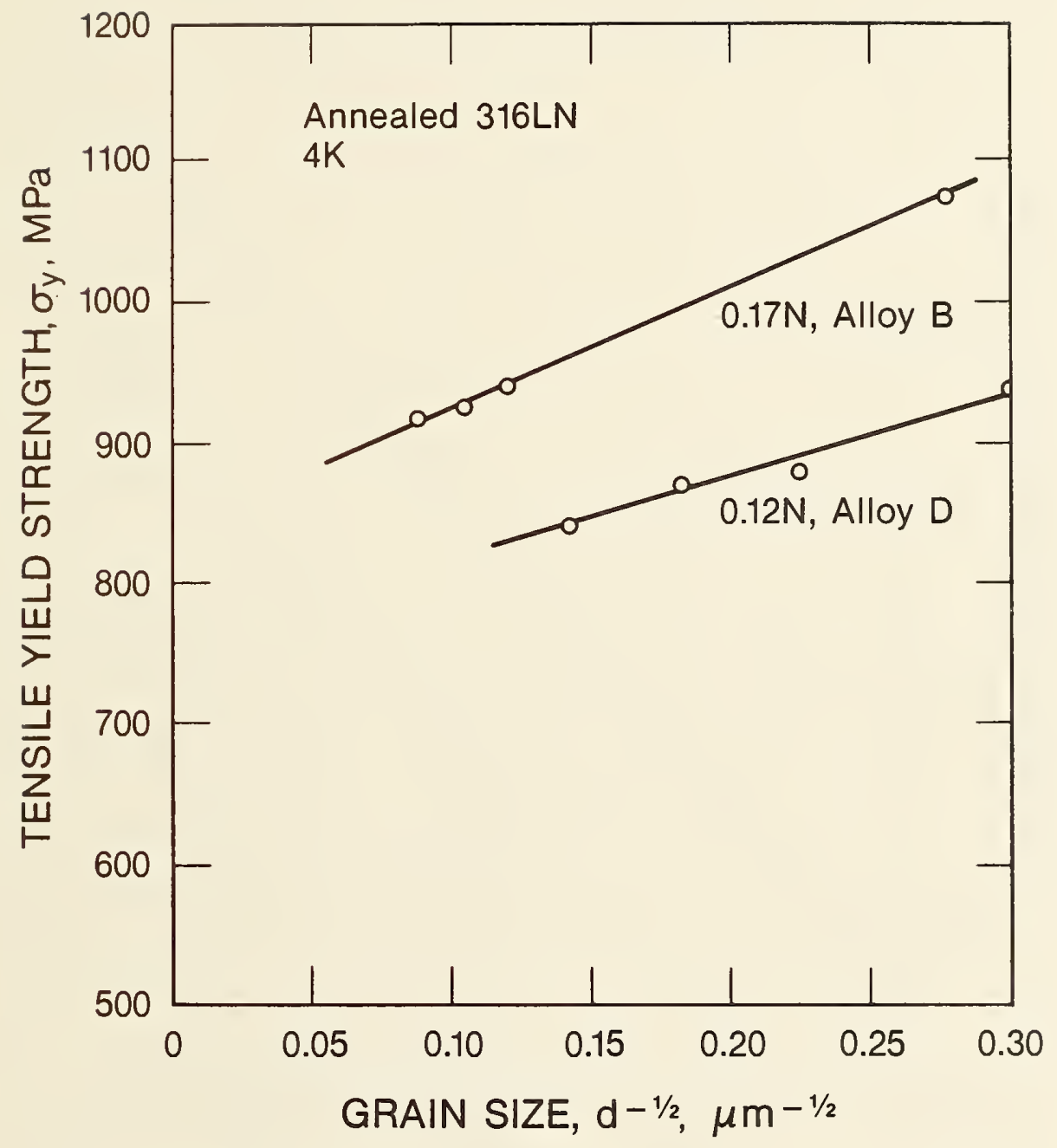

Figure 1. Effect of grain size on the tensile yield strength at $4 \mathrm{~K}$ of two $316 \mathrm{LN}$ alloys. Using Eq. (2), for alloy B, $\sigma_{0}=839 \mathrm{MPa}, m=855$ $\mathrm{MPa}$; for alloy $\mathrm{D}, \sigma_{0}=762 \mathrm{MPa}, \mathrm{m}=570 \mathrm{MPa}$. 


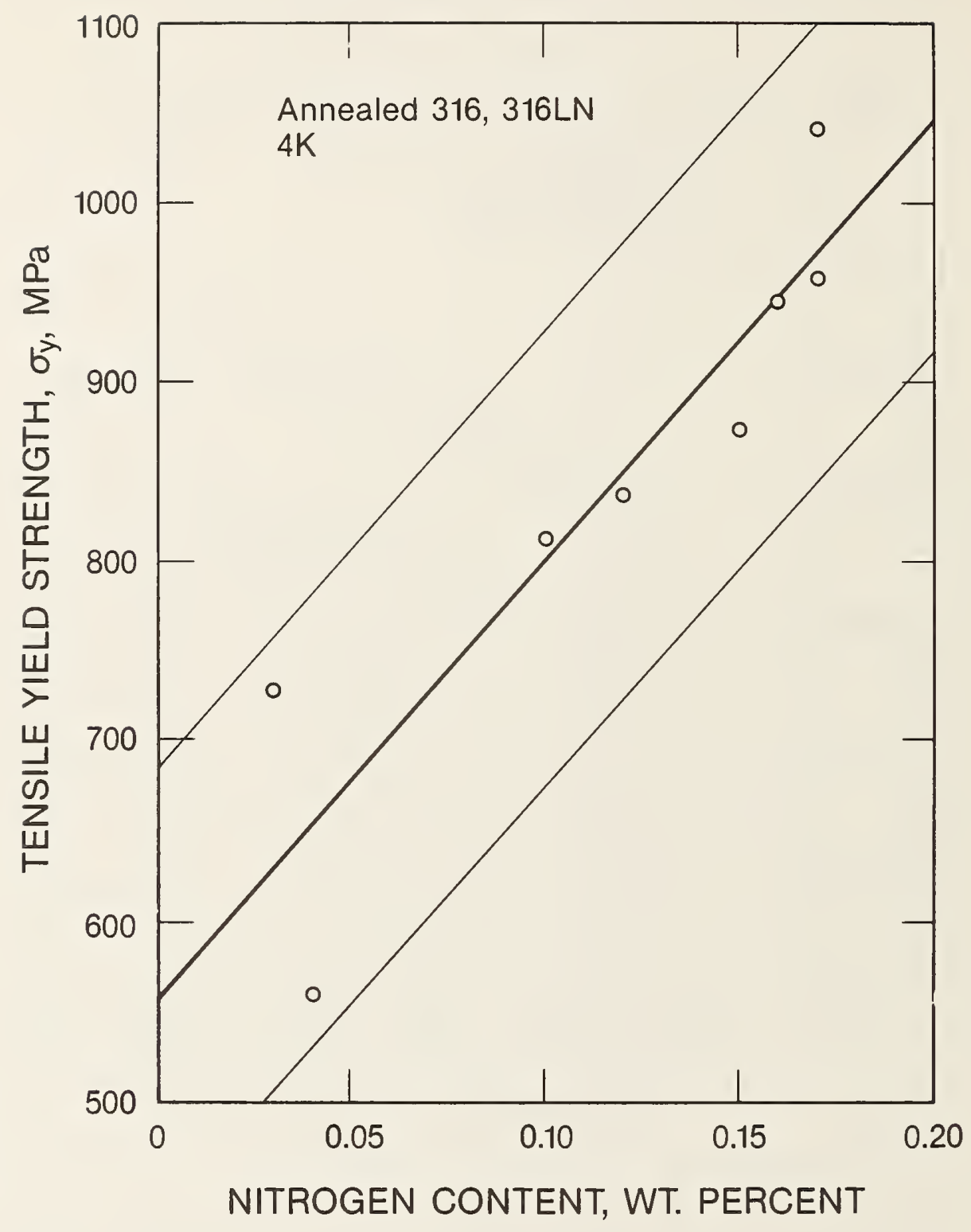

Figure 2. Effect of nitrogen content on the tensile yield strength (normalized to $d=0.50 \mu \mathrm{m}$ ) at $4 \mathrm{~K}$ of 316-type alloys. Data best fit the relation $\sigma_{y}=556+2450[\mathrm{~N}]$ where $S D$ for $\sigma_{y}=64 \mathrm{MPa}$. Scatter bands represent 2 SD. 


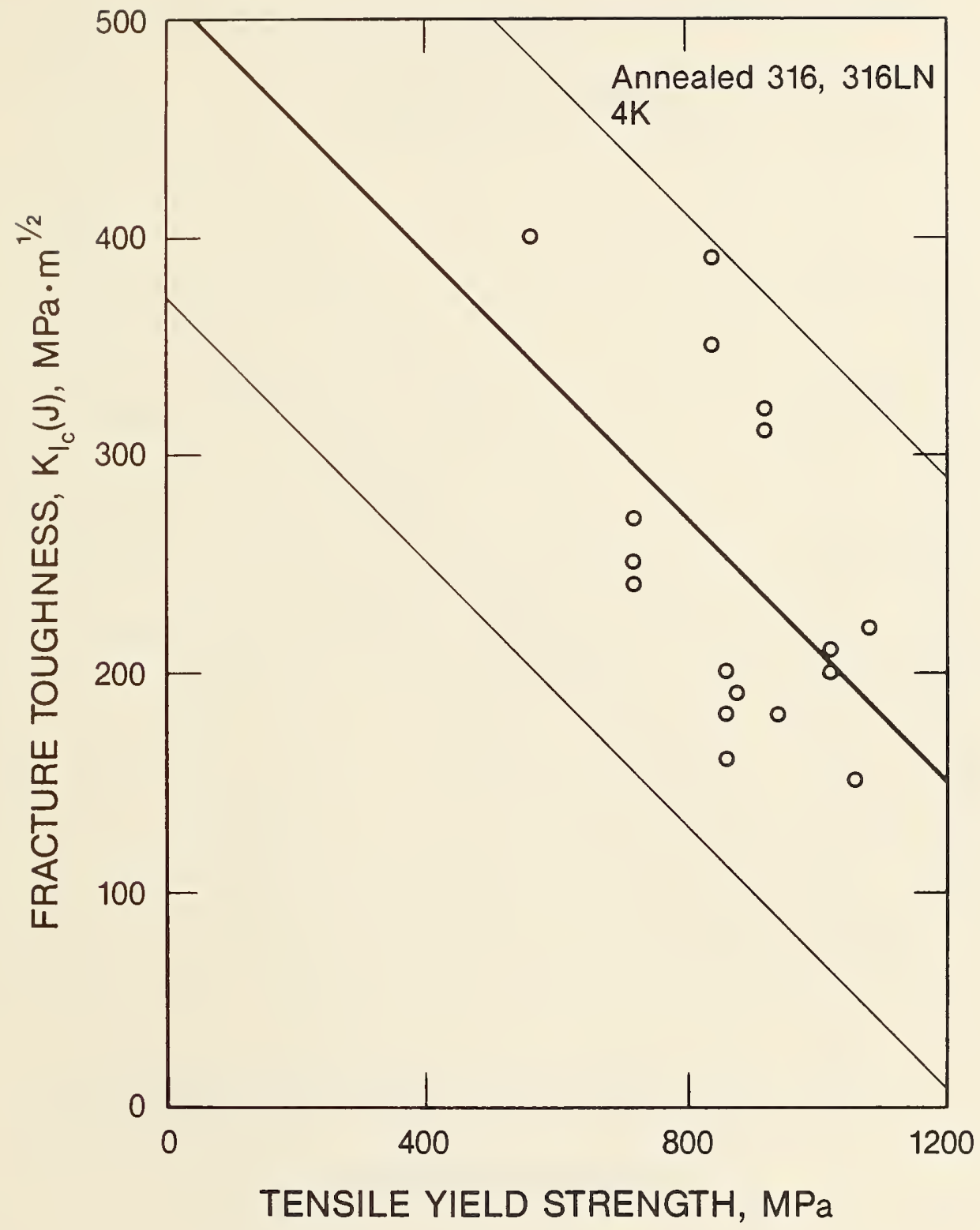

Figure 3. The tensile yield strength versus the fracture toughness at $4 \mathrm{~K}$ for 316-type alloys. Scatter bands represent 2 SD. 


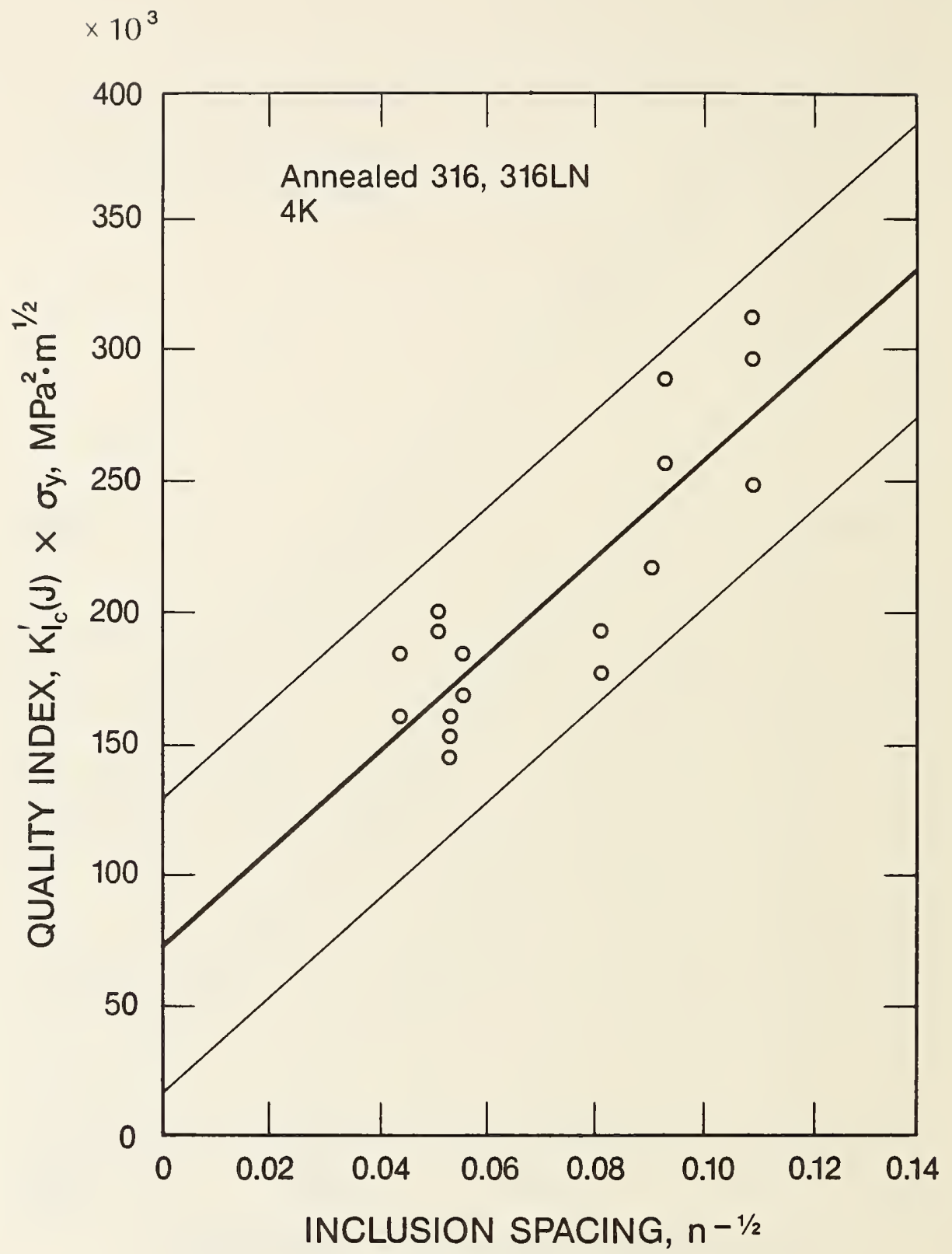

Figure 4. The Quality Index $\mathrm{K}_{\mathrm{Ic}}(\mathrm{J}) \cdot \sigma_{\mathrm{y}}$ at $4 \mathrm{~K}$ versus the average inclusion spacing $\left(n^{-1 / 2}\right)$ for 316 -type alloys. Here $n=$ the number of inclusions $(\geqq 0.5 \mu \mathrm{m})$ in $1 \mathrm{~mm}^{2}$. Data are corrected to $\mathrm{Ni}$ content of 12 wt.\%. Scatter bands represent 2 SD. 




\author{
N. J. Simon and R. P. Reed \\ Fracture and Deformation Division \\ National Bureau of Standards \\ Boulder, Colorado
}

Structural design of superconducting magnets in fusion energy devices requires reliable property data at $4 \mathrm{~K}$. Nitrogen-strengthened AISI 304 and 316 stainless steels are considered to be the best currently available low temperature structural alloys on the basis of their fabricability and their potential to meet the U.S. fusion research goals of combined 1000-MPa yield strength and $200-\mathrm{MPa} \cdot \mathrm{m}^{1 / 2}$ fracture toughness at $4 \mathrm{~K}$. This paper presents provisional equations for the yield strength of 304- and 316-type alloys at $4 \mathrm{~K}$ as a function of $\mathrm{N}$ content and grain size. Provisional equations for the 4-K fracture toughness, $K_{I C}(J)$, of these alloys are presented, in which the effects of yield strength, $\mathrm{Ni}$ and Mn content, and inclusion spacing are expressed quantitatively. The equations result from regression analyses of a matrix of NBS measurements that includes more extensive numerical data on alloying, refining, and processing parameters than have previously been available.

\title{
1. Introduction
}

Superconducting magnets for future fusion energy reactors will require cryogenic structural alloys with improved combinations of yield strength and fracture toughness at $4 \mathrm{~K}$. Recently we have made considerable progress in understanding how quantitative parameters of alloying, refining, and processing can be specified for AISI 300 series stainless steels to achieve the strength/toughness goals of the U.S. fusion program [1].

The structural alloy is required to withstand large magnetic forces in a superconducting magnet system of restricted dimensions, and thus, high strength is needed. In addition, because most structures are complex and have regions of high stress concentration, good fracture toughness is required. Our research has focused on various AISI types of austenitic steels, especially 304 and 316. Metallurgical parameters affecting low temperature mechanical properties have been studied using a series of laboratory heats. Collaboration with recent Japanese austenitic steel development programs has permitted mechanical characterization at $4 \mathrm{~K}$ of some of their new steels. Compilation and critical review of physical and mechanical property data at low temperatures have also been carried out.

*Work supported by the U.S. Department of Energy; not subject to copyright. 
We have found that the strength at $4 \mathrm{~K}$ of austenitic steels depends quite heavily on $\mathrm{N}$ content: each $0.1 \mathrm{wt. \%} \mathrm{N}$ raises the tensile yield strength $\left(\sigma_{y}, 0.2 \%\right.$ offset) by approximately $300 \mathrm{MPa}$ [2]. Additions of other elements, such as $\mathrm{C}, \mathrm{Ni}, \mathrm{Mn}$, and $\mathrm{Cr}$, contribute much less significantly to the low temperature strength. The yield strength is also dependent on grain size: an increase of grain size from 20 to $100 \mu \mathrm{m}$ results in a decrease of $\sigma_{\mathrm{y}}$ of about $90 \mathrm{MPa}$ [3]. Thus, one can affect the strength through alloying and thermomechanical processing.

Toughness is adversely affected by increased strength because less energy is dissipated by plastic deformation during the void growth typical of ductile fracture. We have shown that the elastic stress intensity factor $\mathrm{K}_{\mathrm{Ic}}(\mathrm{J})$ [obtained from measurement of the elastic/plastic critical J-integral $\left(J_{I C}\right)$ and calculated from $K_{I C}(J)=\left(J_{I c} \cdot E\right)^{1 / 2}$, where $E$ is Young's modulus] is linearly inversely proportional to $\sigma_{y}$ at $4 \mathrm{~K}[4]$. Toughness also is adversely affected by the presence of inclusions $[3,5]$, which act as initiation sites for microvoid formation. The addition of some alloying elements, such as $\mathrm{Ni}$, has previously been shown to increase the low temperature toughness of austenitic steels when strength and inclusion content are held constant [6].

In comparing heat-to-heat strength and toughness at $4 \mathrm{~K}$, we found a large amount of scatter in the data, about $\pm 100 \%$. Such large scatter in mechanical property data is typical at $4 \mathrm{~K}$ : a much smaller variation is usual at room temperature [7]. To analyze this variability, we assembled a more extensive set of $4-K$ strength and fracture toughness data than has previously been available, combining our recent test data for the two highstrength cryogenic alloys, $304 \mathrm{LN}$ and $316 \mathrm{LN}$, with earlier NBS measurements. We determined quantitatively the effects of grain size and $\mathrm{N}$ content on strength and the effects of strength, alloying, and inclusions on toughness. Our analyses resulted in predictive relations that considerably reduced the scatter of the data. Alloy design (in terms of strength and toughness) is now feasible, within statistical limits of uncertainty. Of course, at this time only research data are generally available. Before large-scale use of one of these alloys in a low temperature structural application, additional heatby heat qualification testing is imperative.

2. Procedure

\subsection{Data matrices}

A series of specimens from both laboratory and commercial heats of AISI 304- and AISI 316-type alloys were tested. The alloys were prepared in the United States, Japan, Europe, and the U.S.S.R. [3,4]. Measurements were made of fracture toughness $\left[\mathrm{K}_{\mathrm{IC}}(\mathrm{J})\right]$ (TL orientation), tensile yield strength, and other tensile properties at $4 \mathrm{~K}$. Grain size, hardness, and chemical composition were also determined and inclusion counts were obtained, as described by R. P. Reed et al. [3]. Only measurements made at NBS were used to make up the data matrices, because previous experience has indicated that lab-to-lab variations in test results are large enough to obscure dependence of cryogenic properties upon parameters. 
There are 25 complete rows in the $\sigma_{y} \times K_{I c}(J)$ matrix for AISI 304-type alloys and 19 complete rows in the corresponding matrix for AISI 316-type alloys. The additional tensile data without corresponding $\mathrm{K}_{\mathrm{Ic}}(\mathrm{J})$ measurements were used in the regression analyses of the tensile yield strength. Tables I and II show the data used in the regression analyses and the reference symbols. Tables III and IV present the complete chemical analyses and hardness of the alloys. Nitrogen content ranges from 0.03 to 0.29 wt.\% for AISI 304-type alloys and from 0.03 to 0.17 wt.\% for AISI 316-type alloys. Nickel content varies from 7.2 to 14.9 wt.\% for AISI 304-type alloys, and from 10.5 to 13.9 wt.\% for AISI 316-type alloys. Manganese content ranges from 1.0 to 10.22 wt.\% for the AISI 304-type alloys. Variation of Mn and Ni content outside the AISI 304 specifications permitted an evaluation of the effects of these elements; also, AISI 304-type alloys have recently been modified for cryogenic service by addition of $\mathrm{Mn}$ and Ni. Grain size varies from 19 to $385 \mu \mathrm{m}$ in the AISI 304 matrix and from 11 to $138 \mu \mathrm{m}$ in the AISI 316 matrix. Inclusion spacing (defined as $\mathrm{n}^{-1 / 2}$ where $\mathrm{n}=$ the number of inclusions per $\mathrm{mm}^{2}$ ) ranges from 0.041 to $0.12 \mathrm{~mm}$ for the AISI 304 matrix and from 0.044 to $0.11 \mathrm{~mm}$ for the AISI 316 matrix. Hardness $\left(R_{B}\right)$ was not used in the analysis, but was found to vary from 72 to 90 for the AISI 304-type specimens and from 79 to 100 for the AISI 316-type specimens. The $\mathrm{K}_{\mathrm{Ic}}(\mathrm{J})$ values obtained from the relationship $\mathrm{K}_{\mathrm{Ic}}(\mathrm{J})=\left[\mathrm{J}_{\mathrm{Ic}} \cdot \mathrm{E} /\left(1-v^{2}\right)\right]^{1 / 2}$, where $\nu$ is Poisson's ratio, were adjusted in accord with the formulation $\mathrm{K}_{\mathrm{Ic}}(\mathrm{J})=\left(\mathrm{J}_{\mathrm{Ic}} \mathrm{E}^{\mathrm{E}}\right)^{1 / 2}$. All data points of the matrices were weighted equally in the regression analyses described below.

\subsection{Analysis of tensile yield strength}

Enough data were available to assess quantitatively the effects of grain size and nitrogen content upon 4-K yield strength of both AISI 304- and AISI 316-type alloys. Earlier studies cited above have shown that these are the most significant variables. In accord with the well-known Hall-Petch grain size effect on yield strength and the higher temperature results of Norström [15], the form of the equation fitted to the data was

$$
\sigma_{y}=\sigma_{0}+s_{N}[N]+s_{d} d^{-1 / 2}
$$

where [N] is wt.\% $N$, $d$ is the grain size $(\mu \mathrm{m})$, and $\sigma_{0}$ is the yield strength in the absence of $N$ with infinite grain size. Quantification of the strengthening effects of solid-solution alloying elements such as $\mathrm{Ni}$ would require a more extensive data set, but are expected to be much less. The contribution from $C$ is expected to be about one-half that of $N$ [2], but it is best to hold $C$ content low $(-0.03$ wt.\%) to minimize sensitization during welding.

\subsection{Analysis of fracture toughness}

The dependence of $\mathrm{K}_{\mathrm{Ic}}(\mathrm{J})$ upon yield strength at $4 \mathrm{~K}$ has been observed previously in our laboratory $[8,16]$, and a recent study of the effect of $N i$ on toughness of AISI 304-type alloys showed a strong dependence [6]. Manganese is expected to have a similar, but weaker, effect. To assess the relative importance of inclusion spacing with respect to the other two variables, the following equation was fitted to the AISI 304 data: 


$$
K_{I C}(J)=k_{0}+k_{0} \sigma_{y}+k_{N}([N i]+0.5[M n])+k_{n} n^{-1 / 2} \text {, }
$$

where [Ni] represents wt.\% $\mathrm{Ni},[\mathrm{Mn}]$ wt.\% $\mathrm{Mn}$, and $\mathrm{k}_{0}$ is a constant. Another way of handling the effect of inclusion spacing is to to normalize $K_{I C}(J)$ as follows:

$$
K_{I c}(J) / n^{-1 / 2}=k_{0}^{\prime}+k_{0}^{\prime} \sigma_{y}+k_{N}^{\prime}([\mathrm{Ni}]+0.5[\mathrm{Mn}]) .
$$

This equation also was fitted to the 304 data. Since Mn content of the AISI 316-type alloys varied only slightly, the [Mn] term was dropped from Equations (2) and (3) for the analyses of these alloys.

3. Results and discussion

\subsection{Tensile yield strength}

The equation for 4-K tensile yield strength of AISI 304-type alloys resulting from a regression on a set of 30 measurements is:

$$
\sigma_{\mathrm{y}}(\mathrm{MPa})=215+3190[\mathrm{~N}]+1093 \mathrm{~d}^{-1 / 2} \text {. }
$$

The standard deviation (SD) of the fit to the data is $84 \mathrm{MPa}$; the SD'S of the three coefficients are 62, 230, and 383, respectively. For AISI 316-type alloys, the comparable equation resulting from regression on a set of 26 measurements is:

$$
\sigma_{\mathrm{y}}(\mathrm{MPa})=381+2776[\mathrm{~N}]+811 \mathrm{~d}^{-1 / 2} \text {. }
$$

The SD of the fit to the data is $55 \mathrm{MPa}$; the SD's of the three coefficients are 34, 193, and 199. Figures 1 and 2 show the measured $\sigma_{y}$ versus the $\sigma_{y}$ predicted by Equations (4) and (5) for both alloys.

The dependence of $\sigma_{y}$ on $N$ in Equations (4) and (5) is slightly less than that reported by Reed and Simon [2] from a different set of AISI 304-type alloy data (not restricted to NBS measurements). The higher value of $\sigma_{0}$ for AISI 316-type alloys reflects the strengthening contribution of Mo. It is not clear why we obtain a better data fit (lower SD) for the AISI 316-type alloys. Many of the AISI 316 alloys are from commercial heats (17 out of 26 ); more of the AISI 304-type alloys are from laboratory heats (27 of 30). Perhaps these data reflect better quality control of the producers in the larger commercial heats.

\subsection{Fracture toughness}

The fit of Equation (2) to the 304 data gives:

$$
\begin{aligned}
\mathrm{K}_{\mathrm{IC}}(\mathrm{J})\left(\mathrm{MPa} \cdot \mathrm{m}^{1 / 2}\right)= & 209-0.226 \sigma_{\mathrm{y}}+14.4([\mathrm{Ni}]+0.5[\mathrm{Mn}]) \\
& +294 \mathrm{n}^{-1 / 2}
\end{aligned}
$$


where the SD of the fit to the data is $31 \mathrm{MPa} \cdot \mathrm{m}^{1 / 2}$ and the $\mathrm{SD}$ 's of the coefficients are 40,0.026, 2.9 and 316. For the 316 data, the analogous result is:

$$
K_{I C}(J)\left(\mathrm{MPa} \cdot \mathrm{m}^{1 / 2}\right)=130-0.338 \sigma_{\mathrm{y}}+20.2[\mathrm{Ni}]+2252 \mathrm{n}^{-1 / 2}
$$

The SD of the fit to the data is $31 \mathrm{MPa} \cdot \mathrm{m}^{1 / 2}$, and the SD's of the coefficients are $89,0.059,5.2$, and 310. Figures 3 and 4 show the measured $\mathrm{K}_{\mathrm{Ic}}(\mathrm{J})$ versus $K_{I C}(J)$ predicted from Equations (6) and (7). Equations (6) and (7) imply that the fracture toughness of the AISI 316 alloys is more sensitive to all major variables than that of the AISI 304 alloys. The explanation of this awaits more detailed studies of the effects of metallurgical variables on the J-integral fracture toughness at low temperatures. In the set of measurements analyzed here, the AISI 304-type laboratory heats generally have a higher level of inclusions than the commercial heats. However, for the AISI 316-type alloys the situation is reversed: the laboratory heats are cleaner.

The SD's of the fits of both alloy types to Equation (2) were considered to be small enough ( $31 \mathrm{MPa}$ ) that the equations could give useful predictions for alloy design. However, there are significant differences in the coefficients for AISI 304- and 316-type alloys. In contrast, the coefficients resulting from fits of Equation (3) to both alloy series were remarkably similar. The SD's of these fits to Equation (3) were higher than for the fits to Equation (2), so these equations are not recommended for predictive purposes at present, but are set forth here for their heuristic value.

$$
\text { 304: } \mathrm{K}_{\mathrm{IC}}(\mathrm{J}) / \mathrm{n}^{-1 / 2}=5555-4.99 \sigma_{\mathrm{y}}+189([\mathrm{Ni}]+0.5[\mathrm{Mn}])
$$

The SD of the fit $\left[\right.$ to $\left.K_{I C}(J)\right]$ is $76 \mathrm{MPa} \cdot \mathrm{m}^{1 / 2}$; the SD's of the coefficients are $1324,0.92$, and 101 .

$$
\text { 316: } K_{I C}(J) / n^{-1 / 2}=5024-4.80 \sigma_{y}+218[\mathrm{Ni}]
$$

The SD of the fit $\left[\right.$ to $\left.K_{I C}(J)\right]$ is $38 \mathrm{MPa} \cdot \mathrm{m}^{1 / 2}$; the SD's of the coefficients are $1577,1.0$, and 92 .

$-1 / 2$ Compared with a fit of $\mathrm{K}_{\mathrm{Ic}}(\mathrm{J})$ on $\sigma_{\mathrm{y}}$ alone, the additions of both the $\mathrm{n}-1 / 2$ term and the $[\mathrm{Ni}]$ or ( $[\mathrm{Ni}]+0.5$ ( $[\mathrm{Mn}]$ ) term were effective in reducing the SD of the fits, except for Equation (6), in which the addition of the $\mathrm{n}^{-1 / 2}$ term does not affect the SD. This term is presented for comparison with Equation (7). It is difficult to measure inclusion spacing unambiguously [3], but inclusions do have a pronounced effect upon the 4-K fracture toughness of the AISI 316-type alloys. Further inclusion studies should be carried out on commercial heats of AISI 304-type alloys.

\subsection{Alloy design}

Equations (4) through (7) can be used to set provisional design values for yield strength and fracture toughness. For example, to achieve the U.S. research goal of $\sigma_{y}=1000 \mathrm{MPa}$ [1] for a 304LHN (316LHN) with [N] $=0.20$ wt.\%, a grain size of $55(162) \mu \mathrm{m}$ is required. [The uncertainty in grain size is 
$\pm 25(44) \mu m$, assuming that the the fractional error in grain size is given by the square root of the sum of the squares of the fractional errors in the other terms of the equation. The fractional error of each term is obtained by dividing the SD of the coefficient by the value of the coefficient.] Since the control of grain size to $55 \mu \mathrm{m}$ is difficult for most mills when rolling thick-section $(50-120 \mathrm{~mm})$ plate, this implies that AISI 316-type alloys would be a sounder choice to achieve such high strength.

Assuming further that $[\mathrm{Ni}]=12 \mathrm{wt. \%}$ and $[\mathrm{Mn}]=2 \mathrm{wt. \%}$, achievement of the U.S. research goal of $\mathrm{K}_{\mathrm{IC}}=200 \mathrm{MPa} \cdot \mathrm{m}^{1 / 2}$ would require a minimum inclusion spacing of $0.10(0.073) \mathrm{mm}$ for AISI 304LHN(316LHN). However, the uncertainty is too large: $\pm 0.11(0.056) \mathrm{mm}$. This indicates that additional studies are required to characterize the effect of inclusions on the fracture toughness of austenitic steels at $4 \mathrm{~K}$. Further studies to relate composition and other variables to the weldability of these alloys are also necessary [17].

4. Summary

Matrices of NBS measurements of $\sigma_{y}$ and $K_{I c}(J)$ at $4 \mathrm{~K}$ that include numerical data on alloying, refining, and processing variables were analyzed using linear regression methods. The AISI 304- and 316-type alloys tested were obtained from a variety of sources and included both commercial and laboratory heats.

Tensile yield strength: Provisional equations were developed for estimating $\sigma_{\mathrm{y}}$ at $4 \mathrm{~K}$ from $[\mathrm{N}]$ and $\mathrm{d}^{-1 / 2}$.

Fracture toughness: Provisional equations for estimating $\mathrm{K}_{\mathrm{IC}}(\mathrm{J})$ at $4 \mathrm{~K}$ from $\sigma_{y},[\mathrm{Ni}],[\mathrm{Mn}]$, and $n^{-1 / 2}$ were determined. In addition, the predictions of the quantity $\mathrm{K}_{\mathrm{IC}}(\mathrm{J}) / \mathrm{n}^{-1 / 2}$ from $\sigma_{\mathrm{y}}$ and $[\mathrm{Ni}]$ were found to be similar, within the statistical uncertainty, for both AISI 304- and 316-type alloys.

The equations presented are expected be useful for alloy design and for tentative estimates of attainable fracture toughness and tensile yield strength at $4 \mathrm{~K}$ for austenitic stainless steels.

\section{Acknowledgments}

The research was partially supported by the Office of Fusion Energy, U.S. Department of Energy, V. Der, Project Monitor. We are indebted to R. P. Walsh for conducting many of the tensile and fracture toughness tests and to P. T. Purtscher for the inclusion analysis. L. L. Scull also greatly assisted us by determining interstitial contents in most of the alloys. AISI 316-type alloys were supplied by AMAX Materials Research Center (P. J. Grobner), and Nippon Kokan Steel, Technical Research Center (C. Ouchi) kindly supplied a series of laboratory heats. Other alloys were provided by Lawrence Livermore National Laboratory (E. N. C. Dalder), Oak Ridge National Laboratory, and Kernforschungszentrum Karlsruhe, Institut für Technische Physik (A. Nyilas). The laboratory heats of AISI 304-type alloys were suppled by U.S. Steel, ARMCO, Carpenter Technology, and the E. O. Paton Institute of Electrowelding, Kiev, U.S.S.R. (K. Yushchenko). 


\section{References}

[1] H. I. Mcilenry, in: Materials Studies for Magnetic Fusion Energy Applications at Low Temperatures - VIII, Internal Report 85-3025, Ed.

R. P. Reed (U.S. National Bureau of Standards, Boulder, Colorado, 1985) p. 21 .

[2] R. P. Reed and N. J. Simon, in: Advances in Cryogenic Engineering Materials, vol. 30, Eds. A. F. Clark and R. P. Reed (Plenum Press, New York, 1984) p. 127.

[3] R. P. Reed, N. J. Simon, P. T. Purtscher, and R. L. Tobler, Materials Studies for Magnetic Fusion Energy Applications at Low Temperatures IX, Internal Report, Ed. R. P. Reed (U.S. National Bureau of Standards, Boulder, Colorado, 1986) p. 15.

[4] R. L. Tobler, D. T. Read, and R. P. Reed, in: ASTM STP 743 (American Society Testing Materials, Philadelphia, Pennsylvania, 1982), p. 250.

[5] T. Sakamoto, Y. Nakagama, I. Yamauchi, and T. Zaizen, Advances in Cryogenic Engineering - Materials, vol. 30, Eds. A. F. Clark and R. P. Reed (Plenum Press, New York, 1984) p. 137.

[6] R. P. Reed and P. T. Purtscher, Advances in Cryogenic Engineering - Materials, vol. 32, Eds. R. P. Reed and A. F. Clark (Plenum Press, New York, 1986) p. 43; in press.

[7] N. J. Simon and R. P. Reed, Preliminary Draft, Structural Materials for Superconducting Magnets, III. AISI 304 Stainless Steel, (U.S. National Bureau of Standards, Boulder, Colorado, 1985); unpublished.

[8] R. L. Tobler and R. P. Reed, in: Materials Studies for Magnetic Fusion Energy Applications at Low Temperatures - III, Internal Report 80-1627, Ed. R. P. Reed (U.S. National Bureau of Standards, Boulder, Colorado, 1980) p. 15.

[9] R. P. Reed, Test results of an AISI 304-type alloy, National Bureau of Standards; unpublished data.

[10] D. T. Read and R. P. Reed, in: Materials Studies for Magnetic Fusion Energy Applications at Low Temperatures - II, Internal Report 79-1609, Eds. F. R. Fickett and R. P. Reed (U.S. National Bureau of Standards, Boulder, Colorado, 1979) p. 79.

[11] D. T. Read and R. P. Reed, in: Materials Studies for Magnetic Fusion Energy Applications at Low Temperatures - I, Internal Report 78-884, Eds. F. R. Fickett and R. F. Reed (U.S. National Bureau of Standards, Boulder, Colorado, 1978) p. 91.

[12] R. L. Tobler, R. F. Reed, and D. S. Burkhalter, in: Advances in Cryogenic Engineering - Materials, vol. 26, Eds. A. F. Clark and R. P. Reed (Plenum Press, New York, 1980) p. 107. 
[13] R. L. Tobler, R. P. Mikesell, R. L. Durcholz, C. W. Fowlkes, and R. P. Reed, in: Semi-Annual Report on Materials Research in Support of Superconducting Machinery, Internal Report 74-359, (U.S. National Bureau of Standards, Boulder, Colorado, 1974) p. 182.

[14] R. L. Tobler and R. P. Reed, in: Materials Studies for Magnetic Fusion Energy Applications at Low Temperatures - IV, Internal Report 81-1645, Eds. R. P. Reed and N. J. Simon (U.S. National Bureau of Standards, Boulder, Colorado, 1981) p. 147.

[15] L.-A. Norström, Met.Sci. 11 (1977) 208.

[16] R. L. Tobler, T. A. Siewert, and H. I. Mchenry, in: Material Studies for Magnetic Fusion Energy - IX, Internal Report, Ed. R. P. Reed (U.S. National Bureau of Standards, Boulder, Colorado, 1986) p. 239.

[17] E. N. C. Dalder and M. C. Juhas, Nucl. Eng. Des. (1986) to be published. 
Table II. $\sigma_{y} x K_{\text {Ic }}$ Matrix, AISI 316-type Alloys

\begin{tabular}{|c|c|c|c|c|c|c|c|}
\hline Alloy & $\begin{array}{l}\text { ôy, } \\
\text { MṔa }\end{array}$ & $\begin{array}{l}\text { N, } \\
\text { wt.\% }\end{array}$ & $\begin{array}{l}\mathrm{d}, \\
\mu \mathrm{m}\end{array}$ & $\begin{array}{l}\mathrm{K}_{\mathrm{IC}} \\
\mathrm{MPa} \cdot \mathrm{m}^{1 / 2}\end{array}$ & $\begin{array}{l}\mathrm{Ni} \\
\text { wt.\% }\end{array}$ & $\begin{array}{l}\text { Mn, } \\
\text { wt.\% }\end{array}$ & $\mathrm{n}_{\mathrm{mm}}^{-1 / 2}$, * \\
\hline$A[9]$ & 935 & 0.16 & 63 & - & $13 \cdot 7$ & 1.26 & - \\
\hline \multirow[t]{4}{*}{$B$ [9] } & 1076 & 0.17 & 13 & 219 & 11.4 & 1.40 & 0.11 \\
\hline & 942 & 0.17 & 70 & -- & 11.4 & 1.40 & -- \\
\hline & 924 & 0.17 & 91 & 324 & 11.4 & 1.40 & 0.11 \\
\hline & 917 & 0.17 & 129 & 313 & 11.4 & 1.40 & 0.11 \\
\hline \multirow[t]{3}{*}{$C[9]$} & 834 & 0.10 & 31 & 350 & 13.9 & 1.84 & 0.095 \\
\hline & 834 & 0.10 & 31 & 390 & 13.9 & 1.84 & 0.095 \\
\hline & 834 & 0.10 & 31 & 350 & 13.9 & 1.84 & 0.095 \\
\hline \multirow[t]{5}{*}{$\mathrm{D}[9]$} & 1056 & 0.12 & -- & 150 & 10.9 & 1.01 & 0.082 \\
\hline & 935 & 0.12 & 11 & 180 & 10.9 & 1.01 & 0.082 \\
\hline & 885 & 0.12 & 20 & 190 & 10.9 & 1.01 & 0.082 \\
\hline & 869 & 0.12 & 30 & - & 10.7 & 1.01 & - \\
\hline & 842 & 0.12 & 50 & - & 10.9 & 1.01 & -- \\
\hline \multirow[t]{2}{*}{$E[10]$} & 1010 & 0.17 & 105 & 200 & 13.9 & 1.58 & 0.057 \\
\hline & 1010 & 0.17 & 105 & c14 & 13.9 & 1.58 & 0.057 \\
\hline \multirow[t]{5}{*}{$F[10,12]$} & 711 & 0.03 & 65 & 266 & 13.5 & 1.86 & 0.054 \\
\hline & 711 & 0.03 & 65 & 254 & 13.5 & 1.86 & 0.054 \\
\hline & 711 & 0.03 & 65 & 243 & 13.5 & 1.86 & 0.054 \\
\hline & 663 & 0.03 & 67 & -- & 13.5 & 1.86 & -- \\
\hline & 656 & 0.03 & 67 & - & 13.5 & 1.86 & -- \\
\hline \multirow[t]{11}{*}{$G[13,14]$} & 550 & 0.04 & 64 & 400 & 12.2 & 1.55 & 0.092 \\
\hline & 690 & 0.04 & 22 & -- & 12.2 & 1.55 & - \\
\hline & 661 & 0.04 & 28 & - & 12.2 & 1.55 & -- \\
\hline & 640 & 0.04 & 32 & - & 12.2 & 1.55 & - \\
\hline & 553 & 0.04 & 49 & - & 12.2 & 1.55 & - \\
\hline & 540 & 0.04 & 55 & - & 12.2 & 1.55 & - \\
\hline & 562 & 0.04 & 58 & - & 12.2 & 1.55 & - \\
\hline & 535 & 0.04 & 61 & - & 12.2 & 1.55 & - \\
\hline & 535 & 0.04 & 81 & - & 12.2 & 1.55 & - \\
\hline & 530 & 0.04 & 118 & - & 12.2 & 1.55 & - \\
\hline & 505 & 0.04 & 138 & - & 12.2 & 1.55 & 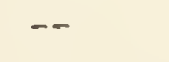 \\
\hline \multirow[t]{4}{*}{$\mathrm{H}$ [9] } & 859 & 0.15 & 70 & 159 & 10.5 & 1.10 & 0.044 \\
\hline & 859 & 0.15 & 70 & 181 & 10.5 & 1.10 & 0.044 \\
\hline & 854 & 0.15 & 70 & 197 & 10.5 & 1.10 & 0.052 \\
\hline & 854 & 0.15 & 70 & 203 & 10.5 & 1.10 & 0.052 \\
\hline
\end{tabular}

${ }^{*} \mathrm{n}=$ the number of inclusions per $\mathrm{mm}^{2}$. 
Table I. $\sigma_{y} \mathrm{x} K_{\text {Ic }}$ Matrix, AISI 304-type Alloys

\begin{tabular}{|c|c|c|c|c|c|c|c|}
\hline Alloy & $\begin{array}{l}\sigma_{\mathrm{y}}, \\
\mathrm{MPa}\end{array}$ & $\begin{array}{l}N, \\
w t . \%\end{array}$ & $\begin{array}{l}\mathrm{d}, \\
\mu \mathrm{m}\end{array}$ & $\underset{\mathrm{MPa} \cdot \mathrm{K}^{\mathrm{I}}{ }^{\prime}}{ }$ & $\begin{array}{l}\mathrm{Ni}, \\
\mathrm{wt} . \%\end{array}$ & $\begin{array}{l}\text { Mn, } \\
\text { wt.\% }\end{array}$ & $\mathrm{n}_{\mathrm{mm}}^{-1 / 2}$ \\
\hline$A \quad[8]$ & $\begin{array}{r}880 \\
1190 \\
530 \\
740 \\
1290\end{array}$ & $\begin{array}{l}0.16 \\
0.29 \\
0.04 \\
0.14 \\
0.26\end{array}$ & $\begin{array}{r}85 \\
98 \\
90 \\
105 \\
90\end{array}$ & $\begin{array}{l}218 \\
118 \\
320 \\
250 \\
118\end{array}$ & $\begin{array}{r}9.91 \\
9.97 \\
10.1 \\
9.9 \\
10.0\end{array}$ & $\begin{array}{l}1.50 \\
1.42 \\
1.57 \\
1.50 \\
1.42\end{array}$ & $\begin{array}{l}0.063 \\
0.054 \\
0.041 \\
0.057 \\
0.055\end{array}$ \\
\hline$B$ [9] & $\begin{array}{r}620 \\
760 \\
880 \\
1050\end{array}$ & $\begin{array}{l}0.11 \\
0.11 \\
0.19 \\
0.21\end{array}$ & $\begin{array}{l}57 \\
57 \\
55 \\
53\end{array}$ & $\begin{array}{l}150 \\
230 \\
110 \\
150\end{array}$ & $\begin{array}{l}8.68 \\
8.62 \\
7.81 \\
7.83\end{array}$ & $\begin{array}{l}1.02 \\
5.81 \\
1.19 \\
5.79\end{array}$ & $\begin{array}{l}0.044 \\
0.041 \\
0.047 \\
0.057\end{array}$ \\
\hline$C[9]$ & $\begin{array}{r}970 \\
1090 \\
1040 \\
980\end{array}$ & $\begin{array}{l}0.20 \\
0.21 \\
0.21 \\
0.19\end{array}$ & $\begin{array}{l}150 \\
130 \\
125 \\
100\end{array}$ & $\begin{array}{l}110 \\
140 \\
160 \\
140\end{array}$ & $\begin{array}{l}7.36 \\
7.15 \\
9.09 \\
7.02\end{array}$ & $\begin{array}{c}4.17 \\
10.22 \\
4.33 \\
7.5\end{array}$ & $\begin{array}{l}0.047 \\
0.050 \\
0.054 \\
0.054\end{array}$ \\
\hline $\mathrm{D}$ [9] & 350 & 0.03 & 210 & 330 & 9.72 & 1.28 & 0.044 \\
\hline$E[10]$ & 770 & 0.13 & 57 & 210 & 8.60 & 1.74 & 0.123 \\
\hline$F[10]$ & 1340 & 0.28 & 55 & 91 & 8.44 & 1.83 & 0.107 \\
\hline$G \quad[6]$ & $\begin{array}{r}950 \\
460 \\
1000 \\
720 \\
1160 \\
870\end{array}$ & $\begin{array}{l}0.28 \\
0.09 \\
0.26 \\
0.14 \\
0.28 \\
0.20\end{array}$ & $\begin{array}{l}200 \\
325 \\
385 \\
340 \\
225 \\
320\end{array}$ & $\begin{array}{l}143 \\
273 \\
204 \\
244 \\
239 \\
254\end{array}$ & $\begin{array}{r}8.9 \\
8.7 \\
12.8 \\
11.5 \\
14.9 \\
14.7\end{array}$ & $\begin{array}{l}4.2 \\
3.7 \\
5.5 \\
3.9 \\
5.2 \\
4.4\end{array}$ & $\begin{array}{l}0.063 \\
0.057 \\
0.066 \\
0.057 \\
0.070 \\
0.070\end{array}$ \\
\hline $\mathrm{H}[9]$ & $\begin{array}{l}720 \\
680 \\
817 \\
784 \\
719 \\
720 \\
697\end{array}$ & $\begin{array}{l}0.12 \\
0.12 \\
0.12 \\
0.12 \\
0.12 \\
0.12 \\
0.12\end{array}$ & $\begin{array}{r}75 \\
80 \\
19 \\
23 \\
161 \\
161 \\
50\end{array}$ & $\begin{array}{l}202 \\
212 \\
-- \\
-- \\
-- \\
-- \\
214\end{array}$ & $\begin{array}{l}10.8 \\
10.8 \\
10.8 \\
10.8 \\
10.8 \\
10.8 \\
10.8\end{array}$ & $\begin{array}{l}1.02 \\
1.02 \\
1.02 \\
1.02 \\
1.02 \\
1.02 \\
1.02\end{array}$ & $\begin{array}{l}0.074 \\
0.074 \\
-- \\
-- \\
-- \\
-- \\
--\end{array}$ \\
\hline I $[11]$ & 794 & 0.12 & 120 & 214 & 9.49 & 1.88 & 0.101 \\
\hline
\end{tabular}

* $\mathrm{n}=$ the number of inclusions per $\mathrm{mm}^{2}$ 
Table IV. Chemical Composition and Hardness of AISI 316-type Alloys

\begin{tabular}{lllllllllllll}
\hline Alloy & & & \multicolumn{8}{c}{ Chemical composition, wt.\% } & & Hardness \\
& Cr & Ni & Mn & Mo & C & N & P & S & Si & $R_{B}$ \\
\hline A & 16.7 & 13.7 & 1.26 & 2.7 & 0.032 & 0.16 & 0.01 & 0.01 & 0.41 & 89 \\
B & 18.5 & 11.4 & 1.40 & 2.5 & 0.008 & 0.17 & 0.002 & 0.001 & 0.40 & 89 \\
C & 16.8 & 13.9 & 1.84 & 2.2 & 0.028 & 0.10 & 0.022 & 0.009 & 0.33 & 88 \\
D & 18.6 & 10.9 & 1.01 & 2.2 & 0.020 & 0.12 & 0.002 & 0.003 & 0.29 & $96-102$ \\
E & 17.4 & 13.9 & 1.58 & 2.5 & 0.016 & 0.16 & 0.021 & 0.021 & 0.48 & 83 \\
F & 17.2 & 13.5 & 1.86 & 2.3 & 0.057 & 0.03 & 0.024 & 0.019 & 0.58 & 79 \\
G & 17.3 & 12.2 & 1.55 & 2.2 & 0.051 & 0.03 & 0.026 & 0.014 & 0.68 & 86 \\
H & 18.0 & 10.5 & 1.10 & 2.1 & 0.016 & 0.14 & 0.020 & 0.015 & 0.54 & 86 \\
\hline
\end{tabular}




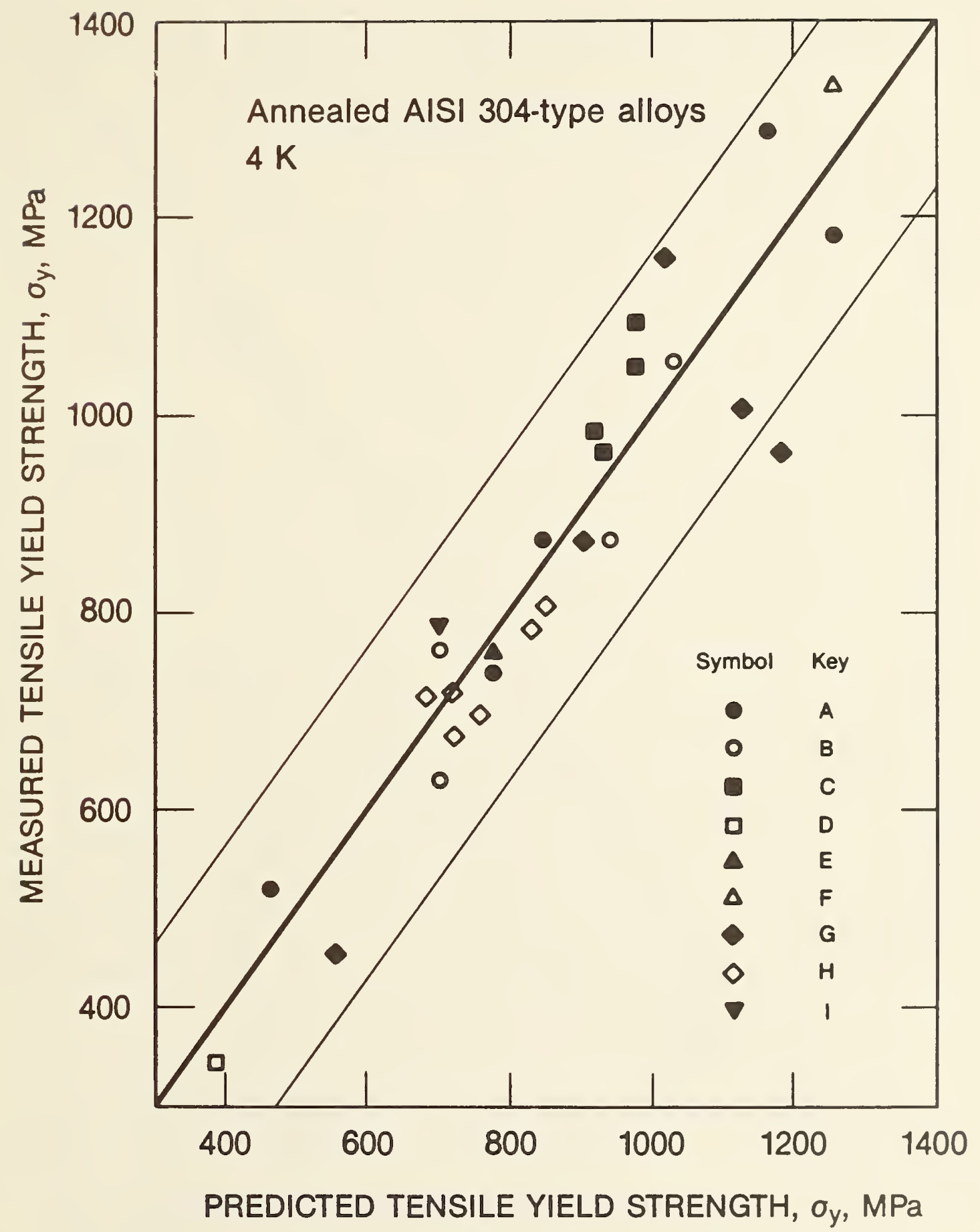

Figure 1. Measured tensile yield strength at $4 \mathrm{~K}$ of AISI 304-type alloys versus tensile yield strength calculated from Equation (4). The scatterband indicates \pm 2 SD's. Keys to symbols representing test specimens are given in Tables I - IV. 


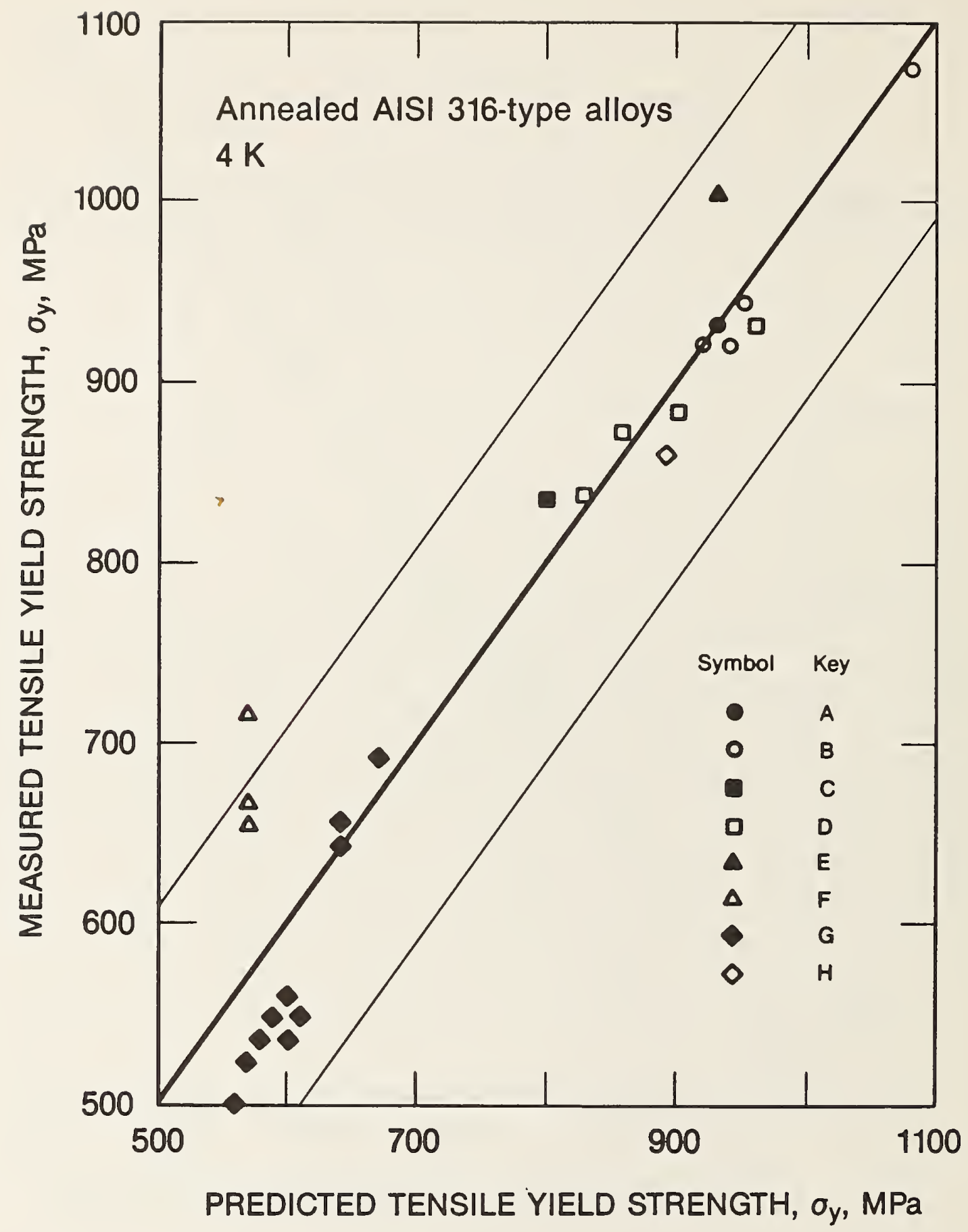

Figure 2. Measured tensile yield strength at $4 \mathrm{~K}$ of AISI 316-type alloys versus tensile yield strength calculated from Equation (5). The scatterband indicates $\pm 2 \mathrm{SD}^{\prime} \mathrm{s}$. Keys to symbols representing test specimens are given in Tables I - IV. 


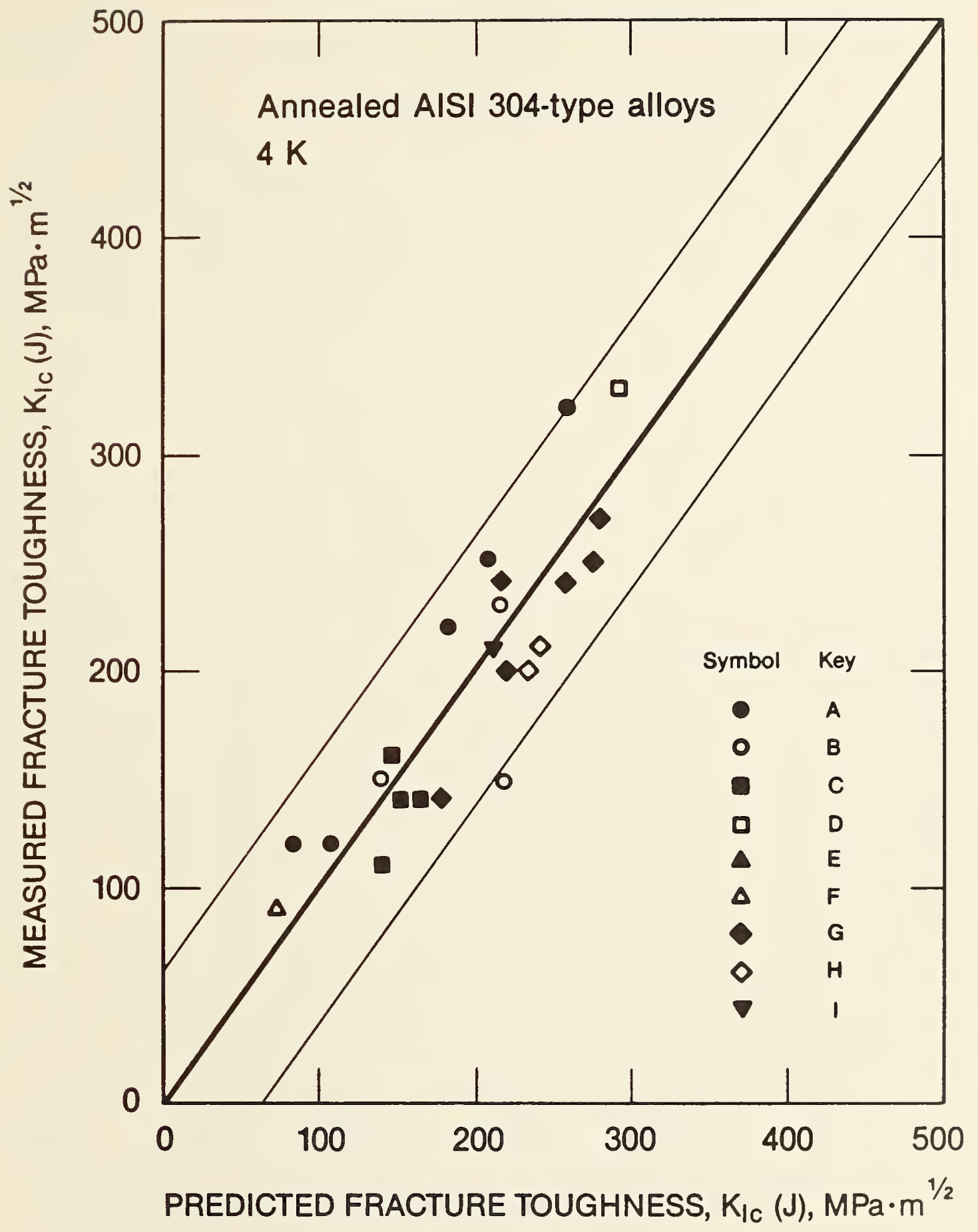

Figure 3. Measured fracture toughness at $4 \mathrm{~K}$ of AISI 304-type alloys versus fracture toughness calculated from Equation (6). The scatterband indicates \pm 2 SD's. Keys to symbols representing test specimens are given in Tables I - IV. 


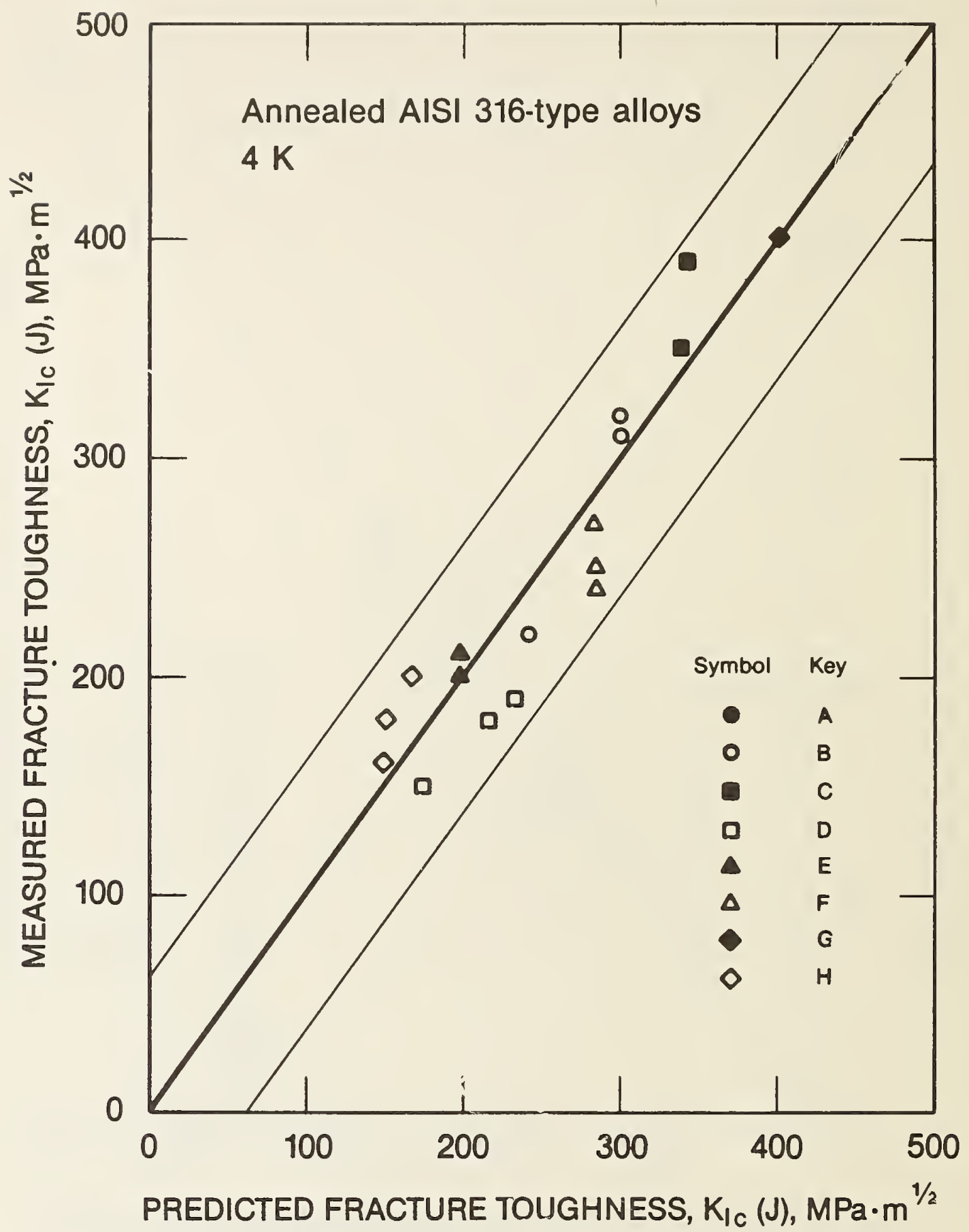

Figure 4. Measured fracture toughness at $4 \mathrm{~K}$ of AISI 316-type alloys versus fracture toughness calculated from Equation (7). The scatterband indicates \pm 2 SD's. Keys to symbols representing test specimens are given in Tables I - IV. 


R. L. Tobler

Fracture and Deformation Division

Center for Materials Science and Engineering

National Bureau of Standards

Boulder, Colorado

The near-threshold fatigue behavior of an AISI 316 alloy was characterized using a newly developed, fully automatic fatigue test apparatus.

Significant differences in the near-threshold behavior at temperatures of 295 and $4 \mathrm{~K}$ are observed. At $295 \mathrm{~K}$, where the operationally defined threshold at $10^{-10} \mathrm{~m} /$ cycle is insensitive, stress ratio and strongly affected by crack closure, the effective threstold stress intensity factor $\left(\Delta K_{\mathrm{Th}}\right)$ eff is about $4.65 \mathrm{MPa} \cdot \mathrm{m}^{1 / 2}$ at $R=0.1$ and $\mathrm{L}=0.3$. At $4 \mathrm{~K}$, the threshold is $\mathrm{higher}$, crack closure is less pronounced, and there is a stress ratio dependency: $\left(\Delta \mathrm{K}_{\mathrm{Th}}\right)$ eff is $5.1 \mathrm{MPa} \cdot \mathrm{m}^{1 / 2}$ at $\mathrm{R}=0.3$ and $6.1 \mathrm{MPa} \cdot \mathrm{m}^{1 / 2}$ at $\mathrm{R}=0.1$. There is also $\mathrm{a}$ significant difference in the form of the da/dN-versus- $\Delta \mathrm{K}$ curves on $\log -\mathrm{log}$ coordinates: at $4 \mathrm{~K}$ the curve has the expected sigmoidal shape, but at $295 \mathrm{~K}$ the trend is linear over the region of $\mathrm{da} / \mathrm{dN}$ from $10^{-6}$ to $10^{-10} \mathrm{~m} / \mathrm{cycle}$. other results suggest that the near-threshold measurements of a $6.4-\mathrm{mm}$-thick specimen of this alloy are insensitive to cyclic test frequency below $40 \mathrm{~Hz}$.

\section{INTRODUCTION}

Near-threshold fatigue crack growth rates (da/dN-versus- $\Delta \mathrm{K}$ curves) and threshold stress intensity factors $\left(\Delta \mathrm{K}_{\mathrm{Th}}\right)$ are relevant mechanical parameters for superconducting magnet design since they lead to the prediction of safe operating conditions below which failures from fatigue crack growth can not occur. Owing to measurement difficulties and costs, however, the existing data base at $4 \mathrm{~K}$ is still quite limited. Liaw and coworkers ${ }^{-3}$ designed a fully automatic fatigue test apparatus and reported threshold data for precipitation hardenable $\mathrm{Fe}-29 \mathrm{Ni}-14 \mathrm{Cr}-1.2 \mathrm{Mo}$ austenitic stainless steel and its welds at 297, 77, and $4 \mathrm{~K}$. Tobler and Cheng designed a similar apparatus and presented data for AISI $304 \mathrm{~L}, 304 \mathrm{LN}$, and 316 stainless steels at $4 \mathrm{~K} .{ }^{4}$ The present paper considers the AISI 316 alloy in greater detail, contrasting the behaviors at 295 and $4 \mathrm{~K}$ and exploring the effects of some mechanical test variables.

*To be published in Arrnces in Cryogenic Engineering--Materials, volume 32. 
MATERIAL

The tested matenial was a 50. S-mm-thick plate of AISI 316 austenitic stainless steel in the annealed condition. The chemical composition in wt.\% is FE-17. $55 \mathrm{~N}-13.25 \mathrm{Ni}-0.057 \mathrm{i}-\mathrm{i} .56 \mathrm{Wm}-2.34 \mathrm{~N} 0-0.024 \mathrm{P}-0.019 \mathrm{~S}-0.58 \mathrm{Si}-0.030 \mathrm{~N}$. rensile, fracture toughness, and midnange fatigue crack growth data were "epontes previousy.s selectec tensile properties are listed in Table 1 , alons with Yougn's mokuli for a similar grade of steel.o

\section{EXFERIVENAL FROCERUE}

The threshold fatigue test apparatus used in this study includes a 100-kN sowroyuauld test wachine and cryostat with minicomputen, programable

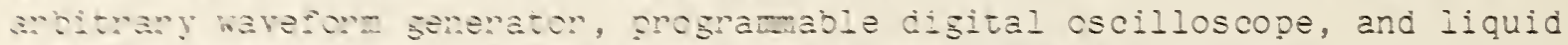
helfum refill system. The procecune is fully automated, allowing continuous Aate collection and loat adjustments to be performed in the absence of a maxine operaton. Tests were conducted at $10 \mathrm{~Hz}$ and lasted about 4 days with cortimous z-h operation. Tynically, is million load cycles are needed to cowlete one threstods Jeasurezent and to accumilate rate measurements ranging

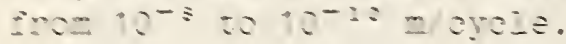

The G.p-u-thich ocugaot specizen used in this study is shown in Eig. 1. $\therefore$ wing sase was attached to the specimen edge, and the load cell and gage curguts wene intenfaved to the computen. The deflection-versus-load curves gurvied the basis lon onack gnowth zeasurezents; they rere continuousiy Etsplayed on the oscilloscope. Eepresentative oscilloscope traces for tests

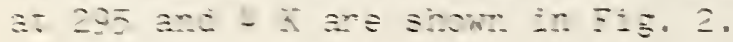

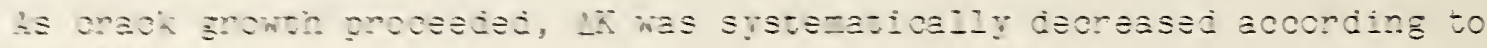
ezus:ism, (n)

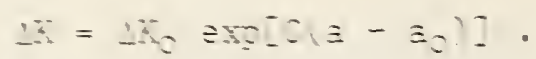

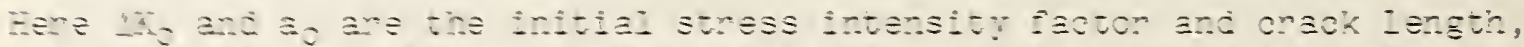

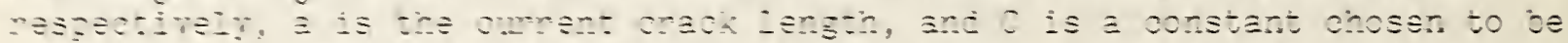

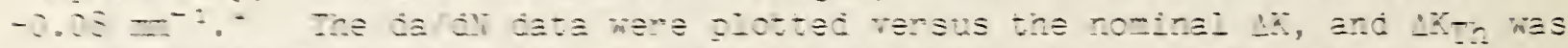

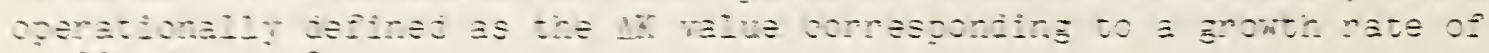

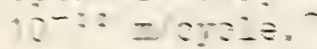

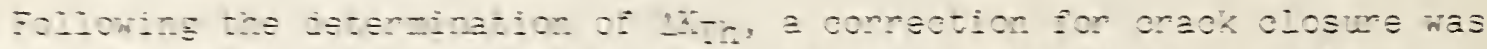

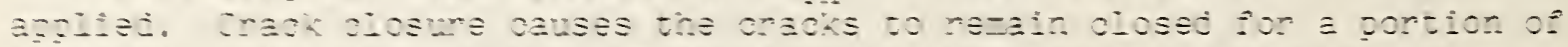
the Zoed orzle: this gortion of the Loei is, therefore, ineflective in

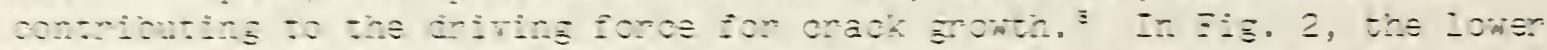

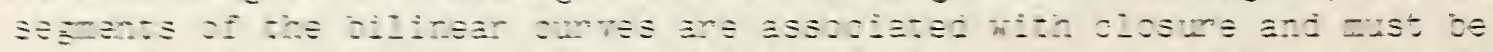

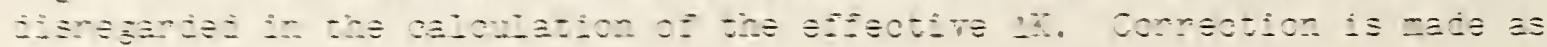
in:icus:

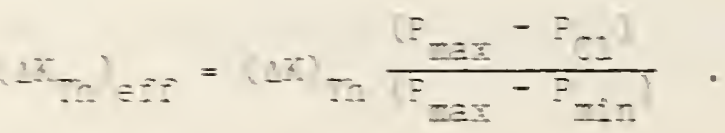


Here $P_{\max }$ and $P_{\min }$ are the maximum and minimum applied fatigue loads, and $\mathrm{P}_{\mathrm{Cl}}$ is the closure load as identified in Fig. 2. Additional details of the test apparatus and procedures are published elsewhere. ${ }^{4}$

RESULTS

The $\mathrm{da} / \mathrm{dN}$-versus- $\Delta \mathrm{K}$ curves for AISI 316 are presented in Fig. 3. The $\mathrm{da} / \mathrm{dN}$ values are plotted versus applied $\Delta \mathrm{K}$ values without correction for crack closure. The rates of $10^{-8}$ to $10^{-10} \mathrm{~m} /$ cycle are two orders of magnitude lower than rates previously published for this alloy, and at the threshold level $\left(10^{-10} \mathrm{~m} /\right.$ cycle), they correspond to one Angstrom per load cycle or less than one lattice spacing per load cycle.

At $295 \mathrm{~K}$ (Fig. 3A), the rates at $\mathrm{R}=0.1$ and $\mathrm{R}=0.3$ are nearly indistinguishable, showing no effect of stress ratio. The data trend is linear on log-log coordinates, and the rates do not exhibit a knee or approach an asymptote at the near-threshold level. Read and Reed ${ }^{5}$ tested the same heat of AISI 316 at $\Delta \mathrm{K}$ from 25 to $50 \mathrm{MPa} \cdot \mathrm{m}^{1 / 2}$. Their data, representing $25.4-\mathrm{mm}$-thick specimens at $20 \mathrm{~Hz}$, are in excellent agreement with and complement the present results.

The results at $4 \mathrm{~K}$ (Fig. 3B) differ from those at $295 \mathrm{~K}$ in that there is a significant effect of $R$ ratio. The rates at $R=0.3$ are higher than at $R=0.1$, and the threshold stress intensity factor is larger at $R=0.1$. At this temperature, the da/dN curves do exhibit the expected sigmoidal shape, and there is approximate agreement with the results for 25.4-mm-thick specimens. ${ }^{5}$

The effect of test temperature at $\mathrm{R}=0.1$ is also shown in Fig. 3C. The linear and sigmoidal trends at 295 and $4 \mathrm{~K}$ are distinct and cross twice. The $\Delta K_{T h}$ value at $4 \mathrm{~K}$ is slightly higher than that at $295 \mathrm{~K}$, and when crack closure corrections are applied, the temperature effect is more pronounced. This can be seen by comparison of the $\left(\Delta \mathrm{K}_{\mathrm{Th}}\right)$ eff values in Table 2 . It is evident from these data that reducing the temperature from 295 to $4 \mathrm{~K}$ increases the threshold fatigue resistance.

Figure 4 presents the effect of frequency variations at $4 \mathrm{~K}$ on the crack growth rate at $\Delta \mathrm{K}$ of 20 and $42 \mathrm{MPa} \cdot \mathrm{m}^{1 / 2}$. For these tests the fatigue apparatus was programmed for constant $\Delta \mathrm{K}$, and replicate crack growth rate measurements were performed. Frequency was varied by two orders of magnitude from 0.4 to $40 \mathrm{~Hz}$. When the range of experimental error and some effects of crack closure and variability are taken into account, these data show that there is no measurable effect of test frequency on the crack growth rates.

\section{DISCUSSION}

At $295 \mathrm{~K}$, the fatigue crack growth rates for AISI 316 appear to follow a linear trend for at least four orders of magnitude in da/dN, and no asymptote is approached at the threshold level of $10^{-10} \mathrm{~m} / c y c l e$. This has several implications. First, it implies that no true threshold is exhibited in this 
range. Hence, the operational definition of $\Delta \mathrm{K}_{\mathrm{Th}}$ at $10^{-10} \mathrm{~m} /$ cycle is inadequate for this alloy/temperature combination, and a new definition must be sought. Second, it points to the necessity of performing additional measurements at still lower growth rates. Note that an average growth rate of $10^{-10} \mathrm{~m} / \mathrm{cycle}$ corresponds to $1 \mathrm{~A} / \mathrm{cycle}$, while the lattice spacing for austenite is about 3.6 月. Rates of crack growth less than a lattice parameter per cycle are possible if the crack growth occurs nonuniformly, that is, in spurts or in highly localized areas along the crack front.

In these tests, crack closure became more significant as the cracks propagated and the loads werre reduced. As shown in Fig. 2, the crack closure was much more significant at $295 \mathrm{~K}$ than at $4 \mathrm{~K}$. The plasticity-induced closure mechanism can be used to explain this observation. According to this mechanism, closure is attributed to residual stresses left in the wake of the advancing crack tip plastic zone. ${ }^{8}$ This closure mechanism would contribute greater closure effects at $295 \mathrm{~K}$ where the yield strength is lower. The fact that the threshold $\Delta K$ values at $R=0.1$ and $R=0.3$ are larger at $4 \mathrm{~K}$ than at $295 \mathrm{~K}$ can be explained as an intrinsic effect of the increased lattice resistance to dislocation movement at cryogenic temperatures.

Frequency effects on da/dN have been observed in AISI 316 at elevated test temperatures because of creep interactions with fatigue ${ }^{9}$. At low temperatures creep is less consequential and cyclic frequency is expected to have little influence on fatigue crack growth rates. At $\mathrm{T}=4 \mathrm{~K}$, however, an exception is conceivable, since local heating can occur in the crack-tip plastic zone due to plastic strain energy dissipation. The amount of heat generated must decrease at lower cycle frequencies and at lower $\Delta K$. Since Fig. 4 shows no measurable variation in rates at $\Delta \mathrm{K}=20$ or $42 \mathrm{MPa} \cdot \mathrm{m}^{1 / 2}$ between 0.4 and $40 \mathrm{~Hz}$, and since the plastic zone size is significantly smaller at lower $\Delta \mathrm{K}$, we tentatively conclude that the $\Delta \mathrm{K}_{\mathrm{Th}}$ and $\left(\Delta \mathrm{K}_{\mathrm{Th}}\right)_{\text {eff }}$ parameters for AISI 316 are not frequency dependent below $40 \mathrm{~Hz}$.

\section{SUMMARY AND CONCLUSIONS}

This study of the near-threshold fatigue crack growth rate behavior of annealed AISI 316 stainless steel at 295 and $4 \mathrm{~K}$ gives the following results:

1. At $295 \mathrm{~K}$, the da/dN-versus- $\Delta \mathrm{K}$ curves on log-log coordinates follow a linear trend for four orders of magnitude. The fact that the data do not approach an asymptote at $10^{-10} \mathrm{~m} /$ cycle leads to the conclusion that still lower rate measurements are necessary to reach a true fatigue threshold, and that the conventional operational definition of $\Delta K_{T h}$ is not satisfactory for this material and temperature combination.

2. At $4 \mathrm{~K}$, the $\mathrm{da} / \mathrm{dN}-\mathrm{versus}-\Delta \mathrm{K}$ curve is sigmoidal, and the operational definition of $\Delta K_{T h}$ is satisfactory at this temperature.

3. The near-threshold behavior of AISI 316 is stress ratio dependent at $4 \mathrm{~K}$, but not at $295 \mathrm{~K}$, for $\mathrm{R}$ ratios between 0.1 and 0.3 . 
4. The threshold stress intensity factor for this material is temperature dependent, increasing as temperature is reilced from 295 to $4 \mathrm{~K}$.

\section{ACKNOWLEDGMENTS}

This project was supported by the Office of Fusion Energy (DOE), Dr. V. Der, project monitor.

\section{REFERENCES}

1. P. K. Liaw, W. A. Logsdon, and M. H. Attaar, in: "Austenitic Steels at Low Temperatures," R. P. Reed and T. Horiuchi, Eds., Plenum Press, New York (1983), pp. 171-185.

2. R. S. Williams, P. K. Liaw, M. G. Peck, and T. R. Leex, Eng. Fract. Mech. 18:953-964 (1983).

3. P. K. Liaw, W. A. Logsdon, and M. H. Attaar, in: "Fatigue at Low Temperatures," ASTM STP 859, R. I. Stephens, Ed., American Society for Testing and Materials, Philadelphia, Pennsylvania (1985), pp. 173-190.

4. R. L. Tobler and Y. W. Cheng, Automatic near-threshold fatigue crack growth rate measurements at liquid helium temperature, Int. J. Fat. $7: 191-197$ (1985).

5. D. T. Read and R. P. Reed, in: "Materials Studies for Magnetic Fusion Energy Applications at Low Temperatures--II," NBSIR 79-1609, National Bureau of Standards, Boulder, Colorado (1979), pp. 81-122.

6. H. M. Ledbetter, J.Appl. Phys. 52:1587-1589 (1981).

7. R. J. Bucci, in: "Fatigue Crack Growth Measurement and Data Analysis," ASTM STP 738, S. J. Hudak, Jr. and R. J. Bucci, Eds., American Society for Testing and Materials, Philadelphia, Pennsylvania (1981), pp. 5-28.

8. S. Suresh and R. O. Ritchie, in: "Fatigue Crack Growth Thresholds Concepts," D. Davidson and S. Suresh, Eds., Met. Soc. AIME (1984), pp. $227-262$.

9. L. A. James, At. Energy Rev. 14:37-85 (1976). 
Table 1. Mechanical properties and grain size of the test material.

\begin{tabular}{ccccccc}
\hline $\begin{array}{c}\text { Test } \\
\text { Temperature } \\
(\mathrm{K})\end{array}$ & $\begin{array}{c}\text { Yield } \\
\text { Strength, } \\
(\mathrm{MPa})\end{array}$ & $\begin{array}{c}\text { Ultimate } \\
\text { Strength, } \\
(\mathrm{MPa})\end{array}$ & $\begin{array}{c}\text { Elongation } \\
(\%)\end{array}$ & $\begin{array}{r}\text { Red. of } \\
\text { Area } \\
(\%)\end{array}$ & $\begin{array}{c}\text { Young's } \\
\text { Modulus, E } \\
(\mathrm{GPa})\end{array}$ & $\begin{array}{c}\text { ASTM } \\
\text { Grain Size } \\
\text { No. }\end{array}$ \\
\hline & & & & & & \\
295 & 228 & 576 & 56 & 73 & 195 & 5.0 \\
4 & 711 & 1301 & 48 & 57 & 208 & - \\
\hline
\end{tabular}

Table 2. Nominal and effective threshold stress intensity factors for AISI 316 stainless steel.

\begin{tabular}{cccc}
\hline $\begin{array}{c}\text { Test Temperature } \\
(\mathrm{K})\end{array}$ & Stress Ratio, R & $\begin{array}{c}\Delta \mathrm{K}_{\mathrm{Th}} \\
(\mathrm{MPa} \cdot \mathrm{m} / 2)\end{array}$ & $\begin{array}{c}\left(\Delta \mathrm{K}_{\mathrm{Th}}\right) \mathrm{eff} \\
(\mathrm{MPa} \cdot \mathrm{m}\end{array}$ \\
\hline \multirow{2}{*}{295} & 0.1 & 7.6 & 4.6 \\
& 0.3 & 7.6 & 4.7 \\
4 & 0.1 & 8.5 & 6.1 \\
& 0.3 & 6.4 & 5.1 \\
\hline
\end{tabular}

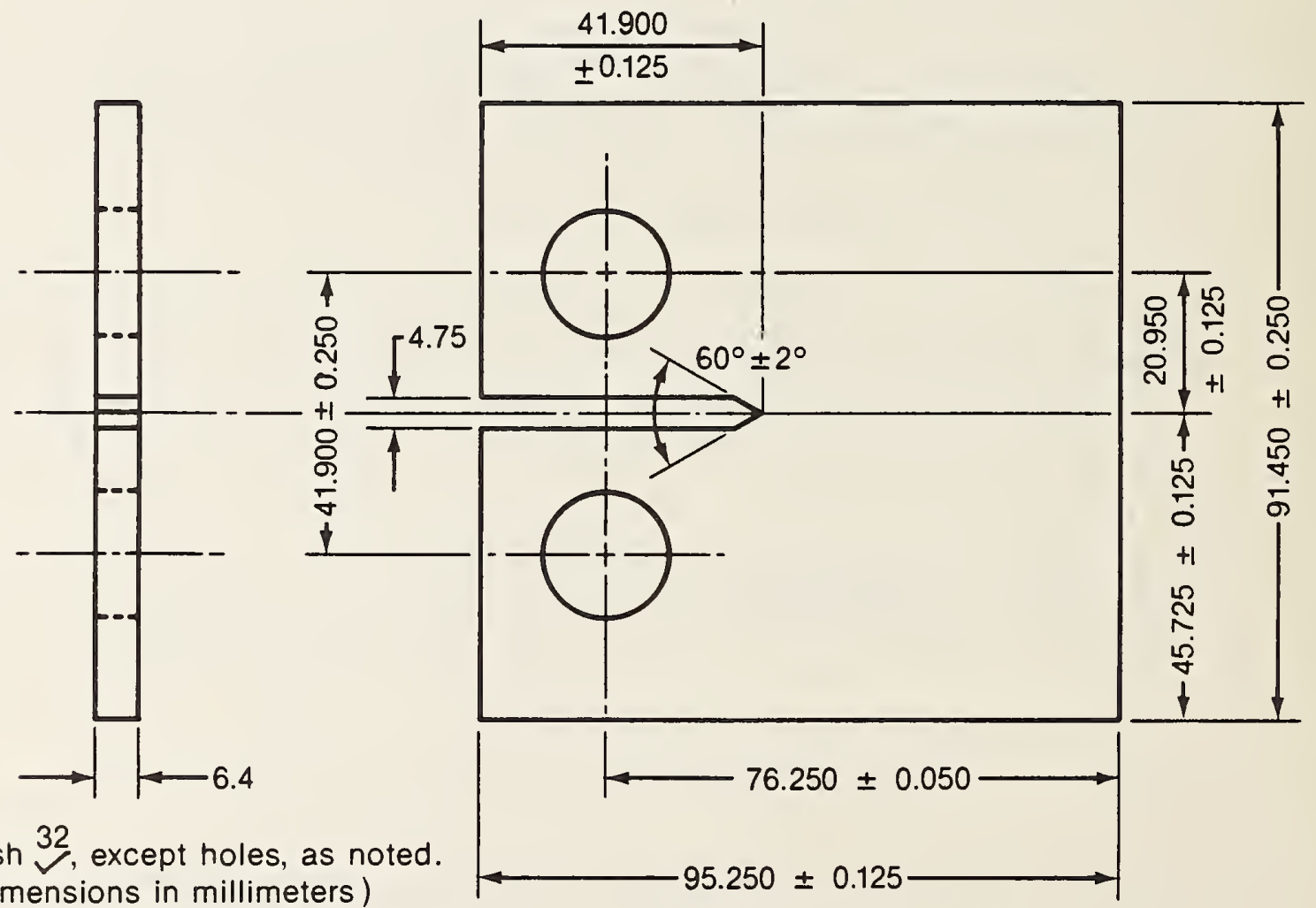

Finish $\checkmark$, except holes, as noted. (Dimensions in millimeters)

Fig. 1. Compact test specimen used in this study. 


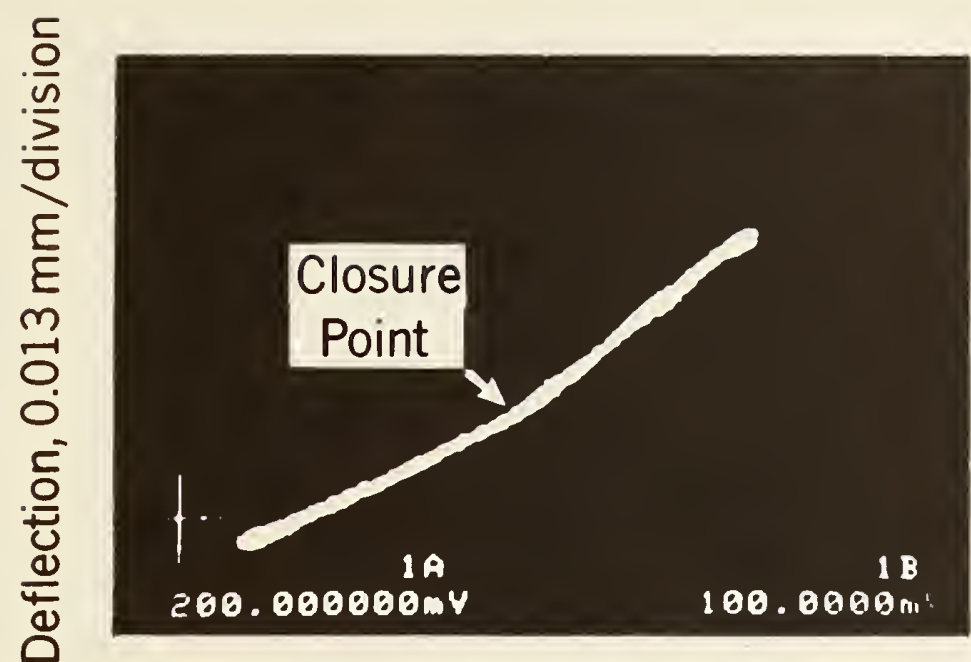

Load, $0.2 \mathrm{kN} /$ division

(A) $\mathrm{T}=295 \mathrm{~K}, \Delta \mathrm{K}=7.6 \mathrm{MPa} \cdot \mathrm{m}^{1 / 2}$

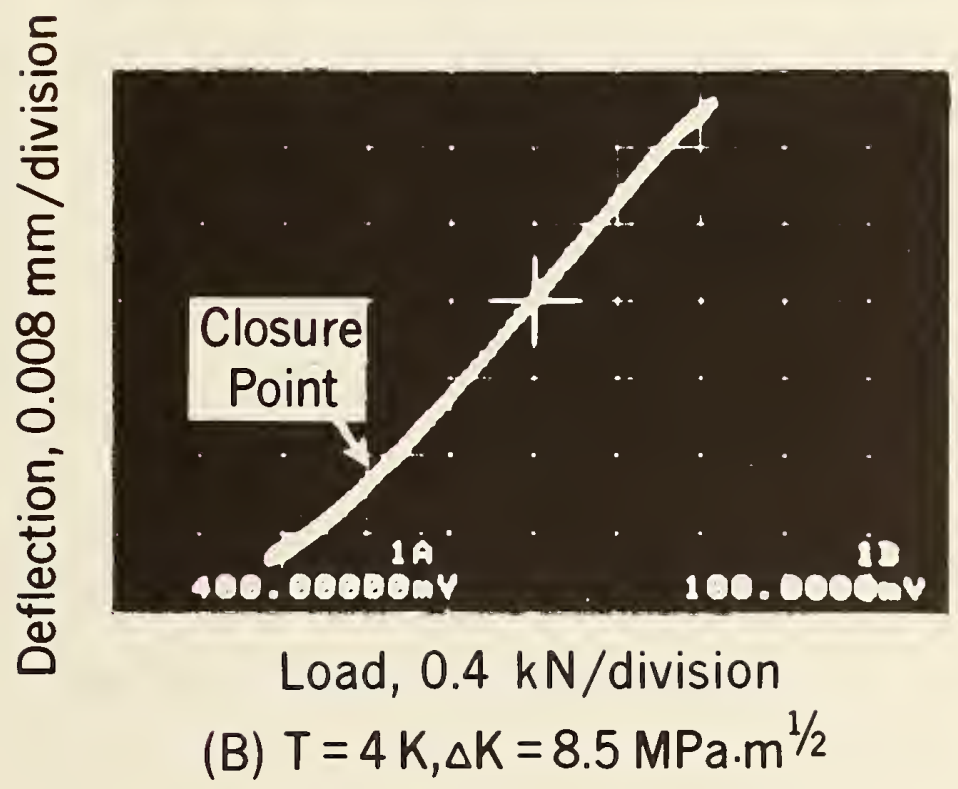

Fig. 2. Deflection-versus-load curves for AISI 316 test specimens at the termination of threshold fatigue tests: (A) $T=295 \mathrm{~K}$; (B) $T=4 \mathrm{~K}$. 


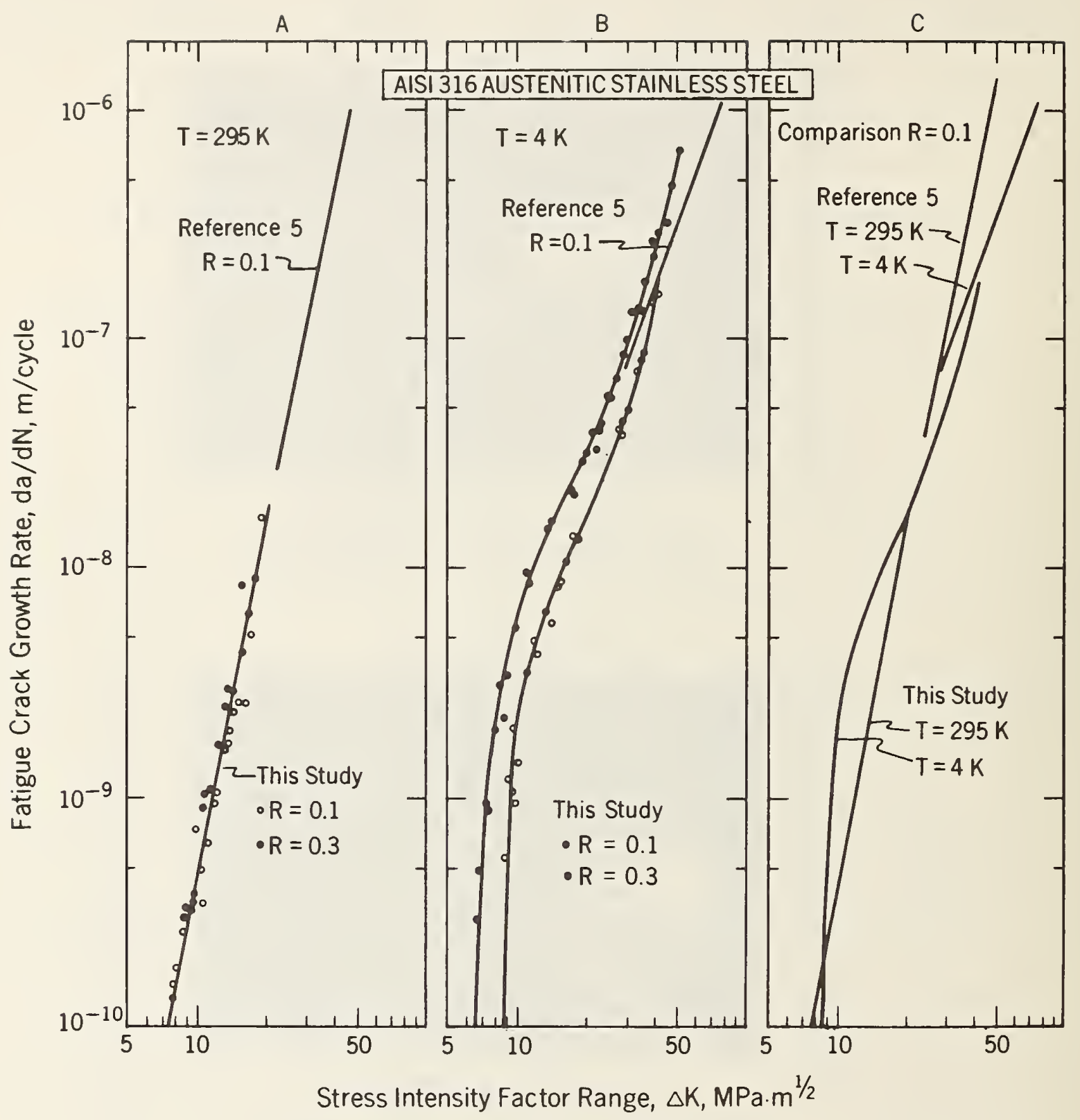

Fig. 3. Fatigue crack growth rate data for AISI 316 stainless steel: (A) at $295 \mathrm{~K},(\mathrm{~B})$ at $4 \mathrm{~K}$, and (C) comparison at $\mathrm{R}=0.1$ 


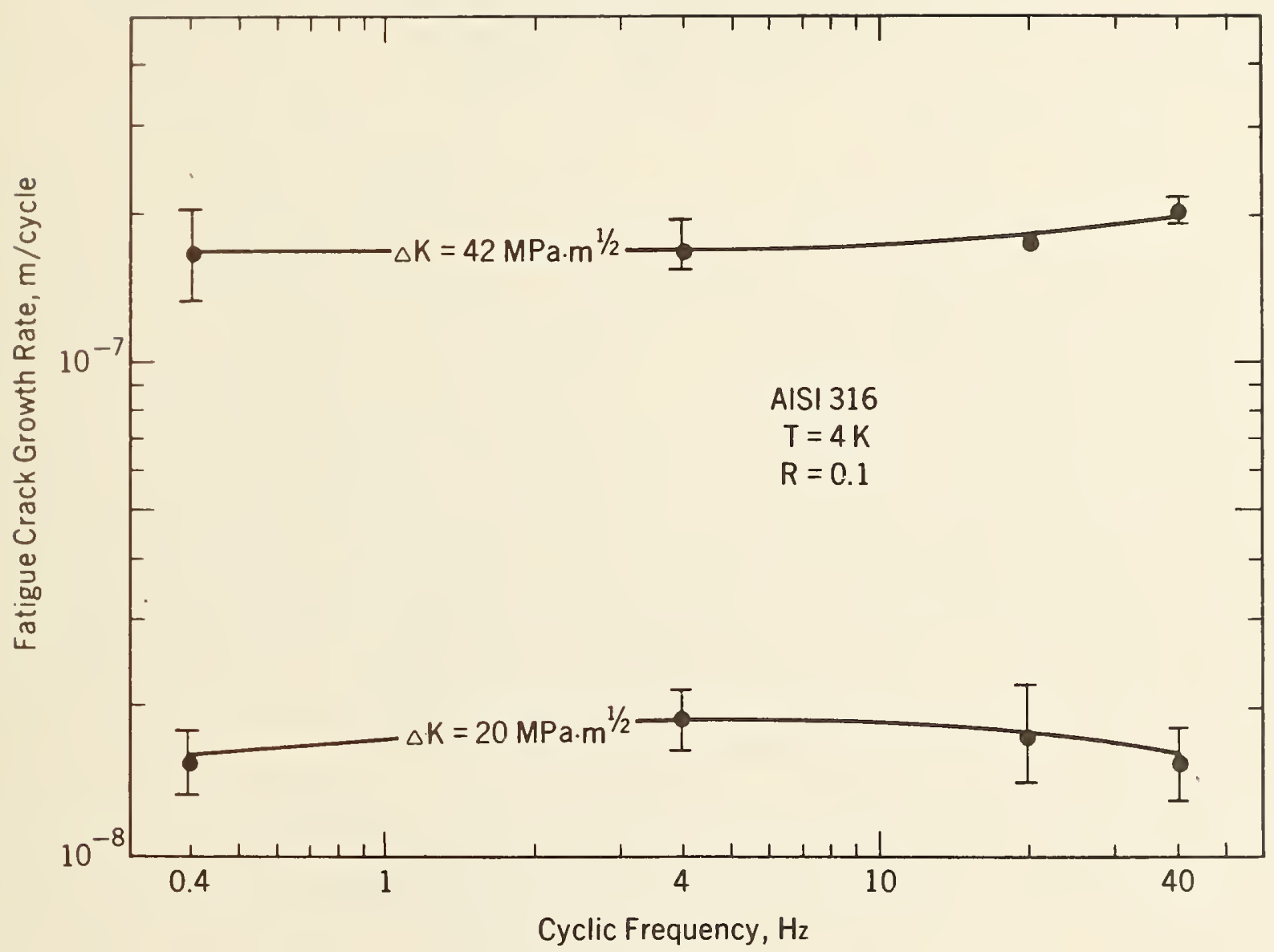

Fig. 4. Effect of cyclic test frequency on 4-K fatigue crack growth rates at two intermediate $\Delta \mathrm{K}$ values. 



THE TOUGHNESS OF AUSTENITIC STAINLESS STEELS AT $4 \mathrm{~K}$ *

\author{
P. T. Purtscher and R. P. Reed \\ Fracture and Deformation Division \\ National Bureau of Standards \\ Boulder, Colorado 80303
}

The fracture toughness values of twenty-four different compositions of austenitic stainless steels were measured in liquid helium in accordance with the ASTM E 813-81 method. Three independent factors were found to contribute to the energy required for the initiation of ductile fracture: yield strength at $4 \mathrm{~K}$, substitutional alloying ( $\mathrm{Ni}$, Mn, and Mo content), and nonmetallic inclusions. Yield strength and inclusions have long been recognized as influencing the toughness of structural alloys and are considered in existing models for fracture toughness. The effects of alloying on the toughness are not directly considered in these models. Experimental results show that substitutional alloying elements can influence the deformation and fracture behavior of these steels in the toughness test in a manner that is not independent of the yield strength or inclusion content.

Key words: austenitic stainless steels; cryogenic properties of materials; ductile fracture; fracture mechanisms; fracture toughness; mechanical properties

*Work supported by the U.S. Department of Energy. 
The construction of high-field superconducting magnets requires structural alloys of high strength and good toughness at $4 \mathrm{~K}$. Austenitic stainless steels $304 \mathrm{LN}$ and $316 \mathrm{LN}$, strengthened by $\mathrm{N}$ additions (an interstitial alloying element), have been used in this application. In the past ten years considerable data for the mechanical properties of austenitic stainless steels at $4 \mathrm{~K}$ have been published. An empirical relationship between yield strength and fracture toughness at $4 \mathrm{~K}$ was first reported by Tobler et al.: 1

$$
\text { Fracture toughness }=500-0.3 \times \text { yield strength }
$$

where yield strength is expressed in MPa and fracture toughness in MPa $\sqrt{\mathrm{m}}$. This equation represents the combination of strength and toughness found in interstitially strengthened 304-type steels.

Superconducting magnet systems now under construction have been designed with existing $304 \mathrm{LN}$ and $316 \mathrm{LN}$ alloys. New concepts for magnet designs require alloys with better properties. The Japanese Atomic Energy Research Institute (JAERI) has proposed a specification for the strength and toughness of structural alloys that cannot be obtained with $304 \mathrm{LN}$ or $316 \mathrm{LN}$. In the United States, design goals ${ }^{2}$ for structural alloys include a slightly lower yield strength level than the Japanese counterpart, $1000 \mathrm{MPa}$ rather than $1200 \mathrm{MPa}$. The fracture toughness requirement is the same. The U.S. design goals also include strength and toughness requirements for welds. For critical areas in the structure where the stresses are the highest, a welding process is needed that will produce welds whose mechanical properties match those of the base metal in all welding positions. For less critical locations in the structures, the toughness requirement is $25 \%$ lower than that for the base metal, and a minimum of two other welding processes are targeted. The different design goals are shown in Figure 1 relative to the properties of 304-type stainless steels. ${ }^{1}$

The relationship between strength and toughness in materials has been a subject of research for years and is well-known in steels, ${ }^{3} \mathrm{Al}$ alloys, ${ }^{4}$ and $\mathrm{Ti}$ alloys $\mathrm{s}^{5}$ that fail in a ductile manner. The ductile fracture process involves the initiation and growth of voids in a plastically deformed region of the material. Typically, the voids initiate at nonmetallic inclusions leaving small ligaments between initiation sites. The voids grow until they coalesce with other voids or a free surface. The extent of void growth is related to the strength and rixctility of the matrix.

Current knowledge of the strength-toughness relationship in austenitic stainless steels at $4 \mathrm{~K}$ is summarized in a recent review article by Morris and Dalder. ${ }^{2}$ They concluded that there are only two ways to improve the strength-toughness relationship, that is, to increase toughness without lowering the strength. The first way is to reduce the inclusion content. With fewer void initiation sites, there will be fewer voids and the growth stage should be longer before the voids coalesce. This method of improving 
the strength-toughness relationship is related to processing methods (such as deoxidation practice, ingot size used, and hot rolling) during steel production. The second way is to distribute the deformation over a larger area. If the deformation is concentrated in a small region ahead of the crack tip, the measured fracture toughness should be relatively low. If the size of the plastic zone at the crack tip increases, the toughness should increase. This method is related to the slip characteristics of the material, namely the interaction of moving dislocations with obstacles to their motion. Cross slip is one type of interaction that is expected to play a major role.

Dislocation interactions are complex and difficult to study. Fundamental theories have employed dislocation interactions successfully to explain the effect of grain size, 7,8 second-phase particles, 9 and alloying additions ${ }^{10}$ on strength. No similar fundamental theories exist for ductile fracture.

Understanding ductile fracture is hindered by its varied definitions: energy absorbed during an impact or static test at a given temperature, transition temperature for ductile to brittle behavior, and blunt machined vs. sharp fatigue precracked notches. All these factors influence ductile fracture and can produce contradictory results. The effect of grain size on $K_{\text {Ic }}$ for .AISI 4340 is opposite to the effect of grain size on the Charpy V-notch energy for the same steel. 11 Work by Lee et al. 12 explains clearly why blunt and sharp notches have different effects.

Continuum mechanics models for ductile fracture attempt to relate fracture toughness to tensile properties. Hirth and Froes ${ }^{5}$ summarized the many different theoretical relationships found in the literature and identified four factors that should be considered: (1) the relationship of toughness to the plastic zone size and to the crack opening displacement; (2) the relationship of crack opening displacement to the spacing of void-initiating inclusions; (3) the inverse relationship of fracture toughness to strength, owing to the presence of plastic instabilities that produce failure along characteristic slip paths; and (4) significant variations in the surface area created during fracture due to crack tortuosity and crack branching. A more recent model for ductile fracture has been proposed by Ritchie and Thompson ${ }^{13}$ that incorporates a different term, the microroughness, $M$. The $M$ term reflects the local strain to failure from measurements of the shape of the voids produced during fracture. In our discussion we shall use this model to analyze our data.

The purpose of this study is to assess the role of alloying and inclusions in changing the toughness of austenitic stainless steels. The alloys were chosen carefully so that the effect of substitutional alloying elements ( $\mathrm{Ni}, \mathrm{Mn}$, and Mo) could be studied; other. variables that influence the strength and toughness were kept to a minimum. This information is particularly valuable in designing alloys that will meet specifications for service at $4 \mathrm{~K}$ with cost effective use of alloying additions. 
Eight completely austenitic alloys, in the form of 25-mm-thick plates, were used to evaluate the effect of $\mathrm{Ni}$ content; their chemical compositions are listed in Table $I$. The as-received plates were annealed at $1060^{\circ} \mathrm{C}$ for $1 \mathrm{~h}$ and then water quenched. The inclusion content of each of the eight alloys was determined to be sure that there were no significant differences among the eight alloys. A polished cross section of a tensile specimen from each alloy was examined in the scanning electron microscope (SEM) at a magnification of 2000. The number of inclusions greater than $0.5 \mu \mathrm{m}$ in diameter in a given area (either 0.34 or $0.17 \mathrm{~mm}^{2}$ ) was used as a means of characterization. Most inclusions were the MnSi type, but there were also CrMn-rich inclusions present. This technique of characterizing inclusions is similar to that used in another study; ${ }^{4}$ its results were given in terms of $n^{-1 / 2}$, where $n$ was the number of inclusions with a diameter larger than $0.5 \mu \mathrm{m}$ in a $0.1 \mathrm{~mm}^{2}$ area. For the eight alloys of this study, all counts were normalized to the same $0.1 \mathrm{~mm}^{2}$ area, and the $\mathrm{n}^{-1 / 2}$ parameter was calculated to be 0.15 to 0.24 .

\section{Alloys with Manganese Additions}

Two groups of alloys were prepared in which Mn content was the major test variable. The first group (69-78) was tested in 1982; results are reported elsewhere. 15 The results are analyzed differently here and compared with those of the second group. Two types of inclusions were found in this first Mn group with the SEM: MnS and AlSiCa-rich inclusions. Figure 2 shows a typical distribution of these inclusions. There were between 30 and 60 inclusions per $0.1 \mathrm{~mm}^{2}$, which translate to values of 0.13 to 0.18 for $\mathrm{n}^{-1 / 2}$

In addition to these inclusions, analysis by scanning transmission electron microscopy (STEM) revealed extremely fine inclusions $(0.1 \mathrm{\mu m}$ in diameter), rich in $\mathrm{Ti}$ and $\mathrm{Al}$ (see Figure 3). These smaller inclusions were found most often in the $1 \% \mathrm{Mn}$ alloys and, to a lesser degree, in the $6 \% \mathrm{Mn}$ alloys.

The four alloys from the second group (297, 304, 300, and 301), supplied as $25-\mathrm{mm}$-thick plate, were austenitic with 1 to $4 \%$ second phase, either delta ferrite or sigma. Their compositions are listed in Table I. The alloys were annealed at $1160^{\circ} \mathrm{C}$ for $6 \mathrm{~h}$ and then water quenched. Figure 4 shows the microstructure of one of the alloys with $4 \%$ second phase. The inclusions were examined in the SEM as described above. The $\mathrm{n}^{-1 / 2}$ parameter values were 0.15 to 1.17. Many types of inclusions were present: MnS, MnSi, AlMn-rich, and AlSi-rich inclusions.

\section{Alloys with Molybdenum Additions}

Molybdenum effects were studied on specimens from two different alloys where the composition differed only in Mo (see Table I). Plates, $25 \mathrm{~mm}$ thick, were supplied in the hot-rolled condition and were annealed at temperatures between 1000 and $1150^{\circ} \mathrm{C}$ for varying lengths of time in order to recrystallize 
the alloys and grow the grains to different sizes. The inclusion density was measured; $\mathrm{n}^{-1 / 2}$ varied from 0.22 to 0.30 . The inclusions were complex, containing $\mathrm{Al}, \mathrm{Mg}, \mathrm{Si}, \mathrm{S}, \mathrm{Ca}$, and $\mathrm{Ti}$.

\section{EXPERIMENTAL PROCEDURES}

\section{Tensile Testing}

Tensile tests were conducted in liquid helium with a cryostat described elsewhere. 16 Round specimens, 6-mm gauge diameter and 25-mm gauge length and machined transverse to the rolling direction, were used for most of the tests. Flat, dog-bone-type specimens with a gauge length of $25 \mathrm{~mm}$ were used in one case (noted in Table II). Load vs. elongation curves were obtained by means of a commercial load cell and strain gauge extensometers. Yield strength at $0.2 \%$ strain, ultimate strength, percent elongation, and percent reduction in area were measured. Estimated strain sensitivity is $10 \mu \varepsilon$ at $4 \mathrm{~K}$.

\section{Fracture Toughness Testing}

Fracture toughness specimens, about $25 \mathrm{~mm}$ thick, were machined in a $\mathrm{T}-\mathrm{L}$ orientation with respect to the rolled plate. The specimens were tested at $4 \mathrm{~K}$ according to the ASTM E 813-81 test method, 17 the single specimen. technique. 1 The elastic unloading compliance method and a clip gauge 18 developed especially for cryogenic service were used to monitor crack growth during the test. Scatter in the $\mathrm{J}_{\mathrm{Ic}}$ value measured at $4 \mathrm{~K}$ resulted in uncertainties of $\pm 15 \%$.

\section{RESULTS}

The tensile properties and the fracture toughness values for all the steels are shown in Table II. Yield strength $\left(\sigma_{y}\right)$ vs. $K_{I c}(J)$ fracture toughness is plotted in Figure 5 along with the scatter band of the previous study of 304-type steels with different interstitial contents. The expected general trend of decreasing toughness with increasing strength is seen, but there is considerable scatter from the previous data on 304-type steels.

Another way to analyze the data is to consider the influence of the substitutional alloying elements within each group of alloys, and thus, to isolate this influence.

\section{Nickel}

The effect of $\mathrm{Ni}$ was presented in another paper ${ }^{19}$ along with the effect of $\mathrm{N}$, but the main results are reiterated here and expanded. The effect of interstitial elements on the yield strength of these alloys is shown in Figure 6. Complete stress-strain curves for the four alloys with the same if content but different $\mathrm{Ni}$ contents ( 5.6 to $14.9 \%$ ) are shown in Figure 7 . The initial strain hardening characteristics are similar. The strain to fallure does vary, but it is not simply related to the Ni content. 
The load drops that occur with strain hardening are related to adiabatic heating of the specimen, 20 a conversion of the mechanical work done on the specimen by plastic deformation to heat. Owing to the low specific heat and thermal conductivity of austenitic stainless steels, the specimen temperature can rise, lowering the yield strength and promoting plastic deformation. Serrated yielding is common in austenitic stainless steels tested at $4 \mathrm{~K}$. The size of the load drops in alloys 413-416 appears to increase with $\mathrm{Ni}$ content, from $180 \mathrm{MPa}$ for alloy 413 to $460 \mathrm{MPa}$ for alloy 416 . This difference could be related to the temperature dependence of the yield strength. For alloy 413, almost all the plastic deformation was associated with the load drops, that is, temperature rises. The other three alloys showed appreciable plastic strain at $4 \mathrm{~K}$.

Fracture toughness is presented as a function of $\mathrm{Ni}$ content in Figure 8 . Five of the alloys had nearly the same interstitial content and yield strength. The measured toughness values of the other three alloys were normalized to a yield strength of $1030 \mathrm{MPa}$, the average of the first five alloys, to minimize the effect of the different $\mathrm{N}$ contents. After accounting for the different yield strengths, $K_{I c}(J)$ increased by about $18 \mathrm{MPa} \sqrt{\mathrm{m}}$ for each percent increase in $\mathrm{Ni}$ content.

The load vs. load-line displacement curves for alloys 413 through 416 , from which the $J_{I c}$ fracture toughness values were determined, are shown in Figure 9. The point on each curve at which crack growth began is noted with a circle. These four alloys vary only in $\mathrm{Ni}$ content. Nickel affects the shape of the curve prior to crack initiation, promoting deformation prior to crack initiation under conditions of severe constraint. Note the sharp load drops that occur after $\mathrm{J}_{\mathrm{Ic}}$ is passed. These load drops are always associated with an audible "pop" that indicates that the crack is growing discontinuously. Audible sounds did not accompany the load drops during the tensile tests shown in Figure 7 .

The four alloys with high nitrogen but varying $\mathrm{Ni}$ contents, 413, 414 , 415, and 416, show a distinct transition in the fracture morphology. A low magnification view of the fracture surface in the region of the specimens where the fracture toughness is measured (Figure 10) shows this distinct transition from faceted fracture to dimpled fracture between 9 and $12 \% \mathrm{Ni}$.

In some areas of the fracture surface of alloy 413 , like that shown in Figure 11, the size of a facet is equal to the grain size, and two or three sets of parallel lines are faintly visible on the facet. The angles between the different sets of lines are approximately equal to the angles between different slip directions in the fcc crystal. The plane of the facet has been identified by back-reflection Laue patterns to be a $\{111\}$ type plane. Another region where the facets are extremely small and stepped in appearance is shown in Figure 12. Here, the $\{111\}$ planes are not favorably oriented with respect to the tensile load, and the crack follows small steps between $\{111$ \} planes. The nonmetallic inclusion does not appear to have affected the fracture process. 
A higher magnification view of the fracture surface that is characteristic of alloys 415 and 416 with the dimpled appearance is seen in Figure 13. For these alloys, the inclusions played a significant role in the fracture process. The voids initiated at the inclusions and grew until they coalesced with surrounding voids.

Strain-induced martensite did form in some of these alloys during mechanical testing. Measurements of martensite content were made and are reported in the earlier work. 19 From those results, it was determined that martensite did not have a direct effect on the toughness values.

To summarize the results, a linear change in toughness was found as a function of $\mathrm{Ni}$ content after the effect of yield strength variation was eliminated. This change in $\mathrm{K}_{\mathrm{IC}}(\mathrm{J})$ was associated with alloys exhibiting brittle, faceted fracture as well as ductile, dimpled fracture behavior. The inclusion content of all the alloys is similar; their influence on the variation in fracture toughness is minimial.

\section{Manganese}

The results of testing the first group of alloys with Mn as a major alloying element (69 through 78 ) were reported previously. 15 The results (see Figure 14) showed a systematic increase in toughness with Mn content at three different $N$ levels. However, the toughness values of all the Mn alloys were lower than expected from the results of the Fe-18Cr-10Ni study; the difference in toughness was noted in the original paper but not examined thoroughly.

In this study, the fracture surfaces of the toughness specimens were examined in detail. The fracture appearance of the alloys offers an explanation for the unexpectedly low toughness of the 1\% Mn alloys. Figure 15 shows the fracture surface of alloy 69 , which contained $1 \% \mathrm{Mn}$. The fracture is relatively smooth at low magnification and appears to have very fine dimples, 1 to $2 \mu \mathrm{m}$ in diameter, over most of the surface. The $\mathrm{f}$ ine dimples initiated at the $\mathrm{Ti}$ - and Al-rich inclusions; the density of these inclusions decreased with increasing Mn content ( 1 to $6 \%$ ) in the alloys.

The fracture surface of alloy 72 containing $6 \%$ Mn (Figure 16) appears rougher than that of alloy 69 (Figure 15), and its dimples are considerably larger, about $20 \mu \mathrm{m}$ in diameter. The dimples have formed around larger MnS inclusions rather than fine $\mathrm{Ti}-$ and $\mathrm{Al-rich}$ inclusions. The difference in toughness between the $1 \%$ and $6 \%$ Mn alloys (Figure 14) appears to be a function of both dimple size and Mn content.

The fracture toughness values for the second group of Mn-alloyed steels are shown in Figure 17 in two different ways: normalized to a yield strength of $1030 \mathrm{MPa}$ and normalized for yield strength plus a $7 \% \mathrm{Ni}$ content, according to the trend noted in Figure 8 for $\mathrm{Ni}$ alloying. The toughness averages for three of the alloys show a trend of increasing $\mathrm{K}_{\mathrm{Ic}}(\mathrm{J})$ with increasing $\mathrm{Mn}$ content that is approximately one-third that found for $\mathrm{Ni}$. The toughness of the fourth alloy did not follow this trend, but normalizing the toughness 
to account for the difference in $\mathrm{Ni}$ content brought it closer to the trend line. These results show considerable scatter, possibly due to the 1 to $4 \%$ of second phase present.

In the second group of alloys, a transition in fracture morphology, similar to that seen for $\mathrm{Ni}$ alloying in Figure 10, was observed and is shown in Figure 18. The transition in fracture appearance is associated with the Mn content: the alloy with $4 \% \mathrm{Mn}, 297$, has a faceted fracture surface, and the alloys with higher Mn content, 304 and 300, have dimpled fracture surfaces. Alloy 301, with $4 \%$ Mn but a slightly higher Ni content, is not shown, but it had a dimpled appearance similar to that of alloys 304 and 300 .

To summarize, Mn appears to increase the 4-K toughness, but the magnitude of the effect is difficult to judge. The results of the two groups are shown together in Figure 19. The two different trends are significant because the steeper trend is thought to reflect an effect of dimple size and Mn content, while the lower trend is a function of Mn content alone. Increasing the Mn or Ni content of alloy 297 does change the fracture appearance significantly, indicating an important role for substitutional alloying elements in the deformation and fracture processes.

\section{Molybdenum}

The measured yield strengths of the Mo-alloyed specimens are shown in Figure 20. The measurements from specimens with similar grain sizes are noted. Solid-solution strengthening from 2.2\% Mo increased the 4-K yield strength of those specimens with a similar grain size by about $80 \mathrm{MPa}$.

The toughness values of the Mo-alloyed group are plotted in Figure 21 , again with the measured values normalized to a strength of $1030 \mathrm{MPa}$. The $2.2 \%$ Mo addition increased the adjusted fracture toughness from $105 \mathrm{MPa} \sqrt{\mathrm{m}}$ up to $165 \mathrm{MPa} \sqrt{\mathrm{m}}$ (about $25 \mathrm{MPa} \sqrt{\mathrm{m}}$ per wt. \% of Mo added).

The fracture appearance of the Mo-alloyed group was completely dimpled and did not change with grain size. However, the dimple sizes were different for the alloys with and without Mo. Figure 22 shows alloy 80, without Mo. The dimples are extremely fine, approximately $2 \mu \mathrm{m}$ in diameter. No inclusions were associated with the fine dimples. Figure 23 shows that the dimples in alloy 79 (with Mo) are generally much larger and contain inclusions.

\section{General Observations}

Certain pertinent observations were common to all specimens tested:

1. Fractography of the broken specimens. No stretch zones were observed in the region of the fracture surface between the fatigue precrack and the J-test-related features. This is characteristic of austenitic stainless steels that are broken at cryogenic temperatures. 21 
2. Nature of the ductile crack growth. Load drops were observed in the load vs. load-line displacement curves from which the toughness is calculated. Load drops were associated with an audible sound, indicating discontinuous crack growth.

\section{DISCUSSION}

The results show a significant effect of substitutional alloying elements on fracture appearance and mechanical properties, particularly fracture toughness. The role of substitutional alloying elements in the fracture process has not been directly incorporated in any existing theory. To explain how $\mathrm{Ni}$, Mn, and Mo can affect the fracture toughness, a simple mechanism is proposed for fracture of annealed materials:

There are three basic stages in the development of the fracture toughness value that we measure in the ASTM E 813 procedure: Stage 1 - The growth of a plastic zone ahead of the sharp fatigue precrack. This stage occurs in all cases. Stage 2 - The creation of a free surface on the microscopic scale within the plastic zone. For ductile fracture, this typically involves the decohesion of the matrix-inclusion interface. Stage 3 - The growth of that microscopic free surface into the macroscopic crack, which is defined as crack initiation. For ductile fracture, this stage is associated with the gradual linking of voids.

The size of crack that is defined as the point of initiation is not clearly specified by the ASTM E 813 standard. The initial standard issued in 1981 requires a crack growth vs. resistance curve to be generated, and $J_{\text {Ic }}$ is defined as the intersection of the resistance curve, extrapolated to zero growth, and the blunting line. This technique provides a reliable, consistent method of evaluating the toughness, but it does not always provide a simple correlation to such metallurgical factors as inclusion size and spacing, dimple size and spacing on the fracture surface, tensile properties, interfacial energies for decohesion of inclusion-matrix interfaces, and stacking-fault energies.

\section{Influence of Alloying}

The effect of substitutional alloying elements appears to be continuous through the brittle-to-ductile transition (Figure 7 and 18), so it seems reasonable to consider stage 1 , the growth of the plastic zone, as the only step in the fracture mechanism where $\mathrm{Ni}, \mathrm{Mn}$, and Mo can affect both ductile and brittle fracture equally.

The growth of the plastic zone in the fcc structure is related to dislocation motion (glide) and the ability of dislocations to cross slip, effectively reducing the stress concentration at the tip of dislocation pileups. Ahlers 22 described cross slip in fcc metals as a thermally activated, strain-rate-sensitive process by which extended dislocations on one glide plane must constrict and come together to form a perfect disloca- 
tion before they can change to another glide plane. Extended dislocations are composed of two partial dislocations with a spatial separation that is related to the stacking fault energy. A concise description of the effect of stacking fault energy on mechanical properties can be found in several sources.23,24 For our case, it is enough to say that cross slip is more difficult in an alloy with a low stacking fault energy, and that it can produce significant effects on the deformation behavior. In the toughness test at $4 \mathrm{~K}$, temperature and strain rate are not variable, and the effect of composition on the stacking fault energy is the parameter most likely to influence cross slip and, hence, the plastic zone formation (stage 1).

A factor that could affect cross slip but was not mentioned by Ahlers is stress state. Figure 7 shows that increasing $\mathrm{Ni}$ content has no significant effect on the engineering stress-strain curves at $4 \mathrm{~K}$ where a uniaxial state of stress exists. However, Figure 9 shows a dramatic effect of $\mathrm{Ni}$ on the deformation behavior of these same alloys where a triaxial state of stress is present.

The transition in fracture morphology seen in Figures 10 and 19 can be interpreted in terms of the fracture mechanisms and the effect of composition on the cross slip characteristics. With the high-strength, but lower-alloyed steels (413, 414, and 297), brittle facets formed because the slip is concentrated on the $\{111\}$-type planes. The addition of alloying elements (Ni in 415, Mn in 304, and $\mathrm{Ni}$ in 301) relieved the concentrated slip, promoting dimple formation.

Qualitatively, the cross slip model can explain why steels with different $\mathrm{Ni}, \mathrm{Mn}$, and Mo contents have different toughness values. Unfortunately, it is difficult to measure stacking fault energy. Schramm and Reed 25 reported a relationship between stacking fault energy (SFE) and content of major alloying elements for commercial-grade austenitic $\mathrm{Fe}-\mathrm{Cr}-\mathrm{Ni}, \mathrm{Fe}-\mathrm{Mn}-\mathrm{Ni}$, and $\mathrm{Fe}-\mathrm{Cr}-\mathrm{Ni}-\mathrm{Mn}$ steels:

$$
\mathrm{SFE}=-53+6.2(\% \mathrm{Ni})+0.7(\% \mathrm{Cr})+3.2(\% \mathrm{Mn})+9.3(\% \mathrm{Mo})
$$

where $\mathrm{SFE}$ is expressed in $\mathrm{mJ} / \mathrm{m}^{2} \cdot \mathrm{wt} . \%$. Other researchers have reported significantly different equations relating chemical composition to stacking fault energy.

Equation 2 predicts high values of SFE, but we feel that it gives a good prediction of the relative effect of the major alloying elements, that is to say, $\mathrm{Ni}$ is 2 times as effective as $\mathrm{Mn}$, Mo is 3 times as effective as $\mathrm{Mn}$, and although $\mathrm{Cr}$ has an effect, it is considerably less. These relative effects correlate with the trends for the effect of alloying elements on toughness that are reported here.

\section{Influence of Dimple Size}

The test results for the first Mn group and the Mo group appear to be a function of both alloy content (stage 1) and dimple size (stage 2 and 3). At present, there is no way to separate the effects of the two factors. One possible solution would be to use a continuum mechanics approach to 
understanding franture. Ritchie and Thompson's model ${ }^{13}$ for ductile fracture incorporates both is orostructural and fractographic observations into the calculation:

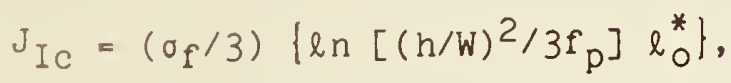

where $\sigma_{f}=$ flow strength $\equiv\left(\sigma_{y}+\sigma_{u}\right) / 2$,

$\sigma_{y}=y i e l d$ strength,

$\sigma_{u}=$ ultimate strength,

$h=$ average height of dimple,

$W=$ average width of dimple,

$f_{p}=$ volume fraction of inclusions associated with dimples,

$\ell_{0}^{*}=$ characteristic distance, taken to be 5 times the average spacing of void-initiating inclusions

The key element in their model is that the shape of the dimple $(\mathrm{h} / \mathrm{W})$ and the inclusion content are simply related to the local strain to failure. They assume a stress-modified critical strain criterion where $\mathrm{J}=\mathrm{J}$ Ic when the local strain to cause failure is exceeded over a characteristic distance that is comparable to the inclusion spacing.

This model can be applied to fracture surfaces that are relatively uniform in appearance and where there are distinct differences in dimple morphology. In our study, the best example of contrasting dimple shape is found in the first Mn group, with extremely fine dimples in the $1 \% \mathrm{Mn}$ alloys (Figure 15) and large dimples in the 6\% Mn alloys (Figure 16).

To apply the model, certain assumptions need to be made concerning the shapes of the dimples and volume fraction of inclusions. The fractographs in Figures 15 and 16 show that the large dimples, about $20 \mu \mathrm{m}$ in diameter, appear to be approximately half as deep as they are wide $(h / W=0.5)$, whereas the rine dimples, about $2 \mu \mathrm{m}$ in diameter, appear to be relatively shallow compared to the ir width. The $\mathrm{h} / \mathrm{W}$ parameter is assumed to be 0.25 , and the characteristic distance is assumed to be 5 times the average dimple diameter. The $f_{p}$ of the $0.1 \mu \mathrm{m}$ diameter inclusions is estimated from the STEM foils to be $10^{p_{4}}$ to $10^{-5}$. The $f_{p}$ of the larger inclusions in the $6 \% \mathrm{Mn}$ alloy was estimated to be 0.015 .

With these measurements and assumptions and the measured tensile properties, the calculated values of $\mathrm{J}_{\text {Ic }}$ for alloy 69 ( $1 \% \mathrm{Mn}$ ) were 21 and $29 \mathrm{~kJ} / \mathrm{m}^{2}$ for the two different values of $\mathrm{f}_{\mathrm{p}}$; the measured value was $109 \mathrm{~kJ} / \mathrm{m}^{2}$. For alloy $72(6 \% \mathrm{Mn})$ the calculated $\mathrm{J}_{\mathrm{Ic}}$ was $65 \mathrm{~kJ} / \mathrm{m}^{2}$; the measured value was $260 \mathrm{~kJ} / \mathrm{m}^{2}$. The model predicts a lower toughness than that measured, but it does predict the correct trend of increasing toughness with increasing dimple size--the toughness ratios for the two alloys, [(21 or 29)/65] calculated and [109/260] measured, are approximately the same.

Another way to test the model is to compare two alloys with very similar dimple shapes. Take, for example, alloy 69 from the first Mn group and alloy 80 from the Mo group. We can see that the shapes of the dimples are similar (compare Figures 15 and 22 ), the volume fractions of void-initiating inclusions should be reasonably close, and the characteristic distances should be the same in both cases. With these assumptions, the model predicts 
that toughness is a function of the flow stress alone. For these two alloys, the flow stress is approximately the same, 1170 and $1133 \mathrm{MPa}$. The calculated toughness values for the two are similar, between 21 and $29 \mathrm{~kJ} / \mathrm{m}^{2}$. However, the measured values found in Table II were considerably different, 109 for alloy 69 and $216 \mathrm{~kJ} / \mathrm{m}^{2}$ for alloy 80 . We conclude that this model does not adequately describe these test results.

If the fracture toughness values of the two alloys are normalized to the same yield strength, $677 \mathrm{MPa}$, the toughness of alloy 80 is still $212 \mathrm{MPa} \cdot \sqrt{\mathrm{m}}$, and for alloy 69 , the $\mathrm{K}_{\mathrm{Ic}}(\mathrm{J})$ value is $132 \mathrm{MPa} \cdot \sqrt{\mathrm{m}}$. Adjusting the toughness to account for the difference in the $\mathrm{Ni}$ content (10.8 for 80 and 8.7 for 69 ) increases the value for alloy 69 to $168 \mathrm{MPa} \cdot \sqrt{\mathrm{m}}$. Now, the comparison between the fracture toughness values of the two alloys is improved.

A possible explanation for the difference in toughness is that a different type of inclusion is responsible for void nucleation, stage 2 in our simple model. When the toughness values of different alloys within one group are compared, the type of inclusion does not vary. In alloy 69, the fine inclusions are $\mathrm{rich}$ in $\mathrm{Ti}$ and $\mathrm{Al}$. The fine inclusions assumed to exist in alloy 80 have not been identified, but because the alloys were made by different suppliers, it seems likely that the type of inclusion is different.

These two examples illustrate specific shortcomings of the model presented by Ritchie and Thompson. The major problem is determining the proper values of the variables: flow stress, dimple shape, and characteristic distance. In addition, there is no method of incorporating the effect of alloying elements into the model if the elements do not affect the tensile properties, for instance, the effect of $\mathrm{Ni}$ on the deformation behavior in the toughness test as compared to the tensile test.

The logarithmic term for local strain to failure provides a good, physical model of the process, but only drastic changes in the fracture features $(\mathrm{h} / \mathrm{W})$, types of fracture (dimpled or quasi-cleavage) or shape (such as shown here for alloys 69 and 72) are quantitatively important in evaluating the toughness.

The characteristic distance is a variable that can be changed to make the data fit the model. In Ritchie and Thompson's presentation of the model, 5 to 6 times the average major inclusion spacing was an appropriate value for ductile fracture of ASTM A533B-1 steel. Lee et al. have shown that 1 to 2 times the inclusion spacing is appropriate to use for high-strength AISI 4340 steel. 12 An analysis of data for high-strength Al alloys (see Appendix A) indicates that $\ell_{0}^{*}$ would also be 1 to 3 times the average spacing of major void-initiating inclusions for these alloys.

Another problem with the existing model is that it does not take into account the different types of inclusions that initiate voids. The tensile ductility of ferritic steels has been shown to vary significantly as a function of inclusion type and shape. ${ }^{26}$ A similar effect of inclusion type could explain why two alloys with similar dimple shape and flow strengths have different fracture toughness values. 


\section{SUMMARY}

The results reaffirm previous results that show toughness decreases with increasing strength. However, at a constant strength level, $\mathrm{Ni}$, and possibly Mn and Mo, significantly increase toughness. This increased toughness is linked to a difference in dislocation interactions and is evidenced by increased plasticity for a triaxial stress state and the transition in fracture morphology. For brittle, faceted fracture, dislocation pileups produce decohesion along slip planes. With higher $\mathrm{Ni}$ content, Mn content, or both, dimpled fracture occurs. For the austenitic stainless steels tested, we suggest that the alloy additions increase the stacking fault energy and make cross slip easier. More cross slip increases plasticity and reduces the stress concentration at the head of dislocation pileups. Then, the preferred site for decohesion would be the interface between inclusions and the matrix.

Another factor affecting toughness appears to be the size of dimples produced in ductile fracture. The Ritchie-Thompson model has correctly predicted the trend of decreasing toughness with decreasing dimple size, but the prediction is not quantitative. Problems occur when attempting to correlate the model quantitatively with the test results.

\section{ACKNOWLEDGMENTS}

The Office of Fusion Energy, Dr. Victor Der, Project Monitor, sponsored this research. We owe special thanks to Robert Walsh and Ralph Tobler who performed most of the mechanical testing. We would also like to thank David Gorni and Chris McCowan for their help in reviewing the document and suggesting ways to improve it.

\section{REFERENCES}

1. R. L. Tobler, D. T. Read, R. P. Reed: in Fracture Mechanics: Thirteenth Conference, ASTM STP 743, R. Roberts, eds., American Society for Testing and Materials, nhiladelphia, 1981, p. 350.

2. H. I. McHenry: in Materials Studies for Magnetic Fusion Energy Applications at Low Temperatures - VIII, NBSIR 85-3025, R. P. Reed, ed., National Bureau of Standards, Boulder, Colorado, 1985, p. 121.

3. J. M. Krafft: Appl. Mat. Res., vol. 3, 1964, p. 88.

4. G. T. Hahn and A. R. Rosenfield: Metall. Trans. A, vol. 6A, 1975, p. 653.

5. J. P. Hirth and F. H. Froes: Metall. Trans. A, vol. 8A, 1977, p. 1165.

6. J. W. Morris, Jr. and E. N. C. Dalder: J. Met., vol. 37, no. 10, 1985, p. 24 .

7. J.P. Hirth: Metall. Trans, vol. 3, 1972, p. 3047.

8. J. C. M. Li and Y. T. Chou: Metall. Trans., vol. 1, 1970, p. 1145. 
9. C.W. Corti, P. Cotterill, and G. Fitzpatrick: Int. Mater. Rev., vol. 19, June 1974, p. 77 .

10. J. C. Fisher, Acta Metall., vol. 2, 1954, p. 9.

11. R. O. Ritchie and R. M. Horn: Metall. Trans. A, vol. 9A, 1978, p. 331.

12. S. Lee, L. Majno, and R. J. Asaro: Metall. Trans. A, vol. 16A, 1985, p. 1633 .

13. R. O. Ritchie and A. W. Thompson: Metall. Trans. A, vol. 16A, 1985, p. 233 .

14. T. Sakamoto, Y. Nakagawa, I. Yamauchi, T. Zaizen, H. Nakajima, and S. Shimamoto: in Advances in Cryogenic Engineering - Materials, vol. 30, Plenum Press, New York, 1984, p. 137.

15. R. L. Tobler and R. P. Reed: in Advances in Cryogenic Engineering Materials, vol. 28, Plenum Press, New York, 1982, p. 83.

16. R. P. Reed: in Advances in Cryogenic Engineering - Materials, vol. 7, Plenum Press, New York, 1961, p. 448.

17. ASTM E813-81, in "Standard Test Method for J Ic, A Measure of Fracture Toughness, 1981 Annual Book of ASTM Standards, Part 10, American Society for Testing and Materials Philadelphia, 1981, p. 763.

18. R, L. Tobler and J. A. Shepic: J. Test. Eval. July 1985, p. 299.

19. R. P. Reed and P. T. Purtscher: in Advances in Cryogenic Engineering Materials, vol. 32, Plenum Press, New York, 1986, p. 43.

20. D. T. Read and R. P. Reed: in Advances in Cryogenic Engineering Materials, vol. 26, Plenum Press, New York, 1980, p. 91.

21. P. T. Purtscher: submitted for publication to J. Test. Eval.

22. M. Ahlers: Metall. Trans., vol. 1, 1970, p. 2415.

23. H. Suzuki: Sci. Rep. Res. Inst. Tohoku Univ., vol. 4A, 1952, p. 455.

24. B. Burton: Acta Metall., vol. 30, 1982, p. 905.

25. R. E. Schramm and R. P. Reed: Metall. Trans., vol. 6A, 1975, p. 1345.

26. R. L. Widner, W. K. Dominik, and A. J. Jenkins: SAE paper 780784 , Automot. Eng., vol. 86, no. 9, 1978, p. 74. 
Table I. Chemical Composition of Steels (wt.\%)

Steel
$\mathrm{Cr}$

$\mathrm{Ni}$
$\mathrm{Mn}$

C

N

$n^{-1 / 2 *}$

\section{for N1 Alloying}

$\begin{array}{lrrrrrrl}413 & 18.8 & 5.6 & 4.1 & 0.020 & 0.256 & -- & 0.15 \\ 415 & 18.4 & 8.9 & 4.2 & 0.018 & 0.218 & -- & 0.20 \\ 414 & 20.5 & 12.8 & 5.5 & 0.024 & 0.265 & -- & 0.21 \\ 416 & 20.8 & 14.9 & 5.2 & 0.028 & 0.277 & -- & 0.18-0.22 \\ 520 & 19.8 & 5.8 & 3.2 & 0.014 & 0.260 & -- & 0.24 \\ 739 & 18.7 & 8.7 & 3.7 & 0.014 & 0.093 & -- & 0.18 \\ 740 & 19.7 & 11.5 & 3.9 & 0.012 & 0.141 & -- & 0.18 \\ 714 & 20.8 & 14.7 & 4.4 & 0.016 & 0.197 & -- & 0.22\end{array}$

1st group for

Mn Alloying

$\begin{array}{llllllll}69 & 18.2 & 8.7 & 1.0 & 0.025 & 0.11 & 0.32 & 0.14 \\ 70 & 18.1 & 8.7 & 2.0 & 0.025 & 0.11 & 0.31 & -- \\ 71 & 18.2 & 8.7 & 4.0 & 0.025 & 0.11 & 0.31 & -- \\ 72 & 18.1 & 8.6 & 5.8 & 0.021 & 0.11 & 0.33 & 0.13 \\ 73 & 19.4 & 7.8 & 1.2 & 0.025 & 0.19 & 0.32 & 0.15 \\ 74 & 19.4 & 7.9 & 2.0 & 0.022 & 0.19 & 0.32 & -- \\ 75 & 19.3 & 7.8 & 3.9 & 0.024 & 0.19 & 0.31 & -- \\ 76 & 19.5 & 7.8 & 5.8 & 0.033 & 0.21 & 0.31 & 0.18 \\ 77 & 18.7 & 8.2 & 4.0 & 0.026 & 0.15 & 0.31 & -- \\ 78 & 18.4 & 8.3 & 5.8 & 0.031 & 0.15 & 0.31 & --\end{array}$

2nd group

for Mn Alloying

$\begin{array}{rrrrrrrl}297 & 19.4 & 7.4 & 4.2 & 0.025 & 0.20 & 0.31 & 0.15 \\ 304 & 19.6 & 7.0 & 7.5 & 0.023 & 0.19 & 0.31 & -- \\ 300 & 19.4 & 7.2 & 10.2 & 0.023 & 0.21 & 0.31 & 0.17 \\ 301 & 21.3 & 9.1 & 4.3 & 0.025 & 0.21 & 0.30 & 0.16\end{array}$

Mo Alloying

$\begin{array}{llllllll}79 & 18.6 & 18.9 & 1.0 & 0.020 & 0.12 & 2.2 & 0.24-0.30 \\ 80 & 18.0 & 10.8 & 1.0 & 0.018 & 0.17 & 0.0 & 0.23\end{array}$

${ }^{*} \mathrm{n}=$ number of inclusions greater than $0.5 \mu \mathrm{m}$ in diameter in a $0.1 \mathrm{~mm}^{2}$ area 
Table II. Mechanical Properties of Steels

$\begin{array}{ccccccc}\sigma_{\mathrm{y}}, & \sigma_{\mathrm{u}}, & \text { elong., } & \mathrm{R} . \mathrm{A} ., & \mathrm{J}_{\mathrm{Ic}}, & \mathrm{K}_{\mathrm{Ic}}(\mathrm{J}), & \text { Grain Size, } \\ \mathrm{MPa} & \mathrm{MPa} & \% & \% & \mathrm{~kJ} / \mathrm{m}^{2} & \mathrm{MPa} \sqrt{\mathrm{m}} & \mu \mathrm{m}\end{array}$

for $\mathrm{Ni}$ Alloying

$\begin{array}{rrrrrrrr}413 & 1075 & 1418 & 11 & 17 & 27 & 75 & 122 \\ 414 & 950 & 1650 & 42 & 54 & 99 & 143 & 165 \\ 415 & 1000 & 1580 & 32 & -- & 201 & 204 & 200 \\ 416 & 1160 & 1630 & 22 & 48 & 276 & 239 & 160 \\ 520 & 960 & 1216 & 7 & -- & 37 & 87 & 180 \\ 739 & 460 & 1417 & 40 & 43 & 360 & 273 & 220 \\ 740 & 720 & 1370 & 42 & 50 & 288 & 244 & 250 \\ 741 & 870 & 1425 & 29 & 48 & 312 & 254 & 207\end{array}$

1st group for

Mn Alloying*

$\begin{array}{rrrrrrrr}69 & 616 & 1724 & 34 & 23 & 109 & 150 & 57 \\ 70 & 661 & 1616 & 29 & 22 & 163 & 184 & 55 \\ 71 & 722 & 1581 & 38 & 31 & 203 & 205 & 49 \\ 72 & 755 & 1506 & 44 & 34 & 260 & 232 & 57 \\ 73 & 883 & 1808 & 34 & 30 & 60 & 111 & 55 \\ 74 & 956 & 1524 & 22 & 20 & 64 & 115 & 55 \\ 75 & 986 & 1668 & 38 & 31 & 98 & 142 & 53 \\ 76 & 1053 & 1584 & 33 & 25 & 116 & 155 & 53 \\ 77 & 857 & 1654 & 38 & 31 & 188 & 197 & 53 \\ 78 & 901 & 1574 & 41 & 37 & 185 & 196 & 53\end{array}$

2nd group for

Mn Alloying

$\begin{array}{rrrlllll}297-1 / 2 & 880 & 1700 & 47 & 45 & 71 / 66 & 128 / 117 & 150 \\ 304-1 / 2 & 950 & 1530 & 41 & 45 & 65 / 112 & 116 / 152 & 100 \\ 300-1 / 2 & 1020 & 1590 & 37 & 43 & 93 / 112 & 139 / 152 & 130 \\ 301-1 / 2 & 1025 & 1580 & 45 & 46 & 99 / 132 & 143 / 165 & 125\end{array}$

Mo Alloying

$\begin{array}{rrrrrrrr}79-1 & 1056 & 1733 & 36 & 49 & 103 & 146 & 7 \\ 79-2 & 935 & 1686 & 41 & 54 & 151 & 177 & 11 \\ 79-3 & 885 & 1618 & 41 & 58 & 169 & 187 & 20 \\ 80-1 & 677 & 1588 & 41 & 50 & 216 & 212 & 80 \\ 80-2 & 715 & 1620 & 42 & 51 & 199 & 202 & 75 \\ 80-3 & 784 & 1654 & 42 & 55 & & & 23 \\ 80-4 & 817 & 1669 & 41 & 57 & & & \end{array}$

*flat, dog-bone-type specimens were used for this group of alloys 


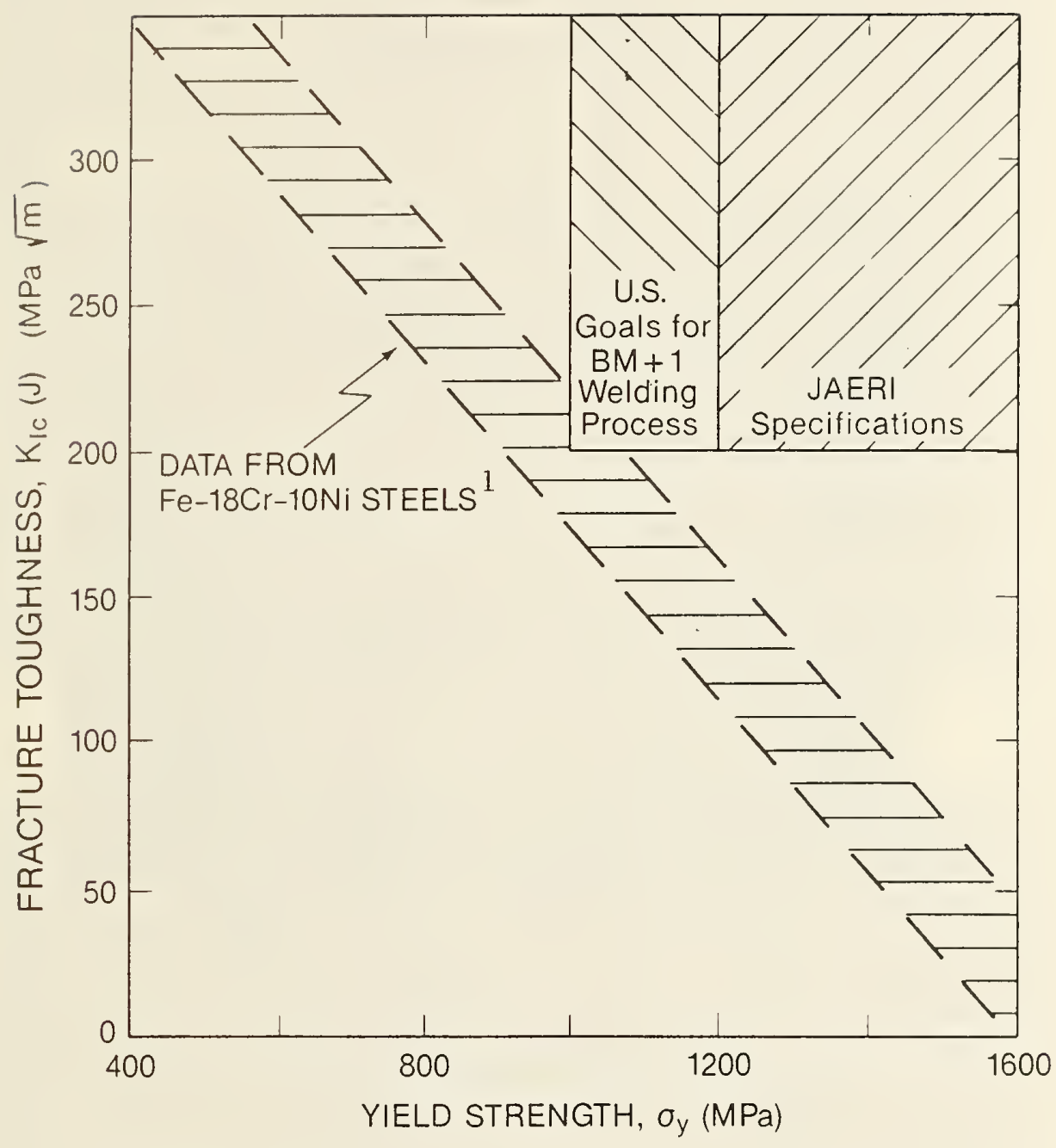

Figure 1. The Japanese and United States design goals for strength and toughness of austentic stainless steels at $4 \mathrm{~K}$ relative to the properties of $304-t y p e$ stainless steels. 1 


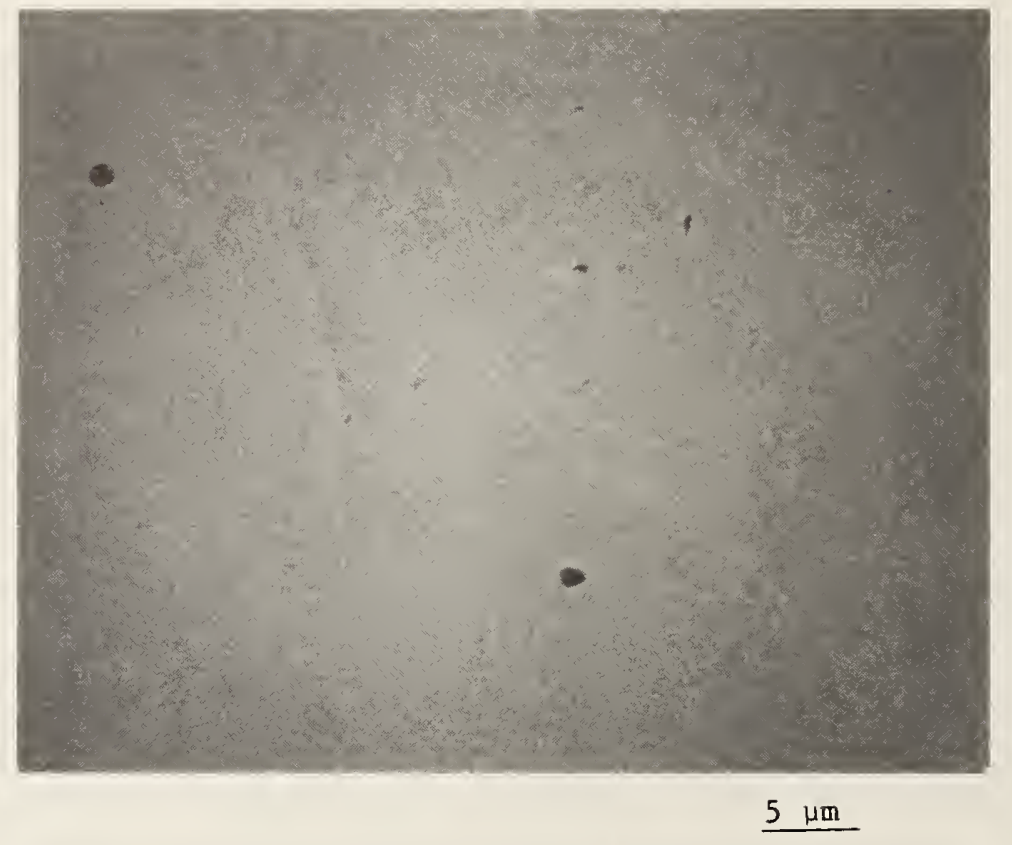

Figure 2. Appearance of nonmetallic inclusions in scanning electron microscope. Size and distribution is representative of all the steels included in this report 

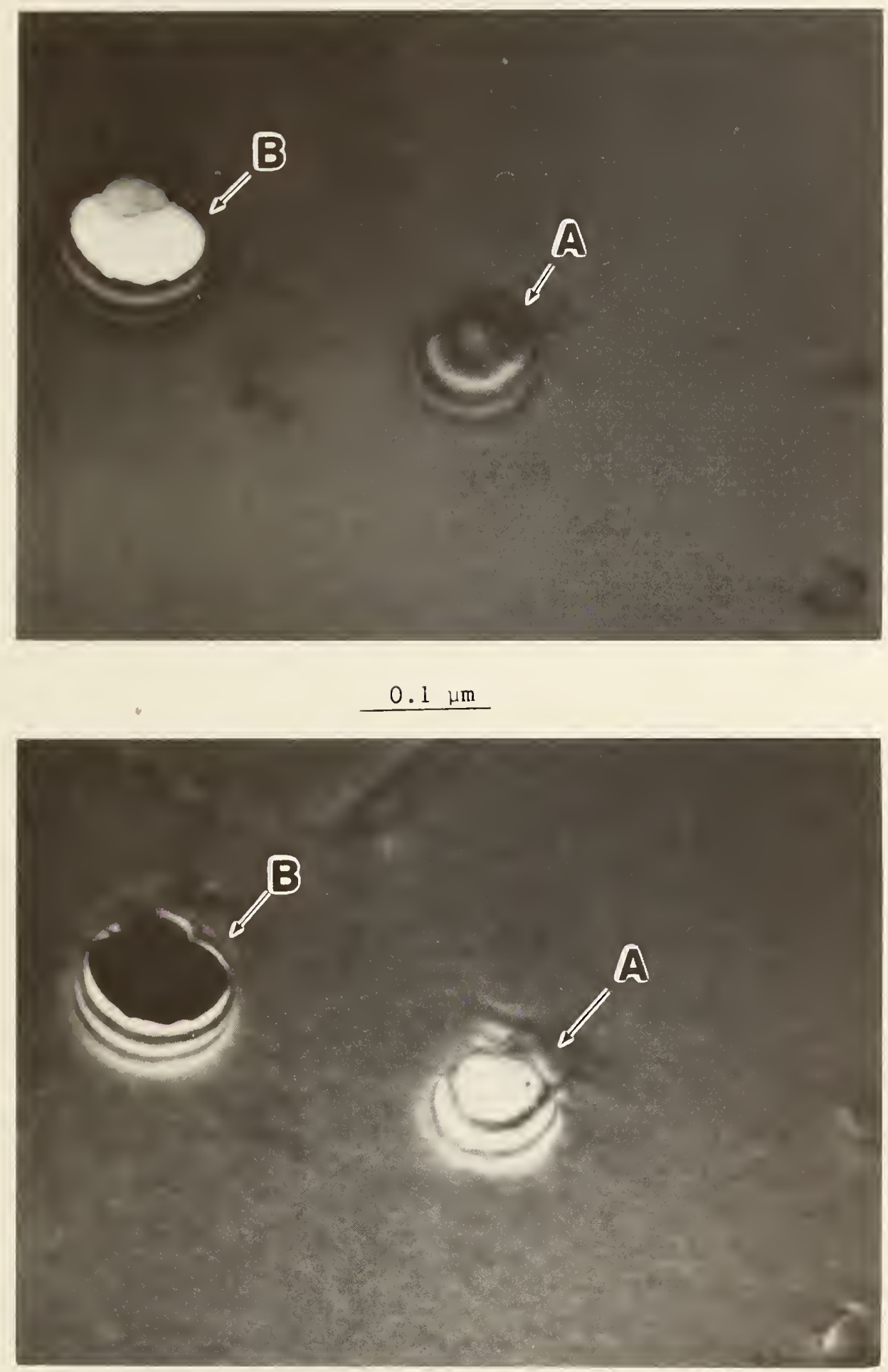

Figure 3. TEM bright field and dark field micrographs showing the $0.1 \mu \mathrm{m}$ diameter inclusions found in alloys 69-78. Region A shows an inclusion, and region $B$ is an area of the foil where an inclusion was before it fell out during electropolishing. 


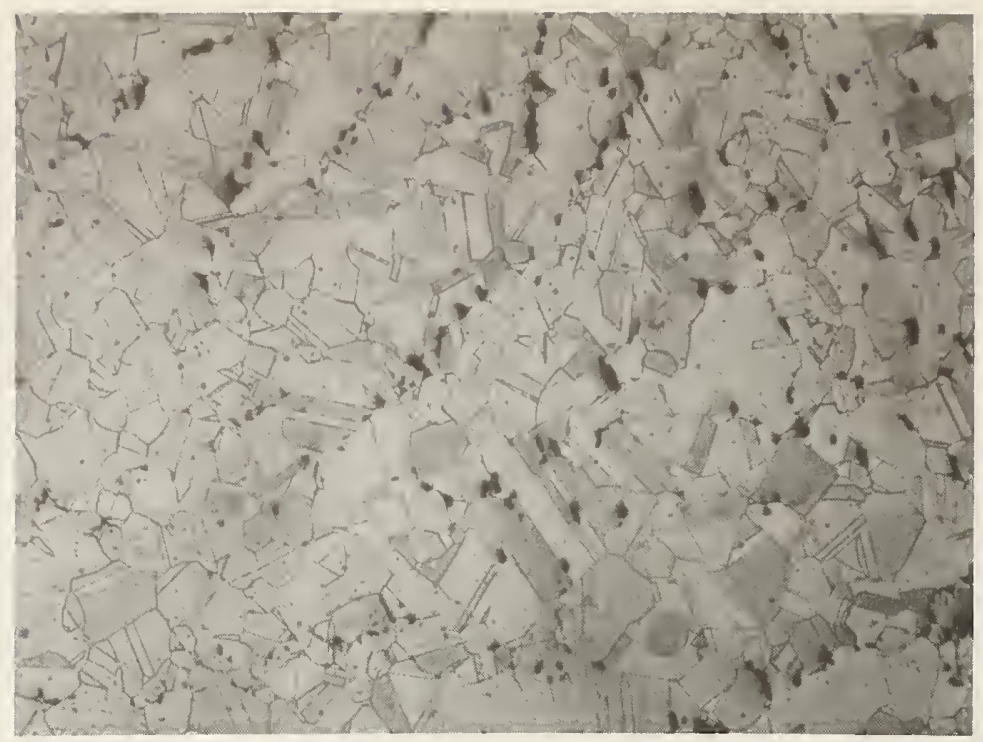

$0.2 \mathrm{~mm}$

Eigure 4. Microstructure of alloy 304 with $4 \%$ second phase in the austenitic matrix.

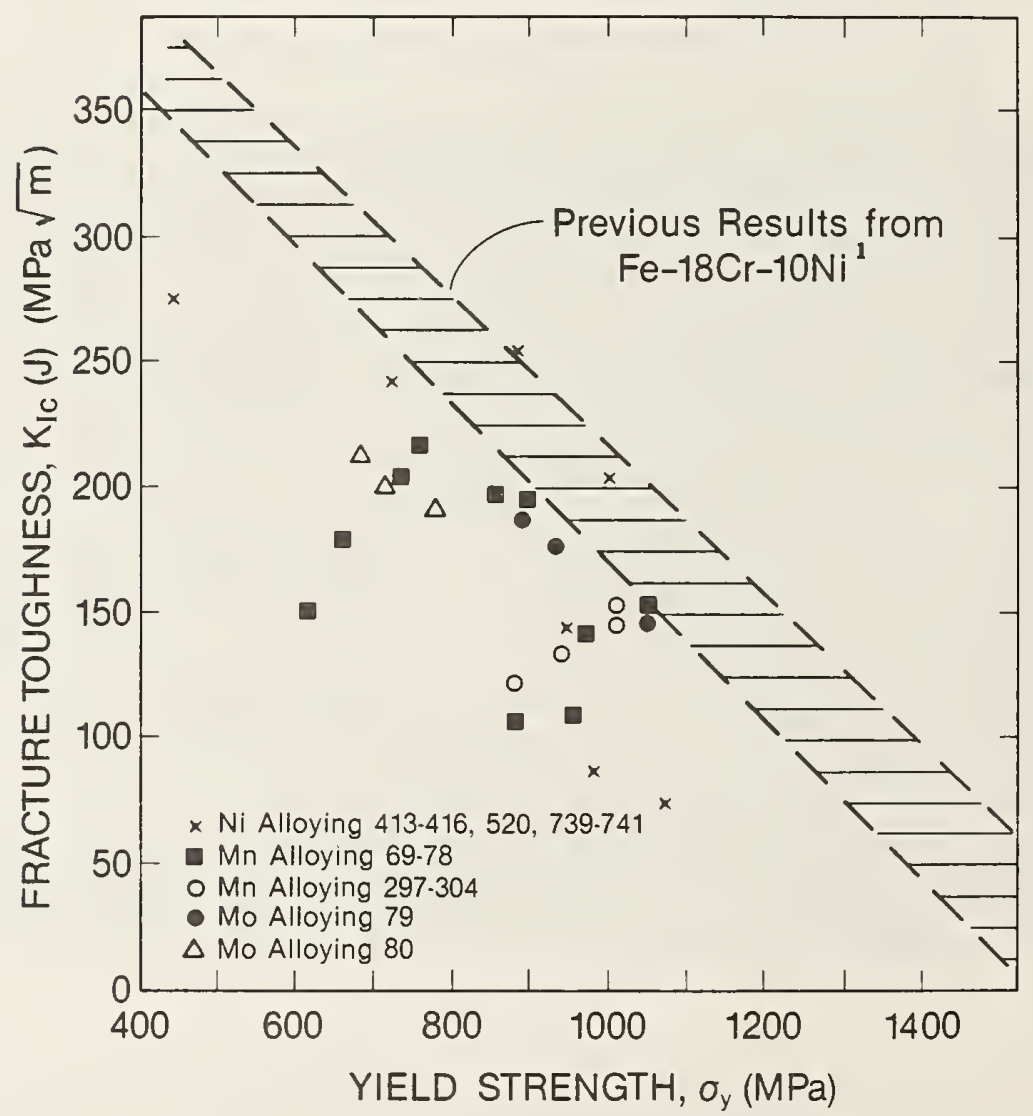

Figure 5. Fracture toughness vs. yield strength for all of the alloys presented in this report. 


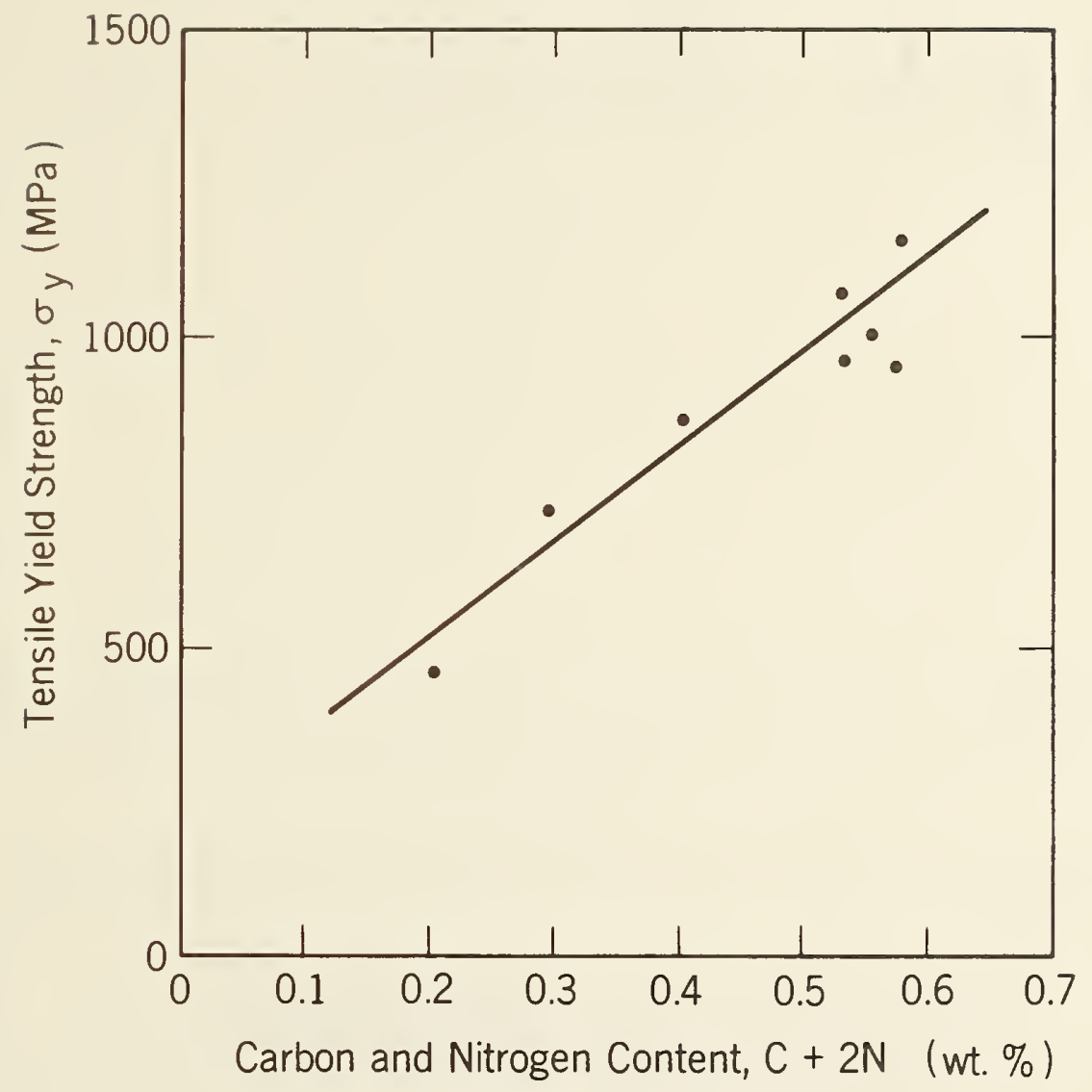

Figure 6. Yield strength at $4 \mathrm{~K}$ as a function of interstitial alloying elements. 


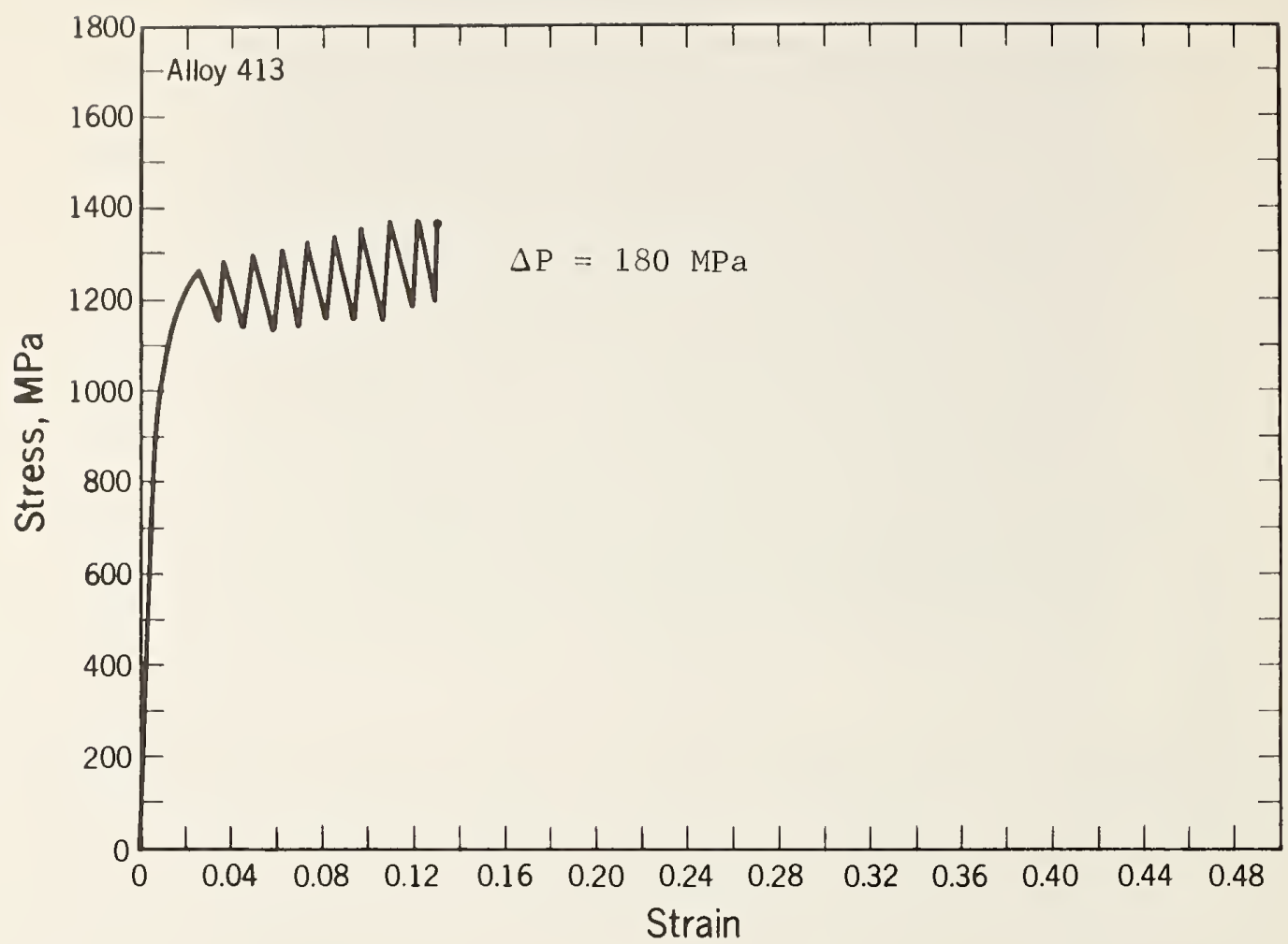

(a)

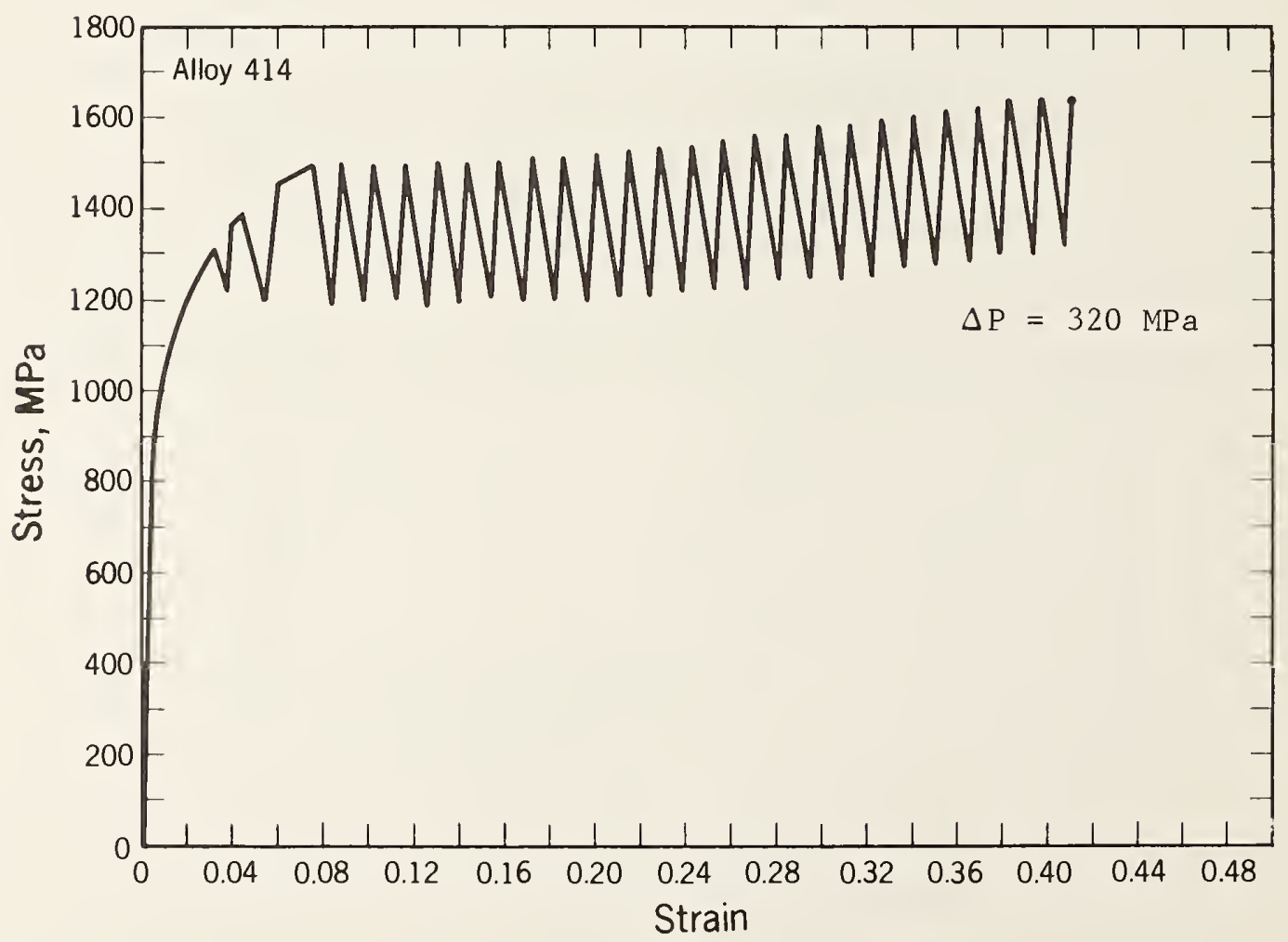

(b)

Fig. $7 \mathrm{a}$ and b. Engineering stress vs. strain diagrams of alloys 413 and 414 at $4 \mathrm{~K}$. 


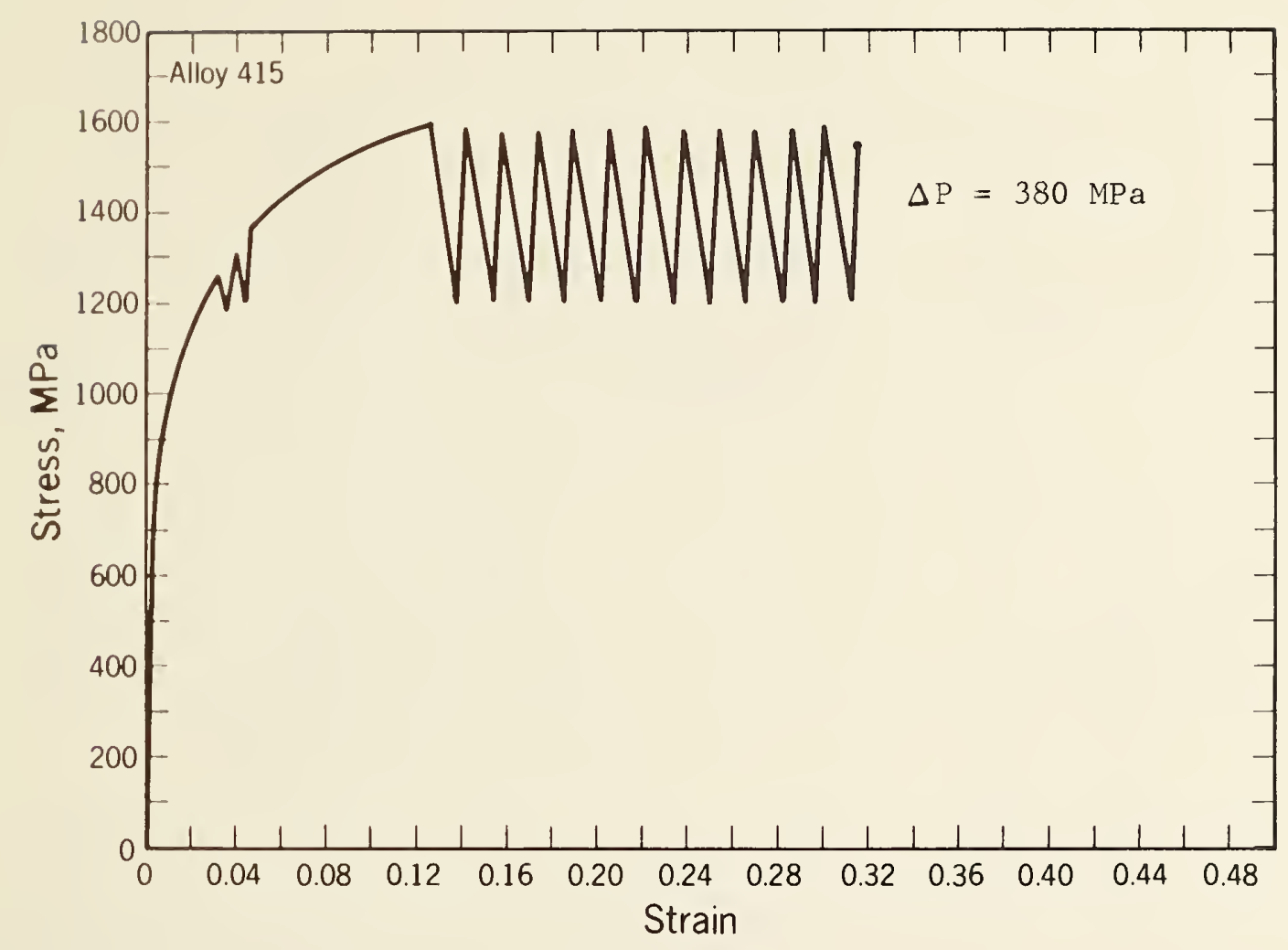

(c)

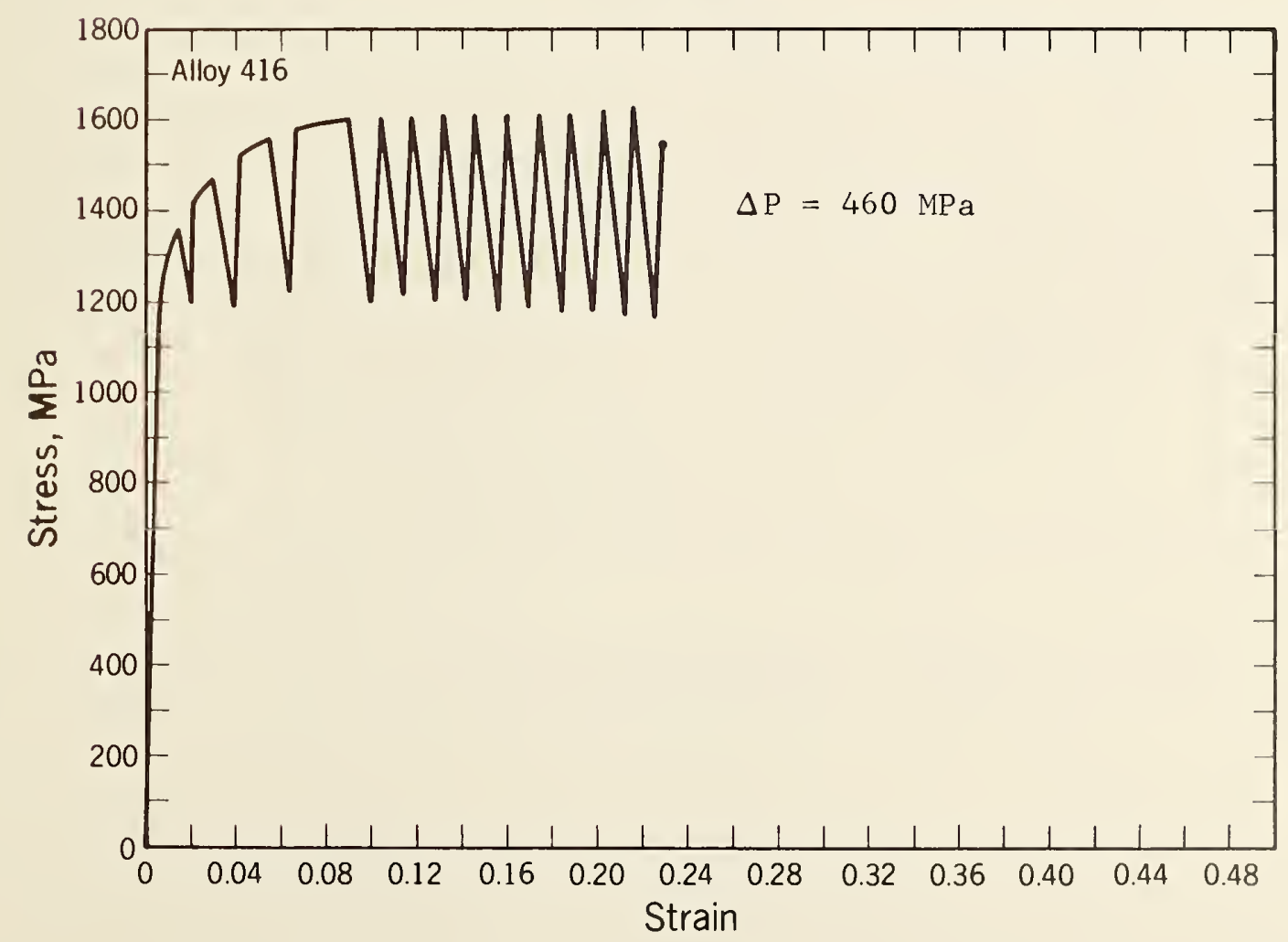

(d)

Fig. 7c and d. Engineering stress vs. strain diagrams of alloys 415 and 416 at $4 \mathrm{~K}$. 


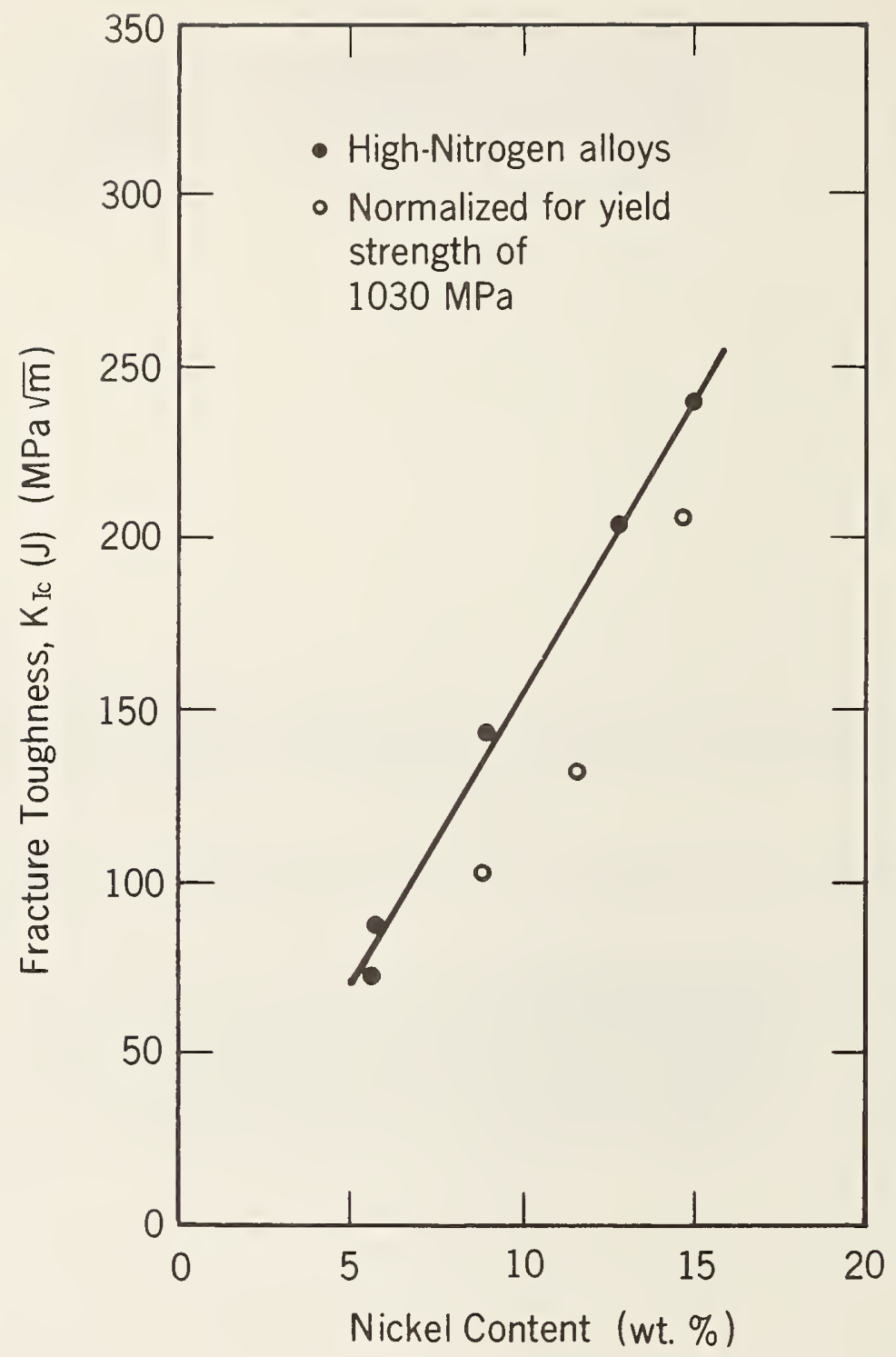

Figure 8. Fracture toughness vs. Ni content 1 for alloys $413-416,520$, and $739-741$ at $4 \mathrm{~K}$. 


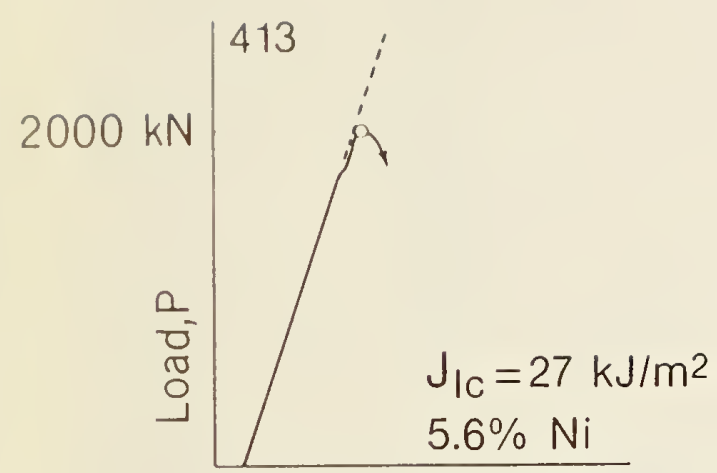

Load-Line Displacement, $u$

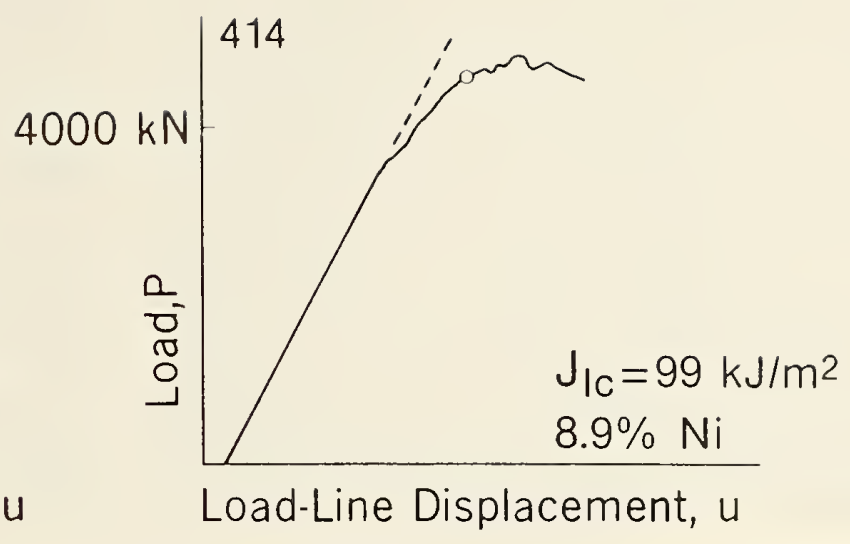

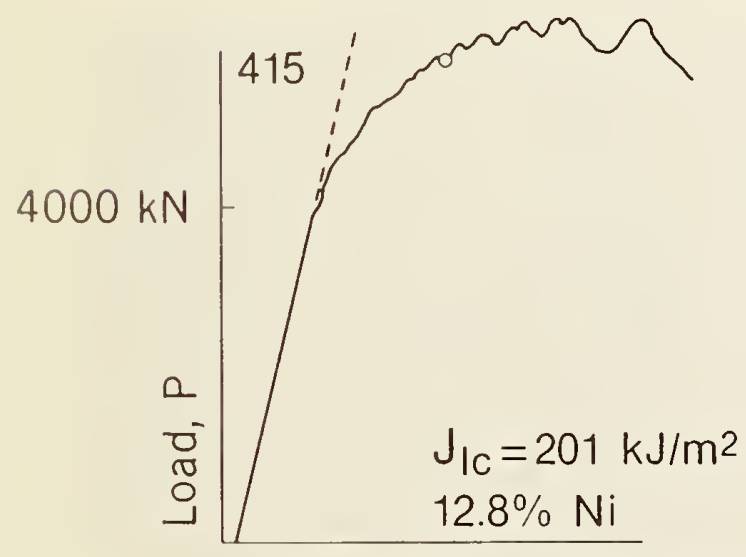

Load-Line Displacement, u

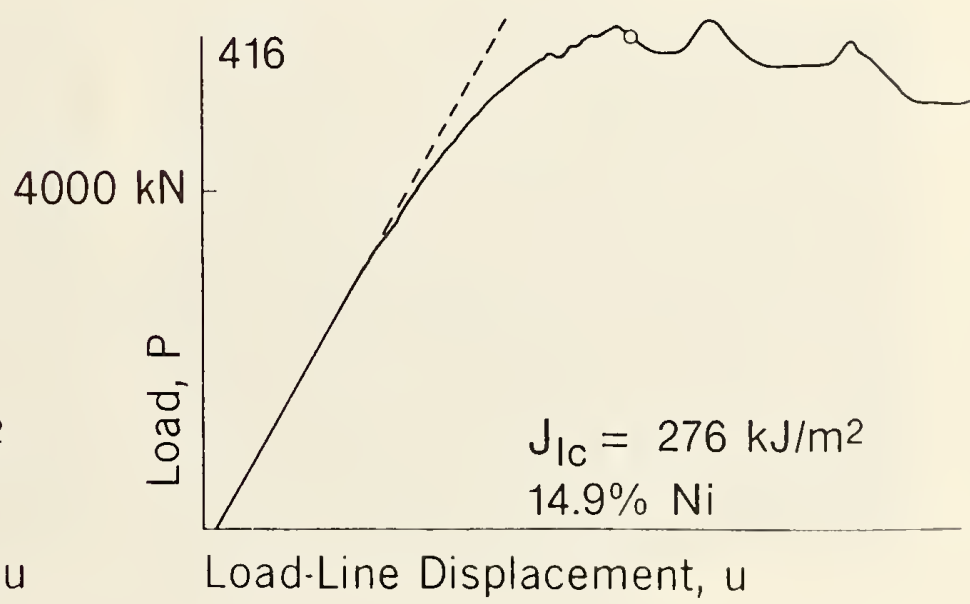

Figure 9. Load vs. load-line displacement curves for alloys 413, 414, 415, and 416 at $4 \mathrm{~K}$. 
(a)

(b)
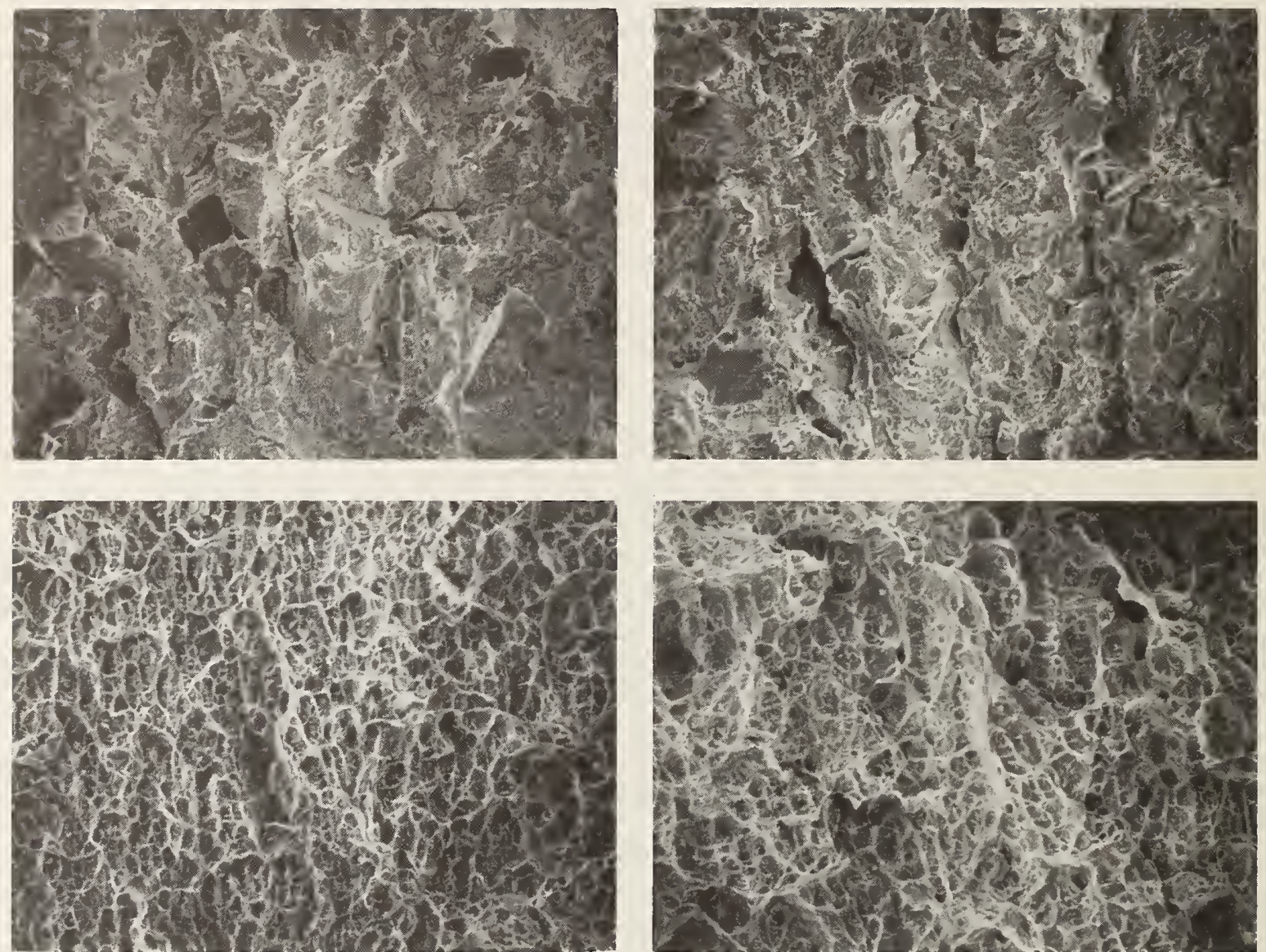

(c)

$200 \mu \mathrm{m}$

(d)

Figure 10. SEM fractographs of the fracture surface of alloys 413, 414, 415 and 416 that were created during the toughness test. 


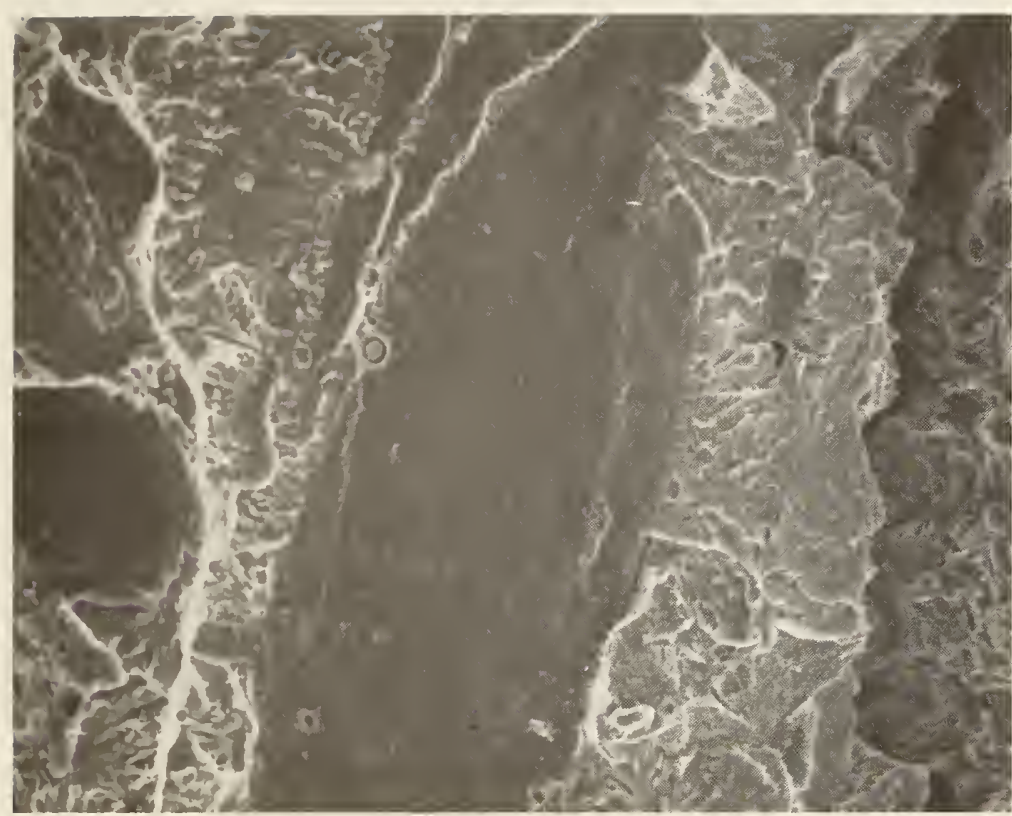

$20 \mu \mathrm{m}$

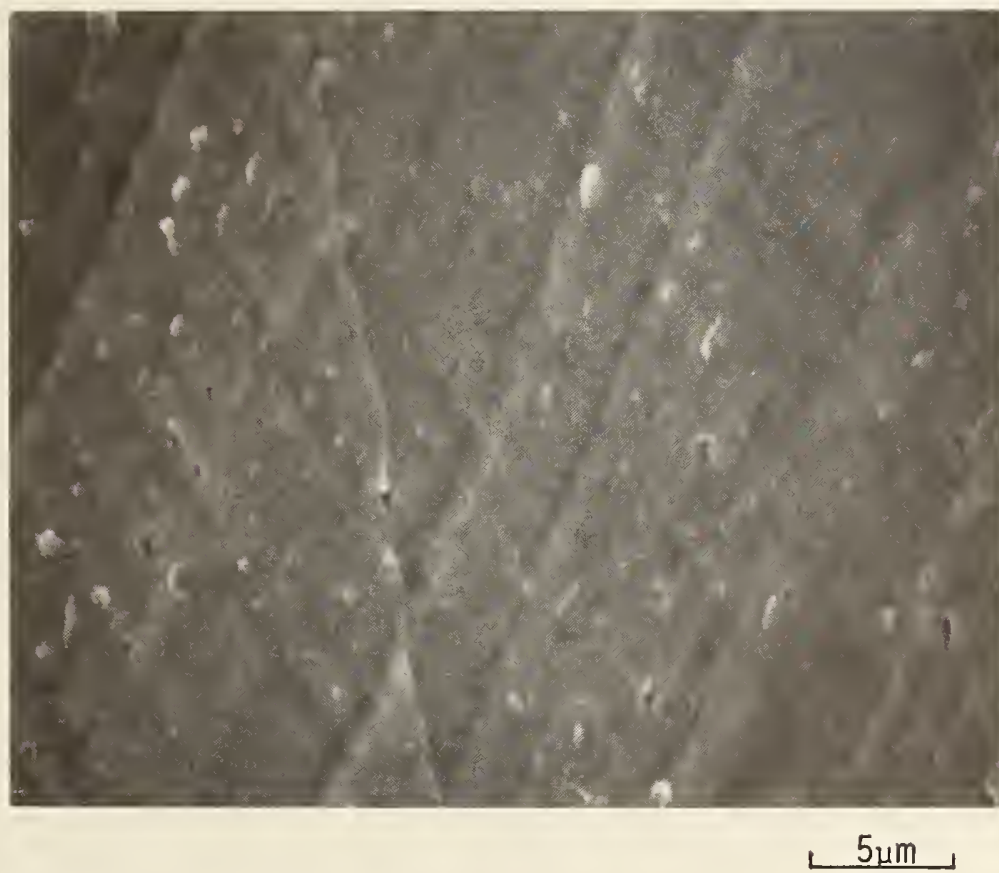

Figure 11. SEM fractographs from the fracture surface of alloy 413 showing large facets that are nearly equal to the grain size. 


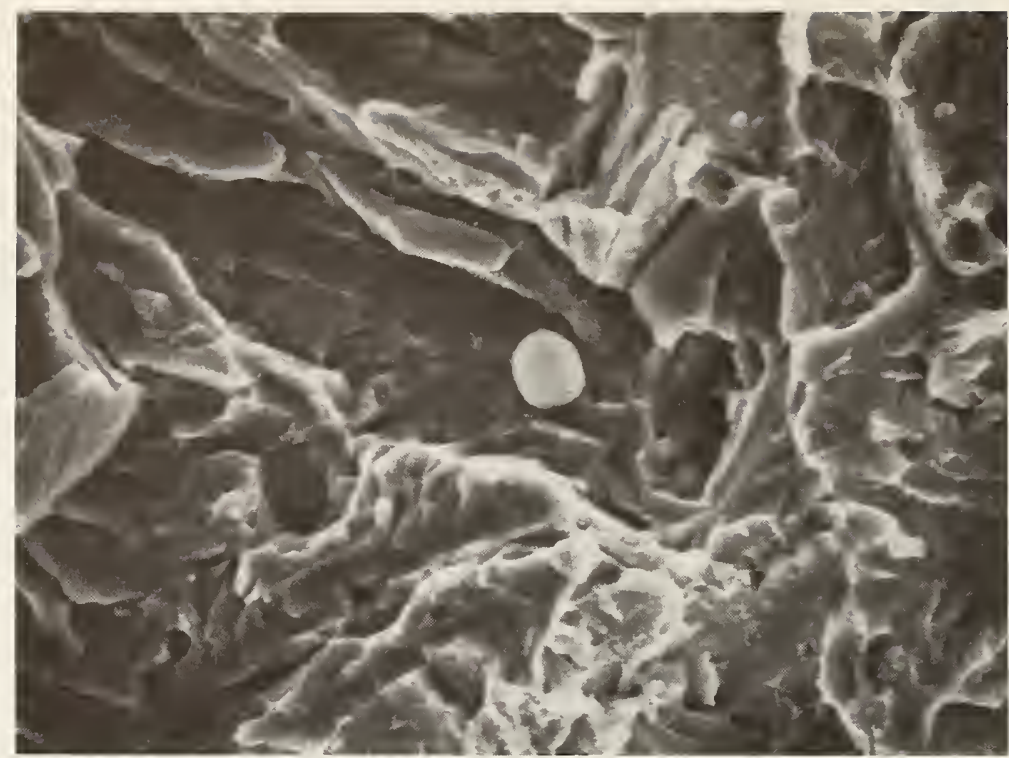

$5 \mu \mathrm{m}$

Figure 12. SEM fractograph from the fracture surface of alloy 413 showing smaller facets in the vicinity of a nonmetallic inclusion.

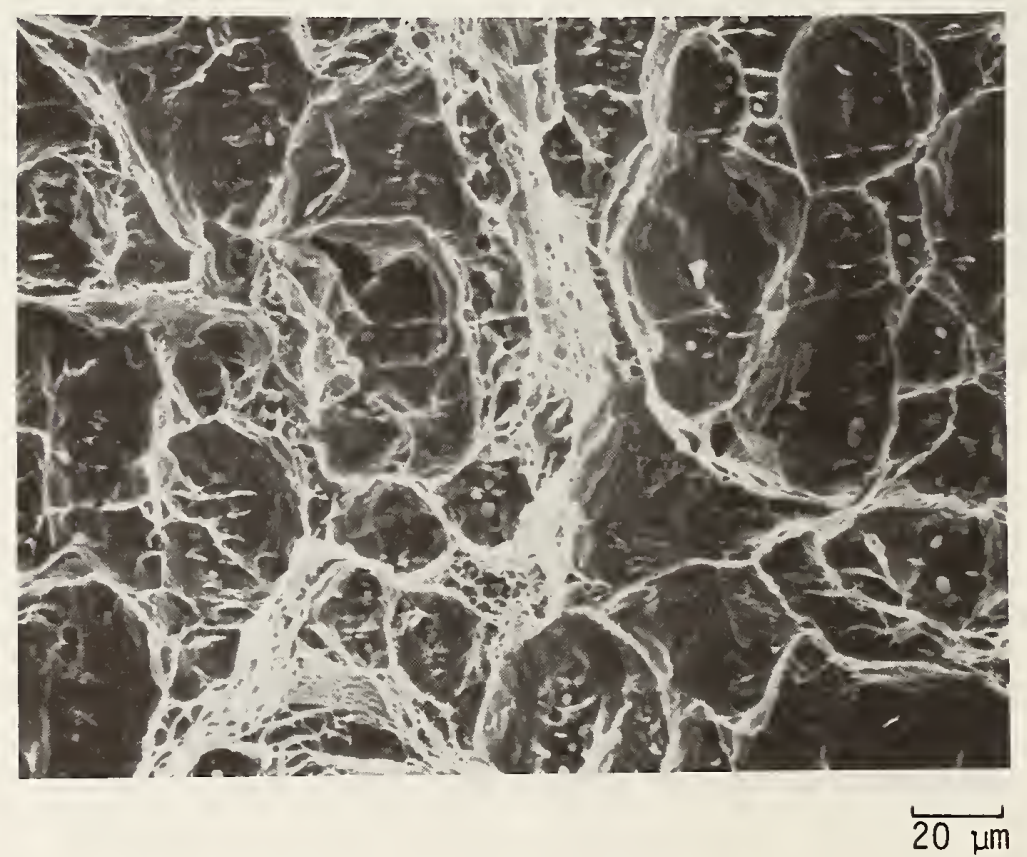

Figure 13. SEM fractograph from the fracture surface of alloy 416. 


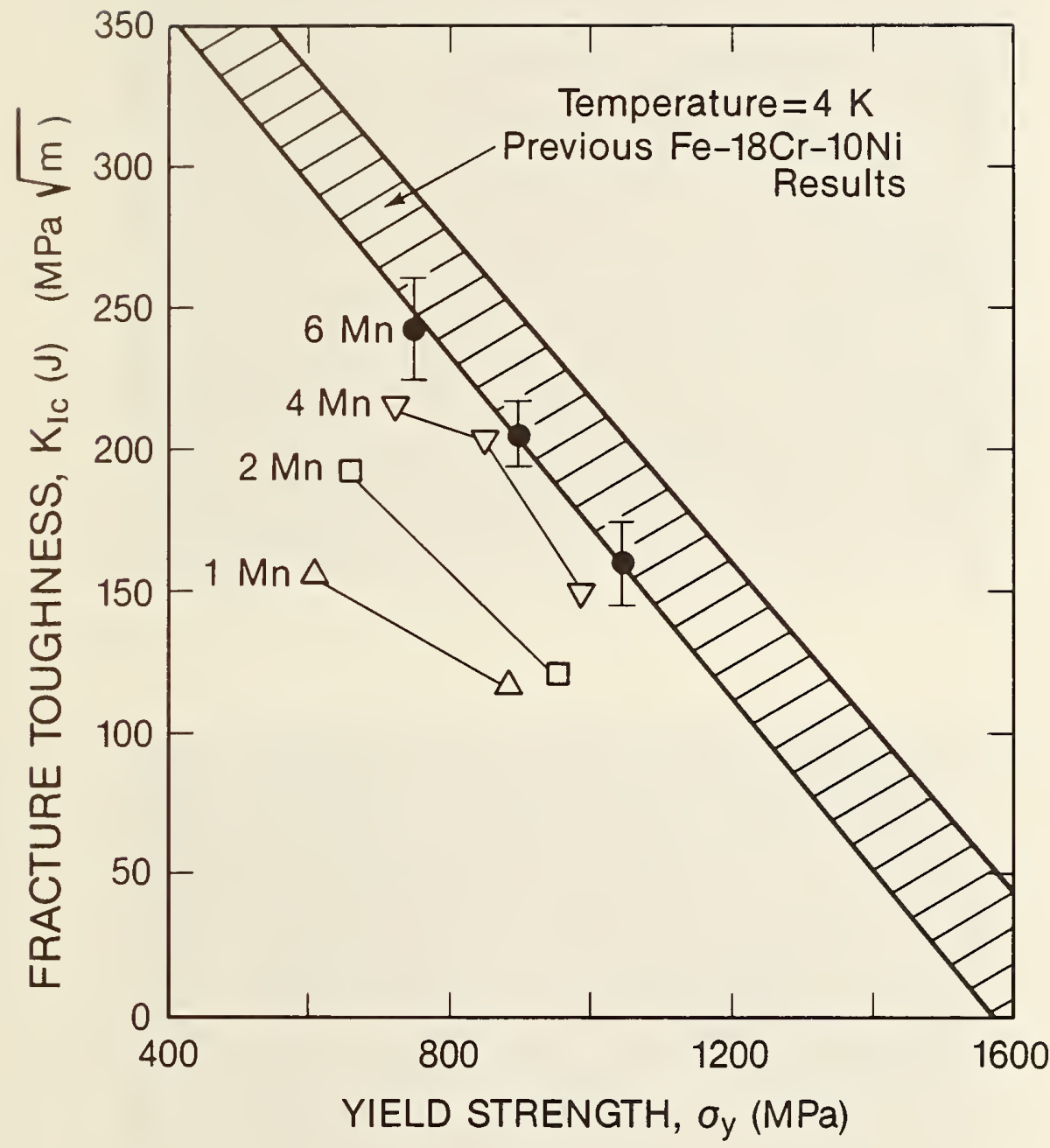

Figure 14. Fracture toughness vs. yield strength for alloys 69-78 (different $M n$ contents) at $4 \mathrm{~K}$. 

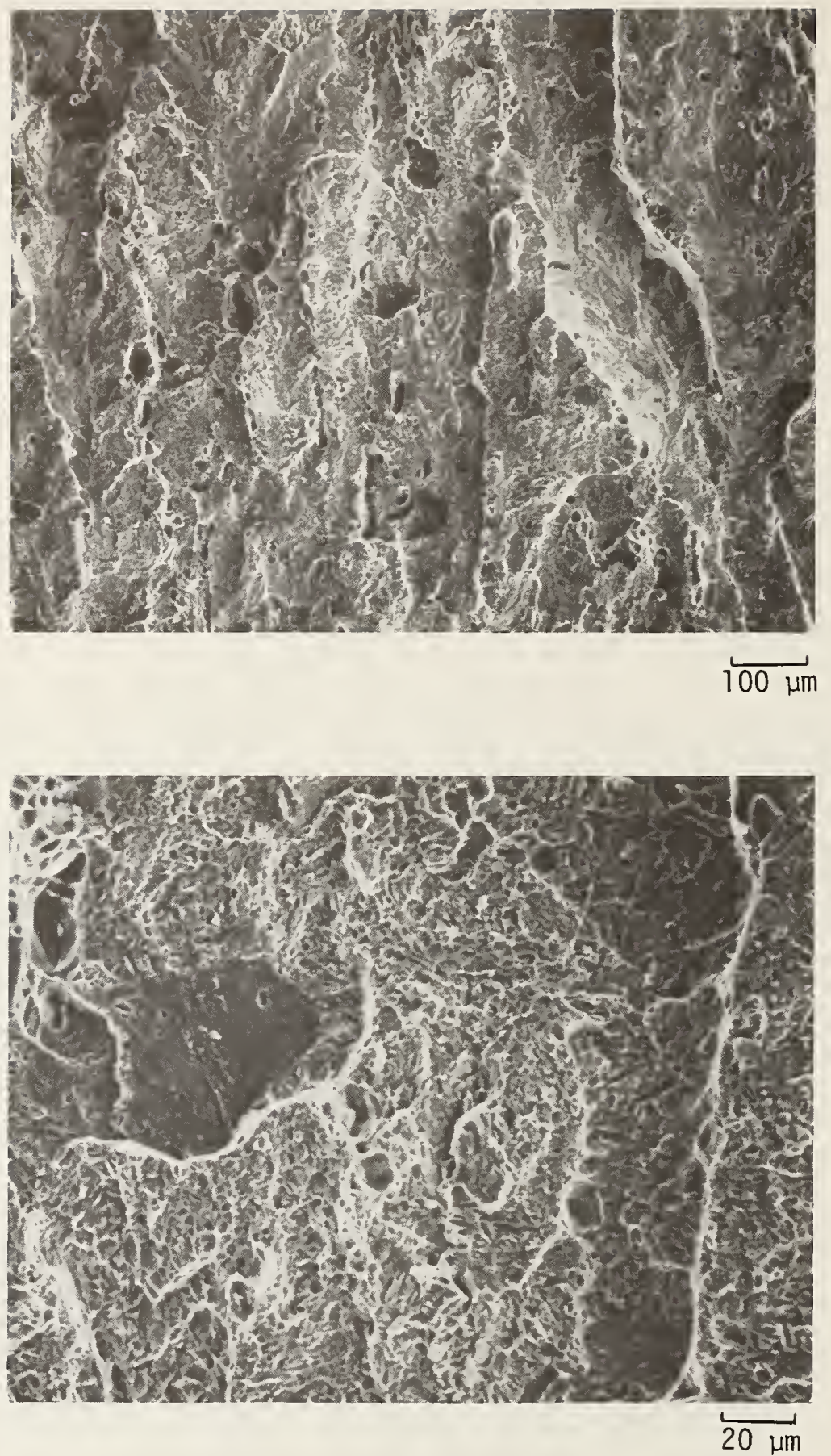

Figure 15. SEM fractograph from the fracture surface of alloy 69 with $1 \%$ Mn. 


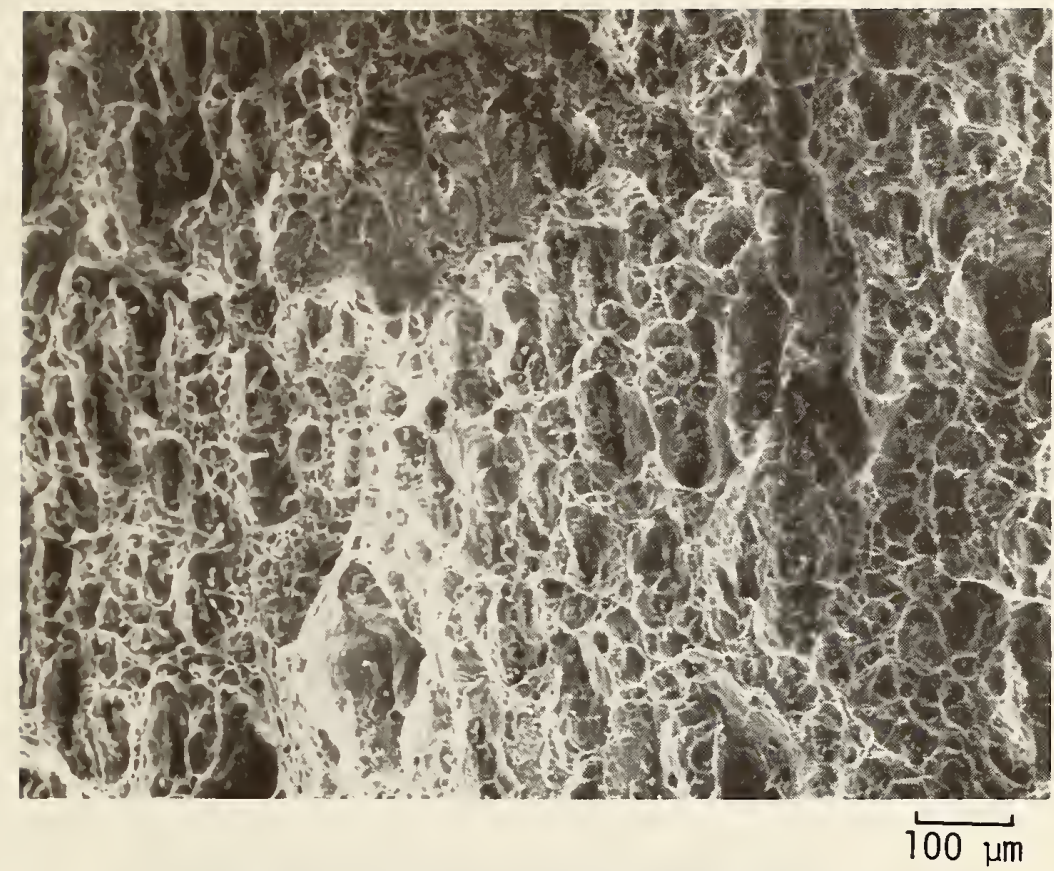

Figure 16. SEM fractograph from the fracture surface of alloy 72 with $6 \%$ Mn.

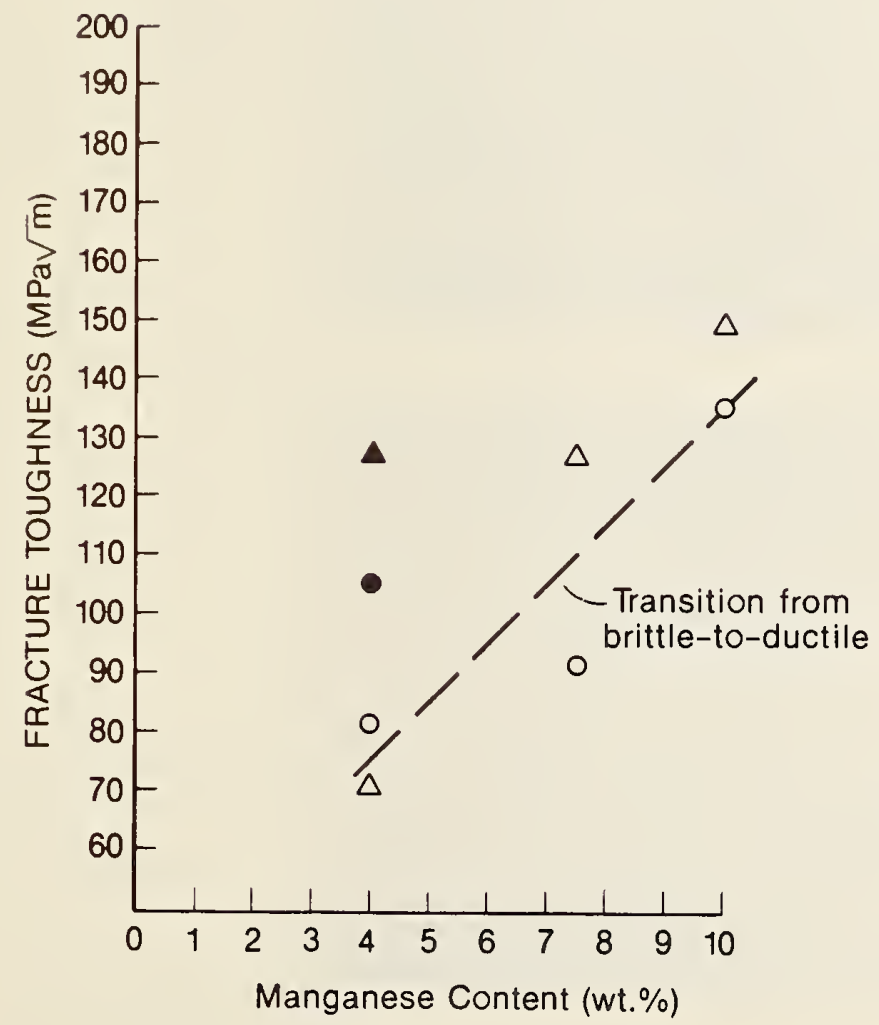

$\triangle=$ compact tension

0 = bend bar

open symbols are corrected to a yield strength of $1030 \mathrm{MPa}$ solid symbols are corrected for strength and $7 \% \mathrm{Ni}$

Figure 17. Adjusted fracture toughness vs. Mn content for alloys $297,300,301$, and 304 , at $4 \mathrm{~K}$. 
(a)

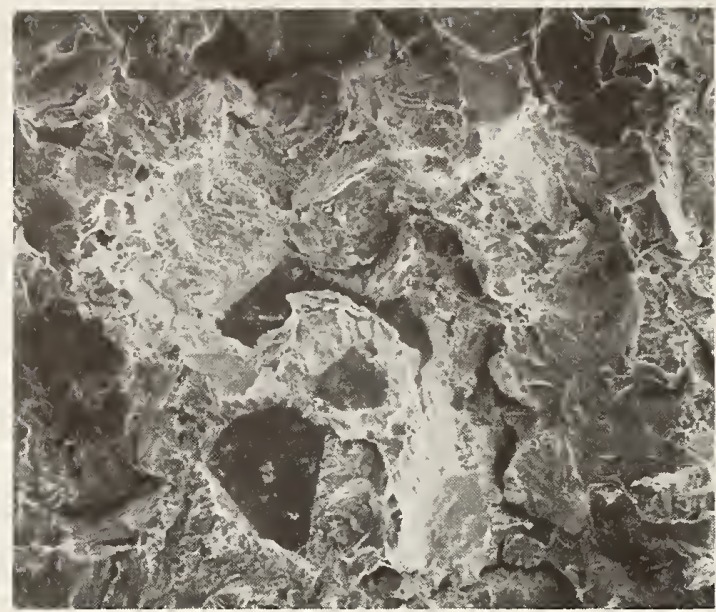

(b)

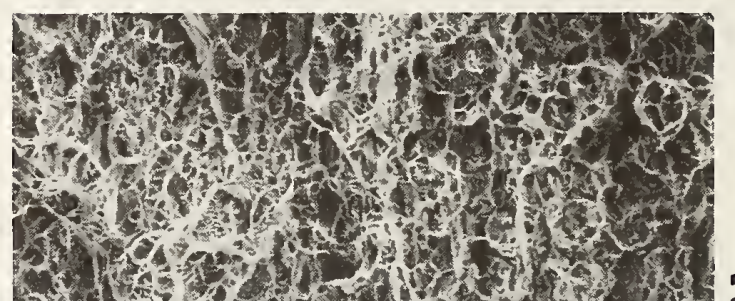

(c)

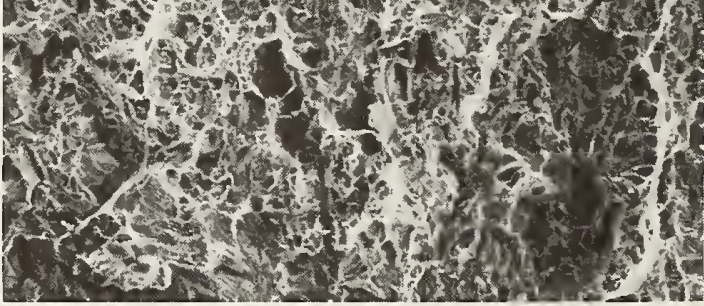

$200 \mu \mathrm{m}$

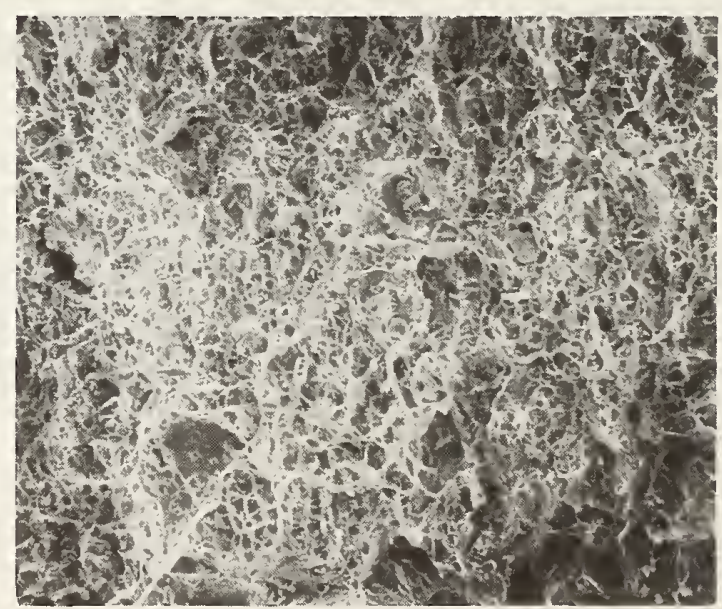

Figure 18. SEM fractographs of the fracture surface of alloys 297, 304, and 300 that were created during the toughness test. 


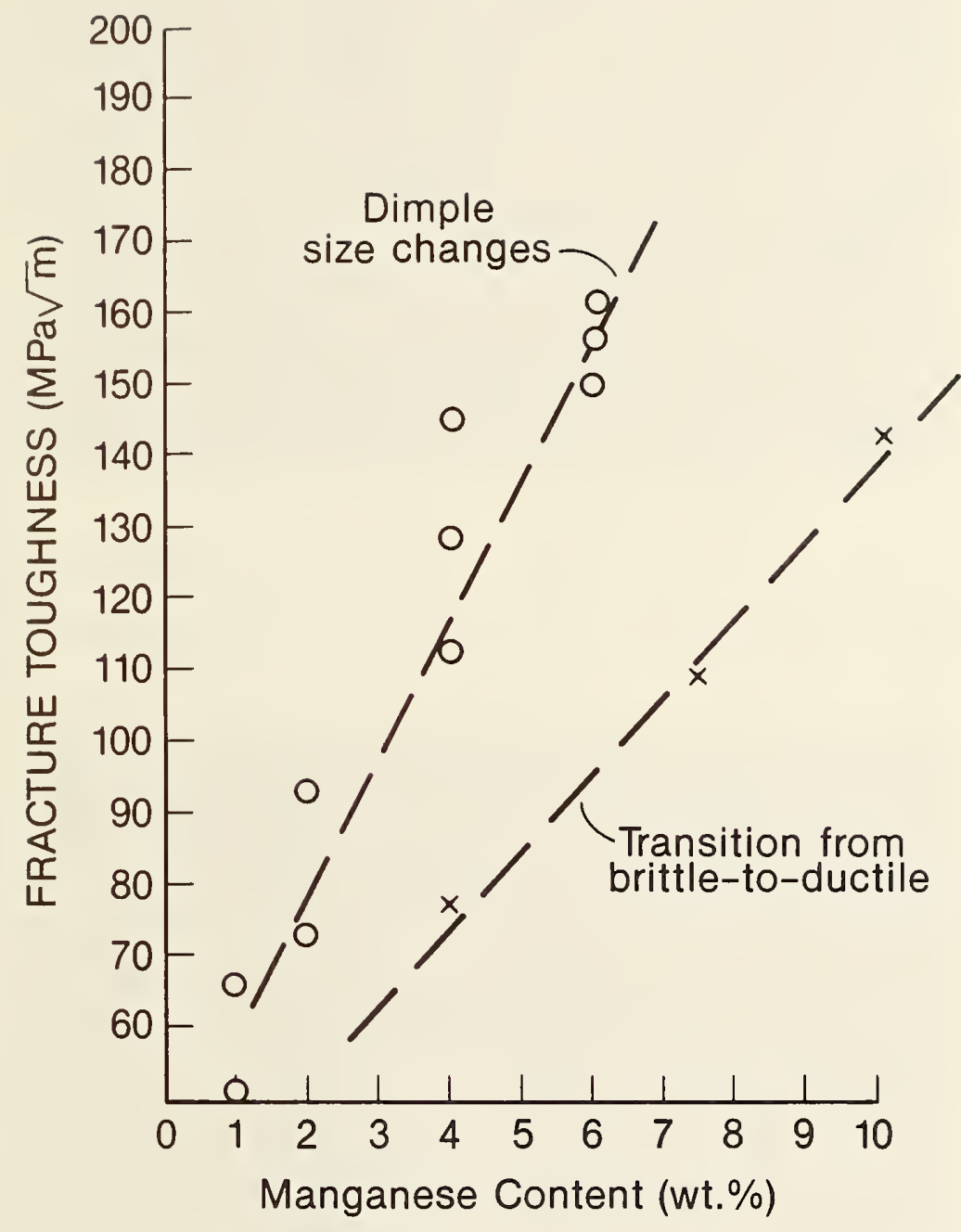

Figure 19. Adjusted fracture toughness vs. Mn content for both Mn-alloyed groups. 


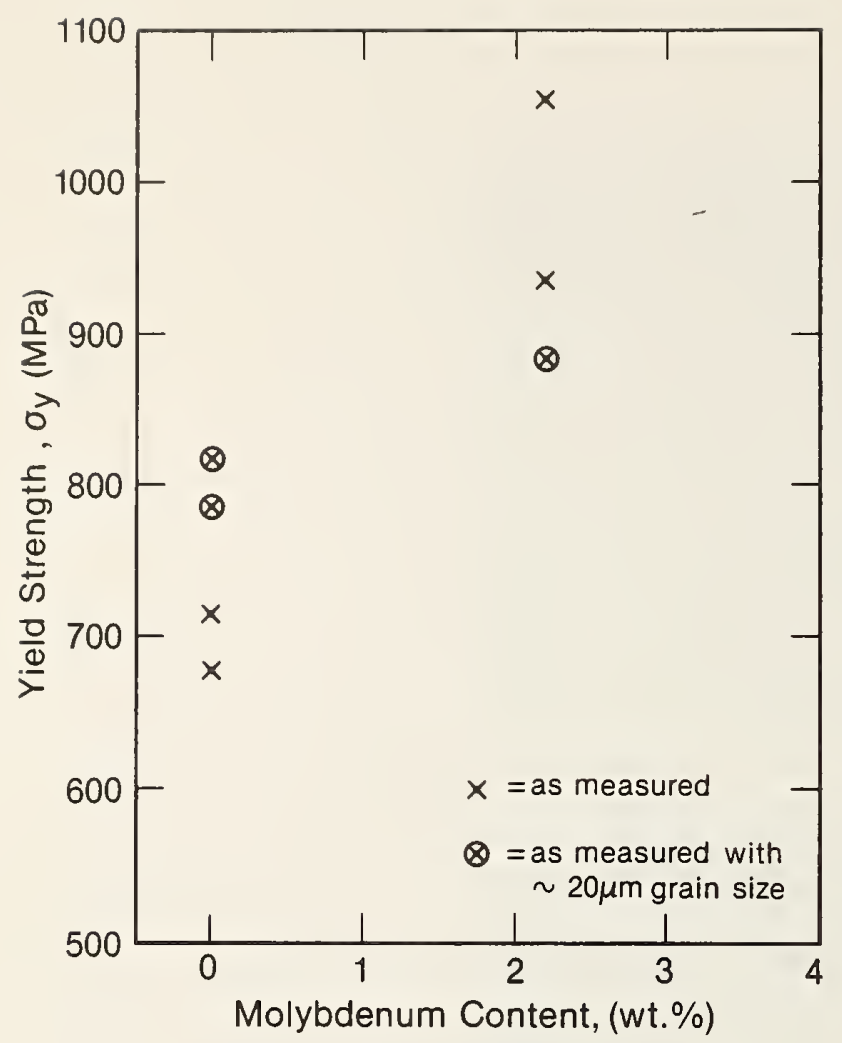

Figure 20. Tensile yield strength vs. Mo content for alloys 79 and 80 at $4 \mathrm{~K}$.

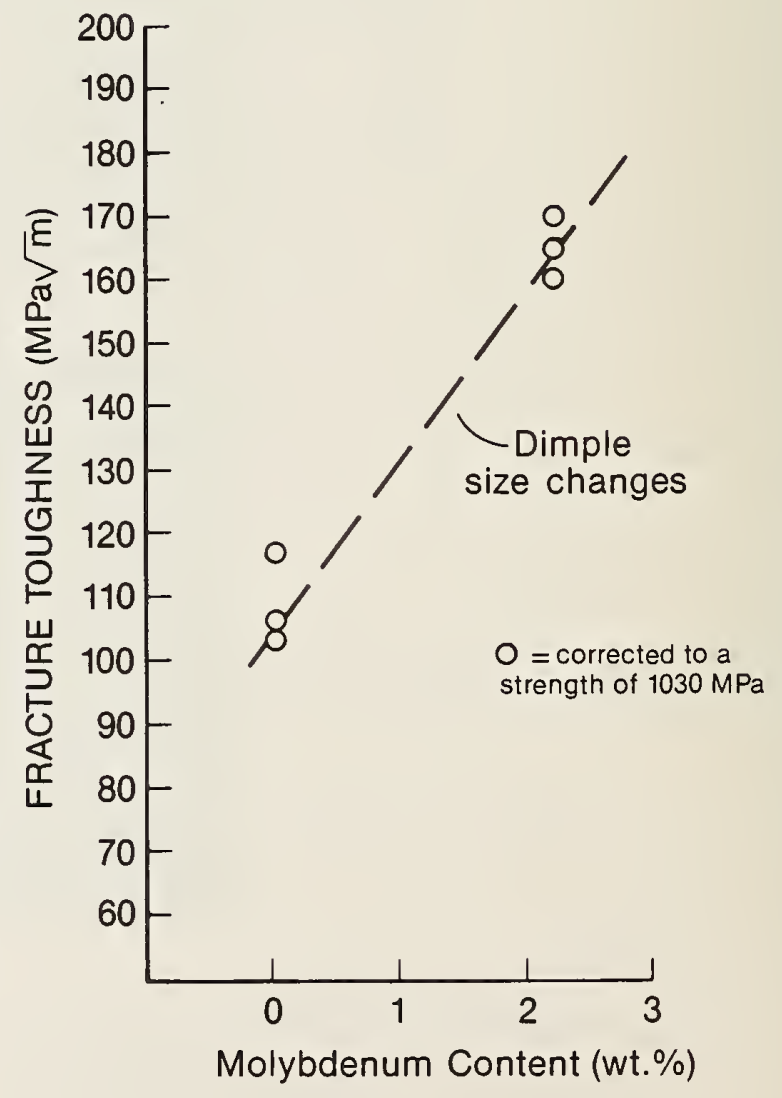




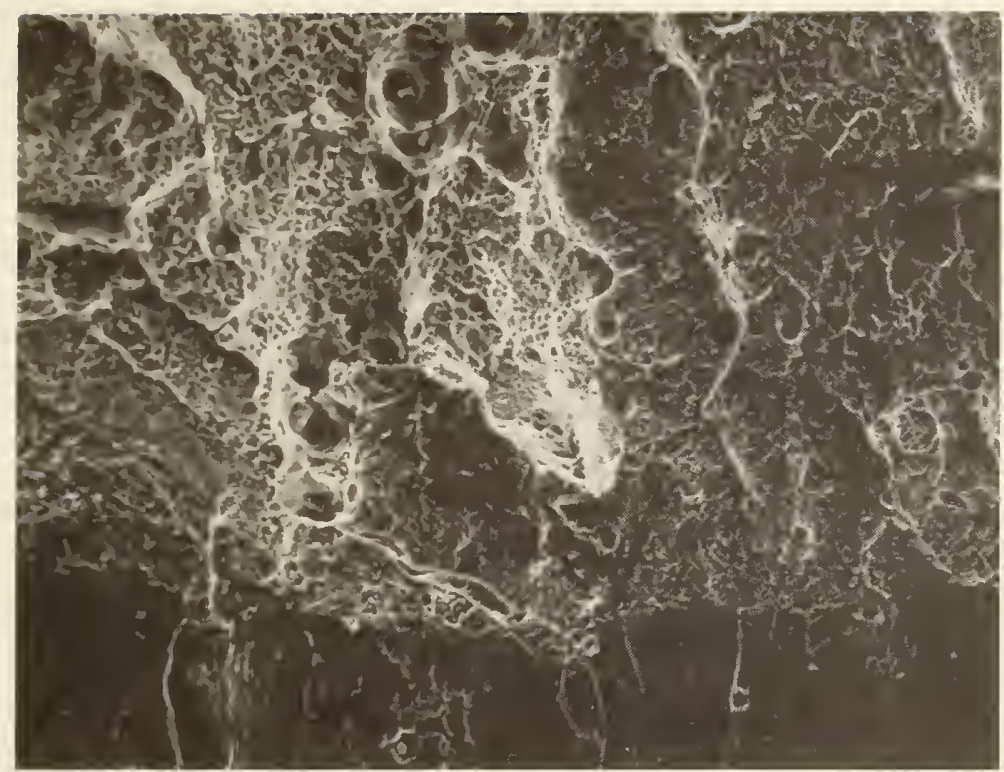

$20 \mu \mathrm{m}$

Figure 22. SEM fractograph of the fracture surface of alloy 80 , $0 \%$ Mo.

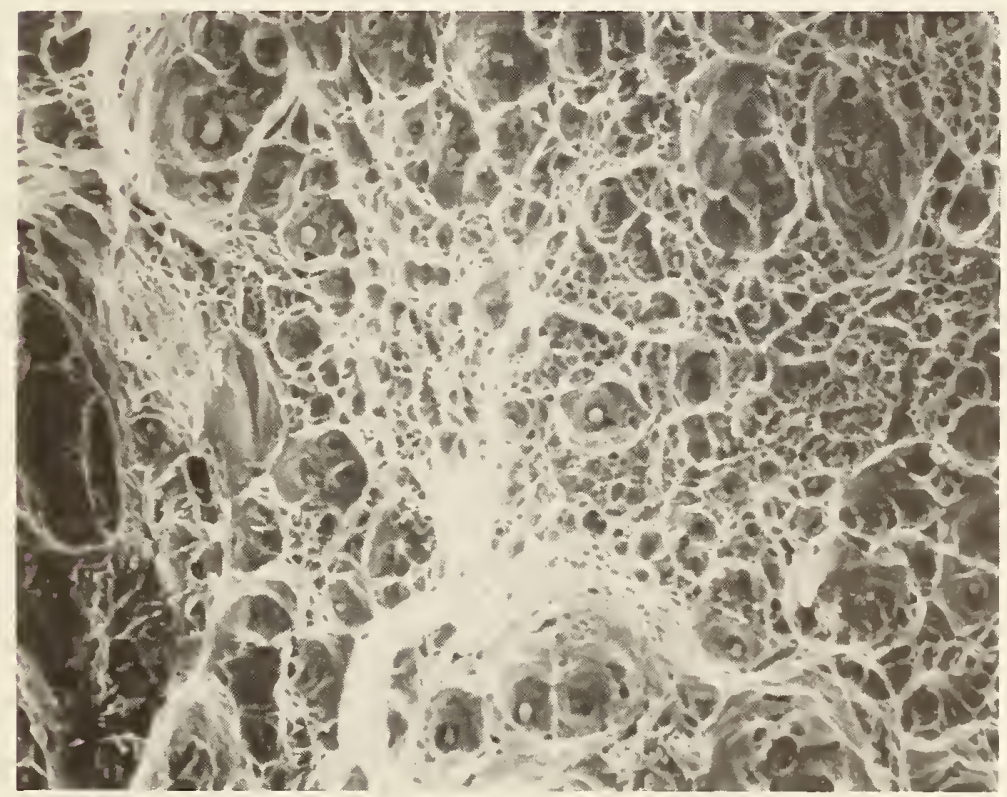

$20 \mu \mathrm{m}$

Figure 23. SEM fractograph of the fracture surface of alloy $79,2.2 \%$ Mo. 
This information is from a paper by Hahn and Rosenfield. A-1 If the shape of the dimples is assumed to be hemispherical, $h / W$ is equal to 0.5 . Combine this assumption with the data in Table $\mathrm{A}^{-1}$ and one can see that the $\ell_{0}^{*}$ term is 1 to 3 times the average spacing of major inclusions, not 5 or 6 times, as described in the text.

Table A-1. Data for High-Strength Aluminum Alloys

\begin{tabular}{lccc}
\hline & $2014-\mathrm{T} 6$ & $2024-\mathrm{T} 851$ & $7079-\mathrm{T} 651$ \\
\hline$\sigma_{\mathrm{y}}(\mathrm{MPa})$ & 436 & 443 & 502 \\
$\mathrm{~K}_{\mathrm{Ic}}(\mathrm{MPa} \sqrt{\mathrm{m}})$ & 19.5 & 20.5 & 27.4 \\
$\mathrm{~J}_{\mathrm{Ic}}\left(\mathrm{kJ} / \mathrm{m}^{2}\right)$ & 1.8 & 2.1 & 3.6 \\
$\mathrm{~d}_{\mathrm{p}}(\mu \mathrm{m})$ & 8.4 & 7.4 & 9.4 \\
$\mathrm{v}_{\mathrm{f}}(\%)$ & 2.9 & 4.4 & 0.9 \\
then $\ell_{0}^{*}(\mu \mathrm{m})$ is & 12 & 22 & 10 \\
\hline
\end{tabular}

$d_{p}=$ average spacing of major inclusions

$v_{f}=$ volume fraction of major inclusions

$\ell_{0}^{*}=$ characteristic distance for ductile fracture

REFF,RENCE

A-1. G. T. Hahn and A. R. Rosenfield: Metall. Trans. A, vol. 6A, 1975, p. 653 . 


ABSENCE OF STRETCH ZONES IN AUSTENITIC STAINLESS STEELS

FRACTURED AT CRYOGENIC TEMPERATURES*

Patrick T. Purtscher

Fracture and Deformation Division

National Bureau of Standards

Boulder, Coloradø

Stretch zones are normally observed on the surface of fracture toughness specimens that break in a ductile manner. However, no stretch zones were observed in the scanning electron microscope on the ductile fracture surfaces of austenitic stainless steels broken in accordance with the ASTM E 813 procedure at cryogenic temperatures.

Key words: stretch zone, fracture toughness testing, ductile fracture, austenitic stainless steel, cryogenic properties.

The purpose of this note is to document an apparent anomaly concerning the formation of stretch zones. The observation of a stretch zone between the fatigue-precrack and overload fracture regions of fracture toughness specimens was first reported by Spitzig ${ }^{1}$ in 1968. Bates and Clark ${ }^{2}$ observed stretch zones on specimens of various carbon and alloy steels, aluminum alloys, and ferritic stainless steel. They related the size of the stretch zone to the measured fracture toughness. More recently, the Japan Society of Mechanical Engineers ${ }^{3}$ has recommended a multiple-specimen procedure in which the J Ic value is determined from the size of the stretch zone.

At the National Bureau of Standards in Boulder, a number of elasticplastic fracture toughness tests have been conducted on ferritic steels. 4,5 Stretch zones have been observed in the scanning electron microscope (SEM) between the fatigue-precrack and overload fracture regions in all tests conducted at temperatures above the ductile-to-brittle transition temperature.

In addition to the testing of ferritic steels, numerous fracture toughness tests of nitrogen-strengthened austenitic stainless steels have been conducted in liquid helium at $4 \mathrm{~K}$ and in liquid nitrogen at $76 \mathrm{~K} .6,7,8$ These tests were conducted according to the ASTM E $813^{9}$ procedure for

*Contribution of NBS; not subject to copyright. 
determining $\mathrm{J}_{\text {Ic }}$ by using the unloading compliance technique to monitor crack growth. At these cryogenic temperatures, the austenitic steels have yield strengths between 200 and $1400 \mathrm{MPa}$, depending upon the exact composition and temperature. The mea sured fracture toughness values vary widely, from 80 to $400 \mathrm{MPa} \sqrt{\mathrm{m}}$. Their extremely high toughness at cryogenic temperatures is attributed to the face-centered cubic ( $f c c$ ) structure of the steel. A ductile-to-brittle transition is not normally observed in austenitic steels. For all the approximately fifty austenitic specimens examined in the SEM, no stretch zones have been observed.

The reason stretch zones are not observed on the ductile fracture surfaces of austenitic stainless steels at cryogenic temperatures is not obvious. Table 1 summarizes the mechanical test results for three samples: a 316LN wrought steel that is completely austenitic, a 308L welded steel that is predominantly austenitic, and an HY80 welded steel that is ferritic. The toughness values of all three samples are approximately the same, but their yield strengths are different. The two examples of austenitic steels were chosen because in one case the yield strength is higher and in the other, the strength is lower than that of the ferritic steel. In addition, the 308L transforms to approximately $75 \%$ martensite in the gauge section during a tensile test at $76 \mathrm{~K}$. The $316 \mathrm{LN}$ does not transform to martensite in a tensile test at $4 \mathrm{~K}$. Therefore, the absence of a stretch zone is not related simply to the size of the plastic zone or to the austenite stability.

The fracture surfaces of the three different steels are shown in SEM micrographs (Figure 1). No stretch zone is visible between the fatigueprecrack and overload fracture regions for the $316 \mathrm{LN}$ and $308 \mathrm{~L}$ samples. The fatigue fracture features appear to be continuous up to the beginning of the dimpled rupture features characteristic of the overload region. The stretch zone should be about the same size as the crack-tip-opening displacement (CTOD) values shown in Table 1. The HY80 sample shows a distinct region between the fatigue and overload regions that corresponds to the stretch zone.

Previous work by Gerberich and Hemmings ${ }^{10}$ on metastable austenitic steels that transform to martensite during plastic deformation showed that stretch zones were easily observed with an SEM, but were not clearly related to the CTOD. Schwalbe 11 noted the presence of stretch zones in aluminum alloys and showed that the logarithm of the stretch zone size correlated well with the logarithm of the stress intensity factor up to the point of stable tearing.

In tests at room temperature, deVries and Schaap ${ }^{12}$ measured stretch zones for ductile crack growth of type-304 stainless steel with a contourograph, but also reported that no distinct separation between blunting and stable crack growth is visible in the SEM. They considered the crack growth process in type-304 stainless steel to be "a continuous process of alternating crack-tip stretching and ductile crack extension ... from the very beginning up to final crack extension." This observation agrees in principle with our experience in testing stainless steels at cryogenic temperatures. 
In summary, the observation of a stretch zone is not a necessary condition for the initiation of ductile fracture. Certainly, in many cases, stretch zones are observable and may be related to the energy required to initiate ductile fracture. However, in the case of austenitic steels tested at cryogenic temperatures, no stretch zones were observed in SEM fractographs.

\section{ACKNOWLEDGMENTS}

Most of the testing of austenitic stainless steels at cryogenic temperatures was supported by the Department of Energy, Office of Fusion Energy. The 308L material was tested in a program supported by the Mobil 0 il Corporation. The testing of the HY80 steel was supported by the D. W. Taylor Naval Ship $R$ \& $D$ Center.

\section{REFERENCES}

1. W. A. Spitzig, A fractographic feature of plane-strain fracture in 0.45C-Ni-Cr-Mo steel; Trans. ASM, vol. 61, 1968, pp. 344-349.

2. R. C. Bates and W. G. Clark, Jr., Fractography and fracture mechanics, Trans. ASM, vol. 62, 1969, pp. 380-394.

3. H. Kobayashi, K. Hirano, H. Nakamura, and H. Nakazawa, A fractographic study on evaluation of fracture toughness, Fracture 1977, Proc. ICF 4 , vol. 3, University of Waterloo Press, Waterloo, Canada, 1977, pp. 583-592.

4. F. Ebrahimi, Ductile-to-Brittle Transition in Steel Weldments for Arctic Structures, NBSIR 85-3020, National Bureau of Standards, Boulder, Colorado (1985). Also to be published in Proc. of the 18th Annual Fracture Mechanics Conference, American Society for Testing and Materials, Philadelphia.

5. T. A. Siewert, R. E. Trevisan, and P. T. Purtscher, The effect of electrode weave procedure on HY-80 GMA welds, submitted to the Weld. J. for publication.

6. D. T. Read and R. P. Reed, Fracture and strength properties of selected austenitic stainless steels at cryogenic temperatures, in Materials Studies for Magnetic Fusion Energy Applications at Low Temperatures $--I I$, NBSIR 79-1609, National Bureau of Standards, Boulder, Colorado, 1979, p. 61 .

7. R. L. Tobler, D. T. Read, and R. P. Reed, Strength/toughness relationship for interstitially strengthened AISI 304 stainless steels at $4 \mathrm{~K}$ Temperature, in Fracture Mechanics: Thirteenth Conference, Richard Roberts, ed., ASTM STP 743, American Society for Testing and Materials, Philadelphia, 1981, p. 250. 
8. R. P. Reed and P. T. Purtscher, Nickel and nitrogen alloying effects on the strength and toughness of austenitic stainless steels at $4 \mathrm{~K}$, Advances in Cryogenic Engineering-Materials, vol. 32, Plenum, New York, 1986, p. 43.

9. Standard test method for $J_{I c}$, a measure of fracture toughness, ASTM E 813-81, part 11, American Society for Testing and Materials, Philadelphia, 1981 , p. 763.

10. W. W. Gerberich and P. L. Hemmings, Fractographic observations of stretched regions in front of fatigue cracks, Trans. ASM, vol. 62, 1969 , p. 540 .

11. K. Schwalbe, Crack propagation in AlZnMgCu 0.5 during static loading, Eng. Fract. Mech., 1974, vol. 6, p. 415.

12. M. I. deVries and B. Schaap, Experimental observations of ductile crack growth in type 304 stainless steel, in Elastic-Plastic Fracture Test Methods: The User's Experience, ASTM STP 856, E. T. Wessel and F. J. Loss, Eds., American Society for Testing and Materials, Philadelphia, 1985, p. 183 . 
Table 1. Mechanical Test Results

\begin{tabular}{|c|c|c|c|}
\hline $\begin{array}{l}\text { alloy } \\
\text { form }\end{array}$ & $\begin{array}{l}316 \mathrm{LN} \\
\text { wrought }\end{array}$ & $\begin{array}{l}308 \mathrm{~L} \\
\text { weld }\end{array}$ & $\begin{array}{l}\text { HY8O } \\
\text { weld }\end{array}$ \\
\hline microstructure & austenite & $\begin{array}{l}\text { austenite } \\
+3 \% \text { ferrite } \\
+4 \% \text { martensite }\end{array}$ & ferrite \\
\hline $\begin{array}{l}\text { fracture toughness, } \\
\mathrm{K}_{\mathrm{IC}}(\mathrm{J})(\mathrm{MPa} \sqrt{\mathrm{m}})\end{array}$ & 220 & $217^{*}$ & 248 \\
\hline $\begin{array}{l}\text { yield strength, } \\
\sigma_{y}(M P a)\end{array}$ & 1022 & 244 & 628 \\
\hline $\begin{array}{l}\text { fatigue precracking condition, } \\
\Delta K_{\text {final }}(\mathrm{MPa} \sqrt{\mathrm{m}})\end{array}$ & $\begin{array}{l}33 \\
\text { at } 76 \mathrm{~K}\end{array}$ & $\begin{array}{l}22 \\
\text { at } 76 \mathrm{~K}\end{array}$ & $\begin{array}{l}25 \\
\text { at } 295 \mathrm{~K}\end{array}$ \\
\hline $\begin{array}{l}\text { plastic zone size, } \\
r_{p}(\mathrm{~mm})^{* *}\end{array}$ & 2.4 to 7.2 & 42 to 126 & 8.3 to 25 \\
\hline CTOD $(\mathrm{mm}) * * *$ & 0.12 & 0.47 & 0.24 \\
\hline test temperature $(K)$ & 4 & 76 & 295 \\
\hline stretch zone & no & no & yes \\
\hline
\end{tabular}

* Not a valid test according to ASTM E-813, 9 because the specimen thickness was less than $25 \mathrm{~J}_{\mathrm{Q}} / \sigma_{\mathrm{y}}$.

** $r_{p}($ plane strain $)=(1 / 3)\left[K_{I c}{ }^{2} /\left(2 \pi \sigma_{y}^{2}\right)\right]$ and $r_{p}($ plane stress $)=K_{I c}{ }^{2} /\left(2 \pi \sigma_{y}{ }^{2}\right)$. *** CTOD (crack-tip-opening displacement) $=(1 / 2)\left[K^{2} /\left(E \sigma_{y}\right)\right]$. 


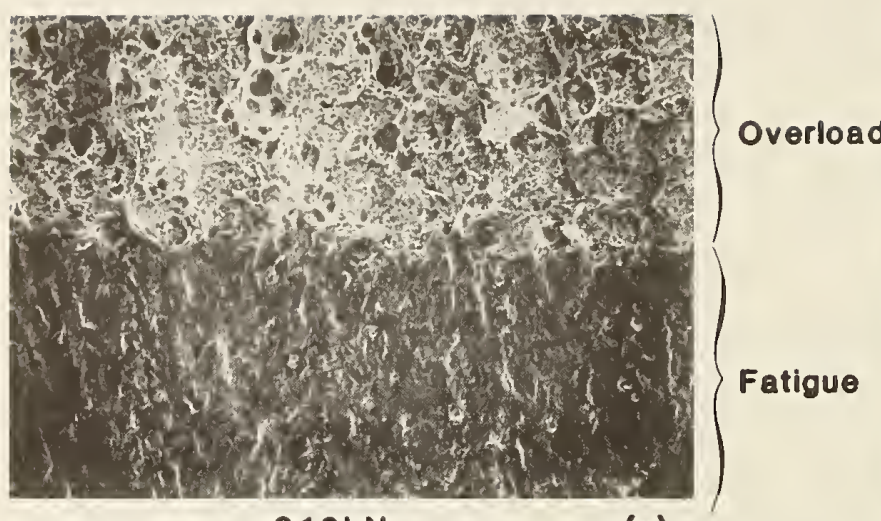

$316 \mathrm{LN}$

(a)

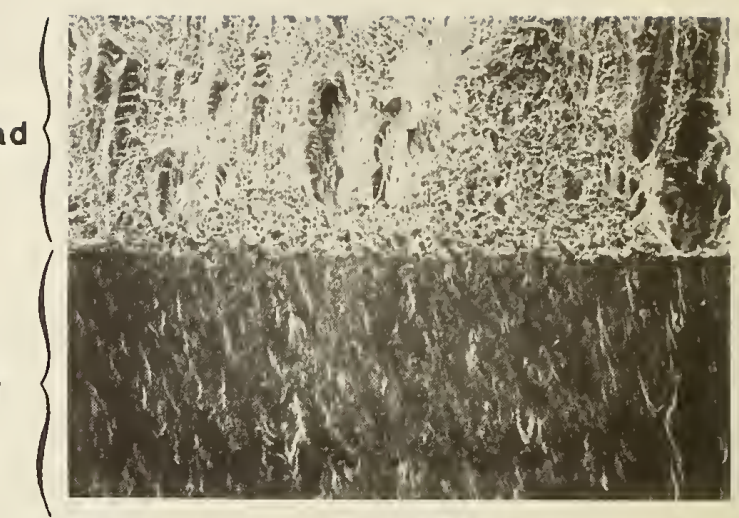

(b)

$308 \mathrm{~L}$

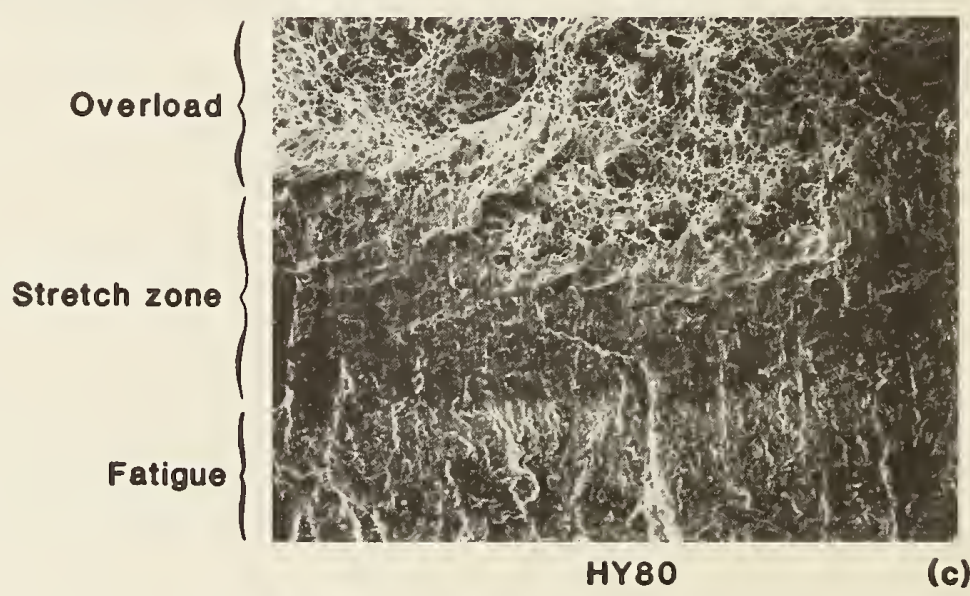

Figure 1. SEM photomicrographs of fracture toughness specimens from a) $316 \mathrm{LN}$, b) $308 \mathrm{~L}$, and c) HY-80. All photos were taken with a $0^{\circ}$ tilt angle. 


R. P. Reed and R. P. Walsh

Fracture and Deformation Division

National Bureau of Standards

Boulder, Colorado

The tensile-deformation characteristics and effect of strain rate were studied on relatively pure CDA $102 \mathrm{Cu}$ and solid-solution-strengthened AISI 310. Tensile strain rate was varied between two orders of magnitude $\left(2 \times 10^{-3}\right.$; $2 \times 10^{-5} \mathrm{~s}^{-1}$ ) at temperatures ranging from 4 to $295 \mathrm{~K}$. Tensile stress-strain and strain-hardening curves were determined for these temperatures. The effect of strain-rate changes on tensile flow strength was measured from strains near 0.002 (yield strength) to over 0.300 . The data reflect three distinct ranges of face-centered cubic, polycrystalline plastic deformation, which have different characteristics depending on solute content.

\section{INTRODUCTION}

Superconducting magnet structural materials deform at greatly different rates, varying from relatively slow stress increases due to $r$ ising magnetic fields to quite high strain rates due to quenching effects. Controlled strain-rate experiments not only provide data on the effects of strain rate on tensile properties, but they also lead to a better understanding of deformation mechanisms. Guntner and Reed varied the strain rate from $0.0008 \mathrm{~s}^{-1}$ to $0.017 \mathrm{~s}^{-1}$ in separate tests to assess the low temperature $(4-295 \mathrm{~K})$ tensile properties of various bar, sheet, and plate forms of alloy 304 . Variations of yield strength up to $10 \%$ and of tensile strength up to $25 \%$ were observed from increasing the strain rate for this metastable austenitic stainless steel.

The dependence of the strain to initiate load drops on the strain rate during tensile testing of alloy 304L was measured by Read and Reed ${ }^{2}$ at $4 \mathrm{~K}$. As the strain rate was increased from about $0.003 \mathrm{~s}^{-1}$ to $0.1 \mathrm{~s}^{-1}$, the strain prior to the first load drop decreased from about 0.05 to $0.01 \%$. From thermocouples embedded within tensile specimens, temperature rises up to $52 \mathrm{~K}$ were detected during load drops. Load drops are associated with macroscopic slipbands, closely resembling the Lüders bands that appear during ambient temperature tensile tests. The temperature $r i s e$ is associated with the very

\footnotetext{
*Partially supported by the office of Fusion Energy, U.S. Department of Energy. Contribution of NBS, not subject to copyright.

+ $\mathrm{To}$ be published in Advances in Cryogenic Engineering--Materials, volume 32.
} 
low specific heat and low thermal conductivity of metals at very low tempera tures, which result in nearly adiabatic localized conditions. Using fine superconducting wire bonded within a slot on the surface of tensile specimens, Read and Reed did not detect temperature rises up to $10 \mathrm{~K}$ ( $\mathrm{T}_{\mathrm{c}}$ of the NbTi wire) during plastic deformation prior to load drops. They concluded that the triggering event for discontinuous yielding in a macroscopic sense was essentially mechanical in nature and that only during the dislocation avalanche, associated with the load drops, was the temperature adiabatically driven up to much higher temperatures. The microscopic triggering event for the macroscopic slipband (dislocation avalanche) has not been adequately identified.

Conrad ${ }^{3}$ reviewed the low temperature deformation of face-centered cubic metals. He analyzed existing strain-rate-dependent data of $\mathrm{Al}, \mathrm{Ag}, \mathrm{Cu}$, and $\mathrm{Ni}$, plotting a strain-rate sensitivity parameter $(\Delta \ln \sigma / \Delta \ln \dot{\varepsilon})$ versus temperature over the range 4 to $300 \mathrm{~K}$. He illustrated that $\Delta \ell n \sigma / \Delta \ell n \dot{\varepsilon}$ gradually decreases at lower temperatures, falling to zero at $0 \mathrm{~K}$ for these metals. Conrad showed that the activation volume (reciprocal of stress sensitivity) decreases as a function of stress (and strain) at constant temperature and that the activation volume of $\mathrm{Cu}$ is greater than that of $\mathrm{Al}$.

Tien and Yen ${ }^{4}$ summarized work on low temperature creep. The review includes some of the tensile measurements on $\mathrm{Cu}$ that use strain-rate-change experiments to measure activation volume. The apparent disparity of experimental results on this subject is compounded by the dependency of activation volume on flow stress $(\sigma)$, strain $(\varepsilon)$, and temperature $(T)$. There have been no low temperature strain-rate-change measurements on austenitic stainless steels; however, Warren and Reed ${ }^{5}$ published tensile stress-strain curves at low temperatures on alloy 310 .

Kocks et al. 6-10 and Mulford ${ }^{11}$ presented a clearer representation of strain hardening, strain-rate sensitivity, and dynamic aging for polycrystalline metals and alloys. They argued that the flow strength at low temperatures is composed of two additive contributions--from dislocation-solute interactions and dislocation-dislocation interactions. Their approach is discussed in more detail later and used to describe some of our data.

This paper presents stress-strain, strain-hardening, and strain-rate sensitivity data at temperatures from 4 to $295 \mathrm{~K}$ for relatively pure $\mathrm{Cu}$ and for a solid-solution strengthened austenitic stainless steel.

\section{EXPERIMENTAL PROCEDURE}

Specimens of relatively pure $\mathrm{Cu}$ (oxygen-free, high-conductivity CDA 102) and a common solid-solution-strengthened austenitic stainless steel (AISI 310 ) were obtained in $1.9-\mathrm{cm}(0.75-\mathrm{in})$ diameter bar stock and tested in the annealed condition. Alloy 310 was annealed at $2050^{\circ} \mathrm{C}$ for $0.5 \mathrm{~h}$ after machining and $\mathrm{CDA} 102 \mathrm{Cu}$, at $650^{\circ} \mathrm{C}$ for $1 \mathrm{~h}$. Round tensile specimens were machined to a $6.35-\mathrm{mm}$ diameter along a gage length of $41.9 \mathrm{~mm}$, increasing with a radius of $9.52 \mathrm{~mm}$ to $12.7-\mathrm{mm}$ diameter threaded ends. The entire specimen length was $71.4 \mathrm{~mm}$. The hardness, grain size, and chemical composition of both alloys are listed in Table 1 . 
Two loading frames were used. At room temperature the loading compliance of the screw-driven assembly was measured as $8 \times 10^{-3} \mathrm{~cm} / \mathrm{kN}\left(8 \times 10^{-7}\right.$ $\mathrm{cm} / \mathrm{kgf}$ ). The compliance of the servohydraulic load train varied from $11 \mathrm{x}$ $10^{-3} \mathrm{~cm} / \mathrm{kN}$ at loads less than about $2 \mathrm{kN}$ to $6 \times 10^{-3} \mathrm{~cm} / \mathrm{kN}$ at larger loads. The $\mathrm{cu}$ specimens were measured at the lower compliance levels of the load train; the austenitic stainless steels, at the higher compliance levels.

The actuator velocity and crosshead movement of the machines were independently measured and found to deviate from expected rates. The "low" crosshead rate of the screw-driven machine was $0.0047 \mathrm{~cm} / \mathrm{min}$ (stated as 0.005 $\mathrm{cm} / \mathrm{min}$ ) and the "high" crosshead rate for this machine was $0.455 \mathrm{~cm} / \mathrm{min}$ (stated as $0.5 \mathrm{~cm} / \mathrm{min}$ ). The servohydraulic "high" actuator speed was 0.540 $\mathrm{cm} / \mathrm{min}$ (stated as $0.5 \mathrm{~cm} / \mathrm{min}$ ), significantly higher than that of the other machine. The "low" actuator speed of the servohydraulic machine was 0.005 $\mathrm{cm} / \mathrm{min}$.

In all tests, specimens were initially loaded at the low strain rate $\left(2 \times 10^{-5} \mathrm{~s}^{-1}\right)$ at constant temperature. After sufficient strain to permit measurement of the yield strength $(0.002$ plastic strain), the strain rate $(\dot{\varepsilon})$ was incrementally increased (to $2 \times 10^{-3} \mathrm{~s}^{-1}$ ) and held long enough for good characterization of the stress-strain curve. The strain rate was subsequently reduced, and the specimen was strained to the next measurement range. The difference between the flow strengths at equivalent strain-hardening rates was considered the stress change $(\Delta \sigma)$ associated with the strain-rate change. The exception to this was measurement of alloy 310 at higher levels of strain, where apparent "yield points" were observed immediately following changes of strain rate. In these cases we used the maximum value of $\Delta \sigma$. Use of extrapolated $\Delta \sigma$ to the onset of the high strain-rate range usually produced a negative dependence (but always positive values) of $\Delta \sigma$ on $\varepsilon$ or $\sigma$.

Temperature measurement and control, measurement equipment variables that affected the accuracy of $\Delta \sigma$ data from strain-rite changes, strain measurement, and other procedures are discussed in Ref. 12. Reference 12 also contains all data from which the strain-rate sensitivity figures of this paper were derived.

At low strains $(-<0.04)$ the attainment of an equivalent strain-hardening rate on changing to the higher strain rate usually consumes more strain. Therefore, interpretation of $\Delta \sigma$ at lower $\sigma$ or $\varepsilon$ values is more difficult. The strain range over which the strain-hardening rates tended to be slower to change was always less than 0.01 . This early portion of the $\sigma-\varepsilon$ curve naturally exhibited larger strain-hardening rates and, when reliable measurements could be obtained, lower values of $\Delta \sigma$. No data in this low strain range were included unless both $\sigma-\varepsilon$ curves (high $\varepsilon$ and $l o w \varepsilon$ ) assumed equivalent strainhardening rates.

Discontinuous yielding at temperatures below about $20 \mathrm{~K}$ was observed in both materials. The strain at which load drops began was much less in the austenitic steel than in $\mathrm{Cu}$. This is atcributed to their differences of low temperature thermal conductivity. The thermal conductivity of alloy 310 at $4 \mathrm{~K}$ is about $0.5 \mathrm{~W} \cdot \mathrm{m}^{-1} \cdot \mathrm{K}^{-1}$, and that of $\mathrm{Cu}$ is $667 \mathrm{~W} \cdot \mathrm{m}^{-1} \cdot \mathrm{K}^{-1}$. The specific 
heat of the austenitic steel is actually somewhat higher $\left(-1.8 \mathrm{~J} \cdot \mathrm{kg}^{-1} \cdot \mathrm{K}^{-1}\right)$ than that of $\mathrm{Cu}\left(0.10 \mathrm{~J} \cdot \mathrm{kg}^{-1} \cdot \mathrm{K}^{-1}\right)$. The occurrence of discontinuous yielding precluded assessment of strain-rate effects and strain-hardening rates on flow stress. Changes to the higher strain rate immediately triggered load drops and more erratic stress-strain behavior. At the higher strain rate it is possible that the flow strengths at $4 \mathrm{~K}$ reflect thermal instability, even at lower strains prior to the onset of discontinuous yielding.

\section{RESULTS AND DISCUSSION}

\section{Copper}

The tensile stress-strain curves of CDA $102 \mathrm{Cu}$ are shown in Fig. 1. At low temperatures there was a decided increase in strain hardening but little increase in yield strength. The tensile yield strength increased from about $27 \mathrm{MPa}$ at room temperature to $32 \mathrm{MPa}$ at $4 \mathrm{~K}$. Only very modest discontinuous yielding occurred at $4 \mathrm{~K}$ at large strains.

The data depicting the dependence of $\Delta \sigma$ on $\sigma$ for $\mathrm{Cu}$ are summarized in Fig. 2. At $4 \mathrm{~K}$ there is a linear dependence of $\Delta \sigma$ on $\sigma$. At higher temperatures the dependence of $\Delta \sigma$ on $\sigma$ is linear at low strain and slightly concave upwards at higher strain. The $\Delta \sigma$ decreases with decreasing temperature and extrapolates to zero at zero stress.

\section{Alloy 310}

Alloy 310 , a stable austenitic stainless steel, has completely different stress-strain and strain-rate sensitivity traits. After deformation neither martensitic product (hexagonal close-packed $\varepsilon$; body-centered cubic $\alpha^{\prime}$ ) was detected at any temperature. The stress-strain curves from 4 to $295 \mathrm{~K}$ are shown in Fig. 3. Alloy 310 shows considerably more strength in the early region of the stress-strain curve than relatively pure $\mathrm{Cu}$ Indeed, the tensile yield strength increased from about $215 \mathrm{MPa}$ at $295 \mathrm{~K}$ to $730 \mathrm{MPa}$ at $4 \mathrm{~K}$. The rate of strain-hardening of alloy 310 at high strain was rather independent of temperature, unlike that of $\mathrm{Cu}$.

Data on $\Delta \sigma / \Delta \ell n \dot{\varepsilon}$ versus o for alloy 310 are summarized in Fig. 4. Notice the differences first between $\mathrm{Cu}$ (Fig. 2) and alloy 310. The $\Delta \sigma$ values of alloy 310 were nearly constant, independent of stress or strain and, extrapolated to $\sigma=0$, always are positive. The maximum of $\Delta \sigma$ as a function of temperature occurred in the range 76 to $100 \mathrm{~K}$. From 76 to $4 \mathrm{~K}$, there was a sharp decrease of strain-rate sensitivity.

At strains in excess of about 0.02 at temperatures near $76 \mathrm{~K}$ and strains of about 0.05 at temperatures near $295 \mathrm{~K}$, very small yield points began to occur in alloy 310 following strain-rate changes. Again, the maximum $\Delta \sigma$ values on changing from a low to high strain rate were plotted. Extrapolation of equivalent strain-hardening rate ranges to the strain at the time of strain-rate change yielded values up to $15 \%$ less than the reported data. Use of these data of lower $\Delta \sigma$ would have resulted in slightly negative slopes of $\Delta \sigma$ versus $\sigma$ or $\varepsilon$. 
The $\Delta o$ data at $4 \mathrm{~K}$ exhibit a negative slope; however, as discussed ear1 ier, these data may reflect partial thermal instability at the higher strain rates. After changes from low to high strain rate, a brief region $(\sim 0.0003 \varepsilon)$ of increased flow strength was observed, followed by a load drop. Although the maximum $\Delta \sigma$ was recorded for each strain-rate change, these $\Delta \sigma$ data should be regarded as minimal; for it is possible that internal specimen heating at the high strain rate effectively reduced the maximum flow strength.

\section{Stress-Strain Characteristics}

Following the general approach of Kocks, 6-11 the flow strength $(0)$ can be expressed as:

$$
\sigma=\sigma_{\mathrm{f}}+\sigma_{\mathrm{d}}
$$

where $\sigma_{f}$ is the frictional strength contribution dependent upon dislocationsolute interactions, and $\sigma_{d}$ is the dislocation-dislocation interaction contribution dependent primarily on number and structure of dislocations. The frictional strength can be regarded as independent of strain; the yield strength is a good measure. The term $\sigma_{d}$ is strain dependent; tensile strainhardening characteristics are reflective of its contribution. Typically,

$$
\sigma_{\mathrm{d}}=\alpha \mu b / \mathrm{p}
$$

where $\mu$ is the shear modulus; $b$, the Burgers vector; $p$, the active dislocation density; and $\alpha$, a constant, which may be dependent on the solute content, $c$, and is slightly less than unity. In face-centered cubic alloys, the strain-hardening rate $(d \sigma / d \varepsilon)$ is dependent on solute content. To account for this, Bloom et al. ${ }^{9}$ suggest

$$
\sigma_{d}=[1+k(c)] \alpha \mu b \sqrt{ } p
$$

with $k(c)$ expressing the effect of solute. The strain-hardening rate is expressed as

$$
\theta=\frac{d \sigma}{d \varepsilon}=\frac{\alpha \mu b}{2} \quad p^{-1 / 2} \frac{d p}{d \varepsilon}
$$

The change of dislocation density with strain is considered to have two components: one concerns the "storage rate" and the other, the dynamic recovery rate. The rate of dislocation accumulation is athermal in nature; the recovery rate is obviously affected by thermal activation. Thus, with these considerations, the strain-hardening rate should have two major terms:

$$
\theta=\mathrm{d} \sigma / \mathrm{d} \varepsilon=\theta_{h}(c)-\theta_{r}(\dot{\varepsilon}, T, \sigma, c)
$$

where $\theta_{h}$ is the athermal hardening rate and $\theta_{r}$ is the dynamic recovery rate contributing negatively to $\theta$.

The strain-hardening curves derived from the stress-strain curves for $\mathrm{Cu}$ are shown in Fig. 5. They are plotted as $\sigma \mathrm{do} / \mathrm{d} \varepsilon$ versus $\sigma$, following 
Mecking and Kocks. 7 There is a linear region with positive slope at low stress followed by deviation to lower strain-hardening rates at higher stress. The linear region is constant at-all temperatures and deviations from linearity occur at higher stresses with lower temperatures.

The strain-hardening curves (Fig. 6) at various low temperatures of alloy 310 indicate two distinct stages. The strain at the transition of the two stages increased from about 0.02 at $295 \mathrm{~K}$ to 0.04 at $4 \mathrm{~K}$. This is, approximately, the restricted strain range that separates the early (difficult-to-measure) stage of strain-rate sensitivity from the higher strain region. The strain-hardening in the early strain range was very sensitive to temperature, similar to the yield strength. The strain-hardening rates in the higher strain range were relatively insensitive to temperature and assumed the same slope, which was negative, but only slightly. In fact, if the curves were normalized by dividing the ordinate by $\mu^{2}$, there would be even less difference in their absolute magnitude. There was no evidence of dynamic recovery, since a recovery stage should be sensitive to temperature and nonlinear.

Thus, if $\mathrm{Cu}$ and alloy 310 are representative of pure and solid-solutionstrengthened face-centered cubic metals, one may make the following conclusions about their strain-hardening characteristics at low temperatures: There is an early stage of rapidly decreasing high rates of strain-hardening in the region of the yield stress for solid-solution-strengthened alloys; this region is strongly temperature dependent. The next stage (first stage for pure metals) exhibits a linear dependence of $\sigma \theta$ on $\sigma$ and, for $\mathrm{Cu}$, is athermal. The slopes of this stage depend on solute content (solute effects on dislocation interactions); in pure metals the strain-hardening dependence extrapolates to zero (indicating only dislocation-dislocation interactions). The final stage is a region of dynamic recovery, not necessarily present in solid-solutionstrengthened alloys. This stage typically exhibits a nonlinear dependence of $\sigma \theta$ on $\sigma$.

\section{Strain-Rate Effects}

Alloy 310, with much larger flow strength than $\mathrm{Cu}$, exhibited strength changes of the order of 20 to $40 \mathrm{MPa}$ with each change of strain rate; Cu had strength changes of less than $5 \mathrm{MPa}$. In both alloys, the stress change approached zero at very low temperatures. However, if the data were normalized by dividing the stress change by the yield strength at temperature, all stress changes would be found to be less than 15\% of the flow strength. All percentages decreased to zero at low temperatures. There is a distinction between measurements of strain-rate effects from experiments that maintain a given strain rate and those that change strain rate during straining. During continuous straining, higher strain rates induce internal specimen heating more rapidly. This heating cannot be quickly removed at the high strain rate; thus the specimen probably remains permanently at a higher temperature during the test. This results in lower flow strengths and failure strengths. On the other hand, the strain-rate change experiments provide time at the low strain rate for the specimen to return to thermal equilibrium and, thus, to return to the higher flow strength at $4 \mathrm{~K}$. 
Mulford and Kocks ${ }^{10}$ have shown that, provided the sum of the contributions of solution strengthening $\left(\sigma_{f}\right)$ and work hardening $\left(\sigma_{d}\right)$ are equivalent to the flow strength, the strain-rate sensitivity has two components:

$$
\left(\frac{\partial \sigma}{\partial \ln \dot{\varepsilon}}\right)_{T}=\left(\frac{\partial \sigma_{f}}{\partial \ell \ln \dot{\varepsilon}}\right)_{T}+\left(\frac{\partial \sigma_{d}}{\partial \ln \dot{\varepsilon}}\right)_{T}=\sigma_{f}\left(m_{f}-m_{d}\right)+\sigma m_{d}
$$

where $m_{f}=\partial \ln \sigma_{\mathrm{f}} / \partial \ln \dot{\varepsilon}$ and $m_{\mathrm{d}}=\partial \ln \sigma_{\mathrm{d}} / \partial \ell n \dot{\varepsilon}$ at constant temperature. A plot of $\partial \sigma / \partial \ln \dot{\varepsilon}$ versus $\sigma$, called the Haasen plot, should have a slope of $\mathrm{m}_{\mathrm{d}}$ at stresses somewhat above $\sigma_{y}$ and extrapolate to $\sigma_{f}\left(m_{f}-m_{d}\right)$ at zero stress. If two contributions are present, they should be reflected in a change of slope at rather low stress: at low stress the contribution from dislocations must be small and, therefore, the contribution from solute strengthening dominates. The $\mathrm{Cu}$ data of Fig. 2 extrapolate to zero as flow stress approaches zero. This indicates the dominance of dislocation-dislocation interactions and the absence of solute strengthening $\left(\sigma_{f}=0\right)$. For alloy 310 , the range of constant $\Delta \sigma / \Delta l n \dot{\varepsilon}$ values corresponds to the second stage of $\sigma \theta$ versus $\sigma$ (Fig. 3 ), where $\sigma \Theta$ is relatively insensitive to $\sigma$.

Alloy 310 exhibited considerable solute strengthening, and extrapolation of the $\Delta \sigma / \Delta l n \dot{\varepsilon}$ data to zero stress yielded large values of frictional stress ( $\sigma_{\mathrm{f}}$ is positive), dependent on temperature. Unlike $\mathrm{Cu}$, the slope of $\Delta \sigma / \Delta \ln \dot{\varepsilon}$ was practically independent of flow stress. Therefore, the solute-strengthening mechanism operative in this second stage (related to strain-hardening behavior) is very rate sensitive and temperature dependent. Both strainhardening and strain-rate data confirm the absence of dynamic recovery in alloy 310 at the measured $\sigma$ levels. There is a distinction between the ratelimiting process that controls the strain-rate response at low strain levels and the process that influences the response at higher strain, and it appears that both are influenced strongly by solutes. At low strains, perhaps the interaction of individual dislocations with discrete solutes is rate controlling and short range. At high strains, perhaps dislocation cell wall interaction with solutes or dislocation multiple solute interactions are rate controlling.

The temperature dependences of both strain-hardening and strain-rate sensitivity showed no unexpected transitions; therefore it appears that the same rate-controlling deformation mechanism that operates at room temperature remains operative at very low temperatures in both metals.

SUMMARY

The stress-strain curves, strain-hardening curves, and strain-rate sensitivities have been determined for $\mathrm{Cu}$ and alloy 310 austenitic stainless steel at temperatures from 4 to $295 \mathrm{~K}$. The results suggest three regions of plastic deformation of polycrystalline face-centered cubic metals and alloys: 
1. For solute-strengthened alloys at low strain, a region of rapidly decreasing strain-hardening rate and rapidly rising strain-rate sensitivity is strongly dependent on temperature and solute content.

2. At low strain for pure metals and at intermediate strains for solutestrengthened alloys, a strain-hardening region where the slope of $\sigma \theta$ versus $\sigma$ is constant and strongly dependent on solute content. In this region, the strain-rate sensitivity plotted against o has a positive or zero slope, dependent also on solute content.

3. At high strain, a region of dynamic recovery in metals and some alloys. Here, the $\sigma \theta$-versus-o trend shows an ever-increasing negative slope, and the plot of strain-rate sensitivity versus stress shows an ever-increasing positive slope.

Finally, there is less strain-rate sensitivity at very low temperatures, although specimen adiabatic heating at higher strain rates does result in the lowering of the flow stress.

\section{REFERENCES}

1. C. J. Guntner and R. P. Reed, ASM Trans. Q. 55:399-419 (1962).

2. D. T. Read and R. P. Reed, Adv. Cryo. Eng.--Mater. 26:91-101 (1980).

3. H. Conrad, in "High Strength Materials," J. Wiley \& Sons, New York (1965), pp. 436-505.

4. J. K. Tien and C.-T. Yen, Adv. Cryo. Eng.--Mater. 30:319-338 (1984).

5. K. A. Warren and R. P. Reed, "Tensile and Impact Properties of Selected Materials from 20 to 300 K." NBS Monograph 63, U.S. Government Printing office, Washington, D.C. (1963).

6. U. F. Kocks, R. E. Cook, and R. A. Mulford, Acta Metall. 33:623-638 (1985).

7. H. Mecking and U. F. Kocks, Acta Metall. 29:1865-1875 (1981).

8. R. A. Mulford and U. F. Kocks, Acta Metall. 27:1125-1134 (1979).

9. T. A. Bloom, U. F. Kocks, and P. Nash, Acta Metall. 33:265-272 (1985).

10. R. A. Mulford and U. F. Kocks, Scripta Metall. 13:729-732 (1979).

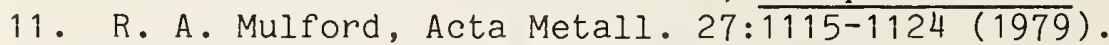

12. R. P. Reed and R. P. Walsh, Low Temperature Tensile Characteristics of Copper and Aluminum, in "Materials Studies for Magnetic Fusion Energy Applications at Low Temperatures--IX," NBSIR 86-3050, National Bureau of Standards, Boulder, Colorado (1986), pp. 107-140. 
Table 1. Material Characterization

\begin{tabular}{lccc}
\hline Alloy & $\begin{array}{c}\text { Chemical } \\
\text { Composition } \\
(\text { wt.\% })\end{array}$ & Hardness & $\begin{array}{c}\text { Grain } \\
\text { Size } \\
(\mu \mathrm{m})\end{array}$ \\
\hline CDA 102 & \multicolumn{1}{c}{$99.99 \mathrm{Cu}+\mathrm{Ag}$} & 22 & 36 \\
310 & $\begin{array}{l}24.8 \mathrm{Cr}, 20.8 \mathrm{Ni}, 1.7 \mathrm{Mn}, 0.093 \mathrm{C}, \\
0.031 \mathrm{~N}, 0.02 \mathrm{P}, 0.02 \mathrm{~S}, 0.7 \mathrm{Si}, \\
0.1 \mathrm{MO}, 0.1 \mathrm{Cu}, \text { balance Fe }\end{array}$ & 72 \\
\hline
\end{tabular}

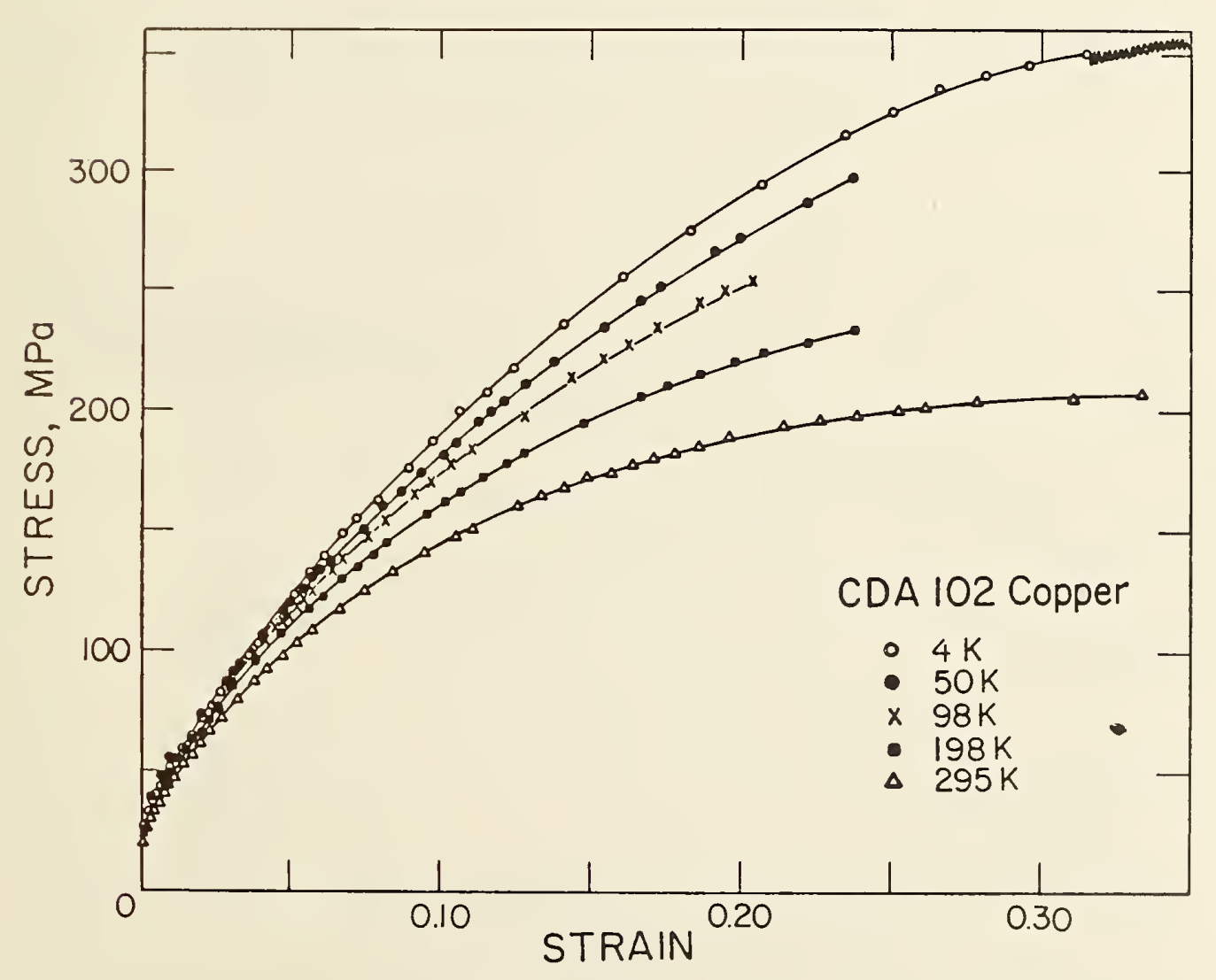

Fig. 1. The tensile stress-strain curves of CDA $102 \mathrm{Cu}$ at various temperatures. 


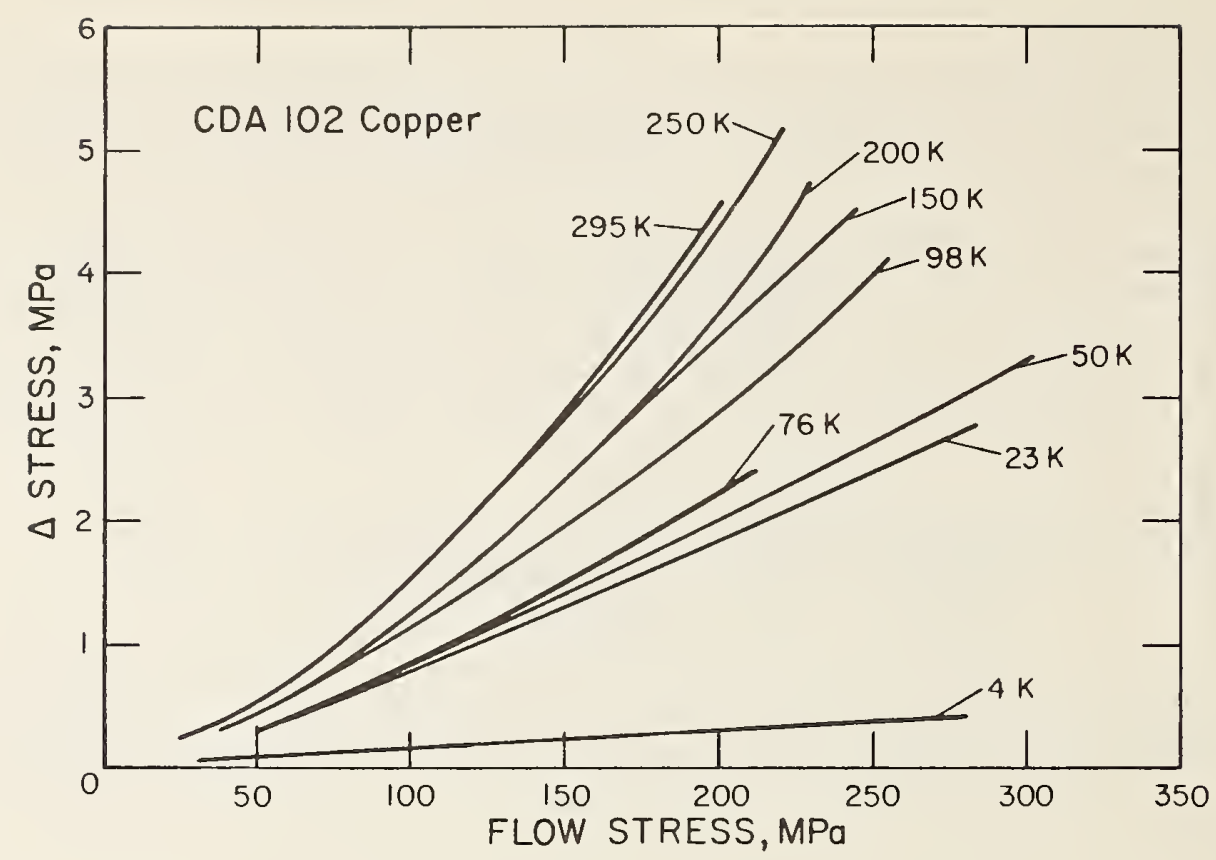

Fig. 2. General characterization for CDA $102 \mathrm{Cu}$ of the effects of strainrate change $\left(2 \times 10^{-5}\right.$ to $\left.2 \times 10^{-3} \mathrm{~s}^{-1}\right)$ on the stress change as a function of flow stress at various test temperatures.

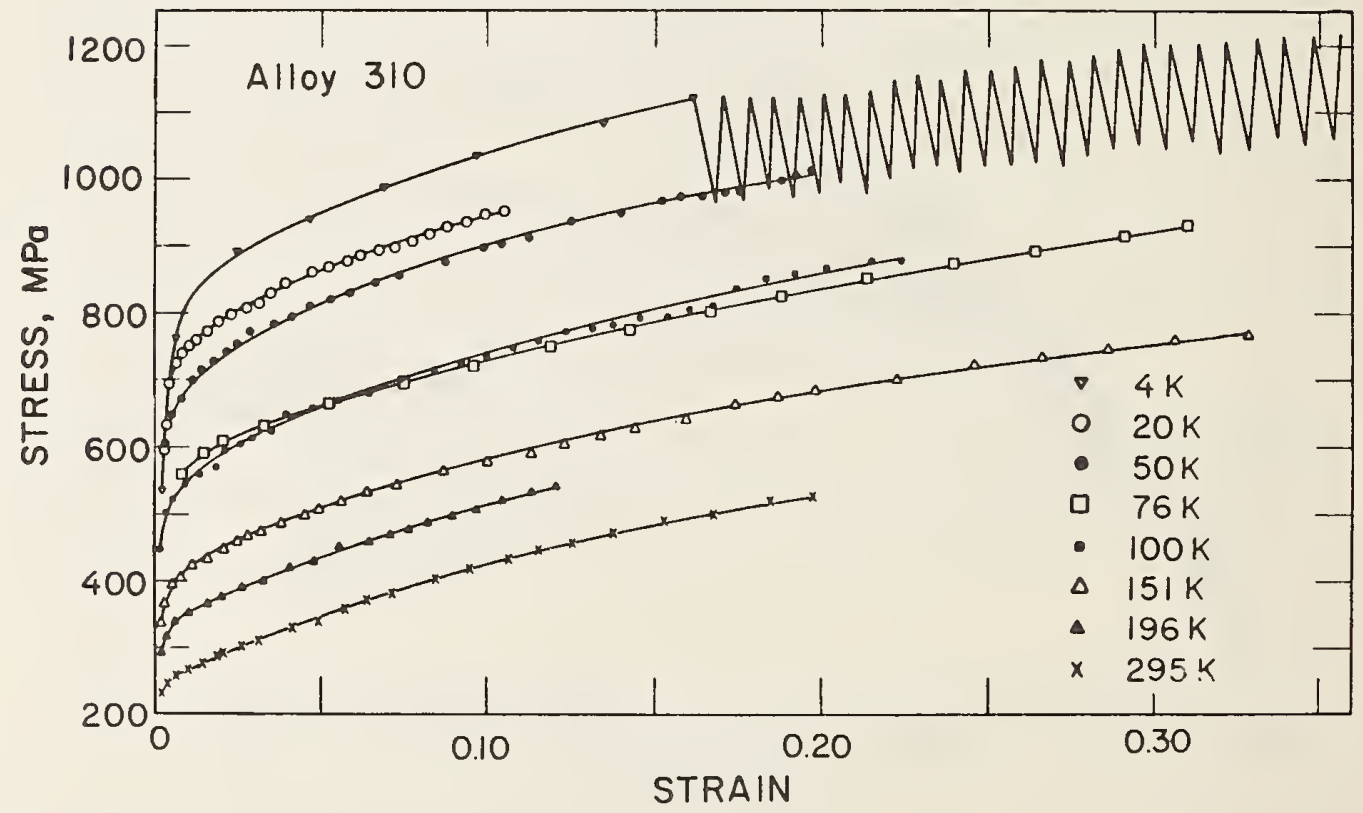

Fig. 3. The tensile stress-strain curves of alloy 310 at various temperatures. 


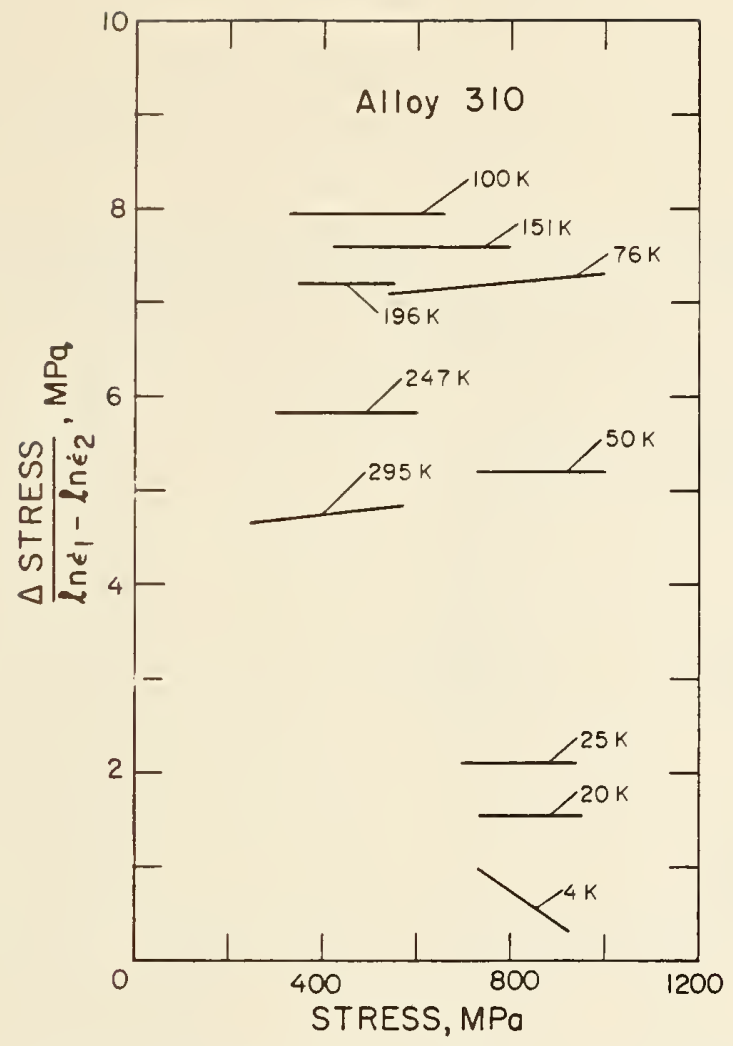

Fig. 4. General characterization for alloy 310 of the effects of strainrate change $\left(2 \times 10^{-5}\right.$ to $\left.2 \times 10^{-3} \mathrm{~s}^{-1}\right)$ on the stress change as a function of stress at various test temperatures.

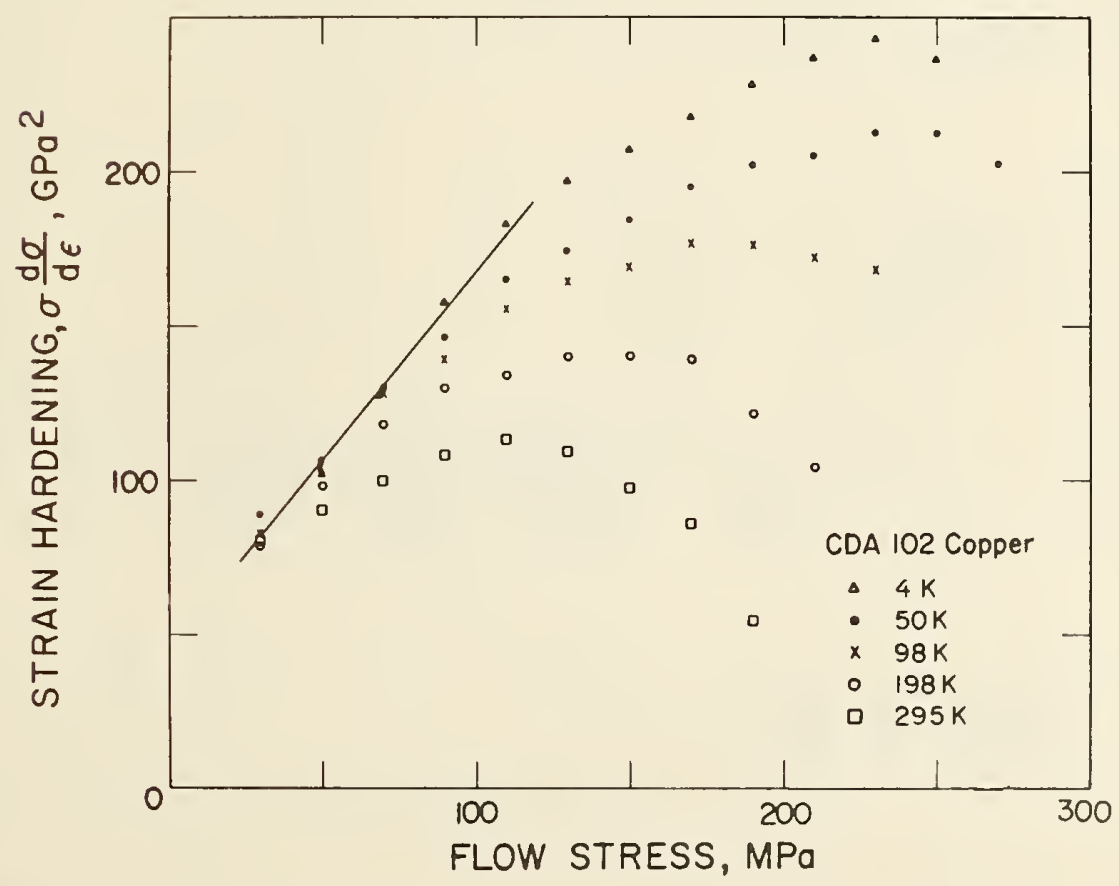

Fig. 5. Strain-hardening curves for CDA $102 \mathrm{Cu}$ derived from stress-strain curves of Fig. 1. 


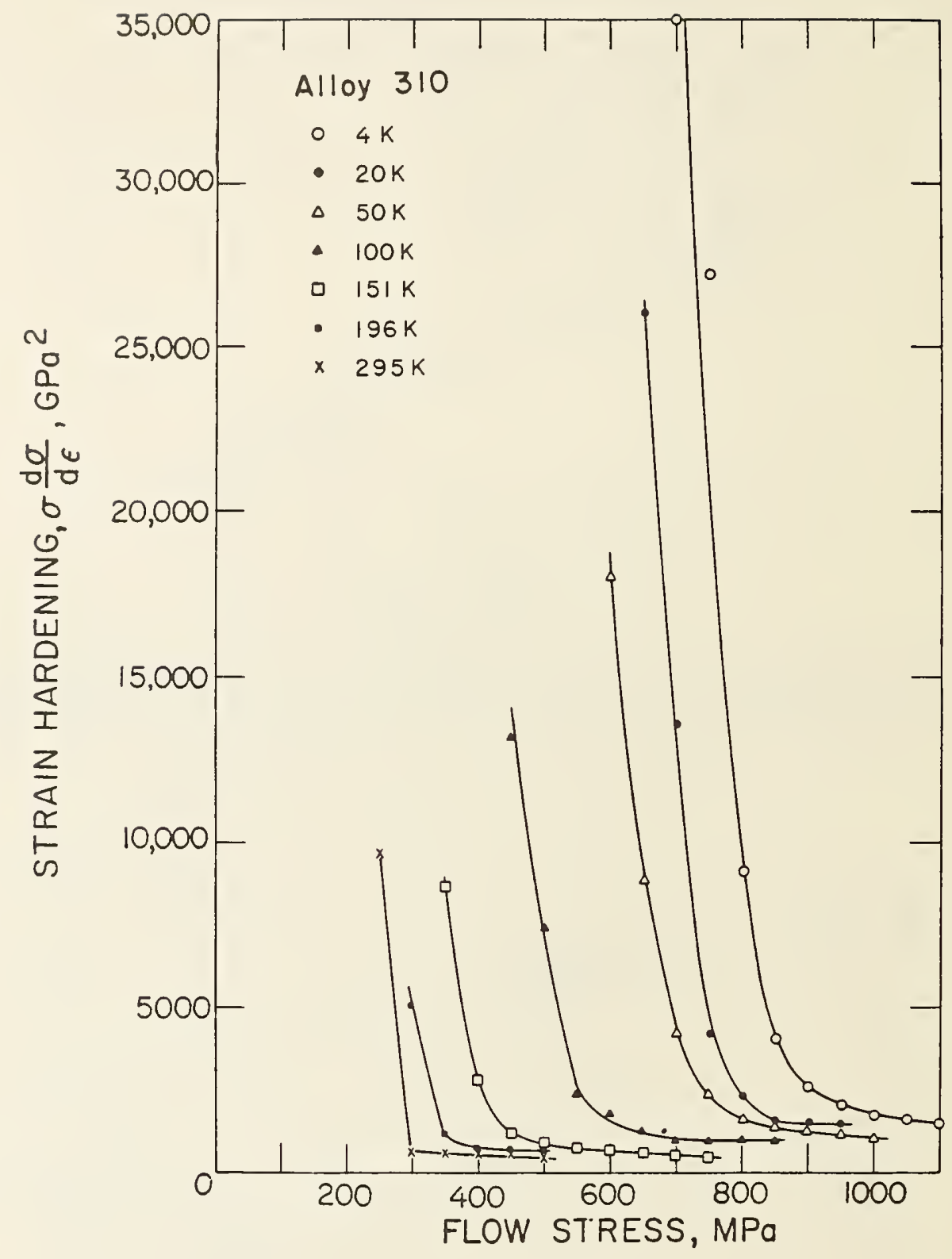

Eig. 6. Strain-hardening curves for alloy 310 derived from stress-strain curves of Eig. 3 . 


R. P. Reed and R. P. Walsh

Fracture and Deformation Division

National Bureau of Standards

Boulder, Colorado

The tensile-deformation characteristics and effect of strain rate were studied on relatively pure copper and aluminum alloys, CDA $101 \mathrm{Cu}$ and $1100 \mathrm{Al}$. Tensile strain rate was varied by two orders of magnitude $\left(2 \times 10^{-3} ; 2 \times 10^{-5} \mathrm{~s}^{-1}\right)$ at temperatures ranging from 4 to $295 \mathrm{~K}$. Tensile stress-strain and strain-hardening curves were determined for these temperatures. The effect of strain-rate changes on tensile flow strength was measured from strains near 0.002 (yield strength) to over 0.300 . The data reflect distinct ranges of face-centered cubic, polycrystalline plastic deformation; their particular characteristics depend on solute content.

\section{INTRODUCTION}

Superconducting magnet structural materials deform at greatly different rates, varying from relatively slow stress increases due to rising magnetic fields to high strain rates due to magnetic-field quenching effects. Controlled strain-rate experiments not only provide data on the effects of strain rate on tensile properties, but they also lead to a better understanding of deformation mechanisms.

Conrad $^{1}$ reviewed the low temperature deformation of face-centered cubic metals. He analyzed existing strain-rate-dependent data for $\mathrm{Al}, \mathrm{Ag}, \mathrm{Cu}$, and

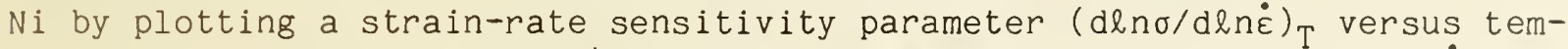
perature, $\mathrm{T}$, over the range 4 to $300 \mathrm{~K}$. He illustrated that dlno/dln $\dot{\varepsilon}$ gradually decreases at lower temperatures, falling toward zero at $0 \mathrm{~K}$ for these metals. Conrad showed that the activation volume (reciprocal of strain-rate sensitivity) decreases as a function of stress and strain at constant temperature and that the activation volume of $\mathrm{Cu}$ is greater than that of $\mathrm{Al}$. The activation volume is expressed as the reciprocal of strain-rate sensitivity: $V=k T(d \ell n \dot{\varepsilon} / d \sigma)_{T}$. Warren and Reed ${ }^{2}$ published tensile stress-strain curves at low temperatures on CDA $101 \mathrm{Cu}$ and $1100 \mathrm{Al}$.

Kocks et al. ${ }^{3-7}$ and Mulford ${ }^{8}$ presented a clear representation of strain hardening $(d \sigma / d \varepsilon)$, strain-rate sensitivity $(d \sigma / d \ell n \dot{\varepsilon})_{T}$, and dynamic aging for polycrystalline metals and alloys, where $\sigma$ is tensile stress and $\varepsilon$ is tensile strain. They argued that the flow strength at low temperatures is composed

\footnotetext{
*Partially supported by the Office of Fusion Energy, U.S. Department of Energy. Contribution of NBS, not subject to copyright.
} 
of contributions from dislocation-solute interactions and dislocationdislocation interactions. Their approach is discussed in more detail later and used to describe some of our data.

The strain-rate sensitivities of the tensile deformation of copper have been measured for single crystals ${ }^{9-13}$ and polycrystals. $14-19$ Butt and Feltham ${ }^{15}$ and den otter and van den Beukel ${ }^{16}$ studied polycrystalline behavior at temperatures as low as $77 \mathrm{~K}$. Christodoulou and Jonas 14 and Regazzoni and Montheillet 17 reported the strain-hardening characteristics of their polycrystalline copper. Mecking and Kocks studied silver. 4 Butt and Feltham found an inverse linear relationship between the log of the activation volume and applied stress between 77 and $290 \mathrm{~K}$. Regazzoni and Montheillet observed a linear dependence of the strain rate sensitivity on applied stress (60-300 $\mathrm{MPa}$ range) at room temperature and reported that do/dlné extrapolates to zero at zero stress. A similar trend was observed by Melander and Thuvander 18 in the stress range 200 to $330 \mathrm{MPa}$. However, Christodoulou and Jonas reported a minimum in the strain-rate sensitivity versus applied stress at room temperature located between $230 \mathrm{MPa}$ for large strain-rate changes $\left(\dot{\varepsilon}=5 \times 10^{-4}\right.$ to $10^{-2} \mathrm{~s}^{-1}$ ) and $410 \mathrm{MPa}$ for smaller changes.

There have been a number of studies to measure the strain-rate sensitivity of $A l$ in single $19,20,21$ and polycrystals.8,19,22-29 Some values were measured at temperatures as low as $4 \mathrm{~K} ; 19,20$ others, to $77 \mathrm{~K} .21-24,26,27$ Saimoto et al. 22 reported a minimum of the term $(1 / T)\left[\Delta \sigma /\left(\sigma-\sigma_{y}\right) /\left(\ln \dot{\varepsilon}_{1}-\right.\right.$ ln $\left.\left.\dot{\varepsilon}_{2}\right)\right]$ versus temperature at about $225 \mathrm{~K}$ from their strain-rate change measurements at temperatures from about 78 to $400 \mathrm{~K}$, where $\sigma_{\mathrm{y}}$ is the yield strength at 0.002 strain offset. Basinski ${ }^{19}$ reported a plateau of $(1 / \mathrm{T})(\mathrm{d} \sigma / \mathrm{d} l \mathrm{n} \dot{\varepsilon})_{\mathrm{T}}$ over the temperature range 10 to $80 \mathrm{~K}$, followed by a decrease from 80 to $295 \mathrm{~K}$.

Saimoto et al.22-26 and Mulford and Kocks $5,7,8$ also considered the tensile strain-hardening characteristics. Saimoto, Sang, and Morris 22 found a convergence of the strain-hardening term $\left(\sigma-\sigma_{y}\right)(\Delta \sigma / \Delta \varepsilon)$ as the adjusted flow stress $\left(\sigma-\sigma_{y}\right)$ decreased and an increasing range of linearity of this relationship as the temperature decreased. This dependence is similar to that reported by Mecking and Kocks ${ }^{4}$ for $\mathrm{Ag}$ and by Bullen and Hutchinson 30 for polycrystalline $\mathrm{Cu}$.

This paper presents stress-strain, strain-hardening, and strain-rate sensitivity data at temperatures from 4 to $295 \mathrm{~K}$ for a relatively pure (99.99\%) $\mathrm{Cu}$ and for a relatively pure (99.1\%) solid-solution strengthened Al.

\section{EXPERIMENTAL PROCEDURE}

The hardness, grain size, and chemical composition of the $\mathrm{Cu}$ and $\mathrm{Al}$ are listed in Table 1. Both materials were obtained in 1.9-cm bar stock and tested in the annealed condition. The CDA $101 \mathrm{Cu}$ (oxygen-free, high conductivity) was annealed at $650^{\circ} \mathrm{C}$ for $1 \mathrm{~h}$ in $\mathrm{Ar} ; 1100 \mathrm{Al}, 500^{\circ} \mathrm{C}$ for $0.5 \mathrm{~h}$ in air; both were air cooled. The residual resistivity ratios were 105 for the CDA $101 \mathrm{Cu}$ and 35 for the $1100 \mathrm{Al}$ alloy following annealing. Round tensile specimens were machined to a $6.35-\mathrm{mm}$ diameter along a gage length of $41.9 \mathrm{~mm}$, tapering with a radius of $9.52 \mathrm{~mm}$ from $12.7-\mathrm{mm}$ threaded ends. The leng th of the entire specimen was $71.4 \mathrm{~mm}$. 
The cryostat equipment is shown in Fig. 1. Tests at 4 and $76 \mathrm{~K}$ were conducted in boiling liquid helium and nitrogen, respectively. Other low temperatures were achieved by testing in helium $(4-76 \mathrm{~K}$ ) or nitrogen (>76 K) gas and automatically adjusting the gas flow and the heater input at the specimens grips with temperature controllers.

The type $E$ thermocouples were taped to the middle of the specimen on a varnished surface and insulated from the gas atmosphere with foam. Silicon diodes inserted into small drilled holes in both specimen grips permitted digital readout and control of temperatures at both the upper and lower grips. By these means, we were able to maintain specimen temperature within $1.0 \mathrm{~K}$ during testing at $20 \mathrm{~K}$ (other temperatures were easier to control). During discontinuous load drops while testing at temperatures from 4 to $20 \mathrm{~K}$, surface temperature increases up to $50 \mathrm{~K}$ were detected. Specimen temperature returned to the desired control temperature during subsequent elastic deformation to the prior flow-stress level.

In all tests, the specimens were initially loaded at the low strain rate $\left(2 \times 10^{-5} \mathrm{~s}^{-1}\right.$ ) at constant temperature. After sufficient strain to permit measurement of the yield strength, the strain rate was abruptly increased to $2 \times 10^{-3} \mathrm{~s}^{-1}$ and held long enough for good characterization of the stressstrain curve. The strain rate was then reduced, and the specimen was strained to the next measurement range. Each strain increment was about 0.002 ; this was sufficient to determine the yield point or unloading effects. However, at temperatures less than about $50 \mathrm{~K}$, specimen warming was observed during the high strain-rate segments. This warming became detectable at strains in excess of about 0.001 ; therefore, smaller strain increments were used at these low temperatures.?

New, high elongation strain-gage extensometers that have been developed for use at low temperatures were used for most of these measurements. These extensometers, capable of sensitivities of $10^{-5}$, have three flexing Al beams. The geometry of the beams permits sensing of specimen strain to elongations of over $30 \%$ at low temperatures. Four $350-\Omega$ strain gages were mounted to each beam and wired in a Wheatstone bridge configuration. A 5-V de power supply was used to adjust excitation.

Two types of tensile machines were used. With the Instron Model TTDML,* the cryostat assembly (Fig. 1) uses the downward motion of a screw-driven crosshead to impart load through a stainless steel compression cylinder to the specimen. A servohydraulic MTS Model 810,* with the actuator repositioned above the crosshead to accommodate a more efficient cryostat system, was also used, but only at temperatures of 4, 76, and $295 \mathrm{~K}$. In this assembly two fiberglass-epoxy compression posts sustained the load imparted through the actuator to the specimen. This low temperature loading system is more extensively discussed by Read and Tobler. 31

*Trade names are used here to describe specifically the method of testing, including loading, compliance, and portions of the load train; this is not an NBS endorsement of these products. 
At room temperature, the loading compliance of the screw-driven assembly was measured as $8 \times 10^{-3} \mathrm{~cm} / \mathrm{kN}$. The compliance of the servohydraulic load train varied from $11 \times 10^{-3} \mathrm{~cm} / \mathrm{kN}$ at loads less than about $2 \mathrm{kN}$ to $6 \times 10^{-3}$ $\mathrm{cm} / \mathrm{kN}$ at larger loads. The $\mathrm{Cu}$ and $\mathrm{Al}$ specimens were measured at the higher compliance levels of the load trains.

The velocity of the actuator and crosshead movement of the machines were measured independently and found to deviate from expected rates. The "low" crosshead rate of the screw-driven machine was $0.0047 \mathrm{~cm} / \mathrm{min}$ (stated as 0.005 $\mathrm{cm} / \mathrm{min}$ ) and the "high" crosshead rate for this machine was $0.455 \mathrm{~cm} / \mathrm{min}$ (stated as $0.5 \mathrm{~cm} / \mathrm{min}$ ). The "high" actuator speed of the servohydraulic machine was $0.540 \mathrm{~cm} / \mathrm{min}$ (stated as $0.5 \mathrm{~cm} / \mathrm{min}$ ); its "low" actuator speed was $0.005 \mathrm{~cm} / \mathrm{min}$.

The responses of the crosshead, actuator, and load and strain recordings to change of strain rate were also assessed. Measured with a digital oscilloscope, the transition with respect to crosshead and actuator stability from low strain rate to $h i g h$ strain rate was quick; the fast strain rate was obtained within the 10-ms sensitivity. However, the transition in the screwdriven machine from fast to slow was much less rapid, and a pause in crosshead motion was observed for time periods from 0.1 to $2 \mathrm{~s}$. This slackening of crosshead motion usually resulted in a dip in stress (indicating apparent strain softening) at the onset of the lower strain rate (illustrated in Fig. 2a). Therefore, all recorded values of $\Delta \sigma$ were measured from increasing strain-rate changes. In both machines, the response time of the strain amplification circuits was adequate to distinguish strain changes from rate changes.

The time constant (cutoff frequency) for the filtering of the load signal of the two machines differed. The servohydraulic machine had a shorter time constant (higher cutoff frequency), and its load response to strain-rate changes of two orders of magnitude was always adequate. The screw-driven machine had a longer time constant, and its load response sometimes lagged the strain response during strain-rate changes. This led to possible ambiguities in interpreting the load-strain data (see Fig. 2b). Particularly, if the rate of strain hardening was large, the load lag during the rate change produced apparently low or even negative stress-change values. High strainhardening rates are predominant in $\mathrm{Cu}$ and $\mathrm{Al}$ at low strains $(<0.04)$; therefore, data from the screw-driven machine at low strains are not included in this paper.

In the subsequent presentation of data, $\Delta \sigma$ is plotted versus $\sigma$ for $C u$ and Al. Here the flow stress, $\sigma$, is taken as the average stress of the two strain rates. Copper and aluminum data from the screw-driven machine were adjusted to match the data at 4, 76, and $295 \mathrm{~K}$ obtained from the servohydraulic machine by considering their different strain rates, compliance, and other machine variables.

Following changes of strain rate, yield point effects were observed at temperatures ranging from $76 \mathrm{~K}$ to room temperature. At lower temperatures transient effects were not detected until there was considerable strain $(-0.10)$. Near room temperature transient yielding effects were observed 
almost immediately. In Figure $3 a$ and $b$, typical strain-rate change sequences depict the observations. The difference between $\Delta \sigma$ and $\Delta \sigma_{i}$ increased with increasing strain; at the end of the test, $\Delta \sigma_{i}$ was approximately $10 \%$ of $\Delta \sigma$ for $\mathrm{Al}$ and $20 \%$ of $\Delta \sigma$ for $\mathrm{Cu}$.

We chose to report $\Delta \sigma$ from our measurements. We obtained $\Delta \sigma$ by measuring the maximum load difference (the difference between the peak load and the extrapolated load at lower strain rate; see $\mathrm{Fig} .3 \mathrm{a}$ ) and dividing by the original specimen area. The value, $\Delta \sigma$, was chosen primarily for the following reason: during straining at the higher strain rate at temperatures at and below $76 \mathrm{~K}$, specimen warming was detected by our temperature monitors. This made distinctions between transient yield-point behavior and warming effects difficult to sort out. Specimen warming was never detected in the early yield-point region.

When changing to the higher strain rate at low strains $(-<0.004)$, an equivalent strain-hardening rate was usually not attained. Therefore, interpretation of $\Delta \sigma$ at equivalent strain-hardening rates was not possible. Extrapolation to the strain at the point of strain-rate change yielded lower values of $\Delta \sigma(\mathrm{Fig} .3 \mathrm{c})$. It is likely that in this early strain range the strain rate influences the rate of dislocation accumulation per unit strain. No data in this low strain range were included unless both $\sigma-\varepsilon$ curves (high $\varepsilon$ and low $\varepsilon$ ) assumed equivalent strain-hardening rates.

Discontinuous yielding at $4 \mathrm{~K}$ was observed in $\mathrm{Cu}$ at high strains (see Fig. 3d). Thermal conductivity of the Al was about $22 \mathrm{~W} \cdot \mathrm{m}^{-1} \cdot \mathrm{K}^{-1}$ and that of $\mathrm{Cu}$ was $667 \mathrm{~W} \cdot \mathrm{m}^{-1} \cdot \mathrm{K}^{-1}$. The specific heat value of $\mathrm{Cu}\left(0.10 \mathrm{~J} \cdot \mathrm{kg}^{-1} \cdot \mathrm{K}^{-1}\right)$ was lower than that of $\mathrm{Al}\left(0.28 \mathrm{~J} \cdot \mathrm{kg}^{-1} \cdot \mathrm{K}^{-1}\right)$. Discontinuous yielding occurred at about $350 \mathrm{MPa}$ at a strain of 0.32 ; at these stress and strain levels, $1100 \mathrm{Al}$ had smooth stress-strain behavior. Therefore, the occurrence of discontinuous yielding in $\mathrm{Cu}$ must be closely associated with the lower specific heat contribution to adiabatic heating and not critically affected by the difference in thermal conductivity. Changes to the higher strain rate immediately triggered load drops and more erratic stress-strain behavior (Fig. $3 e$ ). Changes from high to low rate resulted in load increases until the steady state of the low rate was reached (Fig. $3 \mathrm{e}$ ). The occurrence of discontinuous yielding precluded assessment of strain-rate effects on flow stress.

\section{EXPERIMENTAL RESULTS}

\section{Copper}

The tensile stress-strain curves of $\mathrm{Cu}$ are shown in $\mathrm{Fig}$. 4. At low temperatures there was a decided increase in strain hardening but little increase in yield strength. Only very moderate discontinuous yielding occurred at $4 \mathrm{~K}$ at large strains. The temperature dependence of the yield strength followed the same form as face-centered cubic alloys; ${ }^{32}$ the log of the strength decreased with increasing temperature:

$$
\sigma_{y}=36 \exp \left(-0.28 \times 10^{-3} \mathrm{~T}\right) \text {. }
$$

Therefore, there was a very small dependence of $\sigma_{y}$ on $\mathrm{T}$ from $\sigma_{\mathrm{y}}=36 \mathrm{MPa}$ at $4 \mathrm{~K}$ to $33 \mathrm{MPa}$ at $295 \mathrm{~K}$. 
The data depicting the dependence of $\Delta \sigma$ on $\sigma$ for $C u$ from strain-rate changes are presented in Figs. 5 through 7 for various low temperatures. Data in Fig. 5 represent three independent measurements of separate specimens. At $4 \mathrm{~K}$ (Fig. 7), there was an apparently linear, very gradual, dependence of $\Delta \sigma$ on $\sigma$; at higher temperatures the dependence of $\Delta \sigma$ on $\sigma$ was slightly concave upward. The stress change, decreased with a decrease in temperature and apparently extrapolates to zero at zero stress.

The dependence of $\Delta \sigma$ on $\varepsilon$ was slightly concave downward, contrasting to the dependence of $\Delta \sigma$ on $\sigma$. The $\Delta \sigma$ extrapolated to positive values, ranging from about 0.3 to $1.5 \mathrm{MPa}$, at zero strain.

$\underline{\text { Aluminum }}$

The tensile $\sigma-\varepsilon$ curves of $\mathrm{Al}$ at temperatures from 4 to $295 \mathrm{~K}$ are shown in Fig. 8. As temperature decreased, the rate of strain hardening increased. There was very little increase of flow strength at low strain levels as temperature decreased. Values of $\sigma_{\mathrm{y}}$ increased from approximately $25 \mathrm{MPa}$ at $295 \mathrm{~K}$ to $40 \mathrm{MPa}$ at $4 \mathrm{~K}$, following the expression

$$
\sigma_{\mathrm{y}}=40 \exp \left(-1.67 \times 10^{-3} \mathrm{~T}\right) \text {. }
$$

The dependence of the $\Delta \sigma$ resulting from strain-rate changes on $\sigma$ is shown in Figs. 9 and 10 for Al at temperatures from 4 to $252 \mathrm{~K}$.

At room temperature the effects of strain-rate change on $\Delta \sigma$ are not clear and are not included in this report. Strain-aging significantly influenced the stress-strain characteristics at the low strain rate, since the $\sigma-\varepsilon$ curve is composed of many small serrations. At the high strain rate, the $\sigma-\varepsilon$ curve is irregular and the strain-hardening rates are variable. The best description is that, following an increase of strain rate, $\Delta \sigma$ shows a very small increase initially, but during straining, a negative strain-hardening rate results. This results in a higher $\Delta \sigma$ if the $\sigma-\varepsilon$ curve is extrapolated to the point of strain-rate change or in a lower $\Delta \sigma$ if some intermediate strain is used to represent the data.

The dependence of $\Delta \sigma$ on $\sigma$ increases with increasing test temperature from 4 to $100 \mathrm{~K}$, and then decreases at higher temperatures. At temperatures below $100 \mathrm{~K}$, all curves (at large strains) extrapolate to $\Delta \sigma=0$ at zero flow stress. Above $100 \mathrm{~K}$ all curves extrapolate to positive values of $\Delta \sigma$ at zero flow stress; the extrapolated value increases with increasing temperature. At very low temperatures ( 20 and $4 \mathrm{~K}$ ), the dependence of $\Delta \sigma$ on $\sigma$ is linear; at higher temperatures ( $\geqq 50 \mathrm{~K}$ ), the dependence is concave upward at high flow stress and linear at low flow stress. At very low stress levels (near the yield strength), measurements are more difficult (owing to lower absolute stress change) and arbitrary (owing to changing strain-hardening rates with strain rate). At low stress levels there is some evidence for a second stage that exhibits greater dependence on flow stress. The data points at the lowest flow-stress levels of the 20-, 50-, and $252-\mathrm{K}$ plots may reflect the change of dependency at low stresses. 


\section{DISCUSSION}

\section{Strain Hardening}

Following the general approach of Kocks, $3-8$ the flow strength can be subdivided:

$$
\sigma=\sigma_{f}+\sigma_{d},
$$

where $\sigma_{f}$ is the frictional strength contribution dependent upon dislocationsolute interaction, and $\sigma_{d}$ is the dislocation-dislocation interaction contribution, dependent primarily on the number and structure of dislocations. The frictional strength can be regarded as independent of strain, and the yield strength is a good measure. The term $\sigma_{d}$ is strain dependent, and tensile strain-hardening characteristics reflect its contribution. The dislocation interaction typically is related to the dislocation density,

$$
\sigma_{d}=\alpha \mu b p^{1 / 2}
$$

with $\mu$, the shear modulus; $b$, the Burgers vector; $p$, the active dislocation density; and $\alpha$, a constant. The constant, $\alpha$, may be dependent on the solute content, $c$, and is slightly less than unity. Thus, the strain-hardening rate, $\theta$, is

$$
\theta=\frac{d \sigma}{d \varepsilon}=\frac{\alpha \mu b}{2} p^{-1 / 2} \frac{d p}{d \varepsilon},
$$

and

$$
\sigma_{d} \frac{d \sigma}{d \varepsilon}=\left(\sigma-\sigma_{f}\right) \frac{d \sigma}{d \varepsilon}=\frac{(\alpha \mu b)^{2}}{2} \frac{d p}{d \varepsilon}
$$

is proportional to the change of dislocation density with strain ( $d p / d \varepsilon)$. The change of dislocation density as a function of strain is considered to have two components: one is the rate of storage and the other, the rate of dynamic recovery. The rate of dislocation accumulation is athermal in nature; the recovery rate is obviously affected by thermal activation. With these considerations, the quantity proportional to the dependence of dislocation density on strain (Eq. 6 ), should have two major terms:

$$
\sigma_{d} \Theta=\sigma_{d} \Theta_{h}(c)-\sigma_{d} \Theta_{r}(\dot{\varepsilon}, T, \sigma, c),
$$

where $\sigma_{d} \theta_{h}$ is related to the athermal hardening rate and $\sigma_{d} \theta_{r}$ is related to the dynamic recovery rate contributing negatively to $\sigma_{d} \theta$.

The strain-hardening curves derived from the $\sigma-\varepsilon$ curves for $\mathrm{Cu}$ are included in Fig. 11. They were derived from Eq. 6 and are plotted as $\left(\sigma-\sigma_{y}\right) \Delta \sigma / \Delta \varepsilon$ versus $\sigma-\sigma_{y}$, with the assumption that $\sigma_{f}=\sigma_{y}$. There is a linear region with positive slope at low stress followed by deviation to lower strain-hardening rates at higher stress. The linear region is constant at all temperatures and deviations from linearity occur at higher stresses with lower temperatures. 
The strain-hardening data for Al are shown in Fig. 12. Similar to those for $\mathrm{Cu}$, there is a linear region of increasing $\left(\sigma-\sigma_{y}\right) \theta$ with increasing $\sigma-\sigma_{y}$, whose slope is independent of temperature. The slope of this linear region is slightly greater for $\mathrm{Al}(2.2 \mathrm{GPa})$ than for $\mathrm{Cu}(1.7 \mathrm{GPa})$.

The 99.1 Al is expected to exhibit stronger solute interactions than the 99.99 Cu. These solute interactions resulted in a steeper temperature dependence of $\sigma_{y}$ for Al. "Normalizing" by subtracting $\sigma_{y}$ from both axes produces almost Identical sets of curves for $\mathrm{Cu}$ and $\mathrm{Al}$. Saimoto et al.22 also used this procedure; Kocks et al. 4-7 suggested dividing by the shear modulus. This latter procedure would result in discrete, independent curves as a function of temperature for Al, not in convergence to an "athermal" dependence. Thus, the derivation and use of Eq. 6 to describe strain-hardening behavior is reinforced by the Al data.

Dynamic recovery, as evidenced by the deviations from linearity at higher o values, was apparent for both metals. In this region, the rate of accumulation of active dislocations is decreasing, but always remains positive.

\section{Strain-Rate Effects}

When the two major contributions to the flow strength from solute effects and dislocation interactions are taken into consideration, the strainrate sensitivity has two components:

$$
\frac{\partial \sigma}{\partial \ln \dot{\varepsilon}}=\left(\frac{\partial \sigma_{f}}{\partial \ln \dot{\varepsilon}}\right)_{T}+\left(\frac{\partial \sigma_{d}}{\partial \ln \dot{\varepsilon}}\right)_{T}=\sigma_{f}\left(m_{f}-m_{d}\right)+\sigma m_{d}
$$

where $m_{f}=\left(\frac{\partial \ln \sigma_{f}}{\partial \ln \dot{\varepsilon}}\right)_{T}$ and $m_{d}=\left(\frac{\partial \ln \sigma_{d}}{\partial \ln \dot{\varepsilon}}\right)_{T}$ at constant temperature.

A plot of $\partial \sigma / \partial \ell n \dot{\varepsilon}$ versus $\sigma$ has a slope of $m_{d}$ at stresses above $\sigma_{y}$ and extrapolates to $\sigma_{f}\left(m_{f}-m_{d}\right)$ at zero stress. When both contributions are present, they may be distinguished in the low stress range: at low stress the contribution from dislocation interactions $\left(\sigma_{d}\right)$ is small, and therefore, the contribution from solute strengthening $\left(\sigma_{f}\right)$ dominates.

The strain-rate sensitivity data of $\mathrm{Cu}$ (Figs. 5-7) are summarized in Fig. 13. Curves of each temperature extrapolate to a zero value of $\Delta \sigma / \Delta \ell n \dot{\varepsilon}$ as $\sigma$ approaches zero. Thus, $\sigma_{f} \approx 0$ and the dislocation-dislocation interaction term dominates. This is similar to the single-crystal Ag behavior reported by Mecking and Kocks ${ }^{4}$ and is probably typical of all relatively pure fcc metals. From Fig. 13 it also appears that $\mathrm{m}_{\mathrm{d}}$ is temperature dependent, increasing with increasing temperature. Deviation from linearity at higher stress or temperature is associated with recovery, similar to that discussed in the strain-hardening section. 
Christodoulou and Jonas ${ }^{14}$ recently reported that their strain-rate sensitivity parameter ( $\Delta \ell n \sigma / \Delta \ell n \dot{\varepsilon}$ ) of oxygen-free $99.95 \mathrm{Cu}$, measured at, room temperature, initially decreased to a minimum and then began to rise. Other investigations, 10-13,15-19 some of which also obtained measurements at low strains, do not support their observation. Additionally, our data of Fig. 13 clearly indicate a steady increase of $\Delta \sigma / \Delta \ell n \dot{\varepsilon}$ over the entire deformation range.

The strain-rate dependence of $\mathrm{Al}$ at low temperatures is summarized in Fig. 14. These results agree qualitatively with Takai et al.,20 who measured the strain-rate sensitivity of $1050 \mathrm{Al}(99.6 \mathrm{Al})$ at $4,76,120$, and $295 \mathrm{~K}$ and round a maximum of $(\Delta \sigma / \Delta \ell n \dot{\varepsilon})_{T}$ at $120 \mathrm{~K}$. Very small $(\Delta \sigma / \Delta \ell n \dot{\varepsilon})_{\mathrm{T}}$ values at $4 \mathrm{~K}$ were also reported by Thornton et al. 9

Whereas $\Delta \sigma / \Delta l n \dot{\varepsilon}$ values of relatively pure $C u$ extrapolate to zero over the entire 4-295 $\mathrm{K}$ temperature range, only the very low temperature (4-76 K) $\mathrm{Al}$ values extrapolate to zero stress. Above $76 \mathrm{~K}$ the Al data appear to extrapolate to positive values. It is unlikely that the solute frictional stress, $\sigma_{f}$, is lower at lower temperatures. Typically one considers this stress to originate from short-range stress fields and, thus, to decrease at higher temperatures with assistance from thermal activation. If $\sigma_{f}$ is positive, the term $m_{f}-m_{d}$ must approach zero at low temperatures; thus, $m_{f}$ must approach zero as $\mathrm{T}$ approaches zero more quickly than $\mathrm{m}_{\mathrm{d}}$ does (since the low temperature data reflect dislocation interaction behavior, not solute frictional stress behavior). At higher temperatures, the $\sigma_{f}\left(m_{f}-m_{d}\right)$ term gradually becomes dominant as the slope of $\Delta \sigma / \Delta l n \dot{\varepsilon}$ decreases. The reduction of the extrapolated values of $\Delta \sigma / \Delta l n \dot{\varepsilon}$ at zero stress at higher temperatures now reflect the temperature dependence of $\sigma_{\mathrm{f}}$. This suggests a transition from a short-range, dislocation-interaction rate-controlling deformation mechanism at low temperatures to a long-range, dislocation-solute interaction mechanism at ambient temperatures. Decreases of extrapolated $\Delta \sigma / \Delta \ell n \dot{\varepsilon}$ values (corresponding to $\sigma_{\mathrm{f}}$ ) with increases of test temperature at $\mathrm{T} \geqq 100 \mathrm{~K}$ have also been reported in solid-solution-strengthened $\mathrm{Ni}$-base, $\mathrm{Cr}, \mathrm{Fe}$ alloys, 5,8 $\mathrm{Ni}$-Co alloys, and $\mathrm{Al}-\mathrm{Fe}$ alloys. 25

Finally, we found a clear dependence of $\Delta \sigma$ on $\sigma$ (or $\varepsilon$ ) that decreased at both high and low temperatures. This dependence makes strain-rate sensitivity averaging techniques precarious. In measuring strain-rate sensitivity as a function of temperature for $\mathrm{Al}-\mathrm{Fe}$, Bull and Saimoto ${ }^{26}$ averaged the strains between a minimum of 0.04 and a maximum where $\theta=0$. Two facts oppose this practice: (1) The strain at which the strain hardening reaches zero is dependent on a number of testing parameters; (2) Any averaging range based on strain range results in various stress ranges corresponding to each temperature, thus affecting the range of $\Delta \sigma$ data points to be included. It appears best to compare $\Delta \sigma / \Delta l n \dot{\varepsilon}$ data versus temperature at constant stress ( $\sigma$ ) or at constant normalized stress $\left(\sigma-\sigma_{\mathrm{y}}\right)$.

As discussed earlier, we observed transient yield point effects from strain rate changes in both $\mathrm{Cu}$ and $\mathrm{Al}$ at temperatures above $76 \mathrm{~K}$. In previous studies of transient effects from strain-rate changes, 33-36 most researchers attributed the yield point effects to changes of mobile dislocation 
density, but van den Brink et al.33 made strong measurement correlations between $\Delta \sigma_{i}$ changes and dynamic strain aging (see Fig. 3). However, we observed larger values of $\Delta \sigma_{i}$ in $\mathrm{Cu}$, the purer material. It is most likely that our transient effects were caused by changes of dislocation density, not dislocation mobility.

\section{Activation Volume}

Usually the activation volume parameter has been calculated from strain-rate sensitivity measurements. This parameter is defined 37 as

$$
V=k T\left(\frac{\partial \ln \dot{\varepsilon} / \dot{\varepsilon}_{O}}{\partial \sigma}\right)_{T} \quad,
$$

where $\dot{\varepsilon}_{O}$ is a function of the number and distribution of mobile dislocations. This assumes a single activation process controlling the rate of deformation.

$$
\dot{\varepsilon}=\dot{\varepsilon}_{0} \exp (-Q / k T) \quad,
$$

with $Q$ the activation energy for the process. The parameter $V$ is considered to be related to the average volume of the rate-controlling process by

$$
\overline{\mathrm{V}}=\mathrm{bd} \ell,
$$

with d the distance over which the dislocation interaction process proceeds and $\&$ the dislocation interaction length.

Experimentally, it has been customary to consider $\dot{\varepsilon}_{0}$ to be independent of $\sigma(\mathrm{Eq} .9)$ and thus to measure the term $\mathrm{kT}(\Delta \ell \mathrm{n} \dot{\varepsilon} / \Delta \sigma) \mathrm{T}$ to obtain $\mathrm{V}$. However, one can easily obtain (see, e.g., Frost and Ashby ${ }^{38}$ ) a slightly modified rate equation for obstacle-controlled deformation by using the following two relationships: The strain rate is related to dislocation density and average velocity $(\bar{v})$ by

$$
\dot{\varepsilon}=\rho_{\mathrm{m}} \mathrm{b} \overline{\mathrm{v}} \quad \text {, }
$$

and $\rho_{m}$ is related to $\sigma$ by

$$
\sigma=\alpha \mu b \rho_{m} 1 / 2
$$

where $\alpha$, a constant, is near unity.

The average dislocation velocity may be represented by the rate equation

$$
\bar{v}=B b \nu \exp [-\Delta G(\sigma) /(k T)],
$$

where $B$ is a constant, $\nu$ is the frequency, and $\Delta G$ is the Gibbs free energy for overcoming obstacles. 
Combining Eqs. 12 through 14 yields

$$
\dot{\varepsilon}=\operatorname{Bv}(\sigma / \alpha \mu)^{2} \exp [-\Delta G(\sigma) /(k T)] \text {, }
$$

and we see that the pre-exponential term does include stress. Differentiating Eq. 15 with respect to $\sigma$,

$$
k T\left[\left(\frac{\partial \ln \dot{\varepsilon}}{\partial \sigma}\right)_{T}-\frac{2}{\sigma}\right]=-\frac{\partial \Delta G(\sigma)}{\partial \sigma} \text {. }
$$

Kocks et al. 39 and Frost and Ashby ${ }^{38}$ describe $\Delta G$ as

$$
\Delta G(\sigma)=\Delta F\left[1-\sigma / \sigma_{0}\right]
$$

for relatively large values of $\Delta F$, where $\Delta F$ is the total free energy needed to overcome obstacles in the absence of applied stress. The constant $\sigma_{0}$ is described as the athermal flow strength or, normally, the yield strength at absolute zero. Here,

$$
V=\Delta \mathrm{F} / \sigma_{\mathrm{O}},
$$

when $\Delta F$ is assumed to be large, of the order of $1 \mathrm{ub}^{3}$. On combining Eqs. 16-18,

$$
\mathrm{kT}\left[\left(\frac{\partial \ln \dot{\varepsilon}}{\partial \sigma}\right)_{\mathrm{T}}-\frac{2}{\sigma}\right]=\frac{\partial\left(\Delta \mathrm{F} \cdot \sigma / \sigma_{\mathrm{O}}\right)}{\partial \sigma}=\mathrm{V}
$$

The contribution of the pre-exponential term in Eq. 19 for our $\mathrm{Cu}$ and $\mathrm{Al}$ data is about $10 \%$ of $\Delta l n \dot{\varepsilon} / \Delta \sigma$. Therefore, in our data presentations this term has not been included; this permits better comparison with past measurements. We subsequently refer to this quantity, $k T(\Delta \ell n \dot{\varepsilon} / \Delta \sigma)$, as the apparent activation volume, $V^{*}$.

In Fig. 15 the apparent activation volume, $\mathrm{V}^{*}$, of $\mathrm{Cu}$ is plotted versus test temperature at constant stress. All data, although approaching close to $V^{*}=0$ as $\sigma \rightarrow 0$, clearly extrapolate to small positive values of $V^{*}$ as $\sigma \rightarrow 0$. Butt and Feltham ${ }^{15}$ showed that $\ell_{n} V^{*}$ is linearly related to $\ln \sigma$ at constant $\mathrm{T}$ for oxygen-free copper; this is substantiated by our data (plotted in this manner in Fig. 16). The slope of the curves at $23 \mathrm{~K}$ and above are approximately equivalent; however at $4 \mathrm{~K}$ this equivalence does not hold. Unlike Butt and Feltham, we did not find that the slope of $\ell n V^{*}$ versus $\ell$ no was -1 ( $\sigma V^{*}=$ constant at a given temperature), but instead was less than -1 at temperatures $\geqq 23 \mathrm{~K}$. However, at $4 \mathrm{~K}$ the slope of the curve plotted in Fig. 16 is about -1 .

If one assumes a physical significance in the absolute values of $V^{*}$, we realize that these values are quite large. Interactions of dislocations within volumes from 100 to $1000 \mathrm{~b}^{3}$ indicate quite long distances between interaction points. If $d=b$, then $l$ is in the range 100 to $1000 \mathrm{~b}$. These 
large activation volumes for $\mathrm{Cu}$ are consistent with all previous reports that have calculated $V^{*} .9,10,12,15,16$

For Al, the values of $\mathrm{V}^{*}$ are plotted versus temperature at constant $\sigma$ in Fig. 17. When one considers that $\sigma_{y}$ of $A l$ is almost equivalent to that of $\mathrm{Cu}$, the values of $\mathrm{V}^{*}$ for $\mathrm{Al}$ are less than those of $\mathrm{Cu}$. Secondly, at very low temperature $(4 \mathrm{~K})$, the $V^{*}$ values are larger than those at $20 \mathrm{~K}$. Similar to that of $\mathrm{Cu}$, the $\mathrm{nV}^{*}$ versus $\ell$ no of $\mathrm{Al}$ is linear at low temperatures, as shown in Fig. 18. At higher temperatures $(\geqq 150 \mathrm{~K})$, slight curvature of the logarithmic dependence is apparent.

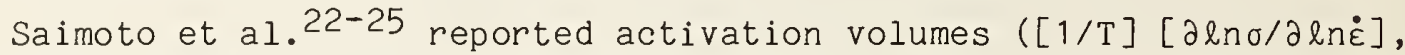
which they label "strain-rate sensitivities") for Al-dilute Fe alloys over the temperature range 41 to $418 \mathrm{~K}$. They found a minimum of $\mathrm{V}$ but at a much higher temperature, near $200 \mathrm{~K}$. As mentioned earlier, their $\Delta \ell n \sigma / \Delta l n \dot{\varepsilon}$ was averaged over a range of stresses, whereas we plotted $\Delta \sigma / \Delta l n \dot{\varepsilon}$ at a constant stress level. Like Basinski, 19 they found no clear trend below about $77 \mathrm{~K}$ (both used the "averaging" method of strain-rate sensitivity analysis).

There have been many reports of dilute alloy softening at very low temperatures. Decreases of yield strength of $\mathrm{Cu}$ - and $\mathrm{Ag}$-based dilute alloys have been found at temperatures less than about $50 \mathrm{~K}$. The minimum of $V^{*}$ in dilute $\mathrm{Al}-\mathrm{Fe}$ at about $20 \mathrm{~K}$, opposed to the lack of a minimum in $99.99 \mathrm{Cu}$, may be a sensitive indicator of this phenomena.

Another possible explanation for the apparent softening associated with the increase of $V^{*}$ at very low temperatures is adiabatic heating. This should manifest itself with a strong dependence on $\dot{\varepsilon}$ and will be explored in the near future.

\section{CONCLUSIONS}

A study of the strain-hardening and strain-rate sensitivity of $99.99 \mathrm{Cu}$ and $99.1 \mathrm{Al}$ over the temperature range 4 to $295 \mathrm{~K}$ found the following ratecontrolling deformation features:

The strain-hardening characteristics are best portrayed using the term $\left(\sigma-\sigma_{y}\right)(d \sigma / d \varepsilon)$ to describe dislocation accumulation as a function of normalized applied stress, $\sigma-\sigma_{\mathrm{y}}$. Two regions are found in $\mathrm{Cu}$ and $\mathrm{Al}$ : (1) an athermal, linear range of strong increase of mobile dislocation density and (2) a range associated with dynamic recovery, where the rate of increase of dislocations levels off and then decreases.

The strain-rate sensitivity characteristics were identified in two ways (1) as a strain-rate sensitivity parameter, $(\Delta \sigma / \Delta \ell n \dot{\varepsilon})_{T}$, and (2) as an activation volume, $\mathrm{kT}(\Delta l n \dot{\varepsilon} / \Delta \sigma)_{T}$. The strain-rate sensitivity of $\mathrm{Cu}$ indicates that the frictional stress between dislocations and solute is effectively zero for $99.99 \mathrm{Cu}$, but positive for $99.1 \mathrm{Al}$. This is also indicated in the increased temperature dependence of the yield strength of the Al. The effect of solutedislocation interactions may be reflected in the low temperature minimum of the activation volume, since it is absent in the $\mathrm{cu}$. 


\section{ACKNOWLEDGMENT}

Partial support for this project was kindly supplied by the office of Fusion Energy, DOE.

\section{NOTATION}

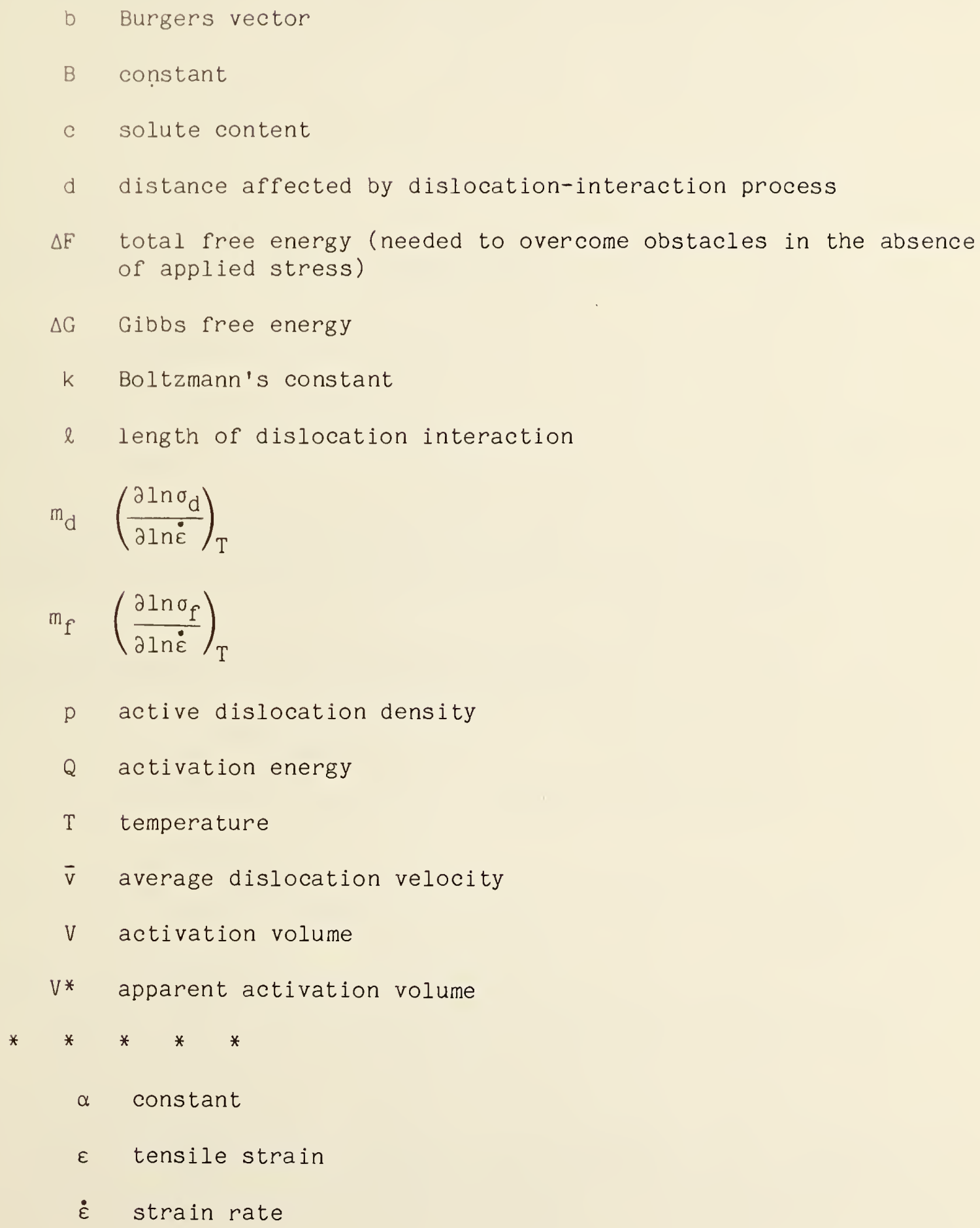




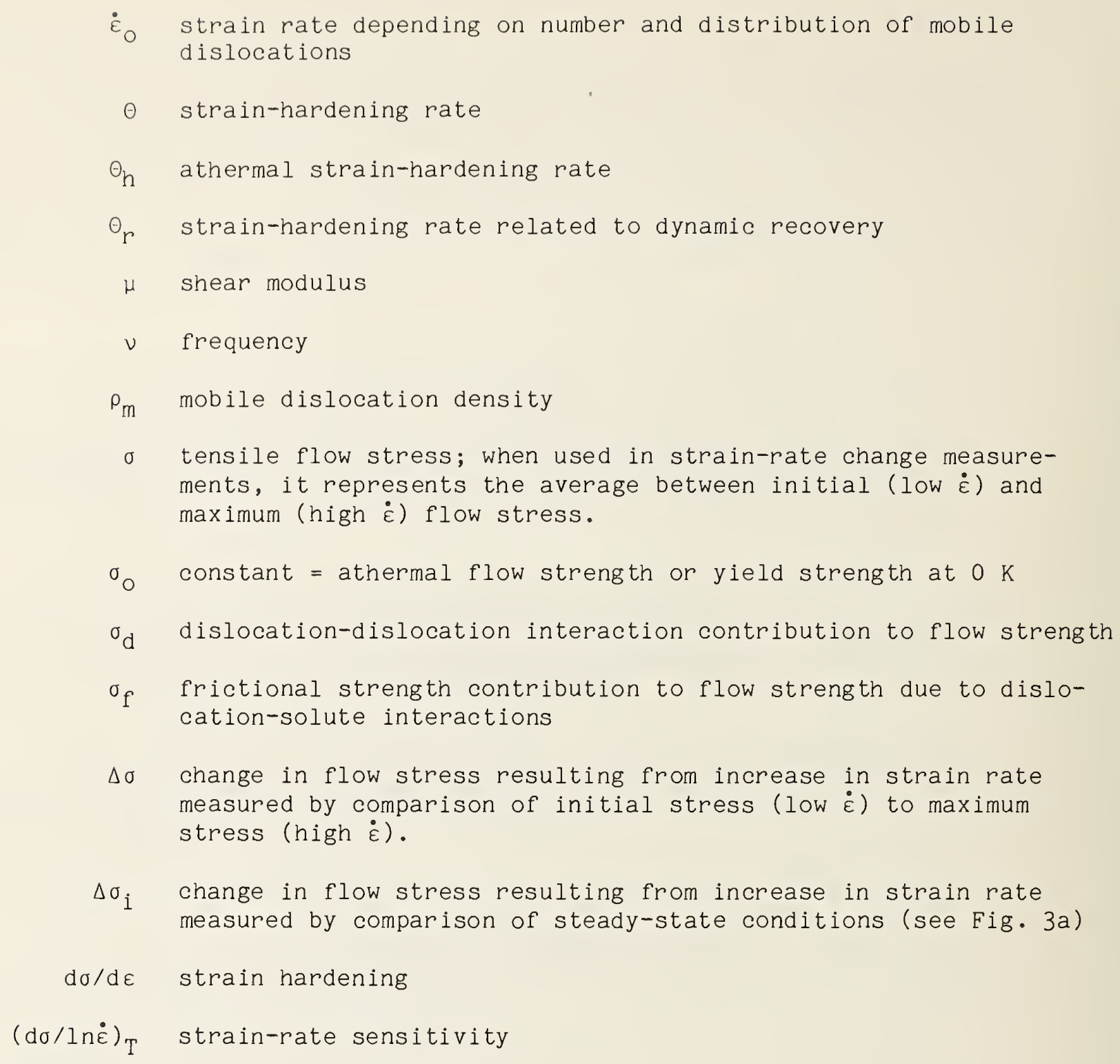

\section{REFERENCES}

1. H. Conrad, in "High Strength Materials," Wiley \& Sons, New York (1965), p. 436.

2. K. A. Warren and R. P. Reed, "Tensile and Impact Properties of Selected Materials from 20 to $300 \mathrm{~K}$." NBS Monograph 63, U.S. Government Printing office, Washington, D.C. (1963).

3. U. F. Kocks, R. E. Cook, and R. A. Mulford, Acta Metall. 33, 623 (1985).

4. H. Mecking and U. F. Kocks, Acta Metall. 29, 1865 (1981).

5. R. A. Mulford and U. F. Kocks, Acta Metall. 27, 1125 (1979). 
6. T. A. Bloom, U. F. Kocks, and P. Nash, Acta Metall. 33, 265 (1985).

7. R. A. Mulford and U. F. Kocks, Scripta Metall. 13, 729 (1979).

8. R. A. Mulford, Acta Metall. 27, 1115 (1979).

9. P. R. Thornton, T. E. Mitchell, and P. B. Hirsch, Philos. Mag. 7, 337 (1963).

10. R. Zeyfang, 0. Buck, and A. Seeger, Phys. Status Solidi (b)61, 551 (1974).

11. P. C. J. Gallagher, Philos. Mag. 11, 51 (1967).

12. H. Neuhauser, N. Himstodt, and Ch. Schwink, Phys. Status Solidi 93, 585 (1970).

13. H. Conrad, Acta Metall. 6, 339 (1958).

14. N. Christodoulou and J. J. Jonas, Acta Metall. 32, 1655 (1984).

15. M. Z. Butt and P. Feltham, Metall. Sci. 18, 123 (1984).

16. G. J. den Otter and A. van den Beukel, Phys. Status Solidi (a) 55,785 (1979).

17. G. Regazzoni and F. Montheillet, Institute of Physics Conferer. Jeries No. 70, The Institute of Physics, London (1984), p. 63.

18. A. Melander and A. Thuvander, Res. Mech. $\underline{5}, 129$ (1982).

19. Z. S. Basinski, Philos. Mag. 3, 393 (1959).

20. T. Takai, T. Tatsumi, and T. Tamura, "Strength of Metals and Alloys," Pergamon Press, New York (1985).

21. S. K. Mitra, P. W. Osborne, and J. E. Dorn, Trans. AIME 221,1206 (1961).

22. S. Saimoto, H. Sang, and L. R. Morris, Acta Metall. 29, 215 (1981).

23. S. Saimoto and M. S. Duesberry, Acta Metall. 32, 147 (1984).

24. S. Saimoto and H. Sang, Acta Metall. 31, 1873 (1983).

25. M. J. Bull and S. Saimoto, "Strength of Metals and Alloys," Pergamon Press, New York (1985), p. 893.

26. M. J. Bull and S. Saimoto, "Proc. International Solute - Defect Interaction: Theory and Experiment," March (1986).

27. S. K. Mitra and J. E. Dorn, Trans. AIME 227, 1015 (1963). 
28. C. Perdrix and F. Montheillet, "Strength of Metals and Alloys," Pergamon Press, New York (1985), p. 571.

29. B. A. Parker, "Strength of Metals and Alloys," Pergamon Press, New York $(1985)$, p. 899 .

30. F. P. Bullen and M. M. Hutchinson, Philos. Mag. 7, 557 (1962).

31. D. T. Read and R. L. Tobler, "Advances in Cryogenic Engineering-Materials" vol. 28, Plenum Press, New York (1982), p. 17.

32. R. P. Reed and J. M. Arvidson, "Advances in Cryogenic Engineering-Materials," vol. 30, Plenum Press, New York (1984), p. 105.

33. S. H. van den Brink, A. van den Beukel, and P. G. McCormick, Phys. Status Solidi (a)30, 469 (1975).

34. B. Wielke and G. Schoeck, Phys. Status Solidi (a)38, 539 (1976).

35. B. Wielke, Acta Metall. 26, 103 (1978).

36. F. Fröhlich and P. Gran, Phys. Status Solidi (a)14, 115 (1972).

37. G. Schoeck, Phys. Status Solidi 8, 499 (1965).

38. H. J. Frost and M. F. Ashby, Deformation Mechanism Maps: The Plasticity and Creep of Metals and Ceramics, Pergamon Press, Oxford, England $(1982), p .6$.

39. U. F. Kocks, A. S. Arogn, and M. F. Ashby, Prog. Mater. Sci. 19 (1975).

Table 1. Material Characterization

\begin{tabular}{cccc}
\hline Alloy & $\begin{array}{c}\text { Chemical } \\
\text { Composition } \\
(\text { wt.\% })\end{array}$ & $\begin{array}{c}\text { Hardness } \\
\left(\mathrm{R}_{\mathrm{B}}\right)\end{array}$ & $\begin{array}{c}\text { Grain } \\
\text { Size } \\
(\mu \mathrm{m})\end{array}$ \\
\hline $\mathrm{CDA} 101 \mathrm{Cu}$ & $99.99 \mathrm{Cu}+\mathrm{Ag}$ & 22 & 36 \\
$1100 \mathrm{Al}$ & $99.1 \mathrm{Al}+0.6 \mathrm{Fe}, 0.2 \mathrm{Cu}, 0.1 \mathrm{Si}$ & 36 & 145 \\
\hline
\end{tabular}




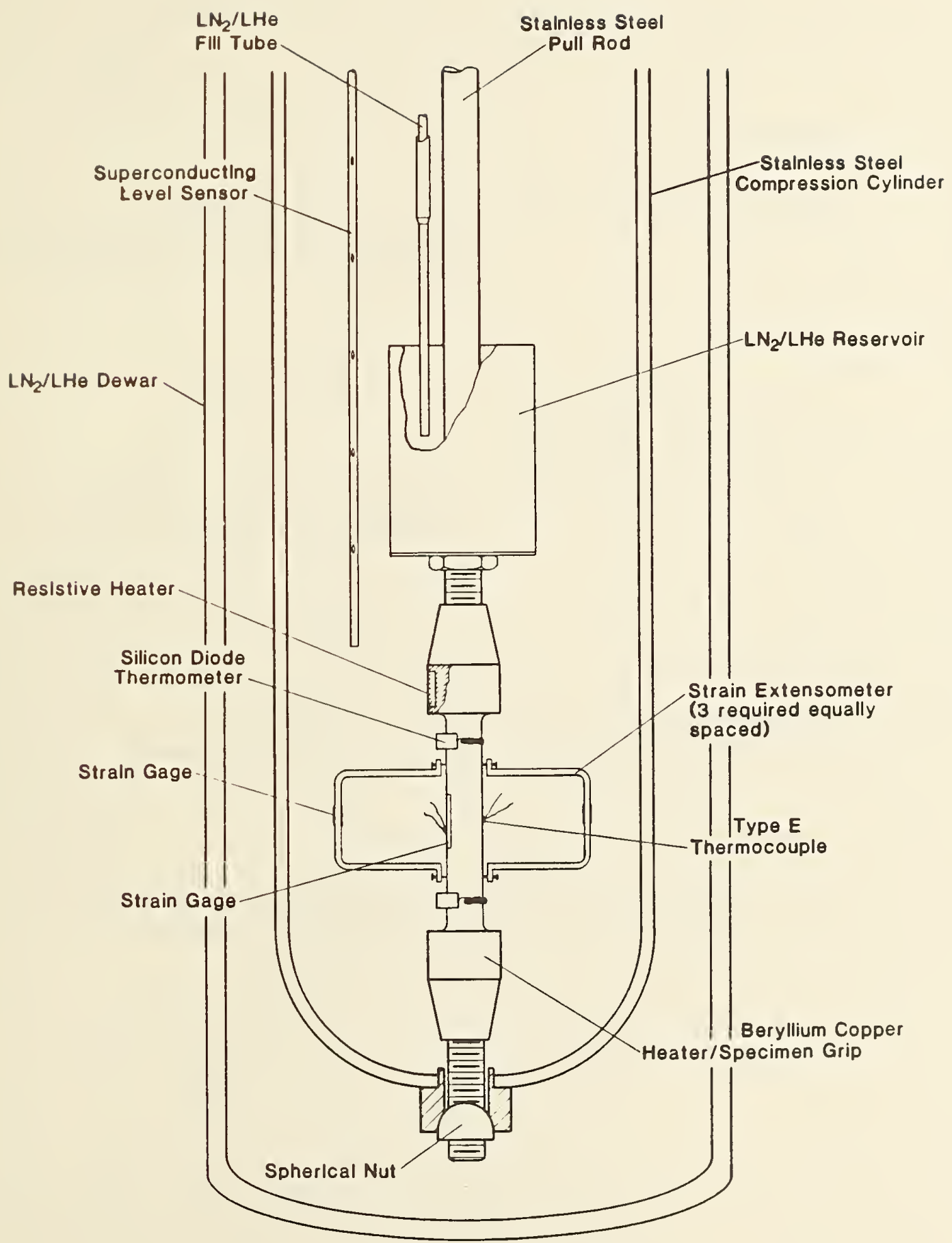

Fig. 1. Cryostat used for conducting strain-rate sensitivity tests at temperatures from 4 to $295 \mathrm{~K}$. 


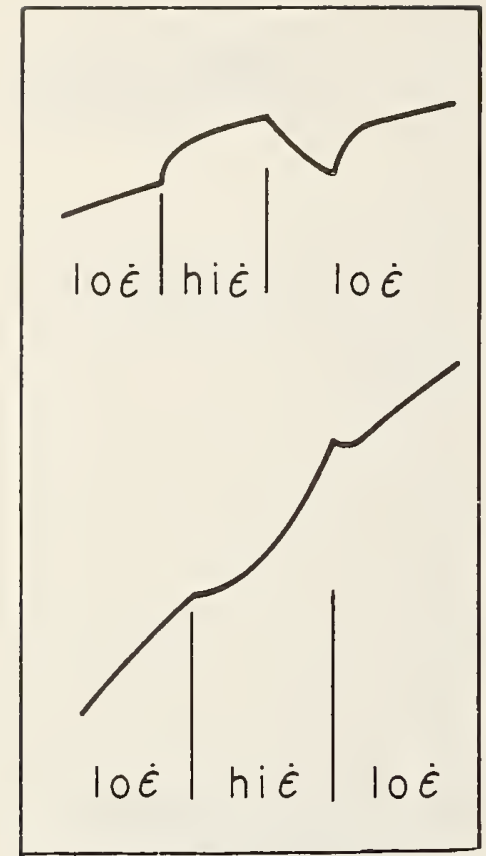

a. Effects of slackening of crosshead following change of strain rate from high to low

b. Effects of low time constant for filtering of load signal

Fig. 2. Measurement variables affecting stress-strain dependence following strain-rate changes. 


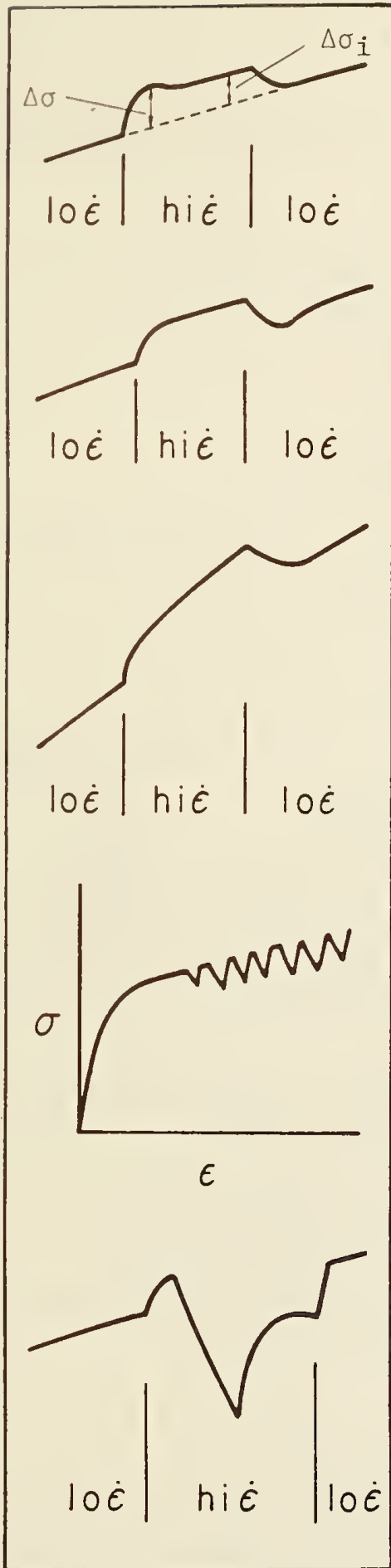

a. Transient at high strain rate

b. Transient at low strain rate

c. Rate of strain hardening dependent on strain rate at low strains in the high strain-rate region

d. Discontinuous yielding (adiabatic heating) at $4 \mathrm{~K}$

e. Incursion of discontinuous yielding on strain rate change at $T \leq \sim 20 \mathrm{~K}$

Fig. 3. Variables affecting stress-strain characteristics following strain-rate changes. 


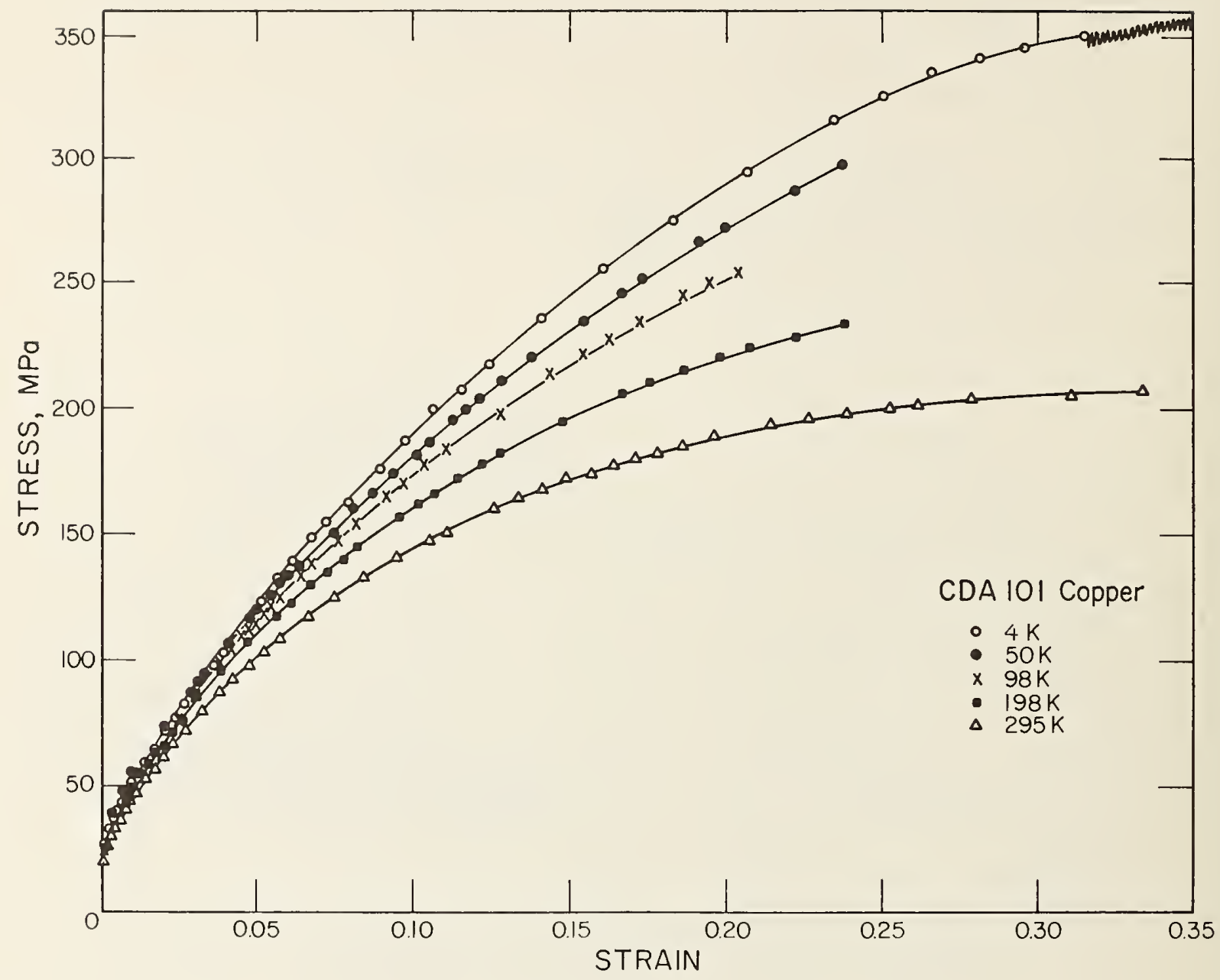

Fig. 4. The tensile stress-strain curves of CDA $101 \mathrm{Cu}$ at various temperatures. 


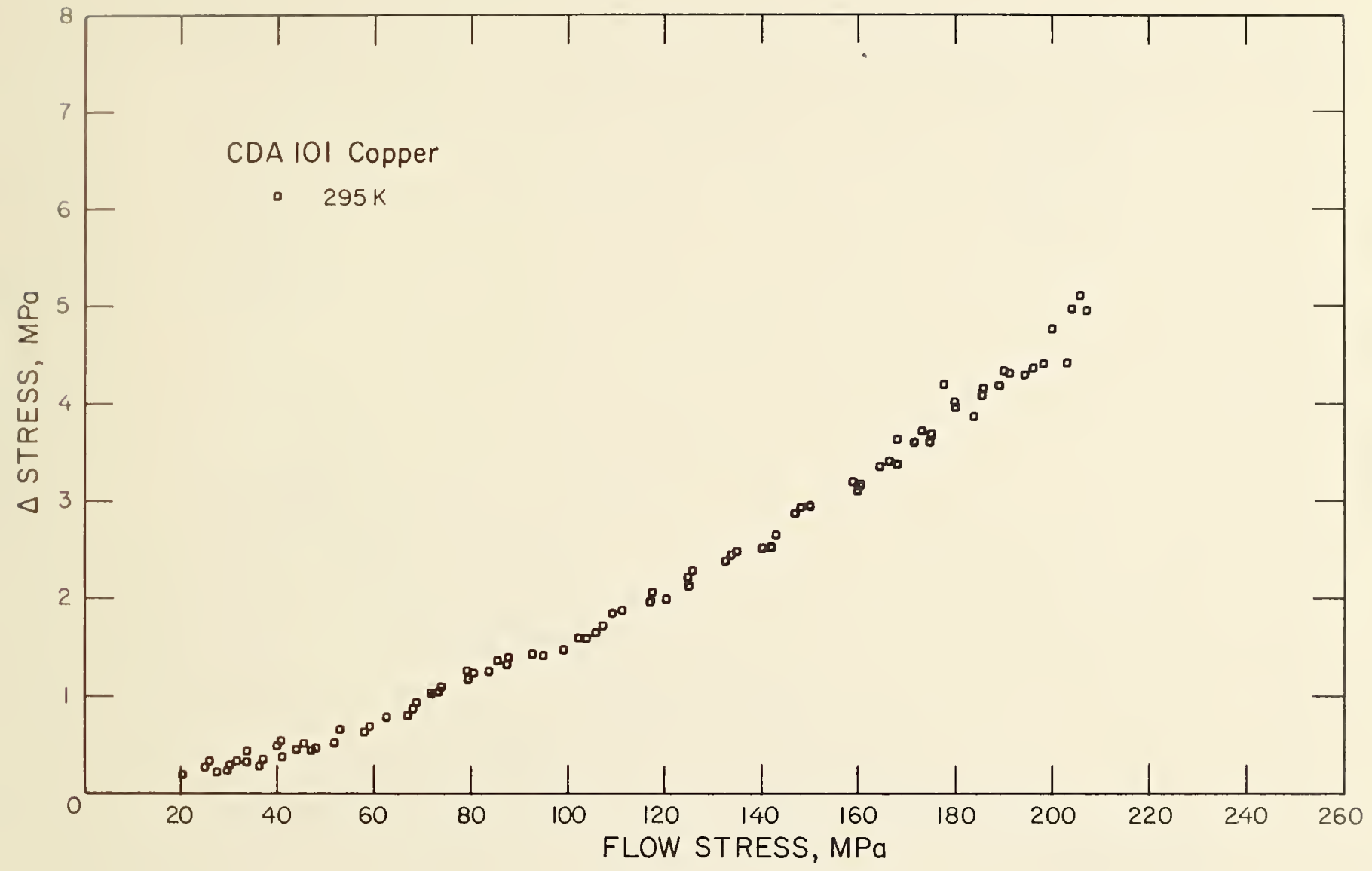

Fig. 5. Stress change of $\mathrm{CDA} 101 \mathrm{Cu}$ due to increasing the strain rate $\left(2 \times 10^{-5}\right.$ to $2 \times 10^{-3} \mathrm{~s}^{-1}$ ) as a function of applied stress at room temperature. Data are from three independent tests. 


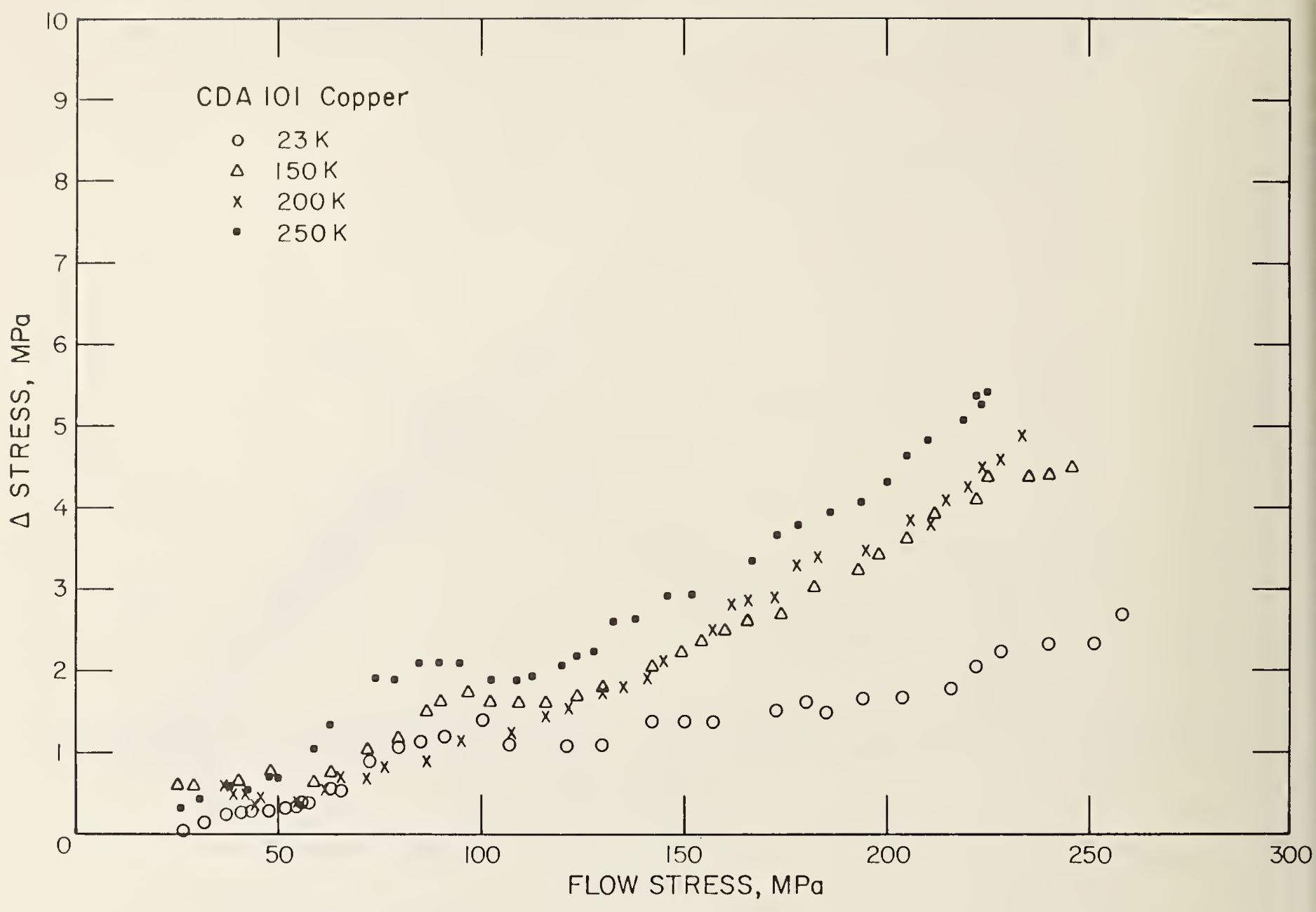

Fig. 6. Stress change of $\mathrm{CDA} 101 \mathrm{Cu}$ due to increasing the strain rate $\left(2 \times 10^{-5}\right.$ to $\left.2 \times 10^{-3} \mathrm{~s}^{-1}\right)$ as a function of applied stress at various test temperatures. 


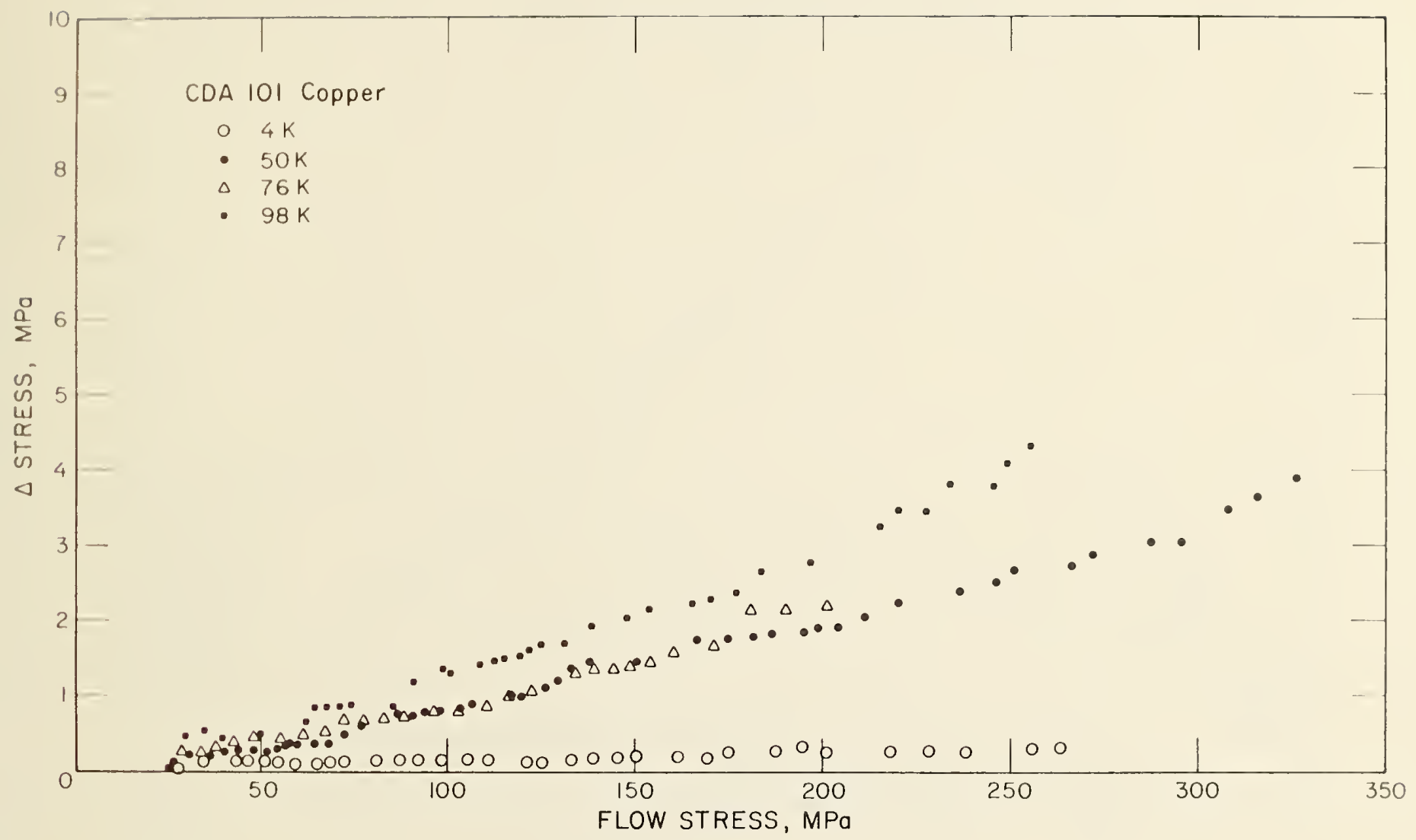

Fig. 7. Stress change of $\mathrm{CDA} 101 \mathrm{Cu}$ due to increasing the strain rate $\left(2 \times 10^{-5}\right.$ to $\left.2 \times 10^{-3} \mathrm{~s}^{-1}\right)$ as a function of applied stress at various test temperatures. 


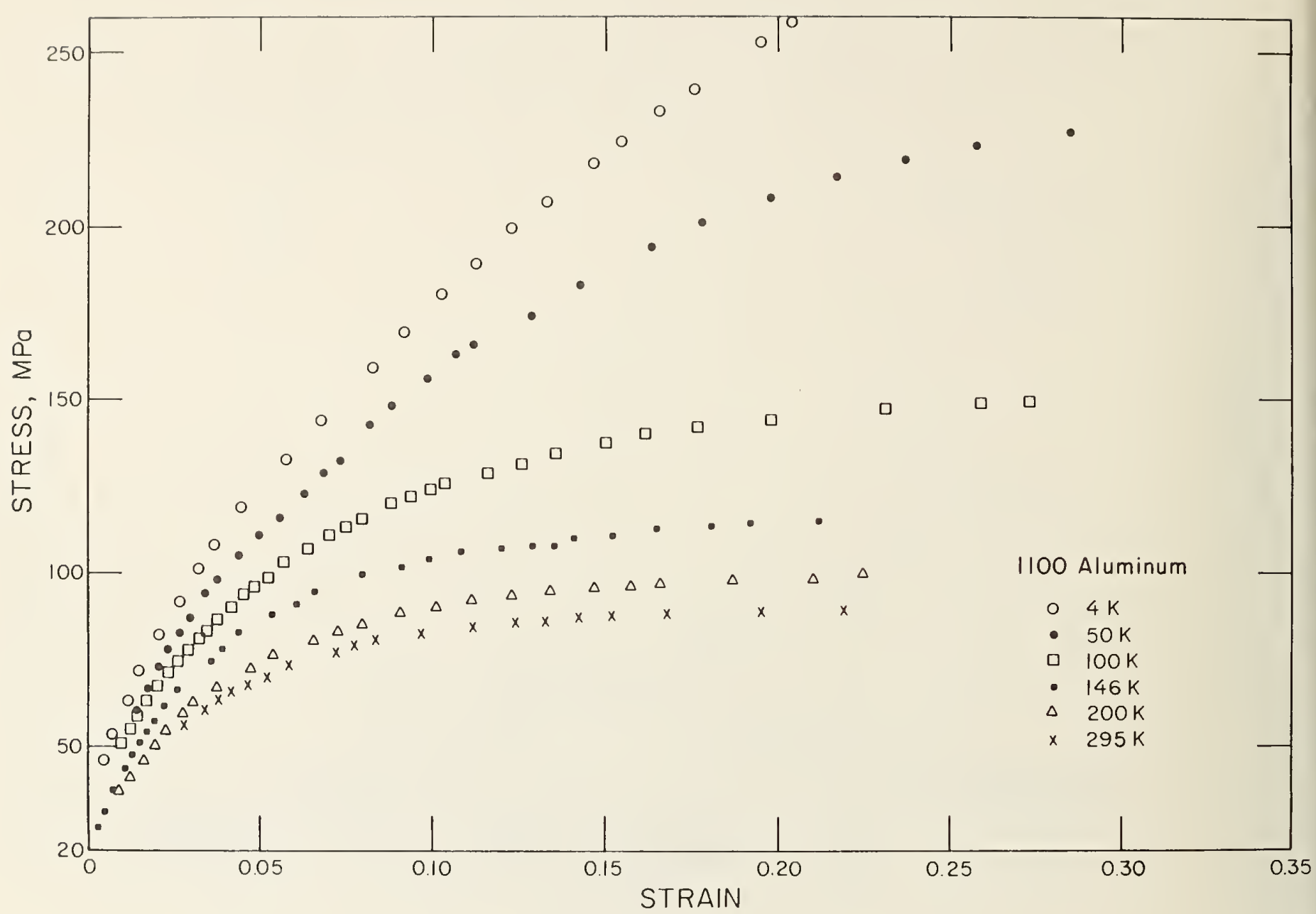

Fig. 8. Tensile stress-strain curves for $1100 \mathrm{Al}$ at various temperatures. 


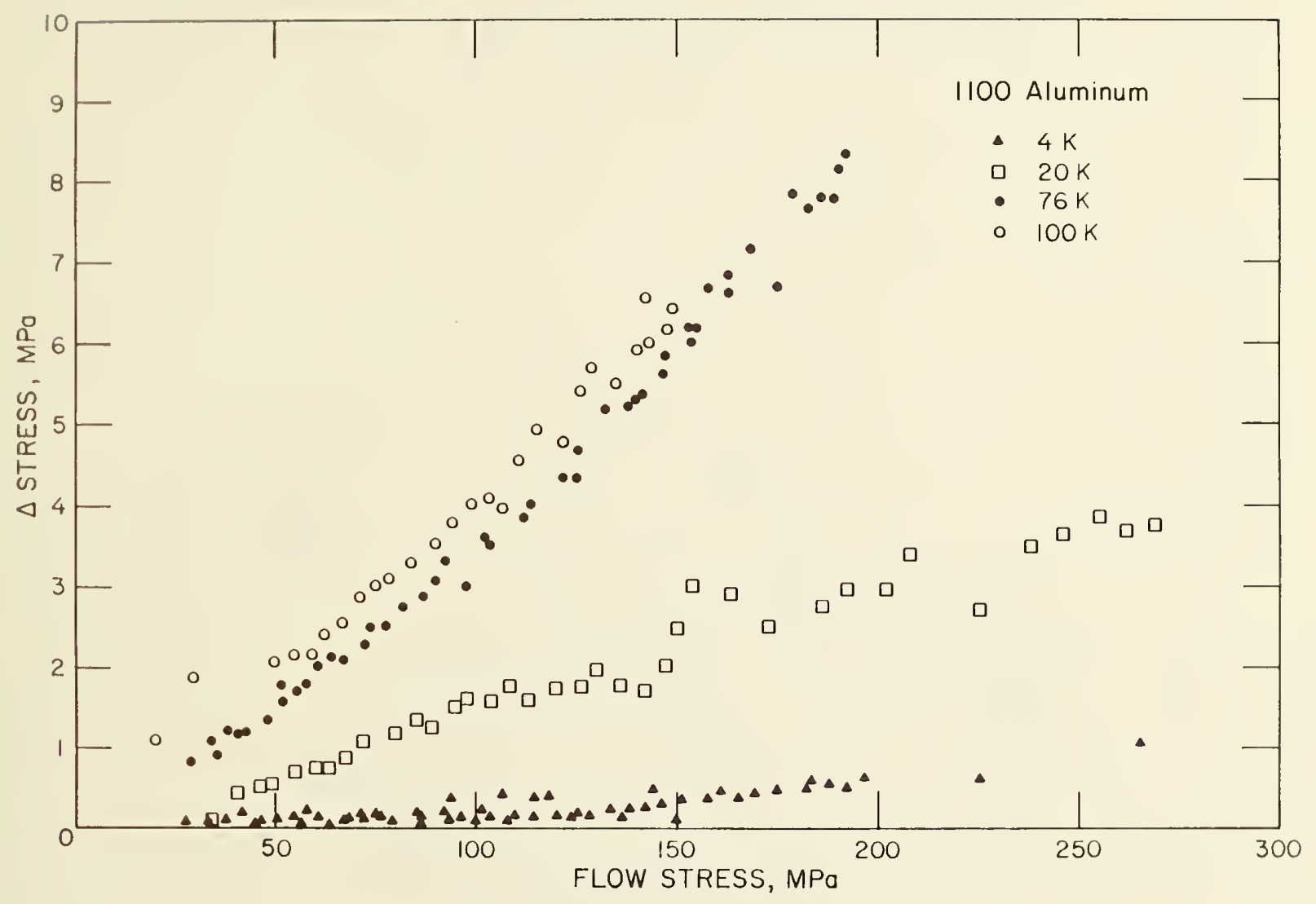

Fig. 9. Stress change of $1100 \mathrm{Al}$ due to increasing the strain rate $\left(2 \times 10^{-5}\right.$ to $\left.2 \times 10^{-3} \mathrm{~s}^{-1}\right)$ as a function of applied stress at various test temperatures. 


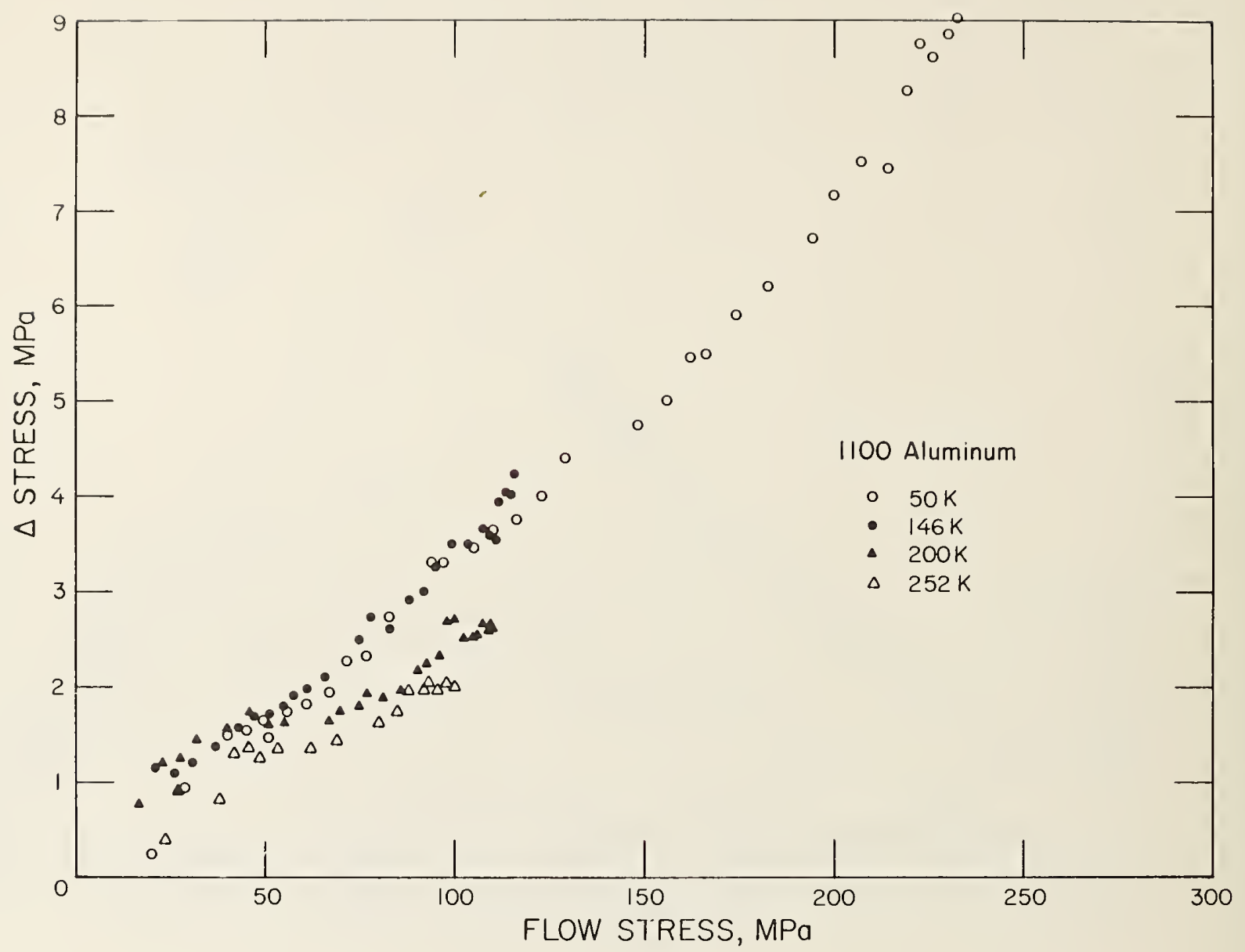

Fig. 10. Stress change of $1100 \mathrm{Al}$ due to increasing the strain rate $\left(2 \times 10^{-5}\right.$ to $\left.2 \times 10^{-3} \mathrm{~s}^{-1}\right)$ as a function of applied stress at various test temperatures. 


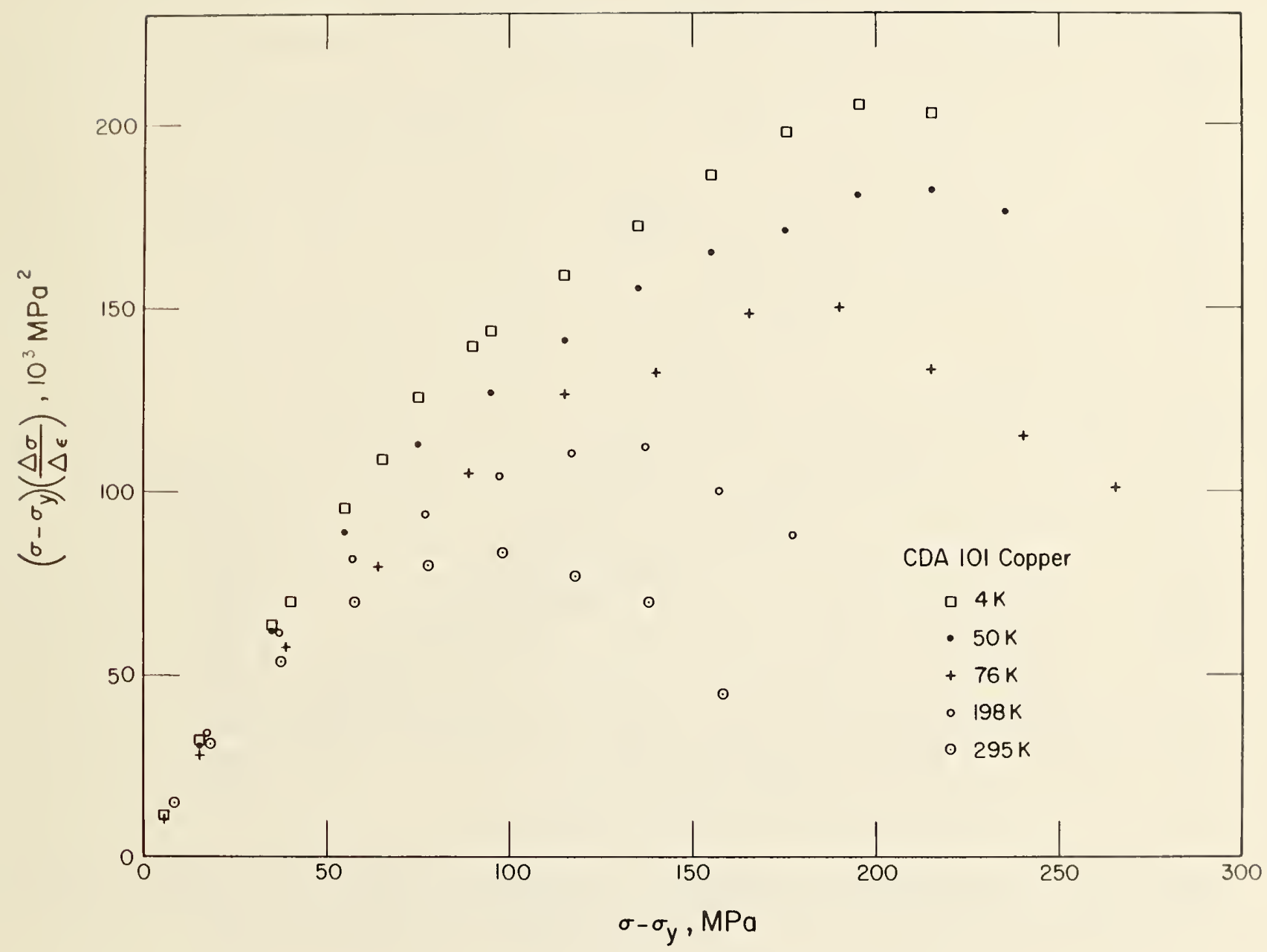

Fig. 11. Strain-hardening characteristics of CDA $101 \mathrm{Cu}$ at various temperatures. 


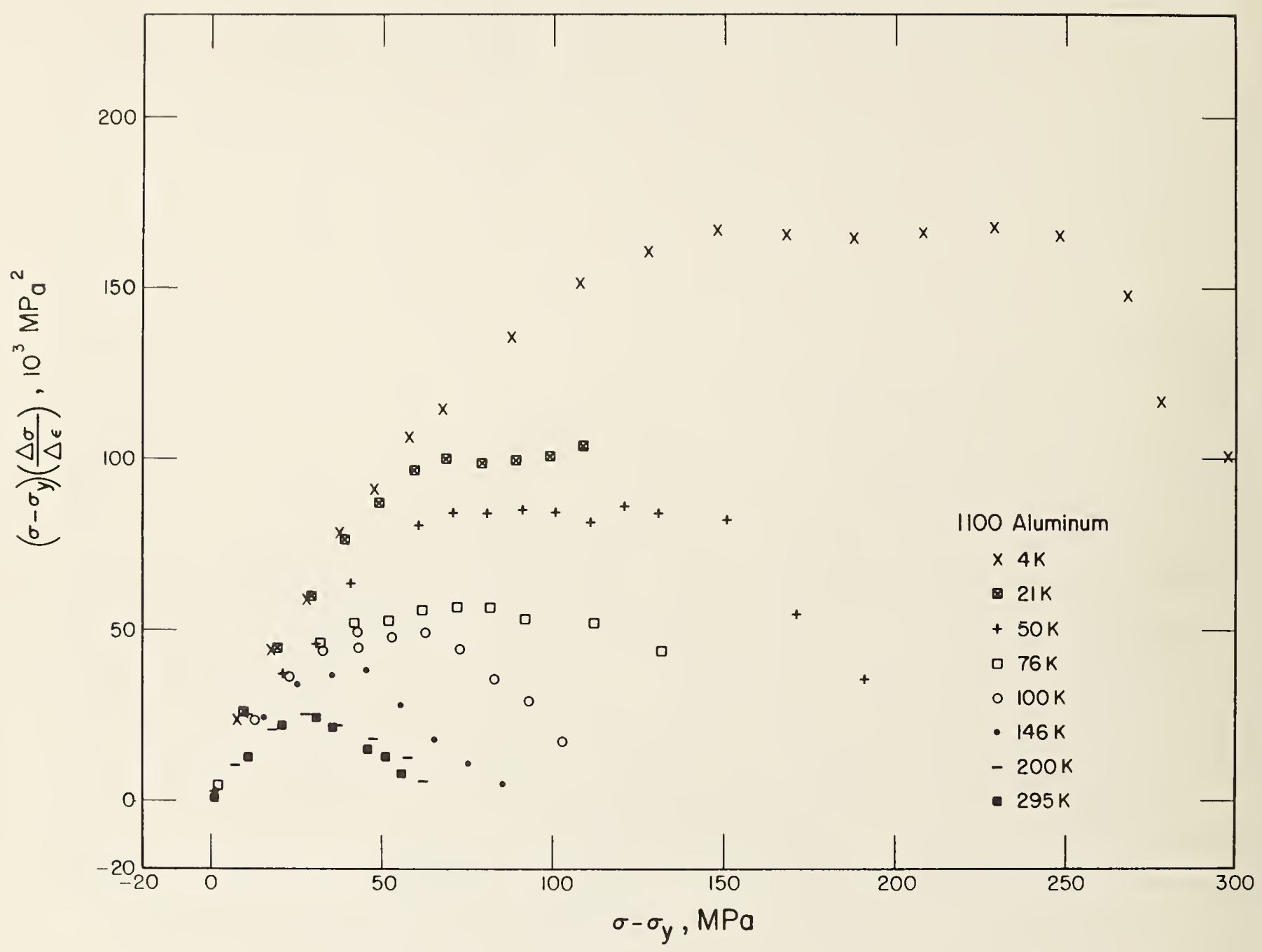

Fig. 12. Strain-hardening characteristics of 1100 Al at various temperatures. 


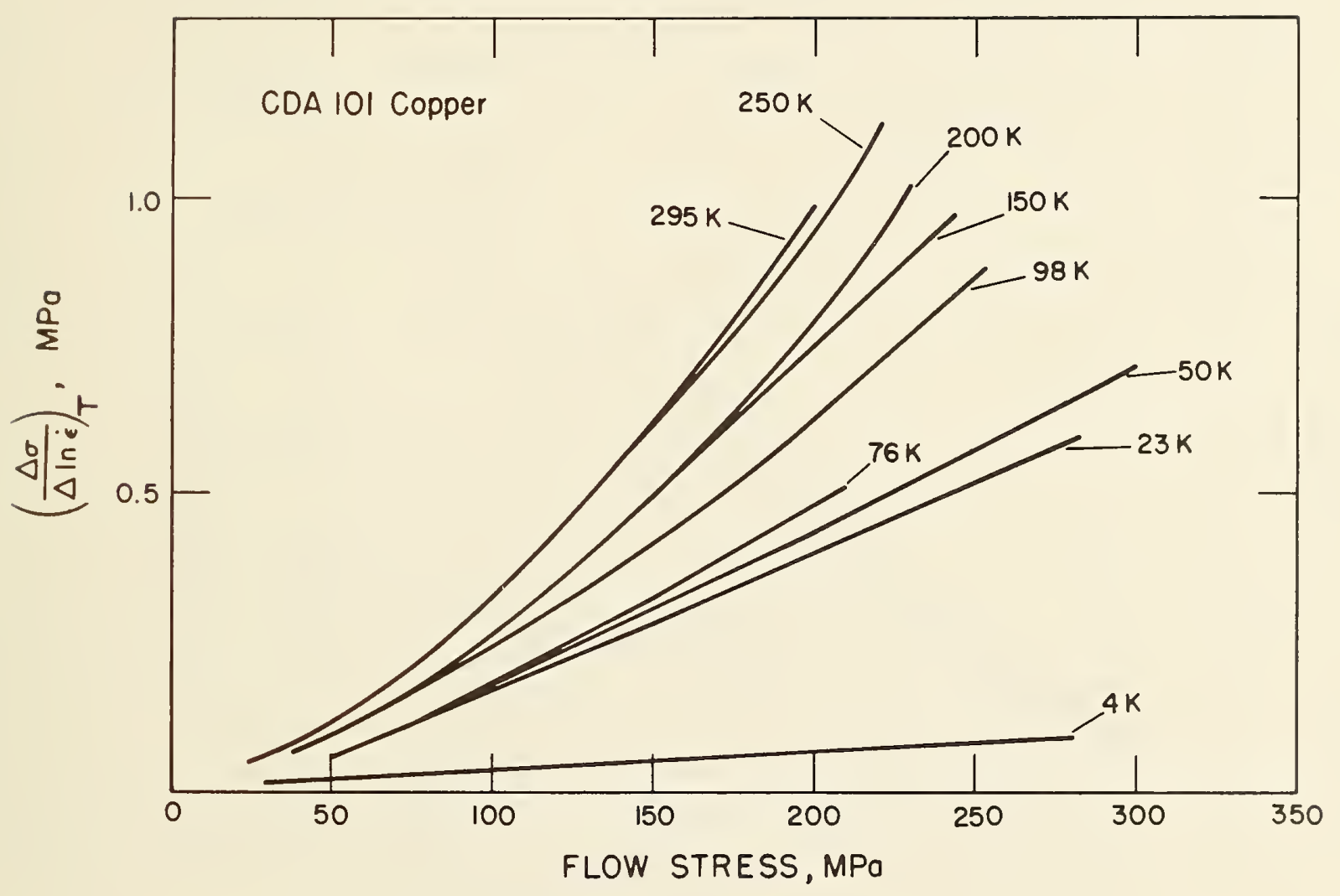

Fig. 13. General characterization for CDA $101 \mathrm{Cu}$ of the effects of strainrate change $\left(2 \times 10^{-5}\right.$ to $\left.2 \times 10^{-3} \mathrm{~s}^{-1}\right)$ on the stress change as a function of applied stress at various test temperatures. 


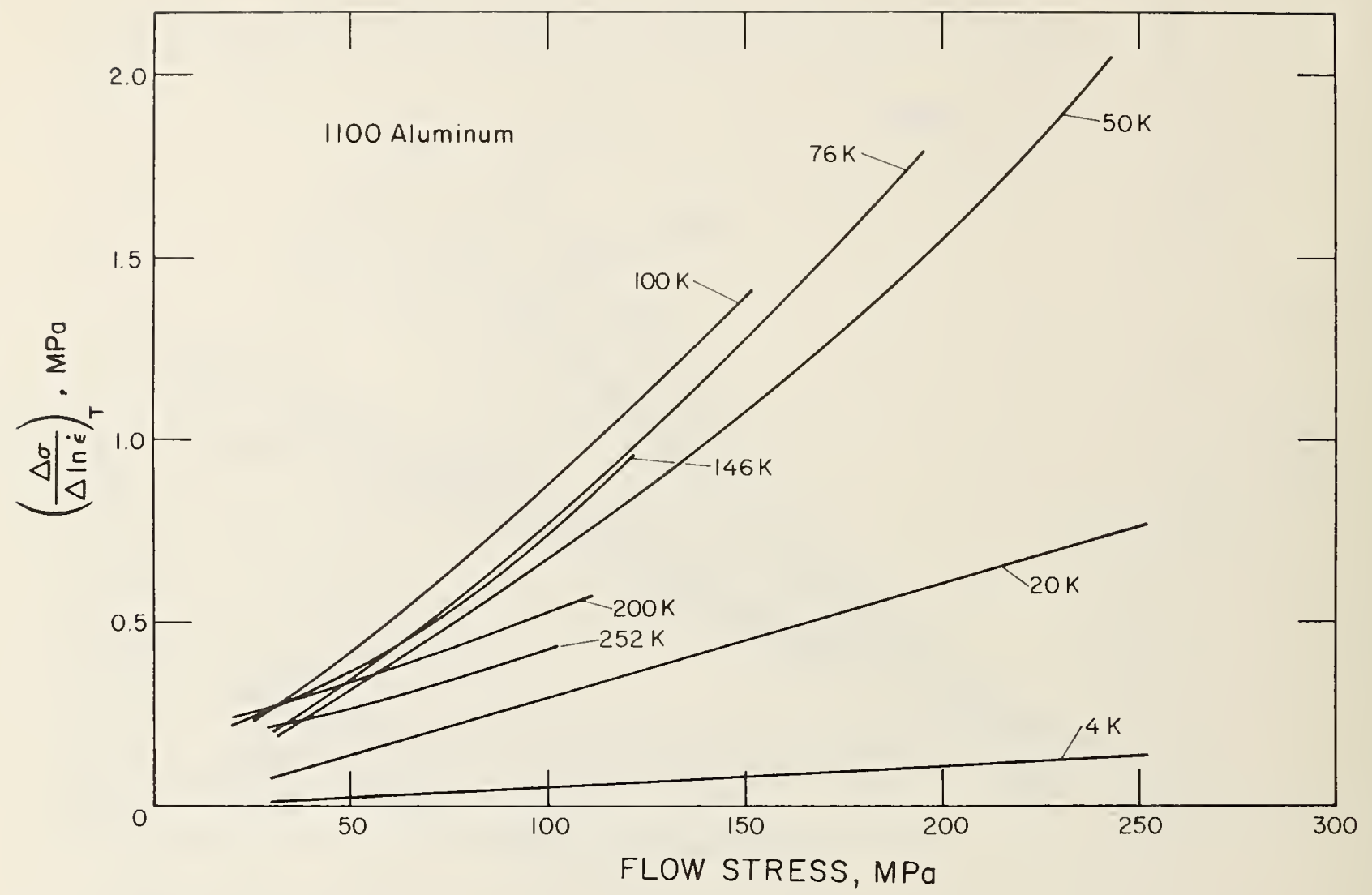

Fig. 14. General characterization for 1100 Al of the effects of strain-rate change $\left(2 \times 10^{-5}\right.$ to $\left.2 \times 10^{-3} \mathrm{~s}^{-1}\right)$ on the stress change as a function of applied stress at various temperatures. 


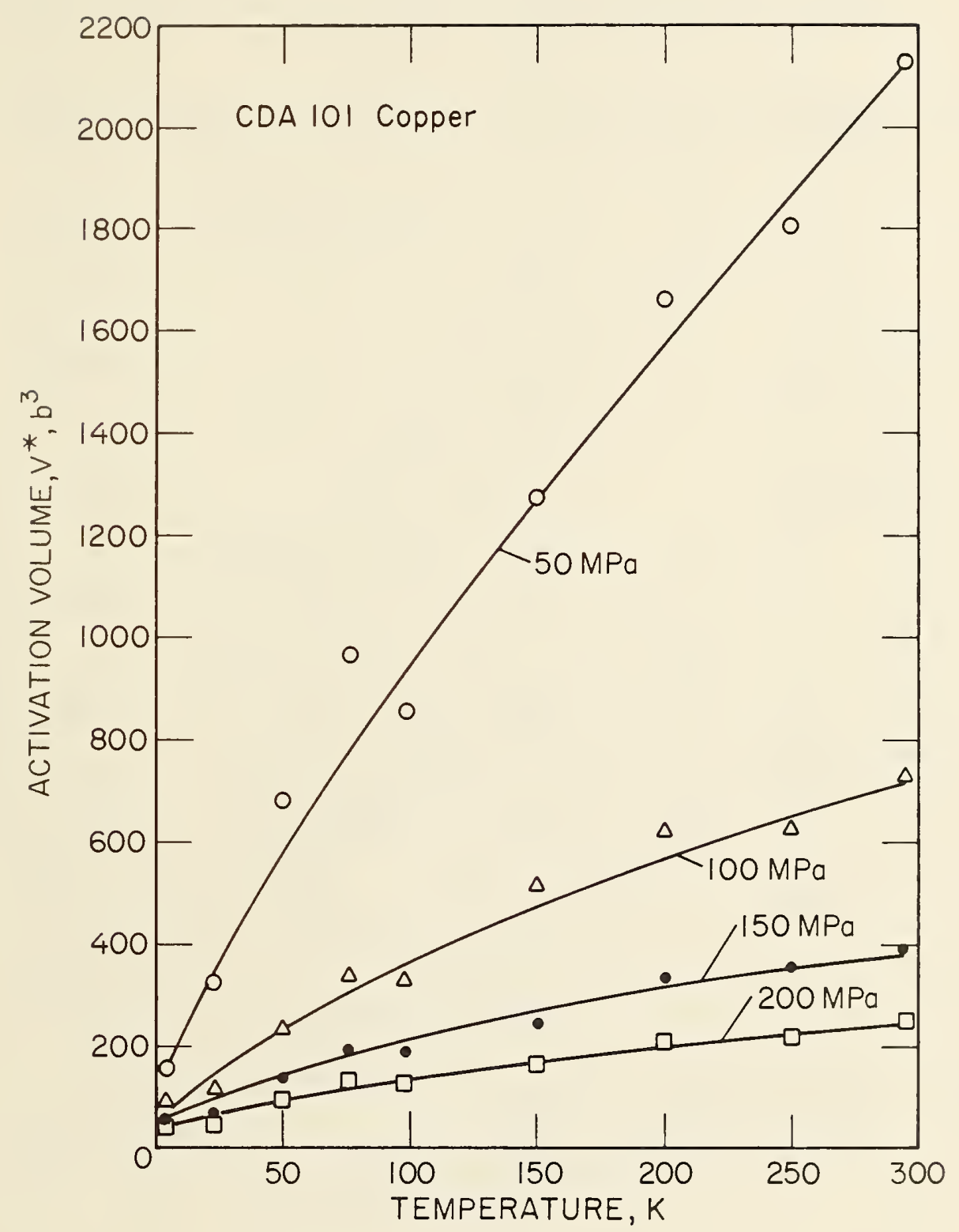

Fig. 15. Apparent activation volume versus temperature at constant stress levels for CDA $101 \mathrm{Cu}$. 


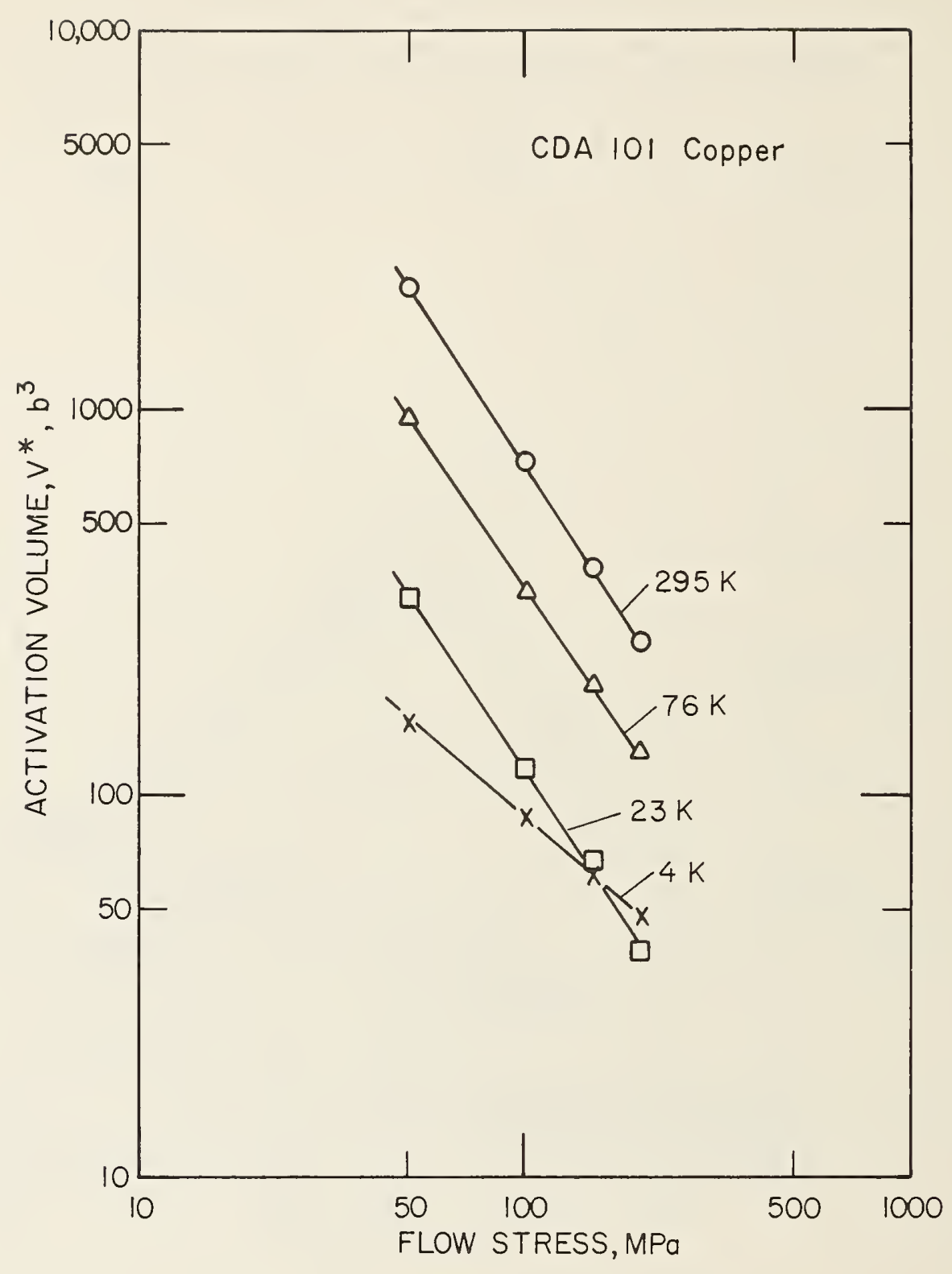

Fig. 16. Apparent activation volume versus stress at constant temperature for CDA $101 \mathrm{Cu}$. 


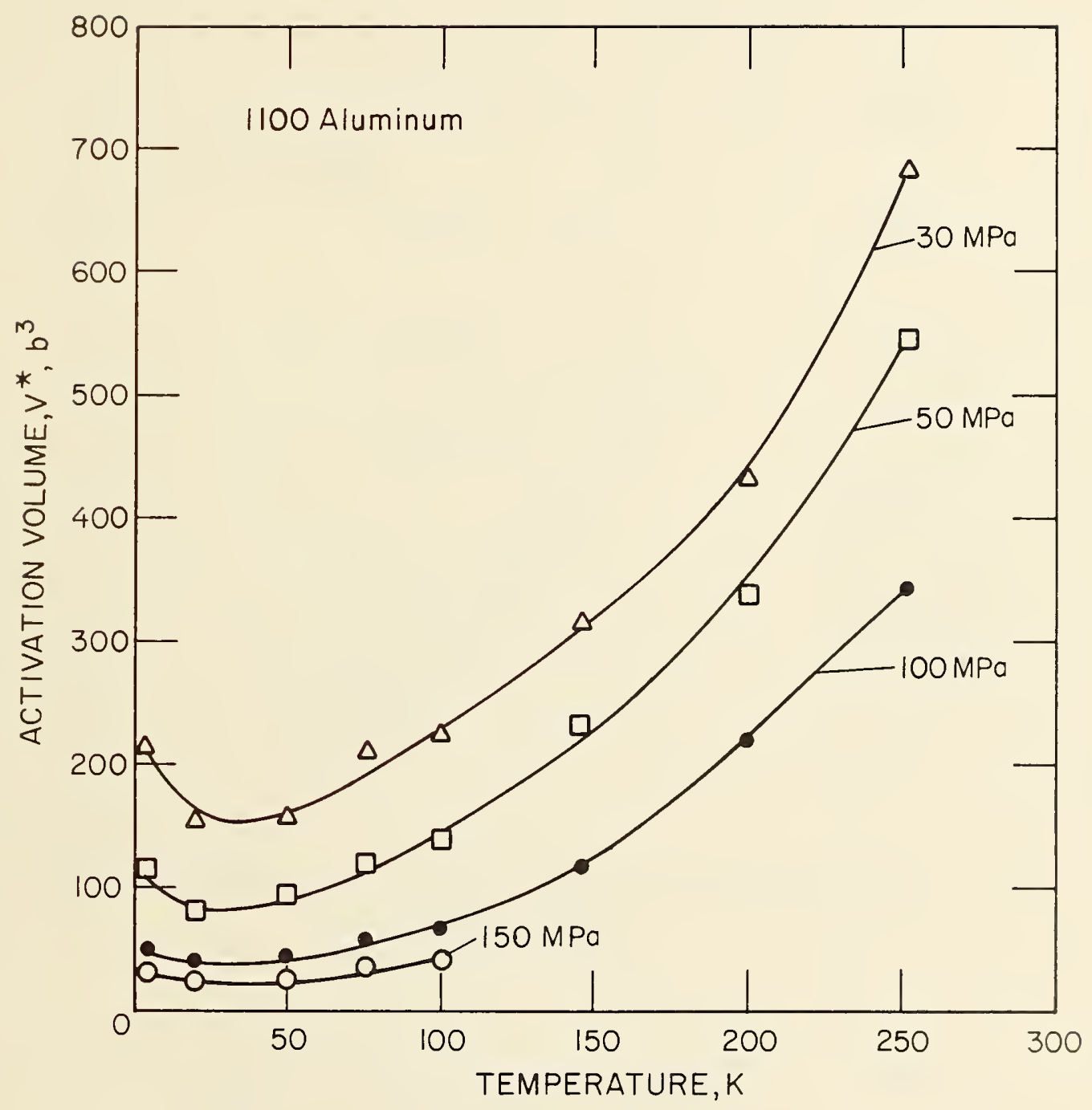

Fig. 17. Apparent activation volume versus temperature at constant stress levels for $1100 \mathrm{Al}$. 


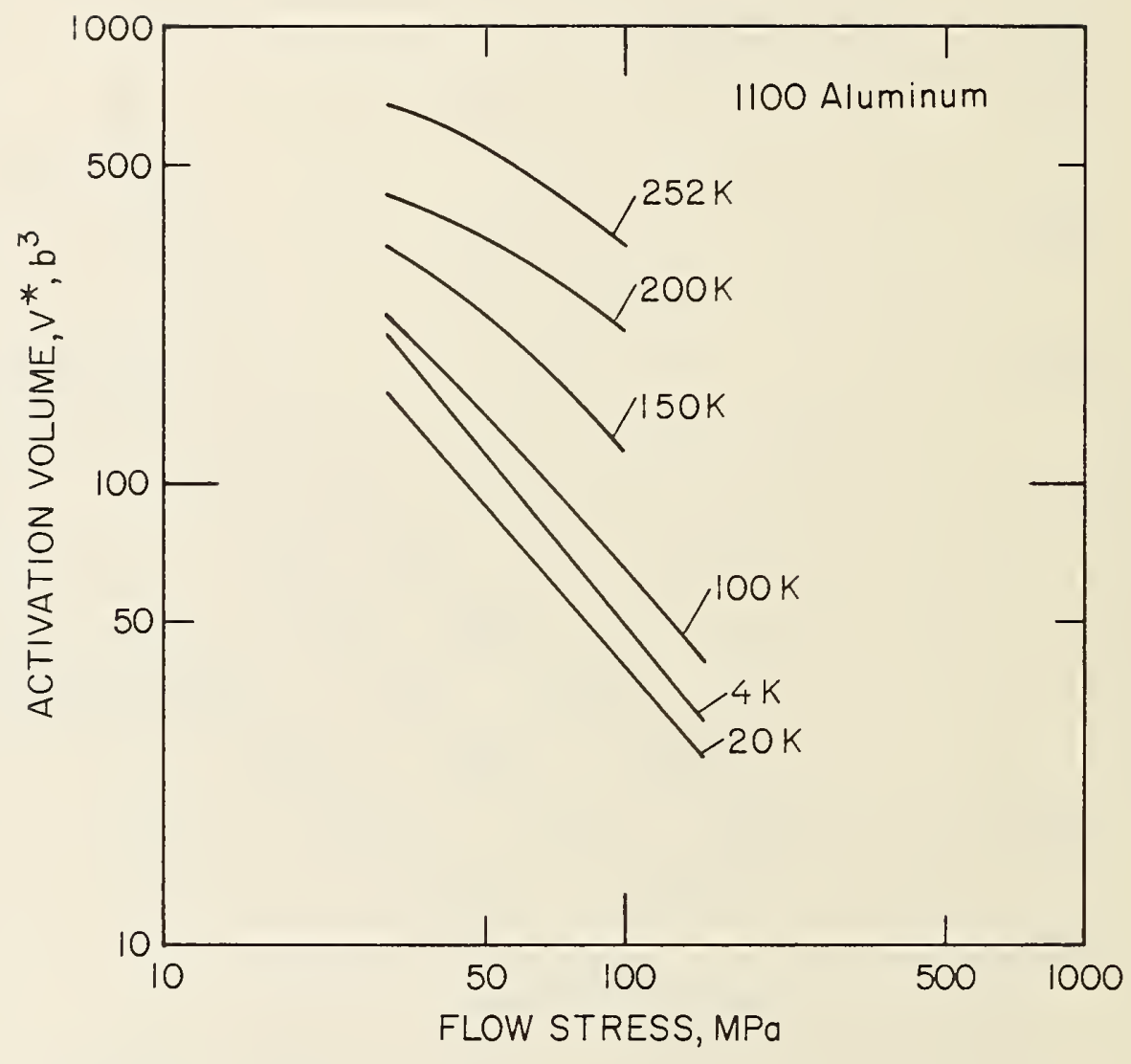

Fig. 18. Apparent activation volume versus stress at constant temperature for $1100 \mathrm{Al}$. 


EFFECT OF PRIOR DEFORMATION ON THE 76-K FRACTURE TOUGHNESS

OF AISI 304L AND AWS 308L STAINLESS STEELS*

P. T. Purtscher and D. T. Read

Fracture and Deformation Division

National Bureau of Standards

Boulder, Colorado

AISI $304 \mathrm{~L}$ and its weld metal, AWS 308L, may undergo a partial transformation to martensite during cryogenic service owing to thermal and mechanical stresses. In this study, the effect of service-induced deformation on the toughness of these materials was determined. Low temperature compressive loading in the laboratory produced larger deformations. Crack initiation toughness, $\mathrm{K}_{\mathrm{IC}}(\mathrm{J})$, and tearing resistance, $\mathrm{dJ} / \mathrm{da}$, at $76 \mathrm{~K}$ were evaluated as a function of martensite content, a measure of the deformation in these steels. The results showed that the toughness properties of the $304 \mathrm{~L}$ decrease gradually as the martensite content increases from the 5 to $8 \%$ level found in the service condition to the 45\% level obtained by compressive loading. The decrease was less than that expected on the basis of the increased flow stress. The toughness properties of the 308L weld metal decreased more sharply with increased martensite content than those of the 304L. The sharp decrease is associated with a degradation of the properties of the delta ferrite rather than that of the austenite.

Key words: austenitic stainless steel, cold work, cryogenic properties of materials, delta ferrite, fracture toughness, martensite

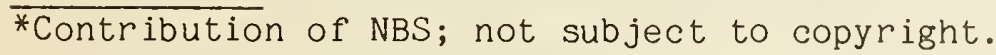




\section{INTRODUCTION}

Austenitic stainless steels are commonly used for cryogenic structural components because they have excellent low temperature properties, specifically, high elastic modulus, high toughness and ductility, and good weldability. Alloy AISI 304L, which contains nominally 18 wt.\% $\mathrm{Cr}, 8$ wt.\% Ni, and less than $0.04 \mathrm{wt} . \% \mathrm{C}$, is commonly used with the filler material AWS 308L, which contains approximately $2 \%$ more chromium and nickel.

Under cryogenic operating conditions, these structural alloys may partially transform to martensite owing to a combination of thermal effects and plastic deformation resulting from thermal or mechanical stresses. Two types of martensite form in these steels: $\varepsilon$, a nonmagnetic phase, and $\alpha^{\prime}$, a magnetic phase. Magnetic measurements provide an easy way to monitor the $\alpha^{\prime}$ martensite content in these steels. Ogawa and Morris ${ }^{1}$ showed that prior deformation improved the relationship between strength and toughness for a $\mathrm{Fe}-\mathrm{Mn}-\mathrm{Cr}$ austenitic alloy at $4 \mathrm{~K}$, but only $\varepsilon$ martensite forms in this alloy. The $\alpha^{\prime}$ martensite may degrade the toughness of the alloy significantly because it has the same bcc crystal structure as delta ferrite, which promotes brittle fracture in austenitic stainless steel castings. ${ }^{2}$ whenever martensite is mentioned in the rest of the text, it refers to the $\alpha^{\prime}$ phase.

Austenite-to-martensite transformation occurs when steels are cooled below their martensite start temperature or when they are plastically deformed below their martensite deformation start temperature. When straininduced martensite forms in areas of plastically deformed austenite, the toughness of the material remains relatively high. The effect of martensite in the microstructure prior to testing has not been studied systematically. A thorough discussion of martensitic transformation in austenitic steels was presented by Reed. 3

In this study, we evaluated the toughness of $304 \mathrm{~L}$ and $308 \mathrm{~L}$ steel obtained from a component that had been in cryogenic service. We also studied the effect of larger deformations. We used a simple fracture mechanics model to illustrate the effect of increased deformation and the resulting increase of the martensite content on the critical crack size required for the initiation of crack growth.

\section{MATERIALS}

Specimens of AISI 304L were removed from a large, forged flange that was part of a liquid natural gas facility, where it experienced temperatures as low as $111 \mathrm{~K}$. Test pieces, $115 \mathrm{~mm}$ long and $25 \mathrm{~mm}$ square, were machined so that the long direction would be parallel to the forging flow lines (similar to an L-T orientation).

Weld metal specimens of AISI 308L were removed from a pipe that joined the large, forged flange. The specimens, $16 \mathrm{~mm}$ square and $115 \mathrm{~mm}$ long, were machined from the pipe-to-flange connection so that the weld metal was in the center of the bar. 
Round tensile specimens of $304 \mathrm{~L}$ and 308L were machined to a 50-mm gauge length and 6-mm diameter. In the flange, the tensile bars were oriented along the forging flow lines. In the weld, the tensile bar was machined transverse to the length of the pipe so that the tensile bar was completely weld metal.

A commercially supplied, spiral spring-balanced, magnetic measuring instrument was used to determine the magnetic susceptibility of the materials. The instrument was calibrated according to AWS A4.2-74 standard procedure. ${ }^{4}$ The $304 \mathrm{~L}$ specimens in the as-received, service condition had a magnetization that corresponded to a ferrite number (FN) of 6 to 9 . The 308L weld metal specimens had a magnetization of approximately $8 \mathrm{FN}$.

\section{MAGNETIC SUSCEPTIBILITY RESULTS}

Initial attempts to induce additional deformation by thermally cycling the as-received $304 \mathrm{~L}$ and 308L material proved fruitless. A small piece of each material was cooled from room temperature to $76 \mathrm{~K}$ and then back again five times without any increase in magnetization. This short experiment proved that the materials in the service condition were thermally stable with respect to the martensitic transformation.

In the next step, the pieces were heat-treated at $1060^{\circ} \mathrm{C}$ for half an hour in an argon atmosphere and water quenched. Then the annealed pieces were thermally cycled from room temperature to $76 \mathrm{~K}$ eight times. This procedure produced 3 to $4 \%$ martensite in the $304 \mathrm{~L}$ and $0.5 \%$ martensite in the 308L before the magnetization appeared to saturate. The values were less than the magnetization of the as-received materials. Additional thermal cycling from room temperature to $4 \mathrm{~K}$ did not produce any further change in the martensite content. This experiment indicated that the two annealed materials were not completely stable with respect to the martensitic transformation and that the martensite found in the service condition was not due solely to thermal effects.

\section{THERMOMECHANICAL TREATMENTS}

Selected specimens of the 304L and 308L material were heat-treated in an argon atmosphere at $1060^{\circ} \mathrm{C}$ for $30 \mathrm{~min}$. and then water quenched. This annea ling treatment did not change the grain size appreciably, which was approximately $100 \mu \mathrm{m}$ in the $304 \mathrm{~L}$, but it did remove all the martensite that formed during the time in service at $111 \mathrm{~K}$. After heat treatment, the $304 \mathrm{~L}$ had a FN of 1 , and the 308L weld metal had a FN of 4 . The residual magnetic susceptibility in the steels after heat treatment was due to the presence of delta ferrite.

Several specimens of the $304 \mathrm{~L}$ and one 308L specimen were subjected to compression loading to increase the cold work in the microstructure. The specimen to be compressed and two larger pieces of steel were cooled to liquid nitrogen temperature by immersion. Then the three pieces were removed from the liquid nitrogen; the specimen was placed between the two larger 
pieces of steel to insulate it from the surroundings. A servohydraulic test machine with a 1-MN load capacity applied the compressive load through the buffer plates. Different loads were used to produce different levels of strain-induced martensite.

\section{TOUGHESS TESTING PROCEDURE}

Selected specimens were heat-treated, loaded in compression, and then notched to produce bend specimens. The fatigue precracking and subsequent testing were performed in a three-point bend fixture with a span that was four times the width of the specimen. The specimens were maintained in a liquid nitrogen bath, $76 \mathrm{~K}$, during all the mechanical testing. A servohydraulic test machine with a load capacity of $100 \mathrm{kN}$ was used.

During the toughness tests, two clip gauges for cryogenic service were employed, one to monitor the mouth-opening displacement of the bend specimen and a second to measure the load-line displacement of the specimen with respect to a comparison bar. From the output of the mouth-opening displacement and the load, the initial crack length and subsequent crack growth were calculated during the test by the unloading compliance technique. ${ }^{5,6}$ From the load and load-line displacement information, values of the $\mathrm{J}$-integral were calculated according to ASTM E 813-81 test procedure. ${ }^{7}$ A computeraided test analysis technique was used, similar to that used for compact tension specimens; ${ }^{8}$ both techniques were developed at NBS-Boulder to simplify and standardize the test procedure.

The results of each test were summarized by a plot of the J-integral vs. the change in crack length during the test ( $J-R$ curve). The crack lengths were corrected after the test by measuring the fatigue precrack and the final crack length and using linear interpolation to scale each intermediate crack length. The J-integral values were recalculated for each unloading point using Ernst and Paris's formula ${ }^{9}$ and the corrected crack lengths.

The $J_{\text {Ic }}$ fracture toughness value for each specimen was determined by the intersection of the calculated blunting line* with the measured data points, as specified by ASTM E 813-81. The value of $J_{\text {Ic }}$ refers to the energy required to initiate tearing. In addition, a value of $\mathrm{dJ} / \mathrm{da}$, the tearing slope over the first $1.5 \mathrm{~mm}$ of tearing, was calculated for each specimen. This value refers to the resistance of the steel to crack growth as a function of martensite content.

The correction technique described above produces reliable $\mathrm{J}-\mathrm{R}$ curves as long as the actual final crack length agrees reasonably well with the final crack length measured by the compliance technique and the correction factor is close to 1.0. If the correction factor is greater than 2, past experience indicates that the $\mathrm{dJ} / \mathrm{da}$ values are not a reliable description of the crack growth. The value of $\mathrm{J}_{\mathrm{Ic}}$ measured in the test is unaffected by this correction factor.

*The blunting line is defined as $J=2 \sigma_{\mathrm{flow}} \Delta \mathrm{a}$, where $\sigma_{\mathrm{flow}}$ is the average of the yield and ultimate strength; a value of $690 \mathrm{MPa}$ was used for these tests. 
Estimates of the plane strain fracture toughness parameter, $\mathrm{K}_{\text {Ic }}$, were obtained from the relationship:

$$
K_{I C}(J)=\left[J_{I C} E\right]^{1 / 2}
$$

where $E$ is Young's modulus, The value of $E$ for stainless steels at $76 \mathrm{~K}$ was estimated to be $206.8 \mathrm{GPa}{ }^{10}$

MECHANICAL TESTING RESULTS

The results of the tensile testing show that both $304 \mathrm{~L}$ and $308 \mathrm{~L}$ have relatively low initial flow strengths, low work-hardening rates, and good ductility. Table 1 contains a summary of the tensile properties. Magnetic susceptibility readings were taken from the deformed gauge length after testing. During the test, the $304 \mathrm{~L}$ transformed to approximately $83 \%$ martensite, and the weld metal, to about $69 \%$ martensite.

Figure 1 shows representative load vs. mouth-opening displacement curves from the toughness tests for both $304 \mathrm{~L}$ and $308 \mathrm{~L}$. In all the tests, J Ic was found at a point on the curve near the maximum load. An approximation of $J_{I_{c}}$ can be obtained by estimating the area under the curve up to the maximum load. An indication of the relative value of $\mathrm{dJ} / \mathrm{da}$ can be obtained by observing the behavior of the curves after the maximum load is reached. If the load drops off very slowly, dJ/da will be high, corresponding to a high resistance to tearing. If the load decreases rapidly, dJ/da will be low, corresponding to a lower resistance to tearing. The load-displacement curves in Figure 1 indicate that the toughness was reduced by additional deformation, shown by the presence of more martensite in the microstructure. The effect is particularly noticeable for the 308L weld metal.

Values of $\mathrm{K}_{\mathrm{Ic}}(\mathrm{J})$ and $\mathrm{dJ} / \mathrm{da}$ were calculated for each of the specimens and are listed in $\mathrm{Table} 2$ along with the average level of martensite present before testing. The values of $\mathrm{K}_{\mathrm{IC}}(\mathrm{J})$ are displayed graphically in Figures 2 and 3 .

No $304 \mathrm{~L}$ annealed specimen was tested because of the scarcity of material. The difference between 304 and $304 \mathrm{~L}$ is anticipated to be relatively small, with $304 \mathrm{~L}$ having a slightly higher $\mathrm{K}_{\mathrm{Ic}}(J)$. A previously reported data point (•) for AISI 30425 -mm-thick plate material in the annealed condition ${ }^{11}$ is shown in Figure 2 for comparison. In addition, two unpublished values $(\Delta)$ of $\mathrm{K}_{\mathrm{Ic}}$ obtained from a 6-mm-thick sheet of AISI 304 with larger deformations, higher martensite contents, ${ }^{12}$ are also shown to define the trend line more clearly.

The toughness of the 308L specimen in the service condition was significantly lower (34\%) than the toughness of the annealed specimen, as shown in Figure 3. A similar decrease can be seen for the toughness of the $304 \mathrm{~L}$ specimen in the service condition compared with that reported for 304 in the annealed condition.

The effects of larger deformations can be evaluated from the results for the specimens in the service-and-deformed condition. In the base metal, 
$304 \mathrm{~L}, \mathrm{~K}_{\mathrm{IC}}(J)$ drops off rather slowly and the tearing slope does not change significantly (Figure 2). In the 308L weld metal, $\mathrm{K}_{\mathrm{IC}}(\mathrm{J})$ decreases significantly as the martensite content increases (Figure 3).

The J-test fracture surfaces of the specimens were studied with a scanning electron microscope (SEM). No significant differences between the service condition and service-and-deformed specimens of $304 \mathrm{~L}$ were apparent; all exhibited dimpled rupture features. Figure 4 shows representative photomicrographs of the surface of the specimen with $45 \%$ martensite.

The fracture surfaces of all three weld metal specimens were different. The fracture surface of the annealed specimen was composed of extremely fine dimples with only an occasional flat area (see Figure 5). Energy dispersive $X$-ray analysis (EDAX) showed that the flat areas had a higher chromium content and lower nickel content than the dimpled area, indicating that the flat areas are regions of delta ferrite in the austenitic matrix.

The surface of the service condition specimen is shown in Figure 6 . A higher percentage of the fracture area is composed of the flat areas as compared to the fracture surface of the annealed specimen. The fracture surface of the service-and-deformed specimen (Figure 7), is almost completely devoid of the dimpled rupture features.

\section{DISCUSSION}

The test results indicate that prior cold work, as shown by the increase in the martensite content from 0 to $45 \%$, can affect crack initiation toughness, $\mathrm{K}_{\mathrm{Ic}}(\mathrm{J})$, and tearing resistance, $\mathrm{dJ} / \mathrm{da}$, of $304 \mathrm{~L}$ and $308 \mathrm{~L}$ specimens. The effect of prior cold work was more pronounced in the $308 \mathrm{~L}$ weld metal that contained $4 \%$ delta ferrite.

In evaluating these test results, the effect of yield strength must be taken into account. The deformation at $76 \mathrm{~K}$ increases the yield streng th by two different mechanisms: martensitic transformation and strain hardening. An austenitic stainless steel, such as AISI 310, that is more stable with respect to the martensite transformation than $304 \mathrm{~L}$, would suffer a loss of toughness after deformation at $76 \mathrm{~K}$ without the formation of any martensite. The loss of toughness in this case is associated with the increase in yield strength by strain hardening.

In this set of tests, the combined effect of the martensitic transformation and strain hardening was measured. Because some specimens were deformed in compression first and then tested in tension, an accurate estimate of the tensile yield strength was not possible and the two effects could not be separated. For the purposes of this study, analyzing the effect of prior deformation on the toughness of $304 \mathrm{~L}$ and 308L, it is appropriate to consider the combined effects for engineering applications because plastic deformation always transforms some austenite to martensite. However, these results and conclusions are valid only for metastable alloys like 304L and 308L and should not be applied to other alloys without review. 
It is possible to estimate the flow stress for each specimen from the loads used in compressing the specimens in the laboratory. From these estimated values, a decrease in $\mathrm{K}_{\mathrm{Ic}}(\mathrm{J})$ that would be predicted for annealed austenitic steels at $4 \mathrm{~K}$ can be calculated. ${ }^{8}$ Table 3 summarizes the results of our estimated flow stresses and the effect that the change in flow strength has on the toughness. The flow stresses in tension would be less than the estimated values shown, but the estimates represent a reasonable measure of the relative increase in flow stress with increased cold work and the effect of increased strength on $\mathrm{K}_{\mathrm{Ic}}(\mathrm{J})$. The predicted loss in toughness for the base metal is more than the measured change in toughness. With increases in strength, the toughness of the base metal apparently decreases at a lower rate than predicted for these cold-worked, metastable steels. For the weld metal, the opposite is true; the predicted-decrease in toughness is less than the measured decrease in toughness.

The results raise a question concerning the difference between base and weld metal. The SEM examination of the base metal specimens shows that martensite does not directly affect the fracture mechanisms (Figure 4); that is, the fracture morphology of the service condition specimen with 5 to $8 \%$ martensite is not appreciably different from the fracture morphology of the specimen with $45 \%$ martensite: there is no ductile-to-brittle transition. A $304 \mathrm{~L}$ specimen with 0\% martensite was not tested; however, previous experience indicates that the fracture surface features of a $304 \mathrm{~L}$ specimen without martensite would not be significantly different from those of the other $304 \mathrm{~L}$ specimens.

For the weld metal specimens, prior deformation does produce changes in the fracture morphology (Figures 5, 6, and 7). The properties of the ferrite in the weld metal microstructure are apparently degraded by the cold deformation more than the properties of the austenite, and as a result, the crack prefers to grow through the delta ferrite.

Fracture Mechanics Considerations

Fracture mechanics provides a means for assessing the fitness of a particular material for a given application. A simple analysis involves a small through-thickness crack in the center of a plate with finite thickness and other dimensions large with respect to the length of the crack, $a$. The driving force for fracture is given by

$$
K=\sigma(\pi a / 2)^{1 / 2}
$$

where $\mathrm{K}$ is the applied stress intensity factor and $\sigma$ is the applied stress. Different formulas are required for different geometries, stress concentrations, or residual stresses. The initiation of tearing is predicted when $k$ exceeds $K_{\text {Ic }}(J)$.

For the $304 \mathrm{~L}$ in the service condition, $\mathrm{K}_{\mathrm{IC}}(\mathrm{J})$ was about $200 \mathrm{MPa} \sqrt{\mathrm{m}}$ ( Table 2). If the stress on the plate were $100 \mathrm{MPa}$ ( $50 \%$ of yield), then a before the predicted initiation of tearing. For the most severely deformed base metal specimen, $\mathrm{K}_{\mathrm{IC}}(\mathrm{J})$ was $157 \mathrm{MPa} \sqrt{\mathrm{m}}$. If the stress were $100 \mathrm{MPa}$, the 
critical crack size for a center-cracked plate would be $1.5 \mathrm{~m}$. In the $308 \mathrm{~L}$ weld metal, $\mathrm{K}_{\mathrm{Ic}}(\mathrm{J})$ was $184 \mathrm{MPa} \sqrt{\mathrm{m}}$ in the service condition. If the stress were $122 \mathrm{MPa}$ (half of yield), the critical crack size would be about $1.5 \mathrm{~m}$.

In the worst case, for the service-and-deformed weld metal specimen where $\mathrm{K}_{\mathrm{Ic}}(\mathrm{J})$ was $95 \mathrm{MPa} \sqrt{\mathrm{m}}$, if the stress were $122 \mathrm{MPa}$, then the critical crack length would still be $0.4 \mathrm{~m}$. The size of the critical crack in each of the aforementioned situations indicates that the material possesses good toughness with respect to crack initiation. Specific structural situations, especially those involving high stresses, stress concentrations, and residual stresses, require more detailed analysis. A small factor of safety is built into the toughness values because the test temperature was lower than the actual service temperature.

In summary, prior deformation decreases the crack tolerance of these materials, but large deformations are required for significant effects. These initial tests indicate that problems are more likely to be found in the weld than the base material.

\section{CONCLUSIONS}

For both $304 \mathrm{~L}$ and $308 \mathrm{~L}$, cryogenic service resulted in lower $\mathrm{K}_{\mathrm{Ic}}(\mathrm{J})$ values than those reported for the annealed condition. Low temperature compressive loading further degraded the resistance to crack initiation and tearing; the 308L weld metal was affected more severely than the $304 \mathrm{~L}$ base metal.

These results do not permit the effects of individual microstructural components, such as strain-induced and thermally induced martensite and delta ferrite, to be separated from the strain-hardening effects. However, it appears that the presence of strain-induced martensite in the microstructure is not detrimental to the fracture toughness properties.

\section{ACKNOWLEDGMENTS}

The authors thank the Mobil Oil Corporation for supplying the materials and $\mathrm{f}$ inancial support to this work and the Department of Energy who supported the development of the clip gauges and test procedures used in this study. We also thank Frank Furillo of Mobil and David McColskey of the Fracture and Deformation Division of NBS-Boulder for their help.

\section{REFERENCES}

1. R. Ogawa and J. W. Morris, Jr., "Influence of Processing on the Cryogenic Mechanical Properties of High Strength High Manganese Stainless Steel," in Advances in Cryogenic Engineering--Materials, Vol. 30, A. F. Clark and R. P. Reed, eds., Plenum Press, New York, 1984, pp. 177-184.

2. E. L. Brown, T. A. Whipple, and R. L. Tobler, "Fracture Toughness of CF8 Castings at Four Kelvin," Metallurgical Transactions, Vol. 14A, No. 8, 1983, pp. 1179-1188. 
3. R. P. Reed, "Martensitic Phase Transformations" in Materials at Low Temperatures, R. P. Reed and A. F. Clark, eds., American Society for Metals, Metals Park, Ohio, 1983, pp. 295-341.

4. "Calibrating Magnetic Instruments to Meàsure the Delta Ferrite Content of Austenitic Stainless Steel Weld Metal," AWS A4.2-74, American Welding Society, Miami, Florida, 1974.

5. R. J. Buzzard and D. M. Fisher, "Load Displacement Measurements and Work Determination in Three-Point Bend Tests of Notched and Precracked Specimens," Journal of Testing and Evaluation, Vol. 6, No. 1, January 1978 , pp. $35-\overline{39}$.

6. J. G. Merkle, R. G. Berggren, and W. J. Stelzman, "Compliance and Fracture," HSST Quarterly Progress Report, ORNL Report TM-4805, Oak Ridge National Laboratory, Oak Ridge, Tennessee, March 1975.

7. "J IC, a Measure of Fracture Toughness" ASTM E 813-81, in Annual Book of ASTM Standards, Part 10, American Society for Testing and Materials, Philadelphia, 1981, pp. 763-781.

8. R. L. Tobler, D. T. Read, and R. P. Reed, "Strength/Toughness Relationship for Interstitially Strengthened AISI 304 Stainless Steels at $4 \mathrm{~K}$ Temperature," in Fracture Mechanics: Thirteenth Conference, ASTM STP 743, Richard Roberts, Ed., American Society for Testing and Materials, Philadelphia, 1981, pp. 250-268.

9. H. A. Ernst and P. C. Paris, "Techniques of Analysis of Load-Displacement Records by J-Integral Methods," Report NUREG/CR-122, U.S. Nuclear Regulatory Commission, January 1980.

10. H. M. Ledbetter, N. V. Frederick, and M. W. Austin, "Elastic-Constant Variability in Stainless Steel 304," Journal of Applied Physics, Vol. 51, 1980, pp. 305-309.

11. D. T. Read and R. P. Reed, "Fracture and Strength Properties of Selected Austenitic Stainless Steels at Cryogenic Temperature," in Materials Studies for Magnetic Fusion Energy Applications at Low Temperatures--II, F. R. Fickett and R. P. Reed, eds., NBSIR 79-1609, National Bureau of Standards, Boulder, Colorado, 1979, pp. 81-122.

12. P. T. Purtscher, Fracture and Deformation Division, National Bureau of Standards, Boulder, Colorado, unpublished data. 
Table 1. Results of Tensile Tests at $76 \mathrm{~K}$

\begin{tabular}{lccc}
\hline & $\begin{array}{c}\text { Yield Strength } \\
(\mathrm{MPa})\end{array}$ & $\begin{array}{c}\text { Ultimate Strength } \\
(\mathrm{MPa})\end{array}$ & $\begin{array}{c}\text { Reduction } \\
\text { of Area (\%) }\end{array}$ \\
\hline $\begin{array}{l}\text { AISI 304L } \\
\text { annealed }\end{array}$ & $164(23.8 \mathrm{ksi})$ & $1475(214 \mathrm{ksi})$ & 65 \\
$\begin{array}{l}\text { AISI 304L } \\
\text { service condition }\end{array}$ & $203(29.5 \mathrm{ksi})$ & $1450(211 \mathrm{ksi})$ & 68.5 \\
$\begin{array}{l}\text { AISI 308L } \\
\text { service condition }\end{array}$ & $244(35.4 \mathrm{ksi})$ & $1360(197 \mathrm{ksi})$ & 69.5 \\
\hline
\end{tabular}

Table 2. Calculated Toughness and Tearing Resistance

\begin{tabular}{|c|c|c|c|}
\hline Condition & $\begin{array}{c}\mathrm{K}_{\mathrm{Ic}}(\mathrm{J}) \\
(\mathrm{MPa} \sqrt{\mathrm{m}})\end{array}$ & $\begin{array}{c}\mathrm{dJ} / \mathrm{da} \\
(\mathrm{kN} / \mathrm{m} / \mathrm{mm})\end{array}$ & $\begin{array}{c}\text { Martensite } \\
(\%)\end{array}$ \\
\hline
\end{tabular}

AISI 304L

Service

Service

Annealed and deformed

Service and deformed

Service and deformed

Service and deformed

Service and deformed

AISI 308L

Annealed

Service

Service and deformed
200

208

191

190

191

183

157

279

184

95
*

166

134

195

174

*

148

$\sim 0$

87

25
0

$5-8$

$5-8$

13

20

18

35

45

4

19

* Not available 
Table 3. Estimated Flow Strengths and Related Toughness Changes

$\begin{array}{cccc}\text { Condition } & \text { Estimated Flow } & \text { Predicted Toughness } & \text { Measured Toughness } \\ & \text { Strengths }(\mathrm{MPa}) & \text { Change }(\mathrm{MPa} \sqrt{\mathrm{m}})^{*} & \text { Change (MPa } \sqrt{\mathrm{m}})\end{array}$

\section{AISI $304 \mathrm{~L}$}

Service

Service

Annealed and de formed

Service and de formed

Service and de formed

Service and de formed

Service and de formed

AWS 308L

Annealed

Service de formed
Service and
690

690

690

860

860

930

1100

$-123$

$-51$

$-72$

$-17$

$-43$

690

690

1035

0

0

$-51$

$-10$

$-10$

$-43$
*Calculated from reference 8 , where $\mathrm{K}_{\mathrm{Ic}}(\mathrm{J})=500-0.3\left(\sigma_{\mathrm{y}}\right)$ for annealed austenitic stainless steels at $4 \mathrm{~K}$. The $\sigma_{\mathrm{y}}$ term is equal to the yield strength. 


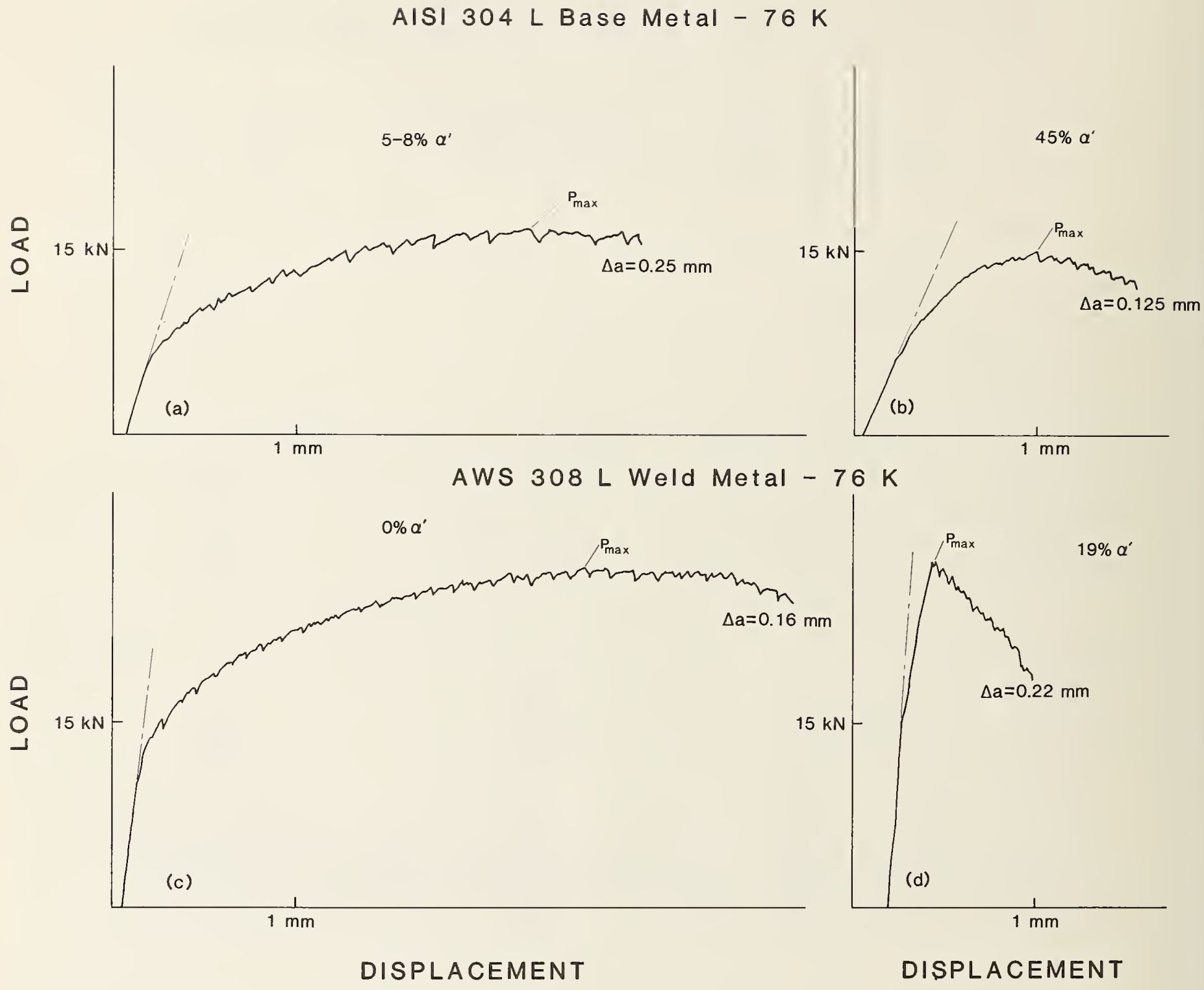

Figure 1. Load vs. mouth-opening displacement curves for (a) $304 \mathrm{~L}$ in service condition, (b) $304 \mathrm{~L}$ in service-and-deformed condition with 45\% martensite, (c) 308L in annealed condition, and (d) 308L in service-and-deformed condition with $19 \%$ martensite. 


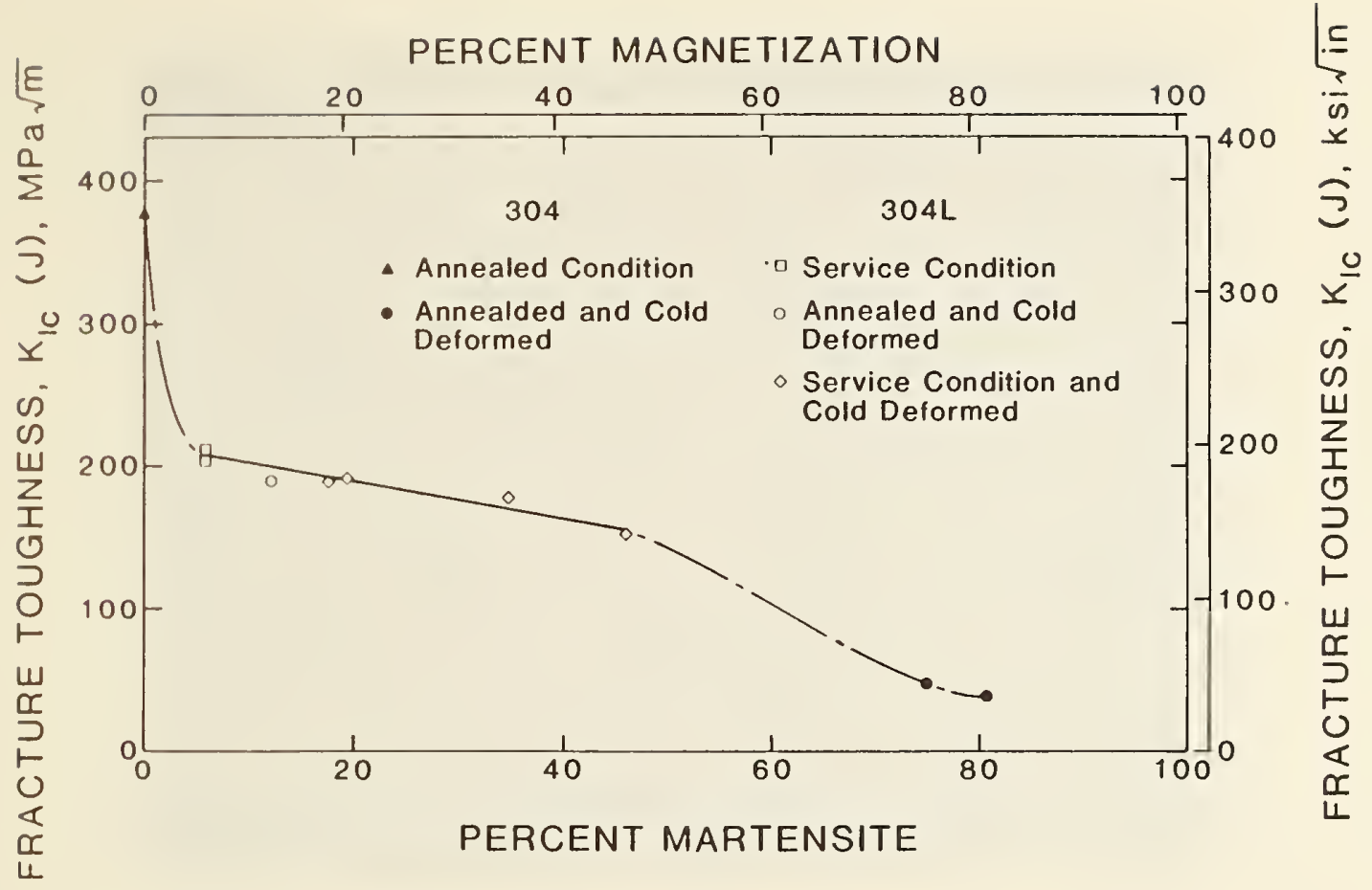

Figure 2. Fracture toughness vs. percent martensite for AISI $304 \mathrm{~L}$ and AISI 304 annealed and AISI 304 annealed and cold deformed. 11,12

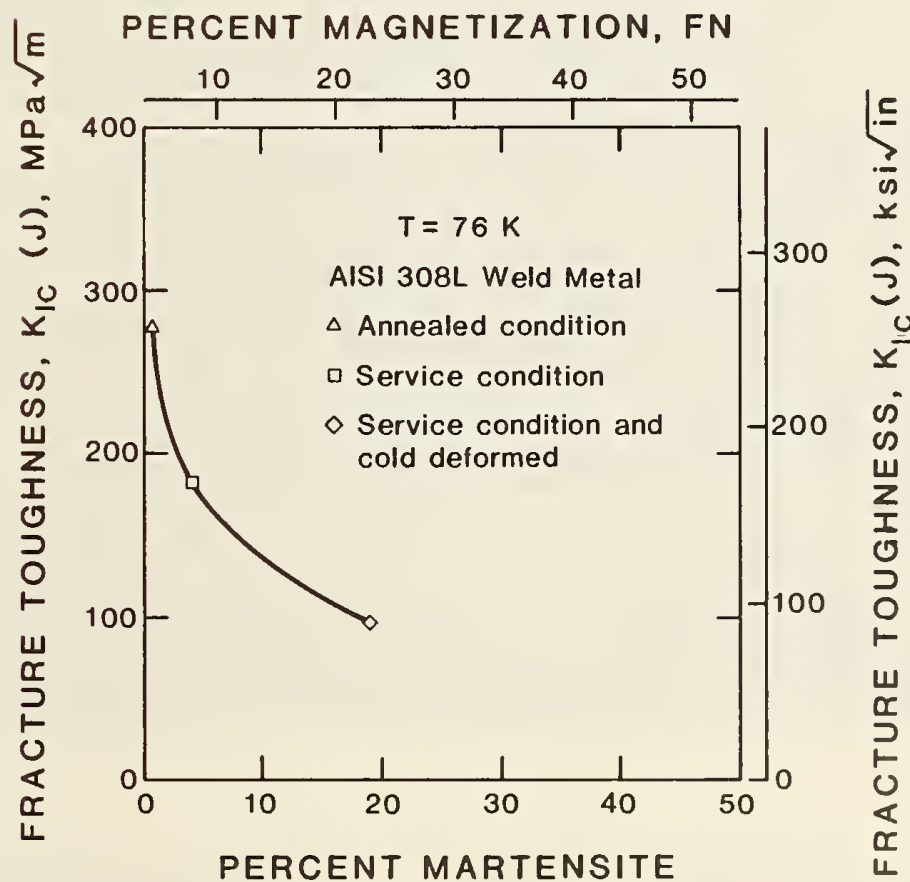

Figure 3. Fracture toughness vs. percent martensite for AISI 308L weld metal. 

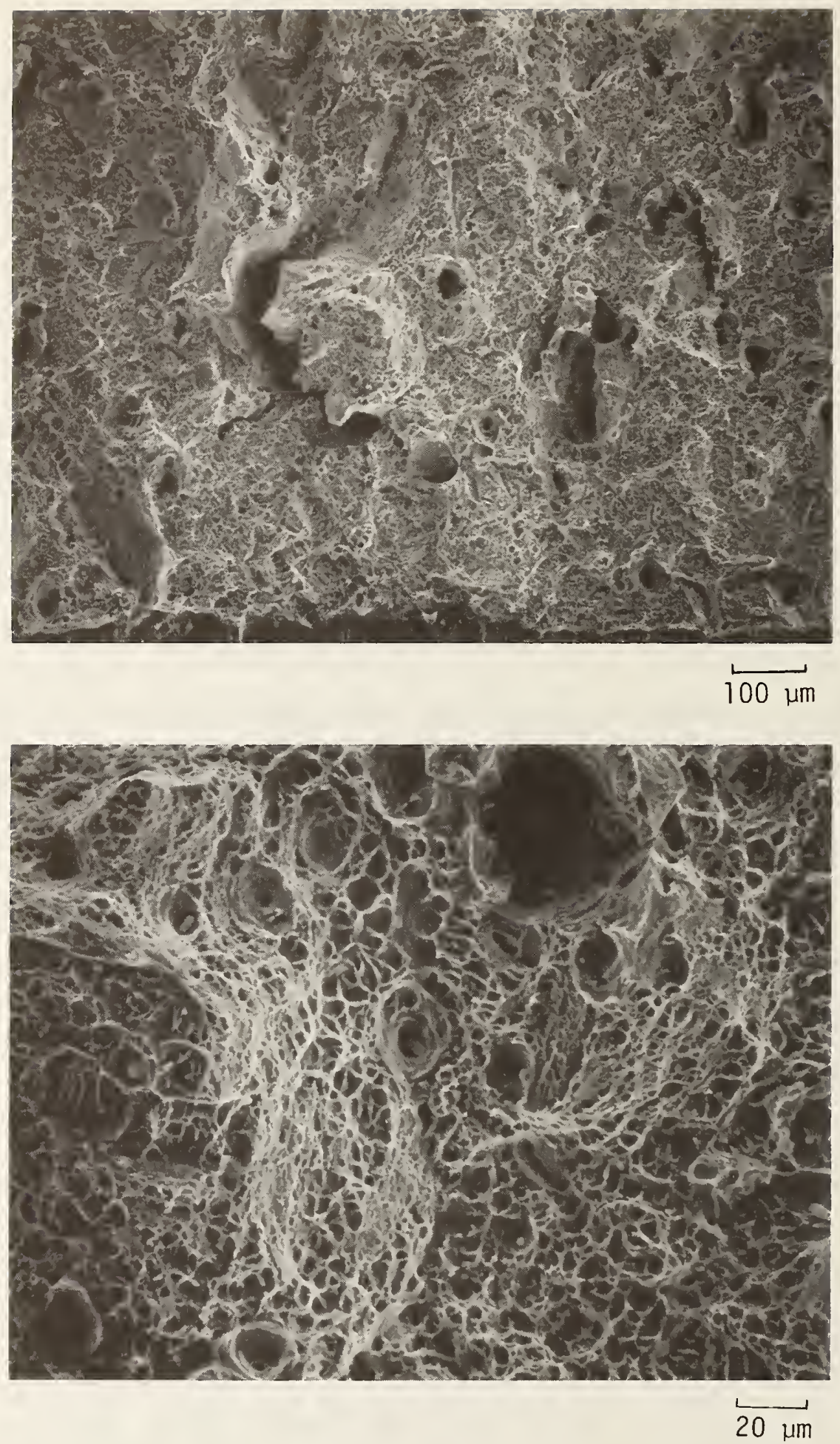

Figure 4. SEM photomicrographs of the J-test fracture surface of $304 \mathrm{~L}$ specimen with $45 \%$ martensite. 


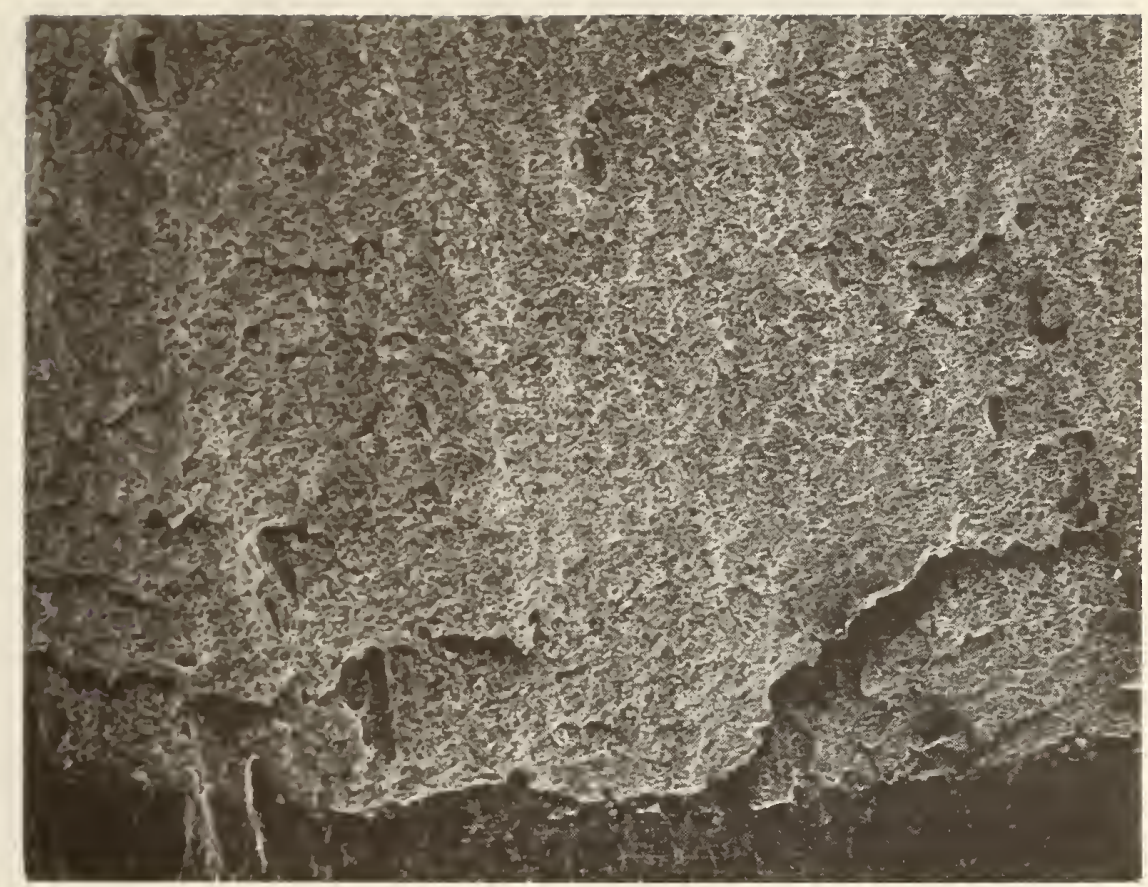

$\longdiv { 1 0 0 \mu \mathrm { m } }$

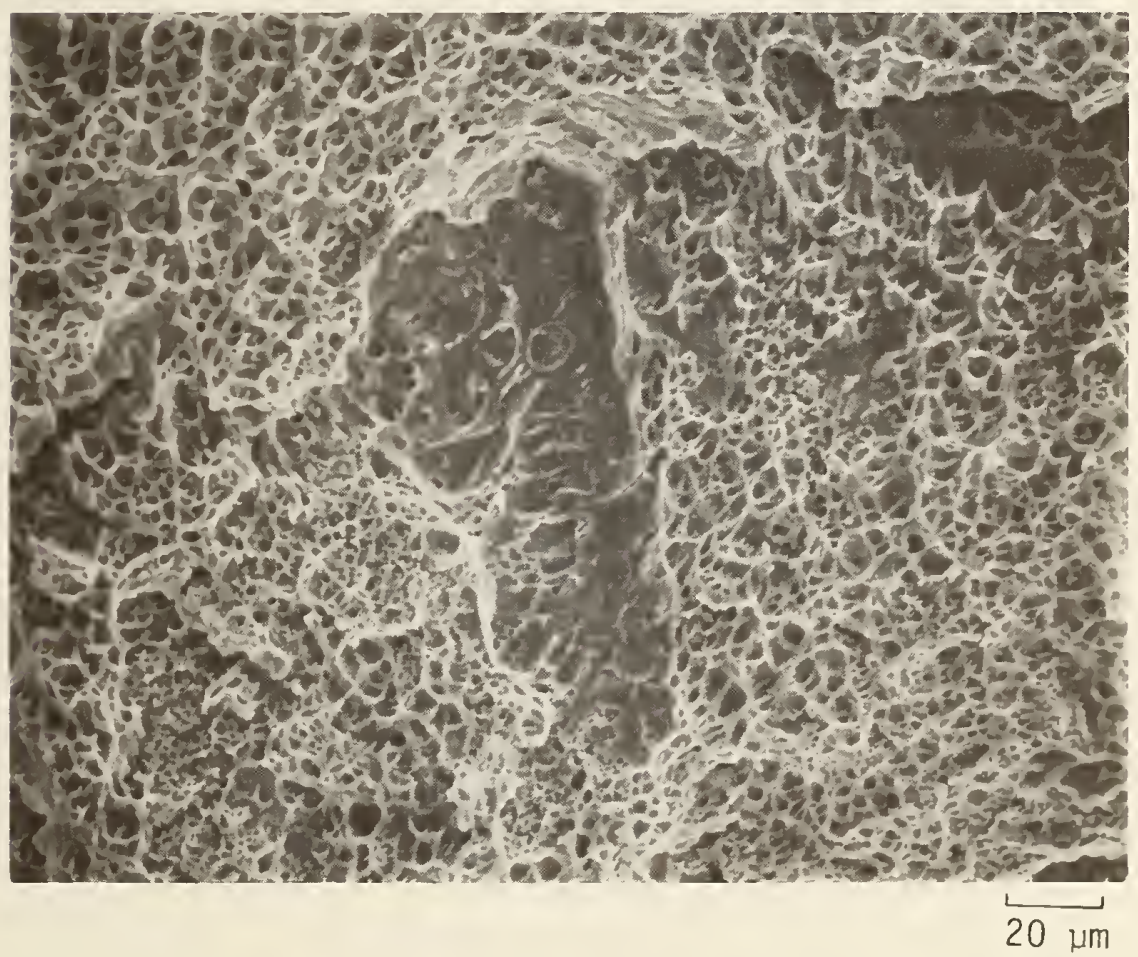

Figure 5. SEM photomicrographs of the J-test fracture surface of $308 \mathrm{~L}$ specimen in the annealed condition. 

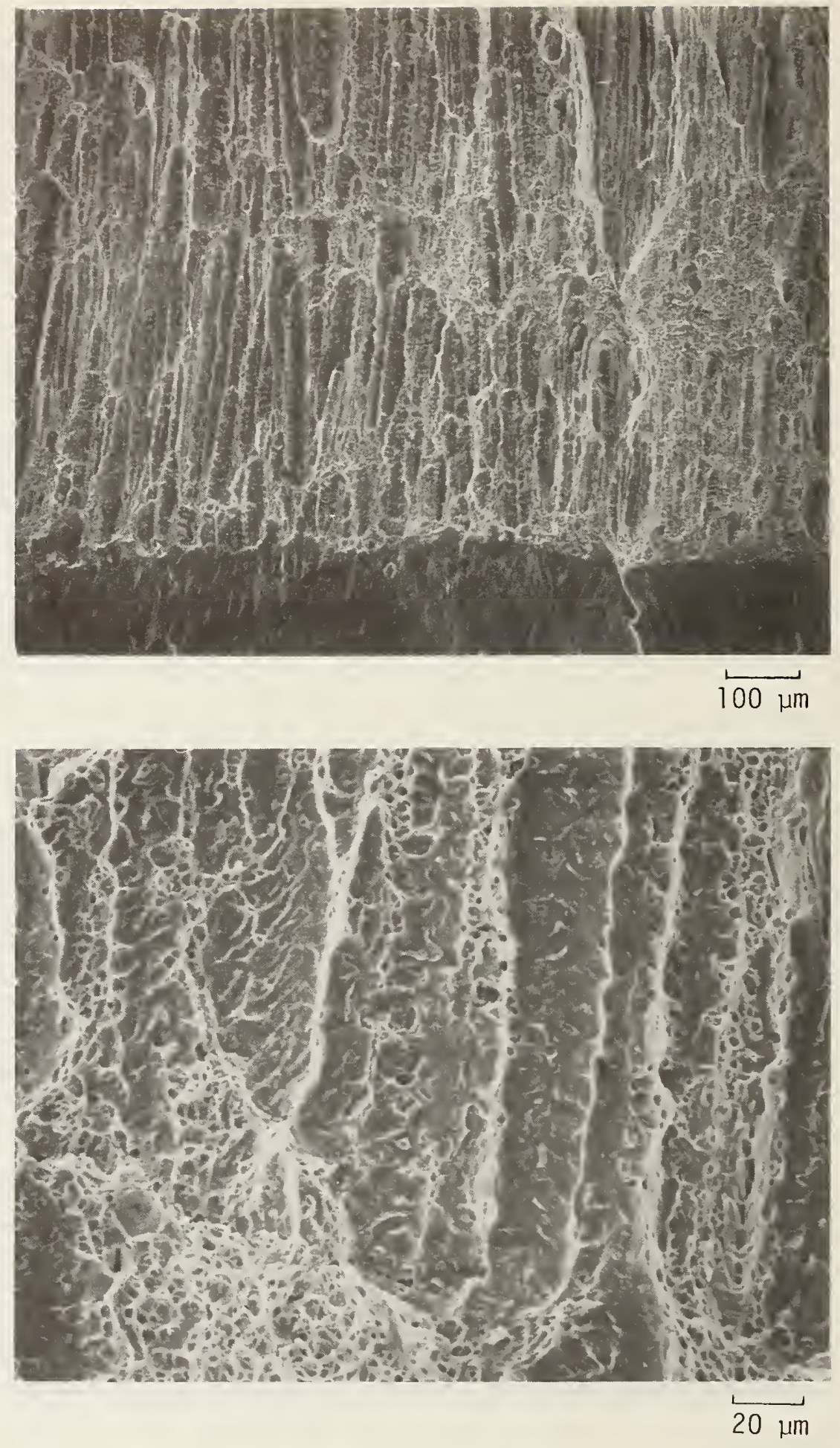

Figure 6. SEM photomicrographs of the J-test fracture surface of 308L specimen in the service condition. 

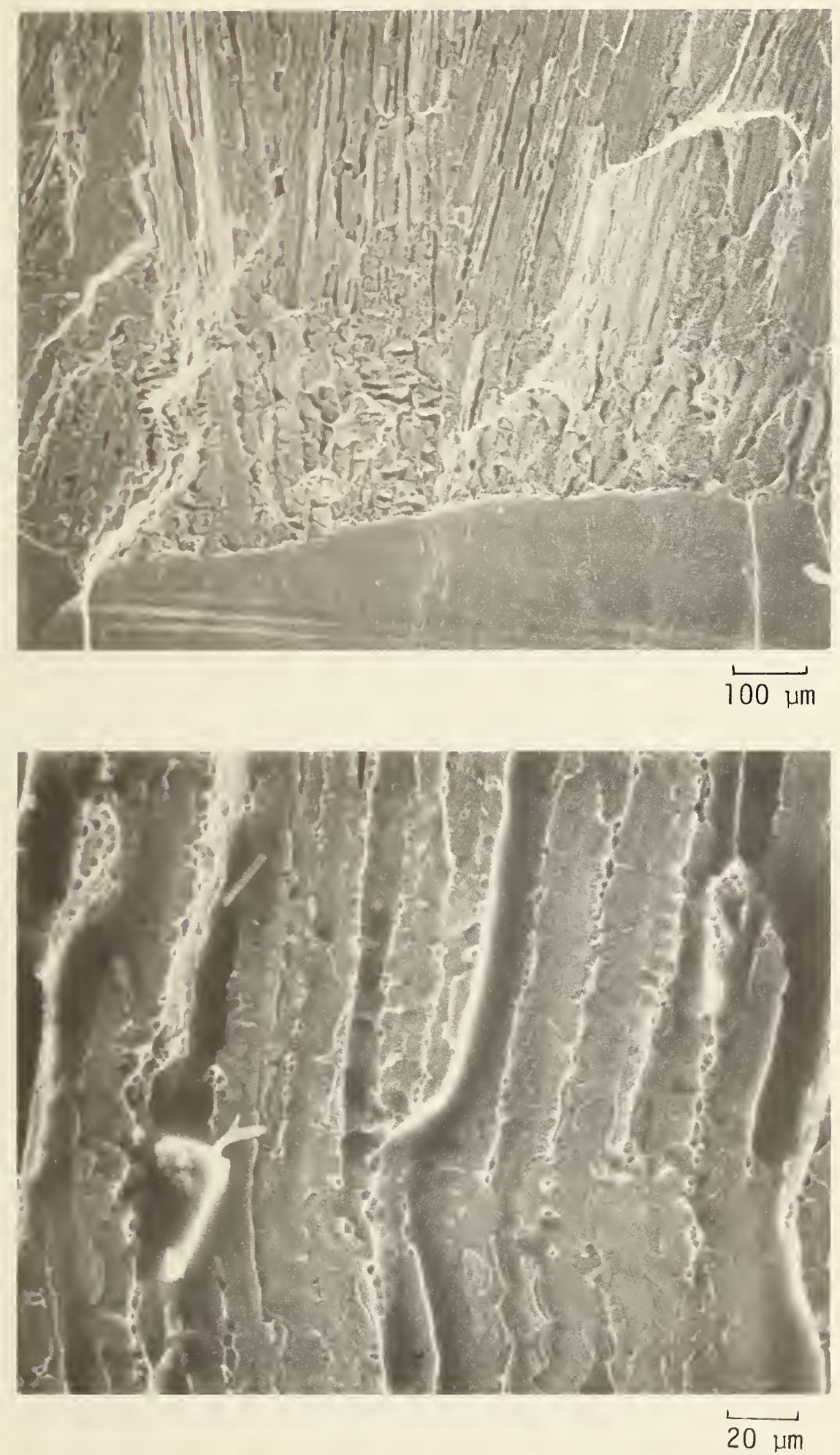

Figure 7. SEM photomicrographs of the J-test fracture surface of $308 \mathrm{~L}$ specimen in service-and-deformed condition. 



CARBON AND NITROGEN EFEECTS ON THE ELASTIC CONSTANTS

OF A STAINLESS STEEL AT $4{ }^{\circ} \%$

H. M. Ledbetter, M. W. Austin, and S. A. Kim

Fracture and Deformation Division,

Institute for Materials Science and Engineering

National Bureau of Standards, Boulder, Colorado

Nine AISI type 304 stainless steel alloys were studied between ambient temperature and liquid-helium temperature. The carbonplus-nitrogen contents of these alloys ranged from 0.080 to 0.359 wt.\% (from 0.3 to 1.5 at.\%). Five elastic constants (the longitudinal modulus, Young's modulus, the shear modulus, the bulk modulus, and Poisson's ratio) were determined by a pulse echo ultrasonic method. Except for the bulk modulus, all the elastic stiffnesses increase slightly with increasing interstitial content. Existing elastic theory predicts decreases in elastic stiffness caused by the volume increase. Previously reported ambienttemperature results show such elastic-constant decreases. Thus, the low temperature results suggest electronic interactions between interstitial atoms and host-lattice atoms, interactions that stiffen the lattice more against shear than against dilatation.

\section{INTRODUCTION}

The aim of this study was to determine how carbon-and-nitrogen interstitial alloying additions affect the elastic constants of AISI type 304 stainless steel alloys at liquid-helium temperature, $4 \mathrm{~K}$.

Both carbon and nitrogen increase the strength of austenitic $\mathrm{Fe}-\mathrm{Cr}-\mathrm{Ni}$ alloys. Nitrogen stabilizes the austenite, reducing the tendency toward martensitic transformations at low temperatures. Carbon functions similarly, but at righer concentrations it causes sensitization during welding. The increasing uses of these alloys, together with a dearth of reliable physical property measurements, prompted the present study.

Because elastic constants are physical properties, they are relatively insensitive to details of internal structure, which are related to thermalmechanical treatment. However, when determined with sufficient sensitivity, elastic constants provide important parameters for indicating interatomic force changes that may occur during alloying. Indeed, small changes in the elastic constants may indicate large changes in the nature of the interatomic bonding.

Commercial austenitic stainless steels always contain some carbon and nitrogen, in amounts up to a few atomic percent. These small foreign atoms

*Intended for publication in Materials Science and Engineering. 
occupy the octahedral hole of the f.c.c. lattice. This largest f.c.c. interstice provides a space of radius up to $\left(2^{1 / 2}-1\right) r_{a}=0.41 r_{a}$, where $r_{a}$ denotes the radius of the host atom on the f.c.c sites. Larger interstitial atoms must expand the f.c.c. lattice. Both carbon and nitrogen atom sizes exceed the octahedral hole size: $\dot{r}_{C} / r_{F e}=0.890 / 1.271=0.70 ; r_{N} / r_{F e}=$ $0.855 / 1.271=0.67$. (The value of the radius of the nitrogen atom is uncertain. Here, as for carbon, we use the Pauling tetrahedral covalent radius corrected for coordination number.) The lattice expansion caused by carbon and nitrogen does not remove the usual metallic properties of ductility and conductivity; these properties are only reduced. Consistent with a trend toward the properties of a covalent material, the strength increases.

Previously, the authors reported a similar study at ambient temperature [1]. They found that carbon and nitrogen decrease all the elastic stiffnesses: $C_{\ell}=$ longitudinal modulus, $E=$ Young's modulus, $G=$ shear modulus, $B=$ bulk modulus, and so on. To explain these results, they invoked Eshelby's model [2], which predicts elastic softening when lattice defects increase volume. Carbon and nitrogen increase the volume of these alloys approximately $0.7 \%$ per atomic percent interstitial [3].

Low-temperature studies assume importance for several reasons: (1) Increasingly, stainless-steel alloys find low-temperature applications; for example, in magnetic-fusion-energy devices. (2) Usually we consider the $\mathrm{T}=0 \mathrm{~K}$ state as a material's ground state. Because this state omits temperature effects, various theoretical calculations and models become simpler. (3) Carbon-plus-nitrogen strengthening of these alloys depends markedly on temperature [4]. Especially at low temperatures, nitrogen strengthens more than carbon. The elastic constants enter prominently into most models of solid-solution strengthening.

\section{EXPERIMENT}

\subsection{Materials and ambient temperature}

For brevity, we omit these, which we gave previously [1]. Figure 1 shows a photomicrograph of one of the nine alloys. Although the previous study used $x$-ray diffraction mass densities, the present study uses Archimedes's method of mass densities, which are approximately one percent lower. Also, the carbon-plus-nitrogen chemical compositions in Table 1 differ from those given previously [1]. We consider the current values more nearly correct.

\subsection{Low-temperature methods}

We achieved cooling to liquid-helium temperature by methods described previously [5]. At each temperature, approximately at 5-K intervals, we made absolute measurements of the velocity of sound in the longitudinal and transverse directions $\left(v_{\ell}\right.$ and $v_{t}$ ) in two coolings of the same specimen. 


\section{RESULTS}

Figure 2 shows relative values of the longitudinal modulus

$$
C_{\ell}=\rho v_{\ell}^{2}
$$

and the shear modulus

$$
G=\rho v_{t}^{2}
$$

versus temperature, where $\rho$ is mass density.

Table 1 gives the principal results of the study: the velocities of sound and the elastic constants for nine AISI type 304 stainless steel alloys with different carbon-plus-nitrogen contents. Figure 3 shows these results graphically, based on smoothed sound-velocity results. Table 2 contains the linear least-squares parameters for the various elastic constants. The last column in Table 2 gives the percent elastic constant changes per atomic percent of interstitials.

\section{DISCUSSION}

Figure 2 shows that the elastic stiffnesses soften anomalously during cooling. This softening, or transition, temperature depends on interstitial content according to the relationship [6]

$$
\mathrm{T}_{\mathrm{t}}=53.6=13.9 \mathrm{x}_{\mathrm{C}+\mathrm{N}}
$$

where $\mathrm{x}$ denotes atomic percent and $\mathrm{T}_{t}$ is in kelvins. As described elsewhere [7], this transition corresponds to a magnetic transition from the high-temperature paramagnetic phase to the low-temperature phase that combines antiferromagnetic and spin-glass states, depending on chemical composition and temperature. Because the antiferromagnetic state involves spin ordering, cooling through the transition increases volume [8] and decreases elastic stiffness.

Figure 3 shows the study's principal results: the $4-K$ variation of elastic constants with interstitial content. When compared with the 293-K results reported previously [1] and shown in Fig. 4, we see a dramatic difference: the shear-mode elastic constants, the Young's and shear moduli, increased with alloying at $4 \mathrm{~K}$; at $293 \mathrm{~K}$ they decreased.

Previously, we explained that the ambient-temperature softening by alloying arose from the volume increase caused by interstitial carbon and nitrogen [1]. In that study, we suggested that carbon-iron and nitrogen-iron electronic interactions might be necessary to understand the shear-modulus behavior. 
The new low-temperature results underscore the necessity to consider electronic effects. Elastic models can not explain increases in shear modulus arising from interstitial atoms that increase volume.

Concerning iron- $X$ ( $X$ denotes carbon or nitrogen interstitial atom) interatomic bonding, we can learn much from previous studies on intermetallic compounds. When an $X$ atom occurs in the f.c.c. unit cell, locally the compound $\mathrm{Fe}_{4} \mathrm{X}$ exists. If $\mathrm{X}$ atoms cluster, then the compound may achieve the FeX stoichiometry. In either case, locally there exists an intermetallic compound. Properties of such compounds include high melting point and high strength. These properties represent localized-electron (ionic, covalent bonding) rather than nonlocalized-electron (metallic bonding) systems.

Localized-electron bonding produces certain elastic-constant effects: one of these is a low Poisson's ratio. At $4 \mathrm{~K}$, the changes in Poisson's ratio due to interstitial alloying effects are approximately five times larger than those at $293 \mathrm{~K}$. Related to this, we repeat the conclusion of Köster and Franz [9]: "Poisson's ratio depends to a much greater extent on the conditions of bonding than do the other elastic coefficients."

Another related effect of localized-electron bonding is the stiffening of shear modulus but not bulk modulus. Diamond represents the paradigm of localized-electron systems. Although diamond's shear modulus exceeds iron's by a factor of 6.4 , diamond's bulk modulus exceeds iron's by only 2.6 . Thus, localized-electron bonding corresponds to shear rigidity but not volume rigidity, to rigid interatomic-bond angles but not rigid lengths.

\section{CONCLUSIONS}

From this study, there arise several conclusions:

1. Previous studies at ambient temperatures showed that alloying interstitial carbon and nitrogen into $\mathrm{Fe}-18 \mathrm{Cr}-10 \mathrm{Ni}$ alloys decreased all of the usual engineering elastic constants. Except for the sheartype elastic constants, Eshelby's model explained that these decreases arise from the volume increase associated with interstitial carbon and nitrogen. The shear-modulus slope $(1 / x)(\Delta G / G)$, too low by a factor of 2 , suggested electronic effects.

2. The new 4-K results differ dramatically from the $293-\mathrm{K}$ results. Especially, the shear-mode elastic constants differ. Both Young's modulus and shear modulus increase with alloying interstitial carbon and nitrogen.

3. These new results, coupled with previous ones, suggest strong electronic interactions between host and interstitial atoms that affect the elastic constants. These interactions involve localizedelectron (covalent, ionic) bonding that strengthens the alloy against shear deformation but does not strengthen against volume deformation. 


\section{ACKNOWLEDGMENTS}

The U.S. DOE Office of Fusion Energy supported this study.

\section{REFERENCES}

1. H. M. Ledbetter and M. W. Austin, Mater. Sci. Eng., 70 (1985) 143-149.

2. J. D. Eshelby, J.Appl. Phys., 25 (1954) 255-261.

3. H. M. Ledbetter and M. W. Austin, Dilation of an fcc Fe-Cr-Ni alloy by intersitial carbon and nitrogen, submitted to Metall. Trans.

4. R. P. Reed and N. J. Simon, Materials Studies for Magnetic Fusion Energy Applications at Low Temperatures - VII, NBSIR 84-3000, National Bureau of Standards, Boulder, Colorado (1984) 13-24.

5. E. R. Naimon, W. F. Weston, and H. M. Ledbetter, Cryogenics, 14 (1974) 246-249.

6. T. Datta and H. M. Ledbetter, unpublished research.

7. T. Datta, D. Thornberry, E. R. Jones, and H. M. Ledbetter, Solid State Commun., 52 (1984) 515-517.

8. V. L. Morruzzi, J. F. Janak, and A. R. Williams, Calculated Electronic Properties of Metals, Pergamon, New York (1978) $1 \overline{64 .}$

9. W. Köster and H. Franz, Metall. Rev., 6 (1961) 1-55. 
TABLE 1

Elastic constants at $4 \mathrm{~K}$

\begin{tabular}{|c|c|c|c|c|c|c|c|c|}
\hline $\begin{array}{l}\mathrm{C}+\mathrm{N} \\
\text { at. } \%)\end{array}$ & $\begin{array}{l}\text { Mass Density } \\
\left(g / \mathrm{cm}^{3}\right)\end{array}$ & $(\mathrm{cm} / \mu \mathrm{s})$ & $\begin{array}{c}\mathrm{v}_{\ell} \\
(\mathrm{cm} / \mu \mathrm{s})\end{array}$ & $\begin{array}{c}\mathrm{G} \\
(\mathrm{GPa})\end{array}$ & $\begin{array}{l}\mathrm{C}_{\ell} \\
(\mathrm{GPa})\end{array}$ & $\begin{array}{c}E \\
(\mathrm{GPa})\end{array}$ & $\begin{array}{c}\mathrm{B} \\
(\mathrm{GPa})\end{array}$ & $\begin{array}{l}\text { Poisson's } \\
\text { Ratio }\end{array}$ \\
\hline
\end{tabular}

$\begin{array}{lllllllll}0.34 & 7.919 & 0.3214 & 0.5808 & 81.80 & 267.1 & 209.3 & 158.0 & 0.279 \\ 0.45 & 7.909 & 0.3218 & 0.5811 & 81.90 & 267.1 & 209.5 & 157.9 & 0.278 \\ 0.69 & 7.900 & 0.3222 & 0.5815 & 82.01 & 267.1 & 209.7 & 157.8 & 0.278 \\ 0.79 & 7.894 & 0.3224 & 0.5817 & 82.07 & 267.1 & 209.8 & 157.7 & 0.278 \\ 0.88 & 7.885 & 0.3228 & 0.5820 & 82.17 & 267.1 & 210.0 & 157.5 & 0.277 \\ 0.95 & 7.876 & 0.3232 & 0.5823 & 82.27 & 267.1 & 210.2 & 157.4 & 0.277 \\ 1.29 & 7.864 & 0.3237 & 0.5828 & 82.40 & 267.1 & 210.5 & 157.2 & 0.276 \\ 1.38 & 7.856 & 0.3241 & 0.5831 & 82.49 & 267.1 & 210.6 & 157.1 & 0.276 \\ 1.47 & 7.847 & 0.3244 & 0.5834 & 82.59 & 267.1 & 210.8 & 157.1 & 0.276\end{array}$

TABLE 2

Least-squares parameters for various elastic constants, $C$, at $T=4 \mathrm{~K}$, where $\mathrm{C}=\mathrm{C}_{\mathrm{O}}+\mathrm{ax}_{\mathrm{C}+\mathrm{N}}$

\begin{tabular}{lccc}
\hline$C$ & $C_{0}(\mathrm{GPa})$ & $\mathrm{a}(\mathrm{GPa})$ & $100\left(1 / \mathrm{x}_{\mathrm{C}+\mathrm{N}}\right)\left(\Delta \mathrm{C} / \mathrm{C}_{\mathrm{O}}\right)$ \\
\hline $\mathrm{B}$ & 158.2 & -0.818 & -0.52 \\
$\mathrm{G}$ & 81.6 & 0.663 & 0.81 \\
$\mathrm{E}$ & 208.9 & 1.283 & 0.61 \\
$\mathrm{C}_{\ell}$ & 267.0 & -0.066 & -0.025 \\
$\nu$ (dimensionless) & 0.280 & -0.0025 & -0.896 \\
\hline
\end{tabular}




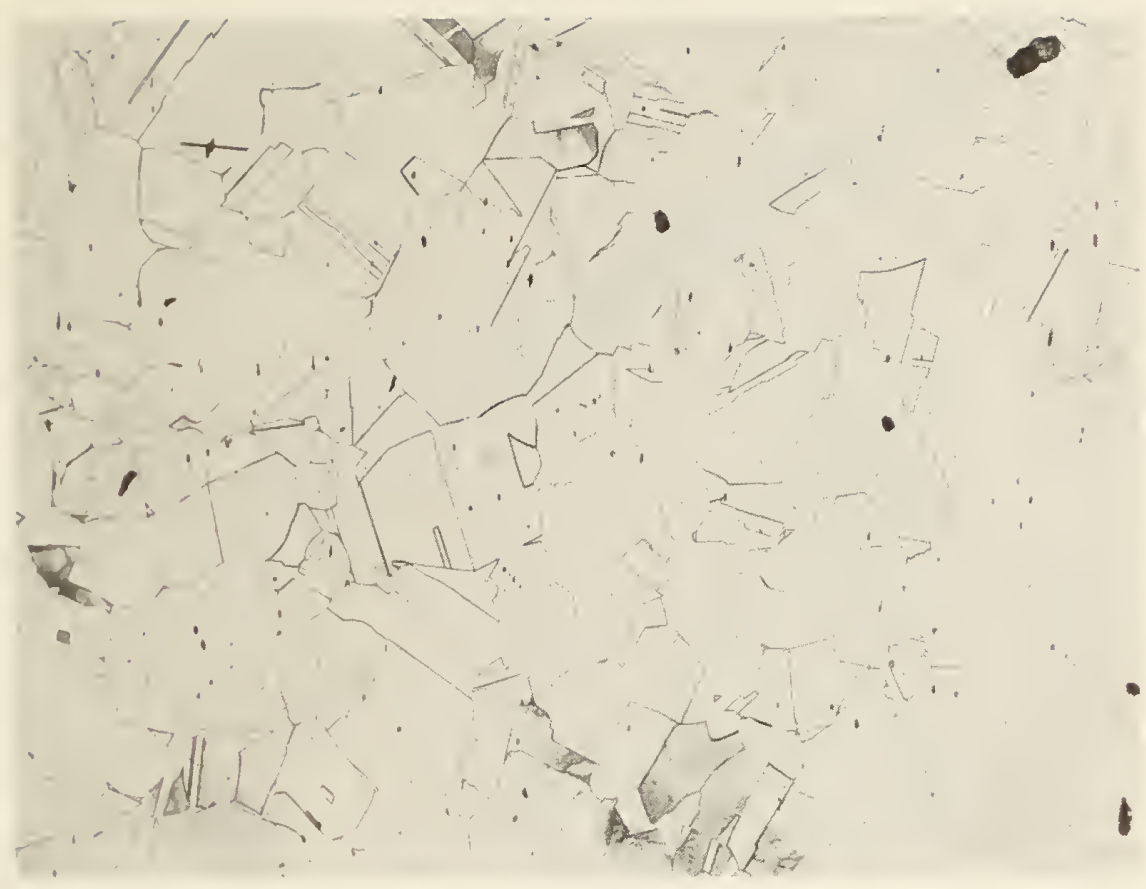

Fig. 1. Photomicrograph of typical studied alloy. Average grain size for nine alloys equals $88 \mu \mathrm{m}$.

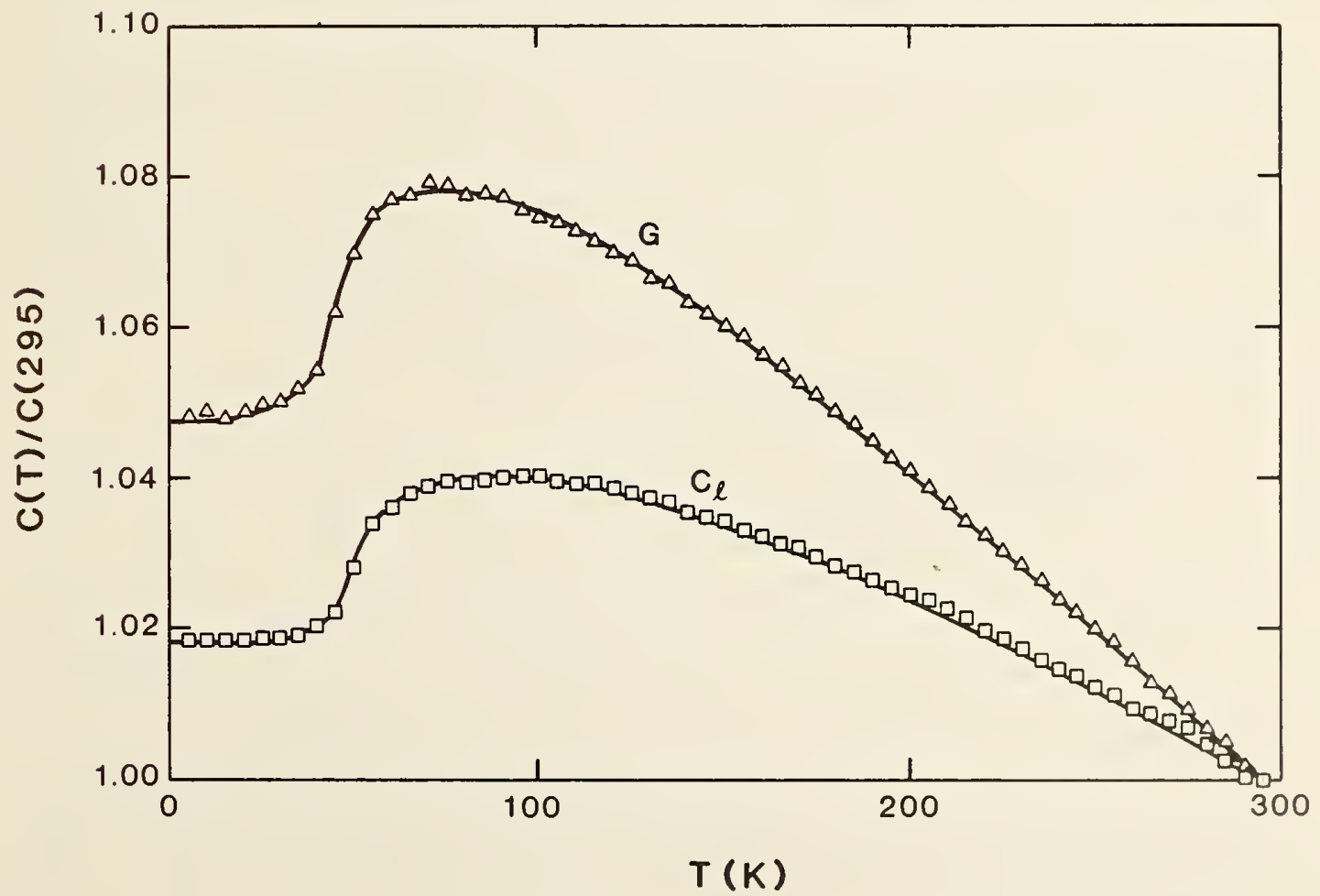

Fig. 2. Relative variation of longitudinal and shear moduli for one alloy versus temperature. Elastic softening near $50 \mathrm{~K}$ during cooling results from a paramagnetic to antiferromagnetic/spin-glass transition. 


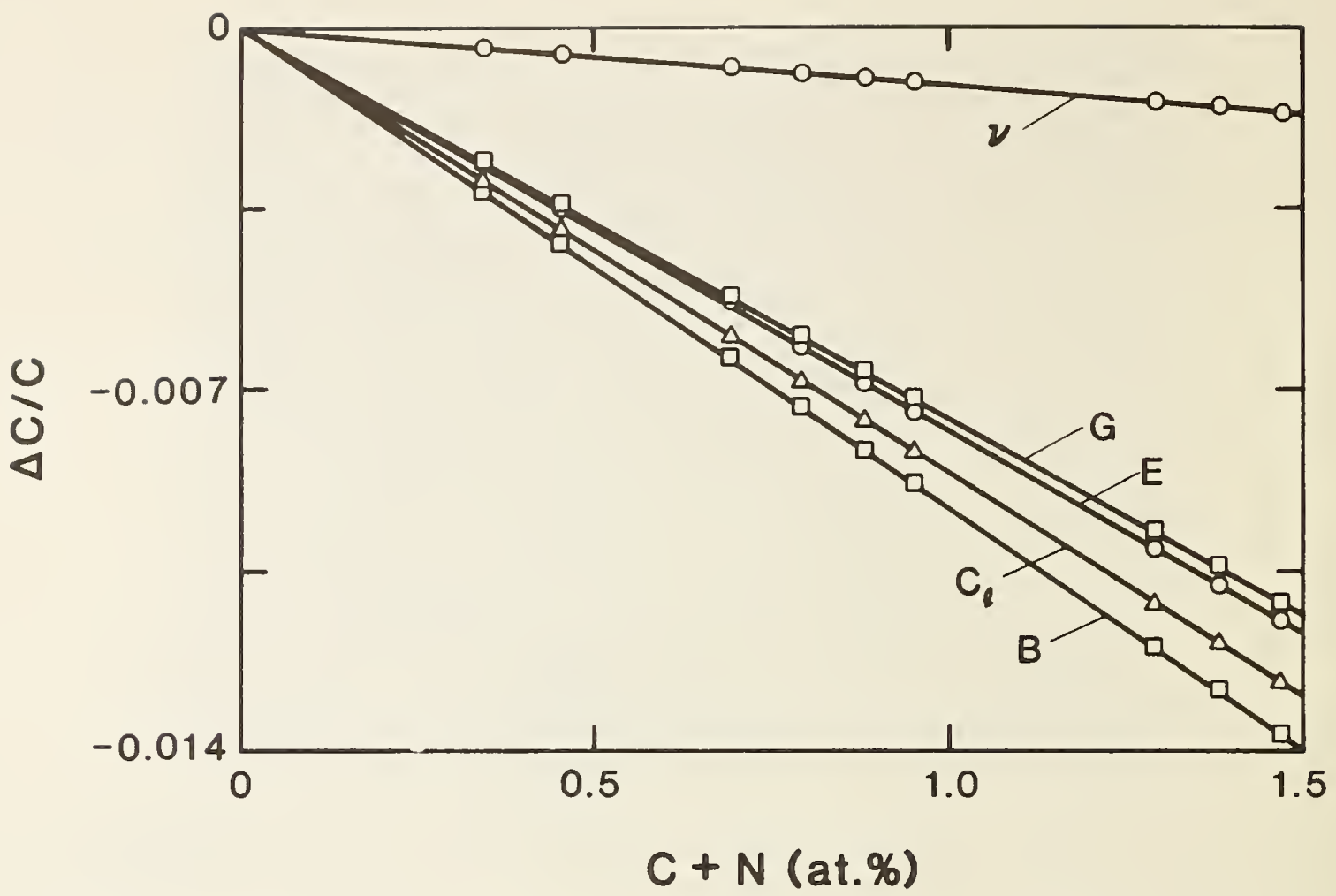

Eig. 3. Variation in elastic constants with interstitial carbon-plusnitrogen content for AISI type 304 stainless steel at $4 \mathrm{~K}$.

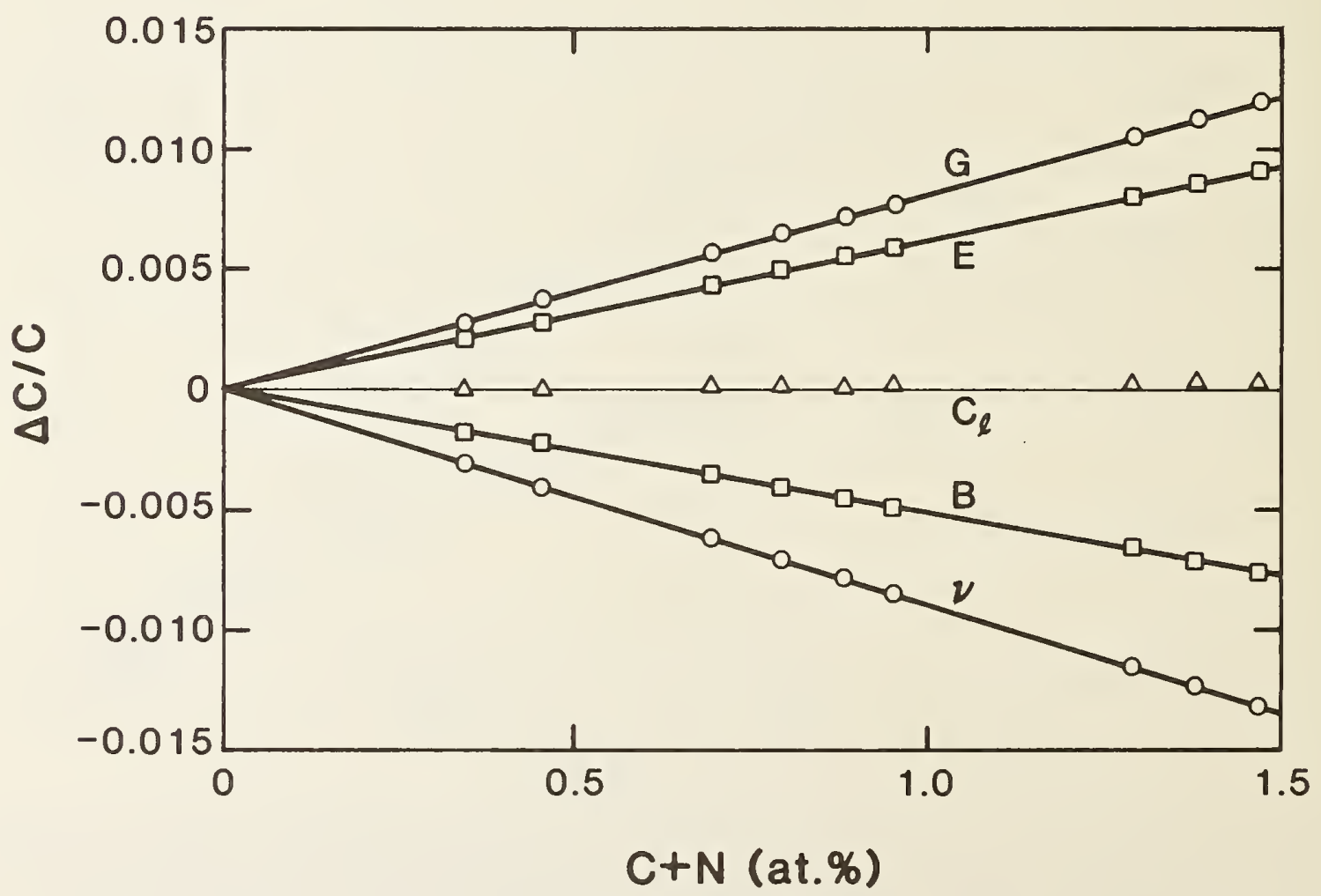

Eig. 4. Companion graph to Fig. 3 showing ambient-temperature behavior. 


EFFECTS OF INTERSTITIAL CARBON AND NITROGEN ON THE LOW-TEMPERATURE

MAGNETIC PROPERTIES OF FCC Fe-Cr-Ni ALLOYS

E. R. Jones, Jr., T. Datta, and C. Almasan
Department of Physics and Astronomy
University of South Carolina
Columbia, South Carolina

and

H. M. Ledbetter

Fracture and Deformation Division

National Bureau of Standards

Boulder, Colorado

We have studied the low-temperature magnetic susceptibility of a series of fcc Fe-Cr-Ni alloys containing varied amounts of interstitial carbon and nitrogen. Characteristic of antiferromagnets, all specimens displayed a distinct peak in magnetic susceptibility as a function of temperature. Above the transition temperature, their behavior was well described by a modified Curie-Weiss law, $x=x_{0}+c /(T+\theta)$. The position of the susceptibility maximum decreased from $47.9 \pm 0.5 \mathrm{~K}$ to $35.0 \pm 0.5 \mathrm{~K}$ as the $\mathrm{C}+\mathrm{N}$ content increased from 0.34 to 1.47 at.\%. Similar behavior was also observed in the transition temperatures determined from the anomaly in the ultrasonic wave velocities.

\section{INTRODUCTION}

The low-temperature magnetic properties of austenitic stainless steels have been of considerable interest since it was learned that they are not all nonmagnetic as previously thought. Following the observation by Kondorskii and Sedov ${ }^{1}$ of antiferromagnetism in a specimen of $18 \mathrm{Cr}, 9 \mathrm{Ni}$ (wt. $\%$ ) commercial stainless steel, there have been numerous studies of the low-temperature structure and properties of the fcc austenitic phase ( $\gamma$ ) stainless steels. Ishikawa et al. ${ }^{2}$ confirmed the long-range antiferromagnetic order at low temperatures in monocrystal fcc stainless steel by neutron diffraction techniques. Evidence for magnetic ordering was also obtained in Mössbauer experiments, 3,4 in which the single resonance line was seen to broaden as the temperature was lowered through the phase transition. 
The additional alloying elements that are found in commercial steels have significant effects on their magnetic behavior. Extensive studies have been direcied at systemalic investigation of the effects of the individual constituents of the alloys. ${ }^{5,6}$ Warnes and King ${ }^{7}$ analyzed the data for 30 austenitic stainless steels and special Fe-Cr-Ni alloys whose compositions fall near the AISI 300 series. A linear relationship was found that predicted the Néel temperature, $\mathrm{T}_{\mathrm{N}}$, with an rms deviation of $3.5 \mathrm{~K}$ on the basis of the weight percentage of alloy compositions. The effect of alloying elements in lowering $\mathrm{T}_{\mathrm{N}}$ increases in the order $\mathrm{Cr}, \mathrm{Ni}$, Mo, and $\mathrm{Si}$, while the effect of $\mathrm{Mn}$ is to raise $\mathrm{T}_{\mathrm{N}}$. Warnes and King examined alloys whose basic compositions lie in the range $16-25 \mathrm{Cr}, 6-32 \mathrm{Ni}, 0-16 \mathrm{Mn}, 0-2.4 \mathrm{Si}, 0-3.0 \mathrm{Mo}$, $0-0.14 \mathrm{C}$, and $0-0.38 \mathrm{~N}$, balance $\mathrm{Fe}(\mathrm{wt} . \%)$. They reported that the interstitial solutes $\mathrm{C}+\mathrm{N}$ exert negligible influence on the Néel temperature. 7,8

The present study is concerned with the low-temperature magnetic properties of austenitic Fe-Cr-Ni alloys. Particular emphas is is given to the effects of $\mathrm{C}+\mathrm{N}$ interstitials on the paramagnetic-to-antiferromagnetic phase transition, as determined from the peak of the dc susceptibility.

\section{EXPER IMENT}

All nine of the specimens studied were 304-type fcc stainless steel alloys. The $\mathrm{C}+\mathrm{N}$ contents were varied in three steps each while the remaining constituents were held essentially constant. The detailed chemical compositions are given in Table $I$. Individual specimens were cut into rectangular prisms with a typical size of $1.5 \mathrm{~mm} \times 3 \mathrm{~mm} \times 5 \mathrm{~mm}$. The specimens were cleaned in a solution containing equal parts of $\mathrm{HCl}$ and $\mathrm{HNO}_{3}$ plus small amounts of $\mathrm{H}_{2} \mathrm{SO}_{4}$. Ultrasonic agitation was used to speed the cleaning. Finally, the samples were rinsed in distilled water.

The magnetic measurements were performed with a computer-controlled superconducting-quantum-interference-device (SQUID) variable-temperature susceptometer. The specimens were initially cooled to $5 \mathrm{~K}$ in zero applied magnetic field. The susceptibility was then measured over the temperature range 5 to $200 \mathrm{~K}$ in applied magnetic fields of $1,5,20$, and $50 \mathrm{mT}$. Thermohysteresis that has been reported in related alloys ${ }^{9}, 10$ was not observed with any of these samples.

The crystal lattice spacings were measured by X-ray diffraction using a modified commercial spectrometer. Details of the X-ray measurements appear elsewhere. 11

Sound velocities were determined by a technique detailed elsewhere. ${ }^{12,13}$ Briefly, a pulse-echo method was used to determine the velocity $v=2 \ell / \tau$, where $\tau$ denotes the round-trip time for an ultrasonic pulse between two flat, parallel specimen faces separated by a thickness, $\ell$. Measurements were made for both longitudinal and transverse waves. 


\section{RESULTS}

The $\mathrm{X}$-ray measurements indicate that the $\mathrm{C}+\mathrm{N}$ present in these alloys occur at interstitial sites. 11 These interstitials contribute to a gradual increase in the average lattice spacing, $\mathrm{a}_{0}$, with increased $\mathrm{C}+\mathrm{N}$ content. The linear relationship is obvious in Fig. 1 , where we have also included the unit cell. The lattice constant increases at the rate of $7.62 \times 10^{-3} \AA$ per at.\% $\mathrm{C}+\mathrm{N}$. A change in lattice spacing of this magnitude would be expected to have a noticeable effect on the magnetic behavior.

The magnetic susceptibility of each of the nine specimens displayed a distinct peak as a function of temperature. This behavior is characteristic of a paramagnetic-to-antiferromagnetic phase transition. 14 A plot of the reciprocal mass susceptibility versus temperature is shown in Fig. 2 . Above the transition temperature, the susceptibility was well described by a modified Curie-Weiss law:

$$
x(T)=x_{0}+C /(T+\theta),
$$

where $x_{O}, C$, and $\theta$ are constants.

The temperature-independent $x_{0}$ results from underlying diamagnetism, Pauli spin paramagnetism, 15,16 and a saturated ferromagnetic component due to small ferromagnetic clusters within the alloy. 5 The constants $C$ and $\theta$ represent the Curie constant and the paramagnetic Curie temperature. Table II gives the values of $X_{0}, C$, and $\theta$ obtained from the computer fit of Eq. 1 for all nine samples. 17 Figure 2 also shows a plot of $1 /\left(X-X_{0}\right)$ versus temperature for sample number 1 in a magnetic field of $20 \mathrm{mT}$. The line represents a fit of Eq. 1 to the data. The value of $x_{0}$ generally decreases as the concentration of $\mathrm{C}+\mathrm{N}$ interstitials increases. This is consistent with expected changes in the Landau-Peierls and Pauli susceptibilities ${ }^{15,16}$ due to the lattice dilation and the reduction of the Fermi energy.

The maximum value of the susceptibility is reduced with increased dc magnetic field. This behavior is similar to that reported by Warnes and $\mathrm{King}^{5}$ for $20 \mathrm{Cr}, 16 \mathrm{Ni}(\mathrm{wt} . \%)$ steel. In the present study, however, the peak was noticeably sharper and, at the fields employed, did not disappear as happened for the specimens studied at higher fields by Warnes and King 5 and Ishikawa et al. ${ }^{2}$ The position of the susceptibility maximum, which we take as $\mathrm{T}_{\mathrm{N}}$, was unaffected by the magnitude of the field over the region studied, 1 to $50 \mathrm{mT}$. In contrast, Warnes and King reported a gradual reduction in $\mathrm{T}_{\mathrm{N}}$ with increasing magnetic field for fields from $46 \mathrm{kA} / \mathrm{m}$ to $367 \mathrm{kA} / \mathrm{m}$ ( 58 to $460 \mathrm{mT}$ ) and a complete disappearance of the peak at still higher fields.

The positions of the maxima were strongly affected by small changes in the $\mathrm{C}+\mathrm{N}$ content, as seen in Fig. 3, where we have plotted normalized susceptibility, $X / X_{\max }$, versus temperature for three of the specimens. Increasing the $\mathrm{C}+\mathrm{N}$ content decreased the temperature of the susceptibility maximum, as shown by the solid circles in Fig. 4. The value of $\mathrm{T}_{\mathrm{N}}$ determined from the position of the susceptibility maximum decreased from 
$47.9 \pm 0.5 \mathrm{~K}$ at 0.34 at. $\% \mathrm{C}+\mathrm{N}$ to $35.0 \pm 0.5 \mathrm{~K}$ at 1.47 at. $\% \mathrm{C}+\mathrm{N}$. The line in Fig. 4 corresponds to a least-squares fit of the data, which gives an intercept at $54.0 \mathrm{~K}$ and a slope of $-12.73 \mathrm{~K} / \mathrm{at} . \%(\mathrm{C}+\mathrm{N})$.

The transition temperatures were also determined from the anomaly in the ultrasonic wave velocities.18,19 In Fig. 4 we have also plotted the values of $\mathrm{T}_{\mathrm{N}}$ obtained from the ultrasonic wave velocities. The values of $\mathrm{T}_{\mathrm{N}}$ obtained from the longitudinal velocities are larger than the values obtained from the susceptibility maxima, whereas the values of $\mathrm{T}_{\mathrm{N}}$ obtained from the transverse velocities are slightly lower. The general trend of $\mathrm{T}_{\mathrm{N}}$ versus $\mathrm{C}+\mathrm{N}$ (at.\%) from the elastic data parallel that of the susceptibility data. A fit of the ultrasonic data to a linear regression gives slightly different slopes for the transverse and longitudinal velocities, but within their statistical uncertainties they agree with the slope obtained from the susceptibilities.

\section{CONCLUSIONS}

We have observed a $27 \%$ decrease in the magnetic transition temperature for an increase in $\mathrm{C}+\mathrm{N}$ content from 0.34 to 1.47 at. $\%$. This considerable change in the transition temperature may be expected from the change in lattice parameter. However, this result is in marked contrast to the negligible influence presumed by previous researchers. 7 The negative result of the earlier work may be attributable to the narrow range of variation in the $\mathrm{C}+\mathrm{N}$ content in their samples.

The present observations warrant an expanded investigation into the influence of $\mathrm{C}+\mathrm{N}$ and other constituents of the $\mathrm{Fe}-\mathrm{Cr}-\mathrm{Ni}$ alloy system. Such a study is under way.

\section{ACKNOWLEDGMENTS}

The work was supported in part by a grant from NSF ISP-80-11451. The study at NBS was supported by the U.S. DOE Office of Fusion Energy.

\section{REFERENCES}

1. E. I. Kondorskii and V. L. Sedov, Sov. Phys. JETP 8, 1104 (1959).

2. Y. Ishikawa, Y. Endoh, and T. Takimoto, J. Phys. Chem. Solids 31,1225 (1970).

3. Y. Gonser, C. J. Meechan, A. H. Muir, and H. Wiedersich, J. Appl. Phys. 34,2373 (1963).

4. L. D. Flansburg and N. Hershkowitz, J. Appl. Phys. 41, 4082 (1970).

5. L. A. A. Warnes and H. W. King, Cryogenics 16, 473 (1976).

6. H. W. King and D. C. Larbalestier, Cryogenics 21, 521 (1981).

7. L. A. A. Warnes and H. W. King, Cryogenics 16, 659 (1976).

8. L. A. A. Warnes and H. W. King, Cryogenics 21, 729 (1981).

9. T. Datta, D. Thornberry, E. R. Jones, Jr。, and H. M. Ledbetter, Solid State Commun. 52, 515 (1984). 
10. T. Datta, D. Thornberry, C. Almasan, and E. R. Jones, Jr., Solid State Commun.; in press.

11. H. M. Ledbetter and M. W. Austin, Metall. Trans.; in press.

12. H. M. Ledbetter, N. F. Frederick, and M. W. Austin, J. App1. Phys. 51, 305 (1980).

13. H. M. Ledbetter and M. W. Austin, Mater. Sci. Eng., 70, 143 (1984).

14. S. Chikazumi, Physics of Magnetism (Wiley, New York, 1964), p. 82.

15. C. Kittel, Introduction to Solid State Physics (Wiley, New York, 1976), 5 th Ed., pp. 449-452.

16. R. M. White, Quantum Theory of Magnetism (Springer-Verlag, Berlin, 1983), 2nd Ed., Pp. 78-96.

17. The curves were fit using the NLIN procedure under SAS R, SAS Institute, Inc., P.0. Box 8000, Cary, North Carolina 25711.

18. E. W. Collings and H. M. Ledbetter, Phys. Lett. 72A, 59 (1979).

19. H. M. Ledbetter, Res. Mechanica; in press. 
Table I. Chemical composition (wt.\%)

\begin{tabular}{|c|c|c|c|c|c|c|c|c|c|c|c|}
\hline Alloy & $\mathrm{Cr}$ & $\mathrm{Ni}$ & Mn & $\mathrm{P}$ & $S$ & $\mathrm{Si}$ & Mo & $\mathrm{Cu}$ & C & $\mathrm{N}$ & $\mathrm{C}+\mathrm{N}$ \\
\hline 1 & 18.3 & 10.1 & 1.57 & 0.021 & 0.019 & 0.50 & 0.20 & 0.210 & 0.038 & 0.042 & $0.080^{\prime \prime}$ \\
\hline 2 & & & & & & & & & 0.062 & 0.043 & 0.105 \\
\hline 3 & & & & & & & & & 0.112 & 0.044 & 0.156 \\
\hline 4 & 18.0 & 9.91 & 1.50 & 0.022 & 0.017 & 0.57 & 0.205 & 0.197 & 0.055 & 0.137 & 0.192 \\
\hline 5 & & & & & & & & & 0.076 & 0.135 & 0.211 \\
\hline 6 & & & & & & & & & 0.096 & 0.129 & 0.225 \\
\hline 7 & 20.3 & 9.97 & 1.42 & 0.024 & 0.016 & 0.55 & 0.195 & 0.200 & 0.036 & 0.287 & 0.323 \\
\hline 8 & & & & & & & & & 0.062 & 0.278 & 0.340 \\
\hline 9 & & & & & & & & & 0.095 & 0.264 & 0.359 \\
\hline
\end{tabular}

Table II. Summary of magnetic measurements

\begin{tabular}{|c|c|c|c|c|c|}
\hline Alloy & $\begin{array}{c}\mathrm{T}^{\mathrm{a}} \\
(\mathrm{K})\end{array}$ & $\begin{array}{c}x_{\mathrm{o}} \\
\left(10^{-7} \mathrm{~m}^{3} / \mathrm{kg}\right)\end{array}$ & $-\left(10^{-5} \mathrm{~K} \cdot \mathrm{m}^{3} / \mathrm{kg}\right)$ & $\begin{array}{l}\theta^{b} \\
(\mathrm{~K})\end{array}$ & $\begin{array}{l}\mathrm{T}_{\mathrm{N}}^{\mathrm{C}} \\
(\mathrm{K})\end{array}$ \\
\hline 1 & $50-139$ & $3.68 \pm 0.15$ & $3.49 \pm 0.19$ & $-13.96 \pm 1.60$ & 47.9 \\
\hline 2 & $50-199$ & $2.89 \pm 0.05$ & $3.64 \pm 0.09$ & $-13.15 \pm 0.80$ & 48.1 \\
\hline 3 & $50-200$ & $2.70 \pm 0.06$ & $3.50 \pm 0.09$ & $-14.86 \pm 0.83$ & 47.1 \\
\hline 4 & $50-90$ & $2.38 \pm 0.10$ & $3.19 \pm 0.15$ & $-14.77 \pm 1.52$ & 44.3 \\
\hline 5 & $50-200$ & $2.71 \pm 0.06$ & $3.66 \pm 0.10$ & $-13.61 \pm 0.90$ & 43.8 \\
\hline 6 & $45-144$ & $2.13 \pm 0.21$ & $4.47 \pm 0.31$ & $-6.10 \pm 2.17$ & 42.25 \\
\hline 7 & $40-200$ & $2.93 \pm 0.03$ & $4.17 \pm 0.07$ & $-4.20 \pm 2.47$ & 36.5 \\
\hline 8 & $70-199$ & $2.17 \pm 0.01$ & $3.05 \pm 0.05$ & $-7.01 \pm 0.83$ & 36.4 \\
\hline 9 & $40-100$ & $1.45 \pm 0.61$ & $4.13 \pm 0.68$ & $-5.75 \pm 4.10$ & 35.0 \\
\hline
\end{tabular}

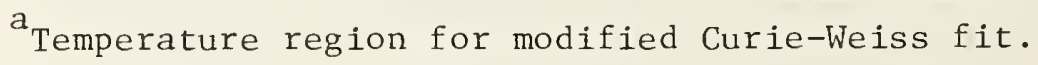

${ }^{b}$ Contants obtained from fit of $x=x_{0}+C /(T+\theta)$ to the data.

${ }^{c}$ ordering temperature obtained from susceptibility maxima. 


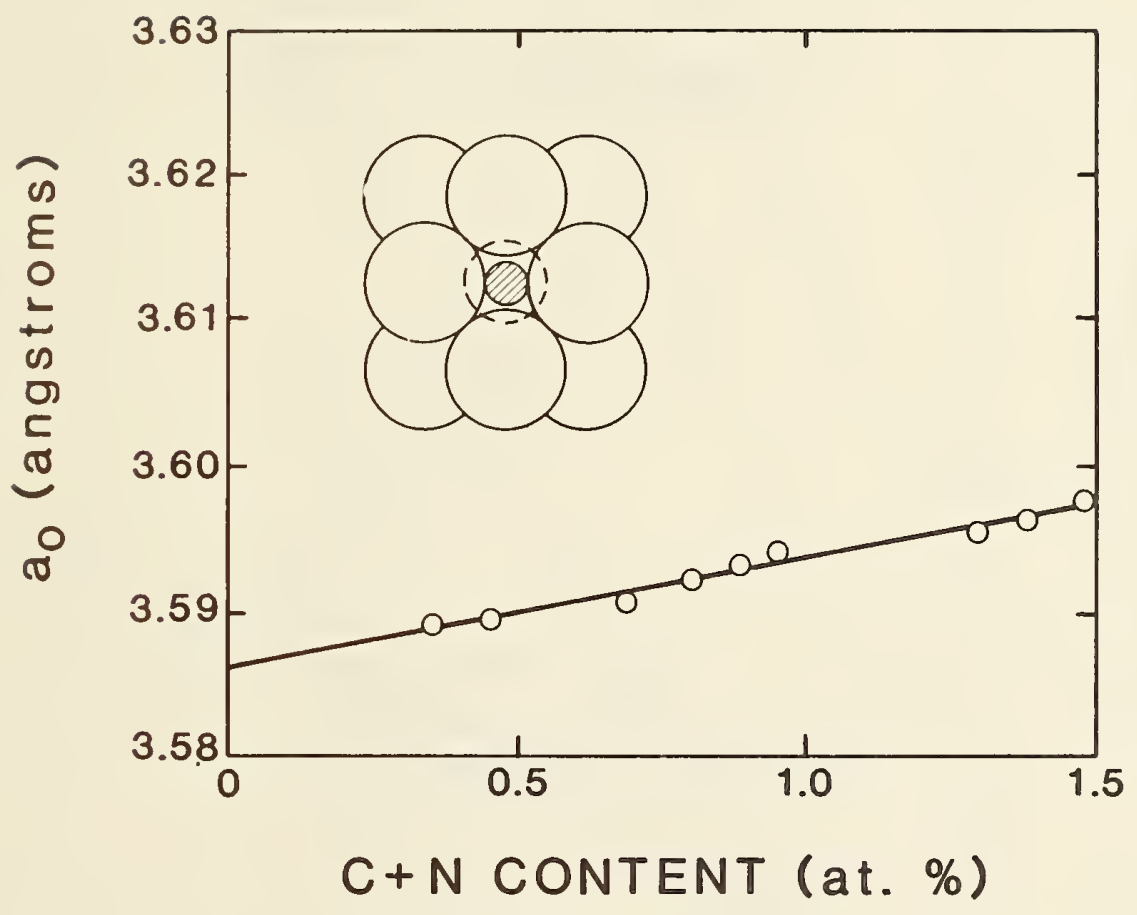

Fig. 1. Effect of $\mathrm{C}+\mathrm{N}$ content on the lattice constant a in fcc $\mathrm{Fe}-\mathrm{Cr}-\mathrm{Ni}$ steel. Insert shows schematic representation of the unit cell. Partly covered circles represent corner atoms. Full circles represent face-centered atoms. Shaded circle represents maximum diameter of octahedral hole. Dashed circle shows relative size of $\mathrm{C}$ atom in $\mathrm{Fe}$. 


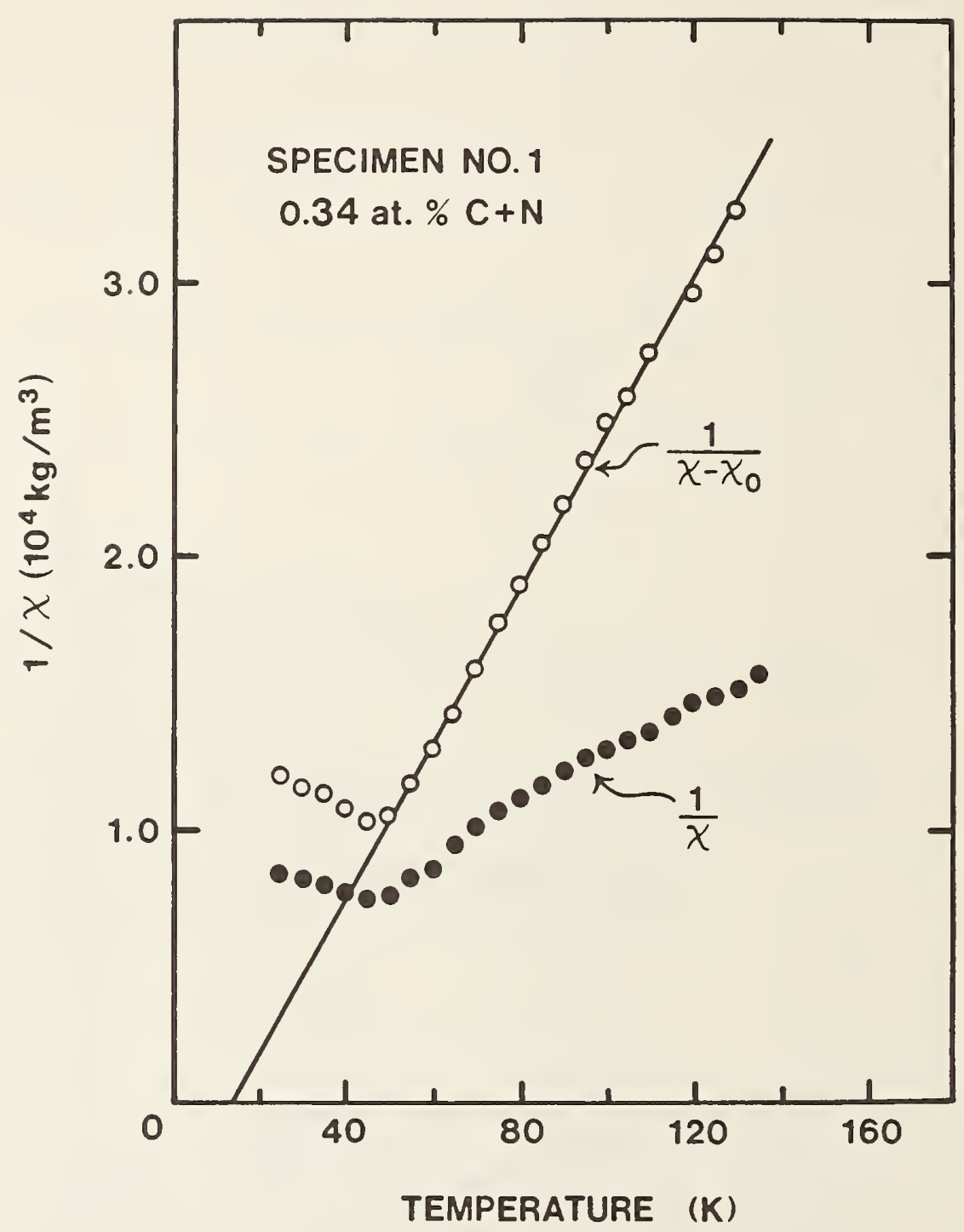

Fig. 2. The filled circles represent the inverse of the magnetic susceptibility, $x$, of Fe-Cr-Ni alloy no. 1 as a function of temperature in a field of $20 \mathrm{mT}$. A nonlinear behavior is observed above the transition temperature. The open circles represent the inverse of $x-x_{0}$. The straight line is the best fit of the data to $x-x_{0}=C /(T+\theta)$. 


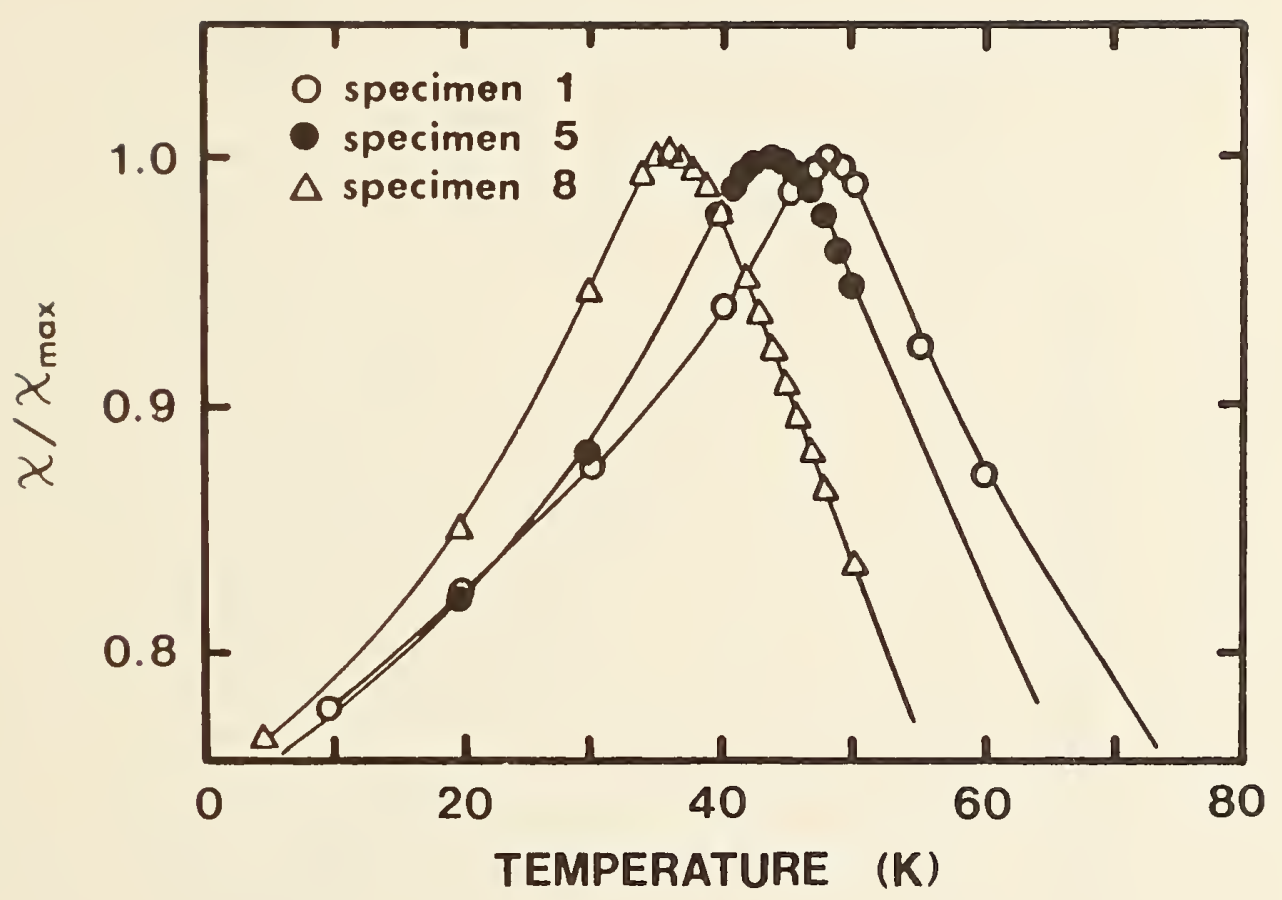

Fig. 3. Normalized magnetic susceptibility vs. temperature for three of the $\mathrm{Fe}-\mathrm{Cr}-\mathrm{Ni}$ alloys. 


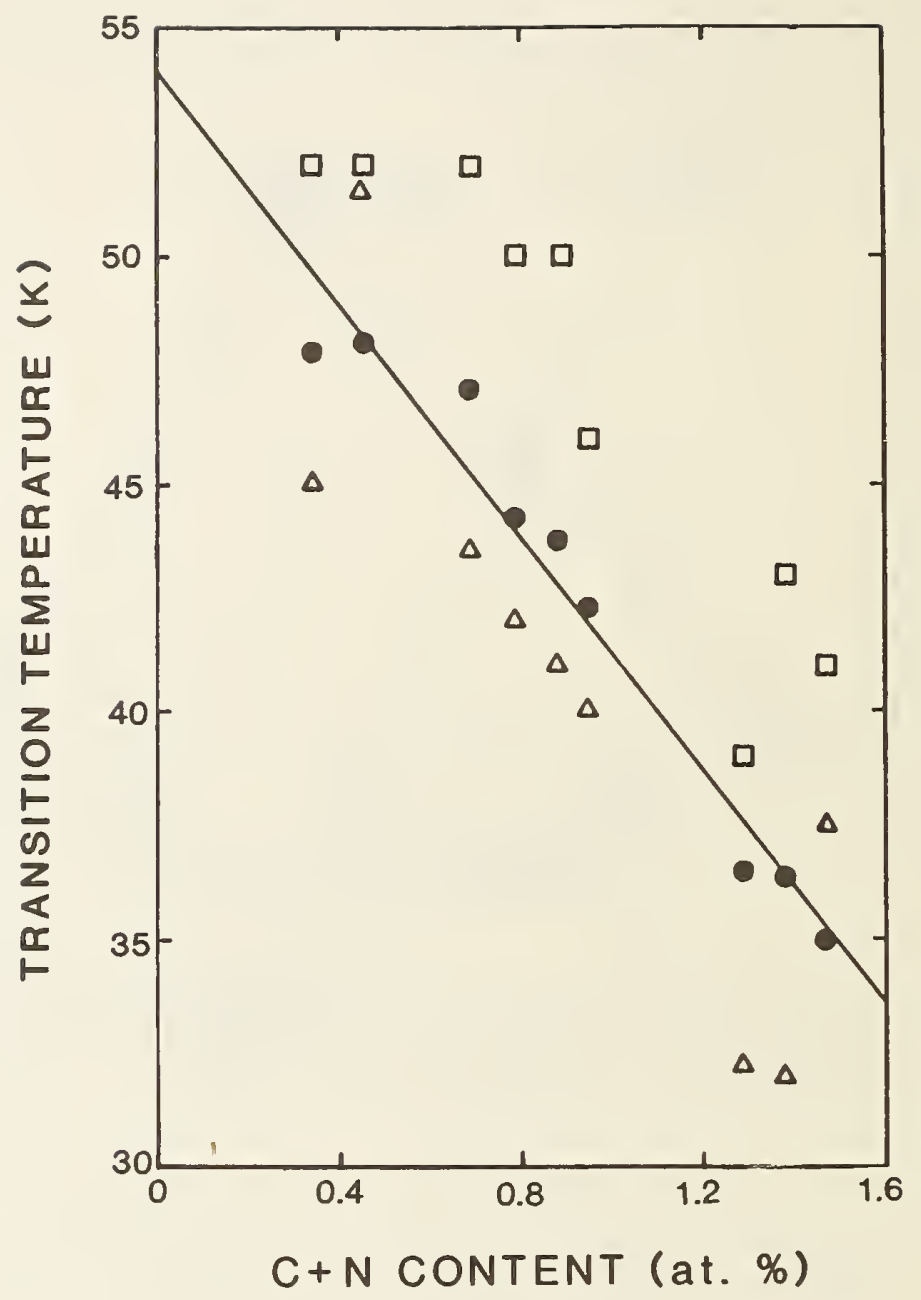

Fig. 4. Effect of $\mathrm{C}+\mathrm{N}$ content (at.\%) on Néel temperature as determined by: susceptibility (filled circles); transverse sound velocity (triangles); longitudinal sound velocity (squares). 


U.S./JAPAN COOPERATIVE PROGRAM COMMITTEE ON TEST METHODOLOGY FIRST DRAFT

FEBRUARY 1986

PROPOSED STANDARD METHOD

FOR TENSILE TESTING OF STRUCTURAL ALLOYS

AT LIQUID HELIUM TEMPERATURE

\section{SCOPE}

This document describes the procedures used in displacement-controlled tensile testing of structural alloys and weldments at liquid helium temperature, $4 \mathrm{~K}\left(-452^{\circ} \mathrm{F}\right)$. The format corresponds closely to ASTM standard designation E 8-83 entitled "Standard Methods of Tensile Testing of Metallic Materials." The contents include modifications to accommodate the special needs of cryogenic testing. To measure the tensile mechanical properties at a temperature of $4 \mathrm{~K}( \pm 1 \mathrm{~K})$, the specimen is tested at a low strain rate while fully submerged in liquid helium. This document addresses the need for the proper cryogenic apparatus and other relevant concerns, such as specimen size, serrated yielding, adiabatic heating, and strain rate.

2. APPLICABLE DOCUMENTS

ASTM Standards:

E 4 - "Practices of Load Verification of Testing Machines" (ANNUAL BOOK OF ASTM STANDARDS, vol. 03.01)

E 6 - "Definition of Terms Relating to Methods of Mechanical Testing" (ANNUAL BOOK OF ASTM STANDARDS, Vol. 03.01)

E 8 - "Standard Methods of Tension Testing of Metallic Materials" (ANNUAL BOOK OF ASTM STANDARDS, Vol. 03.01) 


\section{DEFINITIONS}

The definitions of terms relating to tension testing in ASTM Standard E 6 apply to this standard. Two additional definitions are needed:

a. A cryostat, schematically illustrated in Figure 1, is a chamber consisting of a loading frame and Dewar assembly for applying loads to test specimens in low temperature environments.

b. Adiabatic heating is the internal temperature rise of a specimen owing to tensile testing under conditions such that the heat generated by plastic work cannot be quickly dissipated to the surrounding cooling medium. 4. SIGNIFICANCE

The significance of tensile tests in general is described in ASTM E 8 , section 4. At $4 \mathrm{~K}$, tensile tests of metallic materials are unique in that the typical stress-strain curves obtained in displacement-controlled tests are serrated. The serrations are formed by bursts of unstable plastic flow, followed by arrests. The plastic deformation occurs locally with sizable heat evolution at higher than nominal rates of strain, resulting in periodic reduction of load--or serrated yields.

\section{Note 1}

The exact form of the stress-strain curve during unstable plastic deformation depends on whether load or displacement control is used. Displacement control should be used for conventional material property characterization.

Serrated yielding has been observed in a wide variety of metals and alloys, including austenitic stainless steels, aluminum, and copper alloys, when test temperatures are $20 \mathrm{~K}$ or lower [1-7]. Representative stress-strain curves for an austenitic stainless steel (Figure 2) show no serrations at 295, 195, and $76 \mathrm{~K}$. Serrations appear only in the extreme cryogenic range where (a) the volume specific heat tends toward zero, (b) the thermal 
conductivity rapidly decreases, and (c) the flow strength depends strongly on temperature.

At $295 \mathrm{~K}$ the specimen temperature rise during straining is relatively small, a few degrees or less at the strain rates normally used. As the test temperature decreases, the specific heat decreases so that the temperature rise becomes greater for a given amount of work. Moreover, the thermal conductivity decreases at low temperatures. Thus, when work is done on a specimen during tensile tests at low temperatures, the resultant internal heat is less easily dissipated.

These trends become increasingly pronounced at lower temperatures. At $4 \mathrm{~K}$ if tests are conducted at rates normally used at room temperature, the internal temperature $r$ ise is quite substantial. The effects of adiabatic heating depend on material composition, but in austenitic stainless steels, for example, temperature rises greater than $50 \mathrm{~K}$ have been reported [6]. Such temperature rises may lower the measured yield and ultimate strengths while increasing the elongation and reduction of area [7]. Therefore, specifications are required for the cooling medium and allowable nominal strain rates to ensure accurate and reproducible property measurements at $4 \mathrm{~K}$.

\section{Note 2}

The most widely accepted explanation for such behavior is from Basinski $[1,2]$. His model applies to metals because their specific heat decreases greatly and their flow strength increases greatly as their temperature approaches $4 \mathrm{~K}$.

The adiabatic heating mechanism is pictured as follows: Heating during dislocation movement causes appreciable softening, and deformation becomes unstable. Low thermal conductivity at $4 \mathrm{~K}$ (compared with that at $295 \mathrm{~K}$ ) contributes to a localization of the heat to produce load instability. During instability the plastic flow is localized, and the thermal softening due 
to heat generated by plastic straining is greater than the strain hardening. Rapid load drops (serrated yields) are associated with each local instability. The instability is eventually arrested at some strain and temperature where the flow process becomes stable, owing to local specimen strain hardening that distributes the load over an ever-increasing area at a time when the rise of specific heat precludes continued temperature increases. Once the flow has become stable again, the specimen cools to $4 \mathrm{~K}$, and with further deformation, the process repeats.

Localized specimen strain, associated with each load drop, proceeds along the specimen, in a manner similar to Lueder's band formation at ambient temperatures.

\section{APPARATUS}

\subsection{Test Machines}

Machines used for tension testing shall conform to the requirements of ASTM E 4.

At low temperatures the strengths of most metals and alloys increase significantly, sometimes doubling or tripling between 295 and $4 \mathrm{~K}$. As a result of such strengthening, higher loads must be applied to the specimen, grips, load train, and cryostat at cryogenic temperatures, assuming a constant specimen size. If the loads required to determine the yield and tensile strengths fall outside the range of the available testing apparatus (see ASTM E 4) then the specimen cross-sectional size must be reduced.

\subsection{Grips}

Any of the gripping mechanisms discussed in ASTM E 8, section 5.2 may be used for cryogenic tests. The choice depends on specimen type. For the round-bar and flat specimens, the threaded-end or pin-loaded grips are frequently used at $4 \mathrm{~K}$. 
Grips may be attached at the bottom of cryostats using spherically seated bearings, such as those shown in Figures 2 and 3 of ASTM E 8 . To reduce friction at $4 \mathrm{~K}$, the bearing surfaces may be coated with a suitable dry lubricant, such as solid molybdenum disulfide compounds.

To resist embrittlement at $4 \mathrm{~K}$, the grips should be made of strong, tough cryogenic structural alloys. Austenitic stainless steels (AISI 304LN), maraging steels $(200,250$, and 300 grades), and titanium alloys (Ti-6Al-4V ELI and Ti-5Al-2.5Sn ELI) have worked well.

5.3 Dimension-Measuring Devices

See ASTM E 8, section 5.3.

5.4 Cryostat

A cryostat capable of retaining liquid helium for the entire duration of the test must be provided to achieve the desired temperature of $4 \mathrm{~K}( \pm 1 \mathrm{~K})$. Cryostat load frames must be custom-built, but Dewars for 4-K service are available commercially. Factors contributing to efficient cryostat design are discussed by Fowlkes and Tobler [8]. Several practical designs are described in the literature [8-12], including a rotating-turret cryostat designed for multiple-specimen testing [12].

Either a single- or double-Dewar configuration may be used. In the double-Dewar arrangement, as shown in Figure 1, an outer Dewar of liquid nitrogen is used to provide a jacket for the inner Dewar of liquid helium. In any case, the Dewar and lines for transferring liquid helium must be vacuum insulated.

\subsection{Liquid Level Indicator}

A level indicator is required to ensure that the specimen is submerged in liquid helium at all times during the test. On-off indicators, such as the carbon-resistor type, may be used to verify that the liquid helium level 
exceeds some reference point above the specimen. Alternatively, the position of the liquid level may be continuously monitored with superconducting element sensors of various lengths attached vertically to the cryostat.

\subsection{Extensometers}

Strain during specimen alignment or tensile testing may be measured using surface-bonded strain-gage films or detachable extensometers. Information on appropriate apparatus and techniques is given in References 13 through 15 .

\section{6 .1 Strain gages}

A strain gage bonded to the specimen in the axial direction may be used to measure strain during tensile tests at $4 \mathrm{~K}$. Strain-gage films are produced in great variety, but not every $k$ ind is suitable for $4-K$ service. An appropriate gage active element, backing material, and bonding agent should be selected on the basis of literature precedents and manufacturers' recommendations. One approach that has proven quite successful is a nickelchromium alloy having a self-temperature-compensated active element and a glass-fiber-reinforced epoxy-phenolic resin with a fully encapsulated matrix $(350 \Omega)[14]$.

To compensate for any misalignment, two gages may be used, aligned in the axial direction on diametrically opposite specimen surfaces. Each gage should be wired to a dummy bridge using the three-wire temperature-compensating hookup as shown in Figure 3. A low excitation voltage of about $1.25 \mathrm{~V}$ is preferred for $350-\Omega$ gages at $4 \mathrm{~K}$.

Calibration of strain gages at room temperature requires calibration of the electronics to changes in resistance. Calibration of strain gages at $4 \mathrm{~K}$ requires consideration of the temperature dependence of the resistance in the 
electronlc calibration. Typical full-scale calibration ranges are $1 \%$ at room temperature and $2 \%$ at $4 \mathrm{~K}$.

\subsubsection{Detachable Strain-Gage Extensometers}

With careful materials selection and design, demountable extensometers can be built to resist thermal shock and moisture condensation for operation at $4 \mathrm{k}$. Unlike directly bonded strain gages, these extensometers can be reused $[14-15]$

The most common extensometer of this type is the clip-on gage, which may be custom-built or purchased. A satisfactory example is the cantilever beam gage [15]. The extension of the specimen within its gage length is sensed by the cantilever beam gage, which is clipped to the specimen between retaining pins that are fixed to the specimen. Such extensometers use four strain-gage flims bonded to the gage in a Wheatstone bridge arrangement.

The extensometer must be calibrated directly at room temperature and at $4 \mathrm{~K}$ using a suitable calibration device. For calibrations at $4 \mathrm{~K}$, a barrel micrometer fitted with vertical extension tubes can be used with clip gages mounted at the bottom end and immersed in liquid helium.

Extensometers that use capacitance measurement to monitor strain have also been used. The overlapping cylinder type has an extended strain range, capacitance output that is linear with strain, and adjustable sensitivity. The parallel-plate type has high sensitivity, but its output must be compensated for the hyperbolic dependence of capacitance on strain.

\section{Note 3}

Once the calibration is known and proven to be accurate, linear, and reproducible, then room temperature checks can be performed prior to each test series as an indirect verification of the 4-K calibration. However, the calibration at $4 \mathrm{~K}$ must be directly confirmed periodically and whenever damage is suspected, repair has been performed, or gages replaced. 


\section{TEST SPECIMENS}

\subsection{General}

Any specimen type cited in ASTM E 8 may be used for tests at $4 \mathrm{~K}$. The appropriate specifications for specimens (e.g., dimensions, gage length, location, surface finish) are given in ASTM E 8, sections 6.1 through 6.17 .

Specimens taken from sheet or wire products having relatively small cross-sectional areas can be tested in typical cryogenic apparatus. However, specimens from relatively thick plate or bar products may need to be machined to a reduced cross-sectional area so that the maximum load capability of the cryogenic test apparatus is not exceeded.

\subsection{Round-Bar Specimens}

\subsubsection{Standard specimen}

The recommended standard specimen for $4-\mathrm{K}$ tensile testing is the $6.25-\mathrm{mm}-$ diameter bar specimen. A specimen of this type with threaded ends and a gage length of $25.4 \mathrm{~mm}$ is shown in Figure 4. Its proportions are similar to those of the standard $12.5-\mathrm{mm}$-diameter specimen of ASTM E 8 . A schematic with relevant notes and specifications on tolerances is given in Figure 8 of ASTM E $8-83$.

\section{Note 4}

The 6.25-mm-diameter specimen replaces the 12.5-mm-diameter specimen of ASTM E 8 section 6.2 as standard because of its size. In tests of strong alloys at $4 \mathrm{~K}$, the $12.5-\mathrm{mm}$-diameter specimen requires high loads. For example, about $210 \mathrm{kN}$ is required to test AISI $304 \mathrm{LN}$ (ultimate strength $=1690 \mathrm{MPa}$ at $4 \mathrm{~K}$ ), whereas $100 \mathrm{kN}$ is the upper limit for most cryogenic test machines.

\subsubsection{Subsize specimens}

If it is not appropriate to use the standard 6.25-mm-diameter specimen, then another size or geometry may be selected, following ASTM E 8-83 guidelines. For any subsize specimen: (a) the gage length for measurement of 
elongation should be four times the specimen diameter and (b) the average grain size of the test material should be reported.

\section{PROCEDURES}

\subsection{Specimen Installation}

The specimen must be installed in the gripping fixture such that the instrumentation wires are free of tension and have enough slack so that they will be neither stretched nor crimped during cryostat assembly and testing.

\subsection{Alignment}

Proper alignment is essential to avoid unwanted bending of the specimen. The longitudinal axis of the specimen should coincide with the centerline of the test machine heads. Cryostats may be designed with adjustable loading columns or posts to facilitate the overall alignment.

Alignment may be assessed at room temperature with specimens instrumented with several axial strain gages or extensometers. Axial strain readings from any point around the circumference of the specimen in the gage length area must agree within $5 \%$ of the average value of all readings. During the process of alignment, the applied loads should be kept below one-third of the proportional limit of the test material.

\subsection{Cool-down Procedure}

a. Remove any moisture present on the apparatus prior to cool-down by drying thoroughly with a pressurized air jet or heat gun. Ice formations may block cryogenic transfer lines or cause erratic loading behavior if buildup occurs between various parts of the specimen, grips, and load train.

b. Assemble the Dewar and precool the apparatus by transferring liquid nitrogen into the cryostat. After equilibrium is reached at $77 \mathrm{~K}$, be sure to remove all of the liquid nitrogen (or transfer it to the outer Dewar if a double-Dewar arrangement is used). 
c. Transfer liquid helium into the cryostat until the specimen is fully submerged. Testing may begin after the system has reached equilibrium at $4 \mathrm{~K}$. The specimen must be covered with liquid helium at all times during the test to ensure that the temperature remains constant $( \pm 1 \mathrm{~K})$ and free of gradients along its entire length.

\section{Note 5}

The heat transfer characteristics of gases are poorer than those of liquids. The thermal conductance of the specimen and the heat capacities of both the specimen and gas change with temperature. Therefore, a liquid helium environment is required to minimize internal heating effects.

\subsection{Speed of Testing}

The speed of testing at $4 \mathrm{~K}$ must be specified in terms of the nominal rate of straining. Any convenient speed may be used up to a stress of onehalf the yield strength; thereafter, the rate of straining must not exceed $5 \times 10^{-4} \mathrm{~s}^{-1}$.

Some test machines are equipped with pacing or indicating devices for measurement and control of strain rates. In the absence of such a device, the average rate of straining can be determined by observing the time required to effect a known increment of strain.

\section{Note 6}

Rates of strain exceeding $5 \times 10^{-4} \mathrm{~s}^{-1}$ may cause significant temperature control problems and inaccurate property measurements. Tests are currently in progress to determine the effects more precisely. The present recommendation is based on the current practice of NBS. It may be revised when additional strain-rate sensitivity data become available.

\subsection{Measurement of Mechanical Properties}

a. Measure the yield strength of the specimen according to the $0.2 \%$ offset method, following ASTM E 8, section 7.3.1. If a load drop occurs before the point of intersection of the stress-strain curve and the $0.2 \%$ 
orrset line, then report the stress at the highest load preceeding the intersection point as the yield strength.

b. Use a strain-measurement device (such as a strain gage; strain-gage, clamp-on extensometer; linear variable differential transformer; or capacitance sensor) to obtain yield strength data at $4 \mathrm{~K}$.

\section{Note 7}

Normal efficient cryostat and load trains for testing at $4 \mathrm{~K}$ are comparatively "soft." The effective modulus of the load-train system is low and depends on the liquid helium level and the degree of temperature stabilization that is achievable throughout the load system in the temperature range 295 to $4 \mathrm{~K}$. Therefore, attempts to measure yield strength from offsets of load versus time have large potential error. This technique is not recommended.

c. Measure the tensile strength, elongation, and reduction of area according to ASTM E 8 , sections 7.5 to 7.7 , respectively.

d. Round the calculated test data according to ASTM E 8, section 7.8.

e. If necessary, discard data and test replacement specimens as per

ASTM E 8, section 7.9 .

8. TEST REPORT

\subsection{Individual Specimens}

The test report shall include the following data for each individual specimen:

a. Test temperature and environment

b. Specimen geometry, size, and orientation relative to the principal working directions of the original stock

c. Nominal rate of straining

d. Yield and ultimate strengths

e. Elongation and reduction of area 
f. Optional data, such as the original and final specimen dimensions (areas and gage lengths), the measured value of Young's modulus, and the material's average grain size.

8.2 Replicate Specimens

If replicate specimens are tested, the report should include the number of replicate specimens tested and the average values of all mechanical property measurements with a measure of scatter.

\subsection{Substandard specimens}

For subsize specimens, the average grain size of the material must be given.

8.4 Anomalous Behaviors

Any anomalies observed with respect to test procedures, specimen behavior, or failure location must be described.

9. PRECISION AND ACCURACY

See ASTM E 8, section 8 .

10. REFERENCES

1. Basinski, Z. S., "The Instability of Plastic Flow of Metals at Very Low Temperatures", Proceedings of the Royal Society, vol. A 240, 1957, pp. $229-242$.

2. Basinski, Z. S., Australian Journal of Physics, vol. 13, 1960, pp. 354-358.

3. Powell, G. W., Marshall, E. R., and Backofen, W. A., Transactions of the ASM, vol. 50, 1958, pp. 478-497.

4. Wessel, E. T., Transactions of the ASM, vol. 49, 1957, pp. 149-172.

5. Read, D. T. and Reed, R. P., "Heating Effects During Tensile Tests of AISI 304L Stainless Steel at $4 \mathrm{~K}$ " Advances in Cryogenic Engineering-Materials, vol. 26, Plenum, New York, 1980, pp. 91-101.

6. Ogata, T., Ishikawa, K., Hiraga, K., Nagai, K., and Yuri, T., "Temperature Rise During the Tensile Test in Superfluid Helium," Cryogenics, vol. 25, no. 8, August 1985, pp. 444-446. 
7. Dobson, W. G. and Johnson, D. L., "Effect of Strain Rate on Measured Mechanical Properties of Stainless Steel at $4 \mathrm{~K}$," Advances in Cryogenic Engineering--Materials, vol. 30, Plenum, New York, 1984, pp. 185-192.

8. Fowlkes, C. F, and Tobler, R. L., "Fracture Testing and Results for a Ti-6Al-4V Alloy at Liquid Helium Temperature," Engineering Fracture Mechanics, vol. 8, 1976, pp. 487-500.

9. Reed, R. P., "A Cryostat for Tensile Tests in the Temperature Range $300^{\circ}$ to $4^{\circ} \mathrm{K}$, Advances in Cryogenic Engineering, vol. 7, Plenum, New York, 1962, pp. 448-454.

10. Hartwig, G. and Wuchner, F., "Low Temperature Mechanical Testing Machine," Review of Scientific Instruments, vol. 46, No. 4, 1975, pp. $481-485$.

11. Novikov, N. V., "Mechanical Property Measurement Techniques of Structural Materials at Cryogenic Temperatures," Advances in Cryogenic Engineering, vol. 22, Plenum, New York, 1977, pp. 113-118.

12. Horiuchi, T., Shimada, M., Fukutsuka, T., and Tokuda, S., "Design and Construction of an Apparatus for Testing Materials at Cryogenic Temperatures," Proceedings of the Fifth International Cryogenic Engineering Conference, IPC Science and Technology Press, Guildford, Surrey, England, 1977, pp. 465-468.

13. Sparks, L. L., "Temperature, Strain, and Magnetic Field Measurements," Chapter 14 in: Materials at Low Temperatures, R. P. Reed and A. F. Clark, eds., American Society for Metals, Metals Park, Onio, 1983, pp. 555-559.

14. Tobler, R. L. and Shepic, J. A., "Design and Performance of a Ring-Shaped Clip Gage," Journal of Testing and Evaluation, vol. 13, No. 4, 1985, pp. 299-302.

15. Read, D. T. and Tobler, R. L., "Mechanical Property Measurement at Low Temperatures," in Advances in Cryogenic Engineering--Materials, vol. 28, Plenum, New York, 1982, pp. 17-28. 


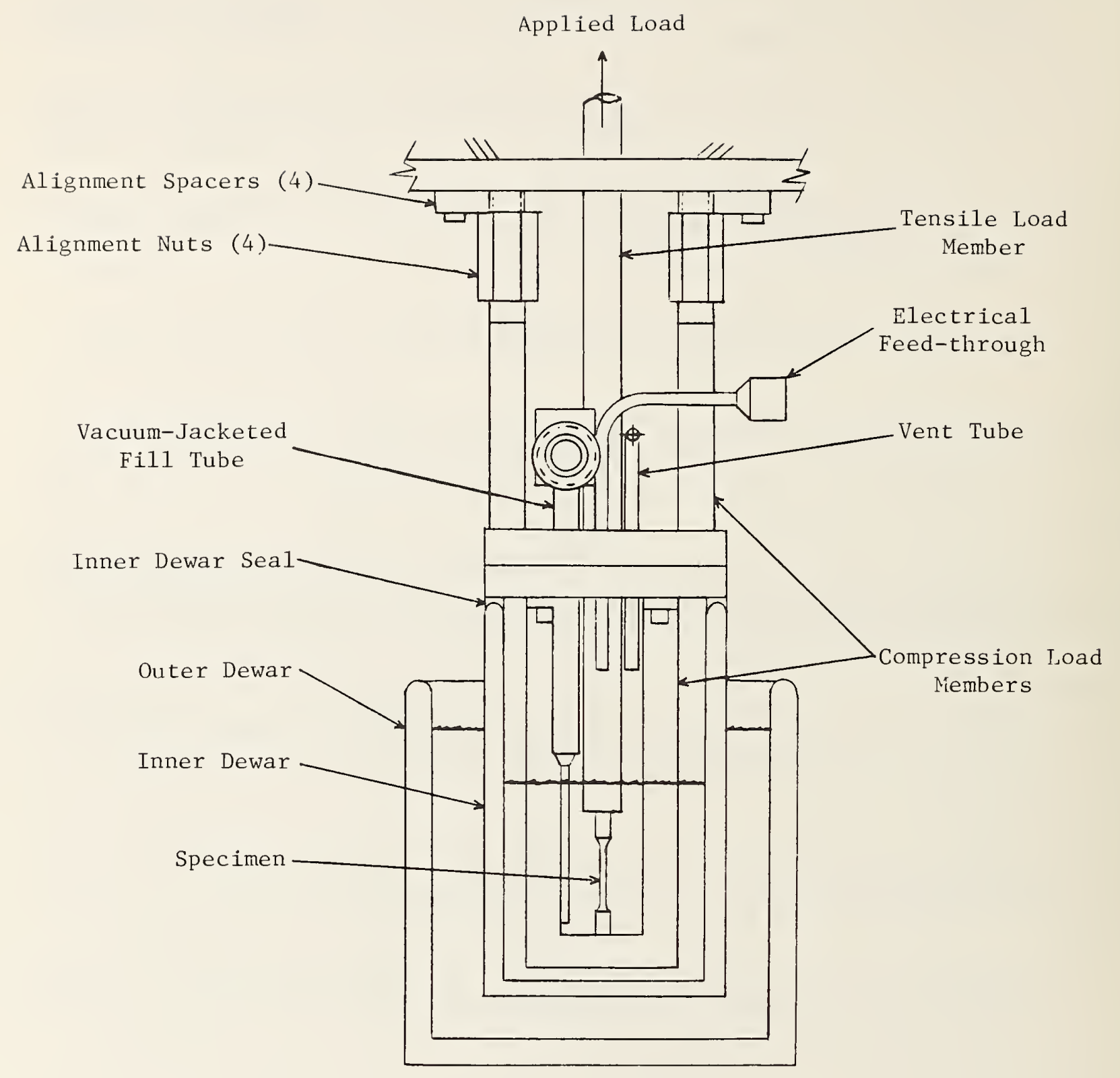

Figure 1. A cryostat with double-Dewar arrangement for tensile testing at $4 \mathrm{~K}$. 


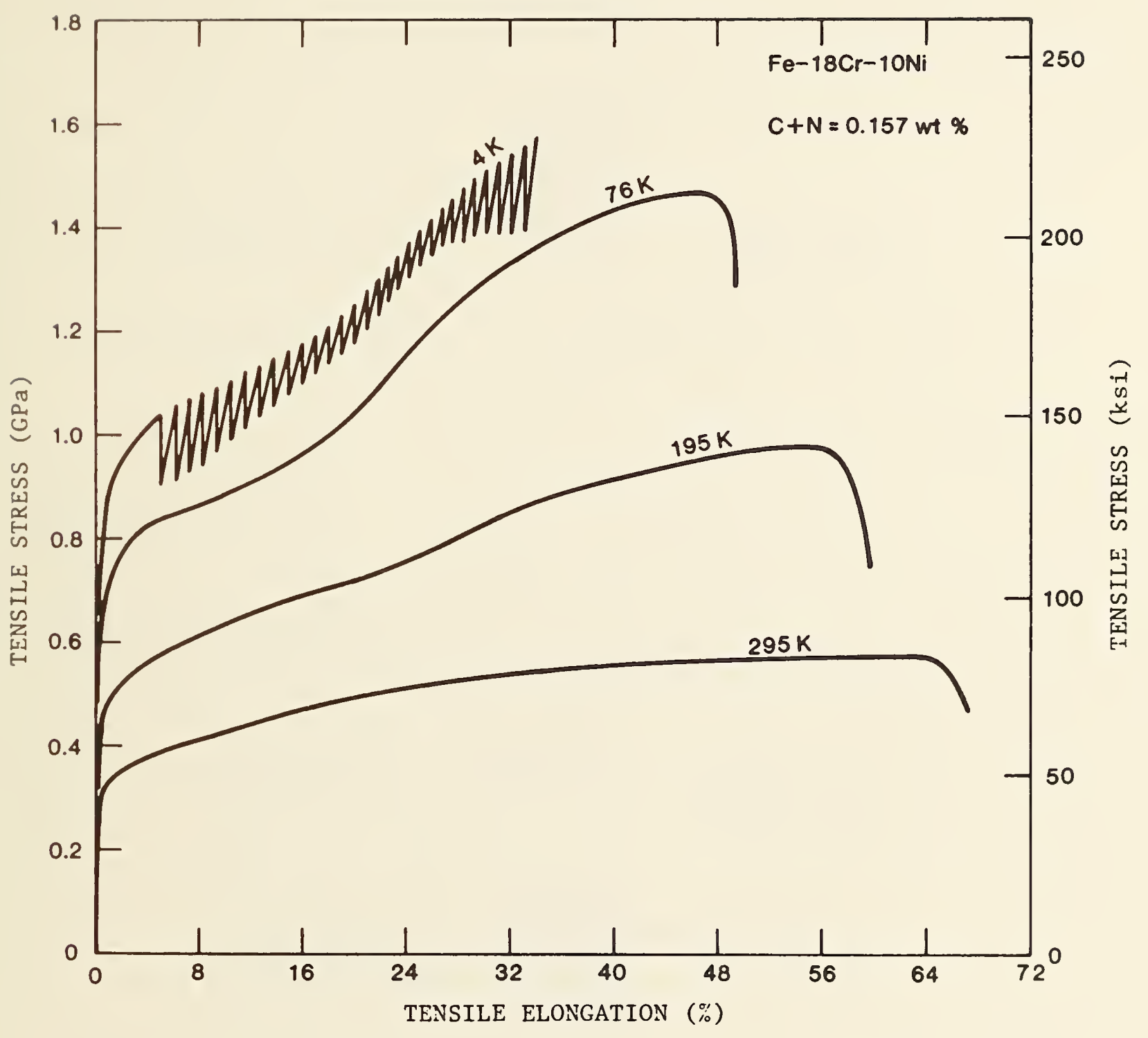

Figure 2. Engineering stress-strain curves for an $\mathrm{Fe}-18 \mathrm{Cr}-10 \mathrm{Ni}$ austenitic stainless steel at 295, 195, 76, and $4 \mathrm{~K}$. 


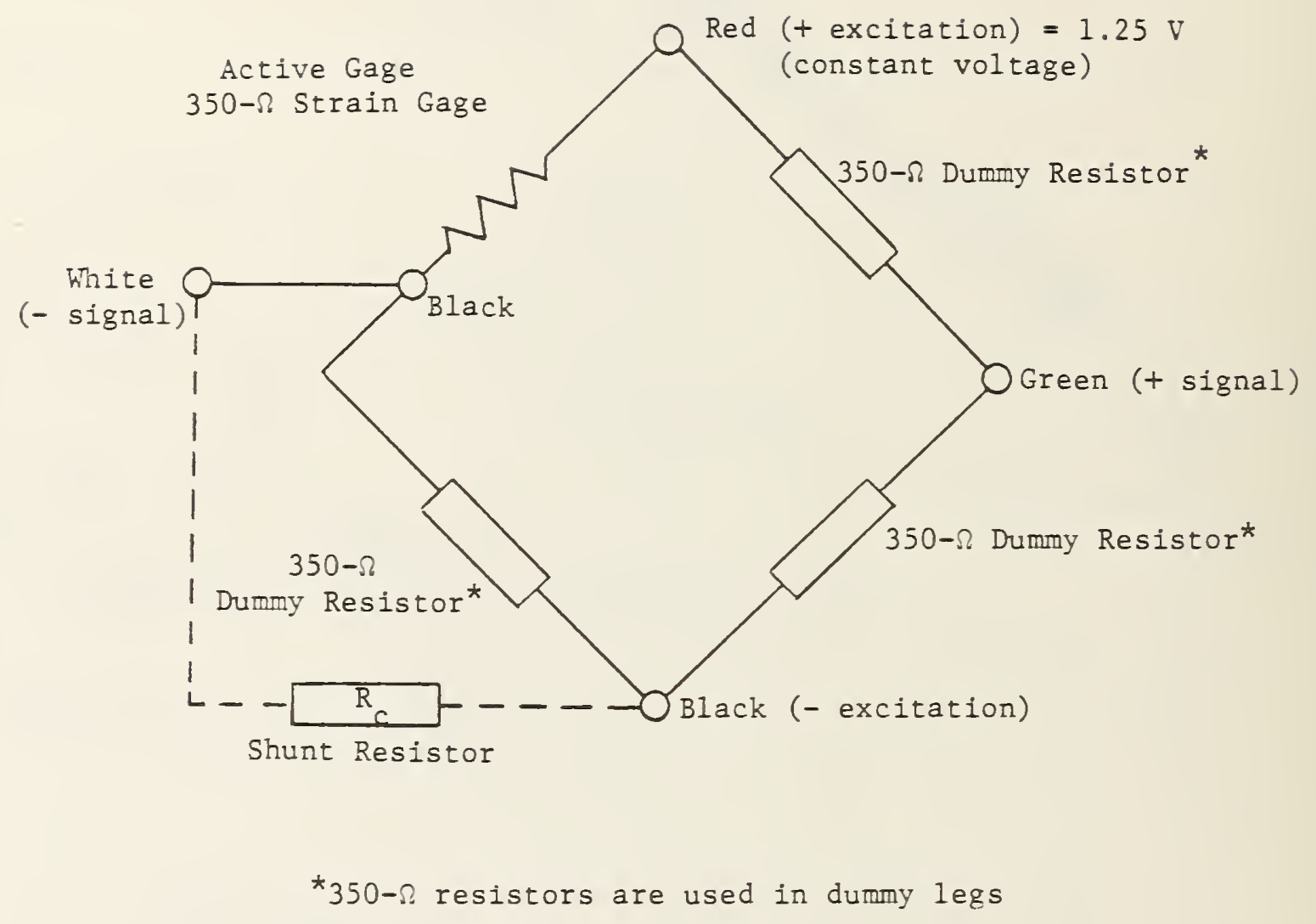

Eigure 3. Method of strain gage wiring for cryogenic tests. 


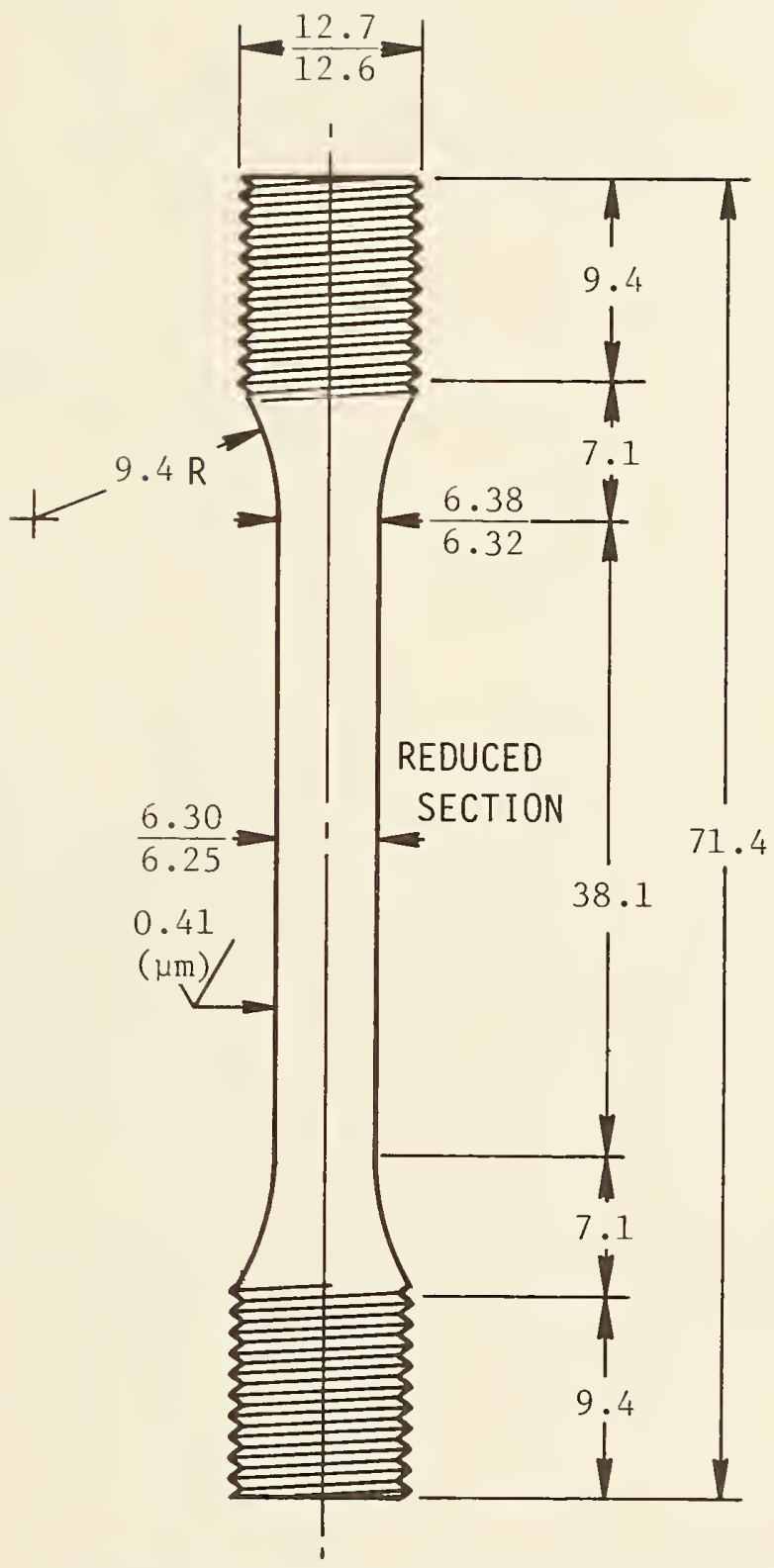

Dimensions are in millimeters

Figure 4. A 6.25-mm-diameter tensile test specimen with threaded ends (see Fig. 8 of ASTM E $8-83$ and all relevant notes). 



U.S. / JAPAN COOPERATIVE PROGRAM COMMITTEE ON TEST METHODOLOGY

SECOND DRAFT

February 1986

PROPOSED STANDARD METHOD

FOR FRACTURE TOUGHNESS TESTING OF STRUCTURAL ALLOYS

AT LIQUID HELIUM TEMPERATURE

\section{SCOPE}

This method covers the equipment, procedures, and data analysis used for determining the fracture toughness of structural alloys and weldments at liquid helium temperature, $4 \mathrm{~K}\left(-452^{\circ} \mathrm{F}\right)$. The procedures described here represent modifications of the $K_{I c}$ and $J_{I c}$ plane strain fracture toughness tests as described in ASTM Standards E 399-83 and E 813-81, to accommodate the special requirements of cryogenic testing. Since materials that show ductile tearing in areas of normal thickness are usually used for liquid helium applications, the $J_{I c}$ test procedure is given primary emphasis in this method.

2. APPLICABLE DOCUMENTS

See ASTM E 399-83, section 2 and ASTM E 813-81, section 2.

3. SUMMARY OF METHOD

See ASTM E 813-81, section 3.

To achieve the desired temperature of $4 \mathrm{~K}$, the specimen is tested while fully submerged in liquid helium using a cryostat (described in 6.1). The pin-loaded compact specimen is preferred, because it offers the largest fracture toughness measurement capacity for its size of any of the common fracture specimens. A relatively low load applied to the compact specimen 
produces a large stress intensity factor. This allows a minimum mass to be used for grips, cryostat frame, and loading train, which significantly reduces the liquid helium consumption and cost per test.

\section{Note 1}

Three-point bend specimens may also be used, but they require more mass for an equivalent ligament size. The longer span of the bend specimen transverse to the load axis necessitates more cumbersome loading fixtures, which may be disadvantageous for some cryostats.

\section{SIGNIFICANCE}

See ASTM E 813-81, section 4.

The type of load-deflection behavior exhibited by a material determines whether $\mathrm{J}_{\mathrm{Ic}}$ or $\mathrm{K}_{\mathrm{Ic}}$ can be directly measured, as indicated in Figure 1. The parameter $J_{I c}$ is used to characterize materials where the load-deflection behavior is nonlinear (i.e., elastic-plastic or fully plastic) and where the plastic zone at the crack tip is relatively large compared with the crack size and specimen dimensions. The parameter $\mathrm{K}_{\mathrm{Ic}}$ is used to characterize materials where the load-deflection behavior is linear or nearly so and where the plastic zone at the crack tip is small compared with the crack size and specimen dimensions.

The two parameters, $J_{I c}$ and $K_{I c}$, are interconvertible under appropriate circumstances. Together, they are suitable for characterizing a broad range of materials. The JIc values are routinely converted to obtain estimates of $\mathrm{K}_{\mathrm{Ic}}$ via the relation: $\mathrm{K}_{\mathrm{IC}}^{2}=\mathrm{J}_{\mathrm{Ic}} \cdot \mathrm{E}$ (see ASTM E 813-81, section 9.4). However, for many austenitic alloys the occurrence of linear-elastic behavior has not been demonstrated and could be expected only in extremely thick sections, if 
at all. It must be appreciated that estimations of $K_{I c}$ from $J_{I c}$ are often performed merely for the purposes of comparison, and this does not necessarlly imply that the given material will display a linear-elastic fracture.

The fracture behavior of ductile alloys at $4 \mathrm{~K}$ may be affected by adiabatic heating during rapid loading $[1-4]$. Therefore, JIc for ductile alloys is measured at low loading rates (see section 8.2 ) to minimize any adiabatic neating.

A number of alloys of intermediate toughness can not be tested satisfactorily according to the E 399-83 and E 813-81 methods. In these materials, fast fracture occurs prior to the full development of the required four-point resistance curve, but the load-deflection behavior is sufficiently nonlinear to invalidate a $\mathrm{K}_{\mathrm{Ic}}$ test analysis. In such cases, increasing the specimen thickness in subsequent tests may result in a valid $K_{I c}$ test. There is, however, no assurance that valid results for practical specimen sizes can be obtained by the procedures of this method.

5. TERMINOLOGY

See ASTM E 616-82, ASTM E 813-81, section 5, and ASTM E 399-83, section 5. 6. APPARATUS

See ASTM E 813-81, section 6.

6.1 Cryostats

A cryostat must be provided to cool and test the specimen at $4 \mathrm{~K}$. A cryostat consists of a load frame and at least one vacuum-insulated Dewar for containing liquid helium. Cryostat designs vary according to function and ingenuity, but the goal is always to achieve a mechanically and thermally efficient design. An analysis has been given of factors entering into optimum cryostat design [5], and several satisfactory designs are reported in 
the literature [5-8]. Single- or double-Dewar arrangements may be used. In a double-Dewar arrangement, the vacuum-insulated inner Dewar contains liquid helium while the outer Dewar contains liquid nitrogen, as shown in Figure 2. 6.2 Grips

Flat-bottomed clevis grips conforming to the design shown in Figure 3 of ASTM E 813-81 should be used for compact specimens. The flats must be free of indentations to avoid undesirable effects of friction on the test results. High-strength materials with adequate fatigue resistance and toughness must be used. Maraging steels (i.e., 200, 250, and 300 grades) and AISI 304LN have given satisfactory service at $4 \mathrm{~K}[5,7]$.

\subsection{Clip Gages}

See ASTM E 813-81, sections 6.4.1 and 6.4.2, and Reference 9.

The clip gage must be able to sustain repeated thermal shock, moisture condensation, and mechanical fatigue while rendering, accurate deflection measurements at $4 \mathrm{~K}$. This is accomplished by careful selection of gage materials and fabrication techniques [9]. Commercially available cryogenic strain gage films are used in a typical Wheatstone bridge arrangement. The gage accuracy and linearity must first be determined by direct physical calibrations at room temperature and at $4 \mathrm{~K}$. This can be done using a barrel micrometer fitted with vertical extension tubes with the gage mounted at one end and immersed in liquid helium for calibration at $4 \mathrm{~K}$ [9].

Prior to each cryogenic test series, the gage calibration must be checked. Checks may be performed at room temperature, as an indirect verification of the 4-K calibration. If so, the 4-K calibration should be verified periodically, or whenever clip gage damage is suspected. 
7. SPECIMEN CONFIGURATION, DIMENSIONS, AND PREPARATION

7.1 Specimen Size

See ASTM E 813-81, section 7.1

7.2 Three-Point Bend Specimen

See ASTM E 813 , section 7.2

\subsection{Compact Specimen}

See ASTM E 813-81, section 7.3

7.4 Fatigue Crack Length Compatibility

For a $J_{\text {Ic }}$ test the initial crack-length-to-width (a/W) ratio must fall in the range 0.5 to $0.75 ; 0.6$ is thought to be optimum. For some tests it may be desirable to choose a crack length in the range $0.5 \leqq a / w \leqq 0.55$.

This maintains compatibility with ASTM E 399-83 and allows a $\mathrm{K}_{\mathrm{Ic}}$ analysis to be employed in case of unexpected low-toughness behavior. For 25.4-mm-thick specimens ( $W=50.8 \mathrm{~mm}$ ) of austenitic stainless steels, the notch should be machined to a depth about $4 \mathrm{~mm}$ shorter than the intended final crack length, because crack front curvature typically amounts to $3 \mathrm{~mm}$ at $4 \mathrm{~K}$. The intention is to minimize the time consumed in fatigue cracking and to anticipate the occurrence of crack curvature while finishing in the desired a/W range.

\section{Note 2}

The clip gage may be attached between razor blades spotwelded to the specimens or between integral knife edges machined into the specimen.

7.5 Alternative Specimens

See ASTM E 813, section 7.5.

Experience indicates that a $25.4-\mathrm{mm}$ thickness $(\mathrm{W} / \mathrm{B}=2)$ is sufficient for most of alloys tested at $4 \mathrm{~K}$ (e.g., Ti-5Al-2.5Sn and Ti-6Al-4V, all ferritic 
steels, and austenitic stainless steels with yield strengths greater than $600 \mathrm{MPa})$.

Side grooves may be employed in attempting to improve the crack front shape, to lower the $\mathrm{J}-\Delta \mathrm{a}$ regression line slope, or to improve the agreement between the true physical crack extension and the calculated value from compliance unloading tests. The rules for side grooving are stated in ASTM E 813-81, section 7.5.1. However, if side grooves are used, the $\mathrm{K}_{\mathrm{Ic}}$ analysis procedures of ASTM E 399-83 cannot be employed, even if a linear elastic fracture is observed. In such case, a retest may be conducted using specimens with plane sides.

7.6 Eatigue Precracking

All specimens shall be fatigue precracked to establish a sharp crack front. The maximum stress intensity factor during the fatigue crack extension shall not exceed:

a. $0.005 \mathrm{~mm}^{1 / 2}$ times Young's modulus, E, or

b. $60 \%$ of $\mathrm{K}_{\mathrm{Ic}}$ (assuming linear-elastic behavior)

Requirement (a) is established by ASTM E 813-81, sections 7.6.1 and 7.6.2; requirement (b), by ASTM E 399-83, section A 2.4.2.

The load range $(\Delta P)$ shall not be less than $90 \%$ of the maximum load. Fatigue precracking may be done at a temperature different from the test temperature, providing that: (a) the maximum fatigue loads are reduced by the ratio of the yield strength at the fatigue temperature to that at the test temperature, and (b) there is no martensitic phase transformation of the material at these temperatures. For materials exhibiting martensitic phase transformations, the fatigue precracking can be done at a temperature 
different from the test temperature only if it can be demonstrated that this does not affect the toughness test result.

\section{Note 3}

Sizable reductions of the maximum load during fatigue cracking are to be avoided because they may retard the crack growth rate and increase the degree of crack front curvature.

For heat treating, minimum crack extension from the notch, and notch radius, see ASTM E $813-81$, sections $7.6 .3,7.6 .4$, and 7.6 .5 .

\section{COOLING AND TESTING PROCEDURES}

\subsection{Cooling Procedure}

The cryostat must be capable of achieving and maintaining a uniform specimen temperature of $4 \pm 1 \mathrm{~K}$ for the duration of the test. This is accomplished by completely submerging the specimen and clip gage in liquid helium and monitoring the liquid helium level with a suitable meter $[1,2]$. Sufficient time at temperature must be allowed prior to testing to be sure that the thermal equilibrium has been reached.

\section{Note 4}

The specimen may be precooled to $77 \mathrm{~K}$ using liquid nitrogen, prior to cooling to $4 \mathrm{~K}$ with liquid helium. Various cool-down procedures are discussed in the literature [5-8]. One must carefully and properly purge the transfer line and remove any moisture from the cryostat to prevent the formation of ice blocks.

\subsection{Mechanical Test Procedure}

Specimens shall be loaded at a rate such that the time taken to reach the load at first deviation from the linear portion of the record lies between 0.5 and $10 \mathrm{~min}$. For other details of test procedure, see ASTM E $813-81$, section 8 . 


\section{NOTE 5}

Because fracture testing in liquid helium environments is time-consuming and costly, a single specimen test technique is recommended. The most familiar technique to date is the singlespecimen unloading compliance test technique. See ASTM E 813, section 8.3.4 and Annex A1 and the Appendix to this document.

\section{CALCULATION AND INTERPRETATION OF RESULTS}

Depending upon the load-versus-deflection behavior, either the J Ic (ASTM E 813-81) or the $\mathrm{K}_{\text {IC }}$ (ASTM E 399-83) analysis procedures should be employed.

For specimens exhibiting highly nonlinear load-versus-deflection curves, the $J_{\text {Ic }}$ test procedure based on the resistance curve technique should be used. See ASTM E 813-81, section 9.

\section{Note 6}

The load-deflection curves of materials tested at $4 \mathrm{~K}$ are unique in that they typically exhibit serrations. These serrations may represent either brittle fracture instabilities or ductile flow instabilities due to adiabatic heating [10]. Calculate the area under the load-deflection curve as given by the autographic recorder in the usual manner. In resistance curve determinations for ductile alloys of medium or high toughness, small errors are introduced into the resulting $\mathrm{J}$-integral values, owing to the probability that the $X-Y$ recorder can not accurately follow the instability event. However, the errors are considered negligible. If the serrations are due to brittle fracture instabilities (as verified by scanning electron microscopic examination of failure mode), a valid resistance curve can not be obtained by the J-integral methodology.

For specimens exhibiting linear-elastic or nearly linear-elastic loading behavior, the $\mathrm{K}_{\mathrm{Ic}}$ test technique should be used. The notch cutout modifications for load-line displacement measurements instead of the usual edge displacement measurements do not invalidate the $\mathrm{K}_{\mathrm{Ic}}$ calculations at $4 \mathrm{~K}$ according to this method. See ASTM E 399-83, section 9.

\section{REPORTING}

See ASTM E 813-81, section 10 and ASTM E 399-83, section 10. 
11. PRECISION AND ACCURACY

See ASTM E 813-81, section 11 and ASTM E 399-83, section 11.

\section{REFERENCES}

1. Ogata, T., Hiraga, K., Nagai, K., and Ishikawa, K., "A Simplified Method for Charpy Impact Testing near Liquid Helium Temperature," Cryogenics, vol. 22, no. 9, September 1982, pp. 481-482.

2. Dobson, W. G. and Johnson, D. L., "Effect of Strain Rate on Measured Mechanical Properties of Stainless Steel at $4 \mathrm{~K}$," Advances in Cryogenic Engineering--Materials, vol. 30, Plenum, New York, 1984, pp. 185-192.

3. Read, D. T., and Reed, R. P., "Heating Effects During Tensile Tests of AISI 304L Stainless Steel at $4 \mathrm{~K}, "$ Advances in Cryogenic Engineering-Materials, vol. 26, Plenum, New York, 1980, pp. 91-101.

4. Ogata, T., Ishikawd, K., Hiraga, K., Nagai, K., and Yuri, T., "Temperature Rise During the Tensile Test in Superfluid Helium," Cryogenics, vol. 25, no. 8, August 1985, pp. 444-446.

5. Fowlkes, C. F. and Tobler, R. L., "Fracture Testing and Results for a Ti-6Al-4V Alloy at Liquid Helium Temperature," Engineering Fracture Mechanics, vol. 8, 1976, pp. 487-500.

6. Read, D. T. and Tobler, R. L., "Mechanical Property Measurements at Low Temperatures," Advances in Cryogenic Engineering--Materials, vol. 28, Plenum, New York, 1982, pp. 17-28.

7. Juhas, M.C., Duncan, D. B., and Streit, R. D., "Development of a Facility for Fatigue and Fracture Testing of Stainless Steels at Liquid Helium Temperature," Cryogenics, vol. 23, no. 11, November 1983, pp. 603-607.

8. Takeuchi, M., Shoji, T., Takahashi, H., and Anayama, T., "Evaluation of Fracture toughness of Cryogenic Structural Materials," Report of the Research Institute for Strength and Fracture of Materials, Tohoku University, Sendai, Japan, vol. 17, nos. 1 and 2, March 1984, pp. 1-12.

9. Tobler, R. L. and Shepic, J.A., "Design and Performance of a Ring-Shaped Clip Gage for Fracture Mechanics Testing," Journal of Testing and Evaluation, vol. 13, no. 4, July 1985, pp. 299-302.

10. Tobler, R. L., "Ductile Fracture with Serrations in AISI 310 S Stainless Steel at Liquid Helium Temperature," Elastic-Plastic Fracture: Second Symposium, Volume II - Fracture Resistance Curves and Engineering Applications, ASTM STP 803, C. F. Shih and J. P. Gudas, Eds., American Society For Testing and Materials, Philadelphia, 1983, pp. II-763, II 776 . 
I. BRITTLE BEHAVIOR: $K_{\text {IC }}$ is measured
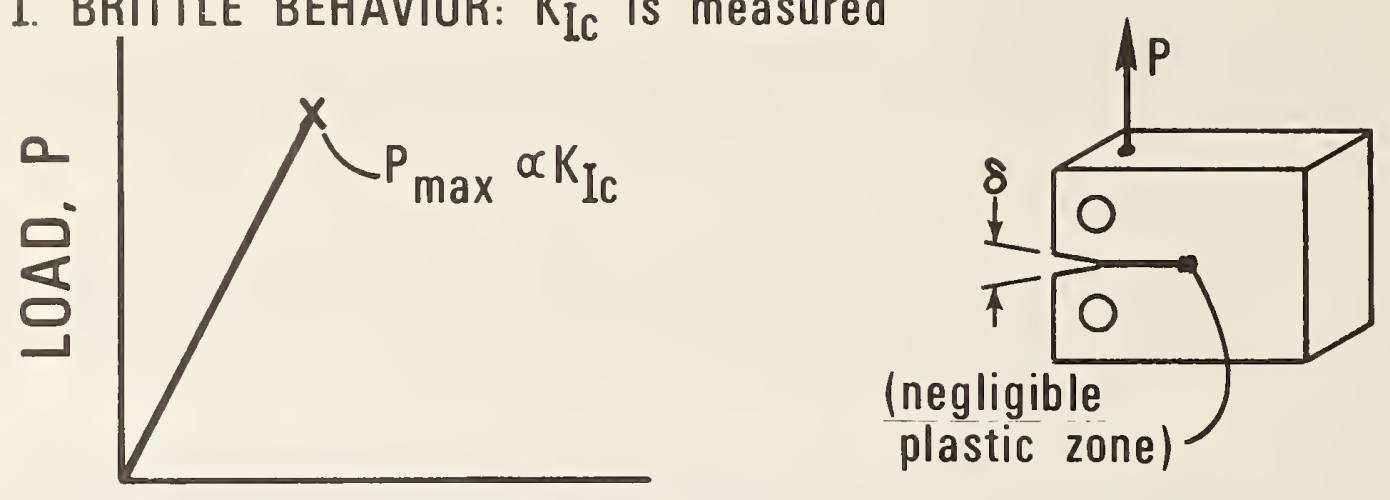

\section{DISPLACEMENT, $\boldsymbol{\delta}$}

(a) Linear-elastic

II. DUCTILE BEHAVIOR: $J_{\text {IC }}$ is measured

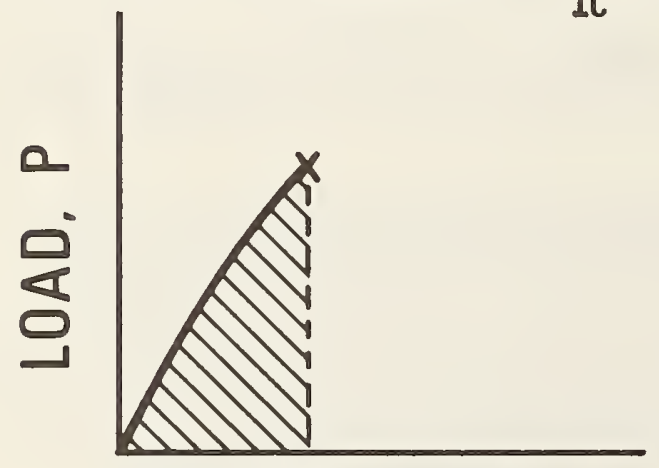

\section{DISPLACEMENT, $\delta$}

(b) Elastic-plastic (failure before limit load)

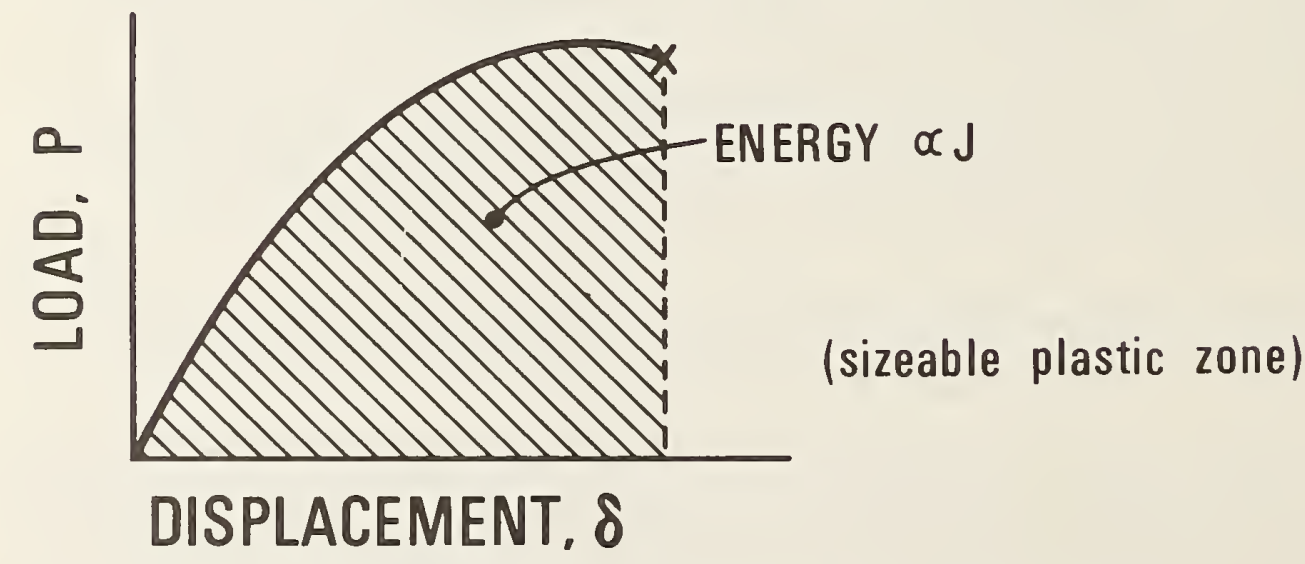

(c) Fully plastic (exhibits a limit load)

Figure 1. Load-deflection behavior observed in fracture toughness tests. 


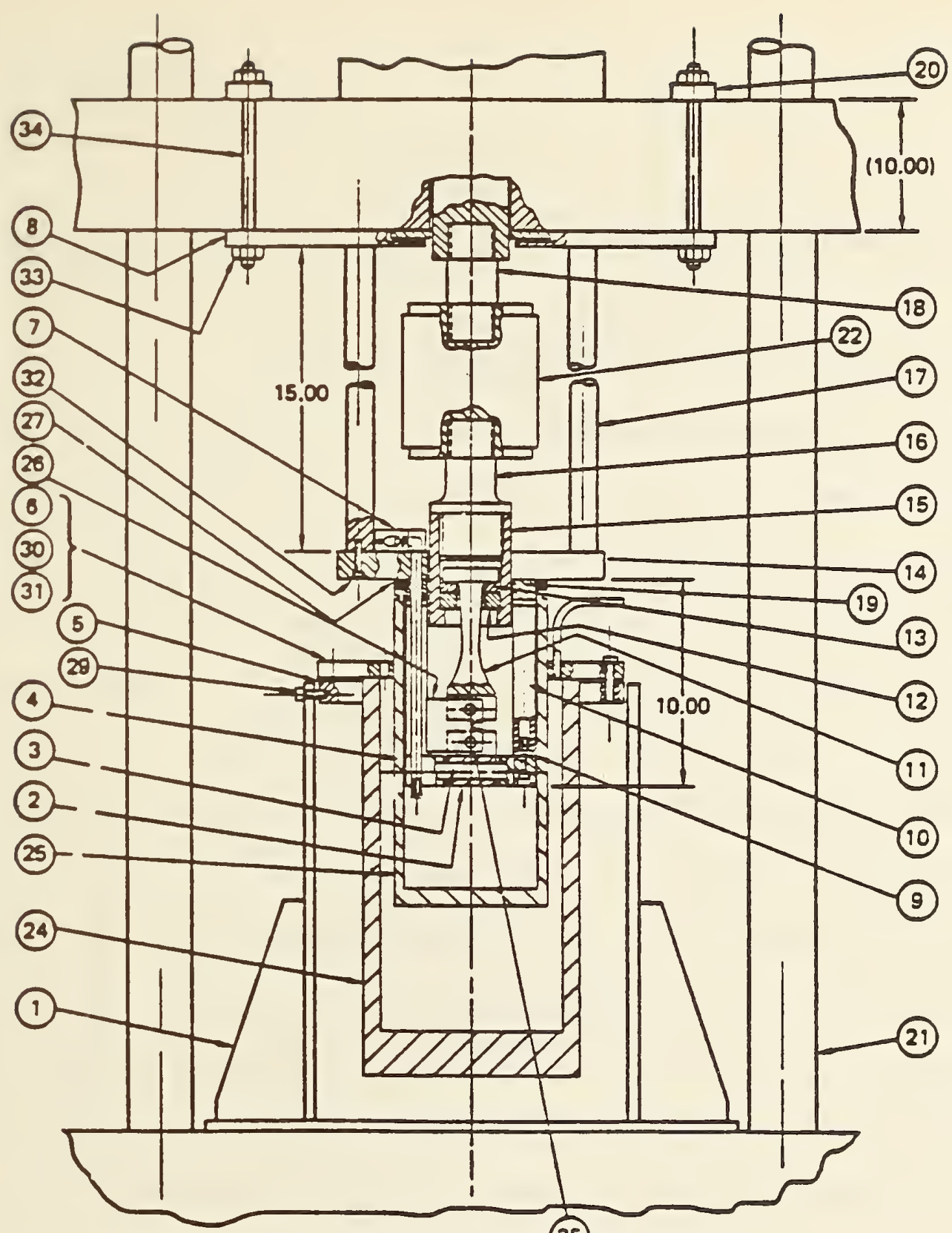

(35)

1 - Dewar pivot frame

2 - Specimen clevis

3 - Shear pin

4 - Pivot plate

5 - Outer Dewar top

6 - Inner Dewar clamp

7 - Transfer hose adapter

8 - Adapter plate

9 - Column adapter

10 - Compression column

11 - Clevis pull rod

12 - Pu11 rod keeper

13 - Pull rod split ring isolator

14 - Load plate

15 - Pull rod coupling

16 - Load cell adapter

17 - Load column

18 - Load cell adapter
19 - Isolator compression ring

20 - Adapter bar

21 - Test machine frame

22 - Load cel1

23 - Clip gage

24 - Stainless stee1 Dewar

25 - Stainless steel Dewar

26 - J-integra1 compact tension fracture specimen

27 - Seal ring

28 - Liquid helium level meter

29 - Socket head cap screw

30 - Socket head cap screw

31 - Socket head cap screw

32 - Socket head cap screw

33 - Nut

34 - Threaded rod

35 - Shear pin

Figure 2. Cryogenic fracture toughness test facility with the double-Dewar arrangement [5]. 
THE USE OF UNLOADING COMPLIANCE TO DETERMINE RESISTANCE CURVE BEHAVIOR

See ASTM E 813-81, sections A1.1 through A1.3.

The single-specimen unloading compliance technique has been successfully applied for tests at $4 \mathrm{~K}[\mathrm{~A} 1]$. However, because of the existence of serrations in the load deflection curves of cryogenic alloys at $4 \mathrm{~K}$, the number of $\mathrm{J}-\Delta \mathrm{a}$ points on the resistance curve may be limited. Partial unloadings should be performed at points of arrest just after each unstable load drop, as illustrated by the example in Figure $1 \mathrm{~A}$.

Comparison of the measured physical crack lengths and inferred crack extensions from the unloading compliance technique will usually reveal a disagreement that increases significantly as the test proceeds. This error may persist even with the use of side grooves. Since this error diminishes at lower $\Delta a$ values, the $J_{I c}$ value obtained by extrapolation of the unloading-compliance $\mathrm{R}$-curve is still deemed valid by this method [A2] However, unless the agreement between the amount of crack extension predicted by the unloading compliance method and the average measured value is within $15 \%$, the resistance curve slope is considered invalid and should not be reported.

REFERENCES

A1. Shimamoto, S., Nakajima, H., Yoshida, K., and Tada, E., "Requirements for Cryogenic Structural Alloys for Superconducting Magnet Cases," Advances in Cryogenic Engineering--Materials, vol. 32, Plenum, New York, 1986, to be published.

A2. Tobler, R. L. and Shepic, J.A., "Design and Performance of a Ring-Shaped Clip Gage for Fracture Mechanics Testing," Journal of Testing and Evaluation, vol. 13, no. 4, July 1985, pp. 299-302. 


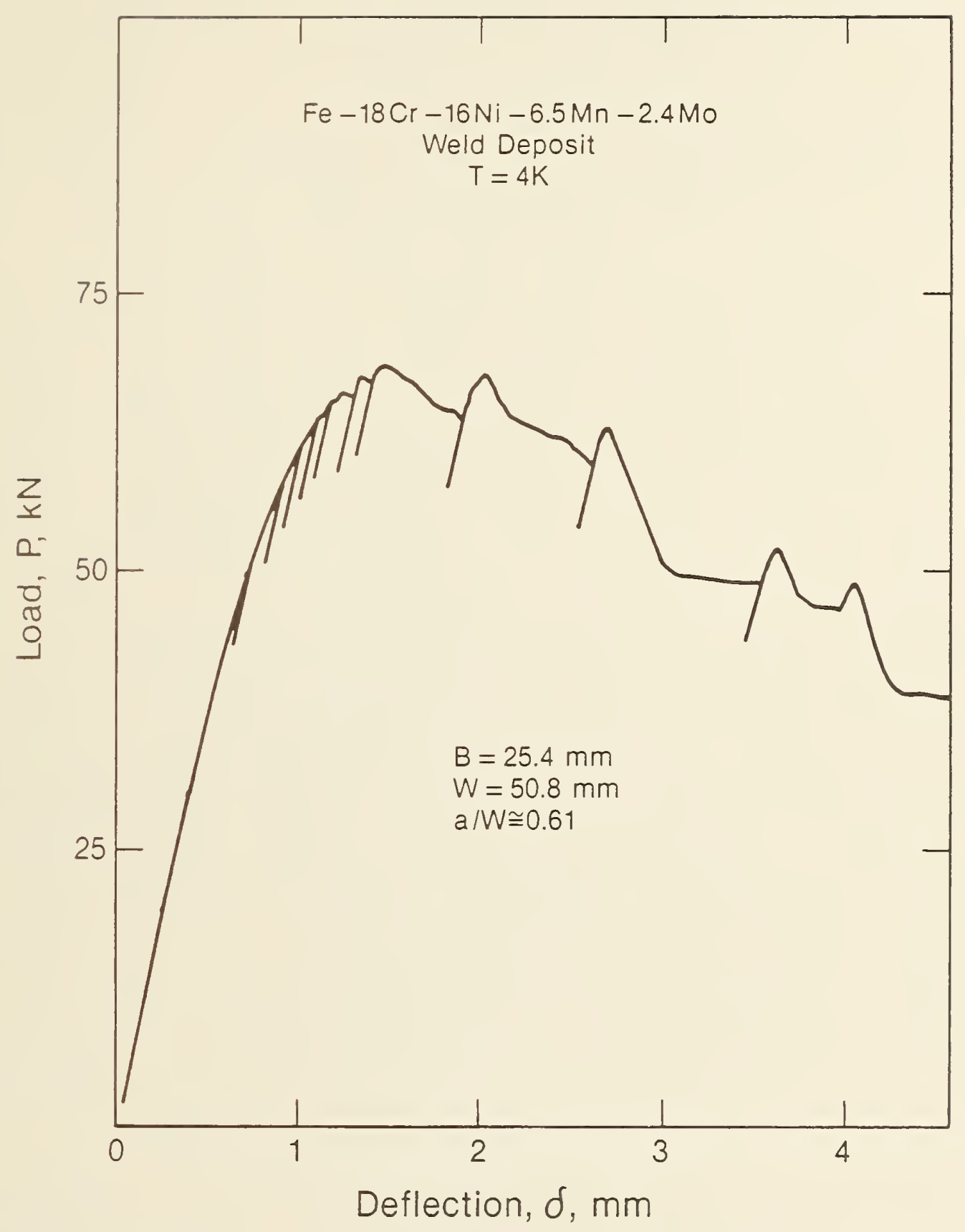

Figure 1A. Typical compact specimen loading behavior at $4 \mathrm{~K}$, showing serrations and points of unloading compliance method. 



Minutes of

LOW TEMPERATURE STRUCTURAL MATERIALS AND STANDARDS WORKSHOP

Tohoku University, Sendai, Japan

March 7, 1986

The Workshop on Low Temperature Structural Materials and Standards was held March 7, 1986 at Tohoku University. Hosting this meeting was the Research Institute for Strength and Fracture of Materials (RISFM). Three researchers from the US participated, so the workshop was conducted in English. The program consisted of: 1) opening remarks and a business session on fracture test standardization, 2) a seminar entitled Recent Topics in Deformation and Fracture of Structural Materials at Cryogenic Temperatures, and 3) closing remarks and conclusion of business.

The opening remarks were made by Dr. Takahashi (RISFM). Plans to provide more scientific support for a fracture toughness testing standard at $4 \mathrm{~K}$ were then discussed by Mr. Tobler (NBS). At the last meeting (January, 1986) a test matrix was proposed to experimentally resolve ten technical items relating to various aspects of standardization. The original matrix called for a total of 88 tests to be conducted using various austenitic stainless steels. But the desired program was too large to be executed by one organization because of limited time and test facilities. Therefore a more general cooperative effort is necessary. At this meeting some modifications to simplify the original proposal were described and assistance of a number of research laboratories was requested to complete the testing by the end of 1986. The attendees were invited to consider their decisions to participate and to respond at the end of the workshop.

The seminar consisted of 13 technical presentations with preprints available in most cases. The preprints or copies of the speaker's viewgraphs were collected for distribution later as a record of the proceedings.

The final session on the business of fracture testing for standard development was chaired by Dr. Shoji (RISFM). After some discussion, specific tests on various materials were delegated to be carried out in cooperation with RISFM where Mr. Tobler is presently a visiting exchange scientist. 
Responsibility for testing the $25 \mathrm{Cr}-15 \mathrm{Ni}$ steel naturally passed to JAERI (Mr. H. Nakajima) as the only laboratory capable of testing the large 3T compact specimens. Kobe Steel ( $\mathrm{Dr}$. M. Shimada) then agreed to test the AISI 304 type steel in view of some mutual interest in the material. Testing of the AISI 316 LN is still unresolved, but might be done at NRIM (Dr. Ogata) if machine time is available. The revised plan for this program is summarized in the attached matrix which shows 69 tests to be conducted by the cooperating laboratories. All of the test materials have been obtained, except for the AISI 304 stainless steel which will be delivered to us at the end of May.

REVISED EXPERIMENTAL TEST MATRIX

\begin{tabular}{|c|c|c|}
\hline \multirow[t]{3}{*}{ LABORATORY } & MATERIAL & TYPE OF SPECIMEN \\
\hline & & Compact Specimens (items 1 to 8 ) \\
\hline & & $\begin{array}{llllll}0.5 \mathrm{~T} & 1 \mathrm{~T} & 1.5 \mathrm{~T} & 3 \mathrm{~T}\end{array}$ \\
\hline JAERI & $\mathrm{Fe}-25 \mathrm{Cr}-15 \mathrm{Ni}$ & - \\
\hline NRIM & AISI 316LN & - \\
\hline \multirow[t]{2}{*}{ Kobe Steel } & AISI 304 & - \\
\hline & & Bend Specimens $(25 \times 25 \times 150 \mathrm{~mm}$; item 6) \\
\hline \multirow{4}{*}{$\begin{array}{l}\text { JAERI and } \\
\text { RISFM }\end{array}$} & AISI $316 \mathrm{LN}$ & 5 \\
\hline & AISI 304 & 5 \\
\hline & & Compact Specimens (items 9 and 10) \\
\hline & & $1 \mathrm{~T}$ \\
\hline \multirow[t]{3}{*}{ RISFM } & AISI $310 \mathrm{~S}$ & 3 \\
\hline & AISI $316 \mathrm{LN}$ & 6 \\
\hline & $\mathrm{Fe}-18 \mathrm{Cr}-3 \mathrm{Ni}-13 \mathrm{Mn}$ & 6 \\
\hline
\end{tabular}

NOTE: Total tests $=69$ 


\section{WELDING}





\section{WELDING PROGRAM}

LEADER:

CONTRIBUTORS:
T. A. Siewert

C. N. McCowan, H. I. McHenry, P. T. Purtscher, R. P. Reed,

R. L. Tobler, D. P. Vigliotti

\section{OBJECTIVES}

- Investigation of the metallurgical factors that affect the mechanical properties of stainless-steel weldments at cryogenic temperatures

- Contributions to the development of improved filler metals for welding stainless steels for use at $4 \mathrm{~K}$

- Evaluation of the mechanical properties of weldments at $4 \mathrm{~K}$

- Development of methods of detecting defects and evaluation of their significance in stainless-steel weldments

\section{RESEARCH PAST YEAR (1985)}

- Clarification of the effects of manganese ( 1.5 to $10 \mathrm{wt} . \%)$, nitrogen ( 0.04 to 0.26 wt.\%), and molybdenum ( 0 to 4 wt.\%) on SMA weld properties on the basis of AWI 308-type welds

- Determination of the 4-K yield strength and fracture toughness of an $\mathrm{Fe}-18 \mathrm{Cr}-20 \mathrm{Ni}-5 \mathrm{Mn}-0.16 \mathrm{~N}$ fully austenitic weld

- Determination of the 4-K yield strength, fracture toughness, and fatigue properties of an $\mathrm{Fe}-18 \mathrm{Cr}-16 \mathrm{Ni}-6.5 \mathrm{Mn}-2$. $4 \mathrm{Mo}$ fully austenitic weld

- Comparison of the strength-toughness relationships for welds evaluated at NBS over the past decade with corresponding base material properties

\section{RESEARCH THIS YEAR (1986)}

- Comparison of the 4-K yield strength and fracture toughness of electron beam and laser welds in AISI 316LN-type base material

- Development of a model to relate the 4-K weld fracture toughness to the microstructure

- Determination of the 4-K yield strength and fracture toughness of $\mathrm{Fe}-8 \mathrm{Cr}-43 \mathrm{Ni}-2 \mathrm{Mo}$ welds

- Study of the effect of molybdenum on the cryogenic mechanical properties of welds in more detail

- Continuation of mechanical property testing in support of superconducting magnet design and construction 


\begin{tabular}{|c|c|c|c|c|c|c|}
\hline $\begin{array}{l}\text { Weld Alloy } \\
\text { (designation) }\end{array}$ & $\begin{array}{l}\text { Welding } \\
\text { Process }\end{array}$ & Tensile & $\begin{array}{l}\text { Charpy } \\
\text { Impact }\end{array}$ & $\begin{array}{l}\text { Fracture } \\
\text { Toughness }\end{array}$ & $\begin{array}{l}\text { Fatigue Crack } \\
\text { Growth Rate }\end{array}$ & $\begin{array}{l}\text { Report Volume* } \\
\text { (page) }\end{array}$ \\
\hline
\end{tabular}

\section{Austenitic Stainless Steels}

$\mathrm{Fe}-13 \mathrm{Cr}-20 \mathrm{Ni}-9 \mathrm{Mn}-2 \mathrm{Nb}$

SMAW

I , I I

I , I I , VII I

I $(159,169)$

I I (299)

VIII (29)

$\mathrm{Fe}-15 \mathrm{Cr}-12 \mathrm{Ni}-10 \mathrm{Mn}$

SMAW

I V

IV , VI I I

IV (453)

VI I (29)

$\mathrm{Fe}-16 \mathrm{Cr}-15 \mathrm{Ni}-4 \mathrm{Mo}$

SMAW IV

$\mathrm{Fe}-16 \mathrm{Cr}-16 \mathrm{Ni}-2 \mathrm{Mo}$

FCAW

I I I

IV

IV (275)

$\mathrm{Fe}-16 \mathrm{Cr}-16 \mathrm{Ni}-4 \mathrm{MO}$

FCAW

IV

I I I

II (155)

VI (199)

Fe-16Cr-35Ni-4Mn

(330 modified)

SMAW

\section{I}

IV, VI I I

IV

IV (275)

VIII (29)

I (159)

II (299)

VIII (29)

$\mathrm{Fe}-17 \mathrm{Cr}-16 \mathrm{Ni}-4 \mathrm{MO}$

SMAW IV

$\mathrm{Fe}-18 \mathrm{Cr}-16 \mathrm{Ni}-9 \mathrm{Mn}-\mathrm{N}$

GMAW

$$
\text { II I , IV }
$$

I , VIII

I I

IV (275)

IV

II (155)

IV $(275,453)$

VI (199)

$\mathrm{Fe}-18 \mathrm{Cr}-18 \mathrm{Ni}-2 \mathrm{Mo}-5 \mathrm{Mn}-\mathrm{N}$

SMAW

IV

IV

IV

(453)

$\mathrm{Fe}-18 \mathrm{Cr}-20 \mathrm{Ni}-5 \mathrm{Mn}$

GMAW

IV

IV

IV

(275)

$\mathrm{Fe}-18 \mathrm{Cr}-20 \mathrm{Ni}-6 \mathrm{Mn}-0.3 \mathrm{Nb}$

GMAW

IV

IV

IV

IV (275)

$\mathrm{Fe}-18 \mathrm{Cr}-20 \mathrm{Ni}-6 \mathrm{Mn}-0.2 \mathrm{Ti}$

GMAW

IV

IV

IV

IV (275)

SMAW

I I

I I , VI II

I I

I I (315)

(316)

ESW IV

IV

VII I (29)

$\mathrm{Fe}-19 \mathrm{Cr}-12 \mathrm{Ni}-2 \mathrm{MO}$

(316L)

\begin{tabular}{|c|c|c|c|c|c|c|}
\hline GMAW & II I, IV & III ,IV,VIII & IV & & $\begin{array}{l}\text { I I I } \\
\text { IV } \\
\text { VIII }\end{array}$ & $\begin{array}{l}(155,195) \\
(275) \\
(29)\end{array}$ \\
\hline GTAW & I I I, IV & III, IV,VIII & IV & & $\begin{array}{l}\text { I I I } \\
\text { IV } \\
\text { VI I I }\end{array}$ & $\begin{array}{l}(155,195) \\
(275) \\
(29)\end{array}$ \\
\hline SAW & I I I , IV , V & I I I , I V, V & I I I , IV & I I I , VI & $\begin{array}{l}\text { I I I } \\
\text { IV } \\
\text { V } \\
\text { VI }\end{array}$ & $\begin{array}{l}(155,195) \\
(275,415) \\
(233) \\
(199)\end{array}$ \\
\hline SMAW & I I, II I, IV & I I , VIII & I I , I I I , IV & I I I , IV , V I & $\begin{array}{l}\text { II } \\
\text { I I I } \\
\text { VI } \\
\text { VI I I }\end{array}$ & $\begin{array}{l}(299,315) \\
(155,167) \\
(199) \\
(29)\end{array}$ \\
\hline
\end{tabular}

* materials studies for magnetic fusion energy apPlications at lOW temperatures: NBSiR 78-884 (I); NBSIR 79-1609 (II); NBSIR 80-1627 (III); NBSIR 81-1645 (IV); NBSIR 82-1667 (V); NBSIR 83-1690 (VI); NBSIR 84-3000 (VII); NBSIR 85-3025 (VIII). 
SUMMARY OF MECHANICAL PROPERTY MEASUREMENTS OF WELDS, continued

\begin{tabular}{|c|c|c|c|c|c|c|c|}
\hline $\begin{array}{l}\text { held Alloy } \\
\text { (deslenation) }\end{array}$ & $\begin{array}{l}\text { Welding } \\
\text { Process }\end{array}$ & Tensile & $\begin{array}{l}\text { Charpy } \\
\text { Impact }\end{array}$ & $\begin{array}{l}\text { Fracture } \\
\text { Toughness }\end{array}$ & $\begin{array}{l}\text { Fatigue Crack } \\
\text { Growth Rate }\end{array}$ & \multicolumn{2}{|c|}{$\begin{array}{l}\text { Report Volume* } \\
\text { (page) }\end{array}$} \\
\hline $\begin{array}{l}\mathrm{Fe}-19 \mathrm{Cr}-12 \mathrm{~N} 1-2 \mathrm{MO}-\mathrm{N} \\
(316 \mathrm{LN})\end{array}$ & SMAW & II & I I , VI I I & II & & $\begin{array}{l}\text { II } \\
\text { VIII }\end{array}$ & $\begin{array}{r}(299) \\
(29)\end{array}$ \\
\hline $\mathrm{Fe}-19 \mathrm{Cr}-16 \mathrm{~N} 1-7 \mathrm{Mn}$ & GMAW & IV & IV & & & IV & $(453)$ \\
\hline $\begin{array}{l}\mathrm{Fe}-20 \mathrm{Cr}-10 \mathrm{~N} 1 \\
(308)\end{array}$ & SMAW & I & I , VIII & & & $\begin{array}{l}\text { I } \\
\text { VIII }\end{array}$ & $\begin{array}{l}(169) \\
(29)\end{array}$ \\
\hline \multirow[t]{3}{*}{$\begin{array}{l}\mathrm{Fe}-20 \mathrm{Cr}-10 \mathrm{Ni} \\
(308 \mathrm{~L})\end{array}$} & FCAW & II I & & II I & II I, VI & $\begin{array}{l}\text { II I } \\
\text { VI }\end{array}$ & $\begin{array}{l}(155) \\
(199)\end{array}$ \\
\hline & GMAW & I I I & & III & II I, VI & $\begin{array}{l}\text { II I } \\
\text { VI }\end{array}$ & $\begin{array}{l}(155) \\
(199)\end{array}$ \\
\hline & SMAW & I I, III, & II, VIII & I I , I I I & I I I , VI & $\begin{array}{l}\text { II } \\
\text { II I } \\
\text { VI } \\
\text { VIII }\end{array}$ & $\begin{array}{l}(299) \\
(155) \\
(199) \\
(29)\end{array}$ \\
\hline $\begin{array}{l}\mathrm{Fe}-20 \mathrm{Cr}-10 \mathrm{Ni}-\mathrm{N} \\
(308 \mathrm{LN})\end{array}$ & FCAW & IV & & IV & IV , VI & $\begin{array}{l}\text { IV } \\
\text { VI }\end{array}$ & $\begin{array}{l}(275,415) \\
(199)\end{array}$ \\
\hline $\mathrm{Fe}-20 \mathrm{Cr}-10 \mathrm{Ni}-9 \mathrm{Mn}-\mathrm{N}$ & SMAW & I & I & & & I & $(159,169)$ \\
\hline $\mathrm{Fe}-20 \mathrm{Cr}-16 \mathrm{Ni}-7 \mathrm{Mo}-2 \mathrm{~W}$ & SAW & IV & & IV & & IV & $(275)$ \\
\hline $\mathrm{Fe}-20 \mathrm{Cr}-34 \mathrm{Ni}-2 \mathrm{Mo}-\mathrm{Nb}$ & SMAW & VII & & VII & & VII & $(253)$ \\
\hline $\mathrm{Fe}-21 \mathrm{Cr}-6 \mathrm{Ni}-9 \mathrm{Mn}-\mathrm{N}$ & SMAW & I , I I & I , I I & & & $\begin{array}{l}\text { I } \\
\text { II }\end{array}$ & $\begin{array}{l}(159,169) \\
(299)\end{array}$ \\
\hline \multicolumn{8}{|l|}{ Austenitic Steels } \\
\hline $\mathrm{Fe}-15 \mathrm{Mn}-8 \mathrm{Ni}-1 \mathrm{MO}-0.7 \mathrm{C}$ & SAW & VIII & & VIII & & VIII & $(15)$ \\
\hline $\mathrm{Fe}-5 \mathrm{Cr}-25 \mathrm{Mn}-1 \mathrm{Ni}$ & & v & & V, VII & V,VI & $\begin{array}{l}\text { V } \\
\text { VI } \\
\text { VII }\end{array}$ & $\begin{array}{l}(233) \\
(199) \\
(245)\end{array}$ \\
\hline $\mathrm{Fe}-6.5 \mathrm{Cr}-25 \mathrm{Mn}-3 \mathrm{Ni}-1 \mathrm{Mo}$ & SMAW & V & & v & $V, V I$ & $\begin{array}{l}\text { V } \\
\text { VI }\end{array}$ & $\begin{array}{l}(233.245) \\
(199)\end{array}$ \\
\hline \multicolumn{8}{|l|}{ Aluminum Alloys } \\
\hline $\begin{array}{l}\text { Al- }-5 \mathrm{Mg} \\
(5183)\end{array}$ & GMAW & I I I & & IV & IV & $\begin{array}{l}\text { II I } \\
\text { IV }\end{array}$ & $\begin{array}{l}(155,217) \\
(323)\end{array}$ \\
\hline $\begin{array}{l}\text { Al-5Mg-0.12 Ti } \\
(5556)\end{array}$ & GMAW & I I I & & IV & IV & $\begin{array}{l}\text { II I } \\
\text { IV }\end{array}$ & $\begin{array}{l}(155.21 \cdot) \\
(323)\end{array}$ \\
\hline
\end{tabular}

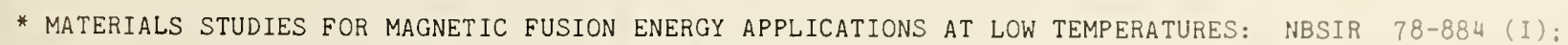
NBSIR 79-1609 (II); NBSIR 80-1627 (III); NBSIR 81-1645 (IV); NBSIR 82-1667 (V); NBSIR 83-1690 (VI); NBSIR 84-3000 (VII); NBSIR 85-3025 (VIII). 



Manganese and Nitrogen in

\author{
Stainless Steel SMA Welds for Cryogenic Service*+ \\ C. N. Mc Cowan, T. A. Siewert, R. P. Reed \\ National Bureau of Standards, Boulder, Colorado
}

and

F. B. Lake

Alloy Rods Corporation, Hanover, Pennsylvania

Evaluation of a shielded metal arc weld test matrix in which manganese ( 1.5 to $10 \mathrm{wt} . \%)$ and nitrogen ( 0.04 to $0.26 \mathrm{wt} . \%)$ were varied independently has clarified the effect of these elements on the cryogenic mechanical properties and predicted ferrite number (FN). Several molybdenum and boron additions were also made, but they had no observable effect on strength or Charpy $V$-notch ( CVN) absorbed energy. The matrix was based on a type 308L stainless steel weld metal composition. Desired compositions and constant FN were attained through alloy additions to the electrode coating. For each weld, one all-weld-metal 4-K tensile specimen and $\mathrm{f} i v e$ 76-K CVN impact specimens were tested.

The addition of nitrogen linearly increased the $4-\mathrm{K}$ yield strength from 600 to $1300 \mathrm{MPa}$ and decreased the $76-\mathrm{K}$ lateral expansion from 0.7 to $0.1 \mathrm{~mm}$. Nitrogen reduced the $76-\mathrm{K}$ CVN absorbed energy but not linearly. The addition of manganese slightly increased the yield strength and slightly decreased the lateral expansion. The $4-\mathrm{K}$ tensile strength was relatively unaffected by alloy additions; values varied between 1300 and $1500 \mathrm{MPa}$.

The DeLong FN predictive equation was improved by substituting a constant manganese term of 0.35 into the DeLong nickel equivalent. Analysis of the remaining $F N$ deviation revealed an interaction between nitrogen and manganese. Addition of manganese-nitrogen interactive terms to the nickel equivalent increased the accuracy of the FN prediction.

\title{
INTRODUCTION
}

Toughness values for 300-series stainless steel welds at cryogenic temperatures have consistently been lower than those for base materials of equal strength $[1,2]$. Several studies have attempted to understand this phenomenon by statistically determining predictive equations for charpy $\mathrm{V}$-notch (CVN) toughness on the basis of the weld composition [3-5]. Although these studies have resulted in tougher welds through optimized electrode compositions, the welds still do not match the toughness of the base material. Recently, controlled additions of nitrogen (along with additions of manganese

* Work supported by the U.S. Department of Energy; not subject to copyright.

+ Submitted to Weld. J. 
to reduce the tendency to form porosity) have increased the plate strength at cryogenic temperatures with little loss in toughness [6]. However, this increased base material strength cannot be totally utilized until welds of comparable toughness at these elevated streng.ths are developed.

This study was intended to contribute to the development of welds with properties comparable to those of the nitrogen-strengthened base materials. We investigated the strength-toughness relationship in a series of shielded metal arc (SMA) welds. The nitrogen and manganese contents were varied to evaluate their effect on the weld properties. Several welds with varying boron and molybdenum contents were also included.

FACTORS INFLUENCING STRENGTH, TOUGHNESS, AND FERRITE NUMBER

Strength

The strengthening potential of nitrogen in stainless steel increases with a decrease in temperature [5,7-11]. Nitrogen occupies interstitial sites and expands the lattice in a manner similar to carbon [12]. Unlike high carbon contents, high nitrogen contents do not result in sensitization problems. The nitrogen content can be increased until porosity occurs at the solubility limit [9]. It can be introduced to the deposit through shieldinggas mixtures with the gas metal arc (GMA) or gas tungsten arc (GTA) processes or through nitrogen-containing alloy additions to the coating with the SMA process. With 0.05 wt.\% nitrogen additions in type 308 stainless steel welds, increases in yield strengths of approximately 120, 150, and $175 \mathrm{MPa}$ were reported by Mukai et al. (lll K), Enjo et al. $(76 \mathrm{~K})$, and Onishi et al. $(76 \mathrm{~K})$, respectively $[13,10,11]$. Onishi et al. report a similar increase in yield strength at $4 \mathrm{~K}$. In comparison, only slight increases in weld yield strength $(<50 \mathrm{MPa})$ have been found at room temperature $[10,11,13,14]$.

The influence of nitrogen on the tensile strength is disputed. Onishi et al. [11] and Ozeki and Ogawa [15] found increases in the 76-K tensile strength of 100 and $400 \mathrm{MPa}$ when nitrogen content was increased from 0.05 to 0.15 and 0.20 to $0.40 \mathrm{wt} . \%$, respectively, whereas Enjo et al. reported a $76-\mathrm{K}$ tensile strength increase of only $20 \mathrm{MPa}$ when the nitrogen content was raised from 0.05 to 0.15 wt.\% [10]. In all cases, the magnitudes of tensile strength increases reported were less than those observed for the yield strength. The influences of other elements (such as manganese, molybdenum, and boron) on cryogenic weld strength have not been published, but Sakamoto et al. reported that manganese increased yield strength in stainless steel base material at $76 \mathrm{~K}[16]$.

\section{Toughness}

The cryogenic toughness of type 308L and 316L stainless steel welds is determined by the interrelated and sometimes opposing effects of the individual alloying elements and the ferrite number (FN). The FN has been found to be the dominant factor in determining CVN toughness in these materials [4,17-20]. Lower FN tends to raise the toughness. On the other hand, increased nitrogen contents, which lower the FN, have been reported to lower the CVN absorbed energy and lateral expansion (LE) values in SMA 
welds [4]. Contradicting this reported nitrogen effect, Enjo et al. [11] found that CVN energies increased with increasing nitrogen content (decreasing FN) in his GMA study of type 308 stainless steel welds. These differences and the variations in toughness values near $0 \mathrm{FN}$ indicate that the role of nitrogen (and other alloying elements) with respect to toughness requires further study. Several researchers $[4,20]$ have studied the effect of alloying elements that influence the ferrite content on the absorbed energy at $76 \mathrm{~K}$. Nickel reportedly increased toughness, whereas carbon and chromium reduced toughness. Nitrogen is generally believed to reduce toughness, but it has been suggested that the effect of nitrogen on CVN toughness may be dependent on the specific alloy composition [19]. Manganese has been reported to decrease 77-K CVN energy in stainless steel base material [16]. The effects of molybdenum are not clear.

Eerrite Number

The strong influence of FN on cryogenic toughness dictates the use of an accurate method for predicting $F N$ in the new high nitrogen and manganese stainless steel electrodes. The diagrams developed by Schaeffler [21] and DeLong [22] are currently the best methods available for the prediction of FN. These diagrams were not designed for use with high manganese alloys; they tend to underestimate FN for higher alloy contents because the austenitizing power of manganese decreases at high manganese concentrations $[23,24]$.

Whether the various FN diagrams or the corresponding mathematical expressions for these diagrams is used, nickel and chromium equivalents represent the relative austenitizing and ferritizing tendency for a given alloy composition. The DeLong nickel and chromium equivalents are:

$$
\begin{aligned}
& \mathrm{Ni} \text { eq }=\mathrm{Ni}+30(\mathrm{C}+\mathrm{N})+0.5 \mathrm{Mn} ; \\
& \mathrm{Cr}_{\text {eq }}=\mathrm{Cr}+\mathrm{Mo}+1.5 \mathrm{Si}+0.5 \mathrm{Nb} ;
\end{aligned}
$$

where the elements are in wt.\%. Numerous studies have determined the dependence of FN on alloying elements. The coefficients and constants proposed to model the effects of nitrogen and manganese are given in table 1. At high nitrogen contents, Espy, in particular, found that the nitrogen coefficient decreases [24]. Most studies involving high manganese contents have proposed constants to represent the effect of manganese and replace DeLong's $0.5 \mathrm{Mn}$ term. The Hull study [25] was the only high manganese matrix to yield a manganese coefficient. However, its second-order term does reduce the influence of manganese on the nickel equivalent at high concentrations. A review of the alloy ranges used in the various studies did not disclose the reason why different terms (either constants or coefficients) were proposed to model the influence of the manganese and nitrogen in the nickel equivalent expression.

\section{MATERIALS AND PROCEDURE}

To clarify the role of manganese and nitrogen on the cryogenic strength, toughness, and FN, and to understand the reason for the varying and sometimes conflicting effects reported in the literature, a test matrix based on a typ 
308 stainless steel weld composition was evaluated. Alloy additions were made to the SMA electrode coating. Manganese (1.5 to $10 \mathrm{wt. \%}$ ) and nitrogen ( 0.04 to 0.26 wt.\%) were varied independently within the matrix. Several molybdenum ( 2 and 4 wt.\%) and boron (0.006 and 0.015 wt.\%) additions were also made to the matrix.

The weld matrix was designed with constant FN (near $3 \mathrm{FN}$ ) to remove ferrite effects from the analysis. The FN of weld pads and the welds were measured magnetically. The measurement device was calibrated with ANSI/AWS Standard A $4.2-74$.

The weld metal carbon and nitrogen were determined with individual element analyzers; the phosphorus and sulfur, by an optical emission spectrophotometer; and the remaining elements, by conventional analytical techniques. The chemical composition and measured FN for the twenty-four welds included in this study are listed in table 2. Molybdenum interference in the optical emission spectrograph probably caused the variations in measured phosphorus contents.

Test welds were produced using a series of $3.2-\mathrm{mm}(1 / 8-$ in) diameter electrodes that had core wires from a single heat of type 308 stainless steel. The base material was $13-\mathrm{mm}$-thick by $305-\mathrm{mm}-10 \mathrm{ng}$ mild steel plate. To overcome the effect of dilution by the base material, the exposed faces and backing strip were buttered with two layers of weld metal prior to beginning the test weld, as specified in AWS A5.4-78. The same welder, power supply, and welding parameters $(110 \mathrm{~A}, 22 \mathrm{~V}$, an identical bead sequence, and a heat input of approximately $0.6 \mathrm{~kJ} / \mathrm{mm}$ ) were used to minimize weld variations. The interpass temperature was maintained at $93^{\circ} \mathrm{C}$.

Two all-weld-metal, 6-mm-diameter tensile specimens, oriented along the axis of the weld, were machined from each weld. The second specimen, reserved as a spare, was tested in a number of cases to check the repeatability of the results; in these cases, the average value is reported. Tensile specimens were tested at $4 \mathrm{~K}$ (liquid helium) with a strain rate of $0.25 \mathrm{~mm} / \mathrm{min}$. A 25-mm gauge length was used. Specific details on the 4-K tensile testing equipment and procedures have been reported previously [29]. Five $10-\mathrm{mm}^{2}$ CVN specimens, with the ir notches oriented perpendicular to the plate surface and located along the weld centerline, were removed from each weld and tested at $76 \mathrm{~K}$.

\section{RESULTS AND DISCUSSION}

\section{Strength}

The yield and tensile strengths determined for the various welds at $4 \mathrm{~K}$ are given in table 2 and plotted for the various nitrogen contents of the welds in figure 1. The yield strength increased linearly with the nitrogen content. The equation relating the yield strength to the nitrogen content was

Weld Yield Strength $(\mathrm{MPa}$ at $4 \mathrm{~K})=400+3700($ wt. $\% \mathrm{~N})$. 
The $F$ value was 256 and the coefficient of determination, $R^{2}$ (a measure of the quality of the regression), was 0.92 . This equation corresponds closely with a previously determined equation relating the yield strength to nitrogen content for stainless steel plate [6]:

Plate Yield Strength (MPa at $4 \mathrm{~K})=350+3400(\mathrm{wt} . \% \mathrm{~N}$ ).

The tensile strength remained near the average of $1400 \mathrm{MPa}$ for nitrogen contents up to 0.16 wt.\% and averaged $1500 \mathrm{MPa}$ for the three alloys that had about 0.26 wt.\% nitrogen. This slight increase in the tensile strength was not statistically related to the nitrogen contents.

Yield strength as a function of the weld manganese content is shown in figure 2. The nitrogen contents were coded, since they are the dominant strengthener. The $0.05,0.10$, and the 0.15 wt.\% nitrogen concentrations all show approximately a 20-MPa increase in yield strength for every 1 wt.\% increase in manganese content. The equation including both the nitrogen and manganese effects on yield strength is:

Weld Yield strength (MPa at $4 \mathrm{~K}$ )

$$
=360+3400(w t . \% \mathrm{~N})+14(w t . \% \mathrm{Mn}) \text {. }
$$

The $F$ value was 154 and the $R^{2}$ value was 0.94 . There was some evidence that the strengthening tendency of manganese changes as a function of nitrogen content (see figure 2), but linear terms express the relative effects of manganese and nitrogen contents quite well for the scope of this study.

\section{Toughness}

Figure 3 shows that the CVN absorbed energy at $76 \mathrm{~K}$ remains relatively constant at $40 \mathrm{~J}$ for nitrogen contents of less than 0.15 wt.\%. Nitrogen contents above 0.16 wt.\% did cause a decrease in absorbed energy. At 0.25 wt.\% nitrogen, a reduction of approximately 50\% was found. All compositions followed this trend closely with the exception of the 3.84 wt.\% molybdenum alloy, which fell far below the trend. No effect of manganese on the CVN energy was determined.

Unlike the CVN absorbed energy, lateral expansion values decreased linearly as a function of nitrogen content (figure 4). A decrease in lateral expansion of approximately $86 \%$ occurred when the nitrogen content was raised from 0.03 to 0.26 wt.\%. The manganese content also affected lateral expansion. The lateral expansion of alloy 12 is $0.1 \mathrm{~mm}$ less than that of alloy 11 in table 3 (both $\approx 19$ wt.\% $\mathrm{Cr}, 0.15$ wt.\% N, $1.5 \mathrm{FN}$ ); we attribute this to its significantly greater manganese content. The alloys with molybdenum additions generally fit the observed trends; however, the lateral expansion values of alloys with combined high nitrogen, manganese, and molybdenum contents (particularly alloys 13 and 6 ) were low.

The CVN absorbed energy and lateral expansion are linearly related for the common type 308L and $316 \mathrm{~L}$ stainless steel compositions $[3,4]$. The nonlinear relationship observed in this study between CVN absorbed energy and 
lateral expansion was therefore unexpected, and its cause was not determined. We suspect that oxygen content, inclusion density, ferrite content, or other factors are responsible for limiting the impact energy to $40 \mathrm{~J}$. If this is indeed the case, the effect of nitrogen would become apparent only at nitrogen contents high enough to lower the CVN absorbed energy below the 40-J shelf. The nonlinear relationship found in this study indicates that it may not apply to other alloys. It also indicates a need to re-evaluate the use of the 76-K CVN test to screen material for $4-\mathrm{K}$ toughness testing.

The strength-lateral expansion relationship for these alloys is illustrated in figure 5. This relationship is better than that for alloy content-lateral expansion and indicates that the strengthening mechanisms (interstitial for the nitrogen and substitutional for the manganese) are controlling the lateral expansion. Relating the lateral expansion to the strength by linear regression techniques produced the equation:

$\mathrm{LE}(\mathrm{mm}$ at $76 \mathrm{~K})=0.95-6 \times 10^{-4}$ [Weld Yield Strength (MPa at $\left.\left.4 \mathrm{~K}\right)\right]$.

This equation had an $F$ value of 344 and an $R^{2}$ value of 0.94 .

\section{Ferrite Number}

Table 4 gives the difference between the value of FN measured magnetically on the weld pads (FNP) and that calculated using the Delong predictive equation for the various welds. The $\triangle F N$, or deviation between the measured and predicted FN, increases as nitrogen and manganese concentrations increase. Three approaches were used to examine and minimize these deviations.

A graphical method was used to express the influence of manganese and nitrogen on the nickel equivalent. In figure 6 , the difference in nickel equivalents ( $\Delta \mathrm{Ni}_{\text {eq}}$ ) is plotted versus the manganese and nitrogen contents [23]. The $\Delta \mathrm{Ni}$ eq is a measure of the difference between the DeLong diagram nickel equivalent, found using the measured FN and calculated chromium equivalent, and a calculated partial nickel equivalent in which either the manganese or nitrogen term is deleted. The difference between the two equivalents measures the effect of the manganese or nitrogen. The slopes of the best fit lines through the manganese- $\Delta \mathrm{Ni}$ eq or nitrogen- $\Delta \mathrm{Ni}$ eq graphs define the respective manganese and nitrogen coefficients. In figure $6 \mathrm{~A}$ for example, the slope indicates a nitrogen coefficient of $16\left(R^{2}=0.70\right)$. A more significance nitrogen coefficient $\left(R^{2}=0.91\right)$ of 21 is obtained, however, when alloy 22 is excluded from the data. Alloy 22 is excluded owing to its deviation from the trend established by nearly identical compositions. Also, by replotting all the data as the DeLong diagram nickel equivalent versus nitrogen, a nitrogen coefficient of 21 is obtained $\left(R^{2}=0.93\right)$. A nitrogen coefficient of 21 agrees well with those reported by Hull, Espy, and Mel'Kumor (see table 1).

The data (in figure $6 \mathrm{~B}$ ) indicate a slightly negative manganese coefficient. A negative slope has not been proposed previously; but this concept is also supported by the Szumachowski-Kotecki type $309 \mathrm{Ni}$ eq data [23]. It is clear that the Espy, Szumachowski-Kotecki, and Hull terms and the line 
representing this study all predict manganese effects better than the 0.5 Delong manganese coefficient. If a constant manganese term is fitted, the manganese constant $(-0.25)$ is less than that proposed by either Espy $(0.87)$ or Szumachowski and Kotecki $(0.35)[24,23]$.

Stepwise linear regression, the second method of analysis, was used to determine the accuracy of existing predictive FN equations and to examine possible improvements to these equations by changing the coefficients and adding new variables. In this approach, twenty variations of the DeLong $[22,30]$, Schaeffler $[21,30]$, and Seferian equations [31] were evaluated and ranked in order of their significance during the stepwise regression. Within each equation type, different combinations of nitrogen and manganese terms were used. For nitrogen, coefficients of $30,24,18,13$, and 0 were included. For manganese, DeLong's 0.5 manganese coefficient and constant manganese terms of 0.35 and 0.74 were included. One equation that contained Hull's manganese terms was included. From this wide variety of predictive equations and modifications, the best equation was selected for the manganese and nitrogen ranges in this study.

In addition to these FN predictive equations, compositional terms such as $\mathrm{Mn}, \mathrm{N}, \mathrm{Si}, \mathrm{Mn}^{2}, \mathrm{MnN}$, and $\mathrm{CN}$ were also available for selection by the regression program. Selection of one of these terms following the selection of a predictive equation indicated that its influence was not properly modeled in the predictive equation.

Figure 7 shows the predicted values for three of these equations (FNCD, FNCDK, FNCSK) plotted against the FN measured on the weld pad (FNP) and illustrates the substantial differences between the predicted and measured FN values. These equations are defined by:

$$
\begin{aligned}
& \text { FNCD }=-30.65+3.49(\mathrm{Cr}+\mathrm{MO}+1.5 \mathrm{Si})-2.5[\mathrm{Ni}+30(\mathrm{~N}+\mathrm{C})+0.5 \mathrm{Mn}] ; \\
& \text { FNCDK }=-30.65+349(\mathrm{Cr}+\mathrm{Mo}+1.5 \mathrm{Si})-2.5[\mathrm{Ni}+30(\mathrm{~N}+\mathrm{C})+0.35] ; \\
& \text { FNCSK }=-39.1+43.5(\mathrm{Cr}+\mathrm{MO}+1.5 \mathrm{Si}) / 2.5[\mathrm{Ni}+30(\mathrm{~N}+\mathrm{C})+2.35] ;
\end{aligned}
$$

where all elements are given in wt.\%. As an example of the notation, FNCSK indicates the Ferrite Number calculated using a Schaeffler diagram equation modified to inçlude niẗrogen and using the Szumachowski-Kotecki manganese constant $(0.35)$. The $D$ in FNCD represents the DeLong diagram FN equation.

The unmodified DeLong equation (FNCD) underestimated the measured FN by as much as $24 \mathrm{FN}$ when the nitrogen and manganese contents exceeded the ranges for which the equation was proposed (figure 7A). Figure 7B shows the improved FN predictions resulting from the replacement of DeLong's 0.5 manganese coefficient with the 0.35 constant manganese term (FNCDK). Although the FN values generated from the FNCDK expression agree well with the measured FN values at lower manganese and nitrogen content, overall the FNCSK equation produces a more linear data set. When modified with a coefficient to adjust its slope and given the appropriate intercept, FNCSK predicted the effect of manganese and nitrogen most accurately. For this reason, FNCSK was a lways 
chosen as the best predictor of FNP by stepwise linear regression analysis. A similar result was found using the ferrite number measured on the actual welds (FNW). Because the results using FNP or FNW are so similar, they will be used interchangeably and are identified simply as FN. The equation found through this method of analysis was:

$$
\mathrm{FN}=3.0+0.26(\mathrm{FNCSK}) \text {. }
$$

This equation had an $F$ value of 98 and an $R^{2}$ value of 0.82 . In each calculation, the program indicated the need for an additional nitrogen- or nitrogenmanganese-containing term in the predictive equation. Overall, this method of analysis showed that although FN prediction is greatly improved by using the modified Schaeffler equation, the manganese and nitrogen terms within the ENCSK expression require further study.

Modification of DeLong's nickel equivalent was the third and final approach to reduce the FN deviations. The nickel equivalent was calculated from the chromium equivalent and measured FN. Only compositional variables associated with the present DeLong nickel equivalent and boron were allowed as choices during linear regression analysis with this method. Here, it was possible to determine which compositional terms were statistically significant and their respective coefficients. A revised nickel equivalent was found that better predicted $F N$ in these high manganese-nitrogen alloys:

$$
\mathrm{Ni}_{\text {eq }}=\mathrm{Ni}+29(\mathrm{C}+\mathrm{N})+0.53(\mathrm{Mn})-0.05(\mathrm{Mn})^{2}-2.37(\mathrm{MnN})+0.94(\mathrm{MnN})^{2}-0.71 ;
$$

where all elements are represented in wt.\%. An F value of 220 and an $R^{2}$ value of 0.98 indicate a high statistical significance for the equation. This modified nickel equivalent can be substituted for the DeLong nickel equivalent to determine $F N$ using the DeLong diagram, or it can be substituted for the Delong nickel equivalent in the mathematical representation of the Delong diagram, equation $5 \mathrm{a}$, y ielding:

$$
\begin{aligned}
\mathrm{FN}= & -30.65+3.49(\mathrm{Cr}+\mathrm{Mo}+1.5 \mathrm{Si})-2.5[\mathrm{Ni}+29(\mathrm{C}+\mathrm{N})+0.53(\mathrm{Mn})- \\
& \left.0.05(\mathrm{Mn})^{2}-2.37(\mathrm{MnN})+0.94(\mathrm{MnN})^{2}-0.71\right] .
\end{aligned}
$$

In developing this equation, alloys with nitrogen contents greater than 0.22 wt.\% and FN of less than 1.0 were not included. Since the DeLong equation was shown to have a large scatter at very high nitrogen or manganese contents in figure 6 and accurate measurements of FN near zero are difficult, these limitations seem reasonable.

The manganese effect is decidedly dependent on the nitrogen level, as shown on the contour map of the equation in figure 8 . At a low nitrogen content, the nickel equivalent first increases as the manganese content is increased. As manganese contents exceed the 4 to 5.5 wt.\% range, however, the nickel equivalent begins to decrease. The observation of a change in the austenitizing power for manganese within this concentration range has been reported by Suutala [32], Hull [25], and Guiraldenq [33]. The fact that increased nitrogen contents modify the behavior of manganese has not been previously reported. At 0.20 wt.\% nitrogen for example, no characteristic 
change in the nickel equivalent takes place as the manganese content is increased. The nickel equivalent slowly and continuously decreases to lower values. On the other hand, at 0.06 wt.\% nitrogen, the nickel equivalent increases from 12 to 12.7 and then decreases to 11.4 as the manganese content is raised. A change in the nickel equivalent from 12 to 13 at the average chromium content of 19.5 results in an FN change of 3 on the DeLong diagram.

If either of the MnN terms is removed from equation 7 , the other becomes insignificant, the magnitudes of their coefficients are reduced, and the coefficient for nitrogen approaches 22. Such an equation is in agreement with those found by Hull [25] and Mel'Kumor and Topilin [27]. It could be argued that equation (6) is in fact an extension of those developed by Hull, Mel'Kumor and Topilin and is also related to that found by DeLong [22] at lower manganese levels.

In summary, the DeLong manganese coefficient of 0.5 is inaccurate for these high manganese-nitrogen alloys. The replacement of DeLong's coefficient with the Szumachowski-Kotecki constant manganese term (0.35) improves EN prediction, but it still does not completely describe the behavior of manganese. The revised nickel equivalent proposed in equation 6 , however, improves FN predictions by quantifying the nitrogen-manganese interactions. From the various manganese and nitrogen terms reported by researchers and the seemingly contradictory nitrogen coefficients indicated through graphical versus computer methods in this study, it is clear that interactions between alloy elements must be more fully understood before better (and, one hopes, simpler) FN predictive equations can be written.

\section{CONCLUSIONS}

1. The 4-K yield strength of these welds is primarily a function of the nitrogen content. Manganese increases the strength slightly. Both effects can be expressed by

Weld Yield Strength $(\mathrm{MPa})=360+3400($ wt.\% $\mathrm{N})+14($ wt.\% Mn).

2. The 76-K lateral expansion had a more linear correlation to the strength and the alloy content than the CVN absorbed energy. The lateral expansion was expressed best by

LE $(\mathrm{mm}$ at $76 \mathrm{~K})=0.95-6 \times 10^{-4}$ [Weld Yield Strength (MPa at $\left.\left.4 \mathrm{~K}\right)\right]$.

3. Present FN predictive equations are inaccurate for $18 \mathrm{Cr}-9 \mathrm{Ni}$ stainless steels with high manganese and nitrogen levels. Two equations were found to improve FN prediction for these alloys. The first is simpler; the second is more accurate.

$$
\begin{aligned}
\mathrm{FN}= & 3.0+0.26[-39.1+43.5(\mathrm{Cr}+\mathrm{Mo}+1.5 \mathrm{Si}) / \\
& 2.5(\mathrm{Ni}+30(\mathrm{~N}+\mathrm{C})+2.35)] . \\
\mathrm{Ni}_{\text {eq }}= & \mathrm{Ni}+29(\mathrm{C}+\mathrm{N})+0.53(\mathrm{Mn})-0.05(\mathrm{Mn})^{2}-2.37(\mathrm{MnN})+0.94(\mathrm{MnN})^{2} \\
& -0.71 .
\end{aligned}
$$


The second equation is a modified $\mathrm{Ni}$ eq, which is to be used with the DeLong diagram or equation ( $5 \mathrm{a}$ ).

\section{ACKNOWLEDGMENT} Energy.

This work was supported by the Department of Energy, Office of Fusion

\section{REFERENCES}

1. McHenry, H. I.; Read, D. T .; and Steinmeyer, P. A. 1979. Evaluation of stainless steel weld metals at cryogenic temperatures. Materials studies for magnetic fusion energy applications at low temperatures - II, NBSIR 79-1609: 299. Boulder, Colorado: National Bureau of Standards.

2. McHenry, H. I. and Elmer, J.W. 1982. Fracture Properties of a $25 \mathrm{Mn}$ austenitic steel. Materials studies for magnetic fusion energy applications at low temperatures - V, NBSIR 82-1667: 245. Boulder, Colorado: National Bureau of Standards.

3. Siewert, T.A. 1978. How to predict impact energy from stainless steel composition. Welding Design and Fabrication 51 (6): 88-90.

4. Szumachowski, E. R. and Reid, H. F. 1979. Cryogenic toughness of SMA austenitic stainless steel weld metal: Part II - Role of nitrogen. Welding Journal 58 (2): $34 \mathrm{~s}-44 \mathrm{~s}$.

5. Mori, T. and Kuroda, T. 1985. Prediction of energy absorbed in impact for austenitic weld metals at $4.2 \mathrm{~K}$. Cryogenics 25: 243-248.

6. Reed, R. P. and Simon, N. J. 1984. Low temperature streng thening of austenitic stainless steels with nitrogen and carbon. Advances in cryogenic engineering - materials 30: 127-136. New York: Plenum Press.

7. Peckner, D. and Bernstein, I. M. 1977. Stainless steel handbook: 4-13. New York: McGraw-Hill.

8. Gunia, R. B. and Woodrow, G. R. 1970. Nitrogen improves engineering properties of chromium-nickel-stainless steel. Journal of Materials 5 (2): $\quad 413-430$.

9. Humbert, J.C. and Elliott, J.F. 1960. The solubility of nitrogen in liquid $\mathrm{Fe}-\mathrm{Cr}-\mathrm{Ni}$ alloys. Metallurgical Transactions 218: 1076-1087.

10. Enjo, T.; Kikuchi, Y.; and Nagata, H. 1982. Effect of nitrogen content on the low-temperature mechanical properties of type 304 stainless steel weld metals. Transactions JWRI 11 (2): 35-42.

11. Onishi, K.; Miura, R.; et al. 1981. Effect of carbon and nitrogen contents on the mechanical properties of SUS 304 and 316 austenitic stainless 
steel at low temperatures down to $4 \mathrm{~K}$. Tetsu-to-Hagane 67 (13): 271.

12. Ledbetter, H. M. and Austin, M. W. 1985. Dilation of an fcc $\mathrm{Fe}-\mathrm{Cr}-\mathrm{Ni}$ alloy by interstitial carbon and nitrogen. Submitted to Metallurgical Transactions.

13. Mukai, K.; Hoshino, K.; and Fujioka, T. 1979. Tensile and fatigue properties of austenitic stainless steel at LNG Temperature. Tetsu-to-Hagane 65 (12): 1756-1765.

14. Erasmus, L. A. and Yang, L. J. 1970. Strengthening welds in the warm-worked grades of austenitic stainless steel by the addition of nitrogen. Welding and Metal Fabrication July: 269-275.

15. Ozeki, T. and Ogawa, T. 1985. The solidification and cryogenic toughness of high nitrogen stainless steel weld metal. Group welding metallurgy document. Japan: Nippon Steel Research Center, unpublished.

16. Sakamoto, T.; Nakagawa, Y.; and Yamuchi, I. 1986. Effect of manganese on the cryogenic properties of high nitrogen stainless steels. Advances in cryogenic engineering - materials 32: New York: Plenum Press. In press.

17. Read, D. T.; McHenry, H. I.; Steinmeyer, P. A.; and Thomas, R. D., Jr. 1980. Metallurgical factors affecting the toughness of $316 \mathrm{~L}$ SMA weldments at cryogenic temperatures. Welding Journal 59 (4): 104s-113s.

18. Szumachowski, E. R. and Reid, H. F. 1978. Cryogenic toughness of SMA austenitic stainless steel weld metals: Part 1 - Role of ferrite. Welding Journal 57 (11): 325s-333s.

19. Siewert, T.A. 1985. Predicting the toughness of SMA austenitic stainless steel welds at $77 \mathrm{~K}$. Submitted to Welding Journal.

20. Ekstrom, U. and Olsson K. 1980. The influence of ferrite and oxygen contents on weld metal mechanical properties of submerged arc welded stainless steel. Proc. Welding Institute conf.: Weld pool chemistry and metallurgy: 80-81. Discussion ISBN 0-85300-138-3, vol. 1, Paper 37: 323-334. Cambridge, England: The Welding Institute.

21. Schaeffler, A. L. 1949. Constitution diagram for stainless steel weld metal. Metal Progress 85 (7): $680 \mathrm{~B}$.

22. DeLong, W. T. 1974. Ferrite in austenitic stainless steel weld metal. Welding Journal $53(7)$ : 273s-286s.

23. Szumachowski, E. R. and Kotecki, D. J. 1984. Effect of manganese on stainless steel weld metal ferrite. Welding Journal 63 (5): 156s-161s.

24. Espy, R. H. 1982. Weldability of nitrogen-strengthened stainless steel Welding Journal 61 (5): 149s-156s. 
25. Hull, F. C. 1973. Delta ferrite and martensitic formation in stainless steels. Welding Journal 52 (5): 193s-200s.

26. Hammar, O. and Svenson, U. 1979. Solidification and casting of metals: 401-410. London: The Metals Society.

27. Mel'Kumor, N. and Topilin, V. V. 1969. Alloying austenitic stainless steel with nitrogen. Obrabotka Metallor (August): 47-51.

28. Okagawa, R. K.; Dixon, R. D.; and Olson, D. L. 1983. The influence of nitrogen from welding on stainless steel weld metal microstructures. Welding Journal 62 (8): 204s-209s.

29. Read, D. T. and Tobler, R. L. 1982. Mechanical property measurements at low temperatures. Advances in cryogenic engineering - materials 28: 17-28. New York: Plenum Press.

30. Johnson, E. W. and Hudak S. J. 1978. $\mathrm{H}_{2}$ embrittlement of austenitic stainless steel weld metal with special consideration given to sigma phase: Welding research bulletin 240. New York: Welding Research Council.

31. Seferian, D. 1962. Metallurgy of Welding. (trans. E. C. Bishop). London: Chapman and Hall.

32. Suutala, N. 1982. Effect of manganese and nitrogen on the solidification mode in austenitic stainless steel welds. Metallurgical Transactions A 13: 191-197.

33. Guiraldenq, P. 1967. Science reviews of metals 64: 907-938. 
Table 1. Various Manganese and Nitrogen Coefficients Determined in Previous Studies

\begin{tabular}{|c|c|c|c|c|}
\hline \multirow[t]{2}{*}{ Researcher } & \multicolumn{2}{|c|}{$\begin{array}{l}\text { Coefficient } \\
\text { or Constant }\end{array}$} & \multirow{2}{*}{$\begin{array}{l}\text { Principle } \\
\text { Matrix Variations } \\
\text { (wt.\%) }\end{array}$} & \multirow[t]{2}{*}{ Comments } \\
\hline & $\mathrm{N}$ & $\mathrm{Mn}$ & & \\
\hline Schaeffler [21] & - & $0.5 \mathrm{Mn}$ & $\mathrm{Ni}(0$ to 30$)$ & $308,309,310,316,410$, and 502 \\
\hline DeLong [22] & $30 \mathrm{~N}$ & $0.5 \mathrm{Mn}$ & $\mathrm{N} \quad(0.03$ to 0.22$)$ & $309,308 \mathrm{~L}, 316,316 \mathrm{~L}, 347$ (Low Mn, N) \\
\hline Hull [25] & $18.4 \mathrm{~N}$ & $\begin{array}{l}0.11 \mathrm{Mn}- \\
0.0086 \mathrm{Mn}^{2}\end{array}$ & $\begin{array}{ll}N i & (0 \text { to } 22) \\
M n & (0 \text { to } 20) \\
N & (0 \text { to } 0.15)\end{array}$ & $\begin{array}{l}70 \text { chill - cast stainless } \\
\text { steel alloys. Mo, Si, V, } \\
\text { W, Ti, Cb, Ta, Al, Co, Cu, } \\
\text { C also varied. Cr }=14 \text { to } 20 \text { wt.\% }\end{array}$ \\
\hline Espy $[24]$ & $\begin{array}{ll}30 & (N-0.045) \\
22 & (N-0.045) \\
20 & (N-0.45)\end{array}$ & 0.87 & $\begin{array}{l}\text { Mn }(5 \text { to } 12.5) \\
\mathrm{N}(0.13 \text { to } 0.33)\end{array}$ & $\begin{array}{l}4 \text { Nitronic series alloys. } \\
\mathrm{N} \text { and } \mathrm{Mn} \text { not varied systematically. } \\
\text { The } 3 \mathrm{~N} \text { coeff. are for }<0.20 \text {, } \\
<0.25 \text {, and }<0.35 \text { wt. } \% \mathrm{~N} \text {, respectively. }\end{array}$ \\
\hline $\begin{array}{l}\text { Hammar } \\
\text { and } \\
\text { Svenson [26] }\end{array}$ & $14.2 \mathrm{~N}$ & 0.31 & $\begin{array}{ll}\mathrm{N} i & (9.0 \text { to } 14) \\
\mathrm{N} & (0.01 \text { to } 0.20) \\
\mathrm{C} & (0.04 \text { to } 0.10)\end{array}$ & $\begin{array}{l}130 \text { austenitic alloys. (Ingots) } \\
\text { Mn content }=1 \text { to } 2 \text { wt. } \% \text {. } \\
\mathrm{Cr}=17 \text { to } 25 \text { wt. } \% \text {. }\end{array}$ \\
\hline $\begin{array}{l}\text { Mel'Kumor } \\
\text { and } \\
\text { Topilin [27] }\end{array}$ & $20 \mathrm{~N}$ & - & $\begin{array}{l}\text { Ni }(10 \text { to } 16) \\
N(0.05 \text { to } 0.46)\end{array}$ & $\begin{array}{l}\text { Austenitic Stainless Steel } \\
0.5 \mathrm{Mn}, 25 \mathrm{Cr}, 0.09 \mathrm{C}\end{array}$ \\
\hline $\begin{array}{l}\text { Szumachowski } \\
\text { and } \\
\text { Kotecki [23] }\end{array}$ & $30 \mathrm{~N}$ & 0.35 & $\operatorname{Mn}(1$ to 12$)$ & $\begin{array}{l}308,309 \mathrm{~L}, 316 \mathrm{~L}, 307 \\
\text { Low nitrogen }(0.05 \text { wt.\%) }\end{array}$ \\
\hline $\begin{array}{l}\text { Okagawa } \\
\text { et al. [28] }\end{array}$ & $13.4 \mathrm{~N}$ & $0.5 \mathrm{Mn}$ & $N(0.04$ to 0.29$)$ & $\begin{array}{l}\text { GTA weld ( } n \text { filler metal) on } \\
304 \mathrm{~L} \text { base metal. } \mathrm{N} \text { added through } \\
\text { shielding gas. }\end{array}$ \\
\hline
\end{tabular}


Table 2. Chemical Composition* and Ferrite Numbers of the Welds.

\begin{tabular}{|c|c|c|c|c|c|c|c|c|c|c|c|c|c|}
\hline $\begin{array}{l}\text { Alloy } \\
\text { No. }\end{array}$ & C & Mn & $\mathrm{Si}$ & $P$ & S & $\mathrm{Cr}$ & $\mathrm{Ni}$ & Mo & $\mathrm{N}$ & B & $\begin{array}{l}\text { FN } \\
\text { Pad }\end{array}$ & $\begin{array}{l}\text { FN } \\
\text { Plate }^{+}\end{array}$ & $\begin{array}{c}\text { FN } \\
\text { Calculated } \\
\text { DeLong }\end{array}$ \\
\hline 1 & 0.033 & 1.57 & 0.29 & 0.013 & 0.006 & $17 \cdot 58$ & 9.19 & 0.02 & 0.047 & $\#$ & 2.8 & 4.9 & 1.35 \\
\hline 2 & 0.034 & 1.49 & 0.34 & 0.020 & 0.006 & 15.37 & 9.06 & 2.03 & 0.034 & \# & 3.4 & 4.4 & 2.2 \\
\hline 3 & 0.034 & 3.23 & 0.39 & 0.014 & 0.006 & 17.87 & 9.02 & 0.02 & 0.035 & $\#$ & 4.0 & 4.7 & 2.07 \\
\hline 4 & 0.036 & 6.54 & 0.37 & 0.015 & 0.007 & 17.61 & 9.13 & 0.02 & 0.046 & \# & 2.8 & 4.2 & -4.3 \\
\hline $5 R$ & 0.039 & 6.31 & 0.34 & 0.021 & 0.007 & 15.39 & 9.14 & 1.99 & 0.047 & \# & 2.8 & 3.6 & -5.4 \\
\hline 5 & 0.039 & 6.31 & 0.34 & 0.021 & 0.007 & 15.39 & 9.14 & 1.99 & 0.047 & \# & 2.8 & 3.6 & -5.4 \\
\hline $6 \mathrm{~A}$ & 0.036 & 6.27 & 0.34 & 0.027 & 0.007 & 15.17 & 9.14 & 3.84 & 0.162 & $\#$ & 2.6 & 2.9 & -8.06 \\
\hline 7 & 0.032 & 1.66 & 0.32 & 0.014 & 0.006 & 18.36 & 8.94 & 0.02 & 0.103 & $\#$ & 1.8 & 3.1 & 0.6 \\
\hline 8 & 0.033 & 2.96 & 0.36 & 0.013 & 0.006 & 18.13 & 9.12 & 0.02 & 0.037 & $\#$ & 3.6 & 5.1 & 0.02 \\
\hline 9 & 0.038 & 6.46 & 0.35 & 0.015 & 0.007 & 18.51 & 9.17 & 0.02 & 0.098 & \# & 2.6 & 3.6 & -5.35 \\
\hline 10 & 0.037 & 9.52 & 0.38 & 0.017 & 0.009 & 17.71 & 9.10 & 0.02 & 0.106 & $\#$ & 1.5 & 2.7 & -12.16 \\
\hline 11 & 0.031 & 3.18 & 0.34 & 0.015 & 0.006 & 18.99 & 9.05 & 0.02 & 0.153 & \# & 1.4 & 1.9 & -2.93 \\
\hline 12 & 0.037 & 6.62 & 0.38 & 0.016 & 0.008 & 19.51 & 9.06 & 0.02 & 0.151 & $\#$ & 2.2 & 3.6 & -5.53 \\
\hline 13 & 0.035 & 6.61 & 0.32 & 0.021 & 0.007 & 17.77 & 9.10 & 1.66 & 0.166 & $\#$ & 2.5 & 3.5 & -7.25 \\
\hline 14 & 0.038 & 9.38 & 0.35 & 0.017 & 0.009 & 18.98 & 9.14 & 0.02 & 0.163 & $\#$ & 1.7 & 2.8 & -12.16 \\
\hline 15 & 0.032 & 6.11 & 0.36 & 0.016 & 0.007 & 20.90 & 9.29 & 0.02 & 0.252 & \# & 1.6 & 2.0 & -7.92 \\
\hline 16 & 0.038 & 9.56 & 0.37 & 0.019 & 0.009 & 20.22 & 9.07 & 0.02 & 0.265 & $\#$ & 1.2 & 1.8 & -14.75 \\
\hline 17 & 0.031 & 2.90 & 0.30 & 0.013 & 0.006 & 18.79 & 9.12 & 0.02 & 0.104 & \# & 2.0 & 3.8 & 2.83 \\
\hline 18 & 0.033 & 3.25 & 0.39 & 0.014 & 0.006 & 17.58 & 9.00 & 0.02 & 0.032 & 0.015 & 3.2 & 3.7 & 1.38 \\
\hline $18 \mathrm{R}$ & 0.032 & 3.16 & 0.42 & 0.013 & 0.006 & 17.90 & 9.05 & 0.02 & 0.041 & 0.006 & 3.0 & 4.6 & 2.04 \\
\hline 19 & 0.039 & 9.55 & 0.34 & 0.017 & 0.009 & 17.70 & 9.26 & 0.02 & 0.037 & $\#$ & 3.6 & 4.8 & -7.81 \\
\hline 20 & 0.033 & 3.10 & 0.36 & 0.015 & 0.006 & 17.75 & 9.07 & 0.02 & 0.152 & $\#$ & 0.8 & 1.0 & -7.17 \\
\hline 21 & 0.033 & 3.46 & 0.37 & 0.014 & 0.006 & 17.82 & 9.10 & 0.02 & 0.150 & 0.008 & 0.6 & 0.5 & -7.25 \\
\hline 22 & 0.032 & 9.72 & 0.34 & 0.018 & 0.009 & 17.60 & 9.06 & 0.02 & 0.259 & \# & 0.2 & 0.7 & -24.00 \\
\hline
\end{tabular}

\footnotetext{
* Weight percent.
}

${ }^{+}$FN plate is the average of $F N$ bead surface and FN impact specimen surface.

"Not determined. 
Table 3. Mechanical Properties of the Welds

\begin{tabular}{|c|c|c|c|c|c|c|}
\hline \multirow[b]{2}{*}{ Alloy } & \multicolumn{4}{|c|}{ 4-K Tensile Properties } & \multicolumn{2}{|c|}{ 76-K CVN Properties } \\
\hline & $\begin{array}{l}\sigma_{\mathrm{y}} \\
(\mathrm{MPa})\end{array}$ & $\begin{array}{c}\sigma \mathrm{\sigma} \\
(\mathrm{MPa})\end{array}$ & $\begin{array}{c}\text { Elongation } \\
(\%)\end{array}$ & $\begin{array}{l}\text { Reduction } \\
(\%)\end{array}$ & $\begin{array}{c}\mathrm{LE} \\
(\mathrm{mm})\end{array}$ & $\begin{array}{c}A E \\
(J)\end{array}$ \\
\hline 1 & 469 & 1586 & $26 *$ & 16.6 & 0.686 & 46 \\
\hline 2 & 527 & 1570 & 20 & 13.5 & 0.711 & 39 \\
\hline 3 & 504 & 1432 & $25^{*}$ & 23.8 & 0.584 & 41 \\
\hline 4. & 455 & 1341 & 26 & 22.7 & 0.584 & 42 \\
\hline $5 R$ & 619 & 1346 & $27^{*}$ & 18.0 & - & - \\
\hline 5 & 665 & 1489 & 37 & 29.1 & 0.533 & 37 \\
\hline 6 & 1169 & 1447 & 12 & 14.1 & 0.127 & 16 \\
\hline 7 & 787 & 1412 & $21^{*}$ & 14.3 & 0.483 & 39 \\
\hline 8 & 502 & 1387 & $24 *$ & 14.9 & 0.686 & 43 \\
\hline 9 & 864 & 1410 & $24 *$ & 22.4 & 0.432 & 42 \\
\hline 10 & 871 & 1395 & 32 & 23.8 & 0.406 & 37 \\
\hline 11 & 932 & 1376 & 20 & 16.8 & 0.406 & 40 \\
\hline 12 & 1020 & 1376 & 18.8 & 15.3 & 0.305 & 37 \\
\hline 13 & 1129 & 1410 & 12.0 & 13.5 & 0.229 & 33 \\
\hline 14 & 1075 & 1527 & 28.5 & 26.6 & 0.305 & 34 \\
\hline 15 & 1344 & 1627 & 16.5 & 18.9 & 0.127 & 20 \\
\hline 16 & 1306 & 1622 & 20.0 & $13 \cdot 3$ & 0.127 & 24 \\
\hline 17 & 748 & 1438 & $25^{*}$ & 10.2 & 0.508 & 42 \\
\hline 18 & 502 & 856 & 6.5 & 10.8 & 0.610 & 43 \\
\hline $18 \mathrm{R}$ & 491 & 1267 & $19 *$ & 14.5 & 0.610 & 38 \\
\hline 19 & 635 & 1299 & 27 & 23.1 & 0.483 & 37 \\
\hline 20 & 888 & 1261 & $16 *$ & 15.1 & 0.457 & 42 \\
\hline 21 & 874 & 1125 & 11.3 & 9.6 & 0.432 & 41 \\
\hline 22 & 1250 & 1498 & 15.5 & 15.4 & 0.152 & 21 \\
\hline
\end{tabular}

LE = lateral expansion; $A E$ = absorbed energy.

* fractured outside the gauge marks 
Table 4. Deviation between the Measured FN and the FN Calculated Using DeLong's Equation

\begin{tabular}{|c|c|c|c|}
\hline Alloy & wt. $\%$ N & wt.\% Mn & $\Delta F N^{*}$ \\
\hline 1 & 0.047 & 1.57 & 1.45 \\
\hline 2 & 0.034 & 1.47 & 1.20 \\
\hline 3 & 0.035 & 2.23 & 1.93 \\
\hline 4 & 0.046 & 6.54 & 7.10 \\
\hline $5 \mathrm{R}$ & 0.047 & 6.31 & 8.20 \\
\hline 5 & 0.047 & 6.31 & 8.20 \\
\hline 6 & 0.162 & 6.27 & 10.66 \\
\hline 7 & 0.103 & 1.66 & 1.20 \\
\hline 8 & 0.037 & 2.96 & 3.58 \\
\hline 9 & 0.098 & 6.46 & 7.95 \\
\hline 10 & 0.106 & 9.52 & 13.66 \\
\hline 11 & 0.153 & 3.18 & 4.33 \\
\hline 12 & 0.151 & 6.62 & 7.73 \\
\hline 13 & 0.166 & 6.61 & 9.75 \\
\hline 14 & 0.163 & 9.38 & 13.86 \\
\hline 15 & 0.252 & 6.11 & 9.52 \\
\hline 16 & 0.265 & 9.56 & 15.95 \\
\hline 17 & 0.104 & 2.90 & -0.83 \\
\hline 18 & 0.032 & 3.25 & 1.82 \\
\hline $18 \mathrm{R}$ & 0.041 & 3.16 & 0.96 \\
\hline 19 & 0.037 & 9.55 & 11.45 \\
\hline 20 & 0.152 & 3.10 & 7.97 \\
\hline 21 & 0.150 & 3.46 & 7.85 \\
\hline 22 & 0.259 & 9.72 & 24.20 \\
\hline
\end{tabular}

${ }^{*} \triangle F N$ is defined as the difference between the measured FN (FNP) and the FN calculated with the DeLong predictive equation. 


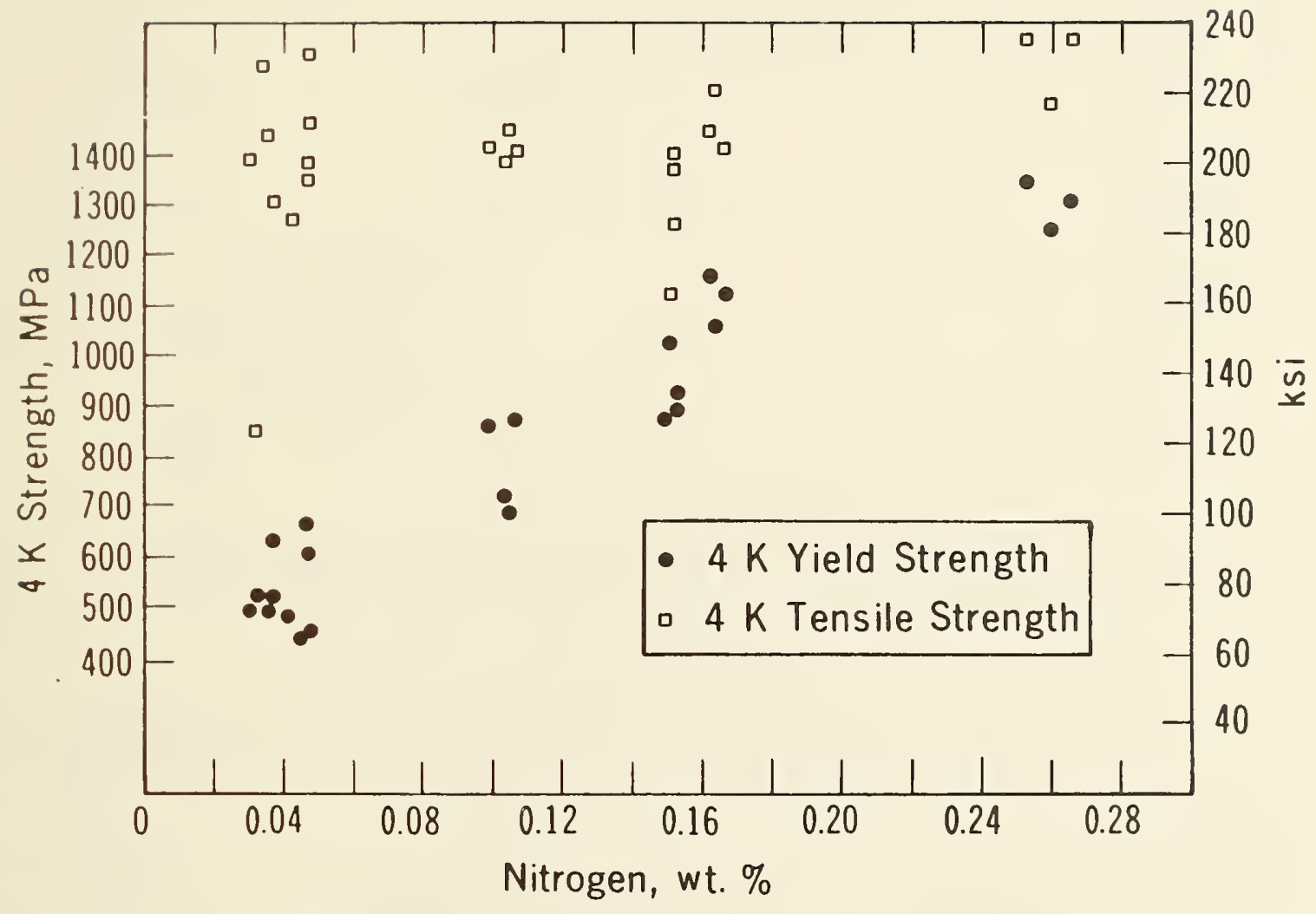

Fig. 1. Strength versus weld nitrogen content at $4 \mathrm{~K}$. 


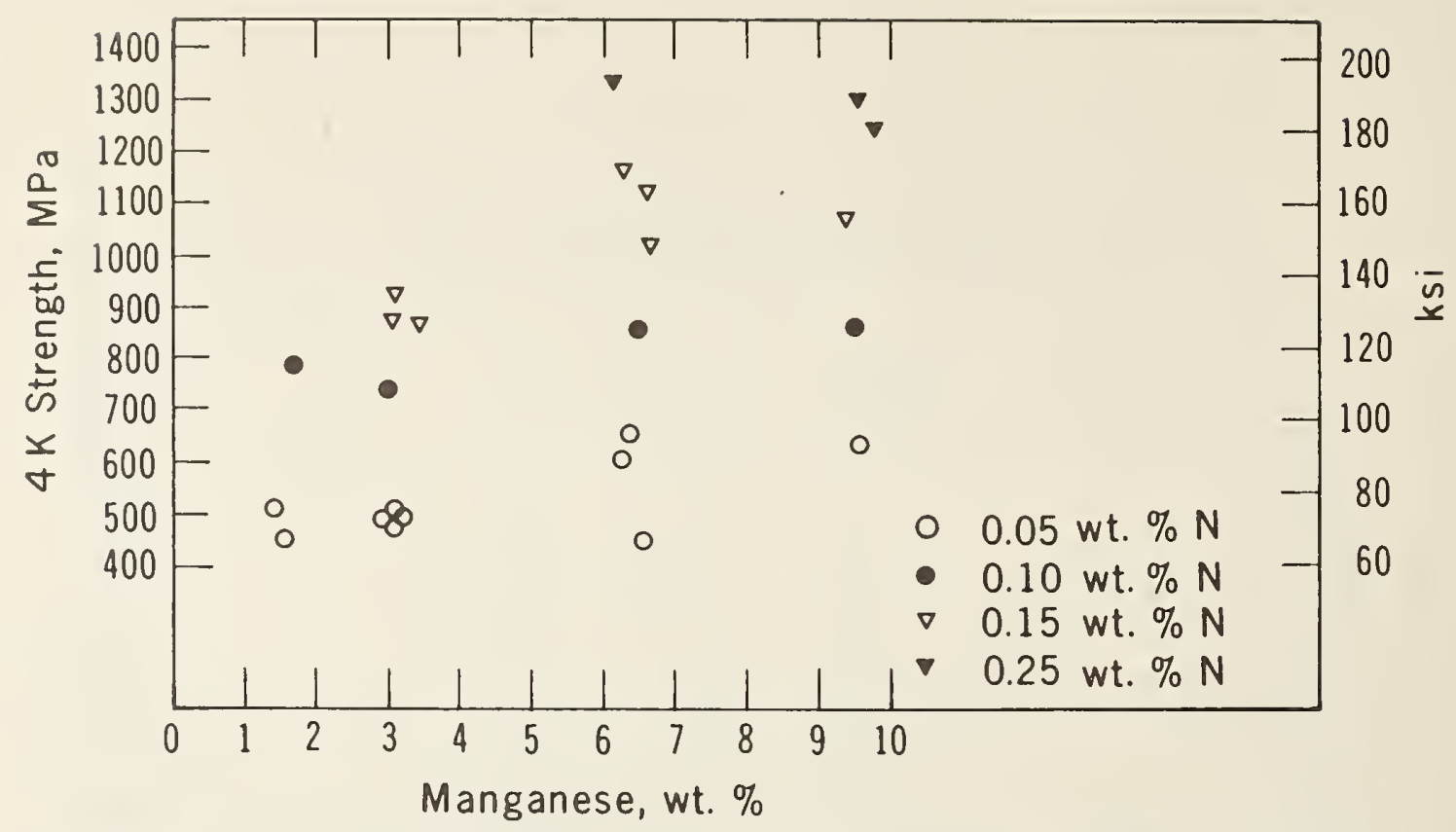

Fig. 2. Yield strength versus weld manganese content at $4 \mathrm{~K}$.

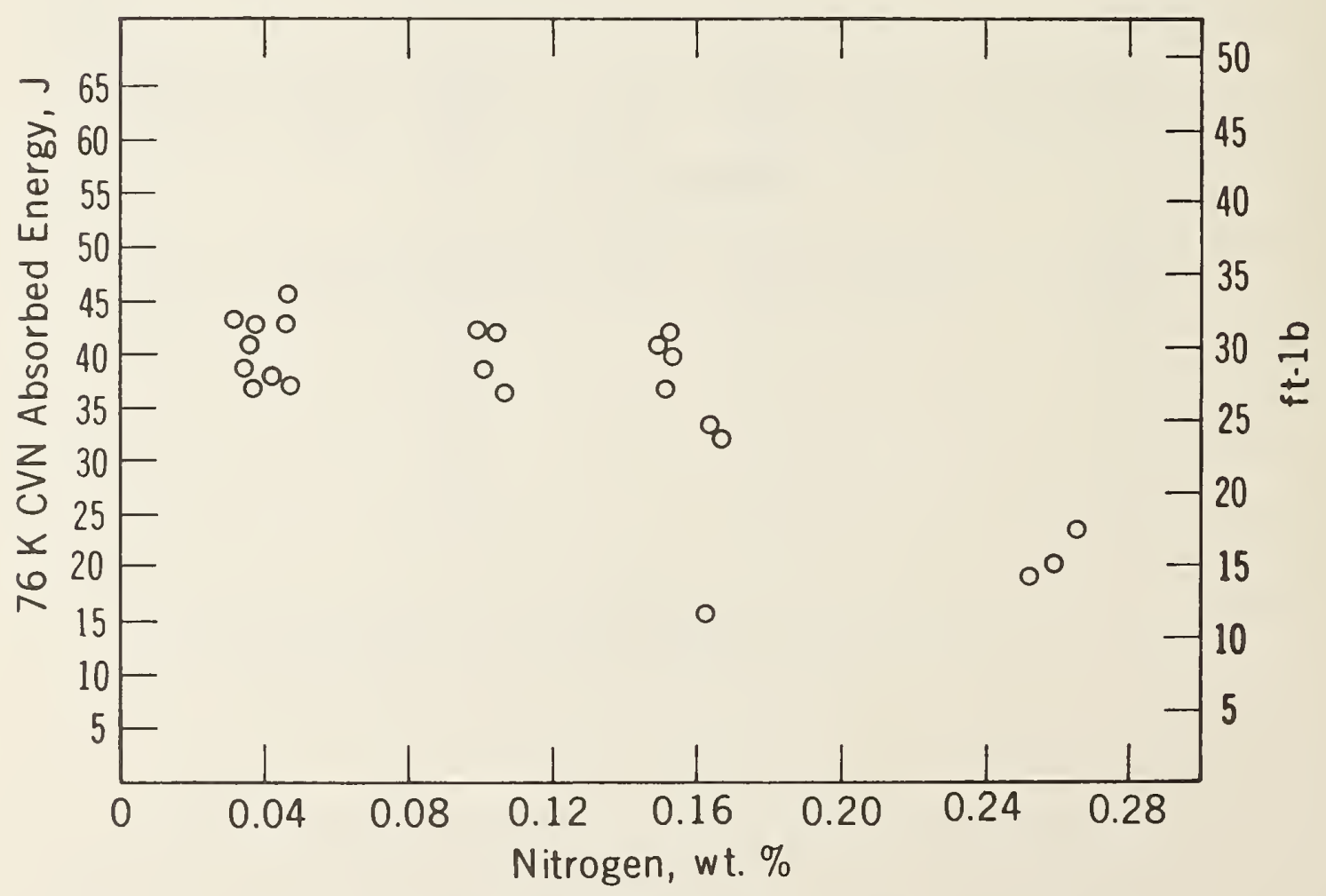

Fig. 3. CVN absorbed energy versus nitrogen content at $76 \mathrm{~K}$. 


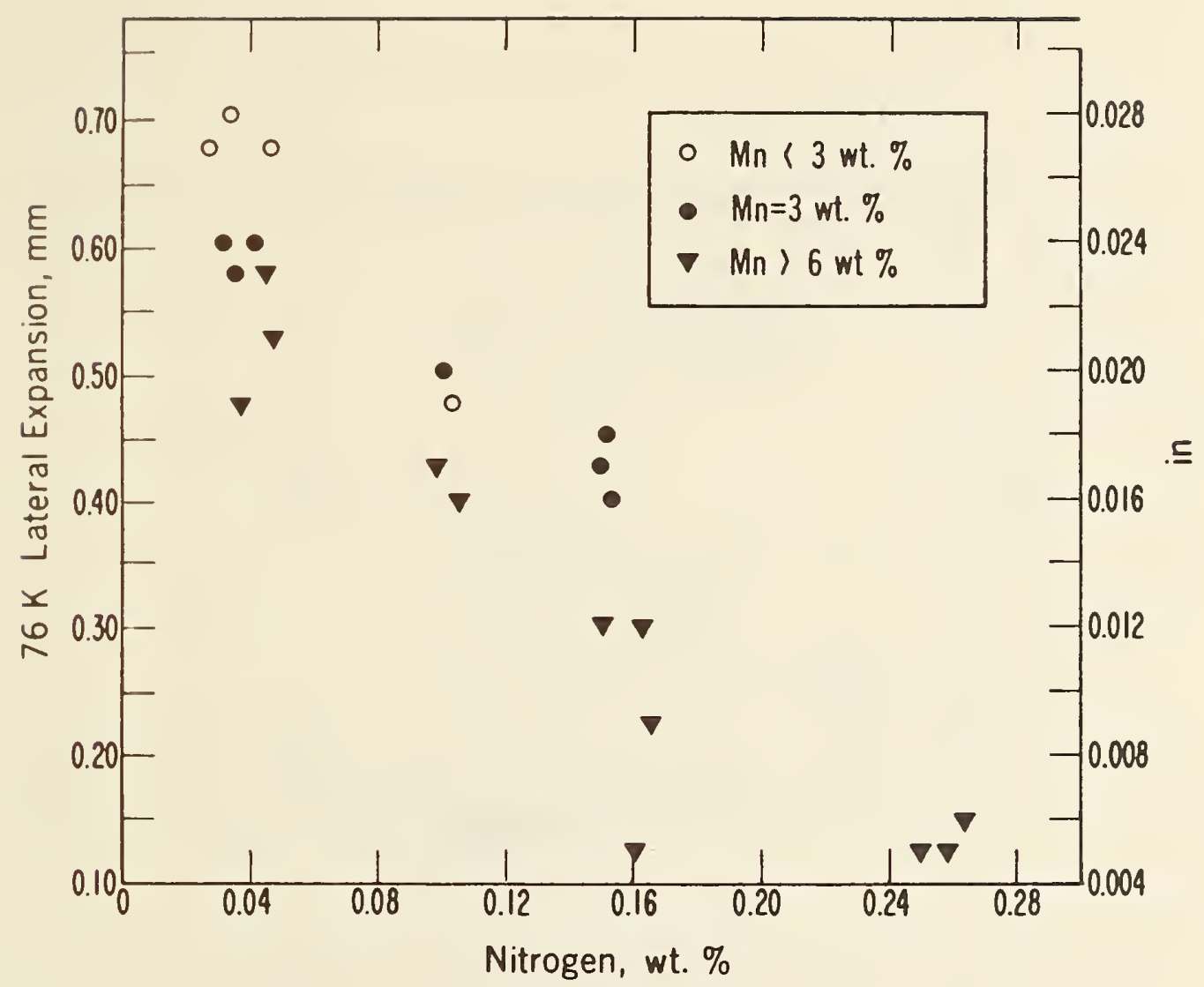

Fig. 4. Lateral expansion versus nitrogen content at $76 \mathrm{~K}$.

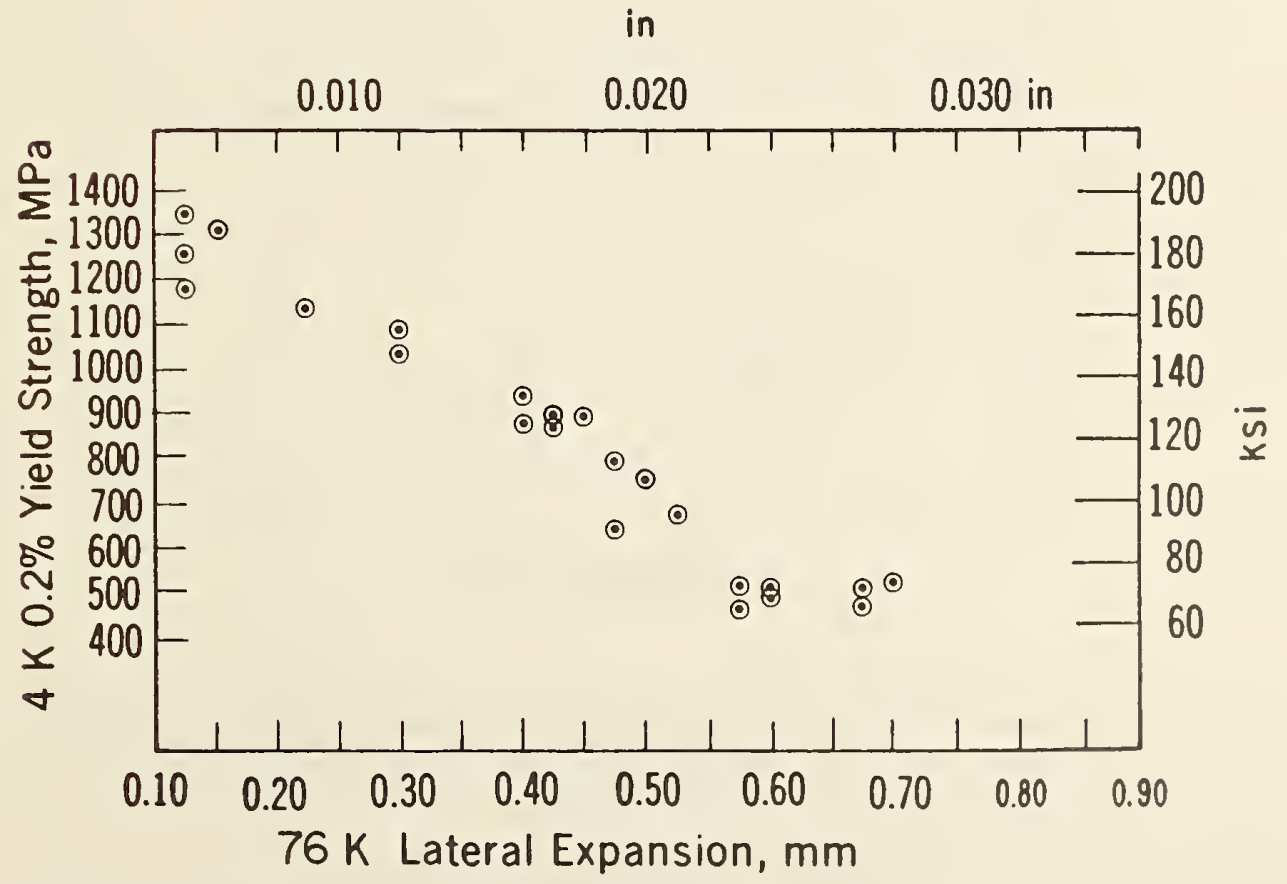

Fig. 5. Yield strength at $4 \mathrm{~K}$ versus lateral expansion at $76 \mathrm{~K}$. 


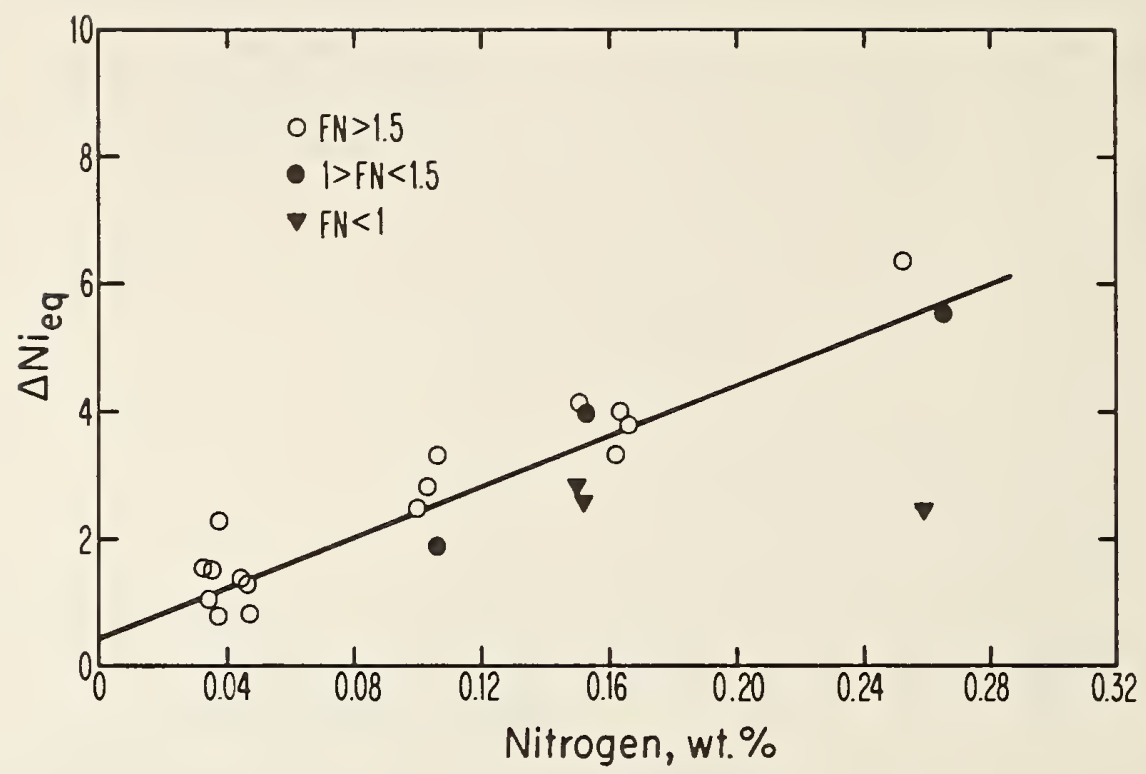

A

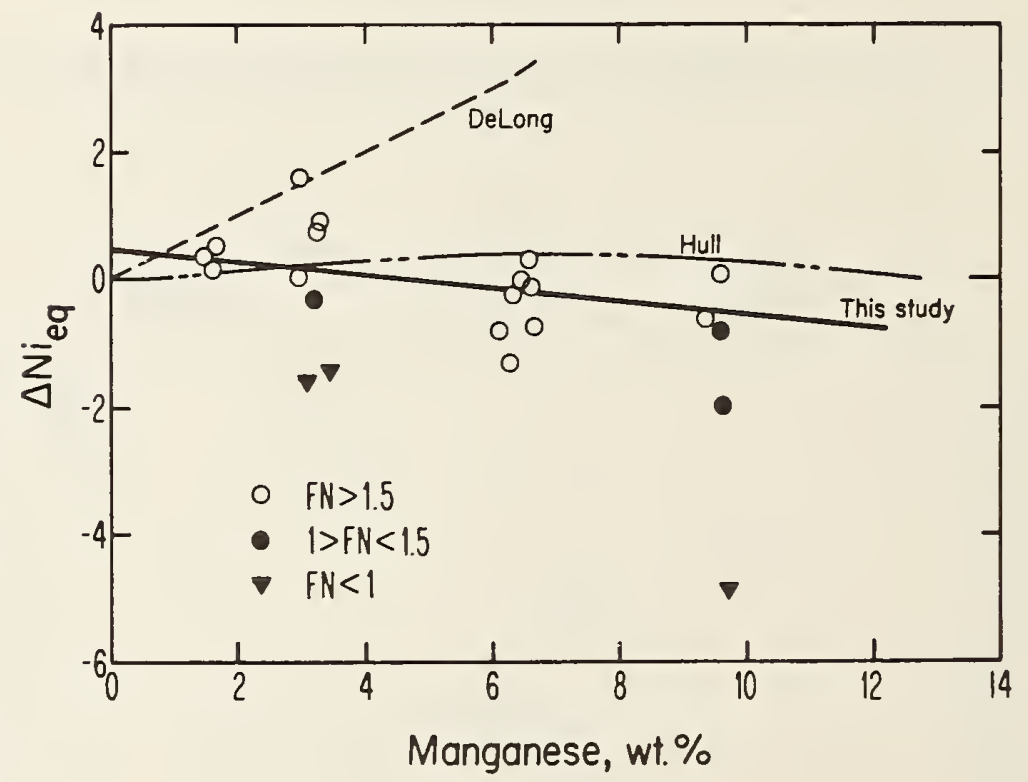

Fig. 6. Difference in nickel equivalent versus weld nitrogen content (A) and versus manganese content (B). 


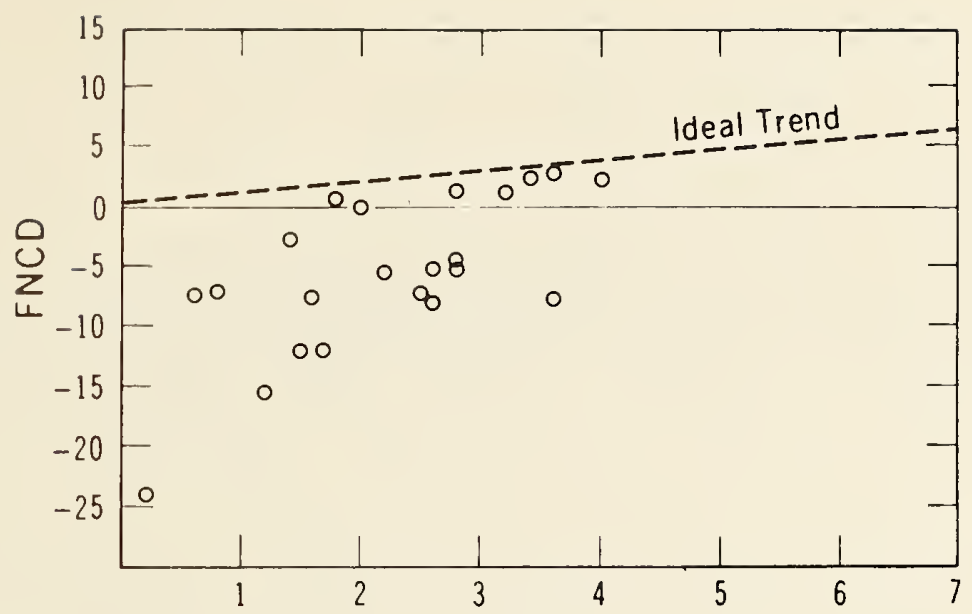

A

FN

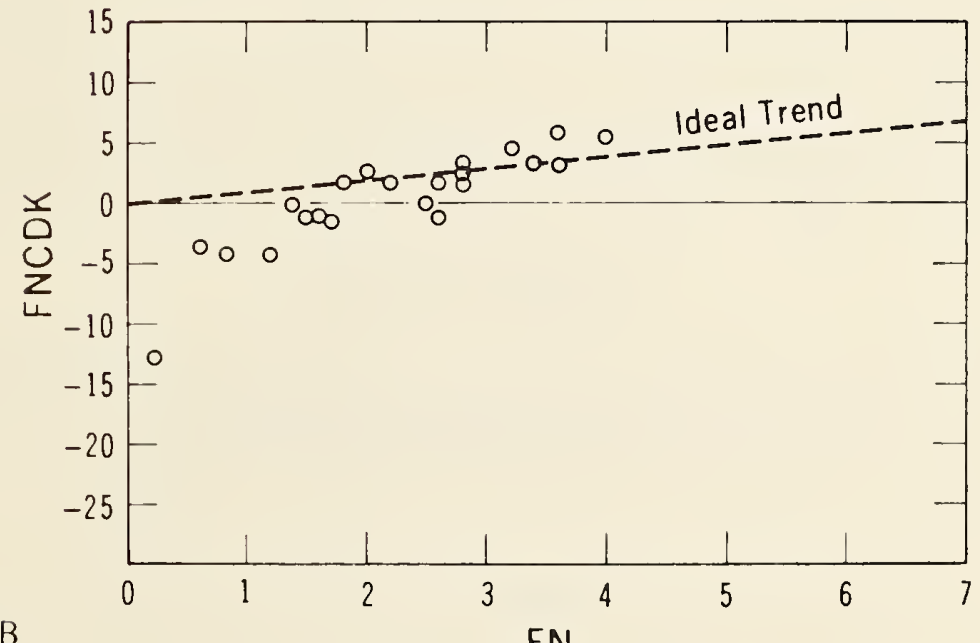

FN

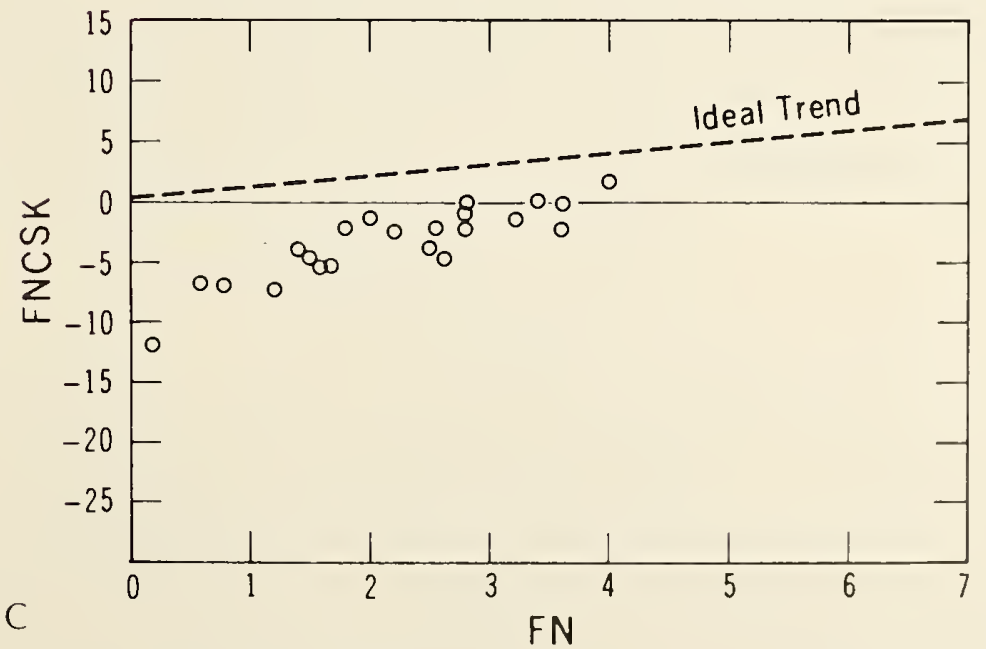

Fig. 7. Measured FN versus calculated FN. 


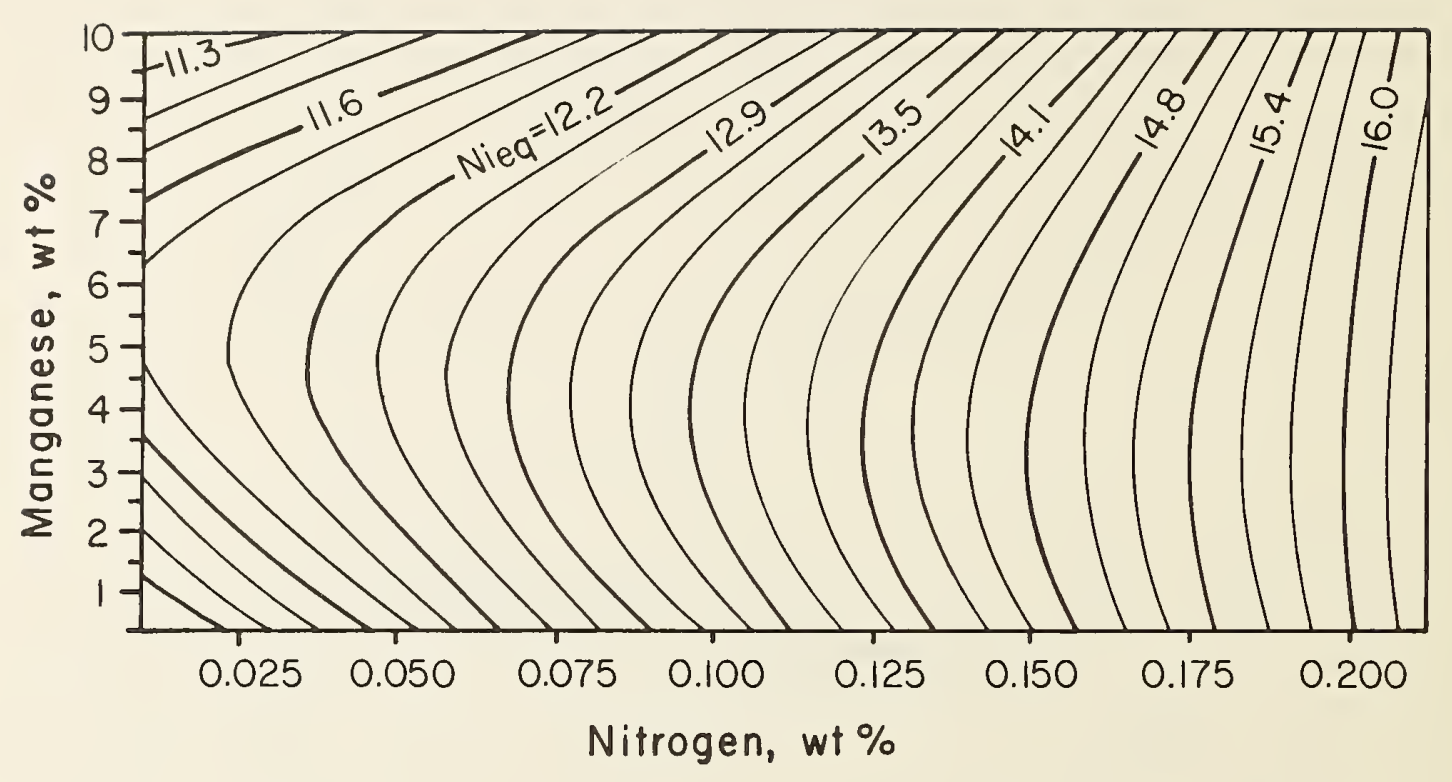

Fig. 8. The nitrogen-manganese interaction expressed in terms of the nickel equivalent. 




\title{
STRENGTH-TOUGHNESS RELATIONSHIP FOR AUSTENITIC STAINLESS STEEL WELDS AT $4 \mathrm{~K}^{*} \dagger$
}

\author{
R. L. Tobler, T. A. Siewert, and H. I. McHenry \\ Fracture and Deformation Division \\ National Bureau of Standards \\ Boulder, Color ado
}

For the past decade the National Bureau of Standards has been compiling cryogenic mechanical property data on structural alloy welds proposed for $4-\mathrm{K}$ service. Analysis of this data demonstrates that: 1) there is an inverse correlation between yield strength and fracture toughness for stainless steel welds at $4 \mathrm{~K}$ and that 2) the welds have significantly lower toughness than base materials of comparable strength. The toughness of types $308 \mathrm{~L}$ and $316 \mathrm{~L}$ welds is described by $\mathrm{K}_{\mathrm{Ic}}=270-0.16 \sigma_{\mathrm{y}}$.

\section{INTRODUCTION}

For the past decade the National Bureau of Standards has been compiling cryogenic mechanical property data on structural alloy welds proposed for magnetic fusion energy components designed to operate at liquid helium temperature, $4 \mathrm{~K}$. A sizable data base has been accumulated and certain general trends are becoming apparent. The most distinct of these is the correlation between yield strength and fracture toughness.

An adequate combination of yield strength $\left(\sigma_{y}\right)$ and fracture toughness $\left(\mathrm{K}_{\mathrm{Ic}}\right.$ ) makes a material suitable for structural applications. At any temperature, however, these properties are antithetical. For wrought austenitic stainless steel materials, $\mathrm{K}_{\mathrm{Ic}}$ estimates are generally found to be a monotonically decreasing function of $\sigma_{y}[1]$. For a controlled series of conventionally processed wrought AISI 304 type ( $\mathrm{Fe}-18 \mathrm{Cr}-10 \mathrm{Ni})$ austenitic stainless steels with varying carbon and nitrogen contents, the empirical relationship is given as [2]:

$$
\mathrm{K}_{\mathrm{Ic}}=500-0.3 \sigma_{\mathrm{y}}
$$

where $\mathrm{K}_{\mathrm{Ic}}$ is the fracture toughness in $\mathrm{MPa} \cdot \mathrm{m}^{1 / 2}$ and $\sigma_{\mathrm{y}}$ is the yield strength in $\mathrm{MPa}$. This equation has been used as a practical means of comparing and evaluating current materials capabilities relative to projected goals or requirements for future superconducting magnet designs $[3,4]$. A corresponding relationship for austenitic steel welds at $4 \mathrm{~K}$, developed from the cryogenic mechanical property data base, is presented and discussed in this paper.

\footnotetext{
*Contribution of the National Bureau of Standards, not subject to copyright. tSubmitted to Cryogenics.
} 
Thirty-three welds fabricated using various candidate electrodes and welding processes have been tested at NBS at $4 \mathrm{~K}$ during the past ten years [5-13]. Tensile tests were typically performed using cylindrical specimens, $6.35 \mathrm{~mm}$ in diameter and $25.4 \mathrm{~mm}$ in gage length. Plane strain fracture toughness tests typically used compact or bend specimens $25.4 \mathrm{~mm}$ thick. In most cases, J-integral tests were performed and $\mathrm{K}_{\text {Ic }}$ was estimated from measurements of JIc [2]. A complete list of the welds is given in Table 1 along with values of $\sigma_{y}$ data and $K_{I c}$ estimates and appropriate references.

The welds can be divided into two groups on the basis of composition. The first group includes type 308L and 316L weld compositions that are commonly used to join type 304 and 316 austenitic stainless steel base metals for cryogenic structures. These welds have broad but clearly specified compositional ranges so that their mechanical properties can be varied significantly by compositional shifts within the allowable ranges. The second group is unrestricted with respect to composition and includes some high manganese welds. Both groups had a range of nitrogen contents so the strength and toughness relationship could be evaluated over a range of strength.

The weld compositions determine the microstructures, which comprise two groups also: single-phase (fully austenitic) or two-phase (austenite plus delta ferrite), with ferrite number (FN) up to 12. The type 308L and 316L weld compositions typically contain a small amount of ferrite to prevent fissuring. The unrestricted compositions are more resistant to fissuring and do not contain ferrite.

In addition to composition, the type of welding process used can significantly influence the purity and/or microstructure of the welds. The various welding processes represented in this study are: shielded metal arc (SMA), gas metal arc (GMA), gas tungsten arc (GTA), flux cored arc (FCA), submerged arc (SA) and electroslag (ES).

\section{RESULTS}

Figure 1 is a plot of the fracture toughness versus tensile yield strength at $4 \mathrm{~K}$ for the thirty-three welds of Table 1. Despite wide variations in composition and processing and sizable scatter in the data, an inverse correlation between yield strength and toughness is indicated. If one considers only type $308 \mathrm{~L}$ and $316 \mathrm{~L}$ welds, the scatter is reduced and the correlation becomes more apparent.

Figure 2 is the plot of yield strength versus fracture toughness developed exclusively for type 308L and 316L compositions. The data show no distinguishable effect of welding processes upon the strength-toughness correlation, apart from the general scatter. Welds with FN $>7$ show relatively low toughness (these are identified on the figure) but welds with lower FN contents fall randomly within the scatterband. Using a linear regression technique, the following empirical relationship was found for the welds of Figure 2: 


$$
\mathrm{K}_{\text {IC }}=270-0.16 \sigma_{\mathrm{y}},
$$

where $\mathrm{K}_{\mathrm{Ic}}$ is the fracture toughness in $\mathrm{MPa} \cdot \mathrm{m}^{1 / 2}$ and $\sigma_{\mathrm{y}}$ is the $\mathrm{yield}$ strength in $\mathrm{MPa}$. The one-standard-deviation scatterband of $\pm 44 \mathrm{MPa} \cdot \mathrm{m}^{1 / 2}$ is shown in the figure.

In Figure 3 the one-standard-deviation scatterband for the welds (types $308 \mathrm{~L}$ and $316 \mathrm{~L}$ ) and the trend line for the conventional base material are compared [2]. The $\sigma_{y}$ vs $K_{I c}$ relationships are dissimilar, with the welds falling substantially below (about $40 \%$ ) the base metals in performance.

\section{DISCUSSION}

Mechanical property data on 33 welds tested at $4 \mathrm{~K}$ indicate that the stainless steel welds have a significantly lower toughness than similar base metals of comparable strength. This is shown in Figure 3 where the onestandard-deviation scatterband for the welds (types $308 \mathrm{~L}$ and $316 \mathrm{~L}$ ) and the trend line for type 304 base metal [2] are compared. The differences in toughness are particularly large at low yield strength.

Recently, five new wrought alloys have been developed in Japan $[3,4]$. These stainless steel alloys are strengthened by nitrogen ( 0.2 to 0.35 wt.\%), like type $304 \mathrm{LN}$, but are substantially different in chromium, nickel, and manganese contents. The new steels include 25Cr-14Ni-4Mn, 12Ni-12Cr-10Mn-5Mo, $13 \mathrm{Cr}-5 \mathrm{Ni}-22 \mathrm{Mn}$, and $15 \mathrm{Cr}-1 \mathrm{Ni}-25 \mathrm{Mn}$. With yield strengths and fracture toughnesses of $1200 . \mathrm{MPa}$ and $200 \mathrm{MPa} \cdot \mathrm{m}^{1 / 2}$, respectively, these alloys are superior to the conventional base metals in Figure 3. Thus, the gap between base metal and weld metal performance continues to widen. This gap emphasizes the practical need for further development of filler metals.

The strength-toughness data obtained from stainless steel welds are from a wide range of compositions, processes, and welding procedures. Yet none of the data are near the Japanese target values of 1200-MPa yield strength and $200-\mathrm{MPa} \cdot \mathrm{m}^{1 / 2}$ fracture toughness. Below, we consider the causes of the relatively poor toughness of the welds.

Since welds are metallurgically more complex than wrought base metals, the upgrading of weld properties represents a significant challenge. To achieve properties comparable to those of the base metals, the strengthtoughness characteristics of welds at $4 \mathrm{~K}$ must be improved by a substantial margin.

Austenitic stainless steel welds generally fail by a ductile fracture mechanism, i.e., by the formation and growth of voids that eventually compose the fracture surface. Thus, toughness improvements must increase the resistance of the weld metal to the nucleation and growth of voids. Voids nucleate most readily near phase boundaries, as a result of interfacial separation, fracture within the second phase, or matrix separation caused by strain concentration. Toughness improvements would be expected in stainless steel welds if the other phases, such as delta ferrite, chromium carbides, and inclusions, were eliminated or reduced. Previous studies have demonstrated the deleterious effects of a multiphase structure. 
A study of four type $316 \mathrm{~L}$ welds with an FN range of 0 to 12 has shown a clear trend toward lower toughness with increasing FN [7]. With the large scatter caused by differing weld processes and techniques in this study, the effect of $F N$ is less apparent. But when the FN is greater than 7, as labeled in Figure 2, the data clearly fall along the lower edge of the scatterband. Thus, the ferrite should be reduced to the lowest level consistent with fissure resistance.

The deleterious effect of sensitization on weld metal toughness [7] is due to the precipitation of chromium carbides, which serve as void initiation sites. The influence of inclusions on weld toughness has been studied indirectly by Whipple and Kotecki [12] who produced a series of type $316 \mathrm{~L}$ welds using three different processes: GTA, GMA, and SA. The toughness at $4 \mathrm{~K}$ was inversely related to the inclusion content, with the highest toughness in the GTA welds $\left(181 \mathrm{MPa} \cdot \mathrm{m}^{1 / 2}\right)$ and the lowest toughness in the SA welds $(104$ $\left.\mathrm{MPa} \cdot \mathrm{m}^{1 / 2}\right)$.

The growth and coalescence of voids relates to the strength, ductility, and strain-hardening behavior of the matrix. As matrix strength increases, less energy is dissipated by plastic deformation during void growth and, consequently, toughness is reduced. Increased matrix strength also tends to activate additional void nucleation sites. Thus, increasing matrix strength by alloying with interstitial elements such as carbon and nitrogen tends to reduce fracture toughness, and the inverse relationship between strength and toughness shown in Figure 3 results. One exception to this inverse relationship may be the influence of grain size as shown by Whipple, McHenry, and Read [9]. As the width of the columnar grains decreased in type 316L SMA welds, the yield strength changed slightly ( $800 \mathrm{MPa} \pm 10 \%)$, but toughness increased significantly (from 95 to $200 \mathrm{MPa} \cdot \mathrm{m}^{1 / 2}$ ).

In summary, to increase the strength-toughness characteristics of welds, the resistance to ductile fracture must be increased. Analysis of existing data indicates that this can be done by eliminating delta ferrite, reducing the inclusion content, avoiding precipitates such as chromium carbides, and reducing the width of the columnar grains. These approaches are not expected to eliminate the inverse relationship between strength and toughness, but to raise the trend line to a level approaching that achieved in the wrought stainless steels.

\section{CONCLUSIONS}

This study demonstrates that 1 ) there is an inverse linear correlation between yield strength and fracture toughness for stainless steel welds at $4 \mathrm{~K}$, and that 2) the welds have significantly lower toughness than base materials of comparable strength.

\section{ACKNOWLEDGMENT}

This research was sponsored by the Office of Fusion Energy, with Dr. V. Der as project manager. 
1. Read, D. T., Reed, R. P. Cryogenics, 21 (1981) 415. [see also: Materials Studies for Magnetic Fusion Energy Applications at Low Temperatures - II, NBSIR 79-1609, National Bureau of Standards, Boulder, Colorado (1979) 79-122].

2. Tobler, R. L., Read, D. T., Reed, R. P. Fracture Mechanics: Thirteenth Conference, ASTM STP 743, R. Roberts, ed., American Society for Testing and Materials, Philadelphia, (1981) 250.

3. McHenry, H. I. Materials Studies for Magnetic Fusion Energy Applications at Low Temperatures - VIII, NBSIR 85-3025, National Bureau of Standards, Boulder, Colorado (1985) 323.

4. Shimamoto, S., Nakajima, H., Yoshida, K., Tada, E. Advances in Cryogenic Engineering--Materials, vol. 32, Plenum (1986) 23.

5. McHenry, H. I. Materials Studies for Magnetic Fusion Energy Applications at Low Temperatures - I, NBSIR 78-884, National Bureau of Standards, Boulder, Colorado (1978) 159.

6. McHenry, H. I., Read, D. T., Steinmeyer, P. A. Materials Studies for Magnetic Fusion Energy Applications at Low Temperatures - II, NBSIR 79-1609, National Bureau of Standards, Boulder, Colorado (1979) 299.

7. Read, D. T., McHenry, H. I., Steinmeyer, P. A., Thomas, R. D., Jr. Welding Journal $\underline{59}$ (1980) 104s.

8. McHenry, H. I., Whipple, T. A. Materials Studies for Magnetic Fusion Energy Applications at Low Temperatures - III, NBSIR 80-1627, National Bureau of Standards, Boulder, Colorado (1980) 155.

9. Whipple, T. A., McHenry, H. I., Read, D. T. Welding Journal 60 (1981) 70 s.

10. Whipple, T. A., McHenry, H. I. Materials Studies for Magnetic Fusion Energy Applications at Low Temperatures - IV, NBSIR 81-1645, National Bureau of Standards, Boulder, Colorado (1981) 273.

11. Elmer, J. W., McHenry, H. I., Whipple, T. A. Materials Studies for Magnetic Fusion Energy Applications at Low Temperatures - IV, NBSIR 81-1645, National Bureau of Standards, Boulder, Colorado (1981) 289.

12. Whipple, T. A., Kotecki, D. J. Materials Studies for Magnetic Fusion Energy Applications at Low Temperatures - IV, NBSIR 81-1645, National Bureau of Standards, Boulder, Colorado (1981) 303.

13. McHenry, H. I., Elmer, J. W., Inoue, T. Materials Studies for Magnetic Fusion Energy Applications at Low Temperatures - V, NBSIR 82-1667, Natinal Bureau of Standards, Boulder, Colorado (1982) 245. 
Table 1. Weld Compositions and 4-K Mechanical Property Data*

\begin{tabular}{|c|c|c|c|c|c|c|c|c|c|c|c|c|c|c|}
\hline \multirow[t]{2}{*}{ Designation } & \multirow{2}{*}{$\begin{array}{l}\text { Welding } \\
\text { Process }\end{array}$} & \multicolumn{9}{|c|}{ Composition (weight percent) } & \multirow[t]{2}{*}{ FN } & \multicolumn{2}{|c|}{ 4-K Properties } & \multirow{2}{*}{ Ref. } \\
\hline & & C & $\mathrm{Mn}$ & $\mathrm{Si}$ & $\mathrm{P}$ & $\mathrm{S}$ & $\mathrm{Cr}$ & $\mathrm{N} 1$ & Mo & $\mathrm{N}$ & & $\begin{array}{c}\sigma_{y} \\
(\mathrm{MPa})\end{array}$ & $\begin{array}{c}\mathrm{K}_{\mathrm{Ic}} 1 / 2 \\
\left(\mathrm{MPa} \cdot \mathrm{m}^{1 / 2}\right)\end{array}$ & \\
\hline $330 \mathrm{M}$ & SMA & 0.14 & 4.6 & 0.48 & 0.019 & 0.006 & 17.8 & 34.4 & 0.3 & 0.04 & 0 & 911 & 153 & 5 \\
\hline $308 \mathrm{~L}-15$ & SMA & 0.02 & 1.9 & 0.22 & -- & -- & 19.5 & 10.6 & 0.1 & 0.06 & 4.1 & 654 & 156 & 6 \\
\hline $316 \mathrm{~L}-15$ & SMA & 0.03 & 2.0 & 0.30 & -- & -- & 17.5 & 13.7 & 2.1 & 0.04 & 0.2 & 769 & 118 & 6 \\
\hline $316 L-15$ & SMA & 0.03 & 1.9 & 0.32 & -- & -- & $17 \cdot 5$ & 13.6 & 2.1 & 0.07 & 0 & 879 & 95 & 6 \\
\hline $316 \mathrm{~L}$ & SMA & 0.03 & 1.7 & 0.58 & 0.033 & 0.011 & 18.5 & 14.0 & 2.3 & 0.04 & 0.5 & 694 & 179 & 7 \\
\hline $316 \mathrm{~L}$ & SMA & 0.03 & 1.7 & 0.56 & 0.034 & 0.012 & 18.6 & 13.0 & 2.3 & 0.05 & 3.5 & 798 & 141 & 7 \\
\hline $316 \mathrm{~L}$ & SMA & 0.03 & 1.7 & 0.57 & 0.034 & 0.009 & 19.2 & 12.0 & 2.3 & 0.04 & 9.0 & 886 & 108 & 7 \\
\hline $316 \mathrm{~L}$ & SMA & 0.03 & 1.8 & 0.59 & 0.029 & 0.008 & 19.7 & 11.0 & 2.2 & 0.07 & 12.0 & 881 & 98 & 7 \\
\hline 316 & SMA & 0.06 & 1.8 & 0.56 & 0.033 & 0.009 & 18.7 & 12.9 & 2.3 & 0.04 & 0.6 & 924 & 154 & 7 \\
\hline $308 \mathrm{~L}$ & FCA & & & & & & & & & & 3.0 & 1117 & 66 & 8 \\
\hline $308 \mathrm{~L}$ & GMA & & & & & & & & & & 7.0 & 776 & 167 & 8 \\
\hline $316 \mathrm{~L}$ & SA & & & & & & & & & & 4.7 & 918 & 132 & 8 \\
\hline $316 \mathrm{~L}$ & SA & & & & & & & & & & 8.0 & 860 & 99 & 8 \\
\hline $316 \mathrm{~L}$ & SMA & & & & & & & & & & & 882 & 171 & 9 \\
\hline $316 \mathrm{~L}$ & SMA & & & & & & & & & & & 727 & 199 & 9 \\
\hline $316 \mathrm{~L}$ & SMA & & & & & & & & & & & 861 & 132 & 9 \\
\hline $316 \mathrm{~L}$ & SMA & & & & & & & & & & & 815 & 161 & 9 \\
\hline $316 \mathrm{~L}$ & SMA & & & & & & & & & & & 772 & 200 & 9 \\
\hline $316 \mathrm{~L}$ & SMA & & & & & & & & & & & 845 & 187 & 9 \\
\hline $316 \mathrm{~L}$ & ES & & & & & & & & & & & 690 & 189 & 10 \\
\hline $308 \mathrm{~L}$ & FCA & & & & & & & & & & & 558 & 134 & 10 \\
\hline $20-16-7$ MoW & SA & 0.03 & 6.7 & 0.09 & 0.010 & 0.003 & 19.5 & 16.1 & 2.8 & 0.23 & 0 & 1110 & 148 & 11 \\
\hline $17-16-4 \mathrm{Mo}$ & SMA & 0.03 & 4.0 & 0.39 & 0.022 & 0.007 & $17 \cdot 3$ & 15.9 & 2.2 & 0.05 & 0 & 814 & 250 & 11 \\
\hline $18-20-6 \mathrm{Nb}$ & GMA & 0.04 & 5.8 & 0.32 & 0.005 & 0.007 & 18.0 & $20 \cdot 3$ & 0.1 & 0.04 & 0 & 696 & 227 & 11 \\
\hline $18-20-6 \mathrm{Ti}$ & GMA & 0.03 & 5.7 & 0.28 & 0.006 & 0.007 & 18.2 & 20.3 & 0.1 & 0.02 & 0 & 686 & 287 & 11 \\
\hline $18-16-9$ & GMA & 0.05 & 8.6 & 0.44 & 0.004 & 0.021 & 18.1 & 15.8 & & 0.08 & 0 & 1076 & 121 & 11 \\
\hline $16-16-4 \mathrm{Mo}$ & FCA & 0.03 & 4.4 & 0.25 & & 0.012 & 16.1 & 15.9 & 1.5 & 0.05 & 0 & 606 & 239 & 11 \\
\hline $16-15-4$ Mo & GMA & 0.02 & 3.7 & 0.22 & 0.020 & 0.012 & 15.7 & 15.0 & 1.8 & & 0 & 717 & 170 & 11 \\
\hline $316 \mathrm{~L}$ & GTA & 0.02 & 1.4 & 0.45 & 0.020 & 0.003 & 18.0 & 11.9 & 2.1 & 0.07 & 1.5 & 807 & 181 & 12 \\
\hline $316 \mathrm{~L}$ & GMA & 0.02 & 1.4 & 0.47 & 0.020 & 0.003 & 18.0 & 11.8 & 2.1 & 0.07 & 3.0 & 779 & 163 & 12 \\
\hline $316 \mathrm{~L}$ & GMA & 0.01 & 2.2 & 0.46 & 0.010 & 0.013 & 18.7 & 15.2 & 2.3 & 0.03 & 0.9 & 608 & 159 & 12 \\
\hline $25-5-1$ & SA & 0.19 & 25.0 & 0.63 & 0.010 & 0.003 & 6.5 & 2.8 & 1.4 & & & 654 & 164 & 13 \\
\hline $25-5-1$ & SMA & 0.16 & 26.6 & 0.13 & 0.003 & 0.006 & 6.4 & 3.2 & 1.2 & & & 962 & 158 & 13 \\
\hline
\end{tabular}

* Since these welds were obtained from various sources, the material characterization is not uniform. 


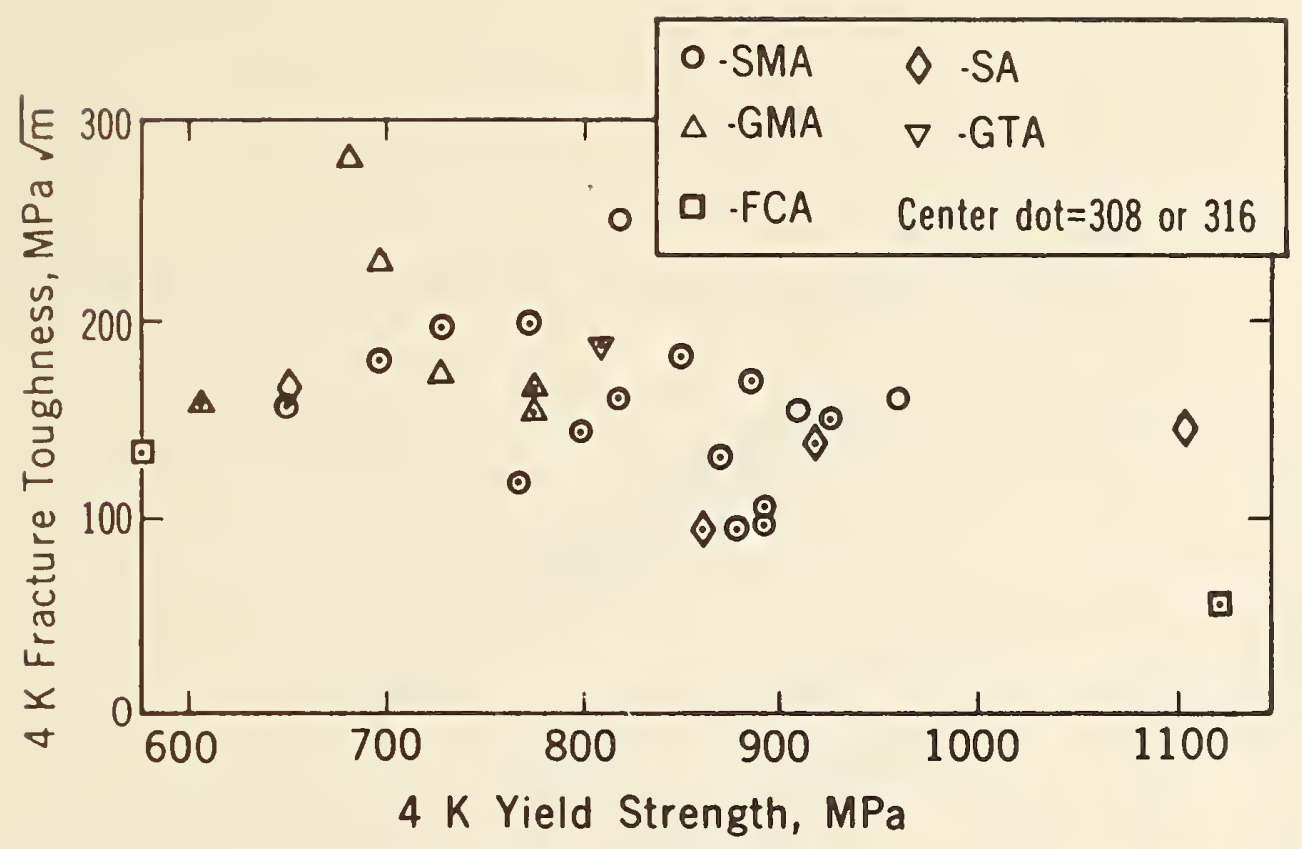

Figure 1. Fracture toughness versus tensile yield strength at $4 \mathrm{~K}$ for weld metals representing various processes and compositions.

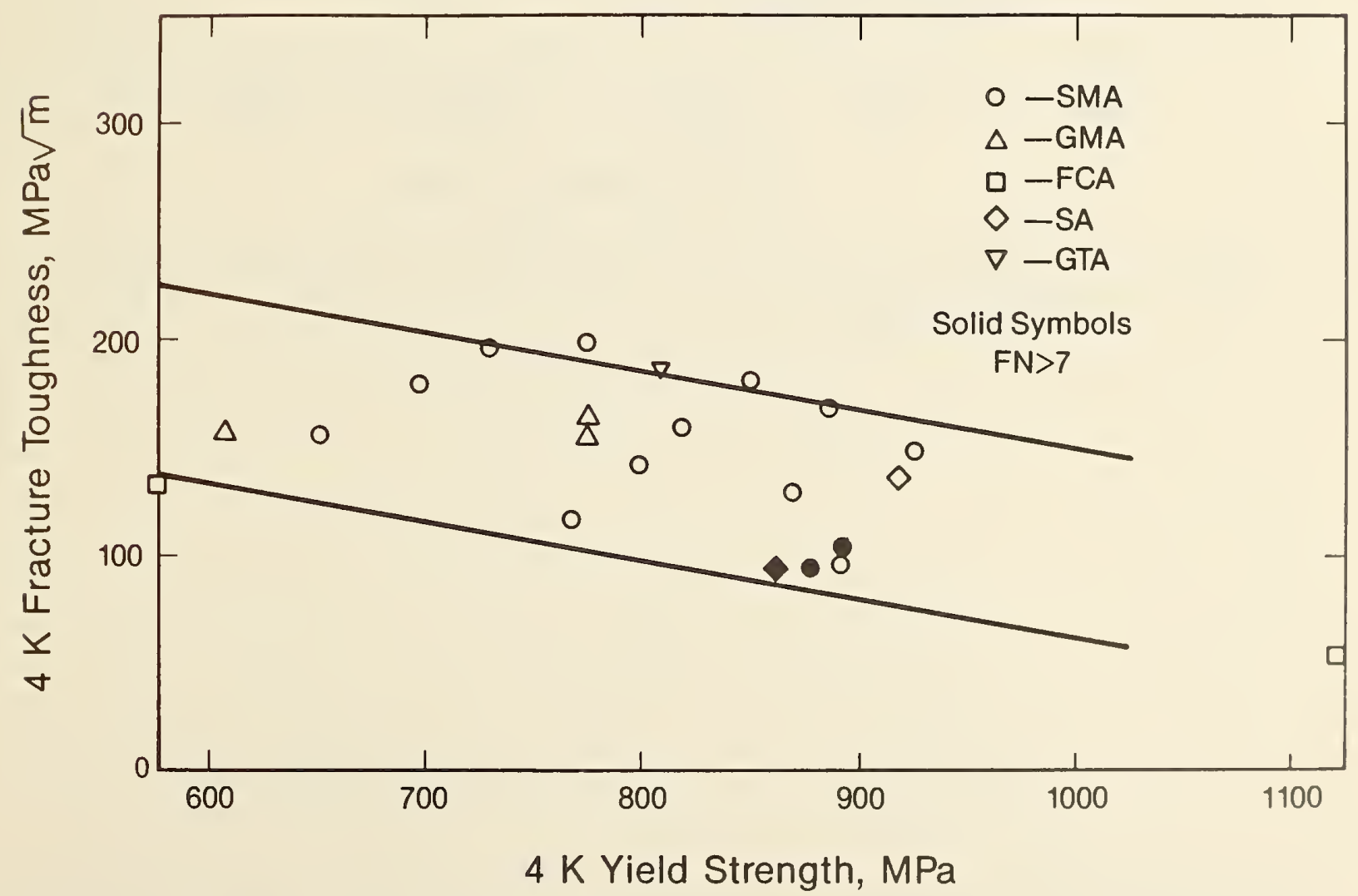

Figure 2. Fracture toughness versus tensile yield strength at $4 \mathrm{~K}$ for type 308 and 316 weld metals in Figure 1. A one-standard-deviation scatterband of $\pm 44 \mathrm{MPa} \cdot \mathrm{m}^{1 / 2}$ is included. 


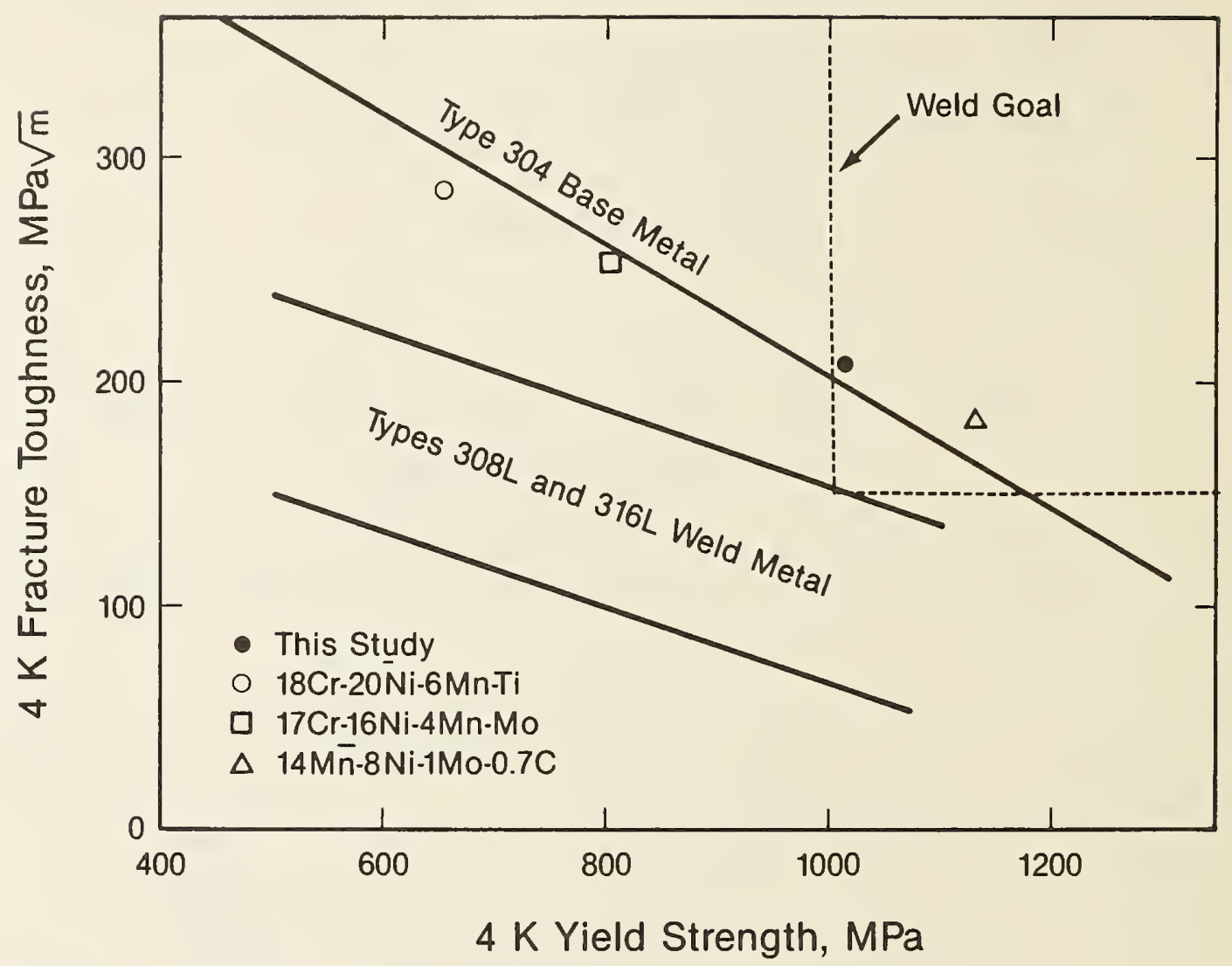

Figure 3. Comparison of the weld and base metal strength-toughness relationships. 


Tensile and Fracture Properties of an Fe-18Cr-20Ni-5Mn-0.16N

Fully Austenitic Weld Metal at $4 \mathrm{~K}^{*+}$

C. N. McCowan, T. A. Siewert, and R. L. Tobler

National Bureau of Standards

Fracture and Deformation Division

Boulder, Colorado

The 4-K tensile and fracture toughness properties of a fully austenitic stainless steel weld are reported. One tensile and two compact tension fracture specimens were tested. The weld was produced by gas metal arc welding using an Fe-18Cr-20Ni-5Mn-0.16N electrode and a $98 \%$ argon-2\% oxygen shielding gas mixture. The yield strength of $1015 \mathrm{MPa}$ and average fracture toughness, $\mathrm{K}_{\mathrm{IC}}(\mathrm{J})$, of $203 \mathrm{MPa} \cdot \sqrt{\mathrm{m}}$ are higher than those of welds produced with $308 \mathrm{~L}$ and $316 \mathrm{~L}$ electrodes and compare favorably with base metal properties. Examination of the fracture surfaces of all samples by scanning electron microscopy showed ductile failure by microvoid coalescence. The suitability of this alloy for welding cryogenic structures is discussed.

\section{INTRODUCTION}

As part of the continuing search to find improved welding electrode compositions for cryogenic applications, the $4-\mathrm{K}$ tensile and fracture. toughness of a high nickel-manganese-nitrogen stainless steel weld were measured; the results are reported here and compared to the U.S. strength-toughness goals for superconducting magnet structural alloy welds. These weld goals (1000 $\mathrm{MPa}$ yield strength and $150 \mathrm{MPa} \sqrt{\mathrm{m}}$ fracture toughness at $4 \mathrm{~K}$ ) were established to guide improvements in welding materials and procedures [1].

The weld metal solidification structure is single-phase, face-centeredcubic austenite. Types 308L and 316L austenitic stainless steel weld metal, currently used in the fabrication of cryogenic structures, typically have 0.5 to $5 \%$ delta ferrite present in their respective structures. Even though the ferrite phase is brittle and exhibits reduced toughness at low temperature [2], it has traditionally been tolerated in the microstructure of these alloys because it reduces their hot-cracking susceptibility [3-5]. Recently, however, some success has been reported in attaining fully austenitic microfissure-free welds [6-8]. The fully austenitic Fe-18Cr-20Ni-5Mn-0.16N

\footnotetext{
* Contribution of the National Bureau of Standards, not subject to copyright.

Submitted to J. Eng. Mater. Technol.
} 
electrode composition evaluated in this study achieves its fissure resistance through control of segregation by reduced phosphorus and sulfur concentrations. Limiting the concentrations of these elements reduces the grain boundary liquation caused by the subsequent weld beads [9].

\section{MATERIAL}

A nine-pass gas metal arc weld was made using an $\mathrm{Fe}-18 \mathrm{Cr}-20 \mathrm{Ni}-5 \mathrm{Mn}-0.16 \mathrm{~N}$ stainless steel electrode. The chemical composition of the 1.2-mm-diameter electrode is given in Table 1. The base material, type 304 stainless steel, had a 25-mm thickness and was beveled to provide a $60^{\circ}$ included angle for the weld joint. Figure 1 shows the weld joint configuration and specimen locations. The specimens were located on the weld centerline to allow evaluation of the undiluted weld metal. The welding was done at $230 \mathrm{~A}$ and $22 \mathrm{~V}$. The travel speed, weave width, and electrode extension values were maintained at $250 \mathrm{~mm}, 7 \mathrm{~mm}$, and $22 \mathrm{~mm}$, respectively. A shielding gas composition of $98 \%$ argon-2\% oxygen was used.

The macrograph in Figure 2 illustrates the dendritic crystal structure present within the test specimens. Orientation differences between dendritic crystals are highlighted by preferential attack of the acid etch. The dark circular areas are welding flaws, which were present only at the start of the weld. The dendritic crystals grow from the weld joint edges toward the weld bead center and into the plane of the page following the welding direction. The fracture specimen notches were positioned to encourage crack growth in the direction of crystal growth (the direction of welding in Eigure 1) to provide the most conservative measurement of toughness. The fully austenitic microstructure and the precipitate distribution of the weld are shown in Eigure 3. In this high-magnification micrograph, the long primary dendrites and the short secondary arms characteristic of primary austenite solidification appear as lighter etched areas. The interdendritic areas are etched darker due to enrichment in chromium and depletion in nickel during the solidification process.

\section{EXPERIMENTAL PROCEDURES}

The tensile and compact tension specimens were tested at $4 \mathrm{~K}$ following previously developed procedures [10]. The AWS A.5.4 all-weld-metal tensile specimen (6.3-mm diameter, 25-mm gauge length), was tested at a strain rate of $4 \times 10^{-4} \mathrm{~s}^{-1}$. The two compact tension specimens (25-mm thick, 50.8-mm wide) were modified for loadline displacement measurements [8] and the notch was oriented normal to the weld axis, as discussed previously. The compact tension specimens were precracked at $76 \mathrm{~K}$, then tested at $4 \mathrm{~K}$. The maximum stress intensity factor during fatigue at $76 \mathrm{~K}$ was $33 \mathrm{MPa} \cdot \sqrt{\mathrm{m}}$, and the stress ratio during fatigue was 0.1 . The single-specimen unloading compliance method was used to obtain fracture toughness values, J $I_{c}$, and estimates of $\mathrm{K}_{\mathrm{Ic}}(\mathrm{J})$ for the test specimens $[10]$.

After mechanical testing, the fracture surfaces were examined with a torsion bar magnetometer and a scanning electron microscope (SEM). 
A 1015-MPa yield strength was determined at $4 \mathrm{~K}$ for the weld material (Table 2). As expected of welds having 0.16 wt.\% nitrogen, this yield strength meets the U.S. goal of $1000 \mathrm{MPa}$ for superconducting magnet structural alloy welds [1]. The tensile specimen had a total elongation of $26 \%$ and a reduction in area of $37 \%$.

The $K_{I c}(J)$ fracture toughness values of the two compact tension specimens were 206 and $200 \mathrm{MPa} \cdot \sqrt{\mathrm{m}}$ (Table 3 ). The J-resistance curve of each specimen consisted of four $\mathrm{J}-\Delta \mathrm{a}$ points in the exclusion rule interval [11]. These $K_{I C}(J)$ values were determined from $J_{I c}$ by the expression:

$$
K_{I C}(J)=\left[J_{I C} \cdot E\right]^{1 / 2} \text {, }
$$

where $\mathrm{E}$ is assumed to be $207 \mathrm{GPa}$ at $4 \mathrm{~K}$. The $\mathrm{K}_{\mathrm{IC}}(\mathrm{J})$ values for both specimens exceed the $150-\mathrm{MPa} \cdot \sqrt{\mathrm{m}}$ fracture toughness goal for cryogenic structural alloy welds with a 1000-MPa yield strength.

When the compact tension fatigue cracks were inspected, the crack fronts were found to be somewhat irregular and bordered on unacceptability, according to the criteria established by ASTM E 813-81. This type of fatigue crack front irregularity is not unusual for welds owing to residual stresses [12]. The first specimen had a cusp-shaped fatigue crack front but was acceptable according to the crack curvature requirements. On the second specimen, one crack edge exceeded the other edge by $11 \%$, whereas the criterion is $10 \%$ or less.

The fracture surfaces of the tensile and the two compact tension specimens were examined by SEM. Ductile dimpling was found to be the dominant feature of the tensile specimen fracture surface (Figure 4). Upon examination of the compact tension specimens, ductile dimpling again dominated the fracture surfaces, indicating that microvoid coalescence was the microscopic failure mode for both types of specimens. The fractograph, shown in Figure 5 , contains areas representing the commonly observed surface features of the two compact tension fractures: (1) equiaxed dimples which nucleated as a result of plastic flow about precipitates, (2) small areas of shear dimpling on regions fracturing out of the primary fracture plane, and (3) secondary cracking (shown at the top of the fractograph). All three features indicate that the weld behaved in a ductile manner during testing at $4 \mathrm{~K}$. No evidence of microfissuring or martensite was found through SEM examination or magnetometer inspection.

Although analysis of the compact tension data and fracture surfaces has shown this weld composition to have very good toughness at $4 \mathrm{~K}$, for an engineering material, it is the relationship between strength and toughness that ultimately determines its usefulness. In Figure 6, fracture toughness versus yield strength at $4 \mathrm{~K}$ is plotted. The trend line representing the type 304 stainless steel base material family is based on data from seven heats [10] and includes alloys with a range of nitrogen contents. The band representing weld properties is based on data from twenty-three type 308L and 316L sta inless steel welds made with several different welding processes [13]. The 
type 308L and 316L welds have toughness inferior to the type 304 base material at all strength levels.

The strength-toughness datum for the Fe-18Cr-20Ni-5Mn-0.16N composition is also shown in Figure 6 , along with data for three other recently developed fully austenitic compositions $[7,8]$. These weld compositions exhibit toughness superior to types 308L and 316L and are similar to those of the type 304 base material. The improved toughness of these new fully austenitic weld compositions is attributed to a increase in the energy required for microvoid nucleation and growth during ductile fracture.

Microvoid nucleation in a stainless steel with a single phase matrix commonly occurs at inclusions. A polished section through the weld (Figure 7) reveals an average of 1000 inclusions per $0.1 \mathrm{~mm}^{2}$. The fracture surface of the $\mathrm{Fe}-18 \mathrm{Cr}-20 \mathrm{Ni}-5 \mathrm{Mn}-0.16 \mathrm{~N}$ weld in Figure 4 contains an average of 12,000 void initiation sites per $0.1 \mathrm{~mm}^{2}$. The order-of-magnitude difference between the measured inclusion density and void initiation site density occurs because a planar surface is being compared to a three-dimensional fracture surface.

\section{CONCLUSIONS}

The 1015-MPa yield strength and the 203-MPa $\sqrt{\mathrm{m}} \mathrm{K}$ Ic values determined for the fully austenitic stainless steel weld at $4 \mathrm{~K}$ meet current weld goals of the U.S. fusion energy program. It is, therefore, a good candidate for cryogenic applications where high strength and toughness are required.

\section{ACKNOWLED GMENT}

The welding electrode was provided by the Wire Division of Sandvik Steel. This work is supported by the U.S. Department of Energy, Office of Fusion Energy.

\section{REFERENCES}

1. McHenry, H. I., Streng th and Toughness Goals for Cryogenic Steels, in: Materials Studies for Magnetic Fusion Energy Applications at Low Temperatures - VIII, NBSIR 85-3025, National Bureau of Standards, Boulder, Colorado, 1981, p 121 .

2. Brown, E. L., Whipple, T. A., and Tobler, R. L. Fracture Toughness of CF8 Castings at Four Kelvin, Meta11. Trans. A, Vol. 14A, June 1983, pp. 11791187 .

3. Arata, Y., Matsuda, F., and Katayama, S., Solidification Crack Susceptibility in Welds of Fully Austenitic Stainless Steels (Report II) - Effect of Ferrite, P, S, C, Si, and Mn on Ductility Properties of Solidification Brittleness, Trans. JWRI, Vol. 6, No. 1, welding Research Institute of Osaka University, Osaka, Japan, 1977. 
4. Matsuda, F., Nakagawa, H., Katayama, S., and Arata, Y., Solidification crack Susceptibility in Welds of Fully Austenitic Stainless steels

(Report VII)-Effect of $\mathrm{Mn}$ and $\mathrm{N}$ on Solidification Crack Resistance, Trans. JWRI, Vol. II, No. 2, Welding Research Institute of Osaka University, Osaka, Japan, 1982.

5. Brooks, J.A., Microstructure and Cracking of Austenitic Stainless Steel Welds, Dissertation, Dept. of Metallurgy and Material Science, Carnegie-Mellon University, Pittsburgh, 1981.

6. Haddick, G. T., Thompson, L. D., Parker, E. R., Zackay, V. F., New Nickel-Free Austenitic Stainless for Ambient and Cryogenic Service, Met. Prog., Nov. 1978, pp. 37-40.

7. Elmer, J.W., McHenry, H. I., and Whipple, T. A., Strength and Toughness of Fully Austenitic Stainless steel Filler Metals at $4 \mathrm{~K}$, in: Materials Studies for Magnetic Fusion Energy Applications at Low Temperatures - IV, NBSIR 81-1645, National Bureau of Standards, Boulder, Colorado 1981 , pp. 289-302.

8. Tobler, R. L., Trevisan, R. E., and Reed, R. P., Tensile and Fracture Properties of an Fe-14Mn-8Ni-1Mo-0.7 Fully Austenitic Weld Metal at $4 \mathrm{~K}$, Cryogenics, Vol. 25, 1985, pp. 447-451.

9. Lundin, C. D. and Spond, D. F., The Nature and Morphology of Fissures in Austenitic Stainless Steel Weld Metals, Weld. J., Vol. 55, Nov. 1976, pp. $356 \mathrm{~s}-367 \mathrm{~s}$.

10. Tobler, R. L., Read, D. T., and Reed, R. P., Strength/Toughness Relationship for Interstitially strengthened AISI 304 Stainless Steels at $4 \mathrm{~K}$ Temperature, in: Fracture Mechanics: Thirteenth Conference, Richard Roberts, Ed., ASTM STP 743, American Society for Testing and Materials, Philadelphia, 1981, pp. 250-268.

11. Standard Test Method for J IC, A Measure of Fracture Toughness, E813-81, in: 1982 Annual Book of ASTM Standards, Part 10, American Society for Testing and Materials, Philadelphia, 1982, pp. 822-840.

12. Towers, O. L. and Dawes, M. G., Welding Institute Research on the Fatigue Precracking at Fracture Toughness Specimens, in: Elastic-Plastic Fracture Test Methods: The User's Experience, E. T. Wessel and F. J. Loss, Eds., ASTM STP 856, American Society for Testing and Materials, Philadelphia, 1985 , pp. 23-46.

13. Tobler, R. L., Siewert, T. A., and McHenry, H. I., Strength-Toughness Relationship for Austenitic Structural steel Welds at $4 \mathrm{~K}$, submitted to Cryogenics. 
Table 1. Electrode composition, wt.\%.

\begin{tabular}{lllllllllllllll}
\hline C & Mn & Si & P & S & Cr & Ni & Mo & N & Cu & Co & Al & B \\
\hline 0.033 & 5.4 & 0.26 & 0.006 & 0.007 & 18.1 & 20.4 & 0.1 & 0.16 & 0.015 & 0.02 & 0.002 & 0.001 \\
\hline
\end{tabular}

Table 2. Tensile test results at $4 \mathrm{~K}$.

$\begin{array}{lcccc}\text { Specimen } & \begin{array}{c}\text { Yield Strength, } \\ \mathrm{MPa}\end{array} & \begin{array}{c}\text { Tensile Strength, } \\ \mathrm{MPa}\end{array} & \begin{array}{c}\text { Elongation, } \\ \%\end{array} & \begin{array}{c}\text { Reduction } \\ \text { of Area, } \%\end{array} \\ 1 & 1300 & 26 & 37\end{array}$

Table 3. Fracture toughness test results at $4 \mathrm{~K}$.

\begin{tabular}{|c|c|c|c|c|c|}
\hline Specimen & $\begin{array}{c}\text { Thickness, } \\
\mathrm{mm}\end{array}$ & $\begin{array}{c}\text { Width, } \\
\mathrm{mm}\end{array}$ & $\begin{array}{c}\text { Crack Length, } \\
\mathrm{mm}\end{array}$ & $\frac{\text { Fracture }}{\begin{array}{c}\mathrm{J} I \mathrm{~g} \\
\mathrm{~kJ} / \mathrm{m}^{2}\end{array}}$ & 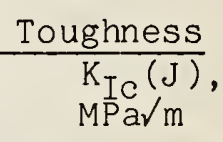 \\
\hline A & 23.9 & 50.8 & 27.8 & 206 & 206 \\
\hline B & 23.9 & 50.8 & 28.7 & 194 & 200 \\
\hline
\end{tabular}




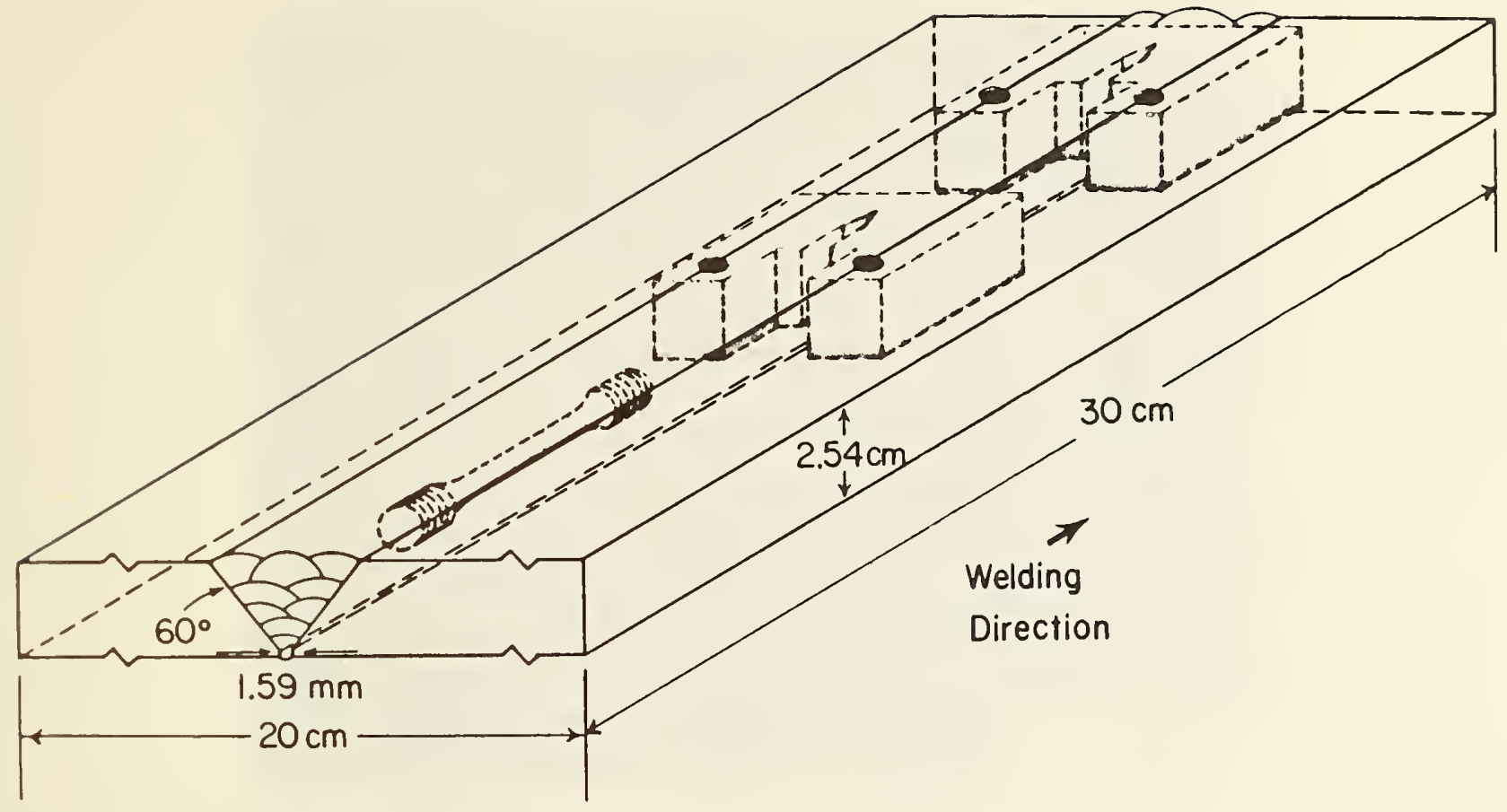

Fig. 1. Weld joint design and specimen orientation.

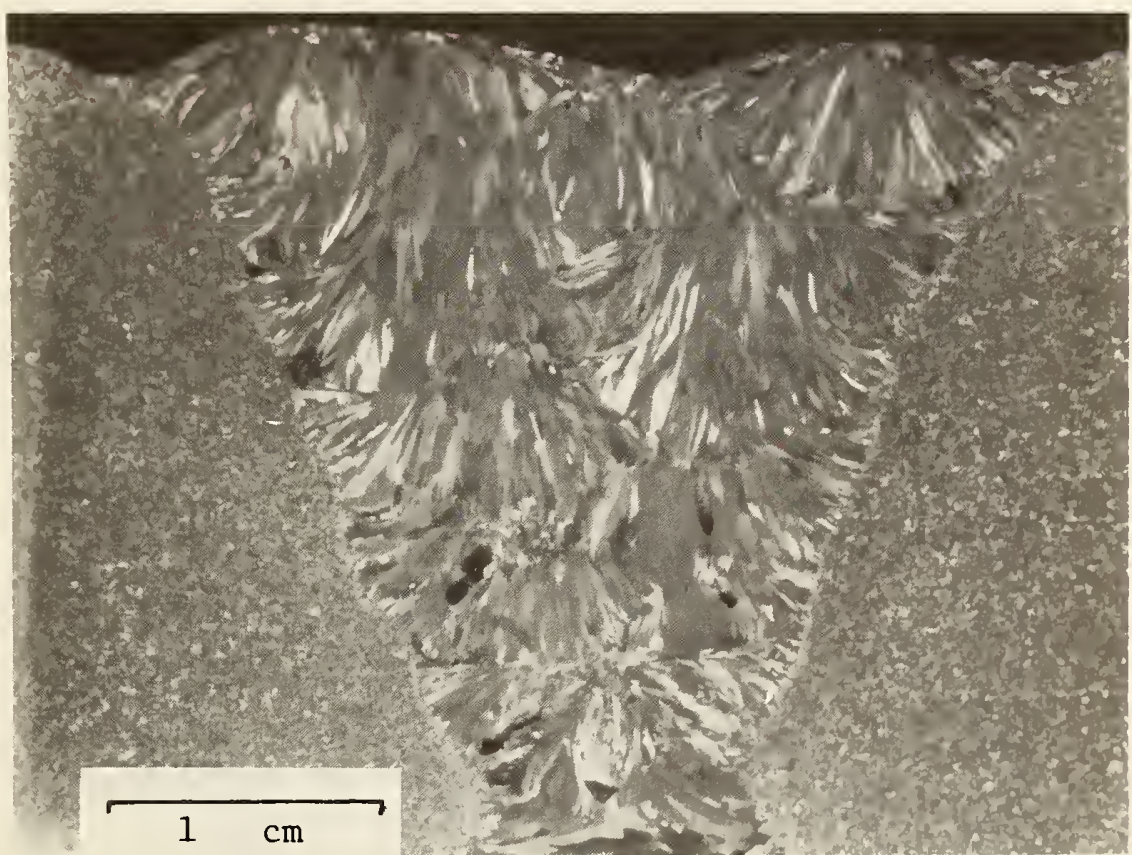

Fig. 2. Macrograph of a transverse section of a weld made with a $\mathrm{Fe}-18 \mathrm{Cr}-20 \mathrm{Ni}-5 \mathrm{Mn}-0.16 \mathrm{~N}$ electrode. 


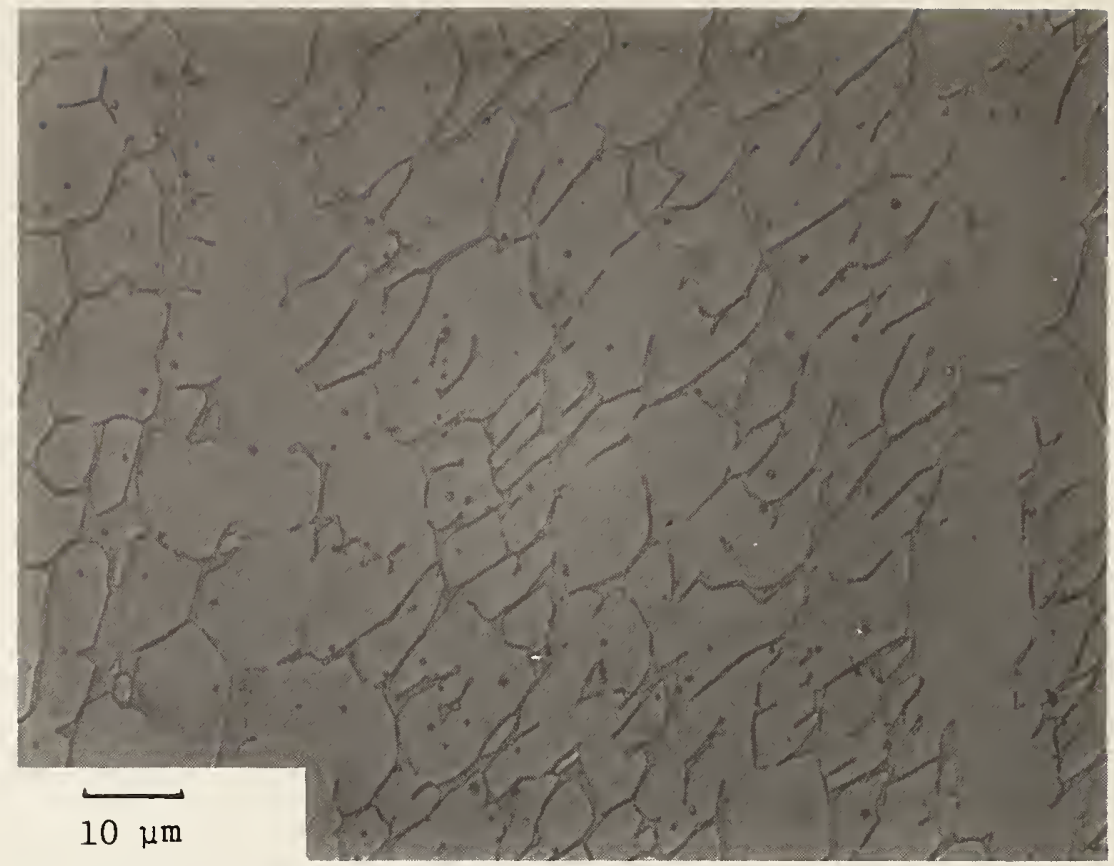

Fig. 3. Micrograph illustrating the austenitic microstructure and precipitate distribution.

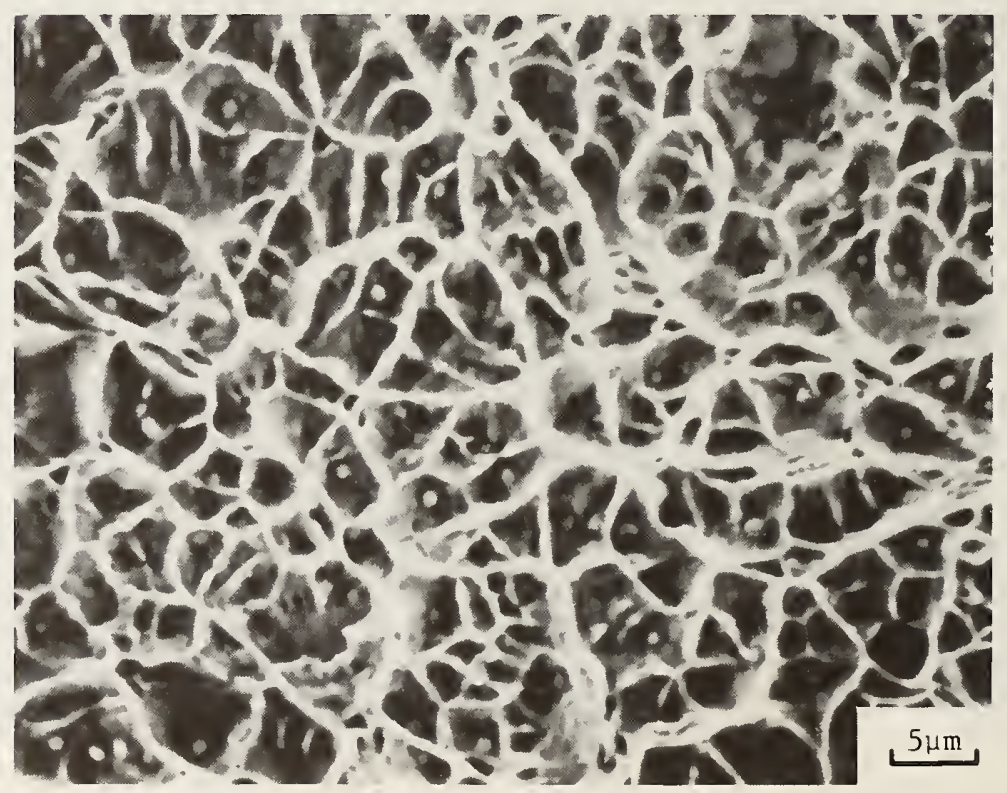

Fig. 4. SEM fractograph of the tensile fracture surface. 


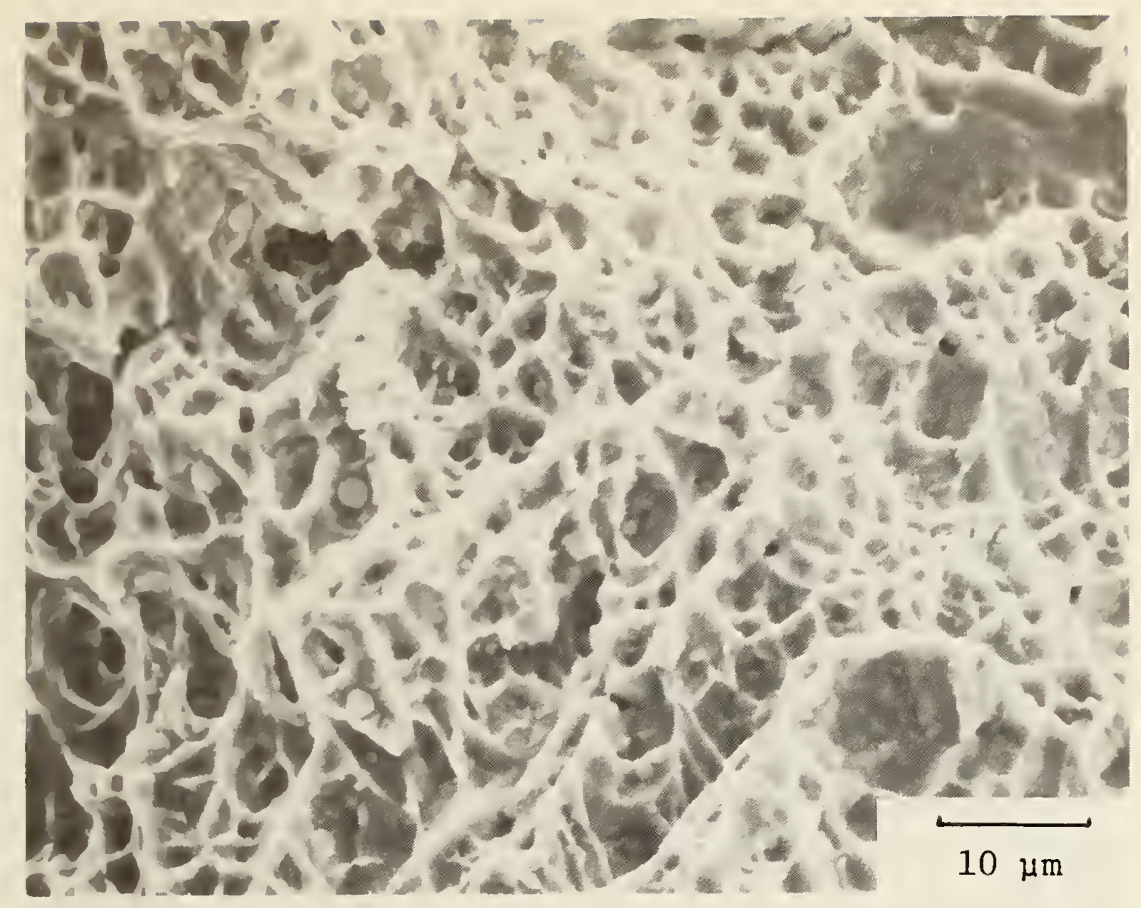

Fig. 5. SEM fractograph of compact tension fracture surface.

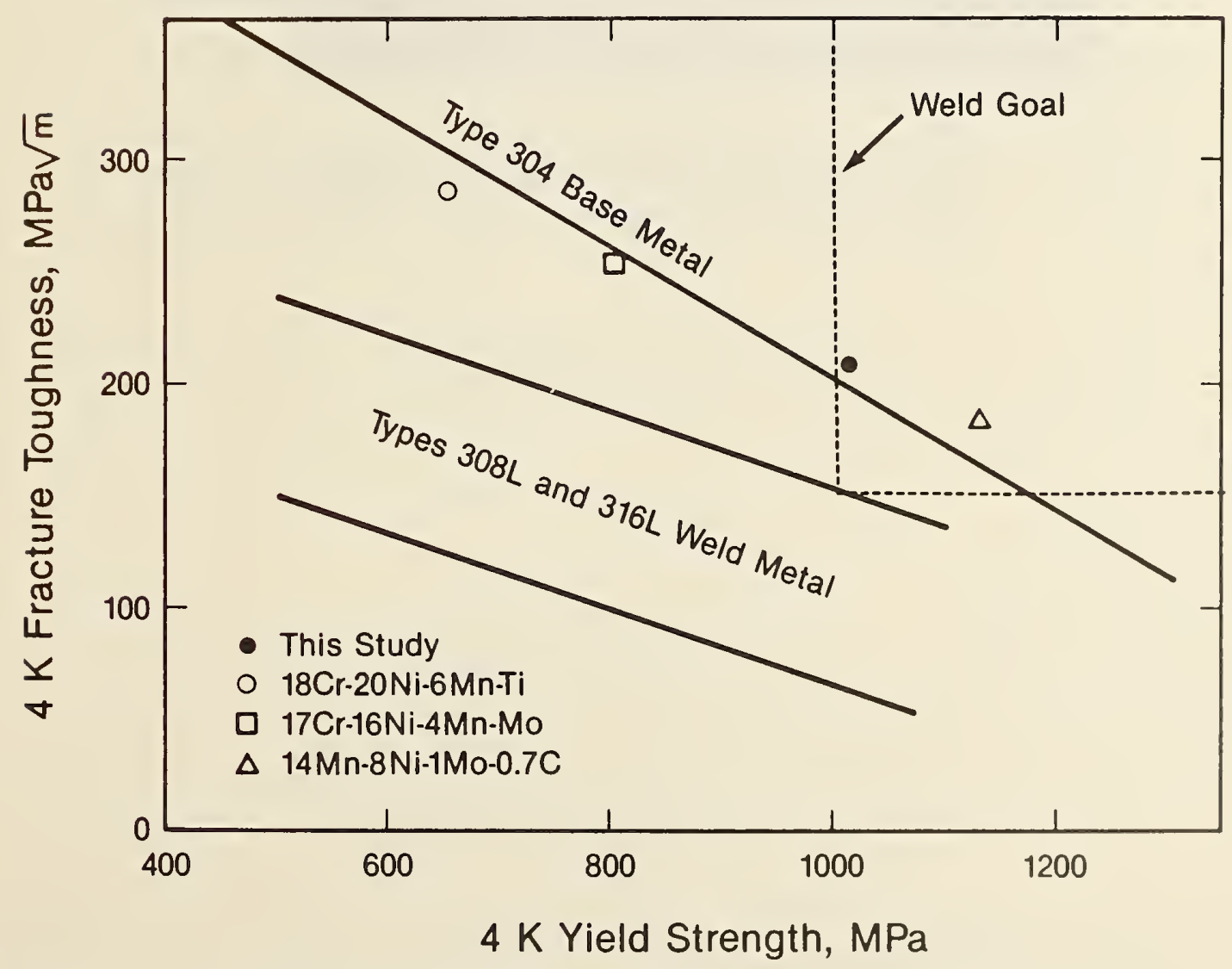

Fig. 6. Fracture toughness versus yield strength relationships for a number of type $308 \mathrm{~L}$ and $316 \mathrm{~L}$ stainless steel welds, austenitic steel welds, and type 304 base material. 


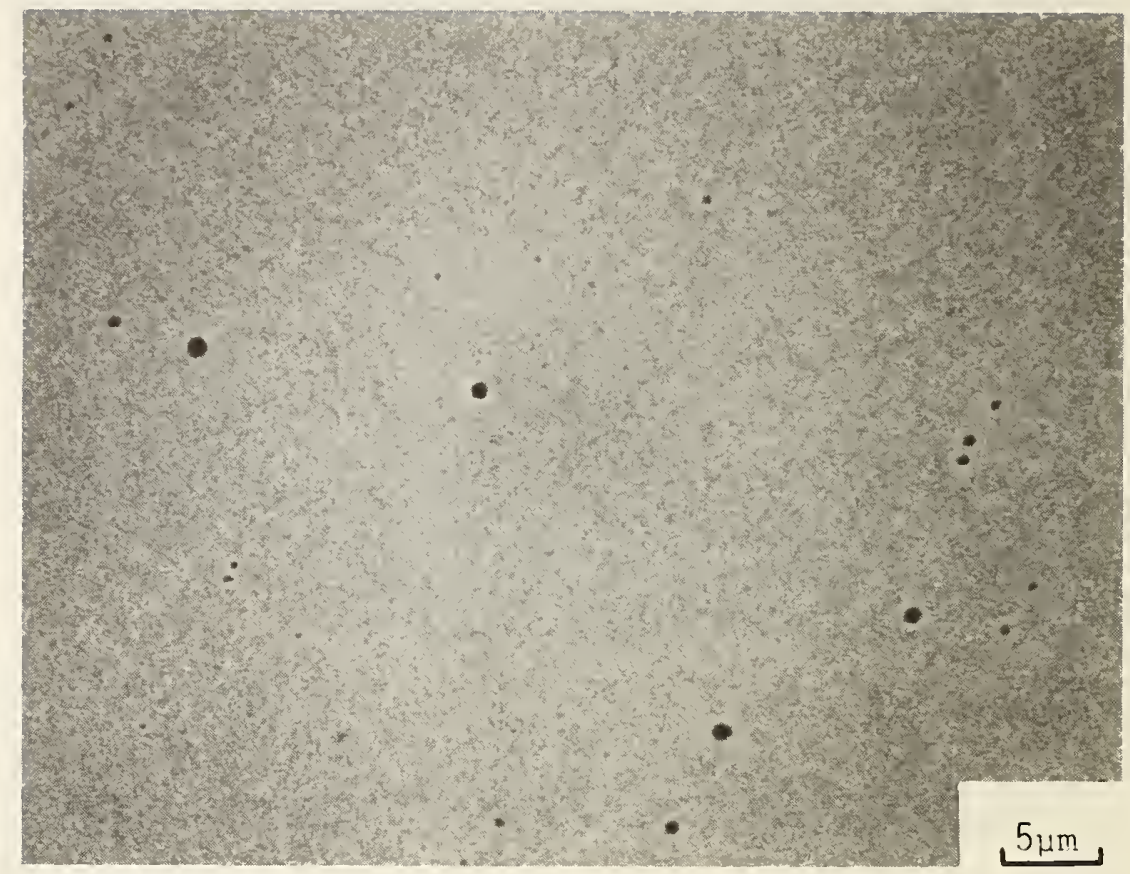

Fig. 7. SEM micrograph of a polished section of a weld made with the Fe-18Cr-20Ni-5Mn-0.16N electrode illustrating the inclusion size and distribution. 


TENSILE, FATIGUE, AND FRACTURE PROPERTIES OF AN

$\mathrm{Fe}-18 \mathrm{Cr}-16 \mathrm{Ni}-6.5 \mathrm{Mn}-2$. $4 \mathrm{MO}$ FULLY

AUSTENITIC SMA WELD AT $4 \mathrm{~K} \dagger$

R. L. Tobler, R. E. Trevisan,* H. I. McHenry, P. T. Purtscher, and T. A. Siewert

Fracture and Deformation Division

National Bureau of Standards

Boulder, Color ado

A fully austenitic stainless steel butt weld was produced by shielded metal arc (SMA) welding using a new filler composition: Fe-18Cr-16Ni-6.5Mn-2.4Mo. The weld was 25-mm thick and contained no microfissures. Tensile, fatigue crack growth rate, and fracture toughness properties for the weld at $4 \mathrm{~K}$ are reported. Fatigue crack growth resistance compares favorably with base metals for the case of crack growth in the longitudinal direction of the weld. A completely ductile fracture with very fine dimple size was evidenced in both tensile and fracture toughness tests. The 4-K weld fracture toughness $\left(\mathrm{K}_{\mathrm{Ic}}=190 \mathrm{MPa} \cdot \mathrm{m}^{1 / 2}\right.$ ) is about $20 \%$ lower than typical values for conventional austenitic stainless steel base metals of equivalent yield strength $\left(\sigma_{\mathrm{y}}=842 \mathrm{MPa}\right)$ but is significantly higher than values for conventional type 308L and 316L SMA welds, which contain some brittle fracture features owing to second-phase $\delta$-ferrite. The lower toughness of the weld relative to base metals is attributed to the effects of a higher density of inclusions on ductile fracture initiation.

Key words: austenitic stainless steel; cryogenic properties of materials; ductile fracture; fatigue crack growth; fracture toughness; microstructure; shielded metal arc welding; tensile properties; weldments.

\section{INTRODUCTION}

A current goal of cryogenic research is to develop microfissure-free, fully austenitic welds that match base metal levels of strength and toughness at liquid helium temperature $(4 \mathrm{~K})$. Austenitic welds traditionally contain some second-phase $\delta$-ferrite to help prevent microfissuring during cooling to room temperature. Unfortunately, the $\delta$-ferrite is undesirable for cryogenic service; having a body-centered cubic structure, it is brittle at low temperatures.

TWork supported by the U.S. Department of Energy; not subject to copyright.

*Guest worker, on leave from the Department of Engineering, UNICAMP,

Campinas - Sao Paulo, Brazil. 
To prevent formation of $\delta$-ferrite and achieve a fully austenitic weld, an appropriate chemical composition must be selected according to the DeLong constitution diagram. Other factors must then be considered, including microfissures, fusion zone width, structural inhomogeneity, austenite-tomartensite transformation tendencies, and inclusion contents [1]. Additional research is necessary to identify the optimum alloy composition and weld process variables, but it does appear possible to obtain both microfissurefree and $\delta$-ferrite-free welds having attractive properties at $4 \mathrm{~K}[2,3]$. In this paper we consider a shielded metal arc (SMA) Fe-18Cr-16 Ni-6.5Mn-2.4Mo weld composition; evaluate its tensile, fatigue, and fracture properties at $4 \mathrm{~K}$; and compare its performance with that of other SMA welds [4] and austenitic stainless steel base metals.

\section{MATERIAL}

The test material was an SMA butt weld produced by joining two sections of 25-mm-thick Fe-18Cr-8Ni base metal with the newly developed Fe-18Cr-16Ni6.5Mn-2.4Mo electrode having a rutile coating. The chemical compositions and welding conditions are shown in Tables 1 and 2. The microstructure was characterized by various techniques, including light microscopy, energy dispersive microchemical analysis, and magnetometry.

\section{EXPERIMENTAL PROCEDURES}

Tests at $4 \mathrm{~K}$ were performed in the as-welded condition using specimen geometries with the nominal dimensions shown in Figure 1. The tensile properties were measured using three cylindrical $(6.35-\mathrm{mm}$ diameter by $25.4-\mathrm{mm}$ gage length) specimens at a strain rate of $4.2 \times 10^{-4} \mathrm{~s}^{-1}$. Fatigue crack growth rates and $\mathrm{J}$-integral fracture toughness values were measured using compact specimens with compliance measurements at the specimen edge and loadline, respectively. The fracture specimens were $25-\mathrm{mm}$ thick with a width-to-thickness ratio (W/B) of 2. The fatigue crack growth rate specimens were $6.4-\mathrm{mm}$ thick with a W/B of 12 . Specimen orientations relative to the weld metal are shown in Figure 2. The cryogenic apparatus and procedures are described elsewhere [5-8].

Single-specimen $\mathrm{J}$-integral tests were used to measure JIc, which is a material parameter for ductile fracture [6]. The computer-aided unloading-compliance technique [6-8] was applied to generate resistance curves, $J$ versus crack extension ( $\Delta a)$ measurements, for three specimens. JIc was defined as the intersection of the resistance curve regression and blunting lines (see the Results section), and estimates of the plane strain linear-elastic stress intensity factor, $\mathrm{K}_{\mathrm{Ic}}(J)$, were calculated from the relation [6]

$$
\mathrm{K}_{I C}(\mathrm{~J})=\left(\mathrm{E} \cdot \mathrm{J}_{\mathrm{Ic}}\right)^{1 / 2} \cdot
$$

The value of Young's modulus, E, was estimated to be $207 \mathrm{GPa}$ at $4 \mathrm{~K}$. 
The first of the three $J$-integral test specimens was fractured completely at $4 \mathrm{~K}$, and then its fracture surface was viewed by scanning electron microscopy (SEM). The second was tested and then metallographically sectioned in the plane perpendicular to the crack surface to observe the crack profile. The third was tested and then refatigued to measure the final physical crack extension increment, $\Delta a_{f}$, which was used to determine the resistance curve slope, $\partial \mathrm{J} / \partial \mathrm{a}$, and the material's dimensionless tearing modulus, $\mathrm{T}$, where

$$
T=\frac{E}{\sigma_{y}^{2}}\left(\frac{\partial J}{\partial a}\right) \text {. }
$$

\section{RESULTS}

\section{General Microstructural Assessment}

The microstructure of the as-received weld consisted of columnar austenite grains aligned in the principal direction of heat flow, which was generally normal to the surface of the weld. Figure 3A shows a cross-sectional view of the austenite dendrites, and Figure 3B shows a view parallel to the dendrite columns. No $\delta$-ferrite is present, as verified by electrolytic etching with $\mathrm{KOH}$ and also by magnetometry. However, a solute-redistribution effect occurred during weld solidification, and this is evident in Figure $3 \mathrm{~A}$.

As shown by the unetched sample of Figure $4 \mathrm{~A}$, a homogeneous distribution of inclusions was present in the weld. The inclusions have various sizes and are composed mainly of $\mathrm{Mn}, \mathrm{S}, \mathrm{Si}, \mathrm{Ti}$ and $\mathrm{O}$, in various proportions. The average diameter, $\bar{d}$, is $0.64 \mu \mathrm{m}$ and the density, $\mathrm{n}$, is 9664 inclusions per $\mathrm{mm}^{2}$. In base metals, the inclusions are typically larger and fewer in number, as shown in Figure $4 \mathrm{~B}$ for AISI 310S. For this material, $\overline{\mathrm{d}}=10 \mu \mathrm{m}$ and $\mathrm{n}=225 / \mathrm{mm}^{2}$. The high inclusion density of the weld adversely affects the fracture properties at $4 \mathrm{~K}$, as described in the discussion.

\section{Mechanical Properties}

The $4-\mathrm{K}$ tensile properties of the Fe-18Cr-16Ni-6.5Mn-2.4Mo weld deposit are listed in Table 3. The data scatter for three replicate tests is modest, and each weld specimen displayed the cup-and-cone morphology that is typical for ductile fracture in uniaxial tension. The tensile properties of a wrought austenitic stainless steel base metal, AISI $310 \mathrm{~S}$ (Fe-25Cr-20Ni-17Mn-0.2MO), are included in Table 3 for comparison. At $4 \mathrm{~K}$, the average yield strength of the weld ( $842 \mathrm{MPa}$ ) is slightly higher than that of AISI $310 \mathrm{~S}$ ( $817 \mathrm{MPa}$ ); however, its ultimate strength, elongation, and reduction of area are somewhat lower.

Figure 5 presents a typical load-versus-deflection curve for a $J$-integral test specimen of the weld at $4 \mathrm{~K}$. The controlled periodic compliance unloadings and the uncontrolled load-point instabilities give these test records a serrated appearance. As explained elsewhere [8], serrations are common during the ductile fracture of steels at $4 \mathrm{~K}$ and may represent either unstable plastic deformation alone or unstable plastic deformation combined with crack extension. 
Figure 6 presents a typical J-resistance curve for the weld deposit at $4 \mathrm{~K}$. In accordance with standard procedure [6], the regression line is characterized by a linear least-squares fit and the blunting line is specified by the expression

$$
J=2 \Delta \mathrm{a} \sigma_{f},
$$

where the flow strength, $\sigma_{f}$, is the average of the uniaxial tensile yield, $\sigma_{y}$, and ultimate strengths, $\sigma_{u}$ :

$$
\sigma_{f}=\frac{\left(\sigma_{y}+\sigma_{u}\right)}{2} .
$$

According to ASTM E 813-81, at least four J-versus- $\Delta a$ points must fall within the exclusion interval defined by the offset lines at $\Delta a=0.15$ and $1.5 \mathrm{~mm}$ (see Fig. 6). This requirement was barely satisfied in our tests; no more than four points were obtained because unstable plastic deformation associated with serrations at $4 \mathrm{~K}$ limited the number of unloadings that could be performed. From the slope of the line connecting $J_{I c}$ and $\Delta a_{f}$ (the final physical crack extension increment [7]), the tearing modulus of the weld metal was determined from Equation (2) to be 50 .

The JIc measurements and $\mathrm{K}_{I c}$ values (estimated from Eq. 1) for each specimen at $4 \mathrm{~K}$ are listed in Table 4 . The three results show mild scatter and an average $K_{I C}(J)$ value of $190 \mathrm{MPa} \cdot \mathrm{m}^{1 / 2}$. Data for wrought austenitic stainless steels $[6,7]$ are compared with those of other austenitic stainless steel welds in Figure $7[2-4]$. In terms of toughness at a given yield strength, the weld of this study (1) falls about $20 \%$ below typical values for conventional wrought steels, (2) is within the range reported for seven other fully austenitic stainless steel welds, and (3) clearly surpasses the toughness of SMA welds containing $\delta$-ferrite.

\section{Fractography}

Fracture of the weld at $4 \mathrm{~K}$ occurred exclusively by a ductile failure mechanism, as verified by examination of the fractured $J$ test specimen of Figure 8. Macroscopically, the 4-K fracture surface is rougher than that of austenitic stainless steel base metals [6]. Observations at higher magnifications, as in Figure 9A, show that the fracture surface of the compact specimen is completely covered by a uniform distribution of very fine dimples, less than $5 \mu \mathrm{m}$ in diameter, originating at inclusions in the austenite matrix. The dimple size is much smaller than typically observed for wrought stainless steels, such as AISI 310 S (see Fig. 9B), where the average dimple is about $35 \mu \mathrm{m}$ in diameter.

Scanning electron microscope examinations of the weld tensile and compact specimen fracture surfaces showed no marked difference in the dimple density or size for fracture in the uniaxial tension or plane strain stress states. Furthermore, magnetic torsion balance measurements revealed no detectable magnetic phase on the fracture surfaces. Thus, the Fe-18Cr-16Ni-6.5Mn-2.4Mo weld is completely ductile and fully stable with respect to the $\gamma-t o-\alpha{ }^{\prime}$ 
martensitic phase transformation at $4 \mathrm{~K}$. There is no evidence of the "corduroy" fracture mechanism that was recently reported in Mn-modified metastable type $316 \mathrm{~L}$ weld metal [1].

In Figure 10, microstructural views of the crack front profile at midthickness of another $J$ test specimen show that the main crack has deviated significantly from the horizontal plane, which is the expected plane of crack propagation. Evidently the crack progresses by successively linking up with individual voids or void complexes, and the material fractures along strings of inclusions, not along grain or weld pass interface boundaries or the plane of maximum stress.

\section{Eatigue Crack Growth Rates}

Figure 11 presents the fatigue crack growth rate data for the $\mathrm{Fe}-18 \mathrm{Cr}-16 \mathrm{Ni}-6.5 \mathrm{Mn}-2.4 \mathrm{MO}$ weld at $4 \mathrm{~K}$. The rates follow a typical power-law expression,

$$
\frac{\mathrm{da}}{\mathrm{dN}}=\mathrm{C}(\Delta \mathrm{K})^{\mathrm{m}}
$$

For a logarithmic plot of $\mathrm{da} / \mathrm{dN}$ versus stress intensity factor range, $\Delta K$, the coefficient $C$ is the ordinate intercept at $\Delta K=1$, and $\mathrm{m}$ is the slope.

As shown in Figure 11, the weld data extend three orders of magnitude from $\mathrm{da} / \mathrm{dN}=10^{-2}$ to $10^{-5} \mathrm{~mm} / \mathrm{cycle}$. A bilinear representation is indicated, but the data below $10^{-3} \mathrm{~mm} /$ cycle $\left(\Delta \mathrm{K}=28\right.$ to $\left.60 \mathrm{MPa} \cdot \mathrm{m}^{1 / 2}\right)$ are of primary interest. For these data, the appropriate power law expression is

$$
\frac{\mathrm{da}}{\mathrm{dN}}=1.22 \times 10^{-14}(\Delta \mathrm{K})^{6} \cdot 0
$$

The fatigue crack growth rates specified by this expression are lower than those for typical base metals, including AISI 310 S and AISI 316 stainless steels. For example, in Figure 11, the trend line for a representative AISI 316 steel is given by the expression [9]

$$
\frac{\mathrm{da}}{\mathrm{dN}}=2.1 \times 10^{-10}(\Delta \mathrm{K})^{3} \cdot 8
$$

\section{DISCUSSION}

\section{Comparison with Other Austenitic Welds}

Data for nine fully austenitic stainless steel welds at $4 \mathrm{~K}$ are available $[2,3]$ and are shown in Figure 7 . In general, three of the nine welds match the base metal strength and toughness levels whereas the rest fall below par by margins like that reported for the weld tested in this study. Unfortunately, detailed metallographic and fractographic characterizations were not reported for the previously tested fully austenitic welds [2,3], and therefore such evaluations are not possible. 
The test weld's toughness exceeds the values for conventional type 316 stainless steel welds at comparable strength levels. The band in Figure 7 for type 316 compositions represents tests of twenty-three welds produced with varying ferrite levels ( 0 to $12 \mathrm{FN}$ ) and five different welding processes [4]. The test weld is tougher because it does not have the cleavage-type mechanisms that cause the 316 weld to be brittle.

\section{Comparison with 310 S Base Metal}

Compared with welds of AISI 310 S austenitic stainless steels of nearly equivalent yield strength $[8,10]$, the test weld at $4 \mathrm{~K}$ has a lower ultimate tensile strength, a lower tensile ductility, a lower J Ic, a lower tearing modulus, and a finer dimple size. Apparently these property differences are due primarily to the effect of inclusions on the ductile fracture process. This comparison is meaningful since both the weld metal and the AISI 310 S steel are fully austenitic and stable; both materials fail by completely ductile mechanisms and are free from the effects of martensitic phase transformations, which would otherwise complicate the interpretation of the fracture process [1].

Ductile fracture involves the initiation, growth, and coalescence of voids to produce a dimpled fracture surface. Typically, voids initiate at inclusions at low plastic strains via decohesion at the inclusion/austenite matrix interfaces. The voids then grow during continued plastic deformation until the intervening ligaments finally rupture to complete the fracture process. In wrought stainless steel base metals, such as AISI $310 \mathrm{~S}$ (Fig. 4B), the inclusion content is relatively low, and the mean free path between inclusions is relatively large. Therefore, void growth plays a major role in the fracture process, and the final dimple size is large (Fig. 9B). In the weld metal, however, the inclusion content is relatively high (Fig. 4A); voids are initiated in large numbers, and they do not grow very large before coalescing (Fig. 9A). This means that significantly less plastic work is required to accomplish void coalescence in the weld, and this explains the differences in uniaxial tensile properties (lower $\sigma_{u}$, elongation, reduction of area) and fracture toughness parameters (lower JIc, lower T).

The estimated volume fraction, $f_{p}$, of inclusions was calculated in the following way: We counted the number of inclusions, $\mathrm{N}$, in a $0.1 \mathrm{~mm}^{2}$ area of a polished cross section that were greater than $0.5 \mu \mathrm{m}$ in size. The average diameter, $\bar{d}$, of the inclusions is the average of ten measurements. The small number of measurements was felt to be adequate because the inclusions in the test weld were uniformly small, and in the $310 \mathrm{~s}$ sample, the inclusions were considerably bigger and relatively uniform.

An areal analysis was used for the final calculations of $\mathrm{f}_{\mathrm{p}}$ :

$$
\mathrm{f}_{\mathrm{p}}=\frac{\sum \mathrm{A} \alpha}{\mathrm{A}_{\mathrm{T}}},
$$

where the total area, $\mathrm{A}_{\mathrm{T}}=0.1 \mathrm{~mm}^{2}$ and total area of inclusions, $\sum A \alpha=N \pi \bar{d}^{2} / 4$. 
For the weld, the estimated volume fraction of inclusions is 0.003 and the dimple size is about $4 \mu \mathrm{m}$ in diameter. For the $310 \mathrm{~s}$ wrought steel, $\mathrm{f}_{\mathrm{p}}$ is 0.0002 , and the dimple size is about $35 \mu \mathrm{m}$. The flow stress for the two appears to be similar, about $1000 \mathrm{MPa}$.

Aside from the inclusion population, the Fe-18Cr-16 Ni-6.5Mn-2.4Mo weld and the AISI $310 \mathrm{~S}$ base metal have dissimilar grain morphologies. The base metal grains are equiaxed, whereas the weld grains are columnar. Data for wrought austenitic stainless steel show that the grain size affects the yield strength and fracture toughness at $4 \mathrm{~K}$ [11]. However, yield strength and fracture toughness are not independent.

The 4-K fatigue crack growth resistance of the SMA weld is significantly higher than that of the AISI 316 stainless steel for the specific orientation and $\Delta K$ range studied (Fig. 11). The SMA weld offers superior performance and has a higher $n$ value $(6.0$ versus 3.8$)$ and a lower $C$ value $\left(1.22 \times 10^{-14}\right.$ versus $2.1 \times 10^{-10}$ ) than those of AISI 316. The differences in rates $f$ or the two materials range from factors of 11 at $\Delta \mathrm{K}=28 \mathrm{MPa} \cdot \mathrm{m}^{1 / 2}$ to 1.7 at $\Delta \mathrm{K}=$ $60 \mathrm{MPa} \cdot \mathrm{m}^{1 / 2}$.

In this case, the base metal had a TL orientation and the crack of the weld was centered in the fusion zone. In both materials, the loading was transverse to the longitudinal plate direction, and crack propagation was in the longitudinal direction. Previous results $[10,12]$ for austenitic stainless steel base metals indicated that orientation and compositional variations are not strong factors if the fatigue crack growth failure modes are ductile. For example, the measured $\mathrm{n}$ values for 14 austenitic stainless steels of the AISI 300 series range from 2.9 to 4.25 at $4 \mathrm{~K}$. Welds, however, appear to be more sensitive to crack location and specimen orientation. Previously, a high $n$ value (5.3) was reported for an $\mathrm{Fe}-13 \mathrm{Cr}-19 \mathrm{Mn}$ austenitic weld at $76 \mathrm{~K}$ [13]. In that case, the crack propagation was longitudinal to the fusion line, as in the present study where $\mathrm{n}=6$. Apparently the higher $\mathrm{n}$ values and superior fatigue crack growth properties of welds in the longitudinal orientation may be due to residual stress effects. If so, the performance of welds relative to base metals should be evaluated thoroughly by considering other specimen orientations.

\section{CONCLUSIONS AND RECOMMENDATIONS}

The fully austenitic Fe-18Cr-16Ni-6.5Mn-2. 4Mo SMA weld metal of this study at $4 \mathrm{~K}$ has a yield strength of $842 \mathrm{MPa}$, a plane strain fracture toughness $\mathrm{K}_{\mathrm{IC}}(\mathrm{J})$ of $190 \mathrm{MPa} \cdot \mathrm{m}^{1 / 2}$, and a tearing modulus of 50 . This weld fails by means of a completely ductile mechanism at $4 \mathrm{~K}$ and is more fracture resistant than type 308L and 316L SMA welds containing brittle second-phase f-ferrite. However, its properties are still lower than those of conventional wrought base metals. Compared with an AISI 31 OS austenitic stainless steel of equivalent yield strength, the Fe-18Cr-16Ni-6.5Mn-2.4Mo SMA weld at $4 \mathrm{~K}$ has a lower ultimate tensile strength, a lower tensile ductility, a lower J Ic, a lower tearing modulus, and a finer dimple size. These differences appear to be due to the effects of a large inclusion population on the ductile fracture process of the $\mathrm{Fe}-18 \mathrm{Cr}-16 \mathrm{Ni}-6.5 \mathrm{Mn}-2.4 \mathrm{Mo}$ weld. 
A high inclusion density is typical of SMA welds, especially those with a rutile (type 16) coating. The inclusion density can be reduced by using shielded metal arc electrodes with calcium oxide/fluoride (type 15) slag system or gas metal arc or gas tungsten arc welding. A reduction of the inclusion size and density is expected to improve the fracture toughness of the weld deposit without changing the chemical composition of the alloy.

\section{ACKNOWLE DGMENT}

The weld was fabricated by Hitachi Research Laboratory, Hitachi, Ltd., Hitachi, Japan and provided to NBS through the courtesy of Mr. T. Matsumoto; we are indebted to $\mathrm{him}$ and also to $\mathrm{Mr}$. C. McCowan of NBS who conducted the tensile tests. The experimental work was supported by the Department of Energy, Office of Fusion Energy.

\section{REFERENCES}

1. J. C. Lippold, M. C. Juhas, and E. N. C. Dalder, The Relationship Between Microstructure and Fracture of Fully Austentic Type $316 \mathrm{~L}$ Weldments at $4.2 \mathrm{~K}$, Metall. Trans. A., vol. 16A, (1985), pp. 1835-1848.

2. J. W. Elmer, H. I. McHenry, and T. A. Whipple, Strength and Toughness of Fully Austenitic Stainless Steel Filler Metals at $4 \mathrm{~K}$, in: Materials Studies for Magnetic Fusion Energy Applications at Low Temperatures - IV, NBSIR 81-1645, National Bureau of Standards, Boulder, Colorado (1981), pp. 289-302.

3. T. A. Whipple, H. I. McHenry, and D. T. Read, Fracture Behavior of Ferrite-Free Stainless steel Welds in Liquid Helium, Weld. J. Res. Suppl., vol. 60, No. 4 (1981), pp. 72s-78s.

4. R. L. Tobler, T. A. Siewert, and H. I. McHenry, Strength-Toughness Relationship for Austenitic Structural Steel Welds at $4 \mathrm{~K}$, in: Materials Studies for Magnetic Fusion Energy Applications at Low Temperatures - IX, National Bureau of Standards, Boulder, Colorado (1986).

5. D. T. Read and R. L. Tobler, Mechanical Property Measurements at Low Temperatures, in: Advances in Cryogenic Engineering-Materials, vol. 28, Plenum Press, New York (1982), pp. 17-28.

6. Standard Test Method for JIc, A Measure of Fracture Toughness, ASTM Designation E 813-81, 1984 Annual Book of ASTM Standards, Amer. Soc. Test. Mater., Philadelphia (1984), pp. 763-781.

7. R. L. Tobler, D. T. Read, and R. P. Reed, Strength-Toughness Relationship for Interstitially Strengthened AISI 304 stainless Steels at $4 \mathrm{~K}$ Temperature, in: Fracture Mechanics: Thirteenth Conference, ASTM STP 743, R. Roberts, Ed., Amer. Soc. Test. Mater., Philadelphia (1981), pp. $250-268$. 
8. R. L. Tobler, Ductile Fracture with Serrations in AISI 310 os Stainless

Steel at Liquid Helium Temperature, in: Elastic-Plastic Fracture: Second Symposium, Volume II - Fracture Resistance Curves and Engineering

Applications, ASTM STP 803, C. F. Shih and J. P. Gudas, Eds., Amer. Soc. Test. Mater., Philadelphia (1983), pp. 763-776.

9. R. L. Tobier and R. P. Reed, Fatigue Crack Growth Resistance of Structural Alloys at Cryogenic Temperatures, in: Advances in Cryogenic Engineering, vol. 24, Plenum Press, New York (1978), pp. 82-90.

10. W. A. Logsdon, J. M. Wells, and R. Kossowsky, in: Proceedings, Second International Conference on Mechanical Behavior of Materials, Amer. Soc. Met., Metals Park, Onio (1976), pp. 1283-1289.

11. R. P. Reed, P. T. Purtscher, N. J. Simon, and R. L. Tobler, Alloy $316 \mathrm{LN}$ for Low Temperature Structures: A Summary of Tensile and Fracture Data, in: Materials Studies for Magnetic Fusion Energy Applications at Low Temperatures--IX, National Bureau of Standards, Boulder, Colorado (1986).

12. R. L. Tobler, H. I. McHenry, and R. P. Reed, Fracture Parameters for an Iron-13\% Chromium-19\% Manganese Stainless Steel and Its Welds at Cryogenic Temperature, in: Advances in Cryogenic Engineering, vol. 24, Plenum Press, New York (1978), pp. 560-572.

13. R. L. Tobler and Y. W. Cheng, Midrange Fatigue Crack Growth Data Correlations for Structural Alloys at Room and Cryogenic Temperatures, in: Fatigue at Low Temperatures, ASTM STP 857, R.I. Stephens, Ed., Amer. Soc. Test. Mater., Philadelphia (1985), pp. 3-30.

Table 1. Chemical compositions of weld deposit and base metal (wt.\%).

\begin{tabular}{c|cccccccccc}
\hline & C & Si & Mn & P & S & Ni & Cr & Mo & N & O \\
\hline Weld Deposit & 0.062 & 0.29 & 6.50 & 0.015 & 0.005 & 16.30 & 17.64 & 2.38 & 0.036 & 0.042 \\
$\begin{array}{c}\text { Base } \\
\text { Material }\end{array}$ & 0.05 & 0.52 & 1.26 & 0.031 & 0.006 & 8.77 & 18.25 & $\ldots$ & $\ldots$ & $\ldots$ \\
\hline
\end{tabular}


Table 2. Welding conditions.

\begin{tabular}{|c|c|c|c|}
\hline $\begin{array}{c}\text { Current } \\
(\mathrm{A})\end{array}$ & $\begin{array}{c}\text { Voltage } \\
(\mathrm{V})\end{array}$ & $\begin{array}{c}\text { Speed } \\
(\mathrm{cm} / \mathrm{min})\end{array}$ & $\begin{array}{c}\text { Inter pass Temperature } \\
\left({ }^{\circ} \mathrm{C}\right)\end{array}$ \\
\hline $140 \sim 150$ & $23 \sim 24$ & 15 & $\leqq 150$ \\
\hline
\end{tabular}

Table 3. Tensile properties of the weld deposit at $4 \mathrm{~K}$ and data for AISI 310 s for comparison.

\begin{tabular}{|c|c|c|c|c|}
\hline $\begin{array}{c}\text { Specimen } \\
\text { No. } \\
\end{array}$ & $\begin{array}{r}\text { Yield Strength, } \\
\sigma_{\mathrm{y}}(\mathrm{MPa}) \\
\end{array}$ & $\begin{array}{l}\text { Ultimate Strength, } \\
\sigma_{11}(\mathrm{MPa}) \\
\end{array}$ & $\begin{array}{c}\text { Elongation } \\
(\%) \\
\end{array}$ & $\begin{array}{c}\text { Reduction of Area } \\
\left(\begin{array}{c}\% \\
0\end{array}\right)\end{array}$ \\
\hline 1 & 875 & 1200 & 34 & 30 \\
\hline 2 & 824 & 1200 & $\mathrm{NA}^{\mathrm{a}}$ & $29^{a}$ \\
\hline 3 & 828 & 1100 & 30 & 22 \\
\hline Average & 842 & 1166 & 32 & 27 \\
\hline AISI 310S [8] & 645 & 1259 & 36 & 31 \\
\hline AIS I $310 S$ [9] & 817 & 1303 & 64.3 & 44.6 \\
\hline
\end{tabular}

abroke outside gage marks.

Table 4. Fracture toughness test results for the weld deposit at $4 \mathrm{~K}$.

\begin{tabular}{|c|c|c|c|c|c|c|}
\hline Specimen No. & $\begin{array}{c}\text { Thickness, } \\
\text { B } \\
(\mathrm{mm})\end{array}$ & $\begin{array}{c}\text { Width, } \\
\text { W } \\
(\mathrm{mm}) \\
\end{array}$ & $\begin{array}{c}\text { Crack Length, } \\
a_{0}{ }^{1} \\
(\mathrm{~mm})\end{array}$ & $\begin{array}{l}\mathrm{JIc} \\
\left(\mathrm{kJ} / \mathrm{m}^{2}\right)\end{array}$ & $\begin{array}{c}\mathrm{K}_{\mathrm{IC}}(\mathrm{J}) \\
\left(\mathrm{MPa} \cdot \mathrm{m}^{1 / 2}\right)\end{array}$ & $\begin{array}{c}\text { Tearing } \\
\text { Modulus, } \\
\mathrm{T}\end{array}$ \\
\hline 1 & 25.425 & 50.775 & 31.250 & 187 & 196 & -- \\
\hline 2 & 25.450 & 50.775 & 30.825 & 175 & 190 & - \\
\hline 3 & 25.425 & 50.775 & 30.900 & 168 & 186 & 50 \\
\hline & & & \multicolumn{2}{|c|}{ Average: 177} & 191 & - \\
\hline AIS I $310 \mathrm{~S}$ [8] & --- & -- & -- & 360 & 285 & 60 \\
\hline
\end{tabular}

${ }^{1}$ Computer-calculated crack length. 


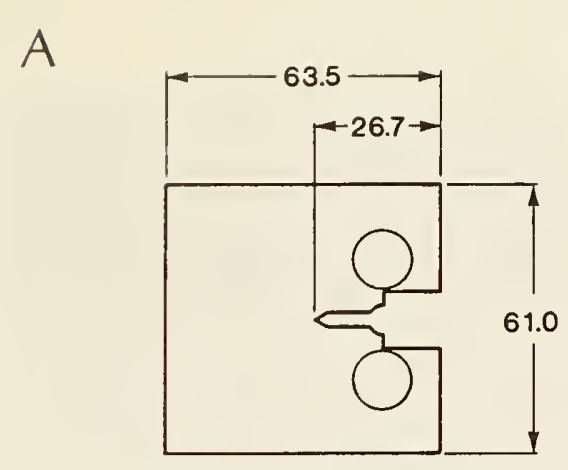

Fracture Toughness
B

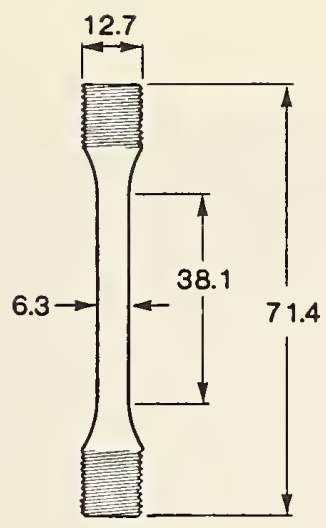

Tensile

C

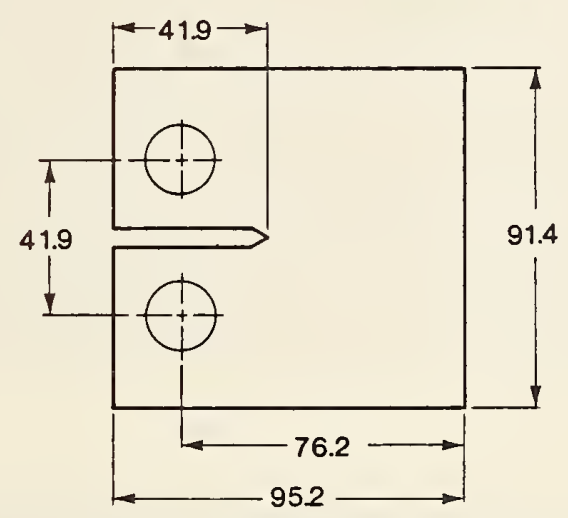

Fatigue

Figure 1. Specimen geometries used in this study: (A) compact J-integral test specimen, (B) cylindrical tensile specimen, and (C) fatigue crack growth rate specimen (all dimensions are in $\mathrm{mm}$ ).

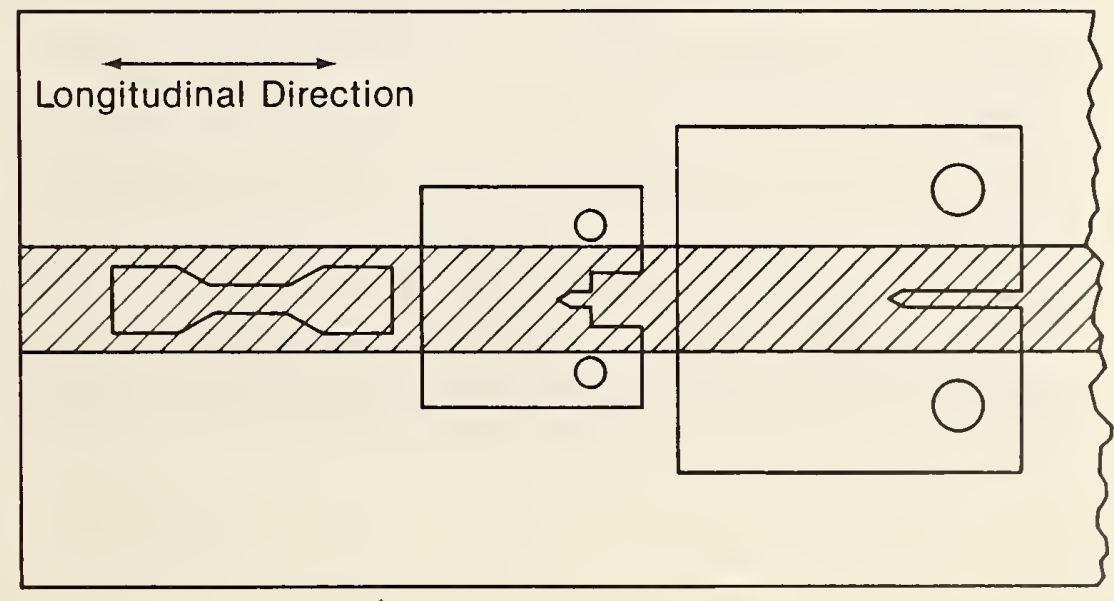

Figure 2. Specimen orientations with respect to the weld. 


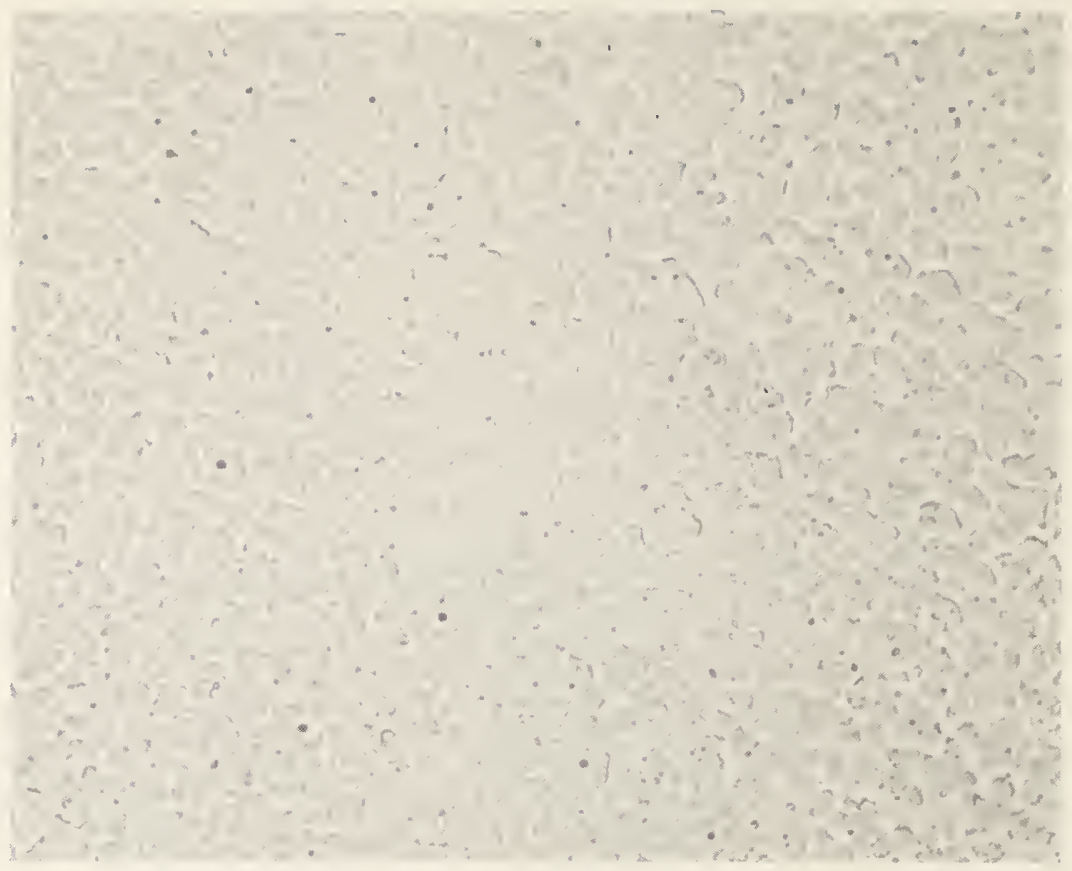

A

$100 \mu \mathrm{m}$

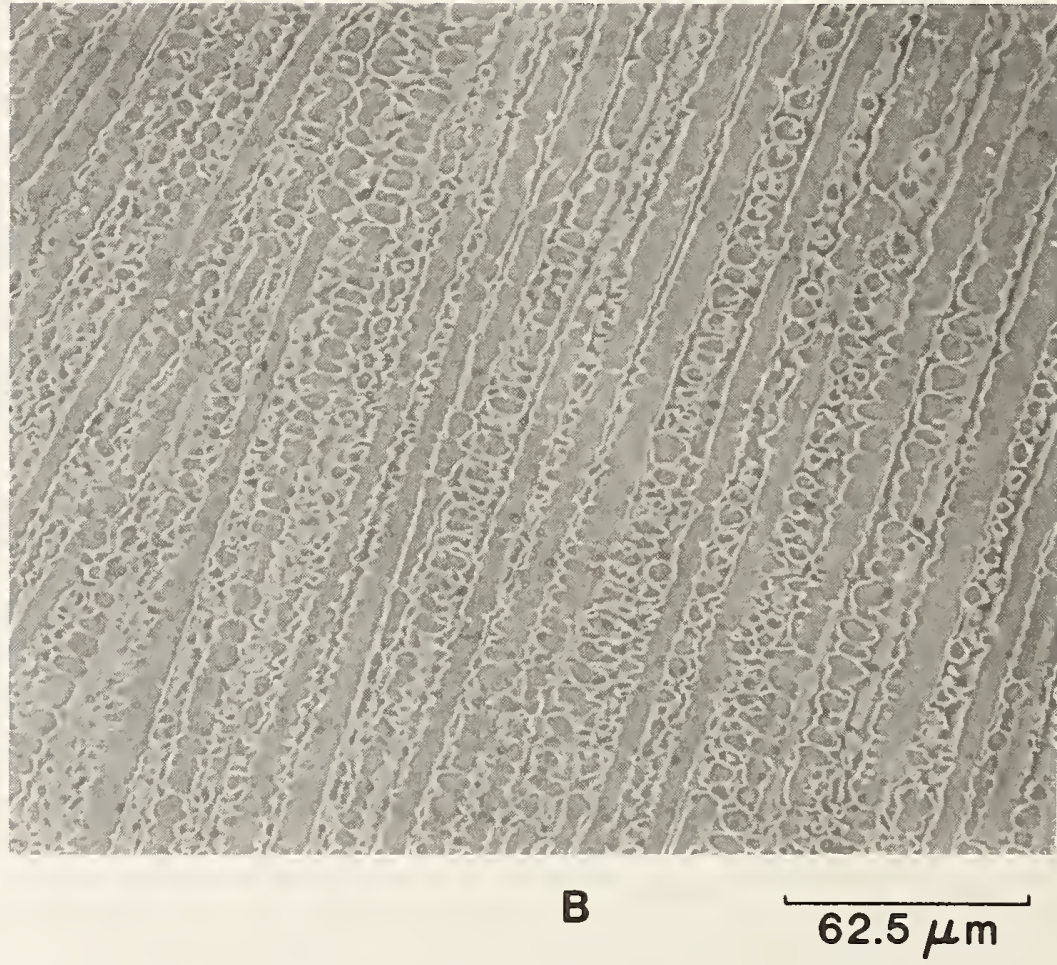

Figure 3. Weld microstructures, revealed by electrolytic etching in a $10 \%$ oxalic acid solution: (A) transverse to the weld direction, showing cross-sectional view of the austenitic dendrites, and (B) normal to the weld direction, showing the dendrite arms. 
A

$50 \mu \mathrm{m}$

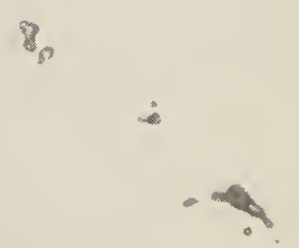

B

$50 \mu \mathrm{m}$

Figure 4. Inclusions: (A) in the present weld, and (B) in a wrought AISI $310 \mathrm{~s}$ alloy [7]. 


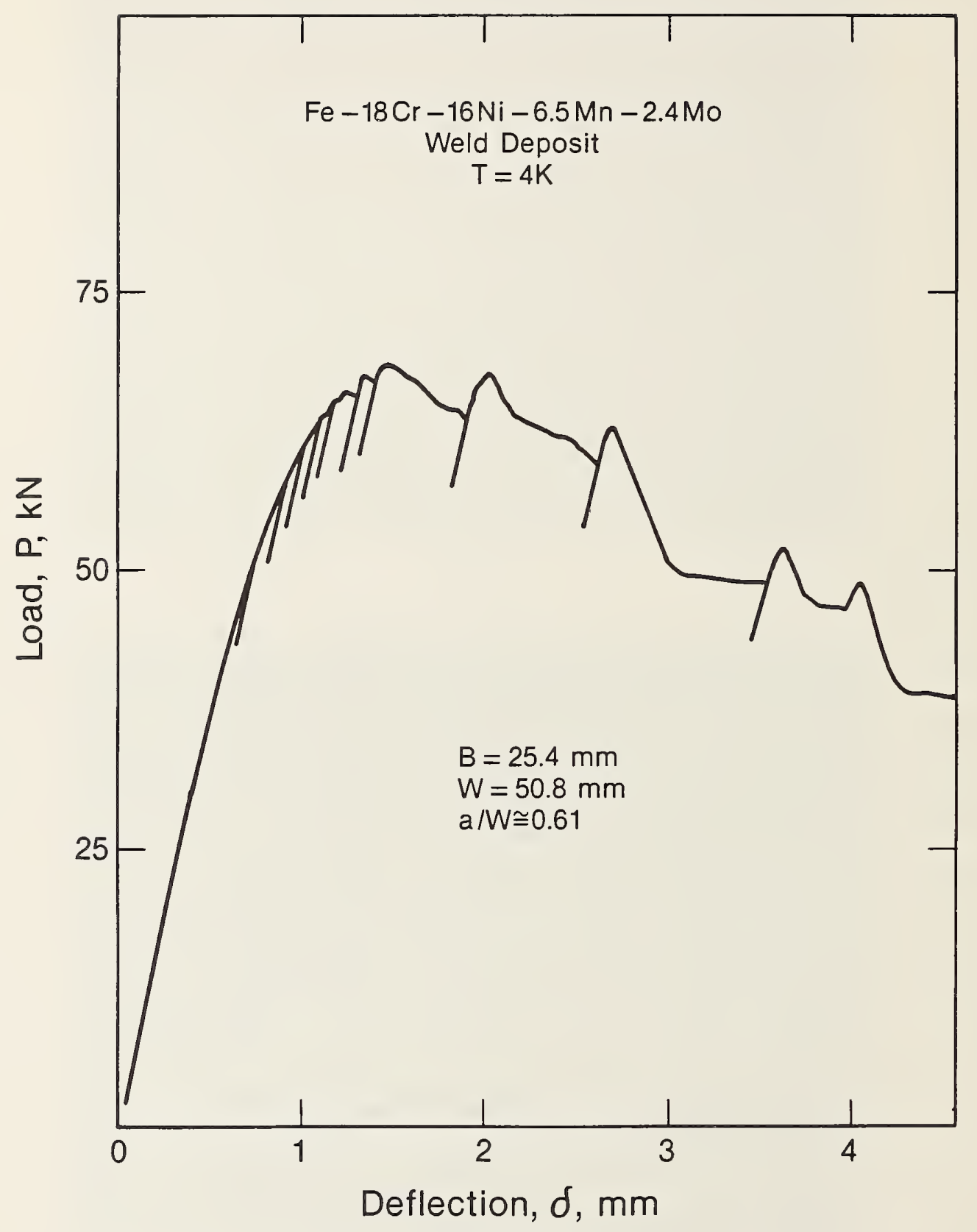

Figure 5. Load-deflection curve for a 25.4-mm-thick compact specimen showing compliance unloadings and serrations during single-specimen J-integral tests at $4 \mathrm{~K}$. 


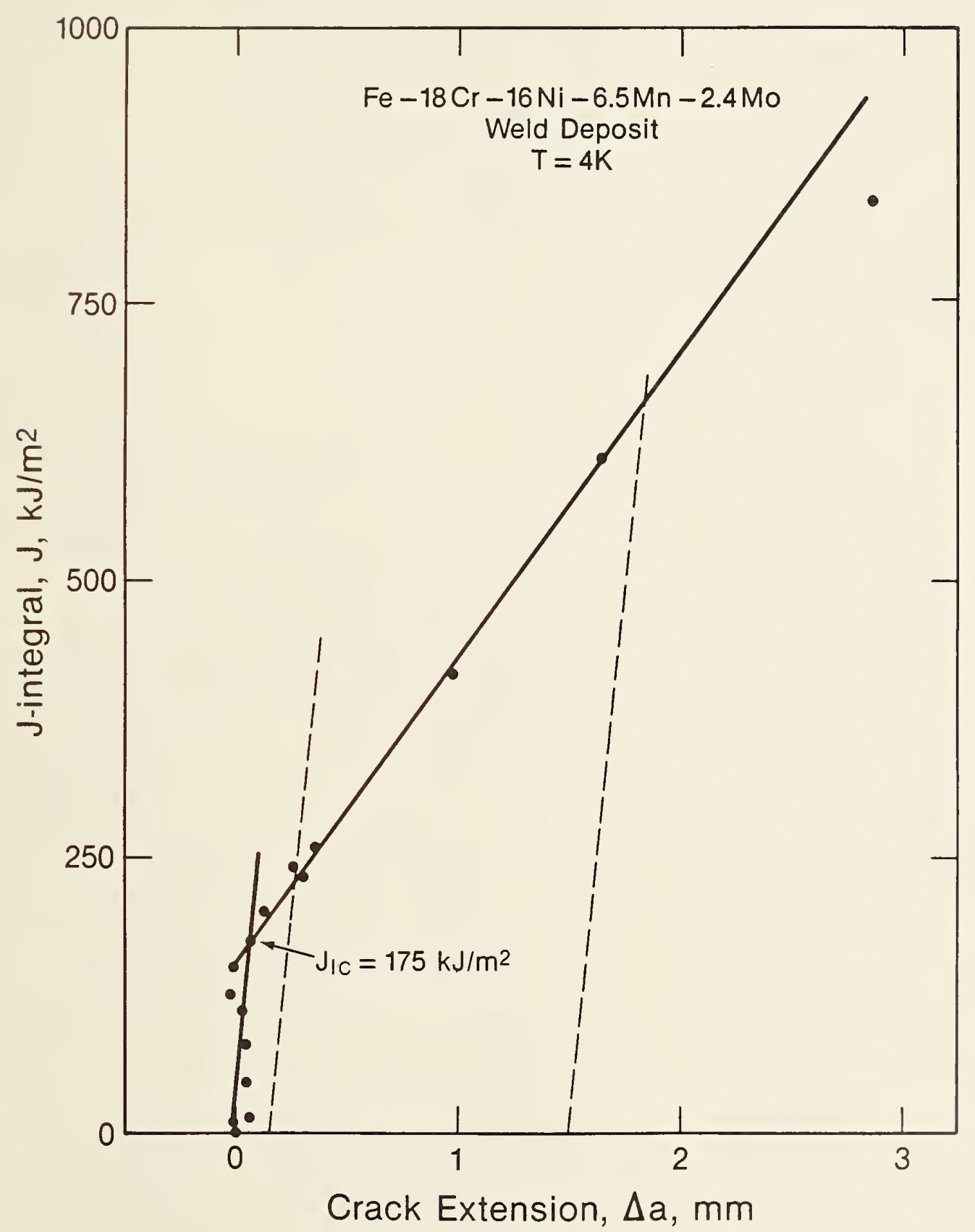

Figure 6. J-resistance curve for the weld deposit at $4 \mathrm{~K}$. 


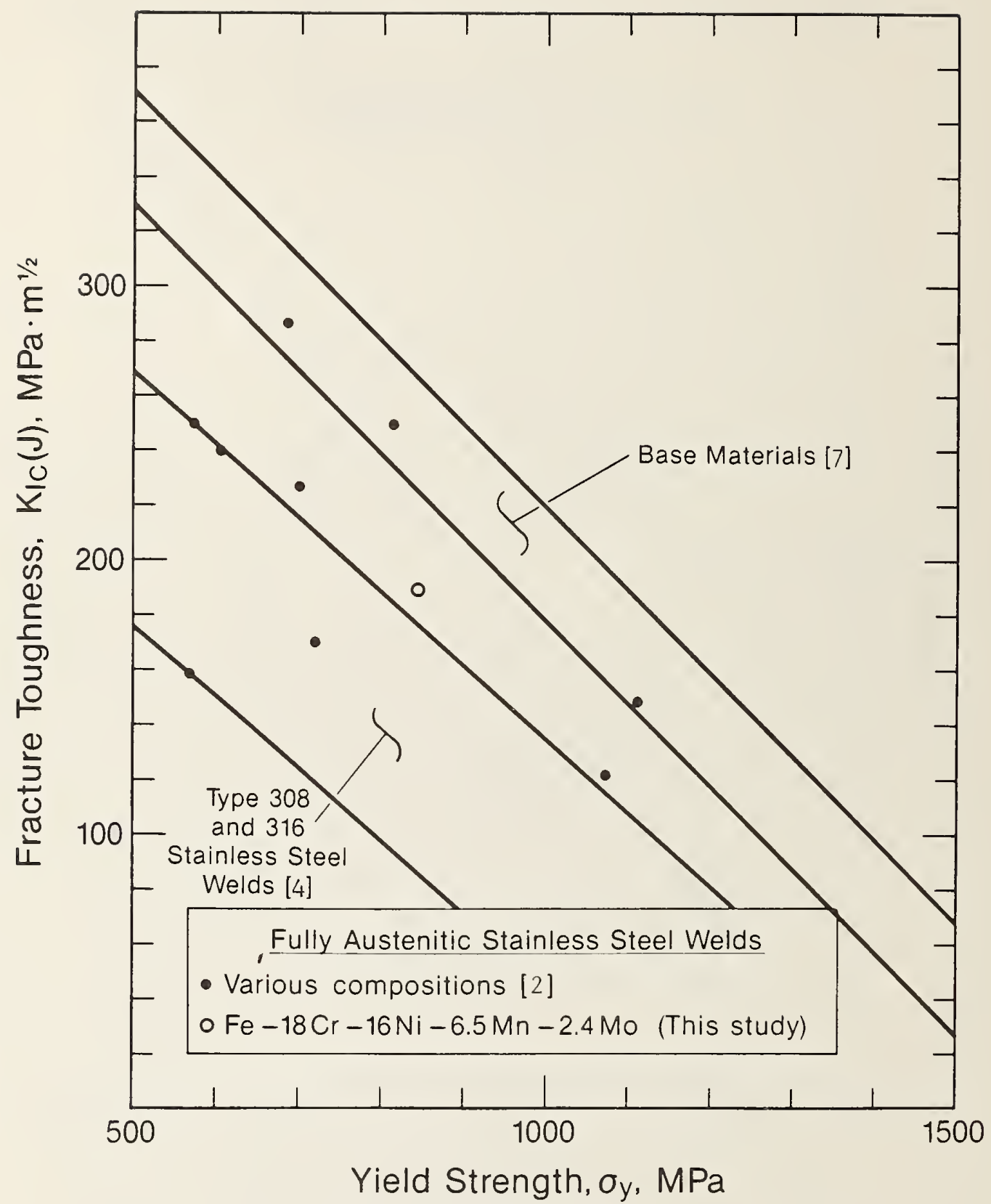

Figure 7. Comparison of fracture toughness and yield strength properties for fully austenitic stainless steel welds and base metals at $4 \mathrm{~K}$. 


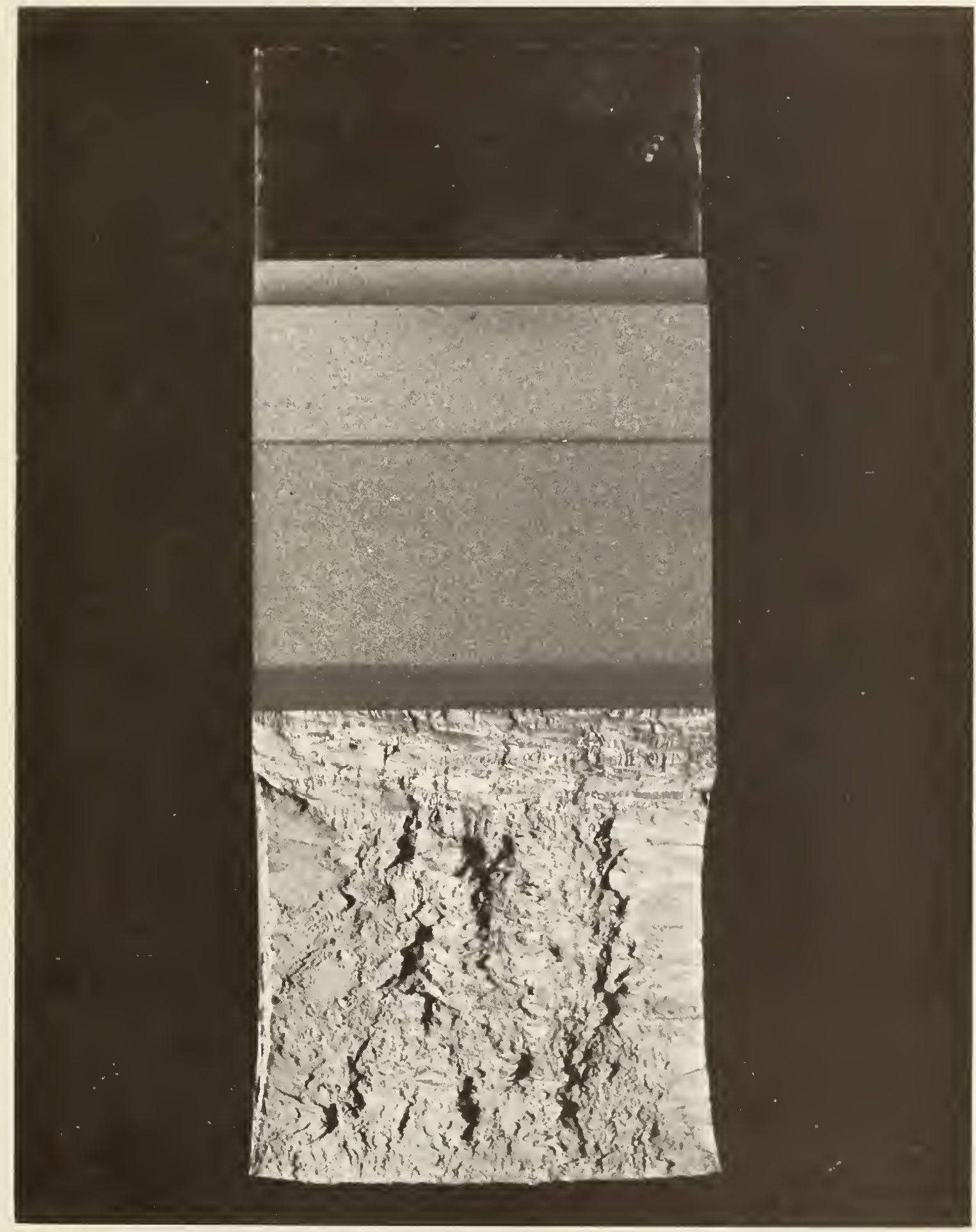

Figure 8. Fracture surface appearance of a 25.4 -mm-thick compact specimen tested at $4 \mathrm{~K}$. 


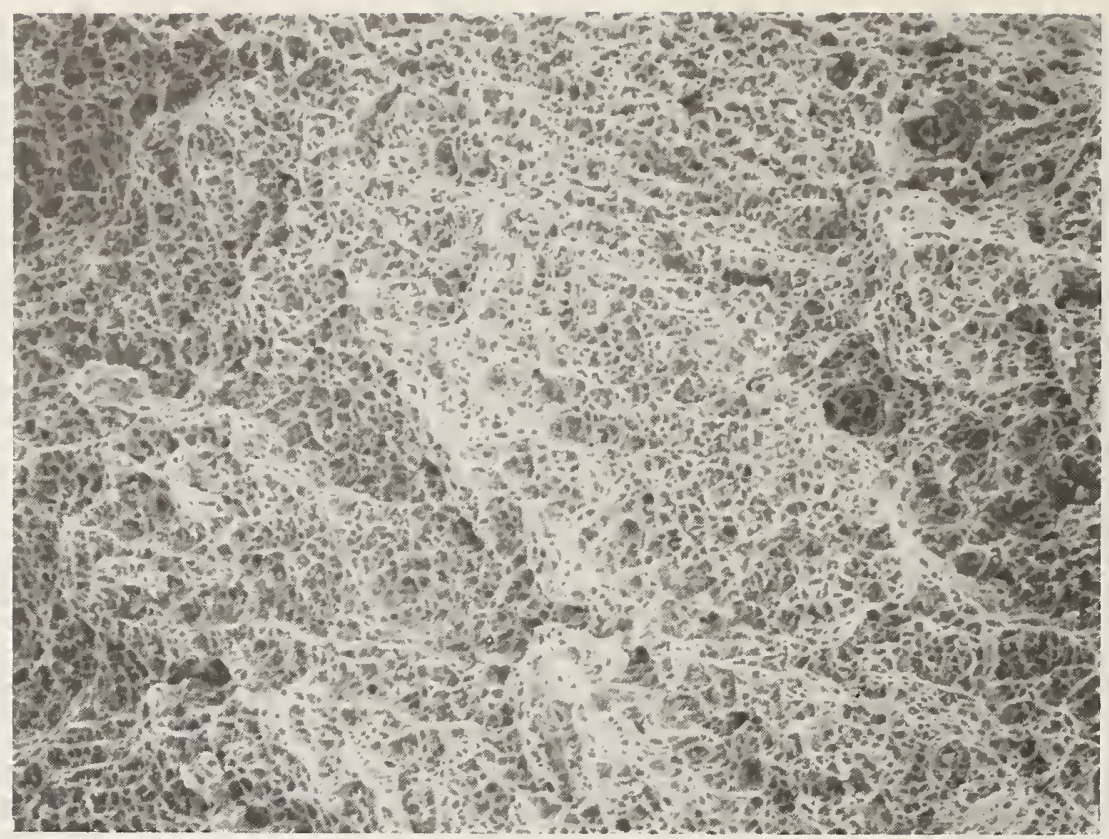

A

$83 \mu \mathrm{m}$
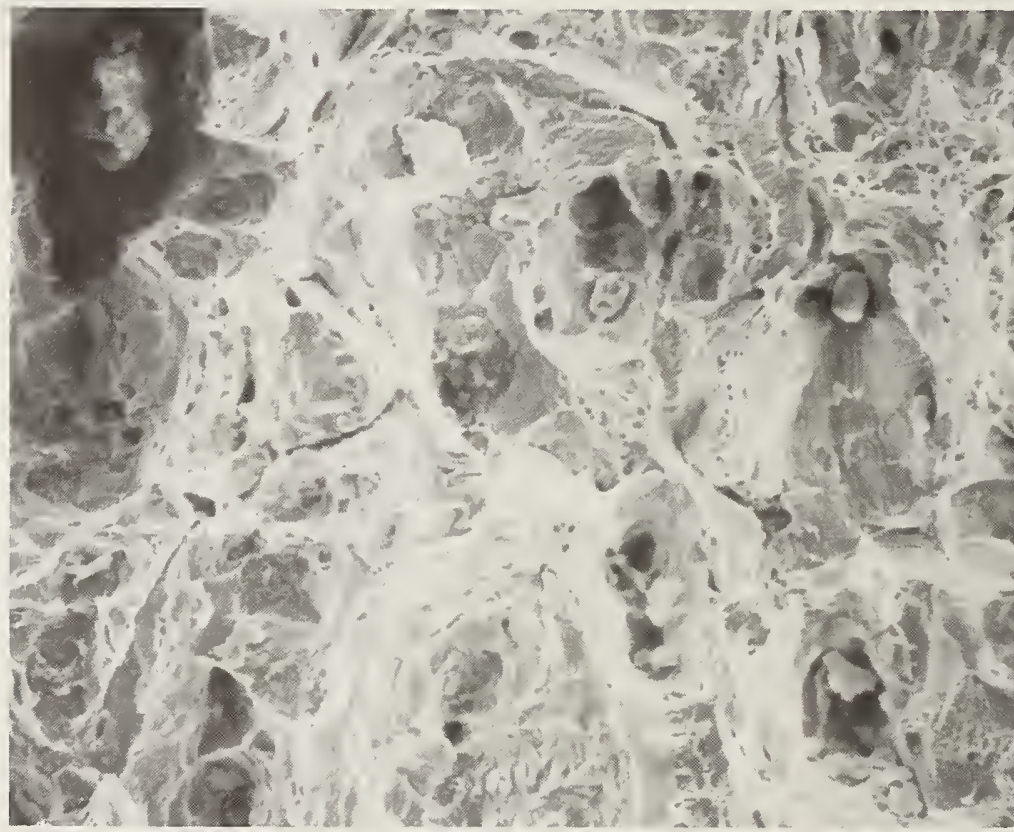


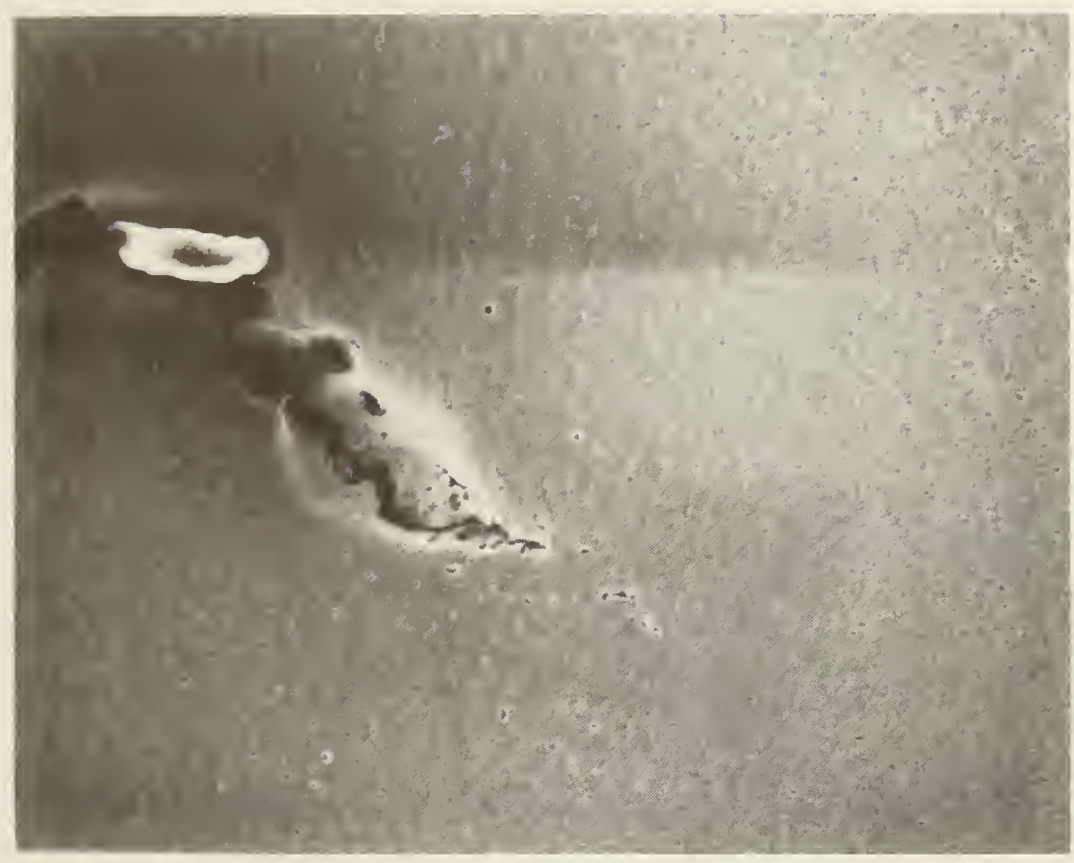

A

$50 \mu \mathrm{m}$

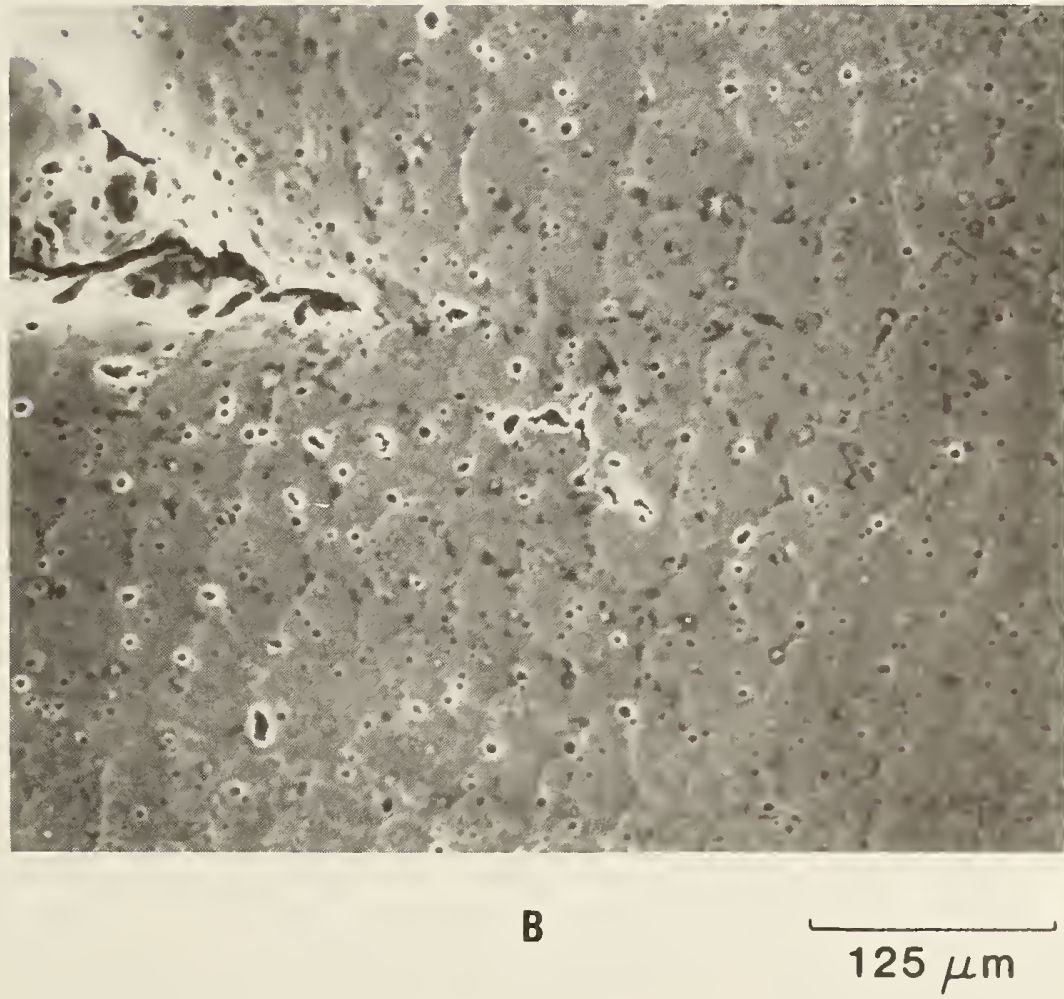

Figure 10. Crack tip profile of a J-integral fracture test specimen showing voids initiated at inclusions ahead of the advancing crack, at low and high magnifications, $A$ and $B$. 


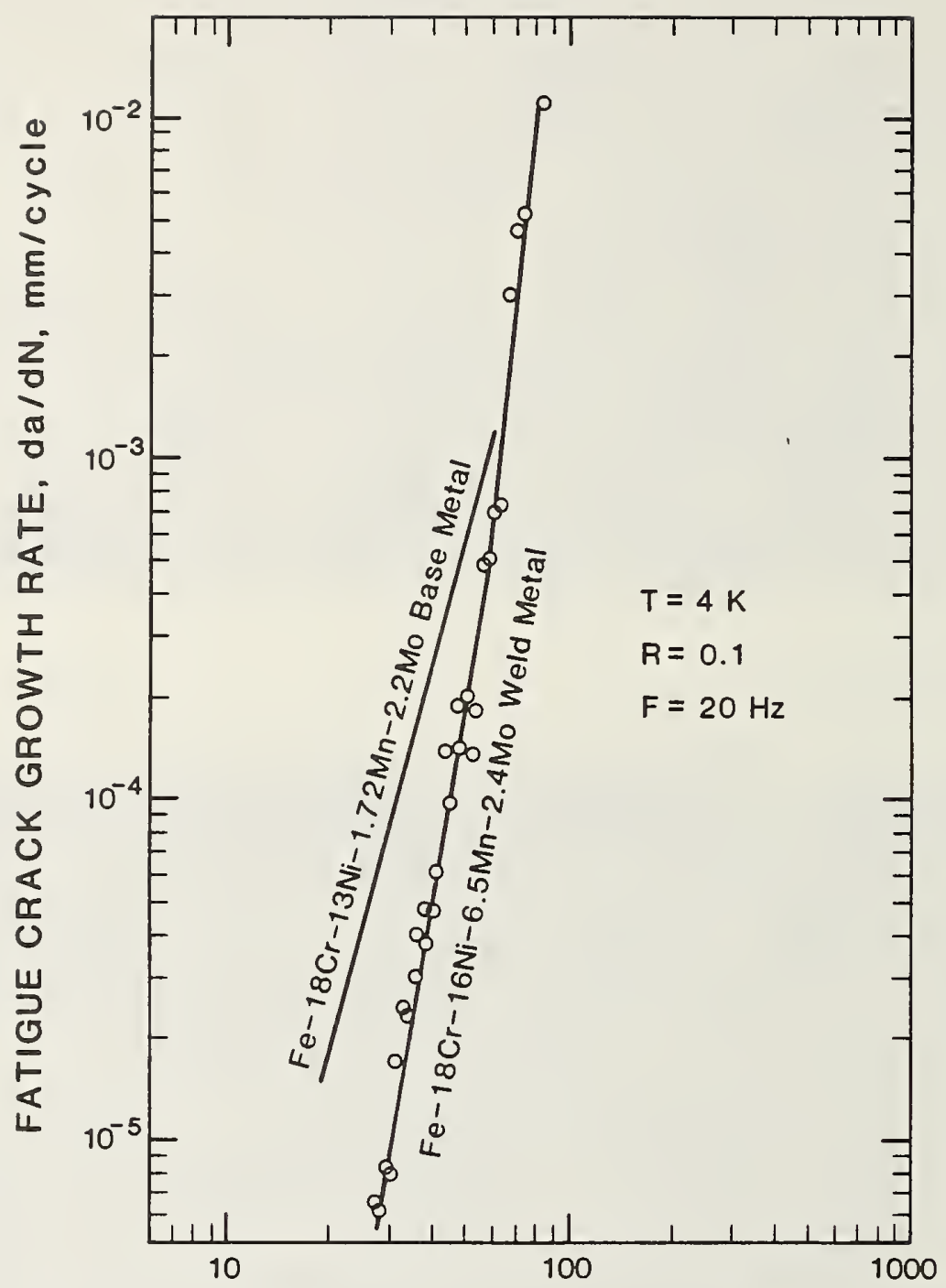

STRESS INTENSITY FACTOR RANGE, $\triangle \mathrm{K}, \mathrm{MPa} \cdot \mathrm{m}^{1 / 2}$

Figure 11. Fatigue crack growth rate data for the SMA weld compared with typical results for an AISI 316 austenitic stainless steel base metal. 
NONMETALLICS 



\section{NONMETALLICS PROGRAM}

LEADER: $\quad$ M. B. Kasen

CONTRIBUTORS: M. W. Austin, R. D. Kriz, H. M. Ledbetter, M. Lei

\section{OBJECTIVES}

- Measurement, modeling, and understanding of the properties of composites that enter essentially into the conception, design, construction, operation, and performance of magnetic-fusion-energy equipment

- In cooperation with industry, the establishment and refinement of cryogenic-grade specifications for insulating laminates and test methods for materials selection

\section{RESEARCH PAST YEAR (1985)}

- Finite element analysis to explain the influence of weave geometry in woven laminates on edge stress singularities

- Determination of Young's modulus and internal friction of a uniaxially fiber-reinforced composite

- Refinement of the methodology for producing and testing standard composite specimens to be used in cryogenic neutron irradiation studies

\section{RESEARCH THIS YEAR (1986)}

- Study of the relationship between damage and load-deformation behavior of woven composites at low temperatures for cyclic mechanical and thermal loads

- Study of the cryogenic neutron-radiation-induced degradation of the mechanical properties of four organic-matrix composite systems

- Development of a computer program to calculate the load-deformation behavior of metallic-nonmetallic laminate structures at low temperatures 




\title{
IRRADIATION EFFECTS ON ORGANIC INSULATORS ${ }^{*+}$
}

\author{
M. B. Kasen \\ Fracture and Deformation Division \\ National Bureau of Standards \\ Boulder, Colorado
}

The system for producing standard $3.2 \mathrm{~mm}(0.125$-in) diameter rod specimens discussed in previous reports ${ }^{1}$ has been further refined to permit the fabrication of both fiber-reinforced and neat-resin specimens from hot-melt resin systems. The method has been successfully used to produce very high quality specimens duplicating the G-11CR system and specimens from a variant of that system eliminating a boron-containing additive. We have also produced specimens from an epoxy system suitable for impregnation or potting operations and from a bismaleimide polyimide system. These materials will be used in the first irradiation program in the National Low Temperature Neutron Irradiation Facility (NLTNIF) reactor at Oak Ridge. We have refined the 4-K torsional shear test method for evaluating radiation degradation of the fibermatrix interface and have developed a method of quantitatively measuring changes in fracture energy as a function of radiation dose. Cooperative work with laboratories in Japan and England in this area is continuing and plans are being formulated for joint production, irradiation, and testing of specimens.

\section{OBJECTIVES}

The overall objective of this work is to contribute to development of organic insulators having the cryogenic neutron irradiation resistance required for MFE systems utilizing superconducting magnet confinement. The first objective is to develop a component data base from which the optimum components may be selected on the basis of performance versus cost. The second objective is to develop a design data base that will provide engineering values of the thermal, electrical, elastic, and mechanical properties of functional insulating laminates constructed with components selected from the component data base.

\footnotetext{
*Work supported in part by the Office of Fusion Energy, U.S. Department of Energy.

+To be published in "Eighth Annual Progress Report on Special Purpose Materials for Magnetically Confined Fusion Reactors," U.S. Department of Energy (1986).
} 
Specimen Development

As described in previous Annual Progress Reports, 1 the selected specimen configuration is a $3.2-\mathrm{mm}(0.125-\mathrm{in})$ diameter rod that can be produced either as neat (unreinforced) resin or as a uniaxial fiber-reinforced composite. Specimens can be cut to length, irradiated and tested without further machining.

The quality of specimens currently being produced is illustrated in Fig. 1. This quality fully meets the program objective of eliminating flaws as a complicating factor when evaluating the significance of specific material parameters on radiation induced mechanical property degradation. We have thus far produced the materials listed in Table 1.

The G-11CR material duplicates that of the commercial product and is intended to serve as a reference standard against which the performance of other materials can be compared. The $\mathrm{G}-11 \mathrm{CR}(\mathrm{M})$ modification eliminates the boror-containing component that serves as a cure accelerator and is expected to improve the neutron irradiation performance of this material. The Rutherford system was suggested by Dr. David Evans of the Rutherford Appleton Laboratories in England as a candidate for magnet applications requiring impregnation or potting operations. Each of these systems has been produced as neat-resin specimens and as specimens reinforced with 48 volume fraction ( $\mathrm{v} / \mathrm{O}$ ) of type E glass.

The chemical description of the selected polyimide system is 4,4:bismaleimidodiphenylmethane. Prior studies ${ }^{2}$ have indicated that laminates fabricated with a bismaleimide polyimide system having the chemical description poly-aminobismaleimide (Keramid 601) can provide substantially improved intrinsic radiation resistance as compared to that of the epoxies, but that such material has generally inferior mechanical properties--in particular, very low interlaminar shear strength. We include a different type of polyimide resin in the present program to determine if there exist significant differences in cryogenic irradiation performance among polyimides differing in chemical composition.

Specimen production follows the flow diagram given in Fig. 2. Blending of the G-11CR and $G-11 C R(M)$ resin systems was performed ultrasonically to eliminate the need for solvents and to prevent premature polymerization of the system. The setup illustrated in Fig. 3 permits two 406-mm (16-in) long reinforced specimens to be produced at the same time. Experience has shown that the critical operations are thorough degassing, thorough vacuum impregnation of the fibers, and curing under $420 \mathrm{kPa}$ ( $80 \mathrm{psi}$ ) of nitrogen gas pressure while maintaining a head of resin above the mold. It is also essential that the 3.2-mm $(0.125-$ in $)$ i.d. TFE tubing that forms the mold has a very smooth interior. 
It is anticipated that the majority of the radiation-induced damage will occur at the interface between the glass fiber and the resin matrix. Test methods sensitive to such degradation were therefore emphasized. Candidate methods are short-beam shear, torsional shear and longitudinal compression.

Development of the short-beam shear test method was described in previous Annual Reports. 1 While such a test appears useful, the complex stress state makes it difficult to quantify results. We therefore concentrated on developing apparatus and techniques for performing torsional shear tests at cryogenic temperatures. We also developed a test method that provides quantitative data on changes in fracture energy with changing radiation fluence. A compression test method compatible with the specimen design has already been developed. 3

\section{Torsional shear}

This method is attractive because, as applied to a uniaxially reinforced specimen, the symmetry causes the resolved shear stress at the fiber-matrix. interface to increase systematically with increasing angular rotation. For a given rotational angle, the magnitude of the shear component will be inversely proportional to the specimen gage length and proportional to the distance of the interface from the specimen centerline. As illustrated in Fig. 4(a), failure initiates at the specimen surface and progresses inward. The interfacial nature of the failure mode is evident in Fig. 4(b).

A typical torsional shear failure at $76 \mathrm{~K}$ is shown in Fig. 5(a). In most cases, seven to ten longitudinal cracks were observed. Some specimens burst open, revealing fiber bundles and indicating a lower integrity of the fiber-matrix interface. A typical 76-K load-deflection curve is illustrated in Fig. 5(b). Because dead weight loading was used, cracking was manifested as a series of discontinuous rotational displacements.

As illustrated in Fig. 6, the specimen, held in aluminum end caps, is inserted into a $12.7-\mathrm{mm}(0.5-$ in) diameter internally polished stainless steel tube and pinned at the bottom. The torsional load is applied by a $6.35-\mathrm{mm}$ (0.25-in) diameter stainless steel rod which mates with the upper end cap through a slot. In the developed version of this test method, the load will be monitored with a torsional load cell, while angular displacement will be monitored by a geared rotary potentiometer. A motor drive will provide a constant torsional displacement with time.

We investigated the feasibility of freezing the specimens into the end caps as an alternative to potting with epoxy. This would reduce testing time and cost and would permit recovery of the undamaged parts of the specimens for additional testing by other methods. It would also allow specimens to be periodically removed from the end caps during a test run for quantitative analysis of damage accumulation by dynamic modulus and damping techniques, should this be desired. We found that several types of aqueous slurries provided sufficient bond strength when frozen to allow the specimen to be brom ken, but progressive cracking of the bond within the end caps increased the 
effective gage section, complicating calculation of the torsional modulus. We solved this problem by incorporating a series of set screws into the end caps near the gage section, as illustrated in Fig. 5(a). Contact of these screws with the specimen prevented rotation and confined the failure to the gage section. This system will be used in all further torsional tests.

Table 2 summarizes ultimate strength values obtained during $76-\mathrm{K}$ torsional testing of neat-resin and reinforced specimens with materials 1 through 4 (Table 1). A somewhat greater coefficient of variability, CV, is found in neat-resin strength as compared to that of the reinforced materials. This is expected owing to the low strain to failure of the embrittled resins. Removal of the $\mathrm{BF}_{3} \mathrm{MEA}$ component had no significant effect on the strength of either unreinforced or reinforced $G^{-} 11 \mathrm{CR}$ materials. The Rutherford resin developed the highest intrinsic strength at $76 \mathrm{~K}$, but the lower strength of the reinforced product made with this resin, as compared with that of G-11CR, suggests a lower fiber-matrix bond integrity. The strength of the bismaleimide resin was similar to that of $\mathrm{G}-11 \mathrm{CR}$.

\section{Fracture energy}

Although mechanical tests provide useful information, the results are difficult to quantify. We therefore worked to develop a test method that provides information on the fracture energy, $G_{I c}$, of the reinforced rod-shape specimens as a function of changes in the specimen condition. The principle of the method is illustrated in Fig. 7(a). A razor blade is pressed $4 \mathrm{~mm}$ into the end of the specimen, causing a crack to propagate lengthwise down the specimen. The fracture energy, $G_{I c}$, can then be calculated by the equation:

$$
G_{I C}=0.01372 d^{3} E^{2} / x^{4}
$$

where $E$ is the Young's modulus, and $d, y$, and $x$ are as defined on $F$ ig. $7(a)$.*

Initial test results using the prototype fixture illustrated in Fig. 7 (b) are presented in Table 3. All specimens contained $48 \mathrm{v} / 0$ of type $\mathrm{E}$ glass. The 76-K toughness of the flexibilized resin specimen (Epon 828/Versamid 140) was found to be much higher than that of the standard G-11CR formulation. The Rutherford potting resin system was also slightly tougher than G-11CR at $76 \mathrm{~K}$. But cooling the Rutherford resin specimen to $76 \mathrm{~K}$ decreased its toughness to about $34 \%$ of its room temperature value. These changes are in the expected direction, and the derived $G_{I c}$ values are comparable to the $1.9-3.2 \mathrm{~kJ} \mathrm{~m}^{-2}$ values reported for the fracture energy of similar materials tested at room temperature by the double cantilever beam method. The test method therefore holds promise for quantitatively following the influence of 4-K irradiation on degradation of the matrix resin and of the fiber-matrix interface.

Equation (1) is based on the original work of obreimoff, 4 who developed a similar expression for evaluating the splitting strength of mica.

*The author acknowledges the contribution of $\mathrm{R}$. D. Kriz in the derivation of this equation. 
Barlow and windle 5 subsequently suggested that the basic method could be applied to determining the $G_{\text {Ic }}$ of uniaxially reinforced composite materials. However, their mathematical derivations assumed a geometry in which a thin layer was split off a block of material that remained undeformed. The derivation of eq. (1) differs in that the moment of inertia was calculated about the centroidal axis of a semicircular cross section to take into consideration the geometry of the present specimens. Also, obreimof ${ }^{4}$ defined the fracture energy, $Q$, as the energy release required to create one of the two new surfaces. This was equated to $G_{I c}$ by Barlow and Windle, 5 and we have followed this convention in deriving eq. (1) to be consistent with the previous authors. It should be noted, however, that this definition of fracture energy differs from the current convention in which the term $G_{I C}$ is used to define the energy required to create both surfaces. Thus, strictly speaking,

$$
Q=G_{I c} / 2=\text { (External Work - Strain Energy) } / 2 \text {. }
$$

\section{FISCAL YEAR 1986 PLANS}

We plan to cooperate with Dr. R. R. Coltman, Jr., ORNL, in performing a 4.2-K irradiation run in the NLTNIF reactor using the materials listed in Table 1. This will involve irradiating both unreinforced and reinforced specimens at several fluence levels. For this initial experiment, the specimens will be warmed to room temperature after irradiation and will be subsem quently cooled to $4.2 \mathrm{~K}$ for testing by short-beam shear and torsional shear. The fracture energy of the reinforced specimens will also be determined. A comparable series of specimens will be tested in the unirradiated condition. A total of 320 specimens will be used.

We shall continue cooperative work with the Institute of Science and Industrial Research, Osaka University, Japan. This group, headed by Prof. Toichi Okada, includes participants from Kyoto University Research Reactor Institute, the University of Osaka Prefecture, and the Hoxan Corporation. This group has developed procedures for producing standard specimens identical to those developed by NBS and is investigating the use of fourmpoint bending as a test methodology. ${ }^{6}$ They have investigated the unirradiated cryogenic performance of specimens reinforced with glass, graphite, silicon carbide, and aluminum oxide fibers, studying physical as well as mechanical properties. Their work has shown that aluminum oxiderreinforced epoxy material has the lowest integrated thermal conductivity of any composite material from $295 \mathrm{~K}$ to $4.2 \mathrm{~K} .7$ These data suggest that such material will be superior to glass-reinforced composite material for fabrication of efficient thermal standoff members in Dewar construction.

Prof. Okada has agreed to produce a series of specimens in Japan to be used in a second irradiation series. Following irradiation in the NLTNIF reactor, these specimens will be sent to NBS for testing and evaluation by personnel from Prof. Okada's laboratory.

Since the required specimens can now be obtained from Japan and possibly from England, we do not anticipate substantial additional specimen production at NBS. This will permit NBS to concentrate on the materials testing and analysis portion of the study. 
1. M. B. Kasen, "Materials and Test Methods," in Annual Progress Report on Special Purpose Materials for Magnetically Confined Fusion Reactors," DOE/ER-0113/3, pp. 48-52; May 1984; DOE/ER 0113/4, pp. 51<57; May 1985.

2. G. F. Hurley and R. R. Coltman, Jr., "Organic Materials for Fusion Reactor Applications," J. Nucl. Mater. 123 \& 124, 1327-1337 (1984).

3. R. E. Schramm and M. B. Kasen, "Cryogenic Mechanical Properties of Boron-, Graphite-, and Glass-reinforced Composites," Mater. Sci. Eng. 30, 197-204 (1977).

4. T. W. Obreimofi, "The Splitting Strength of Mica," Proc. Roy. Soc. A127, 290-297 (1930).

5. C. Y. Barlow and A. H. Windle, "Razor Blade Test for Composite Toughness," J. Mater. Sci. Lett. 4, 233-234 (1985).

6. T. Okada, S. Nishijima, H. Yamoaka, K. Miyata, Y. Tsuchida, K. Kuraoka and S. Namba, "Mechanical Properties of Unidirectionally Reinforced Materials," presented at ICMC Conference on Materials and Composites at Low Temperatures, Heidelberg, Germany (1984). To be published in Nonmetallic Materials and Composites at Low Temperatures - 3, Plenum Press, New York.

7. M. Takeno, S. Nishijima, T. Okada, K. Fujioka, Y. Tsuchida, and Y. Kuraoka", Thermal and Mechanical Properties of Advanced Composite Materials at Low Temperatures," presented at CEC/ICMC Conference, Boston, Mass., August 12 16, 1985. To be published in Advances in Cryogenic Engineering - Materials, vol. 32, Plenum Press, New York. 
Table 1. Experimental resin materials ${ }^{a}$

1) G-11 CR: Araldite 6010/Eporal/BF 3 MEA (100/36/4.2 pbw ${ }^{\text {b) }}$

2) G-11CR(M): Araldite 6010/Eporal (100/36 pbw)

3) Rutherford: Araldite 6010/XU205/D2000 (100/26/37 pbw) (potting)

4) Polyimide: XU292 developmental bismaleimide

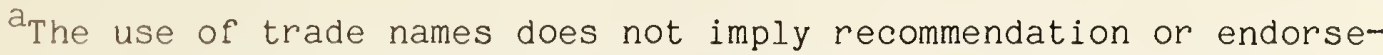
ment by the National Bureau of Standards, nor does it imply that the materials identified are necessarily the best available for the purpose.

parts by weight
}

Table 2. Torsional shear data, $76 \mathrm{~K}$ ( 5 specimens of each condition)

\begin{tabular}{|c|c|c|c|}
\hline Material no. & $\begin{array}{l}\text { Amount of } \\
\text { glass }(\mathrm{v} / \mathrm{O})\end{array}$ & $\begin{array}{l}\text { Ultimate } \\
\text { strength (MPa) }\end{array}$ & $\mathrm{CV}$ \\
\hline 1 & 48 & 154.4 & 0.086 \\
\hline 2 & 48 & 160.8 & 0.036 \\
\hline 3 & 48 & 148.6 & 0.078 \\
\hline 1 & none & 96.6 & 0.099 \\
\hline 2 & none & 98.3 & 0.253 \\
\hline 3 & none & 120.8 & 0.099 \\
\hline 4 & none & 94.7 & 0.190 \\
\hline
\end{tabular}


Table 3. Initial fracture strength. test results on E-glassreinforced specimens ( $48 \mathrm{v} / \mathrm{O})$

\begin{tabular}{lccc} 
Resin system & $\mathrm{T}(\mathrm{K})$ & $\mathrm{x}(\mathrm{mm})$ & $\mathrm{G}_{\mathrm{Ic}}\left(\mathrm{kJ} \cdot \mathrm{mm}^{-2}\right)$ \\
\hline Flexibilized epoxy & 76 & 6.0 & 2.09 \\
G-11CR & 76 & 9.0 & 0.41 \\
Rutherford epoxy & 76 & 8.5 & 0.52 \\
Rutherford epoxy & 295 & 6.5 & 1.52 \\
\hline
\end{tabular}

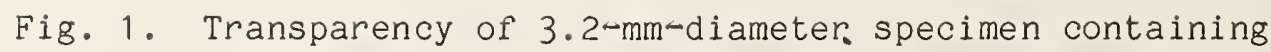
48 volume fraction of glass illustrates freedom from internal defects. Rutherford resin (see Table 1). 


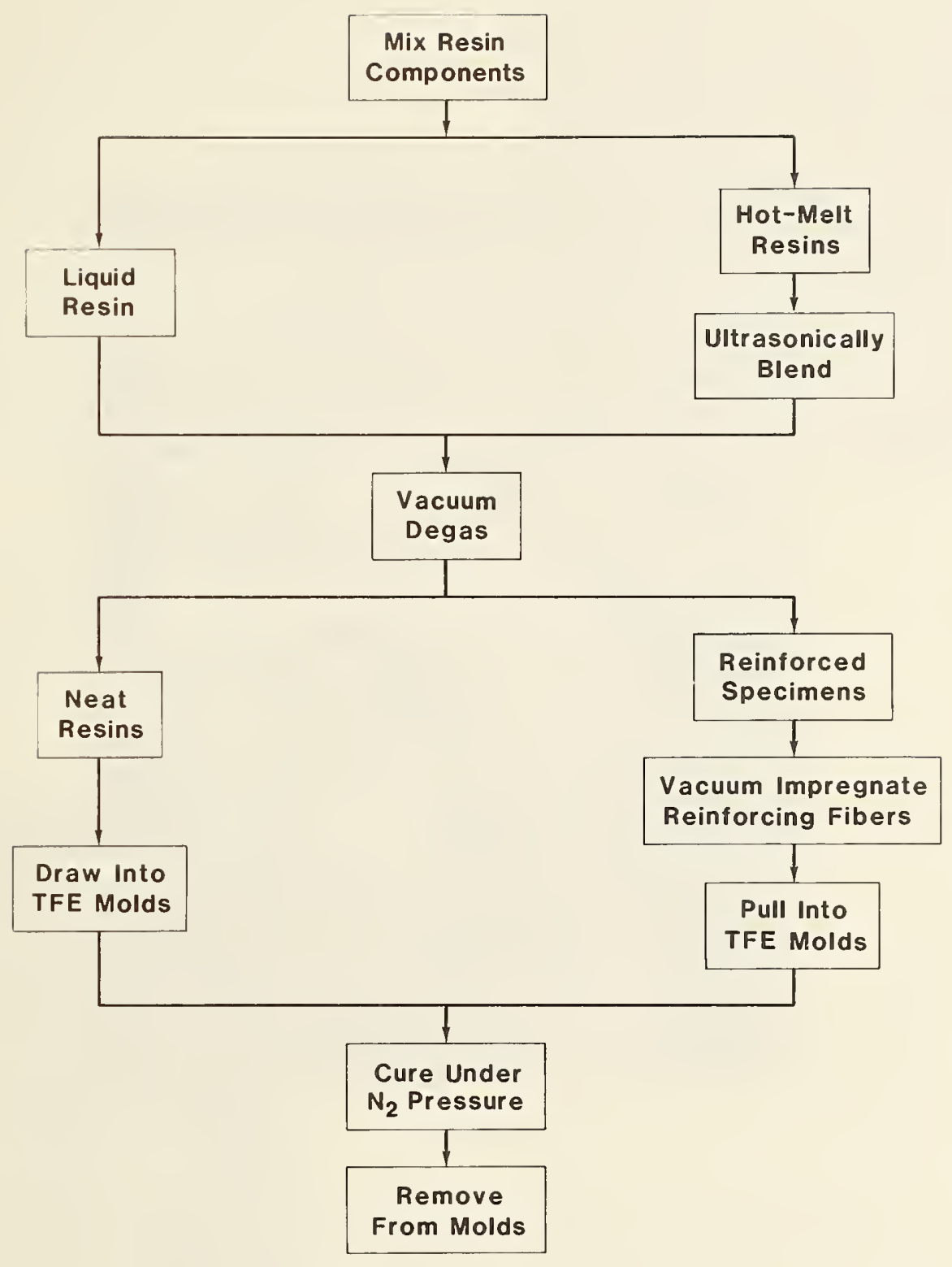

Fig. 2. Flow diagram for standard specimen production. 


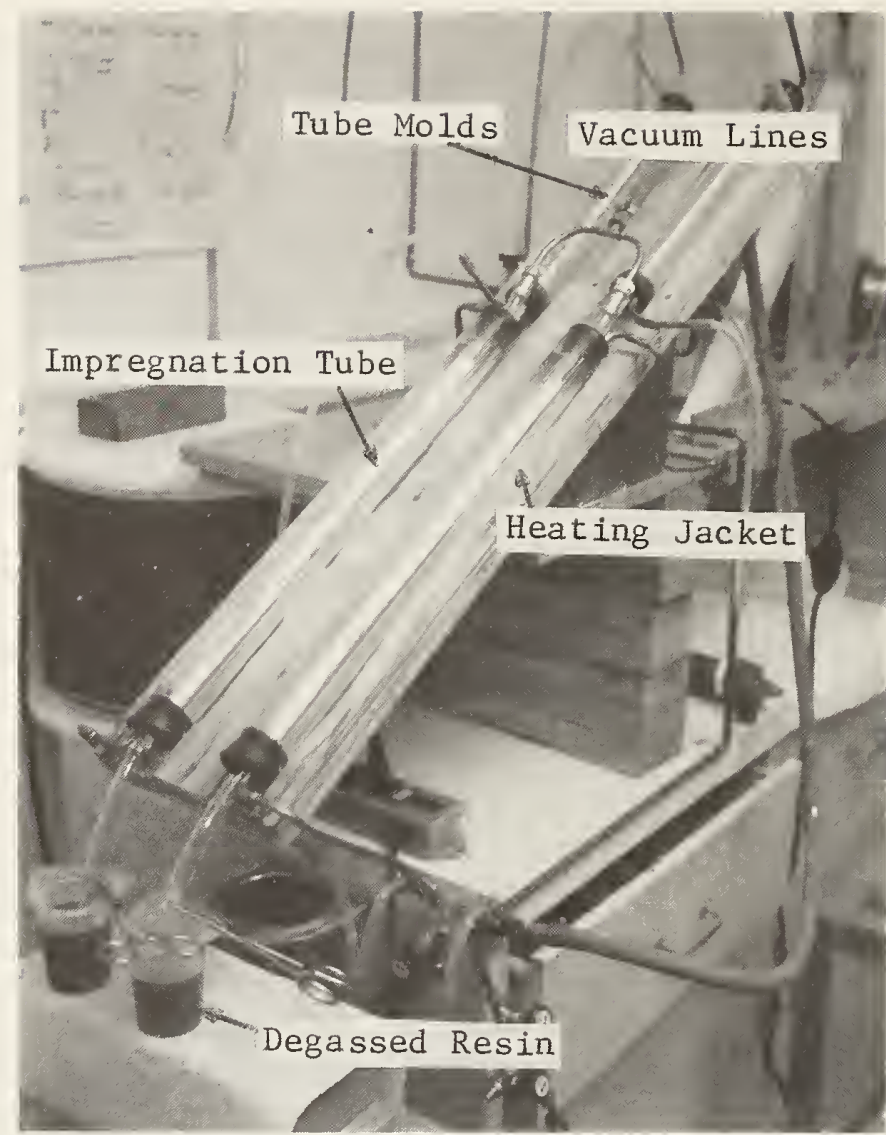

Fig. 3. Equipment for simultaneously producing two standard specimens. Illustration shows the setup prior to vacuum transfer of the degassed resin into the impregnation tubes. The impregnation tubes and the tube molds are maintained at $70-90^{\circ} \mathrm{C}$. 
(a)

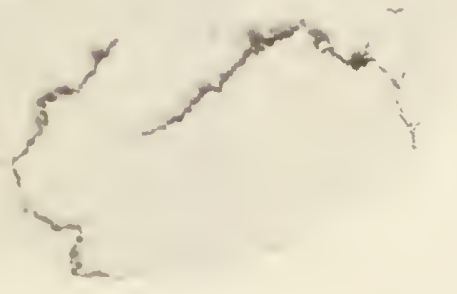

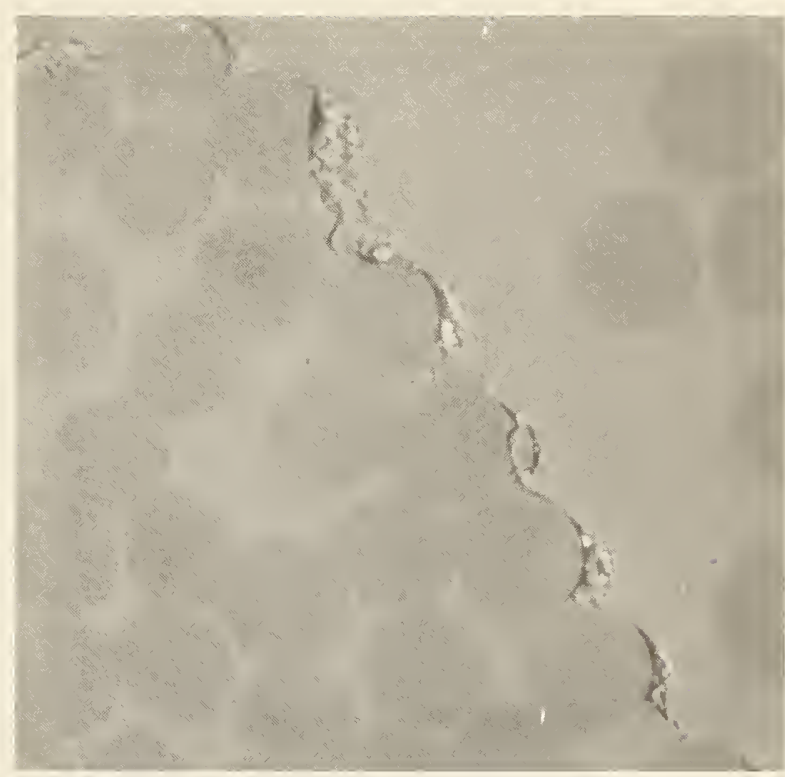

(b)

Fig. 4. (a): Cross section of a 3.2-mm-diameter, 48 v/o glass-reinforced specimen fractured in torsion, illustrating fracture initiation at the surface and propagation inward. (b): Magnified view, illustrating the interfacial failure mode.

(a)

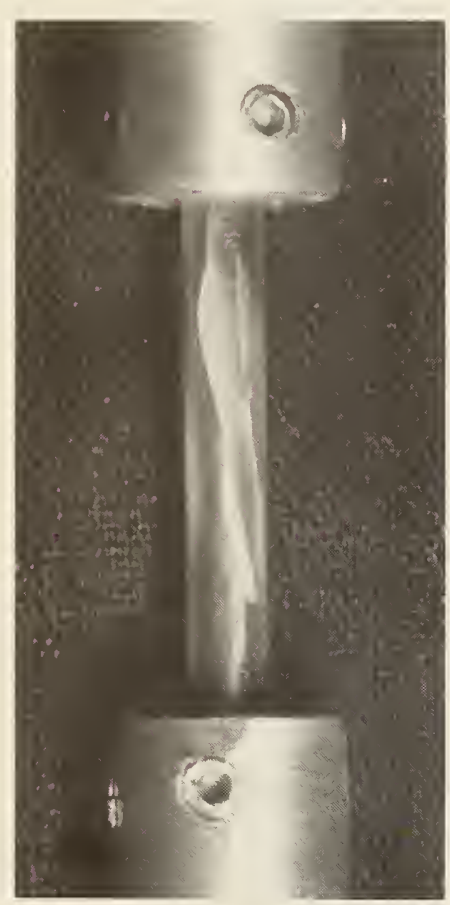

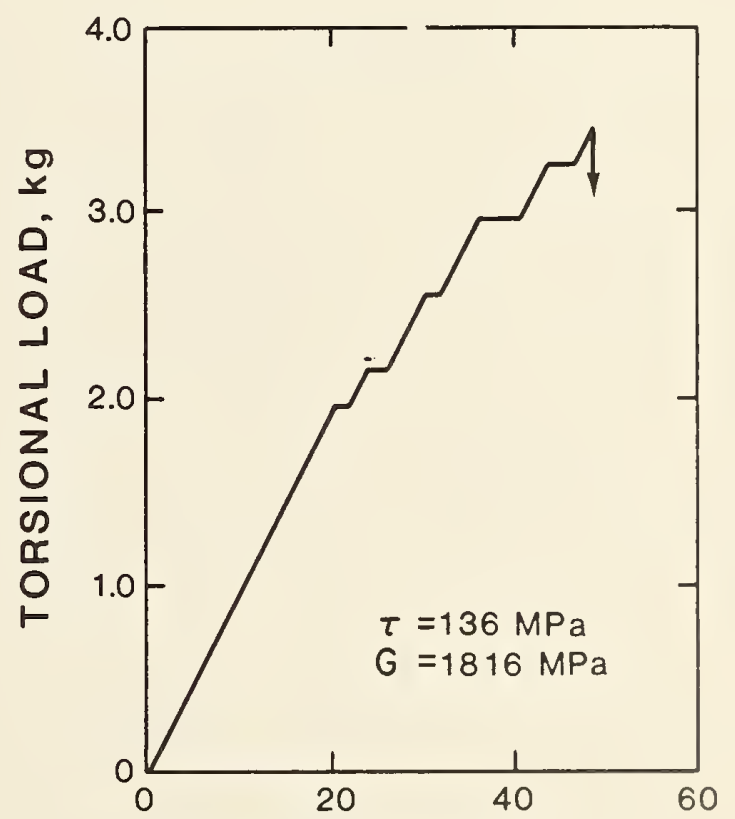

(b)
ANGULAR ROTATION, degrees

Fig. 5. (a): Torsional failure at $76 \mathrm{~K}$. Set screws prevent extension of the failure zone beyond the 19 - mm gage length. (b): Rotational displacements on load-displacement curve reflect sequential cracking during dead weight loading. 
Fig. 6. Schematic of the torsion test method. End caps and drive shaft are sized to permit free rotation at cryogenic temperatures.
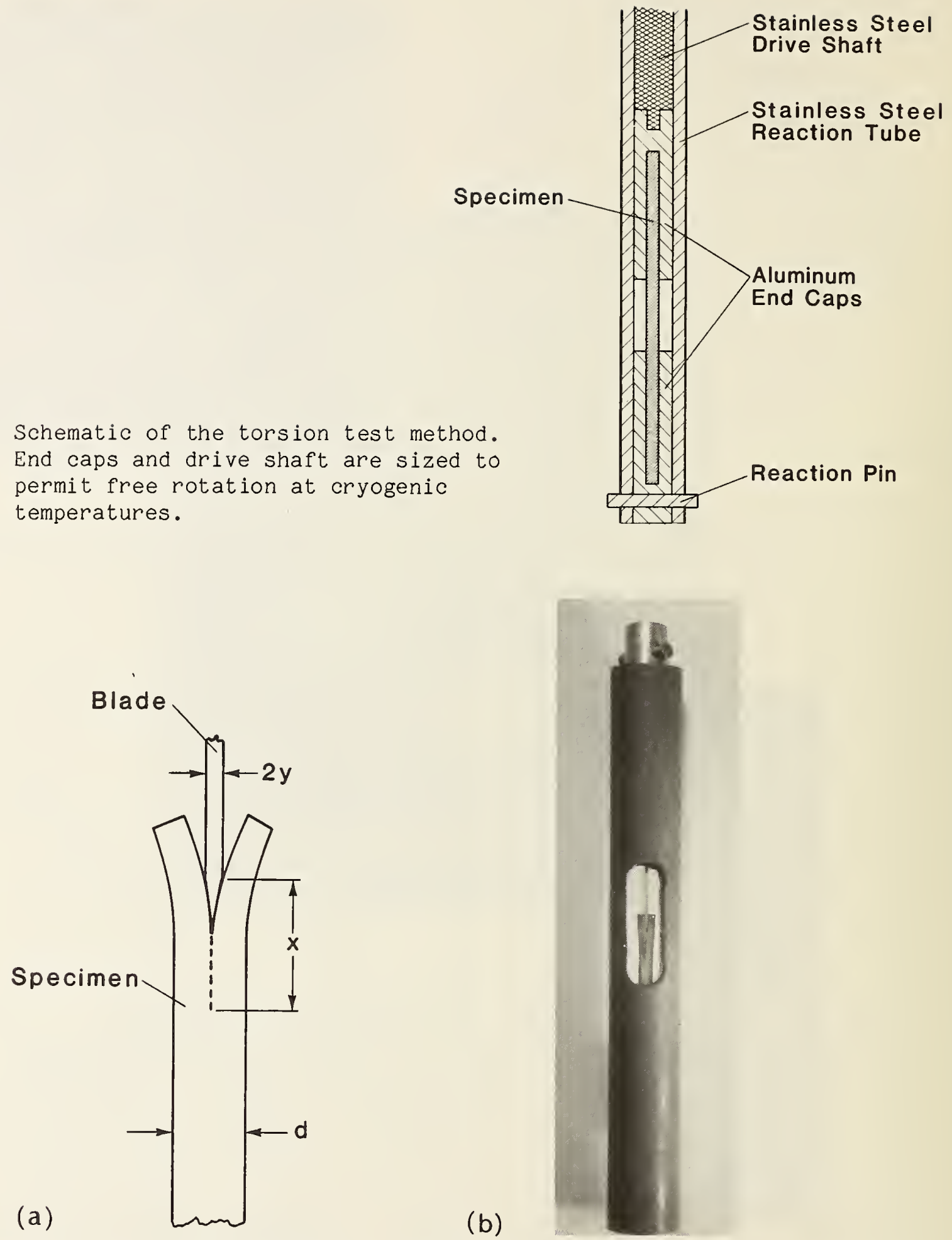

Fig. 7. (a): Schematic of fracture energy test method. Distance $x$ is from the shoulder of the blade to the end of the crack. Dimension $y$ is half the blade width. (b): Prototype fixture. Specimen is held in center-bored aluminum end cap; blade is attached to upper end cap containing a pin to limit penetration of the specimen to $4 \mathrm{~mm}$. Alignment tube is $9.5-\mathrm{mm}$ i.d. linen phenolic. 

SCREENING THE PERFORMANCE OF ORGANIC INSULATORS

UNDER CRYOGENIC NEUTRON IRRADIATION ${ }^{*+}$

Maurice B. Kasen and Robert B. Stoddard

Fracture and Deformation Division

National Bureau of Standards

Boulder, Colorado

\section{ABSTR ACT}

Specimens and test procedures are being developed for determining the significant parameters influencing resistance of organic insulators to neutron irradiation at $4 \mathrm{~K}$. The specimens are 3.2-mm-diameter rods of exceptionally high quality produced by a method allowing a large number of experimental variables to be evaluated. Flexural and torsional shear tests perfomed with these specimens indicate that such tests will be useful in studying cryogenic neutron irradiation damage to the fiber-matrix interface. Results of 76-K tests on unre inforced and glass-fiber reinforced epoxy and polyimide materials are presented.

\section{IN TRODUCTION}

A serious material shortcoming in building superconducting magnets for magnetic fusion energy (MFE) systems is believed to be the inability of conventional organic insulators to withstand the level of neutron irradiation to which they will be exposed in a functioning reactor. It is estimated that portions of the magnets must be exposed to a fluence level equivalent to 550 to $1000 \mathrm{MGy}$ ( $\mathrm{MGy}=10^{8}$ rads) if excessive shielding costs are to be avoided. Although it is technically feasible to fabricate magnets with much more radiation resistant inorganic materials, the cost may be prohibitive.

A facility providing irradiation conditions approximating those in an MFE reactor has thus far been unavailable. Fortunately, this will be rectified with the coming on line of the National Low Temperature Neutron Irradiation Facility (NLTNIF) currently under construction at the Oak Ridge National Laboratory. This facility will provide the desired radiation spectrum at fluence levels that will allow the required experiments to be performed in a relatively short period of time. The comparatively large irradiation volume and associated test chamber will permit simultaneous irradiation of a large number of specimens as well as in-situ postirradiation testing at $4.2 \mathrm{~K}$ wi thout warmup.

*Publication of NBS, not subject to copyright.

+ To be published in Advances in Cryogenic in Cryogenic Engineering-Materials, volume 32 . 
In the United States, the main research effort involves cooperative research between individuals at the National Bureau of Standards, the Oak Ridge National Laboratory, the Los Alamos National Laboratory, and the Massachusetts Institute of Technology. Within this group, NBS has the primary responsibility for providing well-characterized research materials, conducting pre- and postirradiation mechanioal test programs, and determining the influence of irradiation on the material failure mode. Informal but active cooperation in this research has been established with individuals at Osaka University in Japan and at the Rutherford Appleton Laboratories in England.

\section{EXPERIMENTAL PROGRAM}

Our primary objective is to determine the significant parameters influencing the degradation of glass-fiber reinforced polymer insulators during neutron irradiation at $4.2 \mathrm{~K}$. Since many parameters must be evaluated, it is necessary to establish an efficient, systematic screening program.

\section{Specimen Selection and Preparation}

Differential radiation heating of the specimen cross section, the need to minimize residual radioactivity, and the many variables that must be studied dictate the need for small, high-quality, well-characterized specimens. Surface defects introduced by machining should be eliminated. The same specimen configuration must be available in a variety of unreinforced (neat) resin specimens and as specimens reinforced with any desired type and amount of glass fiber. The specimen should lend itself to testing in a variety of modes. There is no commercial source of materials meeting these requirements. We have therefore developed in-house capability of producing the required specimens.

We have selected the rod-shaped specimens illustrated in Fig. $1($ a) as best meeting these requirements. Glass-fiber bundles are vacuum impregnated with well-degassed resin pulled into a 300-mm long, 3.2-mm i.d. smooth-bore TFE mold and cured under approximately 420-kPa nitrogen gas pressure. Neat resin specimens are produced by vacuum drawing degassed resin into the same molds. As illustrated in Fig. 1(b), specimen quality is very high. Fiber volume fractions can be calculated from knowledge of the tube dimensions and glass density. Resin chemistry, cure state, fiber chemistry, and fiber finish can be altered as desired for a given experiment. The specimen surface finish is excellent, and the coefficient of variability in diameter anong rods produced with a given mold is on the order of 0.001 to 0.003 , indicating excellent dimensional reproducibility. These specimens can be cut to length and directly tested.

Some polymer systems of interest require blending of a liquid resin with a solid cure agent. In industrial practice, this is facilitated by the addition of solvents, but this cannot be done with the NBS production method because evolution of the solvents would cause porosity during curing in the closed mold. We avoid this problem by the ultrasonic blending of such systems. 2 
This method was used to produce unreinforced and type E glass-fiber inforced specimens with the resin systems listed in Table 1. Materials 1 through 4 will be used in the initial radiation program to be conducted in the NLTNIF reactor at Oak Ridge. The G-11CR system (material 1) provides a baseline of material performance. However, this basic system contains $\mathrm{BF}_{3} \mathrm{MEA}$ as an accelerator to shorten the cure cycle. Since boron has a high neutron capture cross section, this addition may be contributing to excessive degradation of the resin. We therefore produced a variant of the G-11CR formulation without this addition to evaluate this parameter (material 2). An impregnation resin (material 3) was included in response to suggestions made at the 1984 NBS/DOE workshop that such a system would be of value to magnet fabricators. The proprietary bismaleimide polyimide system (material 4) represents the state-of-the-art in advanced resin design for this type of material. The bisphenol A/polyamide system (material 5) is a simple system used during the development stage of the program and will not be included in the radiation study.

Test Method Development

Evidence suggests that the primary cause of degradation in the mechanical properties of reinforced insulators will be radiation-induced damage to the interface between the fiber and the polymer matrix. 3,4 We therefore concentrate on developing test methods that are sensitive to such damage. Primary candidates are short-beam shear and torsional shear tests.

The fixture used for short-beam shear tests is similar to a conventional three-point fixture for apparent interlaminar shear strength tests, differing primarily in contouring the supports and the loading nose to accommodate round specimens. At the proper span/depth ratio, this test produces an essentially mode-II type loading in which the shear stress is resolved parallel to the fiber direction. Required specimen length is only $15 \mathrm{~mm}$ for a span/depth ratio of 3.0 , making it very economical of material. Typical load-time curves produced at $76 \mathrm{~K}$ and $295 \mathrm{~K}$ by th is test method are shown in Fig. 2. The load drops appearing on the $76-\mathrm{K}$ curve reflect the onset of consecutive shear failures with increasing stress. Continuous bending over of the $295 \mathrm{~K}$ curve is attributed to the high room temperature ductility of the bisphenol A/polyimide resin system.

A typical 76-K shear failure is illustrated in Fig. 3. Narrow shear bands initially progressed into the specimen in an inverted $V$ configuration from the point of contact with the loading nose. These bands subsequently acted as nuclei for massive shear failures that propagated along the specimen length, giving rise to the observed load drops.

Although the flexural shear test appears potentially useful, the change in specimen shape during deformation introduces failure modes which are a combination of tension, compression and shear. This makes it difficult to quantify the results. An alternative is to conduct tests in torsion. Such a test in a uniaxially reinforced composite also produces a combined shear, tension and compression loading on the interface, but in this case the symmetry of deformation simplifies calculation of the various stress gradients and permits the shear component of the stress to be isolated. 
The appearance of $76-\mathrm{K}$ failures produced by applying dead-weight torsional loading to unreinforced and to glass-fiber reinforced specimens bonded into aluminum end caps is illustrated in Fig. 4(a-b). The unreinforced specimens developed typical $45^{\circ}$ shear failures. In most cases, seven to ten longitudinal cracks were observed in the reinforced specimens. But some specimens burst open, revealing individual fiber bundles, indicating a lower integrity of the fiber-matrix interface. A typical load-deflection curve obtained in torsion at $76 \mathrm{~K}$ is shown in Fig. 5. Under dead weight loading, cracks are manifested as sudden fumps in displacement.

We investigated the feasibility of freezing the specimens into the end caps as an alternative to potting with epoxy. This would permit recovery of the undamaged parts of the specimens for additional testing by other methods. It would also allow specimens to be periodically removed from the end caps during a test run for quantitative analysis of damage accumulation by dynamic modulus and damping techniques. Although this approach was found to be feasible using several types of aqueous slurries, it was also found that specimens prepared in this way might develop progressive cracking of the bond between the specimen and the end cap from the gage section into the gripped portion as the torsional load increased. Some of the displacement jumps in Fig. 5 may reflect such cracking. This approach to the test method is undergoing further development.

\section{Preliminary Test Results}

A series of flexural shear tests was conducted with the bisphenol A/polyamide material (material 5) at $76 \mathrm{~K}$. Five specimens each from two rods containing either 48 or 58 v/o type $E$ glass were tested at each temperature at a span/depth ratio of 3.0 . The data, summarized in Table 2 , reflect the stress required to initiate the first massive longitudinal shear failure (first load drop). The low coefficients of variability indicate good consistency from specimen to specimen and between specimens from different rods. No significant difference in shear strength was noted between the rods of differing fiber content. It is probable that this reflects a maximum in shear strength in the vicinity of 50 to $60 \mathrm{v} / 0$ fiber content. At very high fiber content there is insufficient resin to ensure fiber separation.

Torsional tests were conducted at $76 \mathrm{~K}$ with materials 1 through 4 (Table 1). The ultimate strength values are summarized in Table 3. A somewhat greater variability was found in the neat resin strength as compared with that of the reinforced materials. This is expected owing to the low strain to failure of the embrittled resins. Variability among the reinforced materials was slightly higher than for the flexural tests, but still reasonable. Removal of the $\mathrm{BF}_{3} \mathrm{MEA}$ component had no significant influence on the strength of either the unreinforced or reinforced $G-11 \mathrm{CR}$ materials. The Rutherford resin developed the highest intrinsic strength at $76 \mathrm{~K}$, but the lower strength of the reinforced product made wi th this resin, as compared with that of $\mathrm{G}-11 \mathrm{CR}$, indicates a lower fiber-matrix bond integrity. The strength of the polyimide resin was about that of G-11CR. 
These tests appear to be useful in characterizing cryogenic neutron irradiation damage to the various types of materials that will be evaluated during this program.

\section{ACKN OWLEDGMENTS}

This work is supported by the Office of Fusion Energy, U.S. Department of Energy, Dr. Marvin Cohen, Project Manager.

\section{REFERENCES}

1. G. F. Hurley and R. R. Coltman, Organic materials for fusion reactor applications, J. Nucl. Mater. 123 \& 124:1327-1337 (1984).

2. W. T. Hodges and T.L.St. Clair, "Ultrasonic Mixing of Epoxy Curing Agents," Technical Memorandum 85643, NASA Langley Research Center, Hampton, Virginia (1983).

3. S. Egusa, M. A. Kirk, R. C. Birtcher, M. Hagiwara, and S. Kawanishi, Irradiation effects on the mechanical properties of composite organic insulators, Nucl. Phys. Methods Phys. B229:610-616 (1984).

4. A. Udagawa, S. Kawanishi, S. Egusa, and M. Hagiwara, Radiation induced debonding of matrix-interface in organic composite materials, J.Mat. Sci. Lett. 3:68-70 (1984).

Table 1. Experimental Resin Materials
1) Standard G-11CR epoxy system
2) Standard G-IICR epoxy without $\mathrm{BF}_{3} \mathrm{MEA}$ accelerator
3) Rutherford bisphenol A epoxy impregnating resin
4) Proprietary bismaleimide polyimide
5) Bisphenol A epoxy with polyamide cure

Table 2. Flexural Shear Data, Material 5, at $76 \mathrm{~K}$ (10 Specimens of Each Condition)

\begin{tabular}{cccc}
\hline \multirow{2}{*}{ V/O Glass } & Rod No. & $\begin{array}{l}\text { Ultimate } \\
\text { Strength (MPa) }\end{array}$ & CV \\
\hline \multirow{2}{*}{48} & 1 & 23.6 & 0.042 \\
& 2 & $\frac{23.0}{23.3}$ & $\frac{0.087}{0.064}$ \\
& & 23.3 & 0.047 \\
& 1 & $\frac{23.6}{23.5}$ & $\frac{0.013}{0.034}$ \\
\hline
\end{tabular}


Table 3. Torsional Shear Data, $76 \mathrm{~K}$ ( 5 Specimens of Each Condition)

\begin{tabular}{cccc}
\hline Material No. & V/O Glass & $\begin{array}{c}\text { Ultimate } \\
\text { Strength (MPa) }\end{array}$ & CV \\
\hline 1 & 58 & 158.4 & 0.086 \\
2 & 58 & 160.8 & 0.036 \\
3 & 58 & 148.6 & 0.078 \\
1 & none & 96.6 & 0.099 \\
2 & none & 93.3 & 0.253 \\
3 & none & 120.8 & 0.099 \\
4 & none & 94.7 & 0.190
\end{tabular}

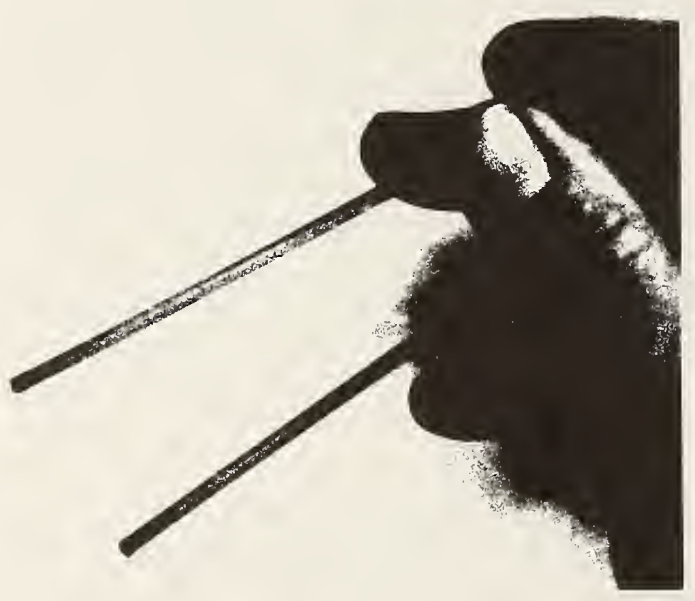

(a)

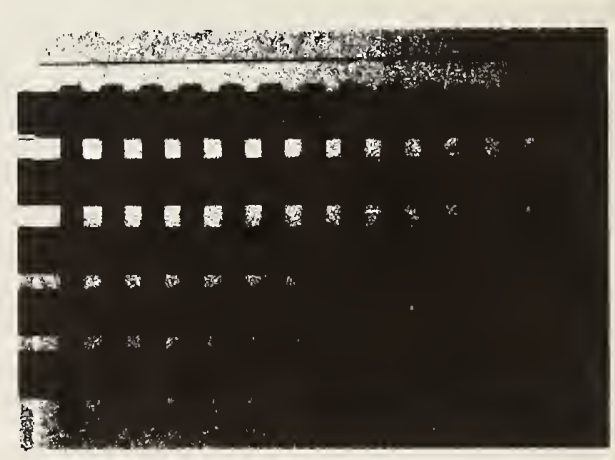

(b)

Fig. 1. (a) Typical 3.2-mm-diameter roc specimens. (b) An indication of the rod quality as revealed by its transparency. Top to bottom in (b) are neat polyimide, reinforced $G-11 \mathrm{CR}$, neat $\mathrm{G}-11 \mathrm{CR}$, reinforced Rutherford resin, and neat Rutherford resin. Reinforced specimens have 58 v/o glass content. 


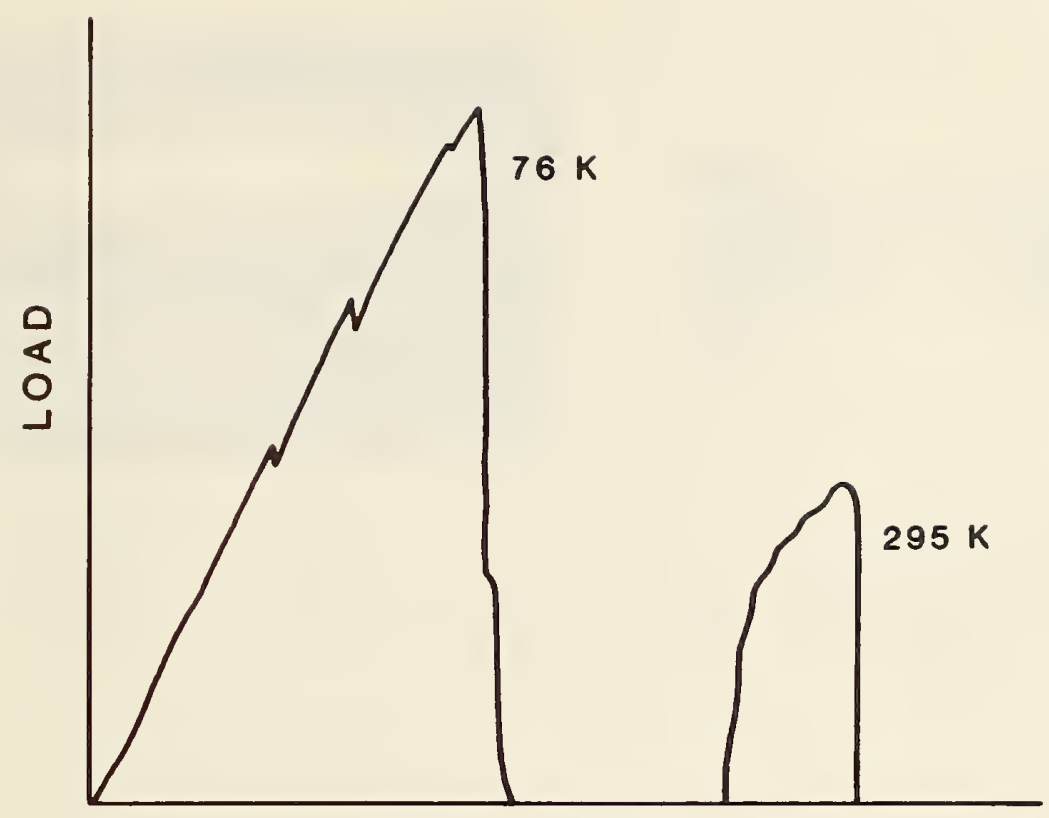

TIME

Fig. 2. Typical load-time curves obtained during flexural shear tests. Serrations at $76 \mathrm{~K}$ indicate onset of longitudinal shear.

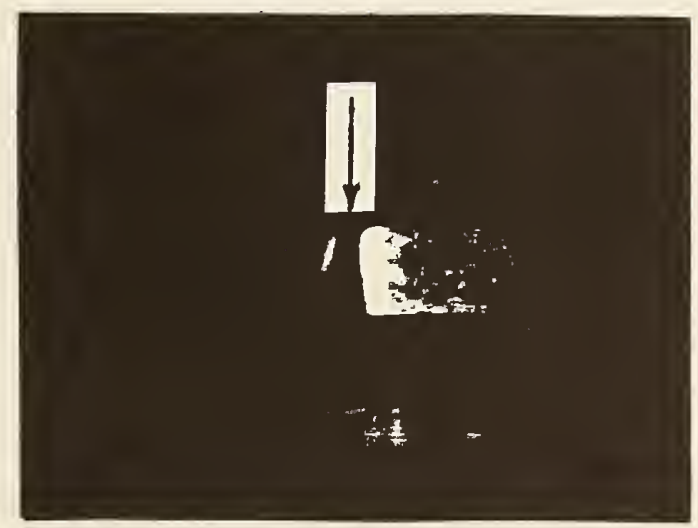

rig. 3. Typical longitudinal shear failure at $76 \mathrm{~K}$. Arrow indicates the point of contact of the loading nose. Shear bands have propagated into the specimen, forming an inverted $V$ and acting as the nucleating point for massive longitudinal shear fallure. 


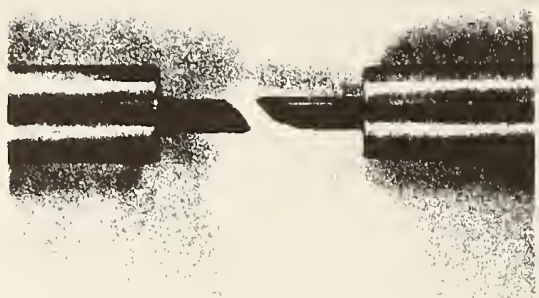

(a)

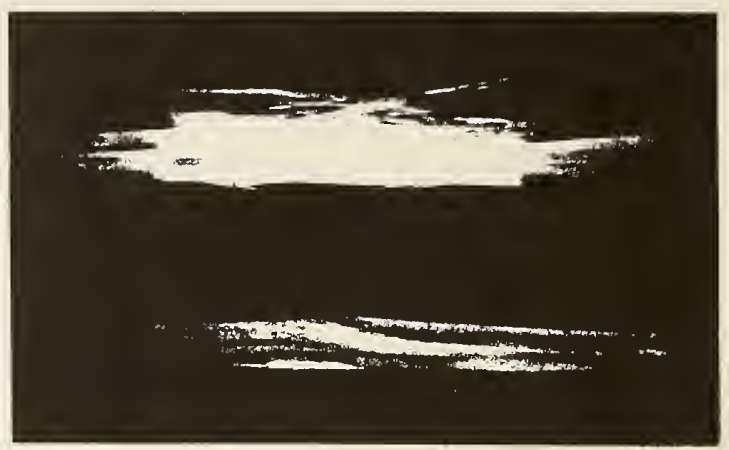

(b)

Fig. 4. (a) Typical 76-K torsional failure in an unreinforced resin specimen illustrating the method of holding in aluminum end caps. (b) Typical 76-K torsional failures in glass-reinforced Rutherford resin system (material 3 , Table 1 ).

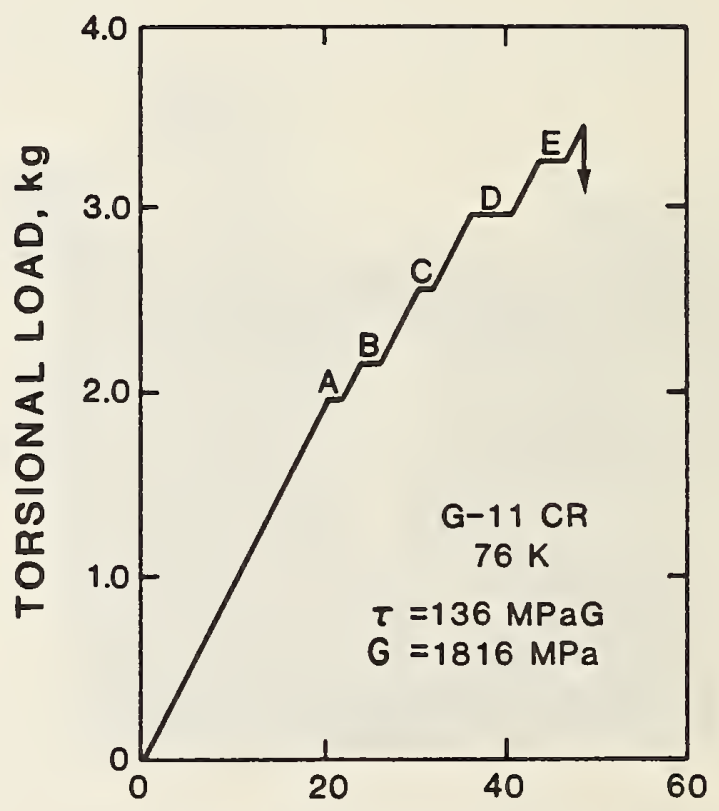

ANGULAR ROTATION, degrees

Fig. 5. Torsional load-deflection curve obtained at $76 \mathrm{~K}$ illustrating sequential interfacial crack development $(A-E)$. 

Young modulus and internal friction of a fiber-reinforced composite

\author{
H. M. Ledbetter, Ming Lei, and M. W. Austin \\ Fracture and Deformation Division, Institute for Materials Science and Engineering, \\ National Bureau of Standards, Boulder, Colorado 80303
}

(Received 28 August 1985; accepted for publication 3 December 1985)

By a kilohertz-frequency resonance method we determined the Young modulus and internal friction of a uniaxially fiber-reinforced composite. The composite comprised glass fibers in an epoxy-resin matrix. We studied three fiber contents: 0,41 , and 49 vol \%. The Young modulus fit a linear rule of mixture. The internal friction fit a classical free-damped-oscillator model where one assumes a linear rule of mixture for three quantities: mass, force constant, and mechanicalresistance constant.

\section{INTRODUCTION}

Glass-fiber epoxy-matrix composites enjoy many uses because they possess special properties. One can tailor many of the physical and mechanical properties for a particular application by controlling fiber orientation and fiber volume fraction. As composites increasingly replace conventional materials, we see strong needs to optimize composite properties. This means understanding the relationships between macroscopic properties and microscopic properties. To use composites effectively, we must explain and predict their properties. Because composites show such complexity, so many variables, usual empirical methods fail to produce the necessary understanding. We believe such understanding will arise only through careful property measurements combined with careful modeling.

The present study considers measurements and modeling of some physical properties of an eposy resin reinforced with continuous uniaxial glass fibers. We considered three glass-fiber volume fractions: $0,0.41$, and 0.49 . A physical property of a composite material depends mainly on three ingredients: matrix property, inclusion property, and phase geometry. Phase geometry includes many variables: volume fraction, inclusion shape, inclusion orientation, inclusion size, and inclusion distribution. For some composites, especially at higher temperatures, the inclusion-matrix interface affects a physical property.

The present study considers two strongly related physical properties: elastic constants and internal friction. Especially, we focus on Young modulus $E$ and internal friction $Q^{-1}$ determined in rod-shaped specimens in a Young-modulus (extensional-wave) mode. $E$ and $Q^{-1}$ relate to the real and imaginary parts of the elastic-stiffness tensor.

Elastic constants enter many aspects of composite-material behavior: stiffness-weight ratio, load-deflection, elastic instability, thermoelastic stress, residual stress, sound-wave velocities, material characterization, relationship to other physical properties (for example, thermal expansivity and specific heat), plastic deformation, theoretical strength, and nondestructive evaluation.

Internal friction of composites relates to many of the above phenomena. In addition, it relates especially to structural damping and to detection of premonitory failure as manifested in cracking, debonding, and delamination.
Besides measuring these two physical properties, we modeled their depencencies on volume fraction. For the Young modulus, especially the Young modulus in the fiber direction $E_{3}$, a plethora of good models and model-measurement comparisons exist. $E_{3}$ represents probably the best understood composite-material elastic constant. It yields easily to various measurement methods, and it usually follows closely a linear rule of mixture. Not so for internal friction $Q^{-1}$. Although considered extensively from an engineeringdesign viewpoint, the systematics of $Q^{-1}$ for composites remain uncertain. Here we consider principally how $E_{3}$ and the associated $Q^{-1}$ depend on volume fraction of reinforcing fiber.

\section{EXPERIMENT}

\section{A. Materials}

Composites were made at NBS using vacuum-impregnation methods described by Kasen. ${ }^{1}$ The manufacturing method yielded $3-\mathrm{mm}$-diam cylinders up to $30 \mathrm{~cm}$ long. Except for cutting to length, we measured these as-received. The matrix material consisted of a commercial epoxide resin formulated for use in a low-temperature radiation environment. The reinforcing phase consisted of tows of commercial glass fibers $7 \mu \mathrm{m}$ in diameter with a reported mass density of $2.60 \mathrm{~g} / \mathrm{cm}^{3}$ and Young modulus of $72.4 \mathrm{GPa}$. Figure 1 shows a photomicrograph of the $41 \%$ glass composite. Table I contains the mass densities of all three studied materials. Fiber volume fraction was determined from three parameters: glass mass, glass mass density, and mold volume.

\section{B. Measurements}

Determining Young modulus $E$ required measuring the sound velocity $v$ and the mass density $\rho$, and using the relationship

$$
E=\rho v^{2}=\rho f_{s}^{2} \lambda^{2},
$$

where $f_{s}$ denotes specimen resonance frequency and $\lambda$ denotes resonance wave length. At half-wave resonance, $\lambda=2 l_{s}$ (where $l_{s}$ denotes specimen length) and

$$
E=4 \rho f_{s}^{2} l_{s}^{2} \text {. }
$$

A Marx ${ }^{2.3}$ oscillator yielded the experimental resonance frequency according to 


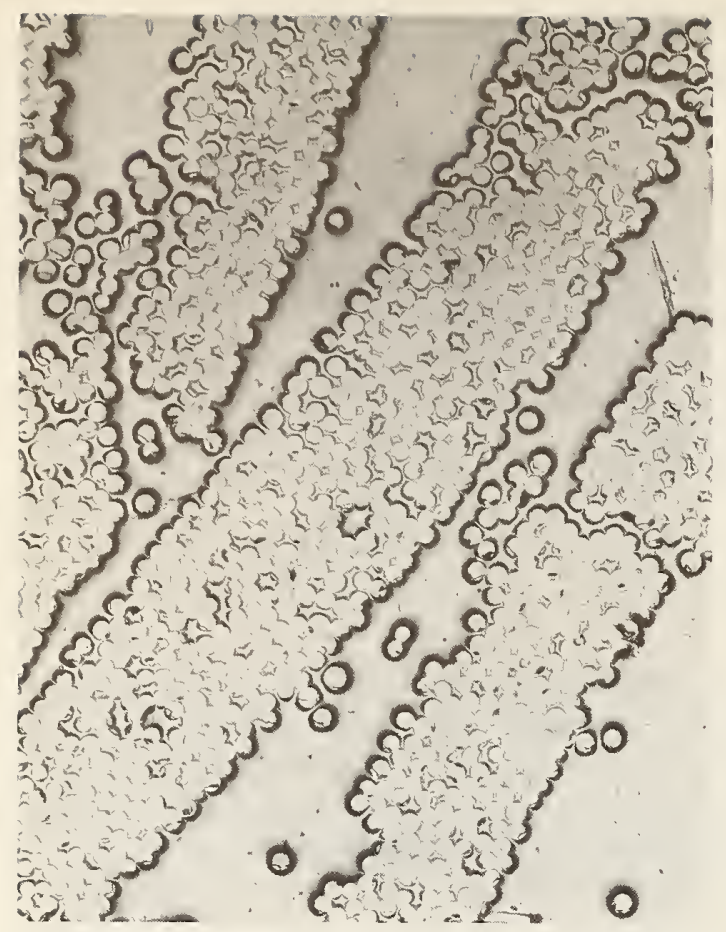

FIG. 1. Photomicrograph of studied composite transverse to uniaxial glassfiber bundles in an epoxy matrix. Fiber diameter equals $7 \mu \mathrm{m}$. Nonhomogeous fiber distribution results from fiber bundles used in manufacture.

$$
m_{o} f_{o}^{2}=\sum_{i} m_{i} f_{i}^{2}
$$

where $m$ denotes mass, $o$ denotes the complete oscillator, and $i$ denotes oscillator components: quartz-crystal driver, quartz-crystal gage, and specimen. It follows simply from Eq. (3) that

$$
f_{s}^{2}=f_{o}^{2}+\left(f_{o}^{2}-f_{q}^{2}\right) m_{q} / m_{s},
$$

where subscript $q$ denotes quartz crystals. The quartz-crystal length fixes $f_{q}$. A maximum voltage $V_{g}$, corresponding to a maximum strain amplitude at the gage-crystal midpoint, detects $f_{o}$. Sweeping frequency $f_{q}$ reveals the voltage maximum. Extensional elastic waves were launched along the rod axis by using $-18.5^{\circ} X$-cut quartz crystals.

For a sharp, Lorentzian resonance peak the composite oscillator's internal friction $Q_{0}^{-1}$ is

$$
Q_{o}^{-1}=\left(f_{2}-f_{1}\right) / f_{o},
$$

the resonance-peak width at $1 / \sqrt{2}$ of maximum in a strainversus-frequency plot where strain is proportional to $V_{g}$. Equation (5) holds for $Q^{-1}$ up to 0.1 or 0.2 . Experimentally one observes $M^{*}$, the modulus in phase with strain. But one

TABLE I. Measured properties of glass/epoxy composites.

\begin{tabular}{lccccc}
\hline \multicolumn{1}{c}{$c$} & $\begin{array}{c}E_{3} \\
(\mathrm{GPa})\end{array}$ & $\begin{array}{c}Q^{-1} \\
\left(10^{-3}\right)\end{array}$ & $\begin{array}{c}\rho \\
\left(\mathrm{g} / \mathrm{cm}^{3}\right)\end{array}$ & $\begin{array}{c}f_{3} \\
(\mathrm{kHz})\end{array}$ & $\begin{array}{c}l_{s} \\
(\mathrm{~cm})\end{array}$ \\
\hline 0.0 & 3.114 & 75.6 & 1.115 & 30.47 & 2.694 \\
0.41 & 32.18 & 6.15 & 1.654 & 89.03 & 2.477 \\
0.49 & 39.12 & 4.57 & 1.852 & 99.94 & 2.294 \\
\hline
\end{tabular}

usually seeks $M_{\text {real }}$, the usually more-relevant storage modulus. For zero internal friction, $M_{\text {real }}=M^{*}$.

Similar to Eq. (3),

$$
m_{o} Q_{o}^{-1}=\sum_{i} m_{i} Q_{i}^{-1}
$$

Thus, a relationship similar to Eq. (4) yields the specimen's internal friction:

$$
Q_{s}^{-1}=Q_{o}^{-1}+\left(Q_{o}^{-1}-Q_{q}^{-1}\right) m_{q} / m_{s} .
$$

The above relationships apply only near resonance, when

$$
f_{s} \cong f_{q} \cong f_{o} \text {. }
$$

Figures 2 and 3 show the errors arising from departures from Eq. (8), expressed as a departure from $f_{q} / f_{s}=1$. In Fig. 2, the Young-modulus measurements are fit to

$$
E=a+b x+c x^{2},
$$

where

$$
x=f_{q} / f_{s} .
$$

In Fig. 3, we used a similar relationship for $Q^{-1}$. For both physical properties $E_{3}$ and $Q^{-1}$ we took the maximum or minimum value, not the values at $f_{q} / f_{s}=1$. For these materials, these two values differed approximately $0.1 \%$ for $E_{3}$ and $1 \%$ for $Q^{-1}$.

We measured mass density by Archimedes's method using distilled water as a density standard.

Concerning errors, based on the author's experience, they estimate the $E$ uncertainty as $1 \%$ and the $Q^{-1}$ uncertainty as $5 \%$.

\section{RESULTS}

Table I contains the study's principal measurement results: values of $E_{3}$ and $Q^{-1}$ for the three studied materials. The table also contains mass densities together with other measurement results. Figure 4 shows graphs of $E$ and $Q^{-1}$ versus fiber volume fraction $c$.

\section{DISCUSSION}

In this section, we want to consider principally the explanation for the dependence of $E$ and $Q^{-1}$ on volume percent inclusion, or fiber. Usually, this requires two models

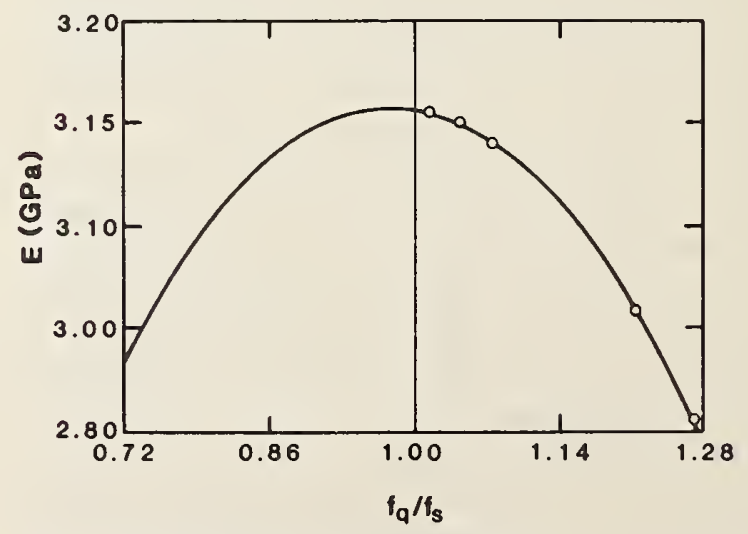

FIG. 2. Graph of apparent Young modulus vs $f_{q} / f_{s}$. We took optimum value, rather than $f_{q} / f_{s}$ value, as correct. 


$$
m x+b \dot{x}+k x=0,
$$

where $m$ denotes mass, $b$ denotes mechanical-resistance constant, $k$ denotes force constant, $x$ denotes displacement, and dots signify differentiation with respect to time. Recognizing that $k$ relates to the fundamental resonance frequency $\omega_{0}$ according to

$$
\omega_{0}^{2}=k / m
$$

and defining

$$
2 \gamma=b / m \text {, }
$$

we rewrite Eq. (16) as

$$
\ddot{x}+2 \gamma \dot{x}+\omega_{0}^{2} x=0 .
$$

If $\omega_{0}^{2}>\gamma^{2}$, then Eq. (19) has a solution ${ }^{11}$

$$
x=C \exp (-\gamma t) \sin (\omega t+\phi),
$$

where the frequency $\omega$ relates to the natural (undamped) frequency $\omega_{0}$ according to

$$
\omega^{2}=\omega_{0}^{2}-\gamma^{2}
$$

and $\phi$ denotes the initial phase. Following French, ${ }^{11}$ neglecting the difference between $\omega$ and $\omega_{0}$, the internal friction is

$$
Q^{-1}=2 \gamma / \omega_{0}=b /(\mathrm{km})^{1 / 2} \text {. }
$$

Following Igata and Kohyama, ${ }^{12}$ we adopt linear rules of mixture for three quantities:

$$
\begin{aligned}
& m=(1-c) m_{m}+c m_{f}, \\
& k=(1-c) k_{m}+c k_{f},
\end{aligned}
$$

and

$$
b=(1-c) b_{m}+c b_{f},
$$

where subscripts $m$ and $f$ denote matrix and fiber. If the interface contributes to the damping, it does so through $b$; one would add a $b_{i}$ term to the right-hand side of Eq. (25). Here, subscript $i$ denotes interface.

Combining Eqs. (22)-(25) leads to

$$
Q^{-1}=Q_{m}^{-1}\left(1+\frac{c}{1-c} \frac{b_{f}}{b_{m}}\right)\left[1+\frac{c}{1-c}\left(\frac{m_{f}}{m_{m}}+\frac{k_{f}}{k_{m}}\right)+\left(\frac{c}{1-c}\right)^{2} \frac{m_{f}}{m_{m}} \frac{k_{f}}{k_{m}}\right]^{-1 / 2},
$$

where

$$
Q_{m}^{-1}=b_{m} /\left(m_{m} k_{m}\right)^{1 / 2} .
$$

Recognizing that

$$
m=\rho V=m_{m}+m_{f}=c \rho_{f} V+(1-c) \rho_{m} V,
$$

where $\rho$ denotes mass density and $V$ denotes volume, then

$$
\frac{m_{f}}{m_{m}}=\frac{c}{1-c} \frac{\rho_{f}}{\rho_{m}}
$$

and we rewrite Eq. (26) as

$$
\begin{aligned}
Q^{-1}= & Q_{m}^{-1}\left(1+\frac{c}{1-c} \frac{b_{f}}{b_{m}}\right)\left[1+\frac{c}{1-c} \frac{k_{f}}{k_{m}}\right. \\
& \left.+\left(\frac{c}{1-c}\right)^{2} \frac{\rho_{f}}{\rho_{m}}+\left(\frac{c}{1-c}\right)^{3} \frac{\rho_{f}}{\rho_{m}} \frac{k_{f}}{k_{m}}\right]^{-1 / 2}
\end{aligned}
$$

Because the glass fiber is much stiffer and less viscous than the resin matrix, we make the approximation that $b_{f}=0$. Then the second term in the left-most brackets on the righthand side of Eq. (30) disappears. The curve in Fig. 4 represents Eq. (30) with $b_{f}=0$. For the force constants, we used the relationship

$$
k=E a,
$$

where $a$ denotes a characteristic interatomic spacing. This led to $k_{f}=24.44 \mathrm{~N} / \mathrm{m}$ and $k_{m}=0.3114 \mathrm{~N} / \mathrm{m}$. We treated $a_{m}$ as the single adjustable fitting parameter in Eq. (30), using $a_{m}=1 \AA$. Altogether, we find the measurement-model fit for $Q^{-1}$ in Fig. 4 better than expected.

We see no need to postulate a matrix-fiber-interface internal-friction term. In Fig. 4, an interface term would raise the model curve above observation. Through the single adjustable parameter $a_{m}$, one cannot lower the curve because $a_{m}$ becomes physically unreal.
Finally, we note that the nonhomogeneous fiber distribution shown in Fig. 1 does not affect the rule-of-mixture calculations for the Young modulus in the fiber direction. Elastic constants that follow a rule of mixture do not depend on fiber-distribution homogeneity. Elastic stiffening in fiberrich regions is compensated exactly by elastic softening in fiber-poor regions. Model calculations by Datta, Ledbetter, and $\mathrm{Kriz}^{13}$ show that other elastic constants depend on fiberdistribution nonhomogeneity. For example, the shear modulus $\mu_{L T}$ and the Poisson ration $v_{T L}$ depend strongly on departures from homogeneity.

\section{CONCLUSIONS}

From this study, we reach four conclusions concerning a composite material consisting of an epoxy resin reinforced with continuous parallel glass fibers:

(1) As expected from many previous studies, the fiberdirection Young modulus $E_{3}$ follows a linear rule-of-mixture.

(2) If one does not know the fiber Young modulus $E_{f}$, one can determine it reliably by measuring $E_{3}$ for a few composites with different $c$ values and extrapolating linearly to $c=1.0$.

(3) The internal friction $Q^{-1}$ follows a classical freedamped-oscillator model that assumes a linear rule of mixture for three quantities: mass, force constant, and mechanical-resistance constant.

(4) No evidence emerged that the fiber-matrix interface contributed to internal friction.

\section{ACKNOWLEDGMENT}

Dr. M. B. Kasen of NBS produced the composite materials. Owens-Corning (Granville, Ohio) furnished the glass 
fiters. M. Lei, a guest worker at NBS, is on leave from Institute of Metals Research, Sheyang, People's Republic of Chinis.

II B Kasen, in National Bureau of Standards Report NBSIR 85-3075 (Maly 1985), pp. 87-97.

2J Marx, Rev. Sci. Instrum. 22, 503 (1951).

'W HI. Robinson and A. Edgar, IEEE Trans. Sonics Ultrason. SU-21, 8 (197\$).

A S Nowick and B. S. Berry, Anelastic Relaxation in Crystalline Solids (Academic, New York, 1972).
${ }^{5}$ Z. Hashin and B. W. Rosen, J. Appl. Mech. 31, 223 (1964).

${ }^{6} \mathrm{Z}$. Hashin, in Mechanics of Composite Materials (Academic, New York, 1970), pp. 201-240.

${ }^{7}$ R. Hill, J. Mech. Phys. Solids 12, 199 (1964).

${ }^{8}$ J. J. Hermans, Proc. K. Ned. Akad. Wet. B 70, 1 (1967).

${ }^{9}$ S. K. Bose and A. K. Mal, Int. J. Solids Struct. 9, 1075 (1973).

${ }^{10}$ S. K. Bose and A. K. Mal, J. Mech. Phys. Solids 22, 217 (1974).

${ }^{11}$ A. P. French, Vibrations and Waves (Norton, New York, 1971), pp. 6267.

${ }^{12}$ N. Igata and A. Kohyama, Trans. Jpn. Soc. Compos. Mater. 2, 30 (1976). ${ }^{13}$ S. K. Datta, H. M. Ledbetter, and R. D. Kriz, Int. J. Solids Struct. 20, 429 (1984). 



EDGE STRESSES IN WOVEN LAMINATES

AT LOW TEMPERATURES

Ronald D. Kriz

Fracture and Deformation Division

Institute for Materials Science and Engineering

National Bureau of Standards

Boulder, Colorado 80303

Woven glass-epoxy laminates are used as nonmetallic components at low temperatures in magnetic fusion energy structures. Previous damage studies on G-10CR and G-11CR cryogenic grade woven laminates revealed that most of the damage occurred in the laminated interior. An existing, generalized plane strain, finite element model was modified to predict stress states at the laminate interior and free edges. Finite element results demonstrated that the weave geometry reduces edge stresses at low temperatures. Delamination edge stresses in woven laminates are more sensitive to small changes in temperature than those in nonwoven laminates. Results suggest that small warp angles suppress edge damage better than large angles.

Introduction

Woven glass-epoxy laminates are used at low temperatures for a variety of applications in magnetic fusion energy (MFE) structures. These woven laminates are used mainly as electrical and thermal barriers that provide minimal structural support. However, when cooled to liquid helium temperatures $(4 \mathrm{~K})$, large internal stresses arise from the differential thermal contractions of dissimilar components within the laminate. When these thermally induced stresses are combined with stresses induced by small mechanical loads (magnetic loads), microcracks may initiate at loads well below yield. The formation of large numbers of microcracks could limit the usefulness of these materials for MFE applications.

Previous studies $[1,2,3]$ measured the mechanical properties of two popular glass-epoxy woven materials, G-10CR and G-11CR. Later studies $[4,5]$ related individual damage events to the mechanical performance of G-1OCR and G-11CR at small strains and low temperatures. All tes.ts were performed on thin laminates where internal and edge damage could be monitored periodically with increasing load. Results from these investigations showed that bimodulus behavior resulted at strains well below the ultimate strain and that damage originated in the interior but not at the edge. For nonwoven laminates, damage in the form of ply cracks and delaminations originates at the edge because a large stress state exists there; this edge damage is representative of damage in the interior. For woven laminates, edge damage is not representative of internal damage. 
In this study, we modeled edge stresses for woven and nonwoven thin laminates and determined the influence of weave geometry and thermal effects on edge stresses. With these results, we explain why edge damage differs for woven and nonwoven laminates.

\section{Edge Stress Analysis}

Figure 1 defines simple geometries for woven and nonwoven laminates loaded in tension in the $\mathrm{x}$ direction. The symmetric stacking sequence $[0 / 90]_{S}$ for the nonwoven laminate is denoted by a subscript (s), and the ordering of the plies is $0^{\circ}$ near the top surface and $90^{\circ}$ near the midplane. Similar stacking sequences exist near the free edge of woven laminates, where we use a superscript $(\theta)$ to denote the weave curvature in the $y-z$ plane. Stresses in the $\mathrm{y}-\mathrm{z}$ plane develop from the mismatch in Poisson's contraction between dissimilar ply or fiber bundle orientations. For a [0/90]s nonwoven laminate, the edge stress, $\sigma_{z}$, develops because the transverse contraction in the $0^{\circ} \mathrm{ply}$ is greater than the transverse contraction in the $90^{\circ} \mathrm{ply}$. Hence, along the midplane nearest the edge, $\sigma_{z}$ is in tension because the $0^{\circ}$ and $90^{\circ}$ plies are bonded together. To satisfy equilibrium, $\sigma_{z}$ must change from tension to compression as we move along the midplane $(z=0)$ away from the edge $(y=-B)$. For the $[90 / 0]_{s}$ laminate, the opposite is true: $\sigma_{z}$ is compressive along the midplane nearest the edge. The contribution of weave geometry and thermal loads to the edge stress problem is not easily understood by simple intuitive models. For a better understanding of the influence of weave geometry and thermal loads on edge stresses, we extended the existing edge stress model of Pipes and Pagano [6] for some simple weave geometries.

The edge stress problem was first defined by Pipes and Pagano [6] for nonwoven thin laminates loaded in tension normal to the $y-z$ plane; it is the generalized plane strain problem. For woven laminates, Kriz [4,5] modified the generalized plane strain problem to include in-plane loads and fiber axis rotation, $\theta$, in the $\mathrm{x}-\mathrm{z}$ plane far from the edge at $\mathrm{y}=0$. In-plane and out-of-plane loads were calculated by simple two-dimensional plate theory. For woven laminates, the formulation for the edge stress problem in the $y-z$ plane is identical to the generalized plane strain problem defined in reference 5 , except for a $90^{\circ}$ rotation about the $z$ axis. The finite-element formulation used in this study is given in Appendix A of reference 5 . The only exception to the previous study is that there are no applied loads in the $\mathrm{y}-\mathrm{z}$ plane. The same elastic-thermal properties from reference 5 are used in this finite element study; they are listed in Table 1.

The finite element grids for the woven and nonwoven edge stress problem are shown in Fig. 2. For the $[90 / 0]_{s}$ nonwoven grid, fibers are oriented at either $0^{\circ}$ or $90^{\circ}$ to the load axis ( $x$ direction). For the $[90 / 0]_{S}^{\theta}$ woven grid, fiber bundles are oriented at either $0^{\circ}$ or $90^{\circ}$ to the load axis, and the fiber bundles oriented at $90^{\circ}$ can have an additional warp angle, $\theta$, in the $\mathrm{y}-\mathrm{z}$ plane.

Both grids shown in Fig. 2 represent only one-quarter of the total symmetric grid geometry. There are four possible symmetric geometries. For the nonwoven laminate we can have the sequence $[90 / 0]_{S}$, shown in $\mathrm{Fig}$. 2 , or 
the sequence $[0 / 90]_{S}$, which can be obtained by interchanging the top surface and midplane. Similarly, we classify woven laminate geometries at the edge as $[90 / 0]_{\mathrm{S}}^{\theta}$ and $[0 / 90]_{\mathrm{S}}^{\theta}$. Figure 3 shows the total symmetry for these two weave geometries.

Both grids have a higher density of elements near the edge, where we predict a large gradient of stress as y approaches B. Each element is a constant strain triangle with three degrees of freedom per node. The nonwoven grid has 2044 elements with 1115 nodes; the woven grid has 2394 elements with 1286 nodes. The global stiffness matrix of the woven grid is larger, with 3805 degrees of freedom and a half bandwidth of 346 .

Both grids model out-of-plane displacements but only for unit depth. Hence, no out-of-plane curvatures are modeled in this study. We assume that this approximation is a serious limitation only for the larger warp angles. Obviously, a three-dimensional finite element model would be more accurate, but we considered only the influence of weave curvature in the $y-z$ plane on the edge stresses in this study:

Mechanical and thermal loads were applied to woven grids with $15^{\circ}, 30^{\circ}$, and $45^{\circ}$ of curvature by increasing the aspect ratio (B/H) of the grid. Typically, the edge stresses are normalized by the mechanical load (outof-plane strain), but in this study we superposed mechanical loads on thermal loads. Hence, we chose a one-percent strain because initial damage was observed at this strain, and we chose a thermal load of $100 \mathrm{~K}$ because at this temperature the in-plane stresses are of the same order of magnitude as those produced by the mechanical load.

\section{Results and Discussion}

In Fig. 4, we compare the $\sigma_{z}$ stress distribution of the $[0 / 90]_{S}$ nonwoven grid in Fig. 2 with the previous results $[7,8]$. In Fig. 4 the values of $\sigma_{z}$ are normalized by the applied out-of-plane strain, $\varepsilon_{X}$. They compare well with results of Wang and Crossman [7], who used a similar finite-element model with constant strain triangles, and Pagano [8], who used an analytic approach based on Reissner's variational principle. Our grid geometry was justified by this comparison. The approximation of the following elastic properties were used to calculate $\sigma_{z}$.

$$
\begin{aligned}
& E_{l}=137.9 \mathrm{GPa}(20 \mathrm{Msi}) \\
& E_{t}=14.5 \mathrm{GPa}(2.1 \mathrm{Msi}) \\
& G_{l t}=G_{t t}=5.86 \mathrm{GPa}(0.85 \mathrm{Msi}) \\
& \nu_{l t}=\nu_{t t}=0.21
\end{aligned}
$$

The more correct elastic properties for glass-epoxy are listed in Table 1, where $v_{\ell t} \neq v_{t t}$ and $G_{l t} \neq G_{t t}$. The influence of this approximation on edge stresses is given in reference 9. Such approximations of elastic properties are often made for a variety of elasticity solutions in composite materials, and they can alter the model predictions significantly. In this study we made no such approximation. 
Stress distributions along the midplane for woven $\left([0 / 90]_{\mathrm{S}}^{45}\right)$ and nonwoven $\left([0 / 90]_{S}\right.$ ) laminates are compared in Fig. 5. The most significant result is that $\sigma_{\mathrm{z}}$ is compressive near the edge $(0.85<\mathrm{y} / \mathrm{B} \leqq 1.0)$ without the thermal load. With the thermal load, the compressive stress, $\sigma_{z}$, increases. For the nonwoven laminate, the opposite is true: $\sigma_{z}$ is tensile near the edge and increases in tension with the thermal load. Hence, the weave geometry suppresses delaminations at the midplane.

The presence of a free edge also shows the symmetry of the $\sigma_{z}$ stress distribution. If no free edge existed at $y / B=1.0$, the midplane $\sigma_{z}$ distribution would be symmetric about $y / B=0.5$. With the presence of a free edge at $\mathrm{y} / \mathrm{B}=1$, the symmetry is skewed where the largest $\sigma_{\mathrm{z}}$ stress occurs at the interior near $\mathrm{y} / \mathrm{B}=0$. The largest tensile $\sigma_{\mathrm{z}}$ stress occurs in the interior $(0.15<y / B<0.8)$.

Stress distributions along the midplane for $[90 / 0]_{S}^{45}$ woven and $\left([90 / 0]_{S}\right)$ nonwoven laminates are compared in Fig. 6. For the nonwoven laminate, $\sigma_{z}$ is compressive near the free edge, as expected. The $\sigma_{z}$ stress near the edge in the nonwoven laminate is in tension and decreases toward compression with the addition of the thermal load $\Delta \mathrm{T}=-100 \mathrm{~K}$. Again, we observe a beneficial effect of weave curvature on the edge stresses at low temperatures. The symmetry of the $\sigma_{z}$ distribution for $[90 / 0]_{S}^{45}$ is skewed, decreasing $\sigma_{z}$ near the free edge and increasing $\sigma_{z}$ in the interior near $y / B=0$ The largest compressive stresses occur at $0.4<\mathrm{y} / \mathrm{B}<0.6$ for the $[90 / 0]_{\mathrm{S}}^{45}$ laminate. The opposite is true for the $[0 / 90]_{\mathrm{S}}^{45}$ laminate.

For both woven grid geometries, the weave geometry was beneficial at low temperatures. The opposite was true for the $[0 / 90]_{S}$ nonwoven laminate -the thermal load increased the opportunity for delamination initiation at the midplane.

Edge stress distributions through the thickness $(0 \leqq z / H \leqq 1.0)$ for woven $\left([0 / 90]_{S}^{45},[90 / 0]_{S}^{45}\right)$ and nonwoven $\left([0 / 90]_{S},[90 / 0]_{S}\right)$ laminates are compared in Figs. 7 and 8 . Again, we observe a beneficial effect of weave curvature on the edge stress at low temperatures for the $[0 / 90]_{\mathrm{s}}^{\theta}$ laminate. The opposite was true for the $[0 / 90]_{\mathrm{S}}^{45}$ woven laminate where there was a large tensile delamination stress, $\sigma_{\mathrm{z}}$, near $\mathrm{z} / \mathrm{H}=0.5$, which increased with the thermal load. The opposite was true at the midplane for the same laminate. Hence, we expect delamination initiation at the $90 / 0$ interface but not at the midplane.

All the above results assumed no weave curvature in the $x-z$ plane. Although this restriction is not a serious limitation for small weave angles, it is most significant at the free edge for large angles. With curvature at the edge in the $x-z$ plane, we expect the $\sigma_{z}$ stress in the $[90 / 0]_{S}^{45}$ to decrease at $\mathrm{z} / \mathrm{H}=0.5$ and increase at $\mathrm{z} / \mathrm{H}=0$ (the midplane). At the edge of the $[0 / 90]_{\mathrm{S}}^{45}$ laminate, we expect $\sigma_{\mathrm{z}}$ to decrease at $\mathrm{z} / \mathrm{H}=0.5$ and $\mathrm{z} / \mathrm{H}=0$. To discover the exact influence of weave curvature in the $x-z$ plane on edge stresses requires a three-dimensional finite-element model. In this study, we described only the effect of weave curvature in the $y-z$ plane on edge stresses. 
For the purpose of discussion, we selected extreme geometries to compare general trends between woven and nonwoven geometries. Actual woven G-10CR and G-11CR laminates have weave angles between $10^{\circ}$ and $15^{\circ}$. Both $[0 / 90]_{\mathrm{S}}^{15}$ and $[90 / 0]_{\mathrm{S}}^{15}$ geometries exist at the edge of a real laminate. In Figs. 9 and 10, we compare edge stress distributions for these geometries. Again, we see the beneficial effect of weave geometry at low temperatures, but expect delaminations to occur at the midplane of the $[0 / 90]_{\mathrm{S}}^{15}$ laminate. When the warp angle, $\theta$, increases to $45^{\circ}$, these midplane stresses become compressive. The opposite trend occurs at the $0 / 90$ interface of a $[0 / 90]_{\mathrm{S}}^{\theta}$ laminate when $\theta$ increases from $15^{\circ}$ to $45^{\circ}$. Hence, the region of possible delamination changes from the $[0 / 90]_{\mathrm{S}}^{\theta}$ midplane to the $[90 / 0]_{\mathrm{S}}^{\theta}$ interface as $\theta$ increases.

In all load cases discussed here, we assumed only a 100-K temperature decrease for the thermal load, which is only one-third of the temperature decrease experienced at an operating temperature of $76 \mathrm{~K}$. Hence, the thermal effects at $76 \mathrm{~K}$ clearly dominate the edge stresses.

Although the weave geometry is, in general, beneficial in reducing edge stresses at low temperatures, we expect delaminations and transverse crack formation in the fill-fiber bundles to occur at or near the laminate free edge for higher thermal-mechanical loads. For some weave geometries it is possible that damage may initiate in the interior. The heterogeneous nature of the weave geometry and stress distributions at and near the free edge explains why the damage at the edge is not representative of damage at the interior.

\section{Conclusions}

In general, the weave geometry is beneficial in reducing edge stresses at low temperatures. For a $[0 / 90]_{\text {s }}$ nonwoven laminate, the edge stress normal to the midplane changes to compression with increasing warp angle. For $[0 / 90]_{\mathrm{S}}^{\ominus}$ woven laminates, compressive edge stresses increase with decreasing temperature. For $[90 / 0]_{S}^{\theta}$ woven laminates, edge stresses at the midplane are tensile and decrease to compression with decreasing temperature. For both woven laminate types, $[0 / 90]_{\mathrm{S}}^{\theta}$ and $[90 / 0]_{\mathrm{S}}^{\theta}$, the free edge skews the symmetry of the midplane stress distribution by decreasing the magnitude of the symmetric edge stress. This trend in skewed symmetry also occurs at low temperatures. Unlike nonwoven laminates, edge stresses in woven laminates are dominated by thermal loads. The larger warp angles demonstrated increased sensitivity of edge stresses to small changes in temperature. If delaminations occur at the higher thermal-mechanical loads, initiation will most likely occur in the interior. If delaminations occur at the edge, initiation will most likely occur at the midplane of the $[0 / 90]_{\mathrm{S}}^{\theta}$ laminates and change to the $90 / 0$ interface of the $[90 / 0]_{S}^{\theta}$ laminates with larger warp angles. In general, smaller weave angles in the $y-z$ plane are better at crack suppression than laminates with larger weave angles. All conclusions are based on predictions where weave curvature is confined to the $y-z$ plane. Improved results are possible if the weave curvature is included in the $x^{-z}$ plane. 


\section{Acknowledgment}

This study was sponsored by the Department of Energy, Office of Fusion Energy.

\section{References}

1. M. B. Kasen, G. R. MacDonald, D. H. Beekman, Jr., and R. E. Schramm, Mechanical, electrical, and thermal characterization of G-10CR and G-11CR glass/epoxy laminates between room temperature and $4 \mathrm{~K}$, Advances in Cryogenic Engineering, Vol. 26, Plenum Press, New York, pp. $235-244$ $(1980)$.

2. M. B. Kasen, Mechanical and thermal properties of filamentaryreinforced, structural composites at cryogenic temperatures, 1 : Glass-reinforced composites, Cryogenics, Vol. 15, pp. 327-349 (1975).

3. M. B. Kasen, Cryogenic properties of filamentary-reinforced composites: an update, Cryogenics, Vol. 21, pp. 323-340 (1981).

4. R. D. Kriz, Influence of damage on mechanical properties of woven composites at low temperatures, J. Compos. Technol. Res., Vol. 7, No. 2, pp. 55-58 (1985).

5. R. D. Kriz and W. J. Muster, Mechanical-damage effects in woven laminates at low temperatures, Materials Studies for Magnetic Fusion Energy Applications at Low Temperatures--VIII, NBSIR 85-3025, National Bureau of Standards, Boulder, Colorado, pp. 49-86 (1985).

6. R. Byron Pipes and N. J. Pagano, Interlaminar stresses in composite laminates under uniform axial extension, J. Comp. Mater., Vol. 4, pp. 538-548 (1970).

7. A. S. D. Wang and F. W. Crossman, Some new results on edge effect in symmetric composite laminates, J. Comp. Mater., Vol. 11, pp. 92-106 (1977).

8. N. J. Pagano, Stress fields in composite laminates, Int. J. Solids Struct., Vol. 14, pp. 385-400 (1978).

9. R. D. Kriz, Effect of material properties on interlaminar stresses in angle-ply composite laminates, Report No. VPI-77-16, Virginia Polytechnic Institute and State University, Blacksburg, Virginia (1977). 
Table 1. Elastic-thermal properties [5]

ISOTROPIC CONSTITUENTS

PROPERTY

$\begin{array}{ll}\text { BISPHENOL } & \text { E-GLASS } \\ \text { EPOXY } & \text { FIBER }\end{array}$

FIBER
TRANSVERSELY ISOTROPIC

COMPOSITE

\begin{tabular}{|c|c|c|c|c|}
\hline $\begin{array}{l}\text { Young's modulus, } \\
\text { GPa }\end{array}$ & $E=7.16$ & $E=82.22$ & $\begin{array}{l}E_{\ell} \\
E_{t}\end{array}$ & $\begin{array}{l}=44.69 \\
=17.88\end{array}$ \\
\hline $\begin{array}{l}\text { Shear modulus, } \\
\text { GPa }\end{array}$ & $G=2.77$ & $G=32.55$ & $\begin{array}{l}G_{l t} \\
G_{t t}\end{array}$ & $\begin{array}{l}=6.801 \\
=6.888\end{array}$ \\
\hline Poisson's ratio & $v=0.293$ & $v=0.263$ & $\begin{array}{l}v_{l t} \\
v_{l t}\end{array}$ & $\begin{array}{l}=0.278 \\
=0.298\end{array}$ \\
\hline $\begin{array}{l}\text { Coefficient of } \\
\text { thermal expansion, }\end{array}$ & -- & -- & $\begin{array}{l}\alpha_{\ell} \\
\alpha_{t}\end{array}$ & $\begin{array}{l}=5.963 \\
=23.39\end{array}$ \\
\hline
\end{tabular}

$V_{f}=$ volume fraction of glass fibers.

Subscript $\ell$ indicates fiber direction; subscript $t$ indicates transverse plane. 


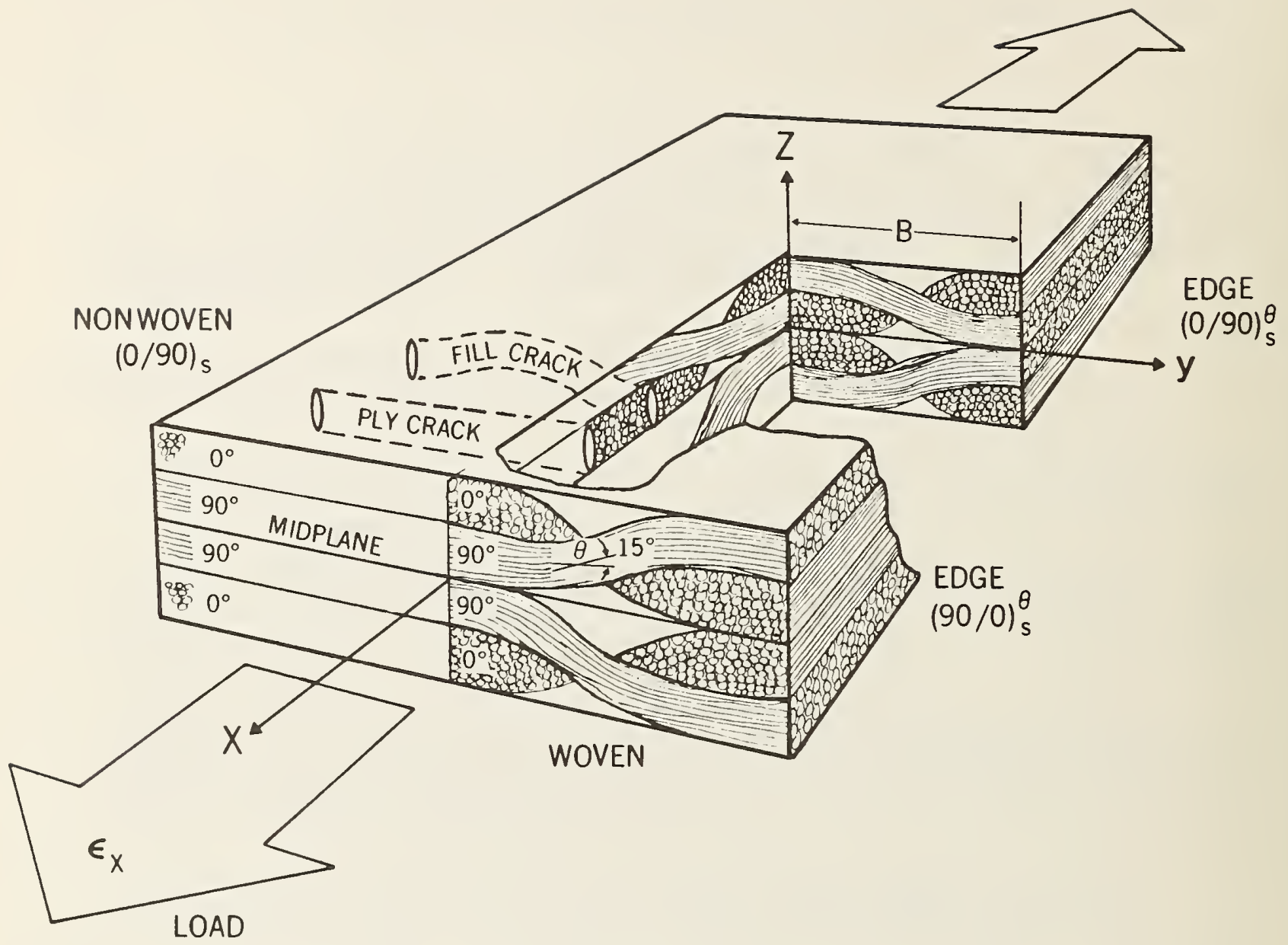

Figure 1. Geometries defined for woven and nonwoven symmetric laminates loaded with uniform axial strain. 


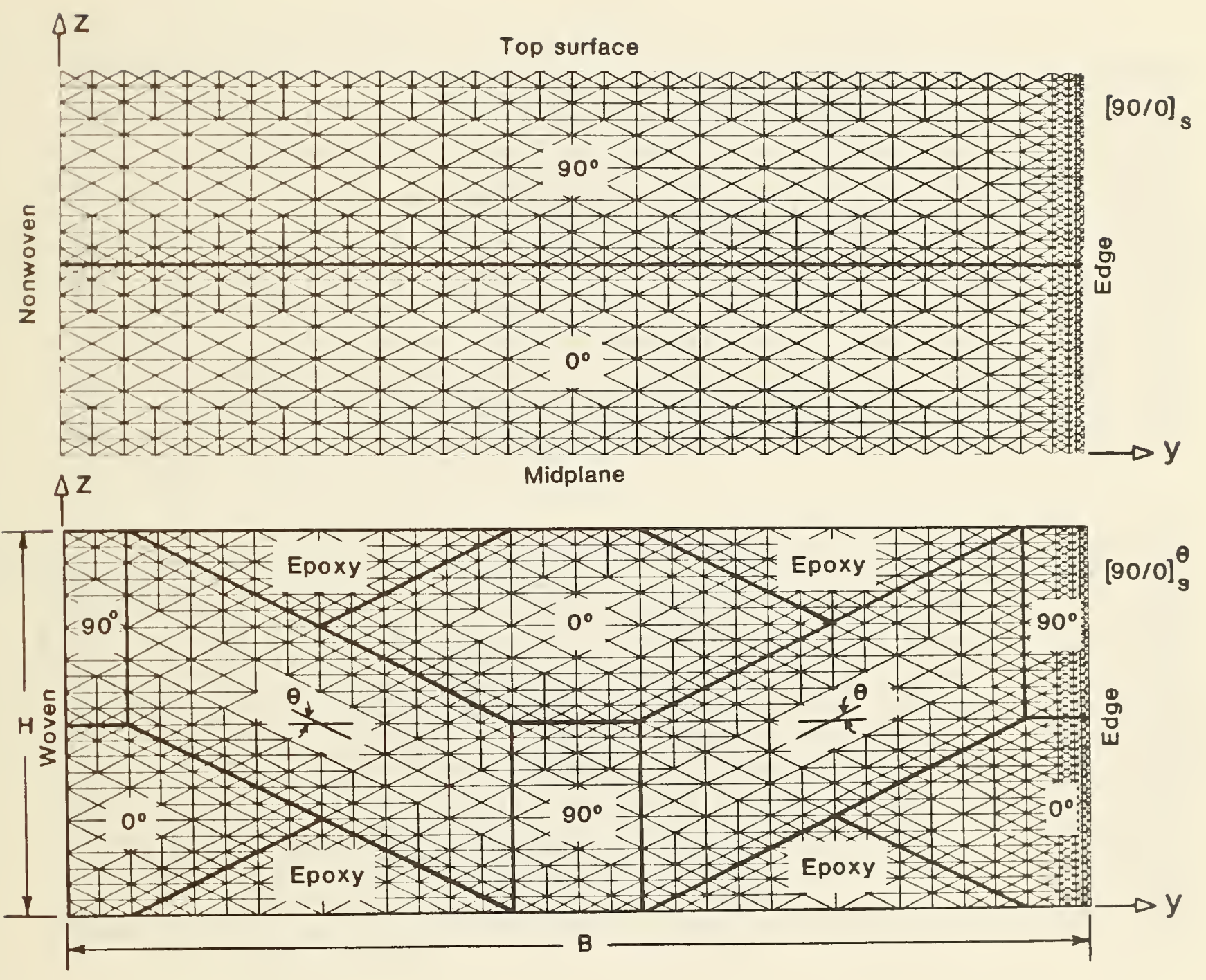

Figure 2. Finite-element grids of woven and nonwoven $[0 / 90]_{S}^{\theta}$ laminates $(\theta=0)$. 


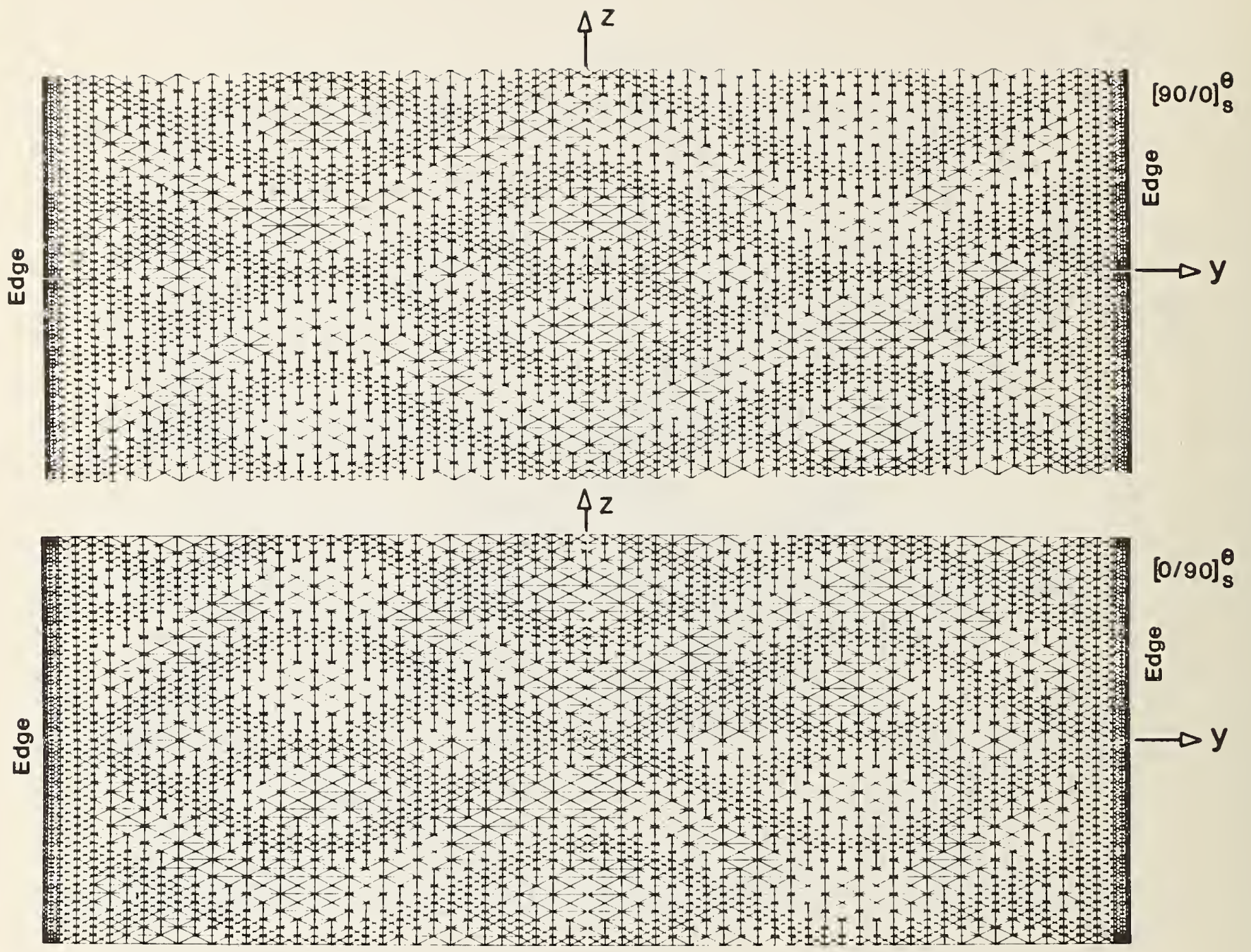

Figure 3. Complete finite element grids of $[90 / 0]_{\mathrm{S}}^{\theta}$ and $[0 / 90]_{\mathrm{S}}^{\theta}$
woven laminates with complete symmetry showing both edges. 


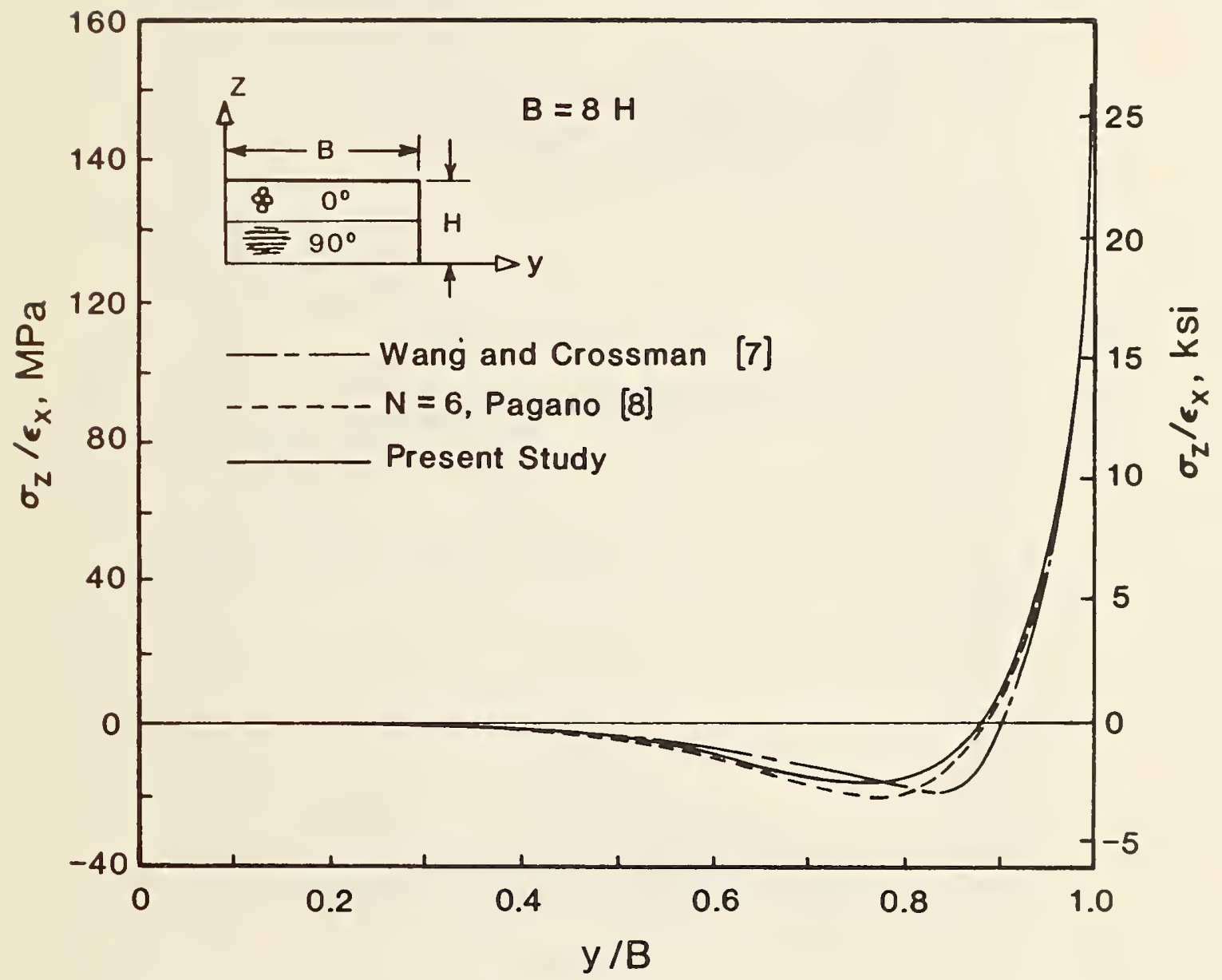

Figure 4. Comparison of present finite element results with previous results for $\sigma_{z}$ stress along the midplane $(z=0)$. 


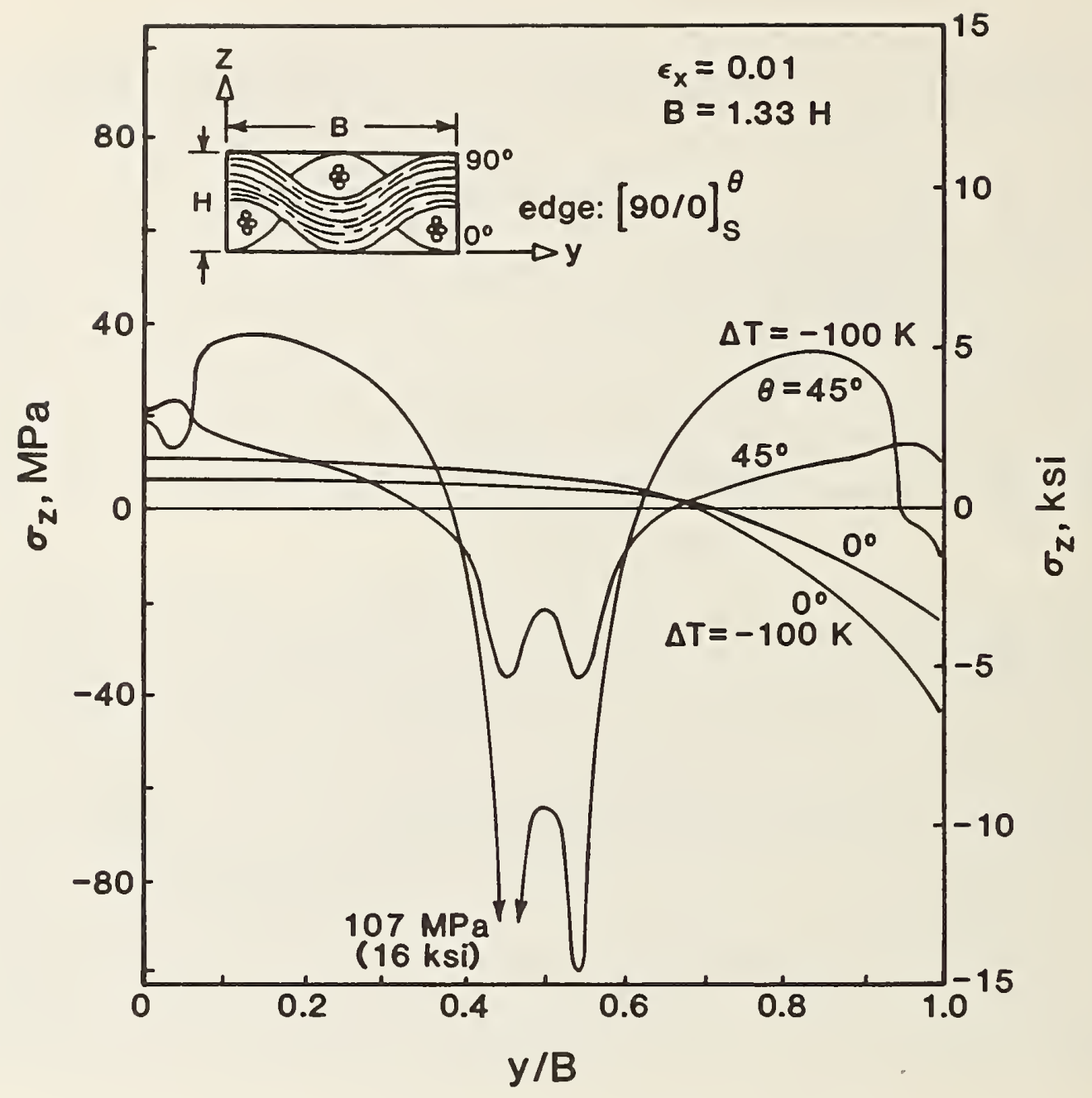

Figure 5. Comparison of midplane stress distribution for $[0 / 90]_{\mathrm{S}}^{45}$ woven and $[0 / 90]_{s}$ nonwoven laminates with and without thermal loads. 


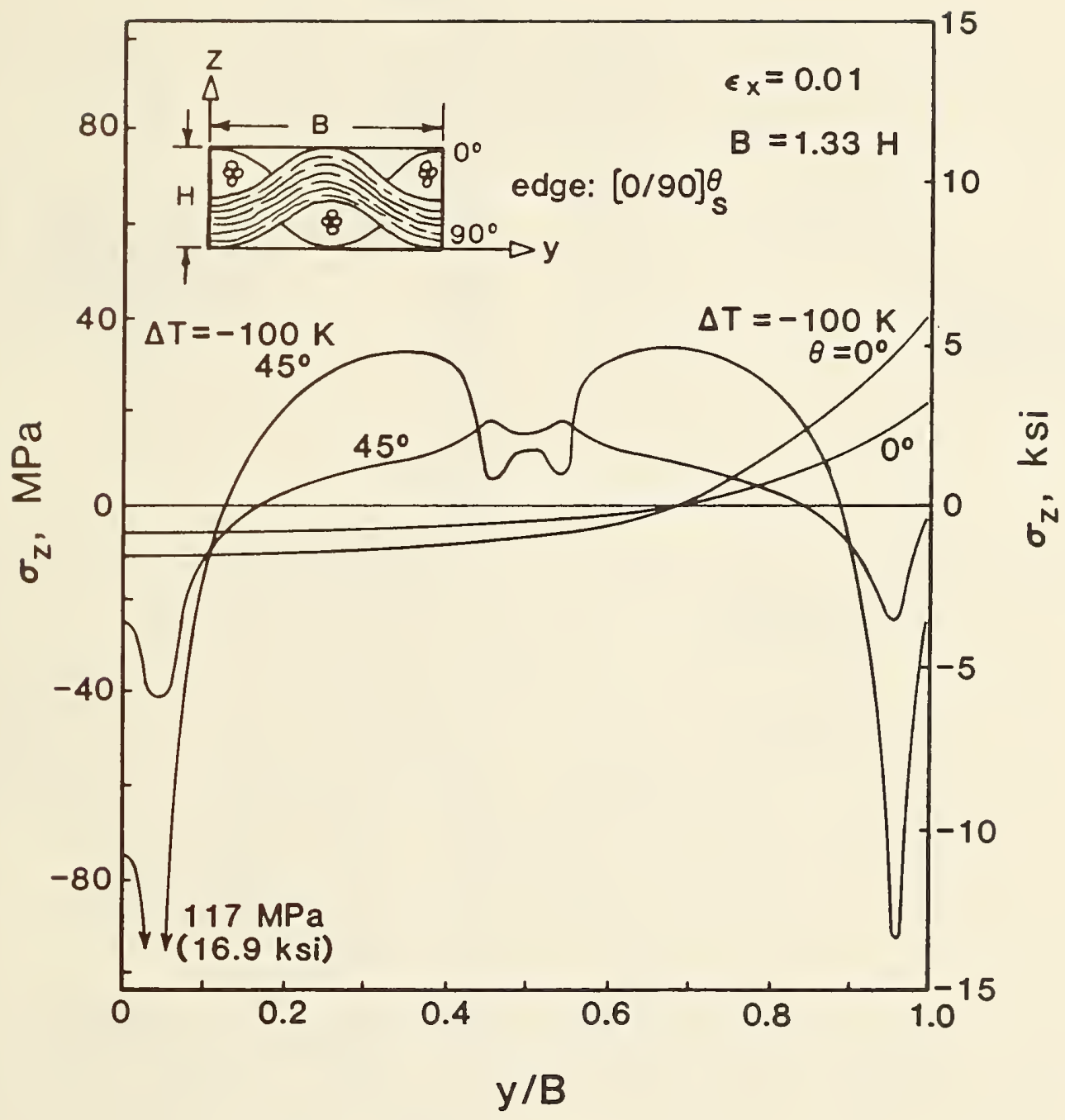

Figure 6. Comparison of midplane stress distributions for $[0 / 90]_{\mathrm{S}}^{45}$ woven and $[90 / 0]_{S}$ nonwoven laminates with and without thermal loads. 


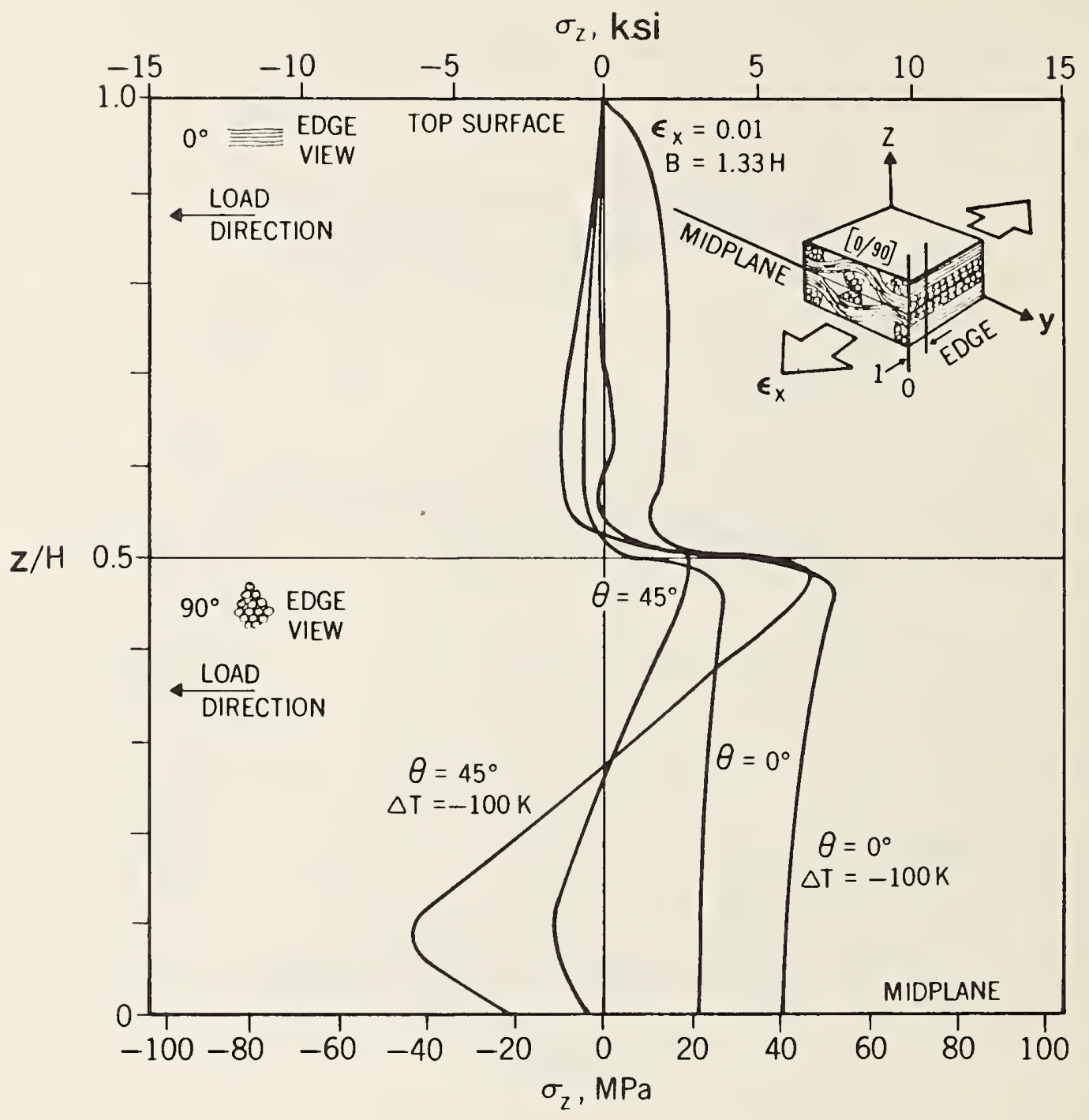

Figure 7. Comparison of edge stress distributions through the thickness for $[0 / 90]_{\mathrm{S}}^{45}$ woven and $[0 / 90]_{\mathrm{S}}$ nonwoven laminates with and without thermal loads. 


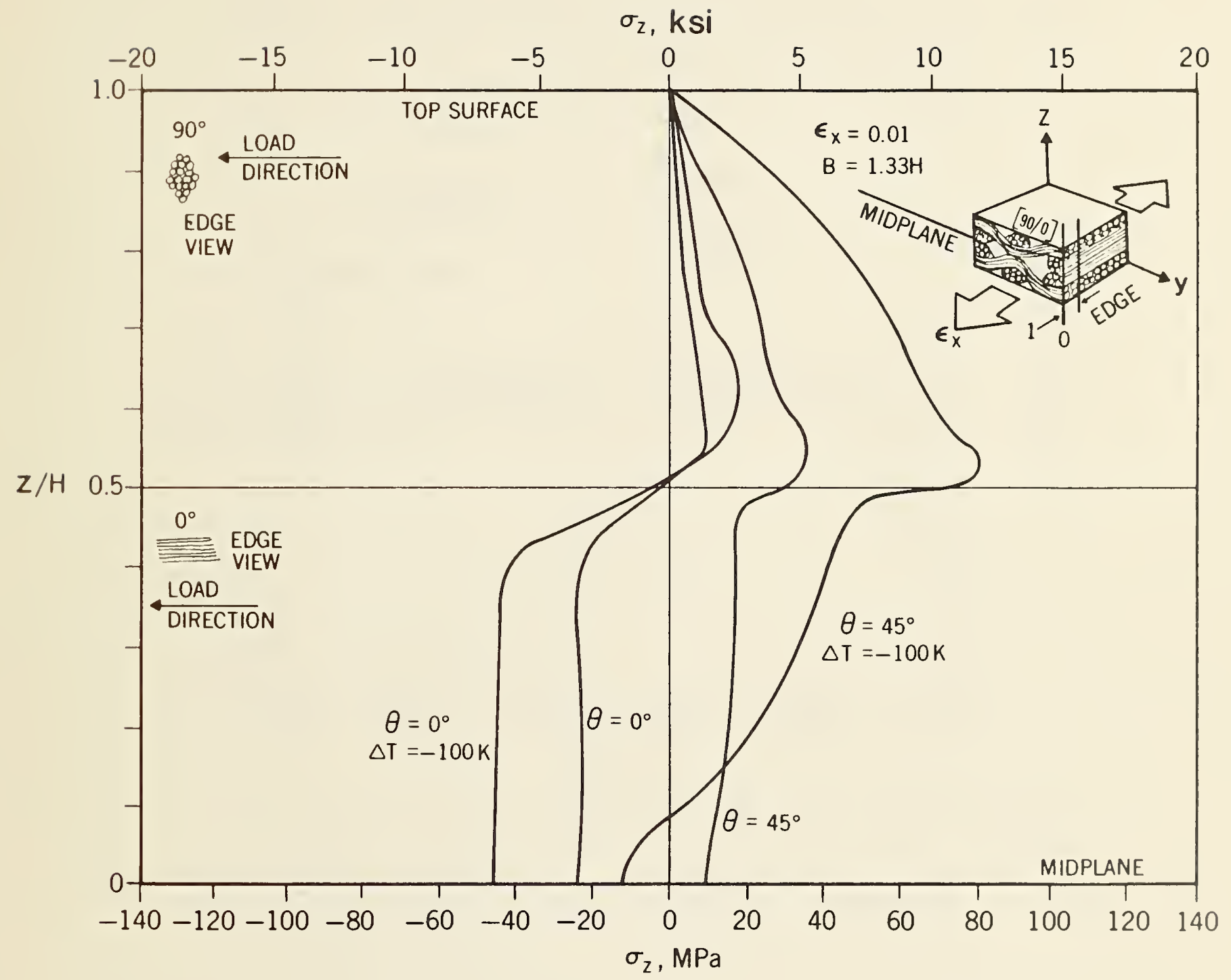

Figure 8. Comparison of edge stress distributions through the thickness for $[90 / 0]_{S}^{45}$ woven and $[90 / 0]_{S}$ nonwoven laminates with and without thermal loads. 


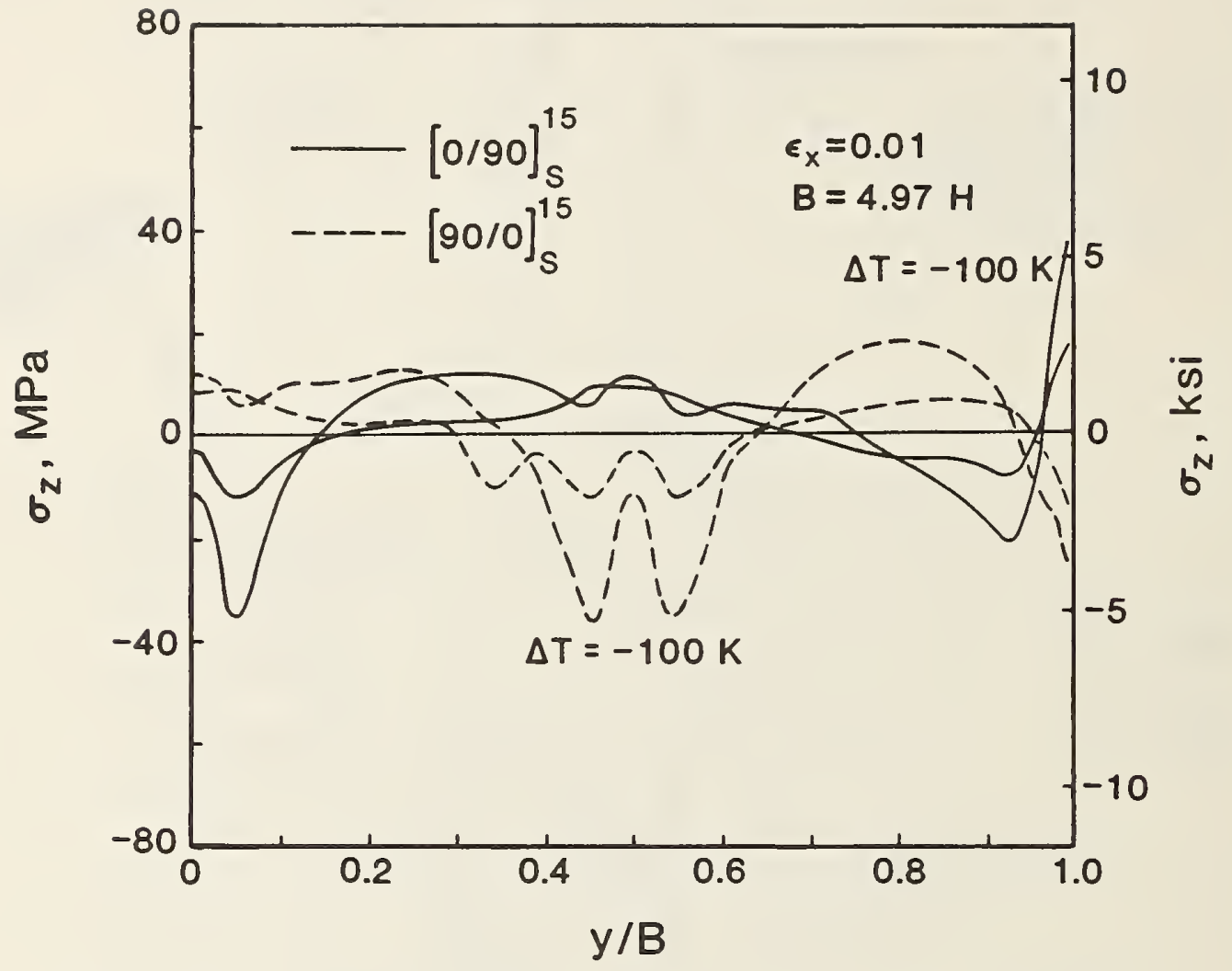

Figure 9. Comparison of midplane stress distributions for $[0 / 90]_{\mathrm{S}}^{15}$ and $[90 / 0]_{S}^{15}$ woven laminates with and without thermal loads. 


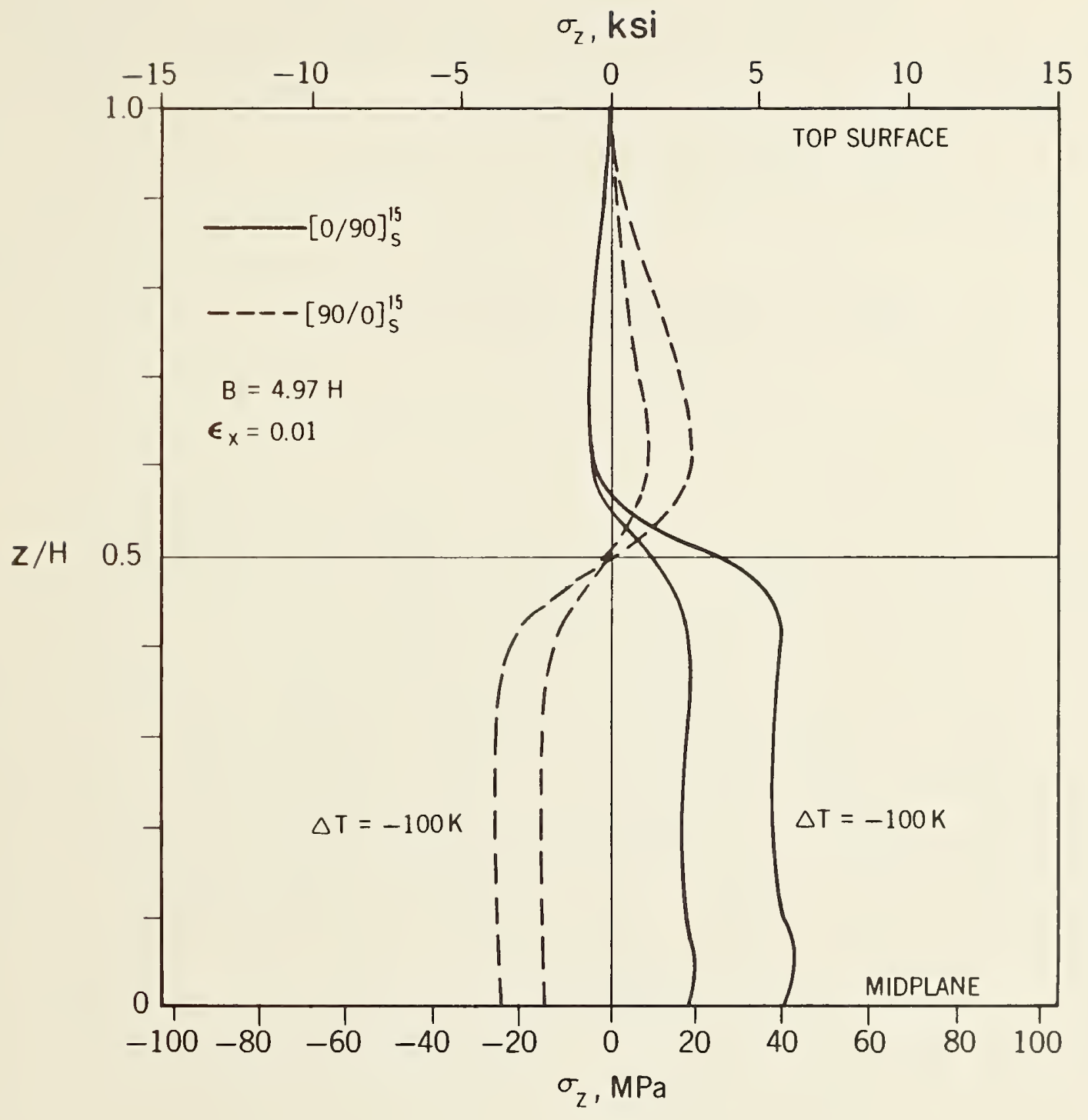

Figure 10. Comparison of edge stress distributions through the thickness for $[0 / 90]_{S}^{15}$ and $[90 / 0]_{S}^{15}$ woven laminates with and without thermal loads. 


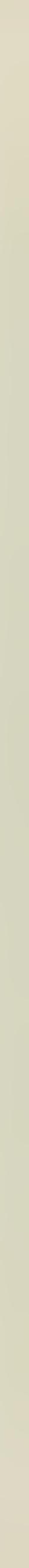


TECHNOLOGY TRANSFER 



\title{
TECHNOLOGY TRANSFER PROGRAM
}

\author{
LEADER : \\ N. J . Simon, NBS \\ CONTRIBUTORS: \\ G. Latsis, P. Pollas, R. P. Reed
}

\section{OBJECTIVES}

- Organization of workshops to promote interaction between designers and material specialists, to discuss issues related to low-temperature material needs of the fusion energy program, and to present new low-temperature data for structural alloys, composites, and weldments

- Preparation of an annual report as well as monthly highlight reports to $\mathrm{OFE} / \mathrm{DOE}$.

- Evaluation of low-temperature mechanical and physical properties of structural materials for superconducting magnets; preparation of handbook pages and supporting documentation; distribution of handbook pages to workshop attendees and others in the low-temperature materials applications community; inclusion of pages in the "Materials Handbook for Fusion Energy Systems"

\section{RESEARCH PAST YEAR (1985)}

- Preparation of "Materials Studies for Magnetic Fusion Energy Applications--VIII," (NBSIR 85-3025, 340 pages, May 1985, editor R. P. Reed)

- Preparation of handbook pages and supporting documentation covering mechanical properties of AISI 304 (N, LN, HN, LHN); evaluation of physical property data of AISI 304 alloys) and preparation of corresponding handbook pages; submission of handbook pages for review to the "Materials Handbook for Fusion Energy Sytems"

- Collection of data for handbook pages on CDA 102 copper and copper alloys

\section{RESEARCH THIS YEAR (1986)}

- Continued preparation for the low-temperature materials workshop to be held October 6-8 1986.

- Preparation of "Materials Studies for Magnetic Fusion Energy Applications--IX," (NBSIR 86-3050, 338 pages, 1986, editor R. P. Reed)

- Establishment of an evaluated data base on CDA 102 copper and selected copper alloy properties to be presented in the form of handbook pages. evaluation of the data proceeds. 




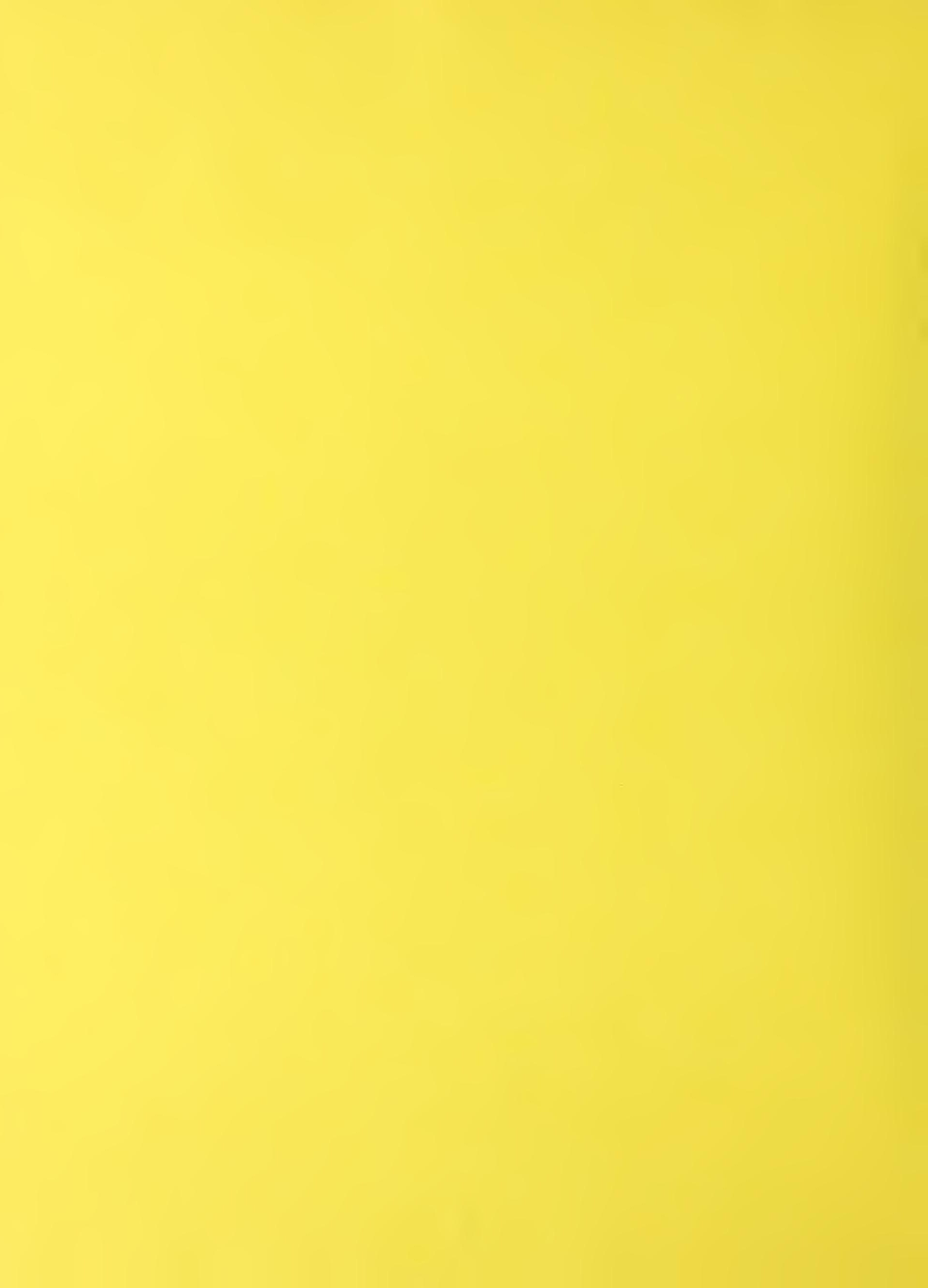




\section{CRYOGENIC STRUCTURAL MATERIALS WORKSHOP \\ Lawrence Berkeley Laboratory \\ University of California \\ Berkeley, California \\ October 2-4, 1985}

This annual workshop provides an opportunity for discussion of problems, advances, and goals in the development of low temperature materials for superconducting magnets for fusion energy systems. The theme of this year's workshop was "Low Temperature Materials - Past Accomplishments and Future Challenges." Emphasis was on the following:

- Recent accomplishments and lessons learned from the construction of the Mirror Fusion Test Facility (MFTF-B) and the Large Coil Task.

- Identification of materials needs for future magnet system.

- New low temperature materials developments in the United States and Japan and international research cooperation. 
PROGRAM

Cryogenic Structural Materials Workshop

Lawrence Berkeley Laboratory, University of California

Berkeley, California

October 2-4, 1985

WEDNESDAY, OCTOBER 2, 1985

OVERVIEW AND RECENT PAST EXPERIENCES

$\begin{array}{lll}\text { 9:00 a.m. } & \begin{array}{l}\text { Overview of Cryogenic Materials Needs } \\ \text { Lessons Learned in Construction of a } \\ \text { Large Number of Superconducting Magnets } \\ \text { for MFTF-B }\end{array} & \text { V. Der, OrE } \\ \text { 9:20 a.m. } & \text { 1. A Laboratory Viewpoint } & \\ \text { 9:50 a.m. } & \text { 2. A Fabricator's Viewpoint } & \text { J. Zbasnik, LLNL } \\ 10: 20 \text { a.m. } & \text { 3. Private Industry's Viewpoint } & \text { R. Bonina, CBI } \\ 11: 10 \text { a.m. } & \begin{array}{l}\text { Future Needs for Cryogenic Structural } \\ \text { Materials Development - Tokamaks and } \\ \text { Tandem Mirrors }\end{array} & \text { E. Baldi, GD/C } \\ & \text { LLNL Dalder, }\end{array}$

STRUCTURAL ALLOY EVALUATION AND DEVELOPMENT ACTIVITIES

\begin{tabular}{|c|c|c|c|}
\hline $1: 30$ & $\mathrm{p} \cdot \mathrm{m}$ & $\begin{array}{l}\text { Status of Evaluation of Cryogenic Structural } \\
\text { Alloys in the NBS Program }\end{array}$ & R. P. Reed, NBS \\
\hline $2: 00$ & $\mathrm{p} \cdot \mathrm{m}$ & $\begin{array}{l}\text { Evaluation of Candidate ICCS Conductor } \\
\text { Sheath Alloys }\end{array}$ & L. Summers, LLNL \\
\hline $2: 30$ & $\mathrm{p} \cdot \mathrm{m} \bullet$ & $\begin{array}{l}\text { Modification and Development of Candidate } \\
\text { ICCS Conductor Sheath Alloys }\end{array}$ & R. Ballinger, MIT \\
\hline $3: 00$ & $\mathrm{p} \bullet \mathrm{m}$ & $\begin{array}{l}\text { Cryogenic Properties of Advanced Aluminum } \\
\text { Alloys }\end{array}$ & J. Glazer, LBL \\
\hline \multirow[t]{2}{*}{$3: 45$} & $\mathrm{p} \cdot \mathrm{m} \bullet$ & $\begin{array}{l}\text { Relationships Between Processing, Micro- } \\
\text { structure, and Properties of Binary Fe-Mn } \\
\text { Austenitic Alloys }\end{array}$ & M. Strum, LBL \\
\hline & & $\begin{array}{l}\text { Joint Collaborations in Development and } \\
\text { Evaluation of New Cryogenic Structural } \\
\text { Materials }\end{array}$ & \\
\hline $4: 15$ & $\mathrm{p} \cdot \mathrm{m}$ & 1. The Japanese Prospective & J. W. Morris, LBL \\
\hline . 20 & $\mathrm{p} \cdot \mathrm{m}$ & 2. The U.S. Pros & R. P. Reed, NBS \\
\hline
\end{tabular}


THURSDAY, OCTOBER 3, 1985

FABRICATION TECHNOLOGY FOR CRYOGENIC STRUCTURAL ALLOYS

$\begin{array}{lll}\text { 9:00 a.m. } & \begin{array}{l}\text { Overview of Welding Development Needs for } \\ \text { Future Cryogenic Magnet Case Materials }\end{array} & \begin{array}{c}\text { E. N. C. Dalder, } \\ \text { LLNL }\end{array} \\ \text { 9:30 a.m. } & \begin{array}{l}\text { Development of Filler Metals for Next } \\ \text { Generation of Cryogenic Magnet Case } \\ \text { Materials }\end{array} & \text { K. Banks, Teledyne } \\ \text { McKay } & \text { T. A. Siewert, NBS } \\ 10: 45 \mathrm{a} . \mathrm{m} . & \text { Fusion Welding of Fe-Mn Austenite Alloys } & \text { J. Chan, LBL } \\ 11: 15 \mathrm{a} . \mathrm{m} . & \begin{array}{l}\text { Cryogenic Mechanical Properties of Welded } \\ \text { 22Mn-13Cr-5Ni Steel }\end{array} & \text { M. Shimada, Kobe } \\ 11: 45 \mathrm{a} . \mathrm{m} . & \begin{array}{l}\text { Mechanical Properties of High Manganese } \\ \text { Austenitic Steels and Their Welds at } \\ \text { Cryogenic Temperatures }\end{array} & \text { S. Onedera and } \\ & \text { R. Miura, Japan } \\ \end{array}$

NONMETALLIC STRUCTURAL COMPOSITES FOR CRYOGENIC SERVICE

2:00 p.m. The Need for High Elastic Modulus, Low CTE

Composites in Future TMR Choke Coils

E. N. C. Dalder, LLNL

2:30 p.m. Progress in Cooperative Irradiation Testing of Composites

M. B. Kasen, NBS

R. D. Kriz, NBS

3:00 p.m. Progress in Model Development and

Verification for Composites

3:30 p.m. Interaction of Face Pressure and Inter-

laminar Shear on Thin Organic Laminates

H. Becker, MIT

4:00 p.m. Use of the NLTNIF for Magnet Materials

Research

R. Coltman, ORNL

FRIDAY, OCTOBER 4, 1985

FATIGUE, CREEP, AND PROCESSING EFFECTS ON PROPERTIES
$9: 00 \mathrm{a} \cdot \mathrm{m}$.
Threshold Effects in Cryogenic Fatigue Crack Growth
R. L. Tobler, NBS
$9: 30$ a.m.
Creep in Cryogenic Structural Materials
R. P. Reed, NBS
$10: 00 \mathrm{a} \cdot \mathrm{m}$.
Time Dependent Deformation in Austenitic Stainless Steels at $4 \mathrm{~K}$
L. Roth, Westinghouse
$10: 45 \mathrm{a} \cdot \mathrm{m}$
Processing Effects on Tensile and Fracture
Toughness of Type 304LN Stainless Steel at $4 \mathrm{~K}$
E. N. C. Dalder, LLNL
11:15 a.m. Processing Effects on Tensile and Fracture Toughness of Type 316LN Stainless Steel
P. T. Purtscher, NBS at $4 \mathrm{~K}$ 
FRIDAY, OCTOBER 4, 1985, continued

CONDUCTOR AND COIL TASK GROUP MEETINGS

1:30 p.m. Identification of Heat Treatment Facilities for ICCS Sheath Materials

M. O. Hoenig, MIT, Chair

1:30 p.m. Identification of Heat Treatment "Windows" for Alloyed $\mathrm{Nb}_{3} \mathrm{Sn}$ Conductors

D. C. Larbalestier, University of Wisconsin, Chair

3:00 p.m. Identification of Structural Failure Modes for ICCS Conductors and Coils

V. Der, OFE, Chair

3:00 p.m. Identification of Heat Treatment "Windows" for ICCS Sheath Alloys

E. N. C. Dalder, LLNL, Chair 


\section{CRYOGENIC STRUCTURAL MATERIALS WORKSHOP}

\section{SUMMARY OF TECHNICAL PRESENTATIONS}

\section{Session 1 - Overview and Recent Past Experiences}

Projected cryogenic materials needs were outlined by $V$. Der (OFE). The importance of data on high performance copper alloys for the Compact Ignition Tokamak (CIT) was stressed. This device will operate with liquid nitrogen cooling, so properties between $77 \mathrm{~K}$ and room temperature need to be determined. Other material data needs for superconducting magnet development included information on the ICCS sheath alloys (e.g., 900-series Inconels), $316 \mathrm{LN}$, and weldments. The need for data on irradiation effects, creep, and standardized methods of testing was also discussed. The importance of balance between near-term and long-term DOE fusion energy program goals in setting priorities for materials studies was stressed.

A summary of lessons learned from the fabrication of superconducting magnets for MFTF-B was also presented in this session. A detailed account was given by $R$. Bonina ( $C B I$ ) of how welding procedures were developed to ensure high quality welds of thick sections in various orientations. Problems of alignment and clearance between the large-scale individual components that make up the entire tandem mirror machine of MFTF-B were some of the unusual aspects of construction discussed by $\mathrm{R}$. Baldi (GD/C).

E. N. C. Dalder (LLNL) spoke on future material needs for both tokamaks and tandem mirrors. The large forces expected in current tokamak designs were stressed; examples are a centering force (directed toward the center post of the tokamak) of over $300 \mathrm{MN}$ for INTOR and stresses of about $700 \mathrm{MPa}$ for the magnet case for TIBER. The need for data on irradiation effects in insulators, creep of structural alloys, and the effects of the large number of cycles to which these machines will be subjected were also discussed.

Session 2 - Structural Alloy Evaluation and Development Activities

R. P. Reed (NBS) discussed factors influencing cryogenic fracture toughness of austenitic steels, particularly where Mn replaces Ni, and also where Mo and interstitial $\mathrm{C}+\mathrm{N}$ additions contribute to increasing the yield strength. The evidence for inclusion effects and the expected magnitude of these effects were examined. New studies on effects of $\mathrm{C}, \mathrm{N}, \mathrm{Ni}$, Mo, and $\mathrm{Mn}$ content on AISI 317LN were outlined. L. Summers (LLNL) presented an evaluation of Inconels 903, 905, and 909 as candidate alloys for the ICCS conductor sheath. These alloys must withstand extensive heat treatment because the $\mathrm{Nb}_{3} \mathrm{Sn}$ superconductor has to be fabricated in situ, owing to its brittleness. Inconel 903 has adequate $4-\mathrm{K}$ toughness $(150 \overline{\mathrm{MP}} \mathrm{a} \overline{\mathrm{m}}$ ) and yield strength $(750 \mathrm{MPa})$ but a low Young's modulus after heat treatment. The potential cryogenic use of a new aluminum alloy with Li additions (2090) was discussed by J. Glazer (LBL). Both toughness and yield strength for this alloy increase with decreasing temperature in contrast to other aluminum alloys. 
This session concluded with a discussion by J. W. Morris (LBL) and R. P. Reed of collaboration between the United States and Japan on the development and testing of new cryogenic alloys, such as high-Mn, high-N austenitic steels and high-purity, Mo-strengthened austenitic steels. Collaboration on test standards and structural design standards is also occurring. Details of the exchange of materials and the test program in the United States at NBS, LLNL, and LBL were explained.

Session 3 - Fabrication Technology for Cryogenic Structural Alloys

In an overview of welding development needs for cryogenic magnet case materials, E. N. C. Dalder noted that two types of welding processes, each with 4-K qualified consumables, were desirable. A welding process with a high deposition rate ( $S A, F C A$, or ES) that could be automated to maximize productivity would be appropriate for many situations. But operator-dependent, highintegrity welding processes (e.g., GMA-P, SMA, or GMA) would be necessary for vertical, overhead, and other difficult welds. Nondestructive inspection methods must be validated before construction: for example, it was impossible to inspect thick section $(7-13 \mathrm{~cm})$ welds on the yin-yang magnets for MFTF-B. The U.S. goals for $4-\mathrm{K}$ weld properties formulated during the 1984 Cryogenic Materials Workshop in Vail, Colorado, were reiterated:

4-K Yield Strength

Automated process

Operator-dependent process
$1000 \mathrm{MPa}$

$1000 \mathrm{MPa}$
4-K Fracture Toughness

$150 \mathrm{MPa} \sqrt{\mathrm{m}}$

$200 \mathrm{MPa} \sqrt{\mathrm{m}}$

Details of the LLNL and LBL welding program with $316 \mathrm{~L}$ and other consumables were also presented.

T. A. Siewert (NBS) discussed his analysis of the cryogenic weld data base. In particular, he showed that Charpy $\mathrm{V}$-notch impact energy at $77 \mathrm{~K}$ cannot at present be well correlated with $4-\mathrm{K}$ fracture toughness, though the 77-K lateral expansion measured in the Charpy test is a somewhat better predictor of $4-\mathrm{K}$ yield strength and toughness. J. Chan (LBL) gave results of weldment properties produced by gas shielded welding $(75 \% \mathrm{He}, 25 \% \mathrm{Ar}$ ) of $\mathrm{Fe}-\mathrm{Mn}$ austenitic alloys. The welding program goals for yield strength were met, but low fracture toughness values had not been overcome yet. M. Shimada of Kobe Steel discussed electron-beam welding (EBW) of a promising alloy under development: $\mathrm{Fe}-22 \mathrm{Mn}-13 \mathrm{Cr}-5 \mathrm{Ni}-0.22 \mathrm{~N}(0.013 \mathrm{P}, 0.004 \mathrm{~S}, 0.34 \mathrm{Si})$. Toughness values of above $250 \mathrm{MPa} \sqrt{\mathrm{m}}$ at $4 \mathrm{~K}$ fall within the JAERI goals for Japanese fusion systems, and no porosity or hot cracking of the weldment was observed. Some decrease in $\mathrm{N}$ content (about $0.017 \mathrm{wt. \%}$ ) occurred, which decreased the yield strength. About twenty $K_{I c}$ tests have been made. The effect of different welding processes (SMA, FCA, GTA) on toughness of high-Mn austenitic steels was discussed by R. Miura (Japan Steel Works). Charpy impact energy data at $77 \mathrm{~K}$ were presented.

Session 4 - Nonmetallic Structural Composites for Cryogenic Service

The need for high-modulus, low-thermal-expansion coefficient composites in future tandem mirror choke coils was described by E. N. C. Dalder. Such coils 
may have fields ranging from 25 to $50 \mathrm{~T}$, and a new superconductor, $\mathrm{PbMo}_{6} \mathrm{~S}_{8}$ $\left(\mathrm{H}_{\mathrm{C}}-60 \mathrm{~T}\right.$ ) may be used. This strain-sensitive superconductor will require a high-modulus nonmetallic such as a graphite filament aluminum matrix composite or the sputtering of the $h i g h-H_{c}$ superconductor onto a spiral grooved reinforcement plate with Kapton deposited as insulation.

M. B. Kasen (NBS) discussed procedures for fabricating small, wellcharacterized specimens to be used in screening nonmetallics for low temperature radiation resistance. The procedure involves vacuum degassing and impregnation. Resins under consideration in a cooperative testing program include the standard G-11CR epoxy system and bisphenol polyimide (a state-ofthe-art resin). A type-E-glass fiber reinforcement with a proprietary finish is being tested. R. D. Kriz (NBS) described modeling studies based upon a unit cell of a woven reinforced composite. Results of compression and torsion tests on a polyimide woven glass composite of $1-\mathrm{mm}$ thickness were also presented at this session. These studies were carried out by $\mathrm{H}$. Becker (MIT) who was unable to attend the workshop.

The use of the National Low Temperature Neutron Irradiation Facility (NLTNIF) at ORNL for magnet material research was the subject of a presentation by $\mathrm{R}$. Coltman (ORNL). This facility will enable both irradiation and testing to be carried out at $4 \mathrm{~K}$ wi thout warmup, but specimen size limits and irradiation heating rates that affect the internal specimen temperatures need to be considered in experiment design. The facility, to be operational in 1986, is the first of its kind.

Session 5 - Fatigue, Creep, and Processing Effects on Properties

Because tokamak fusion energy machines will be operated in pulsed modes, threshold fatigue crack growth rate (FCGR) data is an important consideration in efficient structural design of the superconducting magnets. R. L. Tobler (NBS) described an automated apparatus that has been used to obtain FCGR data on AISI 300 series austenitic steels at $4 \mathrm{~K}$ that are several orders of magnitude below rates of previously published measurements. There was considerable discussion about the significance of the preliminary results for design purposes.

Recent results have indicated that creep may occur at cryogenic temperatures in copper and austenitic steels. R. P. Reed reported results on AISI 316 and 310 at $76 \mathrm{~K}$ that showed that no steady-state creep occurred and that probably a minimum stress would be necessary to initiate creep. Because of the complexity of designs for structural members of magnets, stresses can approach yield strengths in some parts of the structure, so such data are important. Further discussion on possible athermal mechanisms for cryogenic creep, such as quantum mechanical tunneling was given in the next talk by L. Roth (Westinghouse).

A presentation by $P$. T. Purtscher (NBS) on processing effects on $4-K$ tensile and fracture toughness concluded that grain size affected yield strength and fracture toughness inversely, as does nitrogen content, and that rearranging inclusions, precipitates, or their distribution in the microstructure through hot-working could improve toughness. 
The main topic of discussion was the extent of allowable heat treatment for conductor sheath alloys, such as Inconel 905 and 903, that would permit in situ processing of the $\mathrm{Nb}_{3} \mathrm{Sn}$ superconductor but not degrade the 4-K mechanical properties of the alloy.

A discussion of failure modes and design philosophy for superconducting magnets under static and cyclic loading concluded this session. 


Numerous requests for material property data are received by our division each year. During the past year, we completed data searches and supplied the following material properties to other laboratories and companies:

\section{Information}

$\mathrm{K}_{\text {Ic }}$ for Nitronic 33 at $4 \mathrm{~K}$

$\mathrm{J}_{\text {Ic }}$ measurement techniques at $4 \mathrm{~K}$

$J_{\text {Ic }}$ measurement techniques at $4 \mathrm{~K}$

magnetic susceptibility of austenitic

steels at $4 \mathrm{~K}$

tensile properties of Au from 4 to $10 \mathrm{~K}$

for a space application

axial fatigue and notch tensile strength

of AI $6061 \mathrm{~T} 6$ and Al $7075 \mathrm{~T} 73$ at $20 \mathrm{~K}$

for an engine to be used in space

physical and mechanical properties of $\mathrm{Ti}$ and $\mathrm{Al}$ alloys at $3 \mathrm{~K}$ for an electrooptical space application

thermal conductivity of CDA $102 \mathrm{Cu}$ and Al 5657 from $4 \mathrm{~K}$ to room temperature

mechanical properties of 304 alloys at cryogenic temperatures for cryogenic tankage

mechanical properties of 21-6-9 weldments at $4 \mathrm{~K}$ for a particle accelerator

tensile properties, $\mathrm{K}_{\mathrm{Ic}}$, and magnetization of high-N austenitic stainless steels

properties of nonmetallics

load-controlled fatigue of CDA 101-104 Cu at $76 \mathrm{~K}$

3.5 $\mathrm{Ni}$ steels - mechanical properties of base and welded material at cryogenic temperatures
Provided to

national laboratory

institute of technology - Japan

atomic reactor company

research institute - Japan

aerospace company

aerospace company

instrument company

aerospace company

cryogenic equipment manufacturer

national laboratory

university research center

university research center

electrical equipment manuracturer

national laboratory 


\section{Information}

magnetic permeability and $\mathrm{K}_{\mathrm{Ic}}$ for Nitronic 33 at $4 \mathrm{~K}$

cryogenic mechanical and thermal properties of Pt for a temperature monitor

(space application)

cryogenic properties of 304 and 316 alloys and $\mathrm{Cu}$

cryogenic properties of polymers and structural alloys

cryogenic properties of structural alloys

PVT properties of $\mathrm{O}_{2}$ and $\mathrm{N}_{2}$ for highpressure pneumatic systems (military radar applications)

$\mathrm{K}_{\mathrm{Ic}}$ of 304 and $\mathrm{Ti}-6 \mathrm{Al}-4 \mathrm{~V}$ alloys at $4 \mathrm{~K}$ for a particle accelerator

cryogenic properties of 304,316 , and $21-6-9$

fracture properties of Al $2219 \mathrm{~T} 62$ at $20 \mathrm{~K}$ thermal expansion of $\mathrm{Fe}-18 \mathrm{Cr}-18 \mathrm{Mn}$ to $4 \mathrm{~K}$

1) tensile strength, yield strength, shear strength, elastic modulus, and fracture toughness of eleven structural alloys, $\mathrm{G}-10 \mathrm{CR}$, and $\mathrm{G}-11 \mathrm{CR}$ from 300 to $4 \mathrm{~K}$;

2) thermal expansion, thermal conductivity, and specific heat data for structural alloys from 300 to $4 \mathrm{~K}$;

(cryostat design for particle accelerator)
Provided to

national laboratory

manufacturer of aerospace components

national laboratory

university research center

materials laboratory - France

cryogenic equipment manufacturer

aerospace company

aerospace company

aerospace company

university research center

national laboratory 
NBS.l1AA IAEV. 2-OCI

U.3. OEPT. OF COMM.

1. PUBLICATION OR

REPORT NO.

BIBLIOGRAPHIC DATA

SHEET (See instructions)

NBSIR $86-3050$

2. Performing Organ. Report No

4. TITLE AND SUBTITLE

Materials Studies for Magnetic Fusion Energy Applications at Low Temperatures - IX

5. AUTHOR(S)

R. P. Reed, Editor

6. PERFORMING ORGANIZATION (If joint or other thon NBS, see instructions)

7. ContracuGrant No.

MATIONAL BUREAU OF STANDARDS

DEPARTMENT OF COMMERCE

WASHINGTON, D.C. 20234

9. SPONSORING ORGANIZATION NAME AND COMPLETE ADDRESS (Street. City. Stote, ZIP)

Department of Energy

Office of Fusion Energy

Washington, DC 20545

10. SUPPLEMENTARY NOTES

Previous reports in this series: NBSIR 85-3025, NBSIR 84-3000, NBSIR 83-1690, NBSIR 82-1667, NBSIR 81-1645, NBSIR 80-1627, NBSIR 79-1609, NBSIR 78-884

[] Document describes a computer program; SF-185, FIPS Software Summary, is attached.

11. ABSTRACT (A 200-word or less foctuol summary of most significont information. If document includes o significont bibliogrophy or literoture survey, mention it here)

This report contains results of a research program to produce material property data that will facilitate design and development of cryogenic structures for the superconducting magnets of magnetic fusion energy power plants and prototypes. The program was developed jointly by the staffs of the National Bureau of Standards and the Office of Fusion Energy of the Department of Energy; it is managed by NBS and sponsored by DOE. Research is conducted at NBS and at various other laboratories through subcontracts with NBS.

Research results for 1985 are summarized in an initial "Highlights of Results" section and reported in detail in the technical papers that form the main body of this report. The technical papers are presented under four headings reflecting the main program areas: Welding, Nonmetallics, Structural Alloys, and Technology Transfer. objectives, approaches, and achievements are summarized in an introduction to each program area.

12. KEY WORDS (Six to twelve entries: olphobetical order; copitolize only proper nomes; and seporate key words by semicolons) austenitic steels; composites; cryogenic properties; elastic properties; low temperatures; mechanical properties; nonmetallics; stainless steels; structural alloys; welds.

13. AVAILABILITY

[x] Unlimited

[] For Official Distribution. Do Not Release to NTIS $\square$ Order From Superintendent of Documents, U.S. Government Printing Office. Washington, D.C.
20402 .

[X] Order From National Technical Information Service (NTIS), Springfield, VA. 2216I
14. NO. OF

PRINTED PAGES

\section{8}

15. Price 


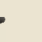



